

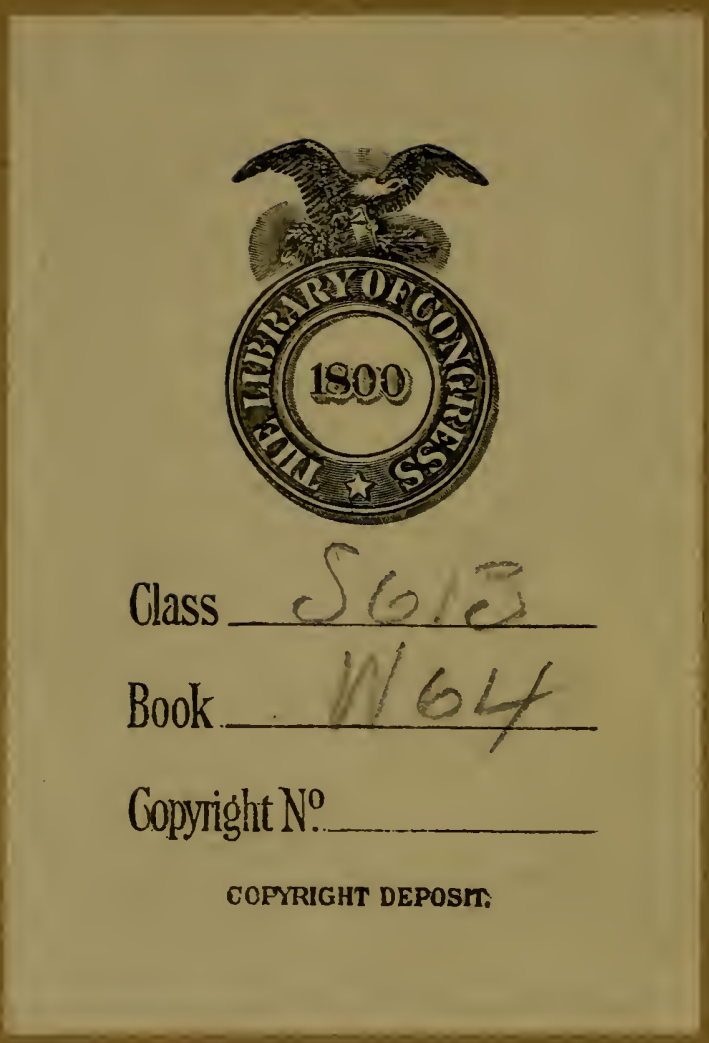








The frural Text-23ook Aeries

Edited by L. H. BaIley

\section{THE \\ PRINCIPLES OF IRRIGATION PRACTICE}




\section{The Ahural Text $=2300 k$ Feries}

Edited by L. H. BAILEY

Mann, Beginnings in Agriculture

Warren, Elements of Agriculture

Warren, Farm Management

Lyon and Fippin, Soll Management

J. F. Duggar, Southern Field Crops

B. M. Duggar, Plant Physiology

Harper, Animal Husbandry for Schools

Montgomery, The Corn Crops.

Wheeler, Manures aNd Fertilizers

Livingston, Field Crop Production

Widtsoe, Principles of Irrigation Practice

Others in Preparation 



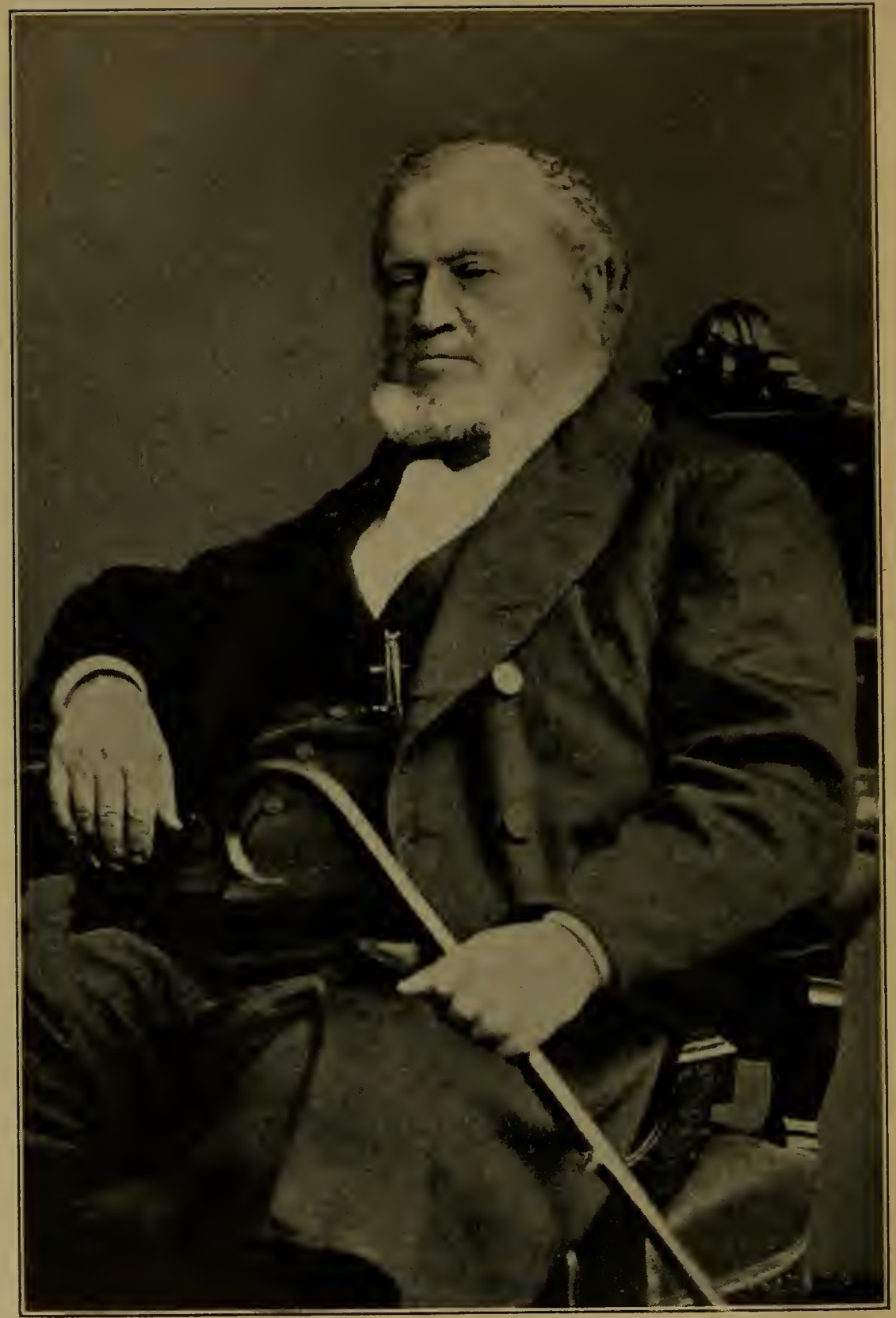

Brigham Young. (Born 1801; died 1877.)

The founder of modern irrigation in America. 


\title{
THE PRINCIPLES OF
}

\section{IRRIGATION PRACTICE}

\author{
BY \\ JOHN A. WIDTSOE, A.M., Рн.D. \\ Presiuent of the Uta Agricultural College
}

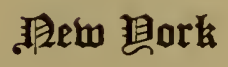

THE MACMILLAN COMPANY

LONDON: MACMILLAN \& CO., Ird.

1914

All rights reserved 


\section{S613 \\ W64}

Coprright, 1914

\section{By THE MACMILLAN COMPANY}

Set up and electrotyped. Published August, 1914

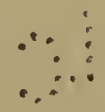

\section{AUG 271914}

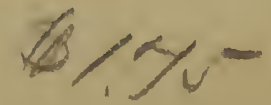

(C) $\mathrm{Cl} A 350119$ 


\section{This 23ook is Bedicated}

BY THE AUTHOR TO THE MEMORY OF THE PIONEERS WHO, ON JULY 24, 1847, ENTERED THE GREAT SALT LAKE VALLEY, AND ON THAT DAY FOUNDED MODERN IRRIGATION IN AMERICA 



\section{PREFACE}

IRRIGATION and dry-farming are rapidly conquering drought. By these twin arts, bountiful and regular harvests may be gathered in the humid regions during the periodic dry seasons; and in the arid regions, the great "deserts" may be converted into most fruitful fields. Irrigation has a splendid record of success from the beginning of history; dry-farming has only in recent days extended its conquests into the more arid regions; both have become more powerful in conquering drought as modern science has been applied to them.

Successful irrigation-farming is the joint product of the engineer and the farmer. To the engineer is given the heavy and responsible task of constructing properly a permanent system of dams and canals from which water may be drawn; to the farmer belongs the apparently humble but unending and difficult task of using the water in the best manner for crop-production. Both workers are essential for success; but, the work of the farmer determines the permanence and extent of agriculture under irrigation.

Much has been written about irrigation for the engineer, but little for the farmer. The few who have written about farming under irrigation have, most frequently, prepared crop or soil manuals, in which the use of water has formed a minor part. This book is an attempt to develop the principles, so far as present knowledge permits, upon which the correct use of water, by the farmer, 
must rest. Crop or soil treatments which are not connected directly with the use of water are not discussed or are greatly subordinated. The various aspects of the complex art of irrigation-agricultural, economic, social and legal-will some day receive separate and special treatment; in this volume one line of thought only has been followed-the correct use of water in irrigation.

The aim of this book is to furnish to students and intelligent farmers a modern view of the principles of irrigation practice. Simple language has been used and unnecessary technical terms have been avoided. Obvious matters, and those which vary with local conditions and must therefore be learned by experience, have been eliminated. The beginner in irrigation has been kept in mind; but the book is essentially a manual for those who, whether in arid or humid climates, having cast their lots with irrigation, desire mastery of their work by an intelligent comprehension of the natural laws involved in irrigation-farming. The actual handling of water can be learned only by experience - that is the beginner's heavy lesson; the refinements of irrigation, by which its success at last is measured, come later, and are unknown to many. The man who lives year after year under the ditch, and raises his family there, needs as much if not more help than the pioneer whose chief sorrow is the aggravating self-will of the water as it flows over the newly broken land.

Some subjects have been touched on lightly in this volume because they are more fully developed in the author's book on "Dry-Farming." In fact, that book and this one are a continued study of the water factor in agriculture - perhaps the most important of the physical factors. Schools of agriculture, whether in arid or humid 
regions, might profitably organize classes in this subject. Classes in fertilizers and related subjects are taught as a matter of course, but the water factor, of greater importance, is given incidental mention in courses on soils or plant physiology. At the Utah Agricultural College it has been found satisfactory to give a half-year course in dryfarming, followed by a half-year course in irrigation practice, the two courses constituting a year's study of the water factor in agriculture.

The irrigation literature of the world has been quite fully examined in the preparation of this book; but, since the work has been done far from large libraries, many important papers have been inaccessible. However, as a possible compensating condition, the work has been done within hearing of the ripple of the irrigation ditch, in the heart of the irrigated section. Free use has been made of all available information, but of especial help have been the magnificent series of irrigation bulletins issued by the Irrigation Investigations of the Office of Experiment Stations of the United States Department of Agriculture. The splendid work of the Bureau of Soils of the United States Department of Agriculture has also been of the greatest assistance. It is a pity that the heated discussion of a theory should overshadow this vast, accurate and remarkable soil work, the like of which, issuing from one institution, is not to be found.

At the end of each chapter has been placed a short list of references for the use of those who desire to carry their studies further. Care has been taken, except in two or three instances, to suggest only such materials as are readily available. These references would make a very good working library on irrigation and may be obtained at a slight cost. In Appendix $\mathrm{C}$ is given a brief 
list of books on irrigation. No attempt is made to supply in this volume a complete bibliography of irrigation.

To friends and colleagues in many parts of the world hearty thanks are offered for valuable help rendered in the preparation of this book. My Utah colleagues, many of whom have been connected with the long experimental study of irrigation at the Utah Station, have given freely of their time and information to make the book accurate and worthy of the cause. I am under particular obligation to Dr. Robert Stewart, Dr. F. S. Harris, Prof. W. W. McLaughlin and Prof. L. A. Merrill, and to Librarian Elizabeth C. Smith, who has kindly gathered irrigation literature from all parts. of the world. My brother, Prof. O. J. P. Widtsoe, has in many ways given most valuable help. If this book and its companion volume shall be of service, the first credit belongs to Dr. L. H. Bailey, the Editor of the Rural Series of books, through whose wise and kindly urging these books were written, and the many others, by other hands, which have made available to humanity the great applications of modern science to rural problems.

LOGAN, Utah.

JOHN A. WIDTSOE.

NOTE.-Unless otherwise stated, wherever "inch" or "foot" of water is used in this book it refers to the depth to which the water would cover the ground. 


\section{TABLE OF CONTENTS}

\section{A. INTRODUCTION}

\section{CHAPTER I}

The Meaning of Irrigation . . . . . . . . . 1-7

Annual rainfall, 1-Seasonal rainfall, 2-Variations in rainfall, 2-Conservation of rainfall on farms, 3 - Conditions of dry-farming, 3-Conditions of irrigation, 4Irrigation defined, 4-Geographical need of irrigation, 5 - Possible extent of irrigation, 5-Mission of irrigation and dry-farming, 7 .

B. THE RELATION OF WATER TO SOILS

\section{CHAPTER II}

SoIl Moisture

Attraction between near bodies, 8-Soil particles, 9The soil-moisture film, 11-Thickness of film and diameter of particles, 12-Hygroscopic coefficient, 13-The wilting coefficient, 14-Lento-capillary point, 16Maximum capillary capacity, 17-Free water, 17Summary, 19.

\section{CHAPTER III}

The Soll as Water Reservoir . . . . . . . . 21-39

Irrigated soils are unsaturated, 22-The movement of soil moisture, 23-The distribution of soil moisture, 25Field moisture capacity, 29-Water distribution in furrow irrigation, 30-Effect of hardpan, 32-Effect of gravel, 34-Water table near surface, 34-Soil treatment, 35-How much water can be stored, 35-Absorption of water by soils, 38 . 


\section{CHAPTER IV}

\section{Saving Water by Cultivation}

The run-off, 40 - The upward movement of water, $42-$ Intensity of evaporation, 44-Conditions determining evaporation, 46-Mulching to check evaporation, 49Self-mulching soils, 52-Time of cultivation, 53Depth of cultivation, 55-Frequency of cultivation, 58Cultivation and soil fertility, 59-Rolling, 62.

\section{CHAPTER V}

Soll Changes Due to Irrigation Water . . . . 64-107

Contraction and moisture film, 64-Cohesion of soil particles, 65-Volume changes of soils, 67-Effect on top soil, 69-Successive wetting and drying, 70-Natural packing of soil, 70-Soil temperature, 71-Water a universal solvent, 72-Humid and arid soils contrasted, 73-Continuous solubility of soils, 74-Absorption by soils, 76-Composition of drainage water, 78-Concentration of soil moisture, 79-Loss by drainage, 79Upward leaching, 81-Salinity of river waters, 82Salinity of lake waters, 86-Salinity of mineral springs, 86- Soil moisture and natural waters compared, 87Ash constitutents added by irrigation water, 87-Use of concentrated waters, 89-Need of water surveys, 90Composition of natural waters, 90 -Classification of natural waters, 92-Plant-food value of irrigation water, 93-Suspended matter in river water, 95-Seasonal variation of suspended matter, 98-Suspended matter added to soil by irrigation, 100-Suspended matter derived from surface soils, 100-Composition of river sediments, 101-Physical effects of sediments, 102-Cultural treatment of sediments, 103-Effect of sediments on crop-yields, 104-Water and soil life, 104. 
C. THE RELATION OF WATER TO PLANTS

\section{CHAPTER VI}

Conditions Determining the Use of Soll Moisture by Plants . . . . . . . . . . . . . 108-126

Absorption of water by roots, 109-Transpiration, 110The initial percentage of soil moisture, 111-Distribution of water in the soil, 114-The effect of time, 115-The depth of soil, 116-Physical composition of soils, 117Chemical compositions of soils, 118-Plowing, 120Cultivation, 121-Manuring, 121-Vigor of plant, 121Root-system, 122-Age of plants, 122-The kind of crop, 123-The seasons, 124.

\section{CHAPTER VII}

The Water-Cost of Dry Matter . . . . . 127-157

Carbon-assimilation, 128-Plant age and carbon-assimilation, 129-Conditions of growth, 130-The transpiration ratio, 131-The seasons, 136-The soil, 137Mineral food or soil fertility, 139-Cultural operations, 141-The vigor of the plant, 143-Varying quantities of water, 144-Maximum yield with given quantity of water, 151-The nature of the crop, 154-Summary, 155.

\section{CHAPTER VIII}

Crop Development Under Irrigation . . . . . 158-172

Response to irrigation, 159-Proportion of roots, 160 Proportion of leaves and stems, 163-Proportion of heads and grain, 166-Other plant parts, 169. 


\section{CHAPTER IX}

The Time of Irrigation

The ideal principle, 173-Fall irrigation, 175-Winter irrigation, 178-Early spring irrigation, 181-Irrigation during growth, 182-Time of irrigating short-season crops, 183-Time of irrigating long-season crops, 184Night versus day irrigation, 187.

\section{CHAPTER X}

The Method of Irrigation . . . . . . . . 189-215

Sub-surface irrigation, 189-Surface irrigation, 193Permanent ditches, 196-Field-ditch or field-lateral method, 198-The border method, 202-The check method, 202-The basin method, 207-The furrow method, 207-Summary, 214.

\section{CHAPTER XI}

Crop Composition . . . . . . . . . . . 216-230

Groups of plant constitutents, 217-Water, 217-Ash, 219-Protein, 220-Fat, 223-Carbohydrates, 224Sugars, 224-Starch, 226-Woodiness, 226-Color and flavor, 227-Flour, 227-Cooking value, 228-Effect of cultural treatment, 228 .

\section{CROPS UNDER IRRIGATION}

\section{CHAPTER XII}

The Use of the Rainfall . . . . . . . . 231-239

Irrigation supplementary to rainfall, 231-Crop-producing power of rainfall, 232-Results of dry-farming, 233-Crop value of rainfall in irrigation, 233-Conserving the rainfall, 235-Distribution of rainfall, 235Storing water in the soil, 236-Cultivation, 237-Proportion of rainfall conserved, 237-Relation of irrigation and dry-farming, 237-Dry-farm homesteads, 238. 


\section{CHAPTER XIII}

Irrigation of Cereals .

Spring vs. fall wheat, $241-$ Quantity of wheat to sow, 241-Method of sowing wheat, 242-Cultivation of wheat, 243-Method of irrigating wheat, 243-Time to irrigate wheat, 246-Quantity of water for wheat, 248Oats, 253-Barley, 255-Rye, 255-Corn, 255-Time to irrigate corn, 258-Quantity of water for corn, 259Rice, 262.

\section{CHAPTER XIV}

Alfalfa and Other Forage Crops and Pastures . 266-285 Alfalfa or lucern, 266-Cultivation of alfalfa, 268Method of irrigating alfalfa, 269-Time to irrigate alfalfa, 270 - Quantity of water for alfalfa, 274-Alfalfa seed, 277 -Hay-making crops, 278-Red clover, 281-Pastures and meadows, 281.

\section{CHAPTER XV}

Sugar Beets, Potatoes and Miscellaneous Crops . 286-313 Sugar beets, 286-Method of irrigating sugar beets, 289 -Time to irrigate sugar beets, 290-Quantity of water for beets, 293-Carrots, 296-Other root crops, 297Potatoes, 298-Peas and beans, 301-Fiber crops, 305Hops, 306-Tomatoes, cantaloupes, etc., 306-Cabbage, cauliflower, etc., 308-Asparagus and celery, 309Onions and miscellaneous crops, 310.

\section{CHAPTER XVI}

Fruit Trees, Other Trees and Shrubs . . . . 314-330

Fruit-growing, 314-Method of orchard irrigation, 315Time of orchard irrigation, 319-Quantity of water for orchards, 322-Other conditions of orchard irrigation, 323-Nursery stock, 326-Small fruits, 326-Grapevines, 327-Plants for ornament and comfort, 328. 


\section{E. MISCELLANEOUS}

\section{CHAPTER XVII}

The Duty, Measurement and Division of Water . 331-370

The duty of water, 331-Classes of duty, 334-Determination of duty of water, difficult, 336-Duty of water in Africa, 338-Duty of water in Asia, 339-Duty of water in Europe, 341-Duty of water in South America, 342-Duty of water in Australia, 343-Duty of water in North America, 343-Bear River Canal experience, 344Idaho results, 345-Miscellaneous results, 345-The Utah results, 346-Need of measuring water, 347-Who shall measure the water? 349 -Classes of measurement, 349-The Cippoletti weir, 353-Divisors, 355-Meaning of the distribution of water, 357-Methods of Distribution, 358-Continuous flow, 358-Continuous rotation, 361-Distribution on application, 364-Organization for distribution, 365-Regulations and records, 368 .

\section{CHAPTER XVIII}

Over-Irrigation and Alkali . . . . . . . . 371-405

Seepage from reservoirs and canals, 371-Loss from excessive irrigation, 373-Ground water, 374-Comparison with humid areas, 375-Lined ditches-a remedy, 376-The economical use of water-a remedy, 381Drainage - the final remedy, 381-Alkali defined, 383Seepage and alkali, 384-Upward leaching, 385-Use of saline water, 387-Alkali deposits, 388-Kinds of alkali, 390-Tolerance for alkali, 392-Cropping against alkali, 397-Chemical treatment for alkali, 398-Scraping the surface, 399-Tillage against alkali, 399-Washing out alkali, 400-Underdrainage-the final remedy, 400. 


\section{CHAPTER XIX}

Irrigation in Humid Climates . . . . . . . 406-418

Dry seasons, 407-Results of irrigation in humid regions, 409-Methods of applying water, 412-The duty of water, 413-Sources of water, 413-Water-conservation methods, 414-Value of sewage water, 414-The use of sewage, 415-Factory and mill waste, 417.

\section{CHAPTER XX}

IrRigation ToOLS AND Devices . . . . . . 419-444

Clearing and breaking the land, 419-Laying-out the farm, 420-Leveling the land, 423-Making farm ditches, 426-Gates and checks, 434-Ridging and furrowing, 439-Mulching the soil, 440-Measuring the flow of water, 441 .

\section{CHAPTER XXI}

The History of Irrigation . . . . . . . . 445-471

The antiquity of irrigation, 445-The Christian era to 1800,449 -Irrigation in recent times, 451-The founding of modern irrigation in America, 454-The growth of American irrigation, 457-The Union Colony of Colorado, 460-The United States Reclamation Service, 461The United States Department of Agriculture, 464The experiment stations, 466-The Irrigation Congress, 470 .

\section{CHAPTER XXII}

Permanent Agriculture under Irrigation $472-476$

The big irrigation problem, 472-The spirit of irrigation, 473-No essential difference between irrigation- and humid-farming, 473-History assures permanence of irrigation, 474-The question of plant-food, 474-Some advantages of irrigation, 476-Finally, 476. 


\section{APPENDIX}
A. Water Constants
B. Discharge over Cippoletti's Weir . . . . . 478-483
C. List of American Books on Irrigation . . . 484

PAGES

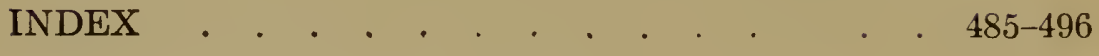




\section{LIST OF ILLUSTRATIONS}

FIG.

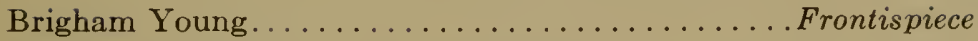

1. Progressive averages of annual rainfall.............. 3

2. The limited water supply makes it unlikely that more than one-

tenth of the land will be irrigated............... 5

3. The value of water in an arid land..................... 6

4. Soil is a mixture of particles of very varying size. . . . . . . . 10

5. The moisture film surrounding a soil particle........... 18

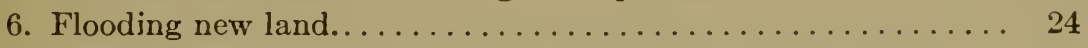

7. Distribution of water in soil immediately after an irrigation... . 27

8. Distribution of water in soil under furrow irrigation........ 31

9. Penetration of roots of prune tree.............. 36

10. Evaporation usually exceeds rainfall................. 44

11. Relation between temperature and evaporation........... 48

12. Evaporation losses from soils protected with mulches of different depths............................ 51

13. Orchard well eultivated to prevent evaporation.......... 57

14. Mulching the garden with a hand cultivator............ 61

15. Adhesion of hairs due to water................ 65

16. Cracked river sediments showing volume changes due to water 68

17. Midsummer snow in the tops of the mountains........... 75

18. Badly corroded ditch due to excessive fall ............. 95

19. Walled ditch to prevent erosion of easily "washed" soil...... . 97

20. Daily discharge of Malheur River. . . . . . . . . . . . 99

21. Daily discarge of Mackenzie River................. 99

22. Deposit in field of suspended matter from irrigation water.... 102

23. Stomatal apparatus in carnation leaf ............... 132

24. Determining the transpiration ratio................ 135

25. Yield of dry matter of eereals with varying quantities of water. . 149

26. Yield of dry matter of cereals per inch of irrigation water.... 149

27. Crop-producing power of 30 acre-inches (wheat) . . . . . . . 152

28. Crop-producing power of 30 acre-inches (alfalfa) . . . . . . . . 152

29. Crop-producing power of 30 acre-inches (sugar beets) . . . . . . 153

30. Effect of little, medium and much water on wheat........ 160

31. Proportion of grain and straw with varying irrigations....... 168

32. Plan of a sub-irrigated farm . . . . . . . . . . . . . . . . . 191

33. Lee's sub-irrigation system. . . . . . . . . . . . . . . . . . . 192 
Fig.

34. A permanent ditch in an orange grove.............. 196

35. Plan of field-ditch irrigation................... 197

36. Flooding from ditches running down the steepest slope....... 198

37. Flooding from field ditch..................... 198

38. Flooding with aid of canvas dam. . . . . . . . . . . . 199

39. Laterals made in field and dammed with small piles of manure

for next year's irrigation. . . . . . . . . . . . . . 200

40. Plan for border irrigation . . . . . . . . . . . . . . . 201

41. Border method of irrigation...................... 202

42. Irrigating cherries under check system. . . . . . . . . . 203

43. Rectangular check method of irrigation.................. 204

44. Contour check method of irrigation................ 205

45. Filling checks with detachable pipes. . . . . . . . . . 206

46. Orchard irrigation by basin method ............... 207

47. Orchard irrigation by basin method............... 207

48. Grading of interior of basins to prevent water from coming in

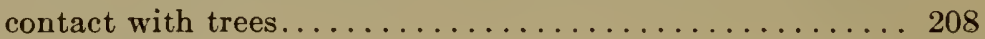

49. Furrow irrigation........................ 208

50. Furrow irrigation of young alfalfa . . . . . . . . . . . 209

51. One-way furrow irrigation . . . . . . . . . . . . . . 210

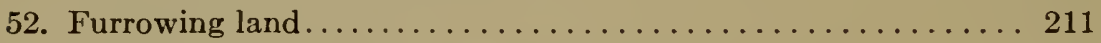

53. Standpipe supplying furrows with water . . . . . . . . 212

54. Zigzag furrows to insure uniform distribution over soil . . . . . . 213

55. Another type of zigzag furrows................. 214

56. Lath-box for distributing water to furrows from head ditch.... 214

57. Yield of crops due to rainfall. . . . . . . . . . . . . 235

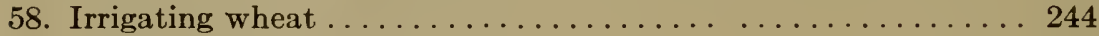

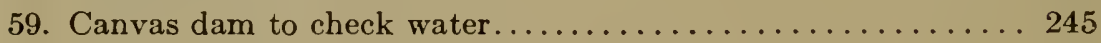

60. Irrigated wheat. . . . . . . . . . . . . . . . . . 249

61. Irrigated oats. . . . . . . . . . . . . . . . . . . . . 251

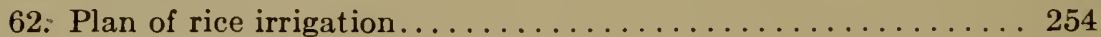

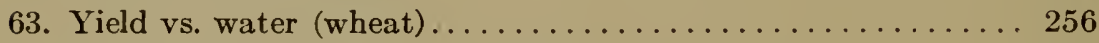

64. Producing power of 30 acre-inches................ 257

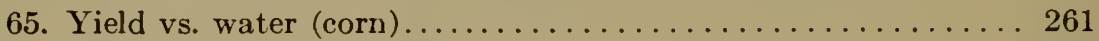

66. Irrigated corn in Arizona...................... 262

67. Plan of irrigating an alfalfa field.............. 270

68. Temporary county fair building constructed of baled alfalfa hay 271

69. An alfalfa field in Nevada.................... 272

70. Yield vs. water (alfalfa) ..................... 276

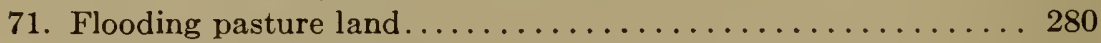

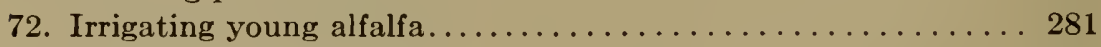

73. Irrigated cane in Kansas...................... 28.3

74. A sugar beet field ......................... 287 
Fig.

75. Loading sugar beets in factory bins................ 288

76. Irrigating potatoes. . . . . . . . . . . . . . . . . . 293

77. Yield vs. water (sugar beets)................... 295

78. Plan of potato irrigation..................... 298

79. Irrigating potatoes. . . . . . . . . . . . . . . . . . 299

80. Irrigated field peas . . . . . . . . . . . . . . . . . . . . 302

81. Irrigated celery .............................. 304

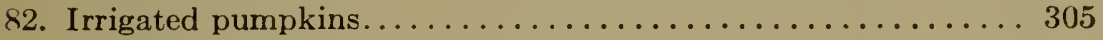

83. Irrigated onions . . . . . . . . . . . . . . . . . . . 307

84. Yield vs. water (potatoes) . . . . . . . . . . . . . . . 309

85. Irrigated Egyptian cotton. . . . . . . . . . . . . . . 311

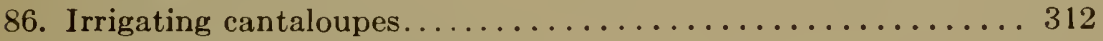

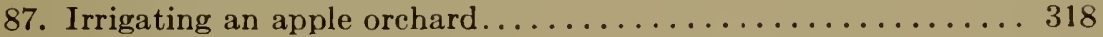

88. On the upper canal. . . . . . . . . . . . . . . . . . 322

89. An irrigated prune orchard . . . . . . . . . . . . . . 325

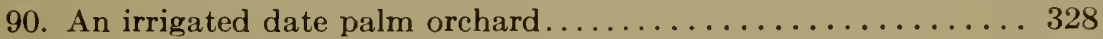

91. Canal crossing river in an inverted syphon............ 332

92. Looking down the Bear River Canal. . . . . . . . . . . . . . 333

93. Lateral outtake from large canal................... 335

94. Headgate of a canal. . . . . . . . . . . . . . . . . . . . 340

95. A cable measuring station with automatic gauge......... 348

96. Lyman rectangular weir. . . . . . . . . . . . . . . . . 350

97. Longitudinal section of Lyman's weir. . . . . . . . . . . . . . 351

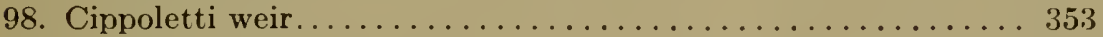

99. Details of Cippoletti weir.................... 354

100. Scale to be screwed on side of Cippoletti weir . . . . . . . . . 355

101. Divisor attached to Cippoletti weir. . . . . . . . . . . 356

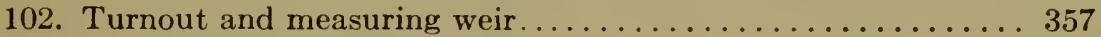

103. Device for diverting a constant quantity of water. . . . . . . 357

104. The need of storing water in reservoirs . . . . . . . . . . . 359

105. Rise of ground water from irrigation. . . . . . . . . . . . 374

106. Chain puddler. Used in making canals watertight. . . . . . . 376

107. Modified chain puddler...................... 377

108. Wooden stave pipe carrying irrigation water........... 378

109. Lateral lined with concrete. . . . . . . . . . . . . . . . 379

110. Cement-lined main canal. . . . . . . . . . . . . . . . . 380

111. Pumping plant........................... 382

112. Drainage of irrigated lands by intercepting drains. . . . . . . 383

113. Structure of an alkali spot................... 386

114. Quaternary Lakes of the Great Basin. Sources of alkali deposits. 389

115. Effect of a strong solution of potassium nitrate on protoplasm. 392

116. Vegetation on alkali lands . . . . . . . . . . . . . . . 393

117. Alkali rising in spots on irrigated pasture............ 396 
FIG.

118. The annual rainfall of Milan compared with that of humid and arid districts in the United States............... 408

119. Comparative yields of strawberries, irrigated and unirrigated 409

120. An irrigation plant in Pennsylvania............... 412

121. Distribution of water on Craigentinny Meadows, Edinburgh. . 416

122. Section of cement flume................... 420

123. Section of $V$-shaped flume................... . 420

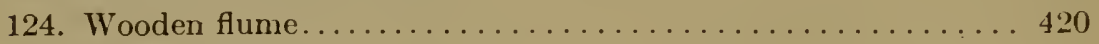

125. Section of rectangular flume. . . . . . . . . . . . . 420

126. Flume with lateral gate. . . . . . . . . . . . . . . 421

127. Buck scraper.......................... 421

128. Leveler or float.......................... 422

129. Shuart grader. . . . . . . . . . . . . . . . . . . 422

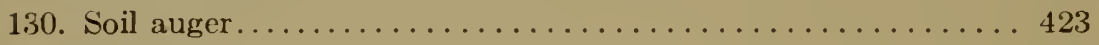

131. Lateral plow . . . . . . . . . . . . . . . . . . . 423

132. V-crowder............................ 424

133. Building a ditch ........................ 424

134. Typical forms of farm ditches................. 425

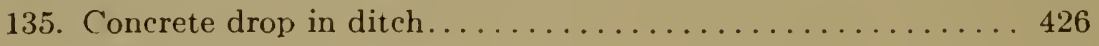

136. Drop in flume........................ 427

137. Distributor for hose . . . . . . . . . . . . . . . 428

138. Attaching hose to distributor . . . . . . . . . . . . . . . 428

139. Leveling device.......................... 428

140. Lateral headgate. . . . . . . . . . . . . . . . . . . . . . . . . . . 429

141. Concrete gate. . . . . . . . . . . . . . . . . . . . 429

142. Dammer............................. 429

143. Board dam............................ 429

144. Canvas dam............................ 430

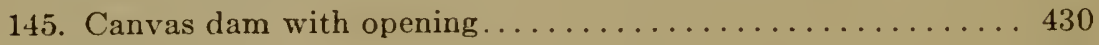

146. Metal dam. ............................ 430

147. Distribution of water from flume to furrows. . . . . . . . . . 430

148. Distribution through wooden tubes............... 430

149. Lath check. . . . . . . . . . . . . . . . . . . 431

150. Conducting water down inclines in concrete pipes......... 431

151. Roller furrower. . . . . . . . . . . . . . . . . . . . 432

152. Utah lay-off and pulverizer................. 434

153. Robinson's adjustable corrugator and renovator. . . . . . . . . 434

154. Ridger in check and basin irrigation. . . . . . . . . . 435

155. Ridger in check and basin irrigation. . . . . . . . . . 435

156. Furrower in action. ...................... 435

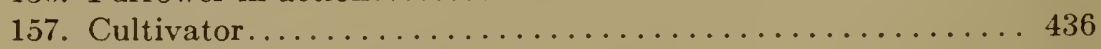

158. Cultivator attachments..................... 436

159. Beet cultivator attachments................. 437 
160. Alfalfa renovator........................ 438

161. Clod crusher, pulverizer, leveler and smoother........... 438

162. Frieze water register. . . . . . . . . . . . . . . . . . . 439

163. Device for measuring miner's inches. . . . . . . . . . . . . . . 449

164. Cross-section of canal for measurement of flow . . . . . . . . . 440

165. Current meters. . . . . . . . . . . . . . . . . . . . . 441

166. Grant-Mitchell meter. . . . . . . . . . . . . . . . . . . . . 442

167. Leveler in action. . . . . . . . . . . . . . . . . . . 443

168. Sagebrush land ......................... 446

169. The Doon. . . . . . . . . . . . . . . . . . . . . . . . 447

170. Shadof of Egypt or Paecottah of India.............. 448

171. Caravan crossing the plains in early irrigation days....... 455

172. Irrigation canals are cut through the mountains. . . . . . . . 459

173. Major J. W. Powell . . . . . . . . . . . . . . . . . . . 463

174. Completed diversion dam of the Truckee Carson, Nev., project of the United States Reclamation Service......... 465

175. Steam power digs the modern canals............... 466

176. View of the irrigation plant of the Utah Experiment Station . . 467

177. Dam of Salmon River project, Idaho, built by private enterprise.............................. 468

178. Plant for the study of the measurement and division of water. 469

179. Work for a man...................... 475 


\section{ACKNOWLEDGMENT FOR ILLUSTRATIONS}

The illustrations in this book are either original or taken from the publications of the United States Department of Agriculture, the United States Geological Survey, and the state experiment stations, with the following exceptions, which have been secured from

Bark, Don H., Irrigation Investigations, United States Department of Agriculture. Figs. 50, 58, 59, 71, 72, 76, 91, 108, 168, 177.

Blinn, P. K., Colorado Experiment Station. Figs. 38, 86, 156.

Blanchard, C. J., United States Reclamation Service. Figs. 6, 49, 69, 87, 93, 110, 174.

Bonebright, J. E., Montana Experiment Station. Figs. 18, 39, 60, $61,167$.

Cutler, Thomas R. Fig. 75

Forbes, R. H. Figs. 22, 66, 83, 90, 117.

Gillette, C. P., Colorado Experiment Station. Fig. 178.

Greeley Commercial Club. Fig. 79.

Harris, F. S., Utah Experiment Station. Figs. 16, 19, 26.

Jardine, W. M., Kansas Agricultural College. Fig. 73.

Jarvis, O. W., Superintendent, Southern Nevada Experiment Farm. Fig. 85.

Johnson Company, The, Salt Lake City. Figs. 14, 17, 82, 92, 94, $171,172,179$.

McLaughlin, W. W., Irrigation Investigations, United States

Department of Agriculture. Figs. 52, 88, 151.

Ogden Commercial Club. Fig. 81.

Quinney, Jos. E. Jr., Fig. 75.

Redland's Commercial Club. Fig. 34.

San José Commercial Club. Fig. 13.

Santa Clara Commercial Club. Fig. 89.

Smith, George Otis, United States Geological Survey. Fig. 173.

Winsor, Luther M., Utah Experiment Station. Figs. 68, 80, 175.

Grateful acknowledgment is made of the assistance rendered by the above persons. 




\section{THE PRINCIPLES OF IRRIGATION PRACTICE}

\section{CHAPTER I}

\section{THE MEANING OF IRRIGATION}

WATER, soil, air and sunshine are the four great groups of physical forces that determine the growth of plants. For the production of plant crops, all of these must be present and active. Water, therefore, is essential to plant-growth and crop-production.

The water that falls upon the earth in the form of rain and snow is the source of all the water used in agriculture. To be of value in plant-growth, this water must be stored, for longer or shorter periods, in the soil in which plants are growing. Whenever the soil becomes too dry or too wet, or if the total quantity is insufficient or too large, plant-growth is hindered. It is the concern of agriculture to maintain in the soil the proper quantity of water during the growth of crops.

1. Annual rainfall.-Water, in the form of rain or snow, falls over the whole earth. No place is known where some rain does not fall at some time during the year. However, the quantity that falls varies greatly in different regions. Over the so-called deserts the annual rainfall is often less than 5 inches, while in various places near the seashore or among the mountains, the annual rainfall 
exceeds 100 inches and occasionally reaches 600 inches or more, as at Assam, India. From district to district, the world over, the quantity of water that falls annually upon the farmers' fields is different.

2. Seasonal rainfall.-Moreover, the time of the year at which the rain comes is not everywhere the same. In some localities the rain falls chiefly in summer, during the season of crop-growth; in others, during the spring; in others, during the fall, and in yet others, during the winter. Going eastward from the Pacific seaboard, this difference in seasonal rainfall is well brought out. In California, the heaviest rainfall comes during midwinter; in the Great Basin, in early spring; on the eastern slope of the Rocky Mountains, in late spring, and on the Great Plains, near midsummer. The annual rainfall may be fairly large in a given locality, but it does not necessarily fall at the time that plants are growing.

3. Variations in rainfall.-Added to these variations in the quantity of total rainfall, and in the distribution throughout the year, is still another: The same quantity of rain does not fall in the same place from year to year. In one year there may be a large precipitation, and in another a very light one; and the time of the year of the heaviest downfall may be shifted somewhat from year to year.

True, the variations are not large. The driest year seldom receives less than two-thirds the rainfall of the wettest year, and usually it receives more. True, also, so far as our records show, the average rainfall over a certain locality for ten or twenty years is practically constant. The average rainfall at any one place is nearly invariable, although distinct variations occur in successive years. (Fig. 1.) 
4. Conservation of rainfall on farms. - It is the business of the farmer so to handle his farm that the largest possible proportion of the rain that falls may be made to enter the soil, and to remain there until needed by plants, unless, indeed, the rainfall is too heavy, when provision must be made for relieving the soil of the harmful surplus. To accomplish this, the farmer must resort to methods for

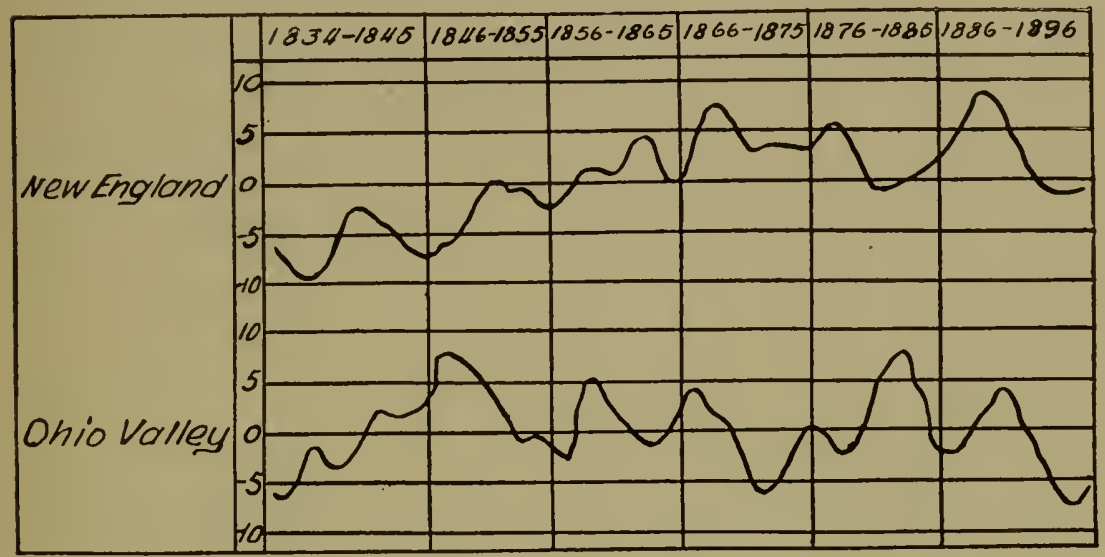

Fig 1. Progressive averages of annual rainfall (1834-1906).

preventing, or reducing largely, the loss due to the runoff, evaporation and seepage. Where the annual rainfall is fairly large and well distributed, these methods are not applied extensively; but where the annual rainfall is light or is not in the growing season, moisture-conserving methods are indispensable. There are relatively few localities on earth where special efforts to conserve the rains for plant-growth are not rewarded by large crop yields. The smaller the annual rainfall, the greater is, naturally, the return for careful moisture-conservation.

5. Conditions of dry-farming.- If the annual rainfall be very light, it frequently happens that, with the best available tillage methods, the water conserved in the soil 
is so small that only certain crops can be grown, and of these crops maximum yields are not obtained. The annual rainfall, below which special moisture-conserving methods are necessary, is different at different places. Ordinarily, where the rainfall is 20 inches or less, the special waterconserving methods of dry-farming must be used. Where the average temperature is high; where heavy winds blow largely; where the soils are shallow or infertile, or where other water-dissipating factors are especially active, the methods of dry-farming must be employed, even if the rainfall reaches 25 or 30 inches annually. On the other hand, with our present experience, we are obliged to admit that when the annual rainfall is less than 10 inches, our present methods of water-conservation are not sufficient, except in a few special localities, to make profitable crop-production possible.

6. Conditions of irrigation.-Wherever proper methods of manuring and tillage for water-conservation are insufficient to produce uniformly profitable or maximum crops, irrigation is employed. The first aim of the farmer should always be to store as much as possible of the natural precipitation in the soil, and to apply water artificially only to make up the deficiency in the quantity of water required by plants. The quantity of irrigation water, then, needed on any farm, will depend on the care with which the rainfall is conserved for the use of plants. The more thoroughly water-conservation methods are practised, the smaller the quantity of irrigation water required; the more carelessly the rain-water is conserved, the larger the quantity of irrigation water required. Irrigation should always be, and in a good system of agriculture always is, supplementary to the natural precipitation.

7. Irrigation defined.-Irrigation is the artificial appli- 
cation of water to lands for the purpose of producing large and steady crop yields whenever the rainfall is insufficient to meet the full water requirements of crops. Irrigation for the purpose of disposing of sewage is of limited extent, and is not always true irrigation.

8. Geographical need of irrigation.-The field of irrigation, as above defined, is very large. About 25 per cent of the earth's surface receives 10 inches or less of rainfall annually, and, with our present knowledge, can be reclaimed only by irrigation. Another 30 per cent of the

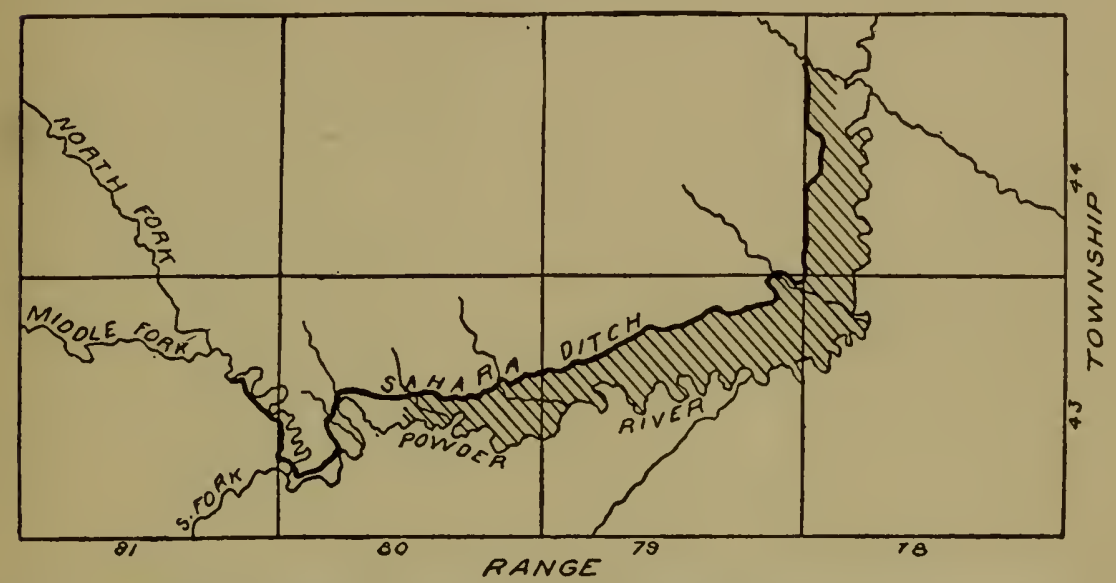

Fig. 2. The limited water supply makes it unlikely that more than one-tenth of the land will be irrigated. The shaded area is irrigated.

earth's surface receives between 10 and 20 inches of rainfall annually. Over this vast area the chief extensive crops may be grown without irrigation, but the intensive crops demand the help of irrigation. That is, nearly six-tenths of the earth's surface will be reclaimed, if at all, by irrigation and dry-farming. The remaining fourtenths will be helped materially by a system of irrigation.

9. Possible extent of irrigation.-The great rivers which, with their numberless tributaries, flow from the 
highlands through the arid and semi-arid lands, together with some of the underground waters, must be the source of the water to be used in irrigation. When a world-system of irrigation shall be perfected, all of the available water will not, in all probability, cover more than onetenth to one-fifth of the thirsting land. The remainder must be left to be conquered by dry-farming methods. Yet, the possible area to be reclaimed by irrigation is

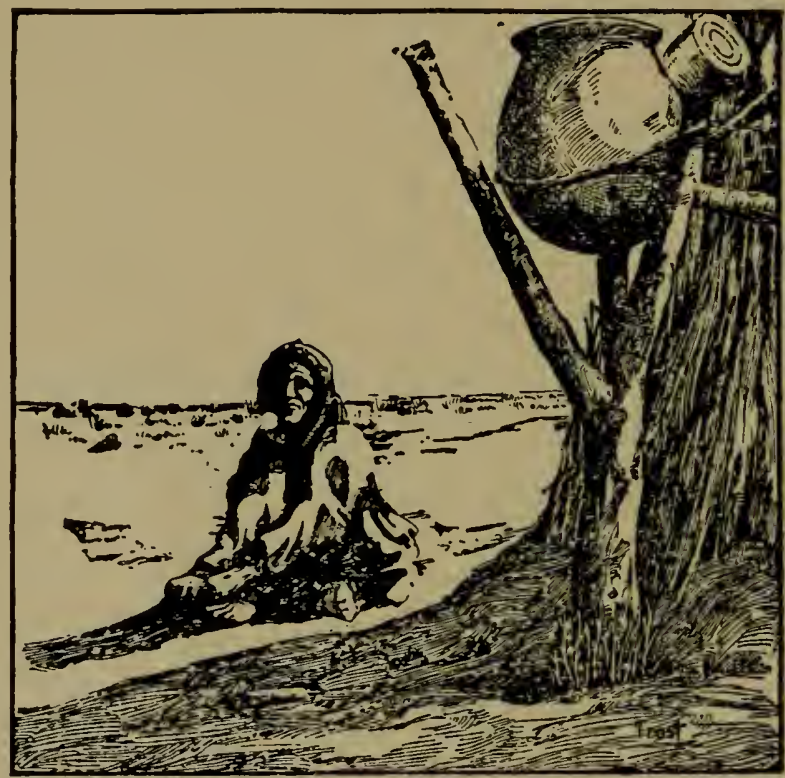

Fig. 3. The value of water in an arid land. A Papago squaw, in Arizona, utilizing the drip from her water bottle to grow a few onion plants beneath, protected by a paling of sticks.

tremendous; and in view of its certainty of large crop yield, farming under irrigation should be the most attractive of all modes of farming. (Fig. 2.)

Irrigation will further find a limited application in humid countries, the occasional dry years of which cause injurious droughts. In many of the humid regions the 
methods of dry-farming will often be found to be as effective and less expensive.

10. Mission of irrigation and dry-farming.-Irrigation and dry-farming go hand in hand in reclaiming the great countries under a low rainfall, and in forever banishing drought from the earth. In this volume the principles underlying a rational practice of irrigation are discussed. The dry-farming methods involved in irrigation are only touched upon in passing, for they have already been somewhat fully discussed in another volume.*

\section{REFERENCES}

Henry. Weather Bureau, United States Department of Agriculture, Bulletin No. D.

Mead, Elwood. Irrigation Institutions. The Macmillan Company. Neweld, F. H. Irrigation. T. Y. Crowell \& Co.

Sмүтне. Wм. E. The Conquest of Arid America. The Macmillan Company.

Widtsoe, J. A. Dry-Farming. The Macmillan Company (1910).

* Widtsoe, J. A., Dry-Farming: A System of Agriculture for Countries under a Low Rainfall. The Macmillan Company, New York. 


\section{CHAPTER II}

\section{SOIL MOISTURE}

AlL bodies in the universe attract each other. The greatest sun in the heavens and the smallest speck of dust under the microscope are mutually attracted. This universal force of attraction finds different expressions under varying conditions. Thus, the heavenly bodies, immense distances apart, are given definite motions and are held in their places by their mutual attractions. Bodies near the earth and belonging to it, instead of revolving in space, fall to the ground by virtue of this attraction which the earth exercises upon all bodies on or near its surface. In both these cases the attracting bodies are considerable distances apart.

11. Attraction between near bodies.-When the attracting bodies are brought very near each other, within reach of the molecular forces, which, probably are only expressions of the universal force, special attractions are observed. For example, if two plates of glass, evenly and highly polished, are laid upon each other they adhere so firmly that it is practically impossible to separate them. A square of iron, with a highly polished surface, may be lifted by simply lifting a similar square which has been placed on the lower square with the polished surfaces in contact. Two pieces of lead, with clean surfaces, will adhere very firmly, as will also india-rubber, wax and similar substances. These attractions act only through extremely small distances. If the polished plates 
of glass are separated by the thinnest piece of paper, they do not adhere; if the iron surfaces are a trifle dusty they do not adhere. The distance apart determines the adhesion.

It is generally held that the ultimate particles of all substances are held together by molecular attractions. Iron is a solid mass and not a pile of loose particles, because of the mutual attraction of like particles, known as cohesion. These molecular forces may be overcome by other forces, notably by heat. When the solid iron is heated, the molecular attraction is weakened until the iron is melted. If the heating is further continued, the molecular attraction is finally overcome, and the iron becomes a gas, in which state the ultimate particles, or molecules, actually repel each other.

This theory of attraction is of great help in understanding the phenomena observed in soils, especially in relation to water. When a pebble is dipped in water, a thin water-film clings around its whole extent. The water has come into very close contact with the surface of the pebble, within the reach of molecular forces, and a certain quantity of water adheres. The quantity of water, thus adhering, is just in proportion to the force of adhesion existing between the water and the rock surface. On the basis of this fact-the adhesion between rock surfaces and water-rest the tillage methods of moisture-conservation.

12. Soil particles.-Soil is composed of broken-down rock mixed with decaying animal and plant remains. The most notable properties of soil result from the minute size of the constituent particles. The coarsest particles useful to plants are from 1 to 3 millimeters in diameter, which means that about twenty-three placed side by side 
would make an inch. The finest are about .00001 millimeter in diameter; and it would require about 25,000 of them, placed side by side, to make an inch. Most of the particles in an ordinary soil are of a size intermediate between these extremes.

The smallness of the soil particles means that the number of them, in an acre of ground to a depth of one foot, fairly transcends the human mind. If a soil were made up entirely of the coarsest particles above mentioned, there would be, in 1 cubic inch, 12,167; if of the finest, there would be in 1 cubic inch, 15,625,000,000,000 particles. These vast numbers of soil grains of all sizes between the extremes given, are jumbled together in the

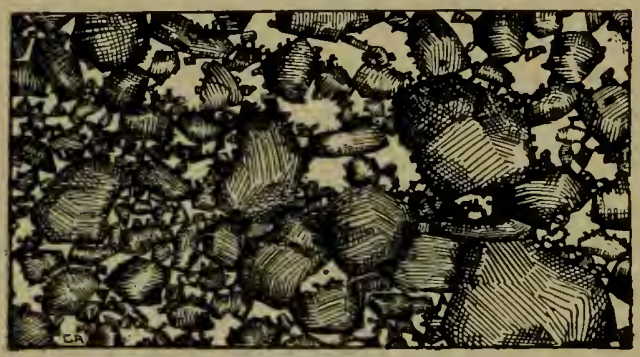

FIG. 4. Soil is a mixture of particles of very varying size.

soil in every conceivable manner. Groups and clusters of them are formed; the larger ones touch in few points, while the smaller ones fall into the spaces between, and lime and other substances often cause the cementing together of particles. The relatively large air spaces between the particles and groups form from 30 to 60 per cent of the whole soil volume. These open or air spaces are sometimes spoken of as pores or tubes. They are of infinite complexity of shape and direction as they wriggle through the soil mass. In spite of the immensity of the numbers and variety of the sizes of the particles, the whole porous sytem is held together as one, and possesses definite properties.

Of chief agricultural interest is the surface exposed 
by the soil particles, for it is to these surfaces that the soil water clings, and from them that the plant-food is largely derived. It is naturally very difficult to make this determination accurately, but approximate figures may be given. One pound of the coarsest particles above mentioned would expose an area of about 11 square feet; while one pound of the finest particles would expose about 110,538 square feet or more than $2 \frac{1}{2}$ acres. The surface of the soil particles in 1 cubic foot of an average soil, lying between the two extremes described above, would be nearly 50,000 square feet. The finer the soil, the larger would be the surface of the soil particles. This immense surface exposed by the particles of agricultural soils is of the highest importance in agriculture.

13. The soil-moisture film. - The result of the attraction between water and rocks is that water added to a soil forms a film over the surfaces of the particles. This film is continuous so far as the water goes, covering every particle, bridging every point of contact and filling every minute opening, the diameter of which is not greater than the distance through which the forces of adhesion act. True, in every soil, even in those composed of the smallest particles, when the soil-water film is of maximum thickness, the majority of the soil pores, which are much larger than the distance through which adhesion attraction can act, are open and free from water except as a thin film may cling to their sides. The shape of this film, as it fits accurately over every exposed surface, is a symbol of multiplied complexity that completely baffles human description or understanding.

When a given quantity of water is added to a given weight of soil, the thickness of the resulting soil-moisture film depends entirely on the fineness of the particles 
constituting the soil. This must of necessity be so, for, as has been shown, the smaller the soil particles the larger is the surface exposed; and the larger the surface, the thinner will be the film produced by a given quantity of water. The thickness of the soil-moisture film is of considerable importance, for from it plants secure the water needed in their growth. If the film be too thin, that is, if it is held very firmly, plants are not able to move it from the surface of the soil particle.

14. Thickness of film and diameter of particle.-A definite mathematical relationship exists for any per cent of moisture between the thickness of the soil-moisture film and the diameter of the soil grains. If a soil of a specific gravity of 2.75 contains 5 per cent of water, the thickness of the soil-moisture film is slightly more than two hundredths of the average diameter of the soil grains; if 10 per cent, a little more than four hundredths; if 20 per cent, not quite eight hundredths; if 30 per cent, a little more than eleven hundredths; and if the soil contains 40 per cent of water, the thickness of the soil-moisture film is about fourteen hundredths of the average diameter of the soil grains.

That is, the thickness of the soil-moisture film in soils that contain from 5 to 40 per cent of moisture, varies from two hundredths to fourteen hundredths of the diameter of the average soil grains. When the very small sizes of the particles themselves are considered, this shows the extreme thinness of the soil-moisture films, with which agriculture has to deal. Meanwhile, it must be remembered that only very fine soils can hold as much as 40 per cent of water. When the thickness of the soilmoisture film is somewhere in the neighborhood of one fifty-thousandth of an inch, it is probably near its maxi- 
mum thickness, and, when this has been reached, there are in average soils about 20 per cent of moisture.

15. Hygroscopic coefficient.-If a thoroughly dried soil be exposed to air, which is always somewhat moist, the attraction between the soil surface and the water vapor in the air immediately becomes active. Some of the water vapor condenses upon the surfaces of the soil grains to form the beginnings of the film. This coating of water is hygroscopic soil moisture. If the air surrounding the soil is saturated with water vapor, the largest possible quantity is condensed upon the soil. The percentage of moisture representing the full condensation of water upon soil from such saturated air, under given conditions of temperature, is known as the hygroscopic coefficient.

The water thus taken from the air is not wholly held as surface film. In every soil are certain substances (colloidal) that absorb water to form loose chemical combinations. Such materials are well represented by the jellies which hold large quantities of water uniformly distributed throughout their mass. Among the substances with more or less strongly marked jelly-like properties are clay, hydrate of iron, humus and decaying organic matter generally, and a number of gums, among which gum tragacanth is the most notable.

The hygroscopic coefficient, therefore, increases as the fineness of the soil increases, and as the quantity of the water-absorbing substances increases. For example, Lyon and Fippin found that very fine sand absorbed 1.8 per cent of hygroscopic moisture; silt, 7.3 per cent; clay, 16.5 per cent, and a muck soil absorbed 48 per cent of water from saturated air. Hilgard examined three soils very much alike, except that one contained 4 per cent, 
the other 19.83 per cent, and the third 51 per cent of iron hydrate. The hygroscopic coefficient of the first was 4.92 per cent; of the second, 15.40 per cent, and of the third, 19.66 per cent. At the Utah Station it was found that on the dry-farms, in the fall, after the baking heat of summer and before the autumn rains, the soil moisture remaining was in proportion to the clay contained by the soils.

The hygroscopic moisture is held very firmly by the soil, and it is very doubtful if it has any direct value for plants. The part clinging around the soil grains probably has no such value, but it is possible that the colloidal soil constituents often containing much water may be made to give up some of their water to the growing plant. King has suggested that in seasons of drought the hygroscopic water may evaporate at one point in the soil and be condensed elsewhere upon the root-hairs in search of water. The chief agricultural interest of hygroscopic soil moisture is that upon it and possibly in part by it, is held the water which really can be used by plants.

16. The wilting coefficent.-Water added to a soil, the hygroscopic coefficient of which has been satisfied, simply thickens the soil-moisture film or more completely saturates the colloidal soil constituents. The first water thus added above hygroscopic saturation is also held very firmly and is of little or no direct value to plants. As more water is added, however, and the film is thickened around the soil grains, the outer layers of the film water are held with less and less force, and a point is at last reached above which plants can use the soil moisture in growth, although it may be with some difficulty. Whenever the soil moisture in a cropped field is reduced to this point, the plants growing on the soil 
begin to wilt, and growth practically ceases. The percentage of moisture corresponding to this point is called the wilting coefficient.

According to the researches of Briggs and Shantz, the wilting coefficient is about one and one-half times the hygroscopic coefficient. That is, in a soil with a hygroscopic coefficient of 6 per cent of water, the wilting coefficient would be about 9 per cent. This relative value of the wilting coefficient appears to be confirmed by field experiments conducted at the California and Utah Experiment Stations.

The wilting coefficient, like the hygroscopic coefficient, varies with the soil used. In sandy soils it is low, often less than 1 per cent of moisture; in clay soils higher, often more than 16 per cent, and in extremely heavy clays as high as 30 per cent; in the average loam, about 10 per cent of moisture. It is ordinarily thought that plants differ markedly in their power of reducing the soil moisture before wilting. Recent researches do not bear out this view. On a given soil, under like meteorogical conditions, the wilting coefficient is within 1 to 3 per cent of each other for all the ordinary plants at the same period of growth, whether grown under arid or humid conditions.

While growth undoubtedly ceases at wilting, yet the plant may slowly take up some of the moisture held in the soil below the wilting point. On the other hand, under proper methods of agriculture the soil moisture is seldom reduced to the wilting point, especially on deep soils, if irrigation has been practised regularly. At the Utah Station, several crops, in their medium stages of growth, were allowed to go for long periods, from twentyseven to fifty-five days, without irrigation. At the close 
of the periods, the grain crops and the peas were practically ripened. No noticeable injury from wilting was observed. Some of the results are presented in the following table:

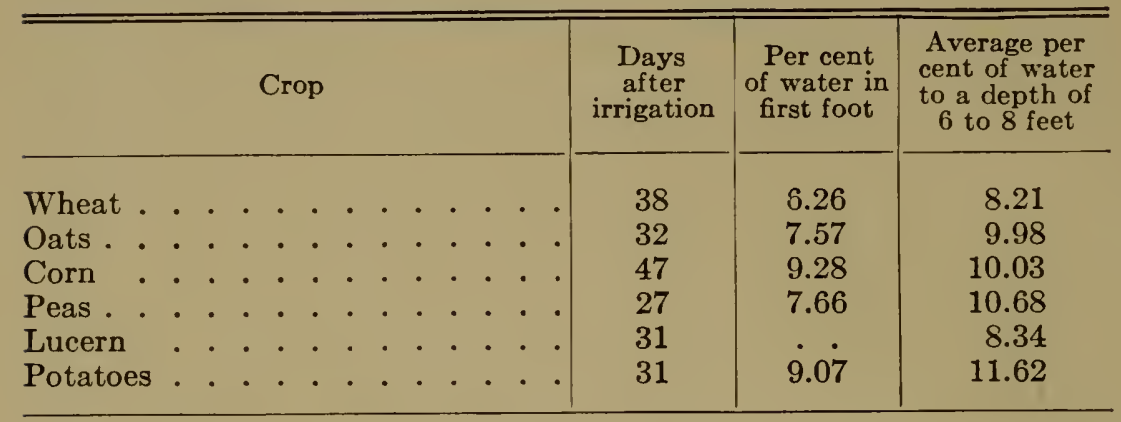

The hygroscopic coefficient of the soil was about 5 per cent, which would make the wilting coefficient about $71 / 2$ per cent. In only one case, that of wheat, did the soil moisture go below this point in the first foot; and, in every case, the percentage of soil moisture to a depth of 6 to 8 feet, through all of which root-action was felt, was above the calculated wilting coefficient.

17. Lento-capillary point.-The water in the soilmoisture film corresponding to the wilting coefficient is held so firmly that plants can absorb it with difficulty. As more water is added to the soil, to thicken the film, the more loosely is the water held, and consequently the more easily can plants secure it. As this thickening goes on, a point is reached above which the film water is held so loosely that it moves freely from soil particle to soil particle under the influence of the forces in the soil. This has been called the lento-capillary point. The water above this point is readily available to plants, and constitutes the main supply of water for plants under irrigated conditions. 
Whenever the soil moisture is above the lento-capillary point, plants secure their water with the least expenditure of energy, and it should therefore be the purpose of irrigation to maintain the moisture in the soil above this point, at least during the periods of most rapid plantgrowth. In practice, this is usually done, except in seasons of water-shortage. The practical irrigator recognizes the need of irrigation by a faint change in the color and rigidity of the plants-possibly a condition preliminary to wilting. When this occurs, the soil moisture is ordinarily just above or below the lento-capillary point.

During two summers, on the experimental fields of the Utah Experiment Station, the moisture in the soil was determined immediately before each of several hundred irrigations. In the first year, the percentage of soil moisture was 13.17 ; in the second, 13 . In every case, the practical irrigator declared the field in need of irrigation. The lento-capillary point was determined for this soil to be about 12.68 per cent, or almost identical with the percentage of soil moisture at which irrigation was declared advisable.

18. Maximum capillary capacity.-As the 'soil-moisture film is thickened by the further additions of water above the lento-capillary point, the force with which the outer layers of water is held becomes weaker and weaker. At last a point is reached above which no more water can be taken up. When this thickness of the film is reached, new additions of water simply slide off the film and are drawn away by gravity. This is the point of maximum capillary capacity.

19. Free water.-Water added to a soil above the maximum capillary capacity is called free water. It moves slowly downward through the pores and tubes of 
the soil until it is all absorbed by the lower drier soil or until it communicates with the standing water-table.

Soil moisture is the term used to designate the water held in the capillary condition in soils. Soil water denotes

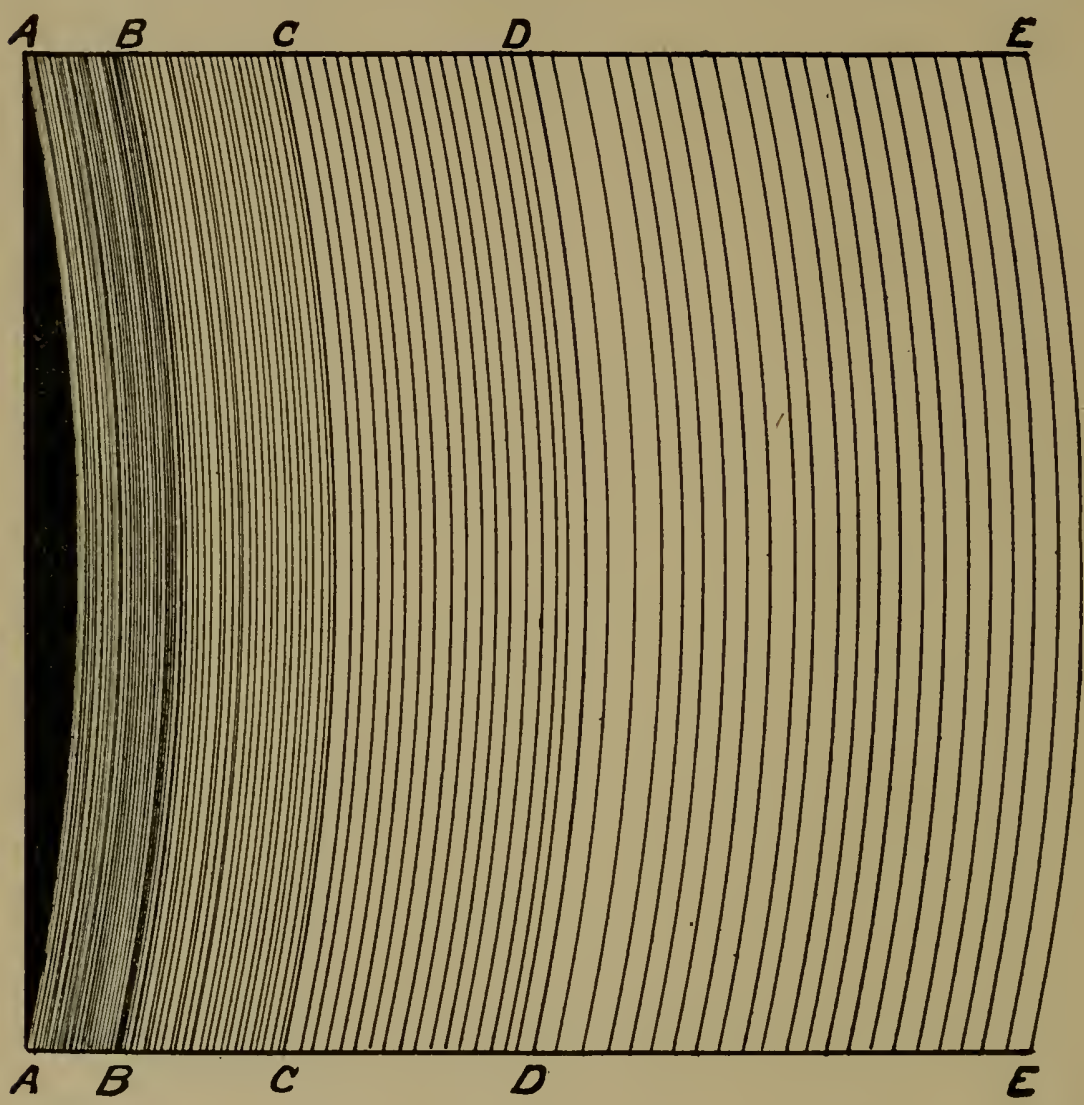

FIG. 5. The moisture film surrounding a soil particle. The black part represents a segment of the particle. (b) Hygroscopic coefficient; (c) wilting coefficient; $(d)$ lento-capillary point; $(e)$ point of maximum capillarity; $(d-e)$ freely moving capillary moisture.

the free water, that beyond capillary saturation, which may exist in soils. Many books on agriculture speak of the maximum water capacity of soils, meaning the water held in a volume of soil artificially confined in a funnel or 
tube, when the air spaces in the soil are completely filled with water. This constant has no great agricultural value. It represents a condition that should be avoided so far as is possible in farming under irrigation, except in the top foot of the soil while water is actually being applied to the land.

20. Summary.-The principles upon which rational irrigation practices are built, rest upon the facts presented in this chapter. The attraction existing between soils and water causes water to cling as a film around the soil grains. The hygroscopic coefficient represents the water which is condensed from the water vapor of saturated air; it is of no practical value to plants. The wilting coefficient, about one and one-half times the hygroscopic coefficient, represents the point below which plants can not secure sufficient water from the soil for their needs. The lento-capillary point is the point above which the soil moisture is readily available to plants. Above this point, also, film water moves freely in obedience to the laws of capillarity. The maximum capillary capacity represents the point at which the attraction between the soil surface and water ceases to be active; it is saturated. From the first hygroscopic coating to the maximum capillary water capacity, the water is said to be in a capillary state. Any water added above this point is free water moving in obedience to the pull of gravity. (Fig. 5.)

Much excellent work has been done on soil moisture by investigators, both in Europe and America. F. H. King, E. W. Hilgard, Milton Whitney and his associates, have done much of the American work. Unfortunately, for the arid regions, most of the work on soil moisture has been done under humid conditions. For instance, capillarity has been studied almost entirely by placing 
tubes filled with soil in pans containing water, and the upward movement has been studied. This is of little interest to the arid regions. Much profitable work may be done for irrigation by the careful study of the movement of water applied to soils as under irrigated conditions.

\section{REFERENCES}

Briggs, Lyman J. The Mechanics of Soil Moisture. United States Department of Agriculture, Bulletin No. 10 (1897).

Briggs, Lyman J., and Shantz, H. L. . The Wilting Coefficient for

Different Plants, and Its Indirect Determination. United States Department of Agriculture, Bureau of Plant Industry, Bulletin No. 230 (1912).

Hilgard, E. W. Soils. Chapters VI and XIII (1906).

KING, F. H. Physics of Agriculture. Chapters IV and V (1901).

Widtsoe, J. A., and McLaughiss, W. W. The Movement of

Water in Irrigated Soils. Utah Experiment Station, Bulletin

No. 115 (1912). 


\section{CHAPTER III}

\section{THE SOIL AS WATER RESERVOIR}

IN an ideal system of irrigation, water would be applied continuously to the soil, and at a rate to meet the actual requirements of the plants growing on it. Except in a very few cases, this ideal method is impossible. In practice, lands are watered intermittently. When the "turn to water" comes, the farmer applies to the soil in a few hours, or in a few days at most, as much water as he is allowed, or as he believes will supply the crop until the next turn comes, which may be a few days or several weeks hence. Even in cases where the farmer has at his disposal a continuous flow of water, it is seldom practicable or wise to attempt continuous irrigation of any one field. Irrigation is essentially an intermittent practice.

Plants can not live long without water. When the water in the soil is reduced to the definite limit known as the wilting coefficient, plants may be seriously injured in a few hours, unless more water is added to the soil. In view of this fact and the common knowledge that crops thrive under systems of irrigation-rotation, it is evident that water applied in irrigation is held by the soil in quantities sufficient to maintain crops in a good condition until the next watering occurs. That is, water may be stored in the soil in considerable quantities. The property of soils to act as storage reservoirs for water is of the highest importance in the practice of irrigation. 
21. Irrigated soils are unsaturated.-In all proper irrigation practice, the farmer is dealing with unsaturated soils. Many of the best results of irrigation are due to this condition; and the irrigation practices to be outlined refer largely to soils which are not fully saturated with water.

Water should ordinarily be applied to crops when the water in the soil has reached the point of lento-capillarity as described in the preceding chapter; that is, the point below which capillary movements become very slow. When the soil water has been exhausted to this point, the plant is obliged to expend an unnecessary amount of energy in securing water, and the soil should be irrigated. Experienced, practical irrigators declare that irrigation is necessary about the time this point has been reached. It may usually be recognized by a flabbiness and a slight change of color in the leaves and stalks of the plants.

The percentage of moisture in the soil which corresponds to this point of slow capillary motion varies according to the fineness of the soil. In coarse soils it may be below 10 per cent; in fine clayey soils, 20 per cent or more. For average loam soils it is in the neighborhood of 12 or 13 per cent.

The maximum capacity for capillary soil moisture also varies with the soil. In coarse sandy soils it frequently falls to 12 , or even 10 , per cent; in fine clayey soils it rises to 30 or 40 , or more, per cent. In average loam soils it is not far from 24 per cent.

The water actually used in a wise system of irrigation varies, then, between the maximum capillary saturation and the point of lento-capillarity, which, in an ordinary loam soil, is a variation of from 24 to 12 per cent. This must be supplied from time to time by irrigation; but, 
the usual quantities of water added in irrigation seldom, if ever, are sufficient to bring the soil beyond the first or second foot to maximum capillary saturation.

The quantity of water that may be applied in any one irrigation depends somewhat upon the nature of the soil, yet varies within rather narrow limits. It is seldom possible to apply at one irrigation less than 2 inches, and practically impossible to apply more than 10 inches, unless the soil be very gravelly. The practical limits are yet narrower; a light irrigation is about 3 inches, a heavy one about 8 inches; and an average one from 5 to 6 inches.

One inch of water is equivalent to 3 per cent of soil moisture to a depth of one foot. A heavy irrigation of 8 inches would, therefore, raise the soil moisture in 1 foot of thoroughly dry loam soil to 24 per cent, or maximum capillary saturation. If the soil, at the time of irrigation, contains 12 per cent of moisture, one such heavy irrigation would raise 2 feet of soil to full capillary saturation. Since the moisture in the upper 8 to 10 feet is concerned in plant-production, the full, soil column under such irrigation is far from saturation. In fact, a loam soil, containing 12 per cent of moisture, will contain, after receiving a heavy irrigation of 8 inches, not more than an average of 15 per cent to a depth of 8 feet; while the full saturation is about 24 per cent. With a medium irrigation of about 5 inches the unsaturated character of the soil would be still more marked.

22. The movement of soil moisture.-The water added to soils by irrigation, instead of saturating the upper soil a foot or two, distributes itself with great regularity to considerable depths in the soil. All soil moisture is acted upon by the two chief contending forces of gravitation and adhesion. Gravity tends to 


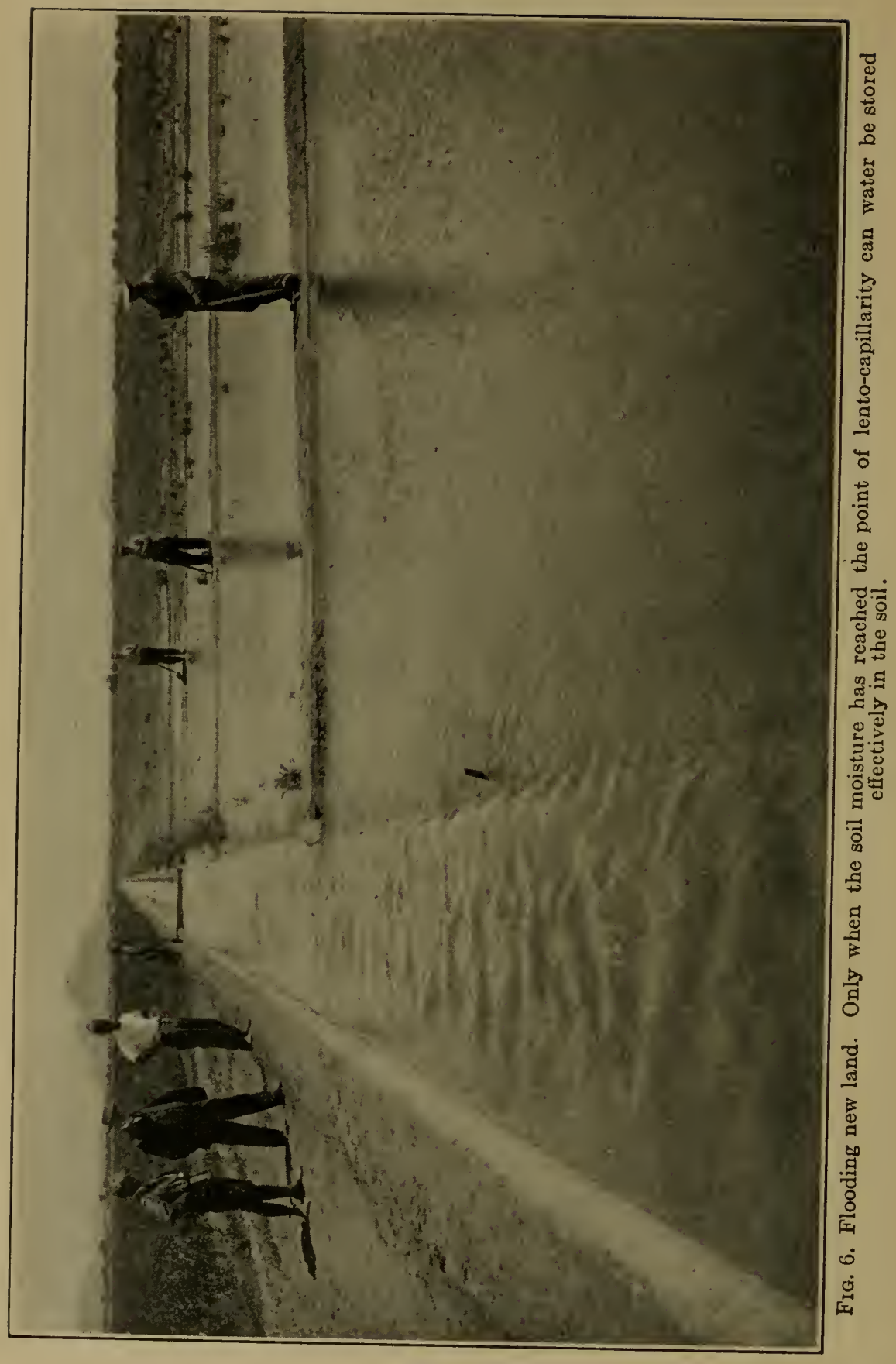


pull the moisture downward, while the attraction between the soil and the water tends to hold it as a film around the soil grains. The actual movement of a particle of water in a soil is a resultant of these forces.

In general, water moves from the thicker to the thinner soil film. Immediately after an irrigation, when the upper soil layers are wettest, the water moves downward; immediately before an irrigation, when the plants have largely exhausted the upper soil layers of water, the soil water is moving slowly upward. The downward movement, aided by gravity, is more rapid than the upward movement against gravity. The film of soil moisture is usually in a state of motion, attempting to place itself in equilibrium with the many contending forces in the soil. As examples, the moisture in the soil moves in all directions toward a point at which a roothair is absorbing water; and, as evaporation occurs at the soil surface, there is a general upward movement of the soil moisture to supply the loss.

The drier the soil, the slower does the soil moisture move. Under the point of lento-capillarity, soil-moisture movements occur with great difficulty; above this point, they occur with great freedom. One proof of this is that at depths of 8 to 10 feet, where plant roots penetrate in small numbers only, the moisture is seldom reduced below the lento-capillary point, while nearer the surface and abundant root-action the moisture is often reduced to the wilting coefficient.

23. The distribution of soil moisture.-After a surface irrigation of a soil with a water content near the lento-capillary point, the upper soil layers are invariably wetter than the lower ones. Any deviation from this rule is only apparent and is due to the fact that the subsoil 
contains more clay or other fine particles than the top soil, and therefore has a higher water-holding power per unit weight of soil. When the thickness of the soil-moisture film is considered, there is, immediately after an irrigation, a steady diminution with increasing depth. In soils of approximately uniform structure, this is well brought out, as in the following table, taken from the work of the Utah Station. In this table are shown the percentages of water in each foot to a depth of 8 feet, one or two days after irrigations of various depths, and in early spring after the winter precipitation has distributed itself.

\begin{tabular}{|c|c|c|c|c|c|c|c|c|c|c|c|}
\hline & & & & & & & & \multicolumn{3}{|c|}{ Depth of water applied } & \multirow{2}{*}{$\begin{array}{l}\text { In the } \\
\text { spring }\end{array}$} \\
\hline & & & & & & & & $\begin{array}{c}7.5 \\
\text { inches }\end{array}$ & 5 inches & $\begin{array}{l}2.5 \\
\text { inches }\end{array}$ & \\
\hline 1st foot & 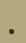 & . & . & . & . & & . & 23.80 & 23.56 & 18.57 & 18.42 \\
\hline $2 \mathrm{~d}$ foot & . & . & - & & . & • & . & 21.88 & 20.73 & 13.81 & 17.49 \\
\hline $3 d$ foot & . & . & . & - & . & - & . & 20.17 & 19.09 & 13.53 & 15.65 \\
\hline 4th foot. & . & . & . & . & . & . & . & 17.72 & 17.84 & 13.46 & 14.07 \\
\hline 5 th foot. & . & . & . & • & . & . & . & 15.91 & 16.29 & 12.32 & 13.98 \\
\hline 6 th foot. & . & . & . & - & . & . & . & 14.55 & 15.83 & 11.81 & 13.14 \\
\hline 7 th foot. & . & . & . & $\bullet$ & - & . & . & 14.21 & 15.60 & 12.31 & 13.26 \\
\hline 8th foot. & . & . & . & . & . & . & . & 14.15 & 14.81 & 12.70 & 12.93 \\
\hline
\end{tabular}

This distribution of soil moisture may be explained as follows: Water added to a soil first saturates the upper soil layers thoroughly, and there is a tendency to keep the top soil as near as possible to this point of maximum capillary saturation. Then, the lower drier layers begin to draw water downward. The wettest particles are near the top; the lower particles are all attracting the water. As water moves downward through the thin capillary film, friction has to be overcome. The farther the particle is away the more friction must be overcome. The water above the point of lento-capillarity therefore 
tends to distribute itself inversely with the distance of a soil particle from the wettest particle which is the source of supply; that is, after an irrigation, the soil-moisture film will be thickest in the top foot, and will become steadily thinner in the lower soil layers. (Fig. 7.)

If the soil is very dry, say near the wilting coefficient, when an irrigation occurs, the downward movement of water is slow. Under such a condition the upper soil sections remain saturated until the moisture in the lower

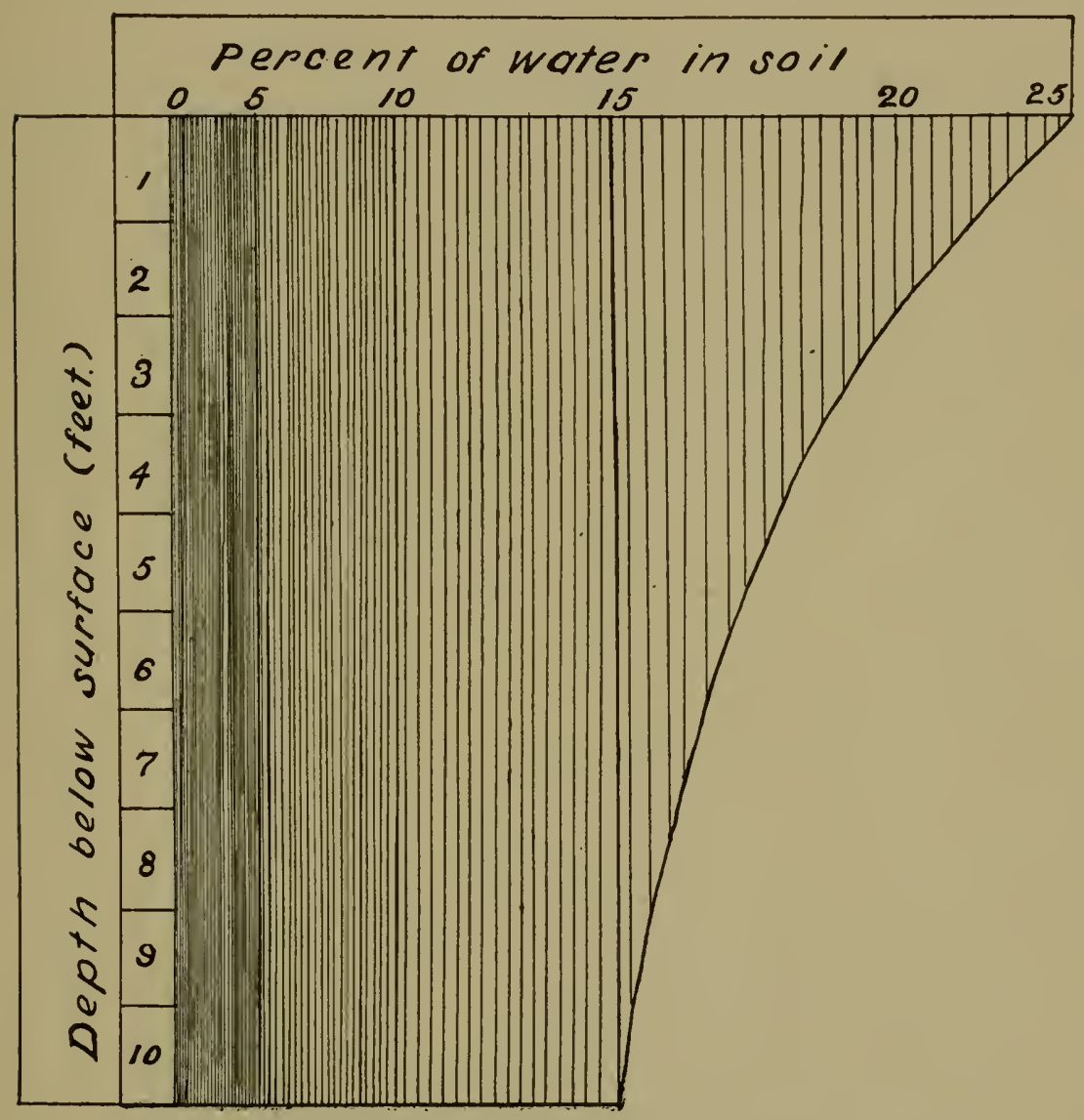

FIG. 7. Distribution of water in soil immediately after an irrigation. 
layers has gone above the point of slow capillarity. Whenever that has been done, the moisture moves downward freely in obedience to the law already stated. This is really a matter of common experience, in opening any irrigation project in the arid region. The farmer finds that the water does not penetrate the soil deeply the first year of irrigation; but, as time goes on, the soil becomes wetter to greater depths, and at the same time less water is required to produce crops. The moisture content of the native undisturbed soil in arid regions is usually below the point of lento-capillarity. The first water added is used to bring the moisture content up to this point. As this is accomplished, water moves downward freely; and plants, also, are enabled to secure their water supply with a smaller expenditure of energy.

The above law of distribution, which appears to hold for all unsaturated soils, above lento-capillarity, is a provision of nature of utmost importance in the economic use of irrigation water. Though water moves steadily downward after an irrigation, by far the largest' proportion is held near the surface where plants can use it. It has been roughly estimated, on the basis of the law. of distribution, that on a deep soil with a moisture percentage at the point of lento-capillarity, 85 per cent of a heavy irrigation will be held in the upper 10 feet, within reach of plants. By reducing the irrigations properly, it is possible to prevent practically any of the irrigation water from descending below the zone of plant activity. On the other hand, if water is applied to a soil too frequently or in excessive quantities, the excess will slide downward to great depths, to reappear somewhere as seepage or drainage water. A good understanding of this principle, properly applied in irrigated districts, will do 
much to lessen the danger of injury from water-logged and alkali lands.

In ordinary practice, lands should not be irrigated until the crop has reduced the soil-moisture content nearly to the lento-capillary point, and a little lower in the upper layers. Then only enough water should be applied to supply the zone of crop-action, say 10 or 12 feet. This quantity varies, in different soils, but seldom exceeds a depth of 6 inches at an irrigation.

24. Field moisture capacity.-The law of distribution of water in soils makes it clear that the average percentage of water held in a soil to a depth of say 10 feet, after even a heavy irrigation, is far below the maximum capillary water capacity. Under the conditions prevailing in irrigated districts, except when over-irrigation is practised, the top foot or often the top layer contains only the maximum capillary percentage of moisture. The percentage becomes steadily smaller with increasing depth until, at 8 to 15 feet, it is very little above the point of slow capillary motion. This is especially well brought out in the spring, in districts where the precipitation comes chiefly in the winter time. In early spring, after the water from the winter snows and rains has soaked into the soil and distributed itself, it was found that, in the Utah experiments, a soil with a maximum capillary capacity of 25 per cent invariably contained, to a depth of 8 feet, an average of 18 or 19 per cent of moisture. Crawley observed similarly that certain Hawaiian soils of a maximum capillary capacity of 32 to 39 per cent contained in the field only 22 to 29 per cent of moisture. The percentage of moisture held in field soils to a depth of 8 to 10 feet, when the top foot is saturated, may be called the field water capacity of a 
soil. It is not far from the optimum water content for plant-growth.

25. Water distribution in furrow irrigation.-Wherever the water supply is plentiful, irrigation by some form of the flooding method is largely employed. Where water is scarce and smaller quantities must cover equal areas of land, the furrow method of irrigation is almost invariably practised. With certain crops, and on certain lands, even if the water supply is large, the furrow method of irrigation is preferred.

Water applied in a furrow moves not only vertically downward, but in every direction from the wetted furrow. The movement downward, aided by the full force of gravity, is the most rapid; it diminishes as it becomes more horizontal. That is, the lateral is smaller than the downward movement. It is a common experience that the lateral capillary movement of water near the surface of deep soils, is slight. In an average loam soil it is seldom more than 6 feet from the wetted center; in clay soils iarger; in sand soils smaller. The law of distribution is of the same nature as for the downward movement.

If neighboring furrows are not too far apart, the moisture films moving in all directions from them finally meet, until, at certain depths, depending on the nature of the soil the size and distance apart of the furrows, and the quantity of water used, the percentage of water is practically the same, whether under or between the furrows. Loughridge, in a study of California orchards, when the furrows were from 6 to 8 feet apart, showed this to be true for a variety of soils. In the Utah work, on a loam soil, at depths of 5 and 6 feet, there was little difference in the moisture content under furrow or row, when the furrows were about 3 feet apart. The longer 


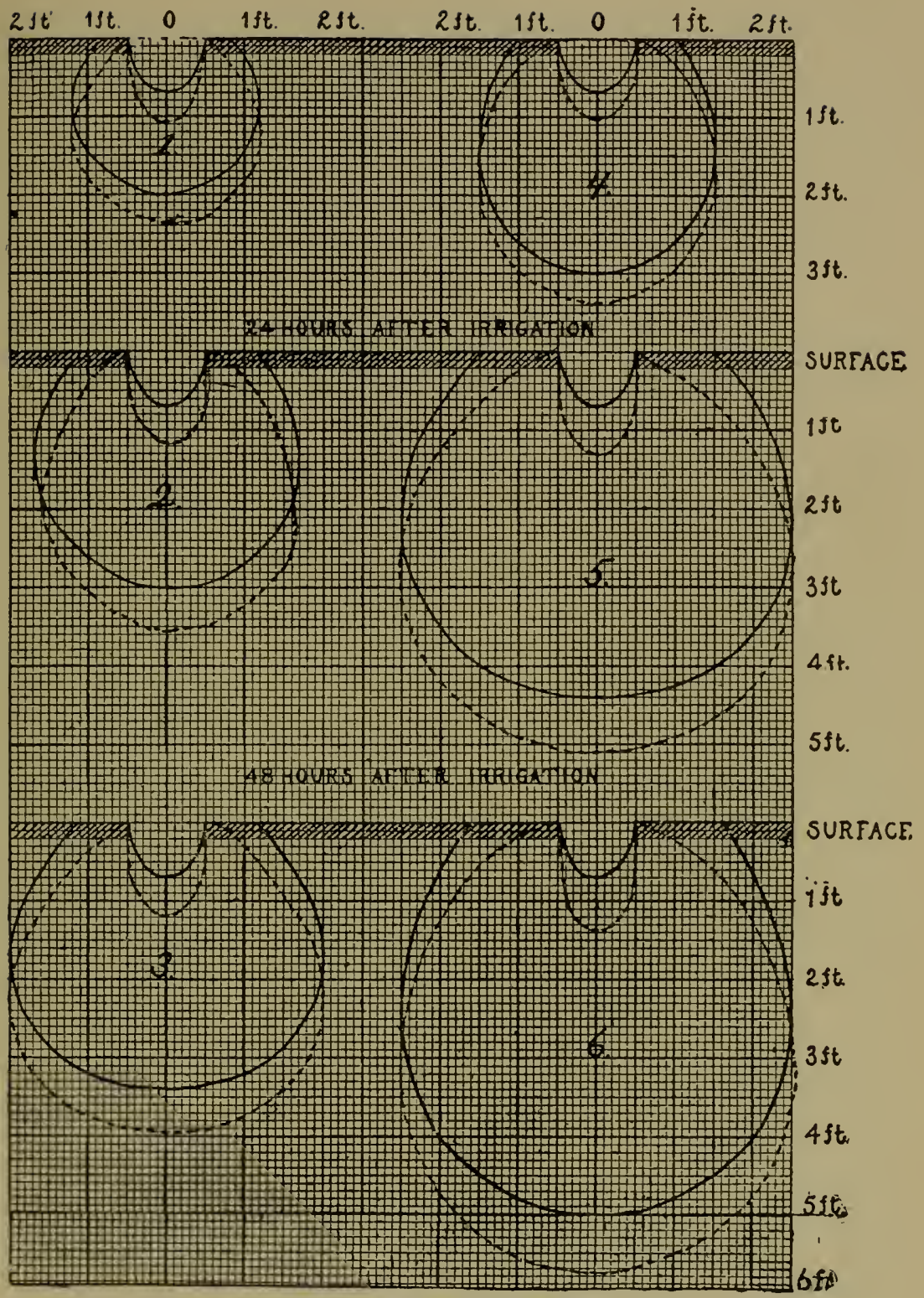

72 HOURS AFTER IRRIGATION

FIG. 8. Distribution of water in soil under furrow irrigation. 
the water flows, the more completely will the lower soil layers be provided with the same percentage of water. In all cases, the law of distribution will be the same, except as modified by the full or partial help given by gravity, according to the direction in which the movement is taking place. (Fig. 8.)

26. Effect of hardpan.-A layer through which water can pass with great difficulty, if at all, is often found a short distance below the soil surface. Sometimes it is merely the "plowsole," resulting from the repeated plowings of a somewhat clayey soil to the same depth. More often it results from the mutual relations of climate and soil. For example, in a country where the rainfall is heavy, the very fine particles of a heavy clay soil are washed downward, until the whole subsoil becomes more or less impervious to water. In regions of light rainfall, that is, in true dry-farming and irrigation regions, this washing down of fine material stops abruptly at a point representing the depth of penetration of the rainfall. Approximately the same quantity of rain falls from year to year on a certain soil. In the course of time there is formed at this point an accumulation of material commonly called hardpan. Under a light rainfall, on a clay soil, the hardpan may be only a foot or two below the surface; on a sandier soil, from 4 to 10 feet, or even more, below the surface. Students of arid soils often estimate the annual precipitation of rain and snow by the depth of the hardpan.

Not only are the fine clay and silt particles washed downward by the rains. Lime and other similar substances are dissolved by the descending water, which cement together firmly the materials of the hardpan. Such calcareous hardpans are often so hard that they 
can be broken only by explosives, and, usually, in the beginning are impervious to water.

As the practice of irrigation continues, the hardpan formed by the natural precipitation is softened, the materials of which it is made are distributed over larger soil depths, and frequently it wholly disappears.

Under vast areas of the soils of arid regions, and not far from the surface, are found layers of shale or other stone. These were deposited by geological forces upon the soils then existing, and later, through ages, new soils were deposited upon these layers. In other cases, the original rock is only a few feet below the surface. Such hindrances to the free descent of water cannot, of course, be removed by frequent irrigation.

An impervious layer a short distance below the surface, whether of a temporary or permanent nature, establishes conditions which change the laws of distribution of water in soils as outlined previously in this chapter. When the irrigation water, in its descent, encounters the hardpan, the downward movement stops, the soilmoisture film thickens; if more water is added, water accumulates on the hardpan and fills the soil pores, thus producing an undesirable habitat for the plant-roots, and leads to serious crop injury.

A soil underlaid with hardpan is always in danger of being water-logged, for the tendency is to apply as much water to such soils as to deeper lands. True, as will be shown later, in wet soils plants use more water than in dry ones. Yet, ordinarily, more water is added than plants can use. Moreover, the excess of water in the soil is a positive hindrance to successful plant-growth. Soils underlaid with hardpan should be irrigated more moderately and more frequently than deeper soils. It is often 
found profitable to blast occasional holes through the hardpan to serve as outlets for the excess water that stands on the hardpans. Such holes, to be effective, should occur frequently, in which case the process becomes very expensive.

27. Effect of gravel.-When the soil is underlaid with gravel, or if gravel seams pass through it within 10 or 12 feet of the surface, the normal distribution of the soil moisture is disturbed. By such gravel is meant the loose, open gravel which makes the soil discontinuous. If gravel is mixed uniformly with the soil from the surface downward, or at varying depths, the soil may be looked upon as being continuous so far as the distribution of water is concerned.

When water, moving downward, reaches a layer of loose gravel, the descent of the moisture film is first arrested, then the film is thickened until the lower soil pores are filled, and, if irrigation is continued, gravitational water drips from the soil into the gravel below. The water which thus passes into the gravel can not move back by capillary means, and usually drains away into the subsoil and is lost to plant use.

Soils, made faulty because of gravel seams, should therefore be irrigated lightly. Not enough water should be added to allow any part to move into the subsoil. Under such conditions, more frequent applications of water become necessary. On the benches and foothills, such soils are of frequent occurrence.

28. Water table near surface.-When the standingwater table is within reach of plant-roots, heavy irrigation should be avoided. Just enough water should be added to keep the soil moist without allowing any appreciable quantity to drain into the ground water. 
29. Soil treatment.-A deep, continuous soil is the best under irrigated conditions. On such a soil enough water may be added at each irrigation to leave the top foot saturated after distribution has occurred. This quantity varies usually from a depth of 5 to 8 inches over the whole area. To make more rapid the entrance of water into the soil, the surface should be kept in a loose, absorptive condition. The deeper the soil is plowed, the greater the quantity of water that may be stored in a given time, in the top soil, to move gradually downward into the subsoil. Since the application of water tends to compact the soil, it becomes necessary to stir the soil between irrigations. Such stirring not only makes it easier for water to enter the soil; it also reduces the loss from evaporation.

Soils, which within 10 or 12 feet from the surface are underlaid with hardpan or ground water, or made discontinuous by gravel streaks or layers, must be irrigated cautiously. In such cases the quantity of water to be added should be such as to allow only a thin soil-moisture film to reach the hardpan, ground water or gravel. Small, frequent irrigations must be the rule in such cases -smaller and more frequent as the faults are nearer the surface.

30. How much water can be stored.-It is clear from the statements of this chapter that water may be stored. in soils to considerable depths as a film surrounding the soil particles and filling the capillary spaces. Since water, whether from rain or irrigation, is ordinarily applied intermittently, it is important to know how much of the water added at any one time is retained by soils for the use of plants.

At the Utah Station, where most of the precipitation 
comes in winter, a long series of experiments showed conclusively that in the spring most of the water that fell throughout the winter was held in the upper 8 feet of soil. The quantity held in the soil section varied with

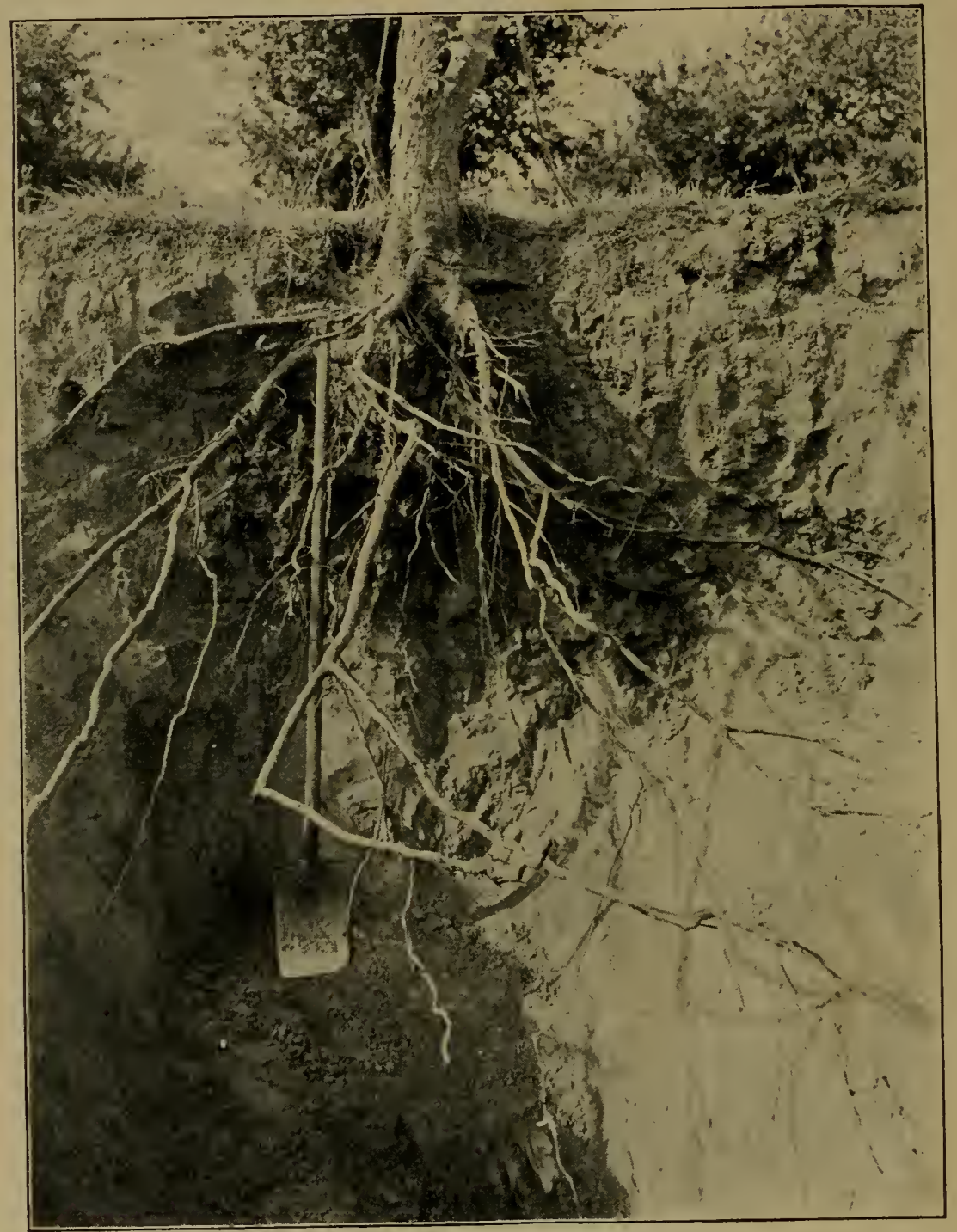

FIG. 9. Penetration of roots of prune tree. 
the percentage of water in the soil in the fall. If the soil went into the winter in a dry condition, practically all of the winter precipitation was found in the spring in the upper 8 feet. If, on the other hand, the soil was well filled with water in the fall, from fallowing or fall irrigation, a relatively small quantity of the winter precipitation was found in the upper 8 feet of soil, when spring opened. In both cases the soils were saturated in the spring. That is, the upper foot was fully saturated; the percentage diminished steadily with each succeeding foot in accordance with the law of distribution already explained. It was clear that when the soil was fairly completely saturated in the fall, the winter precipitation soaked down below the 8-foot limit. During six years, 1902 to 1907 , the percentage of the total winter precipitation found stored in the soils that went into the winter in the driest condition varied from 63 to 96 per cent.

This teaches, incidentally that, when the soil is saturated to a depth of 10 to 12 feet, there is not an advantage in adding more water. Therefore, in districts where the precipitation comes in winter, early spring irrigations may have little value. On the other hand, where the winters are dry and the summers wet, early spring irrigations should prove very profitable.

At the North Platte substation of the Nebraska Station, where the precipitation comes chiefly in early summer, a similar series of experiments were conducted. It was found that, in spite of the water-dissipating conditions of summer, from 40 to 50 per cent of the rain which fell from May 1 to September 1 was stored in the soil to a depth of 6 feet at the end of the period. Since it was evident that the water passed below the 6 -foot limit, 
it is probable that considerably more of the summer precipitation would actually have been found if moisture determinations had been made to greater depths.

Similar results were obtained from the irrigation experiments of the Utah Station. Water was added in varying quantities to a deep loam soil already well filled with water. The soil was sampled to a depth of 8 feet twenty-four hours after irrigation. The results for one year follow:

Depth of water applied, in inches . . . Per cent of the water added, found one

Some of the water was no doubt lost by evaporation; some moved below the 8-foot limit, yet from 69 to 100 per cent of the total quantity added was found to be stored in the soil, for the use of plants, one day after irrigation.

It is clear, therefore, that water, whether of rain or irrigation, may be stored in soils. In clay soils, with fine particles and a large surface, much more water may be stored than in sandy soils, with coarse particles and a small surface. If evaporation is prevented, and crops are not growing on the soils, such stored water may remain in the soil for long periods of time. If the water is in the film condition, there is no great downward movement after equilibrium is once restored.

31. Absorption of water by soils.-Water storage is best accomplished when the water is made to enter the soil quickly. This happens when the top soil is kept in a loose condition and when the soil, to a depth of several feet, is tolerably moist. If the surface is hard, the runoff is large; if the soil is dry, the downward penetration is slow. 


\section{REFERENCES}

Alway, F. J., and Clark. A Study of the Movement of Water in a Uniform Soil under Artificial Conditions. Nebraska Experiment Station, Twenty-fifth Annual Report, p. 246 (1912).

Burr, W. W. Storing Moisture in the Soil. Nebraska Experiment Station, Bulletin No. 114 (1910).

Leather, J. W. Water Requirements of Crops in India. Part II. Agricultural Research Institute, Pusa, Memoirs of the Department of Agriculture in India, Chemical Series, Vol. I, No. 10 (1911).

Loughridge, R. H. Distribution of Water in the Soil in Furrow Irrigation. United States Department of Agriculture, Office of Experiment Stations, Bulletin No. 203 (1908).

Widtsoe, J. A. Dry-Farming (1911). Chapter VII, Storing Water in the Soil.

Widtsoe, J. A. The Storage of Winter Precipitation in Soils. Utah Experiment Station, Bulletin No. 104 (1908).

Widtsoe, J. A., and McLadghlin, W. W. The Movement of Water in Irrigated Soils. Utah Experiment Station, Bulletin No. 115 (1912). 


\section{CHAPTER IV}

\section{SAVING WATER BY CULTIVATION}

WATER added to the soil by the natural precipitation or by irrigation is disposed of in two chief ways: One part runs off the land; another part soaks into the ground.

The water which soaks into the soil may be disposed of in three ways: (1) Immediately after water has entered the soil, evaporation begins at the surface and, in time, if not checked, the water in the greater depths will be brought to the surface, to be returned to the air in the form of water vapor. (2) If an excess of water has been applied, another part sinks below the reach of the plant roots and may connect with the country drainage, and thus be lost to the farmer. (3) A part remains in the soil and supplies the plant with the water needed in its growth.

The vital thing in irrigation practice is to bring the water into the soil properly and to keep it stored there, within reach of the roots, until it is needed by the plant.

32. The run-off.-The run-off collects in hollows or cuts channels to connect it with the larger streams of surface water. The quantity of water thus lost often forms a very large part of the total water added by the natural precipitation or by irrigation. To prevent this, it is necessary to keep the top soil in a loose, open condition, so that the water that falls upon it may be absorbed quickly. Where the major part of the precipitation comes during the winter or spring, the best way of 
accomplishing this is to plow the land in the fall and, unless fall crops are planted, to allow it to lie in a rough state throughout the winter. Where the precipitation comes largely during the summer and spring, it is much more difficult, because of the growing crops, to keep the top soil in a condition to absorb water readily.

Much water is nearly always lost at the time of thawing and melting snow. In such districts all furrows and rows of plants should be made to conform with the slope of the land. A furrow plowed up and down a gentle slope forms an admirable channel for the escape of water, while a furrow plowed at right angles to the slope tends to catch and to hold back the water which flows downward. This is also true with regard to planting. Drill culture is now the only acceptable method of planting; and it is always desirable, from the point of view of preventing the run-off, to plant the rows of crops at right angles to the general slope of the land. Each row then tends to prevent excessive run-off.

In irrigation, the loss due to run-off is frequently a very serious matter. When water is applied by the flooding method, it is relatively easy to control the runoff by building dikes around the field. In fact, some kind of diking is usually thrown up around large fields, whenever water is applied by the flooding method. The various systems of irrigation by flooding differ chiefly in the means devised for preventing the surface loss of water. If no diking is used, the lower end of the field is usually crossed by a ditch, which receives the waste water and carries it to some other field.

In the furrow method of irrigation it is very difficult, if not impossible, to prevent wholly the run-off. By the furrow method, water is usually applied at one end of the 
field and allowed to run down long furrows, often several feet apart. It is practically impossible so to regulate the stream that all the water is absorbed just at the end of each furrow. In fact, if this is attempted by using a very small stream, it means that the upper end will receive a very large quantity of water, while the lower end will be relatively dry and often without a sufficient supply of moisture for abundant plant-growth. If a large stream is used, the whole furrow is given a thorough wetting, but a large quantity of water is wasted at the end of the furrow. This waste water is usually received by a transverse ditch and used on some lower field. To reduce the run-off and, at the same time, give each furrow a sufficient irrigation, the best plan seems to be to use a small stream and a rather short furrow, repeating the furrow below as many times as may be necessary. The shorter the furrow is, the more thoroughly and uniformly may water be applied to the soil.

In any event, the run-off water must be carefully and skilfully used on lower fields. The run-off presents a problem which must be solved in its own peculiar way on each individual farm. No general rules can be laid down for using the run-off, since the layout of one farm is generally different from that of any other.

33. The upward movement of water.-Under methods of irrigation that use water in moderation, very little water drains below the zone of root-action, yet under the most favorable conditions water may move upward and be lost from the soil surface. The movement of water is usually from the thick to the thin film, that is, from the moister to the drier parts of the soil. When, therefore, a soil dries at the surface, there is a steady upward movement of water from particle to particle to 
supply that lost by evaporation at the top and to place the remaining water in full equilibrium with all active forces. Such loss of water is felt to the full depth of soil concerned in plant-growth.

As evaporation proceeds from the top soil, the water in every soil layer diminishes to the full depth of rootaction. The process may be likened roughly to the behavior of cotton packed loosely in a box. If a small quantity is removed from the top, the remainder expands and fills the box again, the difference being that the whole mass is looser from the top downward than it was before. So, after evaporation has occurred, and water has moved upward to replace the loss, there is a thinner soil-water film throughout the soil. This process may go on until the soil-water film has been reduced to the minimum thickness that allows capillary movement. When this degree of dryness has been reached, it does not follow that the film is of the same thickness at every point to the full depth involved. On the contrary, the lower layers, to a depth of 8 to 10 feet, contain more water than do the upper soil layers. At first, as evaporation proceeds, the tendency is to distribute the water evenly over the soil sections below the upper one, which is immediately exposed to the atmosphere and therefore always drier. As the lento-capillary point is approached, the upward movement becomes more and more sluggish; and, in fact, it is ordinarily very difficult to reduce the lower soil layers below this point, though the upper layers may be brought considerably lower in their moisture content. When living plant-roots fill the soil, this distribution does not hold, for the roots draw moisture directly from the soil, and the percentage of soil moisture is in inverse proportion to the distribution of the roots. 
To stop the upward movement of soil water due to surface evaporation is a chief consideration of a system of irrigation-farming in which economy in the use of water is a vital factor.

34. Intensity of evaporation.-It is well known that water evaporates into the air whenever the air is not fully saturated with water vapor. Under the conditions

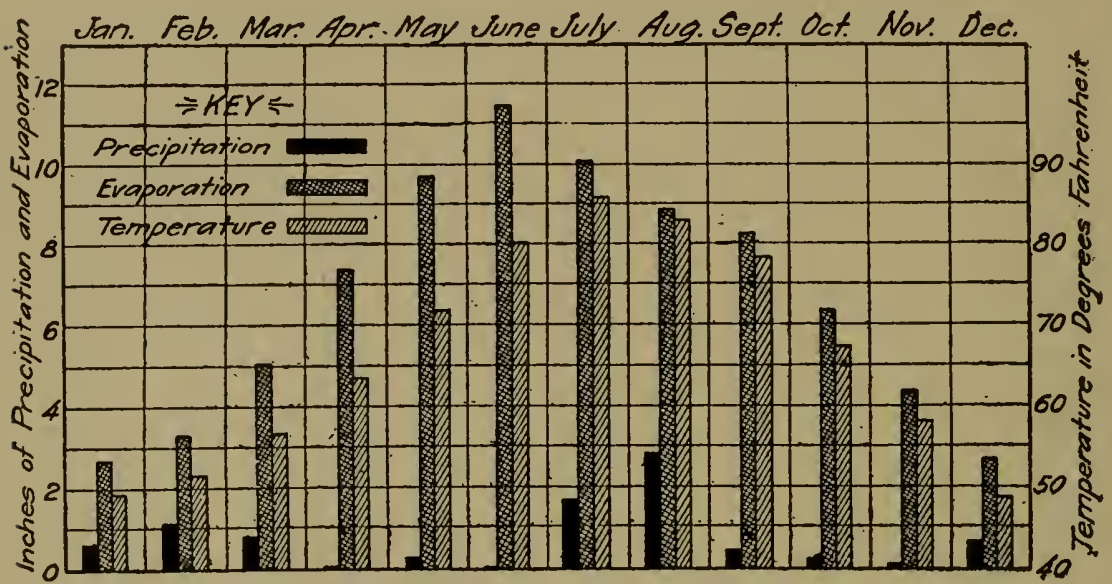

FIG. 10. Evaporation usually exceeds rainfall.

prevailing over the earth's surface, the air is always unsaturated. In arid regions the air is very dry, as is well shown by the high heat that may be endured in such places, due to the rapid evaporation of perspiration into the dry air.

The rate of evaporation from water surfaces is much larger than commonly believed. Briggs and Belz have sought out all available records in various sections of the United States, of the quantities of water that will evaporate from a free-water surface during the six summer months, April to September inclusive. A summary of their findings is presented in the following table: 
Water Lost (in Inches). by Evaporation from a Free-Water Surface from April to September, Inclusive

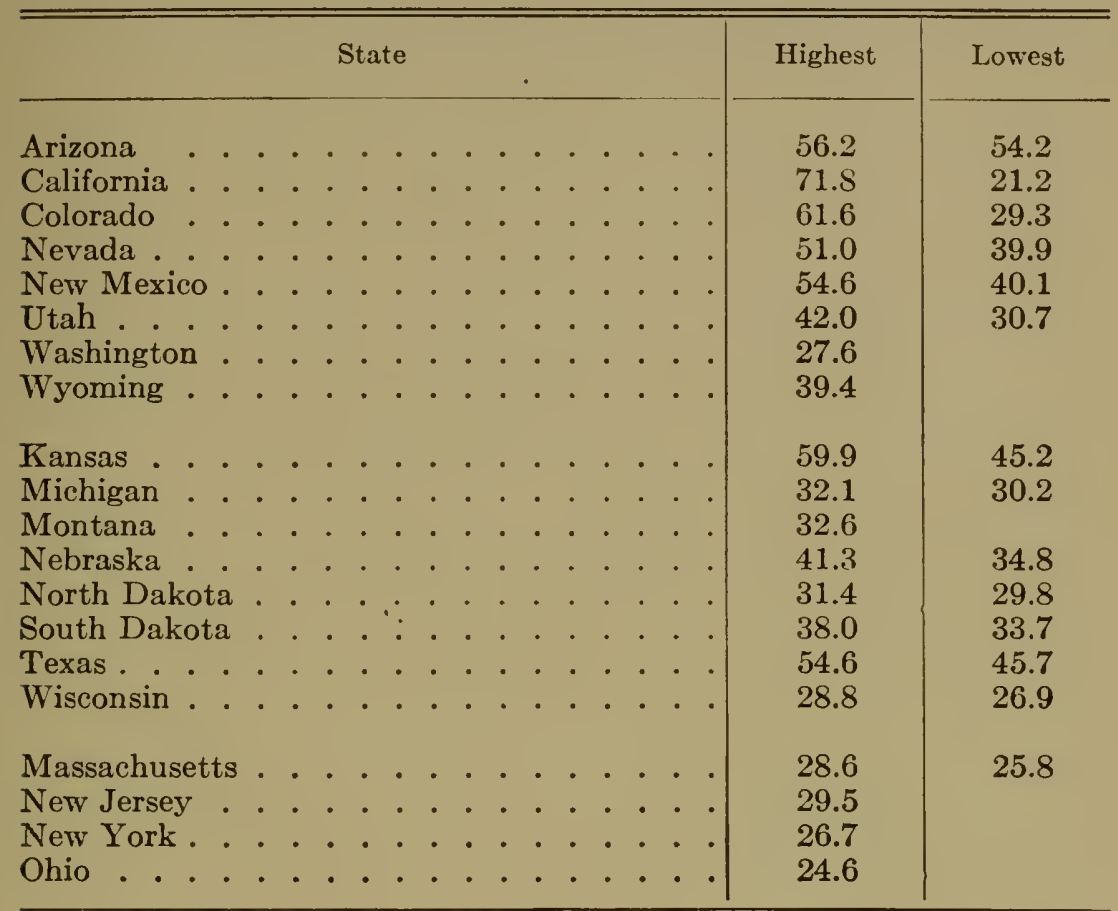

This table is not complete, but it shows unmistakably, first, that evaporation is much greater in the arid than in the humid region, and, second, that in both humid and arid regions the evaporation from a free-water surface, during the six summer months, is considerably more than the total quantity of irrigation water that should properly be applied in any one year. In the arid states, as, for instance, California, with its high evaporation record of nearly 72 inches, several times the quantity of water that should be applied in irrigation may easily be evaporated into the air during the growing season.

From soils kept wet at the surface, evaporation goes on even faster than from a water surface. For instance, 
Fortier reports an average weekly evaporation from a wet soil of 4.75 inches and from a water surface placed under like conditions only 1.88 inches-two and one-half times as much. The explanation of this must of course be sought in the higher temperature of the soil due to a lower specific heat and a higher absorptive capacity for heat.

This strong tendency of water to return to the air by way of evaporation makes it fundamentally important to devise and put into operation methods that will prevent, to the largest possible degree, this form of the dissipation of water. (Fig. 10.)

35. Conditions determining evaporation.-Many factors are concerned in the evaporation of water from the surface of water or any moist substance such as an irrigated soil. These may be classified as follows:

1. Nature of soil.
(a) Physical.
(b) Chemical.
(c) Depth.

2. Meteorological conditions.

(a) Temperature.

(b) Sunshine.

$(c)^{*}$ Relative humidity.

(d) Winds.

(e) Showers.

3. Initial percentage of water.

4. Condition of top soil.

(a) Plowing.

(b) Cultivation.

(c) Rolling.

(d) Packing 
The nature of the soil is of considerable importance. The finer the texture of the soil, the more rapidly does the water move upward to be changed into vapor. The darker the color of the soil, the more rapid the evaporation; for dark-colored soils absorb the heat of the sunshine much more quickly than do lighter-colored ones such as characterize the arid region. The richer the soil is in soluble salts, the slower is the evaporation of water into the air. For that reason, evaporation from alkali lands is slow. The rate of evaporation is more rapid from a deep than from a shallow soil, for a given loss of water does not so greatly reduce the percentage of moisture in a deep as in a shallow soil.

Meteorological conditions determine very largely the rate of evaporation of water from soils. Of these, temperature is most important. The higher the temperature, the more rapid is the conversion of water into water vapor. Of almost equal importance is the intensity and quantity of sunshine. Much more water is lost from a wet soil on a sunny day than on a cloudy one. Shade is extremely effective in checking evaporation. In the Utah work, a saving of 25 per cent of the water evaporated was effected when the soil was shaded; and, in all probability, as the temperature is very much lower in the shade, an even higher degree of saving may be effected. Frequently, a high temperature and much sunshine go together, so that their effects are felt at the same time. The drier the air, the more rapidly will the air take up water vapor. In the arid region, the relative humidity of the air is low, and evaporation goes on, as has been shown, much more rapidly than in humid sections. Winds, likewise, exert a strong drying effect on soils, especially in districts where the air is relatively dry. The 
water, as it evaporates from the soil, saturates the air immediately above the soil surface; and thus evaporation is diminished. Winds remove this layer of saturated air, and the rate of evaporation is increased. Summer showers, likewise, by establishing capillary connection with the lower soil layers, hasten evaporation.

Finally, the wetter the soil is at the surface, the more rapidly is water evaporated from it. This vitally impor-

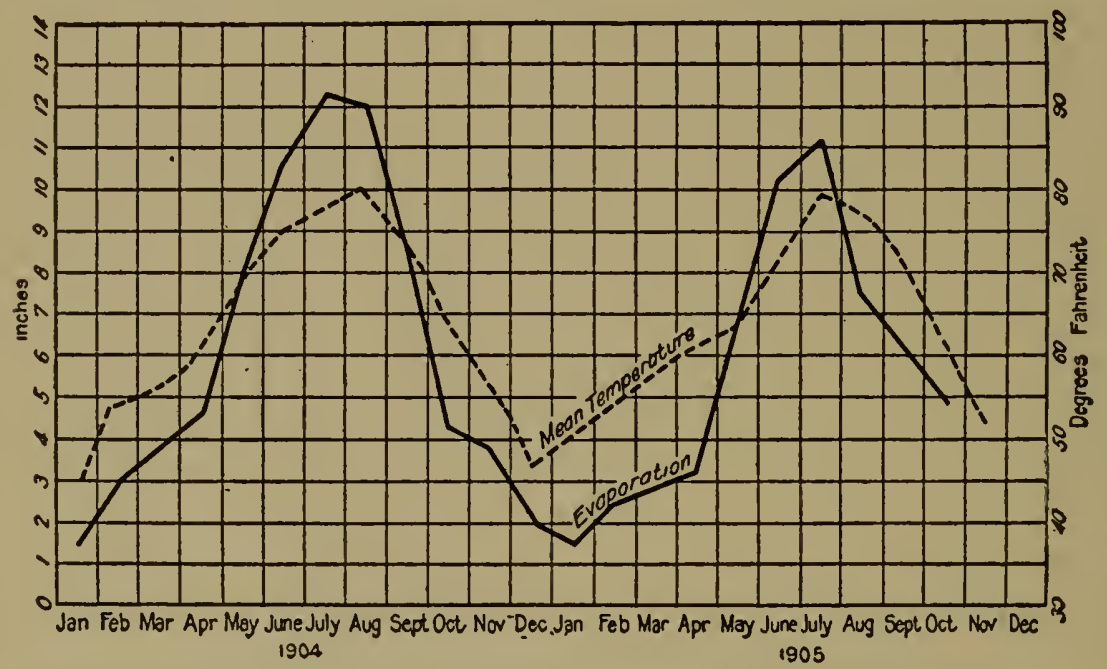

FIG. 11. Relation beween temperature and evaporation (Tulare, Calif.).

tant principle was observed in the Utah work, and has been confirmed by Whitney and Cameron and by Fortier. This law of the initial percentage declares that the evaporation of water from a soil surface varies as the initial percentage of soil moisture,-that is, the moisture at the beginning of the test.

The three most important factors in determining the evaporation of water from a soil are undoubtedly the average temperature, the relative humidity of the air, the wind, and the percentage of water held by the soil. 
The temperature cannot be controlled, effectively, by the farmer; neither can the relative humidity; and, if the land is to produce the largest and best crops, there must be in the soil a fair abundance of water. To diminish the rate of evaporation by controlling these three factors seems, therefore, almost hopeless. The control must come from the proper treatment of the top soil. (Fig. 11.)

36. Mulching to check evaporation.-It was observed many years ago, that evaporation of water from soils may be quite effectively stopped by covering the soil loosely with straw, manure, litter of any kind or loose soil. This method has been tried out practically in so many countries and by so many investigators that there can be no question about its effectiveness.

Fortier recently re-examined the matter, under the climatic conditions of the irrigated sections of the United States, and found that a covering of sand, if of proper depth, applied to the soil immediately after irrigation, could be made to reduce the evaporation to less than 2 per cent of the water applied. In earlier days, it was advocated rather largely that straw and other litters be placed upon the soil to prevent evaporation. This method, however, is too expensive to be of wide application.

The method of today is to stir the top soil with proper implements. The process is called cultivation. The layer of loose dirt which is thus left upon the soil hinders very effectively the movement of soil water into the atmosphere. In the Utah work it was found that, by cultivation, an infertile clay soil lost only 63 per cent of the quantity lost by the non-cultivated soil; a fertile clay loam, 13 per cent, and a loose sandy soil, 34 per cent. Fortier found that by thorough cultivation of a southern California soil the loss by evaporation could be reduced 
to less than half of that from a non-cultivated soil. Scores of other investigators have demonstrated that the mulch formed by cultivation reduces largely the evaporation.

This saving, due to mulching, is easily understood. As has been explained, soil moisture is held as a film around the soil particles. Water moving toward the soil surface must pass from particle to particle through the narrow films at the points of contact of the soil particles. The smaller or the fewer these points of contact, the more difficult is the upward movement of the water. If water were passing through a large tube into several smaller tubes, the flow of water would be retarded. When the top soil is loosened, the points of contact between the loose soil above and the compacted soil below become reduced. At the zone of loose earth, the ascending water finds it difficult to pass through the fewer points of contact, and at the same time to maintain its rate of flow. The more thoroughly the soil is cultivated, that is, the fewer the points of contact, the more difficult will the movement become, and the more greatly will the evaporation be reduced.

Likewise, as a soil becomes dry, the flow of moisture through it is lessened. This is clearly understood when it is recalled that a dry soil means a soil with very thin moisture films around the particles. Water passing through thin films encounters much friction, and the rate of flow is diminished. Stirring the top soil tends to dry it out very rapidly, and to leave a very dry mulch, through which water can pass only with difficulty. Cultivation, therefore, retards evaporation by breaking the points of contact between the upper and lower soil layers and by drying out the loosened top layer.

It is true that from the surface of every soil particle, 
at any depth, water is evaporated, until, if the soil is moist, the pores of the soil are filled with air saturated with vapor water. This saturated soil air moves, however, very slowly into the atmosphere. Buckingham has shown that water vapor escapes from the soil air only by the slow process of diffusion; that is, the particles of water vapor find their way, one by one, into the atmosphere, while there is a corresponding movement of atmospheric gases into the soil air. This interchange of gases between the soil air and the atmosphere is so small as to be of little or no consequence in the loss of soil water

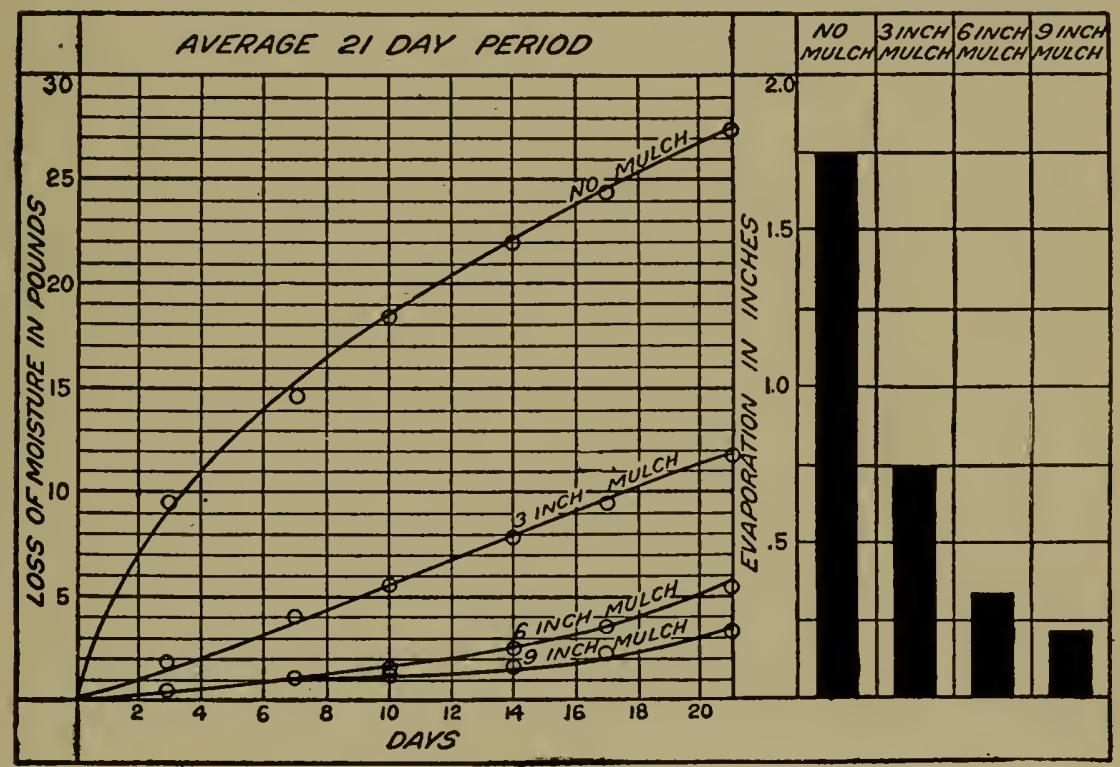

Fia. 12. Evaporation losses from soils protected with mulches of different depths.

by evaporation. Practically all soil water is lost by evaporation at the soil surface.

Buckingham has shown, also, that very little water is lost by direct evaporation 2 inches below the surface. From below a 12-inch layer of dry soil the evaporation- 
loss is insignificant, amounting at most to only 1 inch of rainfall in six years.

The most effective method of checking evaporation from the soil is to stir the top soil thoroughly with any one of the many kinds of cultivators now found on the market and built especially for the purpose. (Fig. 12.)

37. Self-mulching soils. - Under arid conditions, some soils possess a self-mulching power. The abundant sunshine, high temperature and low relative humidity of arid sections, cause a very rapid evaporation. After an irrigation on a very hot summer day the top soil may be dried out so rapidly that the lower soil layers cannot send moisture upward in time to supply the loss. Under such conditions the evaporation is automatically decreased. The dry top soil, thus induced, is an effective check upon the upward movement of water. This may be one explanation of the fact that in many virgin arid lands much of the rainfall remains stored for months at a time. Added to this is another condition of frequent occurrence. Arid soils are, as a rule, rich in lime. In some cases the calcareous substances of arid soils make up onefourth to one-half of the soil itself. Such soils, as they dry out, become loose. It frequently happens, therefore, that when such a soil, after an irrigation, is dried out by rapid evaporation, the surface layer falls into a natural mulch which is fairly effective in stopping evaporation. Buckingham reports an interesting experiment, in which he found that the rapid evaporation due to arid conditions so dried out the top soil that the loss of water in a year was only 11.2 inches as against 51.6 inches from a similar soil under humid conditions which permitted a slow but steady evaporation.

The stirring of such self-mulching soils does not always 
save soil moisture. In the Utah work such a soil was found, from which one and one-half times more water was lost during the growing season when cultivation was practised. The natural mulching of this soil permitted the lowest evaporation of a large series of tests with several varieties of soil. Nevertheless, even on such soil, the stirring of the soil carried with it other beneficial results of high value to crops. That is, even though cultivation on such soils may cause a greater loss of water, the soil becomes able by the cultivation to produce more dry matter with the water actually at its disposal. This was well brought out in the Utah work, for the selfmulching soil produced a crop 14 per cent larger on the cultivated areas.

Self-mulching soils are not plentiful, and too much reliance should not be placed upon them. The irrigation farmer is safe only when he cultivates his soils thoroughly and frequently throughout the season.

38. Time of cultivation. - The rate at which water soaks into a soil depends largely upon the physical condition of the land. If the soil is coarse and loose, the downward movement is rapid; if fine and compact, the downward movement is slow. In any case the top soil remains saturated or too wet for cultivation during several hours, or days, after an irrigation. A sand or loam soil may often be cultivated within one or two days after irrigation; but, on a clay soil, this cannot be done until three to seven days after irrigation. During this period before cultivation, when the top soil remains moist, evaporation losses occur very rapidly. In fact, from one-fifth to one-third of the loss due to evaporation throughout a three- or four-week period occurs before the cultivator can be applied to form a protective soil mulch. 
The chief protection against the great losses immediately after irrigation and before cultivation is possible, is a loose, spongy top soil that absorbs the water the moment it is applied and permits it to soak deeply into the soil away from the immediate action of the sun's rays. Occasionally it may be profitable to scatter a mulch of some kind over the soil, immediately after an irrigation, but this is of extremely limited application. If water is applied by sub-surface methods this precultivation loss may be prevented, but sub-irrigation is seldom profitable except in districts were natural subirrigation is feasible.

The soil should be cultivated just as soon as it is possible to do so after an irrigation, without doing injury to the soil. If cultivation is performed too soon after irrigation there is danger of leaving the top soil puddled or in an otherwise undesirable physical condition for plantgrowth. By too early cultivation a soil may be permanently injured for the season or even for several seasons. The farmer who cultivates too early, and thereby leaves the top soil in a poor physical condition, ultimately loses more than does he who permits evaporation to go on a day longer, to make sure that the soil is in the right condition for cultivation. Whenever the soil is dry enough to support the man and horse with the cultivating tool, it is usually safe to begin cultivation.

On the other hand, it must be said that, in the great majority of cases, the farmer permits evaporation to go on many days after the time of safe cultivation has been reached. Few fields are injured from too early cultivation. Over the whole irrigated area, the farmers have looked upon cultivation as an incidental matter, because they have not realized the tremendously large quanti- 
ties of water that may be lost from the soil by evaporation. The magnitude of such losses is well shown in the following typical results taken from the Utah work. The soil at the beginning of each test contained practically 17.5 per cent of water.

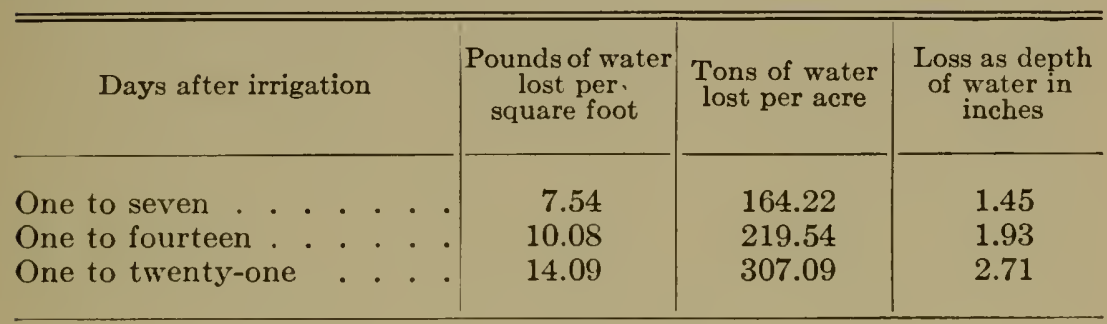

During the first seven days after irrigation, a quantity of water equivalent to nearly 1.5 inches was lifted from the soil by the power of the sunshine; during the first fourteen days, nearly 2 inches, and, during the first twenty-one days about $23 / 4$ inches. Fortier and Beckett found that during a twenty-eight-day period after irrigation a non-cultivated soil lost 2.13 inches of water, of which about .8 of an inch or nearly 40 per cent was lost during the first three days after irrigation, before cultivation could begin. Such great losses in an arid section justify every effort of the farmer to conserve the soil moisture by cultivation, - and it should be done as early as possible so that the water saving may be large.

39. Depth of cultivation.-The depth to which a soil is cultivated, that is, the thickness of the soil mulch produced, determines the rate of evaporation and therefore the quantity of soil moisture that may be saved. This is only to be expected, for the thicker the dry mulch above the moist soil from which evaporation proceeds, the greater is the hindrance offered to the diffusion of 
water vapor into the atmosphere, and the less effectively can the sunshine heat the evaporating surface. The best investigations on this subject are those recently conducted by Fortier, and Fortier and Beckett, under true arid conditions. These experiments were made at five different points in the arid region-in California, Montana, Nevada, Washington and New Mexico-so that the validity of the results could be checked under the varying climatic conditions of the irrigated region. Immediately after each irrigation, "fine, dry, granulated soil mulches," of different depths, were placed upon the soil, and the water losses were determined during a period of four weeks. Some of the average results are as follows:

\begin{tabular}{c|c|c}
\hline \hline $\begin{array}{c}\text { Depth of mulch in } \\
\text { inches }\end{array}$ & $\begin{array}{c}\text { Loss of water } \\
\text { during 28 days } \\
\text { in inches }\end{array}$ & Per cent \\
\hline None & 1.75 & 100.0 \\
3 & 0.78 & 42.3 \\
6 & 0.34 & 19.4 \\
9 & 0.22 & 12.5 \\
\hline
\end{tabular}

The thicker the mulch placed upon the soil the smaller was the evaporation, varying from 1.75 inches, when no mulch was applied, to .22 inch or 12.5 per cent, when a 9 -inch mulch was spread over the soil surface.

In another series of experiments, a 10-inch mulch practically stopped evaporation. When the mulch is made by cultivation, similar results are obtained, the difference being the loss immediately after irrigation and just before cultivation, discussed above.

It may be said safely that the deepest cultivation is the most effective for the checking of evaporation from 


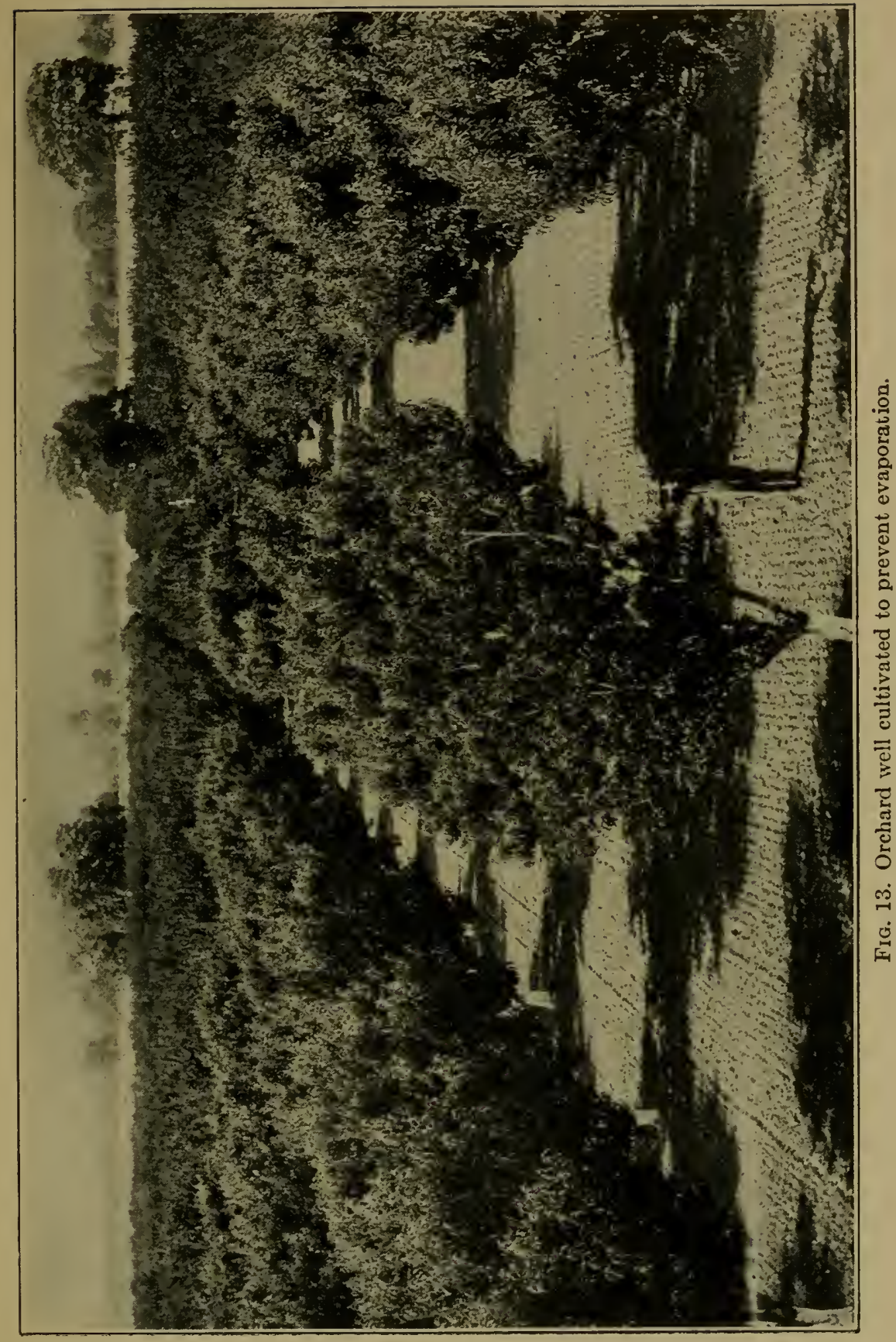


irrigated soils. However, in practice it is often difficult to cultivate below a depth of approximately 6 inches, unless the soil is of the right character and proper implements are used. The greatest depth to which any soil may be cultivated must be determined by the individual farmer. There has been considerable opposition to deep cultivation on the ground that it tends to destroy the roots which feed in the upper layers of the soil. Some plants are naturally more shallow-rooted than are others, but an important thing in all arid agriculture is to compel plant-roots to go deeply into the soil. Shallow-rooted plants, under conditions of irrigation, usually indicate that the farmer has used water unwisely by irrigating too frequently or too heavily. Proper irrigation, moderate in quantity and at proper intervals, causes practically all the ordinary cultivated plants to strike their roots deeply into the soil-so deeply that no damage results from the deep cultivation indicated by the experiments here recorded. In many sections of the West, notably in the orange districts of southern California, where the rainfall is light and irrigation water scarce, deep cultivation has become a general practice in spite of the general belief that citrous trees are shallow-rooted. Before a rational irrigation practice is firmly established, farmers must become convinced that there is no harm whatever in cultivating deeply and as soon as possible after each irrigation.

40. Frequency of cultivation.-Few experiments have been conducted on this subject, but the principles already laid down give a fairly clear indication of the cultivations a field should receive throughout the season. Even after a thorough cultivation, most soils gradually settle into a more compact mass. In some soils this settling is so great 
that it re-establishes capillary connections between the mulch and the moist soil below, and evaporation is then resumed. Such soils, which are soon recognized, should be cultivated several times between each irrigation. When soils show no such tendency to settle, it may be sufficient to give them one good cultivation after each irrigation. Generally, it is well to cultivate the soil at least once every three weeks throughout the irrigating season and a bi-weekly cultivation is probably better.

Summer showers also determine the frequency of irrigation. A summer shower, unless it is very light, beats down the the mulch and usually saturates the soil sufficiently to establish vigorous capillary communication with the lower soil layers. This condition may lead in a few hours to large evaporation losses. For that reason, every summer shower should be followed, as soon as the soil is dry enough, with a thorough cultivation. Where the precipitation comes chiefly in the fall, winter or spring, the summers are relatively dry and the few light summer showers may easily be followed by the cultivator; but, where the winter is relatively dry and the precipitation comes chiefly in early or midsummer, the rains are often so frequent and heavy that to follow them with cultivators is difficult, if not practically impossible. True, under such conditions, the water necessary in irrigation is relatively smaller, so that evaporation losses can better be sustained there than in districts of dry summers, where the annual precipitation is also usually low. Wherever possible, however, cultivation should follow both summer shower or rain and irrigation.

41. Cultivation and soil fertility.- So much has been said concerning the value of cultivation in the conservation of soil moisture that one may be led to believe that 
the whole virtue of cultivation lies therein. However, cultivation has other beneficial effects quite as important as the direct saving of soil moisture. The loosening of the top soil permits the entrance of the atmosphere, with the free exchange of gases between the atmosphere and the soil air, which ventilates the soil and enables various physical, chemical and biological changes to take place. The result is of the highest importance to plant life. The condition of the top soil, the part turned by the plow and stirred by the cultivator, is of first importance in all agriculture. A striking illustration of this other value of cultivation was secured in the Utah work. In a series of tests designed to show the moisture-saving possibilities of cultivation, a very careful account was kept of the total yield of dry matter produced under the various soil treatments. Corn was grown on four different soils varying from a coarse sand to a fine clay, and from high fertility to great infertility. The following are some of the results obtained:

Pounds of Water Transpired for One Pound of Dry Matter

\begin{tabular}{l|c|c}
\hline \hline & Not cultivated & Cultivated \\
& & \\
Infertile sand . . . . . . . . . & 454 & 732 \\
Fertile sandy loam . . . . . . . & 603 & 252 \\
Fertile clayey loam . . . . . . . & 535 & 428 \\
Infertile clay . . . . . . . . . & 753 & 582 \\
\hline
\end{tabular}

In every case, excepting the abnormal infertile sand, the careful stirring of the soil enabled the plant to produce one pound of dry matter with a smaller quantity of water than when the soil was not cultivated. The sandy loam was of a self-mulching nature, and really lost water by cultivation, yet on this soil, also, cultiva- 


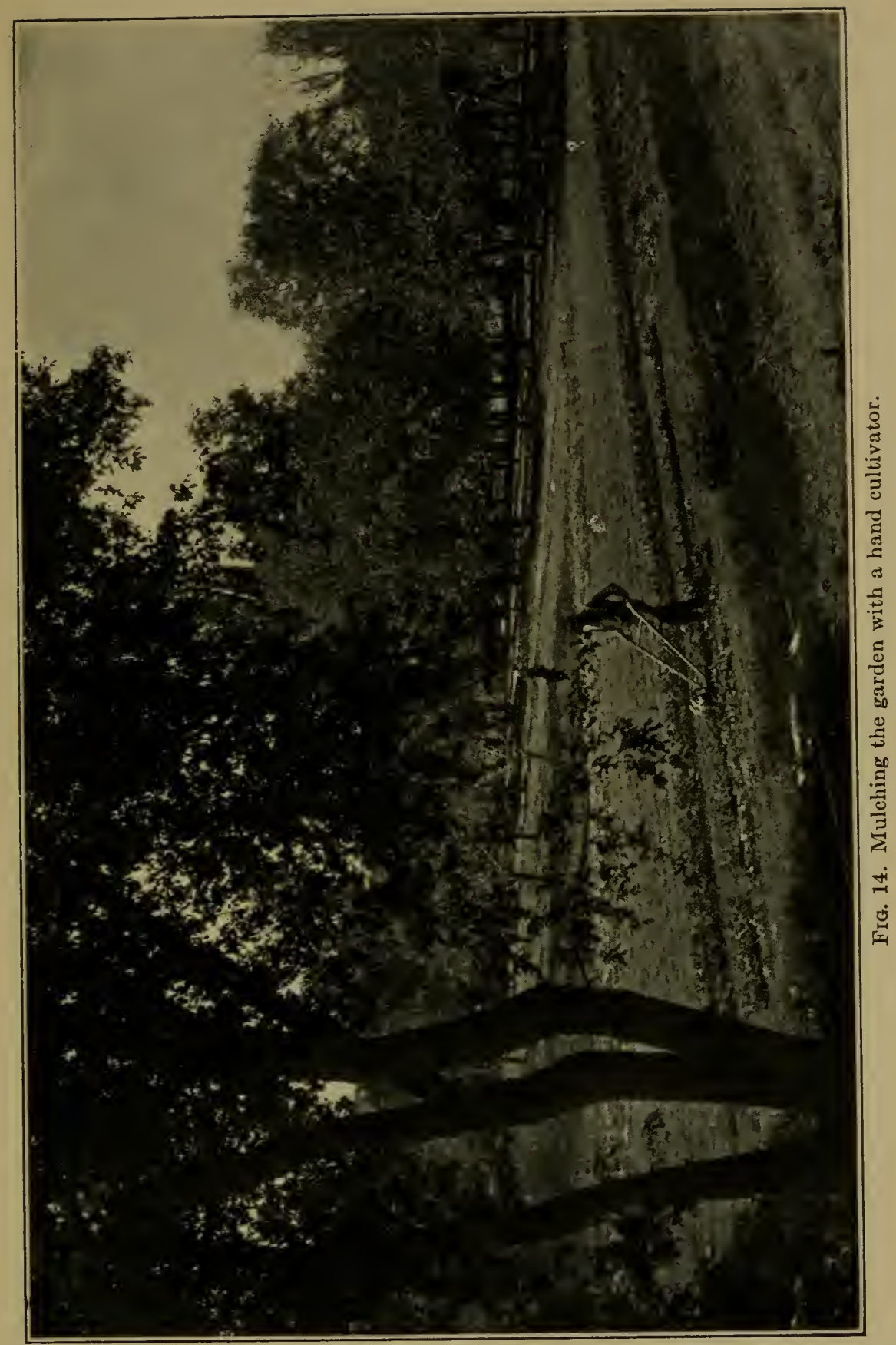


tion enabled the plant to produce dry matter at a smaller water cost.

Cultivation of the soil, therefore, prevents the waste of water by evaporation, and induces soil changes that enable the crops to produce larger yields with a given quantity of water. In truth, cultivation may take the place of irrigation.

42. Rolling.--Rolling is the opposite of cultivation. It compacts the top soil. As a result, excellent capillary connections are established between the top and the subsoil and water is enabled to move upward, rapidly, from the lower layers to the surface, there to be evaporated into the air. There is no more dangerous practice than this, if evaporation of soil moisture is to be prevented. Moreover, a soil which has been compacted by rolling offers much resistance to the entrance and downward movement of water. Rolling, therefore, (1) prevents the water from entering the soil easily, and (2) allows the water which does enter the soil to evaporate rapidly. From the point of view of water-conservation it is an extremely wasteful process.

In a few special cases rolling may be permitted in a good system of irrigation agriculture. For instance, in raising sugar beets for factories, the soil is carefully rolled after the planting of the seed, chiefly to insure good germination. This, however, is not necessary except in districts where the spring precipitation is light or where the soils have been so handled as to be too dry for satisfactory germination. By proper methods of fall plowing this precaution would probably be unnecessary.

A special phase of rolling may be of importance. Campbell recommends highly a sub-surface packer, designed to pack the soil at the bottom of the plow fur- 
row while it leaves the top soil loose and open. The merit in this process is that the loose top soil permits the easy entrance of water into the soil and also acts as a mulch to prevent evaporation. To accomplish such sub-surface packing the Campbell machine may be used, or the soil may be thoroughly cross-disked.

Rolling, whether on top or below the surface, is of small and questionable value in any system of irrigation practice.

\section{REFERENCES}

Briggs, Lyman J., and Belz, J. O. Dry-Farming in Relation to Rainfall and Evaporation. United States Bureau of Plant Industry, Bulletin No. 188 (1911).

Bdckingham, Edgar. Contributions to Our Knowledge of the Aëration of Soils. United States Bureau of Soils, Bulletin No. 25 (1904).

Buckingham, Edgar. Studies on the Movement of Soil Moisture.

United States Bureau of Soils, Bulletin No. 38 (1907).

Fortier, Samuel. Evaporation Losses in Irrigation and Water

Requirements of Crops. United States Office of Experiment Stations, Bulletin No. 177 (1907).

Fortier, SAMuel, and Becketr, S. H. Evaporation from Irrigated Soils. United States Office of Experiment Stations, Bulletin No. 248 (1912).

Whitnex, Milton, and Cameron, F. K. Investigations in Soil Fertility. United States Bureau of Soils, Bulletin No. 23 (1904). WidTsoe, J. A. Factors Influencing Evaporation and Transpiration. Utah Experiment Station, Bulletin No. 105 (1909).

Widtsoe, J. A., and McLaughlin, W. W. The Movement of Water in Irrigated Soils. Utah Experiment Station, Bulletin No. 115 (1912).

Widtsoe, J. A. Dry-Farming. Chapter VIII (1911). 


\section{CHAPTER V}

\section{SOIL CHANGES DUE TO IRRIGATION WATER}

THE soil cannot, directly, be greatly changed by the farmer. As it is, so, in a large measure, it must remain. Tillage implements modify only slightly the upper layer of the soil. Water, however, may cause fairly large changes in the soil to the full depth to which it penetrates. Irrigation, therefore, with its power of regulating the quantity of water applied, may be made a means of modifying soil properties. Physical, chemical and biological soil changes are induced by irrigation, and some of the most important principles of a permanent system of irrigation agriculture, depend upon the effects of water upon soil.

43. Contraction and moisture film.-If a camel's-hair brush be dipped in water, and then removed, the hairs cling together to form a narrow and rather hard brush suitable for use in painting. If a trifle of the water in the brush be squeezed out, the brush becomes rather stiffer than it was before, but if more water be removed, the brush become looser and looser until it is dry and fluffy. This adhesion of the hairs is due (1) to the contraction of the films surrounding each little hair, and (2) to the contraction of the water film enveloping the whole brush. (Fig. 15.)

In like manner, the particles of a soil, when wetted or dried, tend to move either 'more closely together or farther apart, and the soil becomes more or less rigid. When 
water is applied to a soil it forms a film around each of the particles of widely differing sizes; and further, many small and large particles may form a larger composite particle or crumb with one continuous film surrounding it. The soil should possess a well-developed crumb structure; for the plant has then a better chance to develop than if the individual particles remain separate in single-grain structure.

44. Cohesion of soil particles.-By direct examination, every good farmer may determine whether the soil is in proper condition for plowing or for other cultural operations. Usually this condition means that the proportion of moisture in the soil is such that a plow or a cultivator may be passed through it with the least resistance and without destroying the crumb structure or tilth. The question of the force with which dry or moist soil particles stick to each other is not of itself of very great importance; but it is of interest in showing the effect

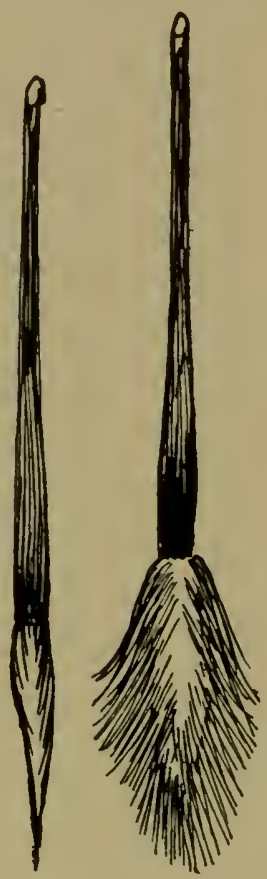

FIG. 15. Adhesion of hairs due to water. of various proportions of water on the properties of the different soils. Pure clay dries to a very hard mass, difficult to break. If to the clay be added sand, humus, gypsum or lime, the resulting mass, when dry, may be broken with less than one-fifteenth the force necessary to break the pure clay. In fact, coarse sands or soils rich in gypsum or lime, as they dry, often fall apart into a coarse mass, which forms a natural mulch over the soil.

The force with which soil particles are held together depends, primarily, upon three factors: (1) the physical 
constitution of the soil; (2) the water content, and (3) the presence of various salts. The finer the soil is, the more firmly the dry particles are held together. As the soil water increases, clay is less firmly, and sand more firmly, held together. The presence of soluble salts tends, in general, to reduce the force with which soil particles stick together, though lime and other substances have the opposite effect.

Of chief importance to the irrigation farmer is the knowledge of how varying amounts of water affect the cohesion of soil particles, since it is within his power to regulate the quantity of water in the soil. Cameron and Gallagher have done some excellent work on this subject. They concerned themselves only with the percentages of soil water which are found in actual agricultural practice; for, large additions of water, beyond the saturation point of the soil, always cause the soil crumbs to fall apart into their constituent particles; and, likewise, at moisture contents below the wilting point, the cohesive powers of the soil grains have little agricultural meaning.

Sand, loam, clay and humus soils were studied. In all of these, save the clay, as the soil moisture increased, the force with which the soil crumbs were held together at first decreased up to a definite point, then increased, and, by the addition of more water, decreased again to the point of minimum cohesion. In other words, as water is added to a dry soil, the soil first gradually softens; then gradually hardens; then rapidly softens until it is a mushy mass. The point of low cohesion, or easy penetration at which tillage implements may be passed through the soil with small resistance, corresponded, generally, with the so-called point of optimum water content in the soil; that is, the degree of wetness at which, according to the 
judgment of experienced tillers of the soil, the soil is in the best condition for plant-growth. In the case of the clay soil, as more water was applied, the force of cohesion continued steadily to diminish, with no definite point at which a temporary hardening occurred. At a definite degree of wetness, however, the clay soil is in the best condition for working and for plant-growth. This is in full harmony with the known properties of clay.

The point of optimum water content is, approximately, identical with the field water capacity discussed in Chapter II. It seems clear that, when the soil contains a medium amount of water, that is, a quantity lying between the maximum water capacity and the point of lento-capillarity, it can be most easily worked, and is in best condition for plants. It is interesting to note how this intermediate point continually appears in the study of the relation of soils and plants to varying water content.

45. Volume changes of soils.-It follows that, if such differences in the force with which the soil crumbs are held together are induced by the application of varying quantities of water, the soil particles themselves must actually move and rearrange themselves, as water is added to or removed from the soil. Such movements of the soil particles would naturally cause, also, corresponding changes in the volume of the soil. This is an established fact, well known to every practical farmer. If wet clay is allowed to dry it shrinks, with the formation of large cracks in the ground. When water is again added, the clay swells and the cracks largely disappear. In a large measure, this is true of all agricultural soils. As they receive water, they swell; as they dry, they contract.

The changes in the soil volume, due to the addition of water, are very great. In clay and humus soils they 
are often as high as 50 to 75 per cent of the original volume; with average soils, receiving moderate quantities of water within the limits of practical agriculture, the volume changes are from 7 to 12 per cent of the original volume. Such fairly large variations, occurring over acres of land, represent great total changes, capable of modifying deeply the character of the soil.

The reason for such volume changes is simple. In a dry soil the particles, lying rather closely side by side, occupy a relatively small space. When water is added, the soil particles group themselves into larger loose aggregates or crumbs, which occupy more space. There is a

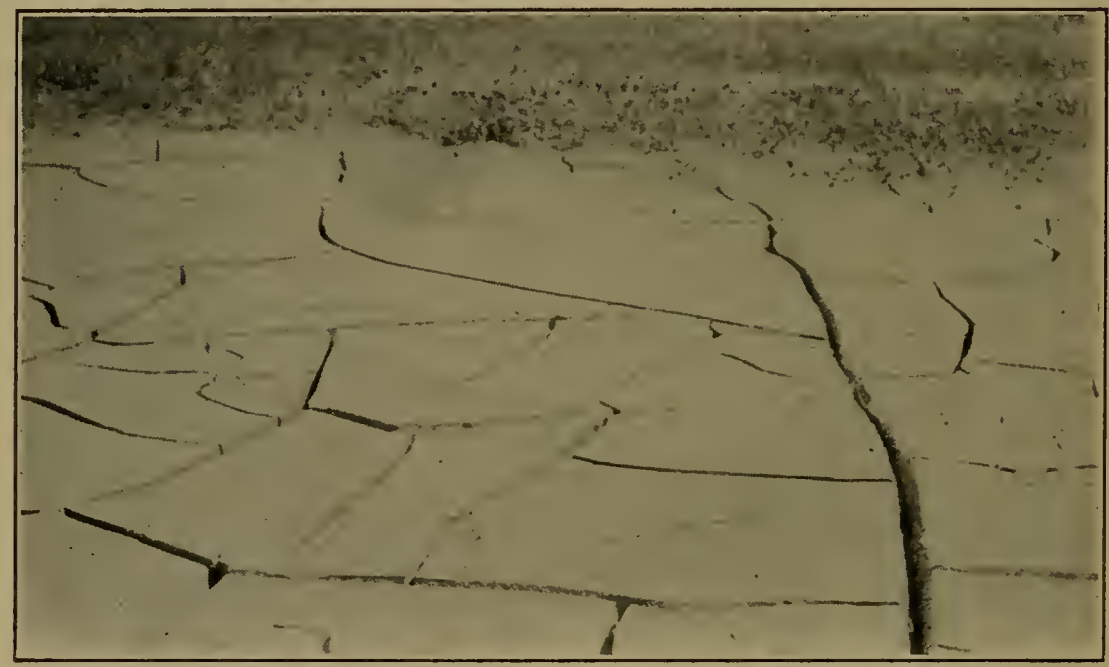

FIG. 16. Cracked river sediments showing volume changes due to water.

continuous arrangement and rearrangement of soil particles, and a corresponding variation in the soil volume as the percentage of water in the soil changes.

Cameron and Gallagher found that, as water is added to the soil, the volume becomes larger and larger, until a certain definite point is reached, after which the volume 
becomes smaller and smaller. This point of largest volume coincides almost exactly with the point at which the penetration of the soil is easy; which, as has been said, is the point of optimum water content. The farmer who desires to keep the soil in the best tilth, from top to lower depths, in order to increase the air space in the soil and to permit the easy penetration of roots, can do so by maintaining in the soil a moderate quantity of water, between the point of lento-capillarity and maximum capacity, somewhere in the neighborhood of the field capacity. The farmer who depends upon the rainfall and, therefore, cannot control his water supply, cannot well maintain the soil in this good condition. The irrigation farmer, on the other hand, who may, usually, apply water at will, can so plan his irrigation, when he knows his soil, as to maintain the land during the larger part of the season in the most desirable condition for plant-growth. (Fig. 16.)

46. Effect on top soil.- Through the top soil, whether under irrigation or rainfall, all water added to a soil ordinarily passes. The top soil first becomes completely saturated, then it dries out quite thoroughly, and the process is frequently repeated. It follows, therefore, that the top soil is subject, almost from day to day, to the greatest changes, physical, chemical and bacteriological. In the greater depths, more water is held over from irrigation to irrigation, and consequently the changes due to varying moisture content do not go on to the same degree. It is interesting to note that, in a soil properly irrigated, the lower layers of soil to the depth of 10 to 12 feet are kept, from irrigation to irrigation, within 1 to 4 per cent of the point at which the structure of the soil is the most desirable.

It is a common observation that irrigation tends to 
pack the top soil, and that cultivation must be performed after each irrigation, if the top soil is to be kept in a thoroughly loose condition. This is probably due, chiefly, to the excessive wetting after each irrigation, which breaks down the soil crumbs into a single-grain structure. The effect of the successive thorough wetting and drying characteristic of irrigation is of interest to the farmer.

47. Successive wetting and drying.-When irrigation water is applied, the soil mass expands, only to contract gradually as the water is lost by evaporation or transpiration. The effect of this successive expansion and contraction was also investigated by Cameron and Gallagher, with rather definite results. At the first irrigation the soil expands, and then contracts to a certain definite degree; at the second irrigation the soil does not expand quite so much, but contracts a little more than at the first irrigation; at the third irrigation the expansion is yet smaller and the contraction proportionally larger; at each successive irrigation, the soil becomes more and more compacted, until a condition of natural packing is reached at which the expansion and the contraction, after each irrigation, are so nearly the same as to result in no practical volume change. If too much or too little water is applied at each irrigation, so that the soil is permanently kept too dry or too wet, the condition of natural packing is prevented.

48. Natural packing of soil.-The condition of natural packing is, however, far from being the closest possible packing; it is rather the packing of highest advantage to plant-growth. If the soil has become too tightly packed, then the expansions and contractions of successive irrigations will tend to loosen the soil, until the condition of natural packing is reached; if the soil has become 
too loose, it will be brought to the condition of natural packing by excessive irrigations. A soil properly irrigated, that is, one which contains, after each irrigation, the optimum percentage of water (approximately with the field water capacity saturated) will, in time, under this law of natural packing by successive irrigations, acquire a structure best fitted, considering the nature of the soil, for the support of plant-life. The top soil, only, which is over-saturated at each irrigation, and thoroughly dried out at each cultivation, needs mechanical means to be kept in the best structural condition.

When the soil is in the condition of natural packing, the soil-water film is continuous, and water can move through it rather freely from soil crumb to soil crumb. From the surface of such a soil, if allowed to remain uncultivated, the water stored in the lower depths may readily escape by evaporation from the top. Under irrigated conditions, where water economy is paramount, the top soil must be kept much looser than in the condition of natural packing. For that reason, as was emphasized in the preceding chapter, it is necessary to follow every irrigation with a thorough cultivation, so that the top soil may always be a dry, loose mulch to prevent evaporation.

49. Soil temperature.-The temperature of the soil is often of very high importance, especially in the spring at the time of germination and early growth. It is of importance, also, at all ages of plant-growth. Patten has made elaborate investigations to determine the quantity of water that will permit the most ready transmission of heat in the soil. He found that a medium quantity of water, not far removed from that which corresponds to the point of easy penetration and largest 
volume - the point of optimum water content as discussed-is the point at which heat moves most readily through the soil. The growing season in the irrigated region is usually very warm, and it might be of considerable importance in hastening maturity, or in aiding plantgrowth, to enable the soil to absorb much heat and to conduct it readily into the lower layers, where the plant roots are working.

This is of special importance in districts where the irrigation water is taken from the cold mountain streams that are often only a few degrees above the freezing point. Under such conditions, the ready absorption and conduction of heat by the soil may determine the rate of growth and length of the growing season, both of which are often of vital importance. All in all, our knowledge of the relation of water to the physical properties of soils would indicate that the wise irrigation farmer will apply to the soil only moderate quantities of water. Too little or too much water at a time are equally dangerous, and threaten loss to the farmer.

50. Water a universal solvent.-Practically every known substance is soluble to some degree in pure water. The rocks and minerals, the fragments of which constitute soil are, therefore, partly dissolved in the soil water. Many of the common minerals of chief occurence in soils, such as apatite, clay, mica, hornblend and serpentine, dissolve in water to the amount of 4 per cent to 1 per cent of their total weight. The solvent power of water depends on a number of conditions, the most important of which under field conditions are (1) temperature, (2) dissolved carbon dioxide, (3) dissolved inorganic salts, (4) dissolved organic compounds, and (5) living organisms. The higher the temperature, the more rapidly does 
solution go on. In districts where irrigation is indispensable, the average temperature during the growing season is generally high, and the solution of soil in the applied water goes on rapidly. In many places the irrigation water itself, taken from comparatively large rivers, is very warm, which, added to the high average daily temperature, accelerates greatly the rate of solution. In other places, however, the water, as it issues from the mountain canyons, is almost immediately spread over the soil. Such water, fresh from the melting snow-banks, is of low temperature and chills the soil considerably, and in all probability retards the rate of solution of the soils.

In practically all natural waters there is an abundance of the gas carbon dioxid obtained by the water from decaying organic remains in the soils through which it passes. Such carbonated waters exert a strongly solvent action upon the minerals of the soil; indeed, carbon dioxid is by far the most important of the factors that influence the solubility of the soil in water. Natural waters generally contain also a large proportion of inorganic salts which, as a rule, increase the solvent action of water. Likewise, solutions of the organic substances formed from the decomposition of plant and animal residues exert a strongly solvent effect on soils. Finally, the presence of living organisms in irrigation water or in soil have much to do with the rate at which the soil constituents are dissolved.

51. Humid and arid soils contrasted.-The solvent power of water modifies so deeply the composition and properties of soil that it is one of the most important factors in the establishment of a rational system of irrigation practice. The soil-making forces, from the beginning, have tended to make soils more soluble, that is, to 
make their constitutents more easily available to plants. Under humid conditions, with a high annual rainfall, the soluble soil constituents thus formed have been largely washed out of the soil into the country drainage and finally into the ocean. In arid districts, with a scanty rainfall and less ample drainage, most of the soluble soil constituents remain in the soil. Humid soils, therefore, contain little soluble matter; arid soils, relatively much. This is one of the chief differences between the two classes of soils. Normal arid soils do not, however, contain large proportions of soluble matter. In an investigation of a great variety of fertile Utah soils, 50 grams of soil were shaken with $500 \mathrm{cc}$. of distilled water for twentyfour hours. The soluble matter thus extracted varied from .2 per cent to .48 per cent. Under more abnormal conditions, as will be explained in the chapter on alkali, soluble matter may be present to the extent of several per cent, and then the soil must be subjected to special treatment before it can serve the farmer.

52. Continuous solubility of soils.-It is practically impossible to wash the soil so thoroughly as to remove from it all substances capable of going into solution. Many experiments have been made on this subject, all with fairly concordant results. For example, Schultze treated a given weight of soil with a definite quantity of water for six days, after which the solution was filtered off and analyzed. This was repeated every six days during six periods. During the first treatment, $1,000,000$ parts of solution contained 535 parts of mineral matter dissolved from the soil; during the second, 120 ; then 261,203 , 260 , and 200 parts during the sixth period. That is, while the first treatment dissolved most, every successive treatment dissolved considerable quantities of soil con- 
constituents, and more went into solution during the sixth than during the second period. In all probability, if these successive washings had been continued, they would have resulted in the continuous removal of appreciable quantities of valuable soil constituents. The continuous solubility of soils has a very important bearing upon the permanent production of crops on any one soil.

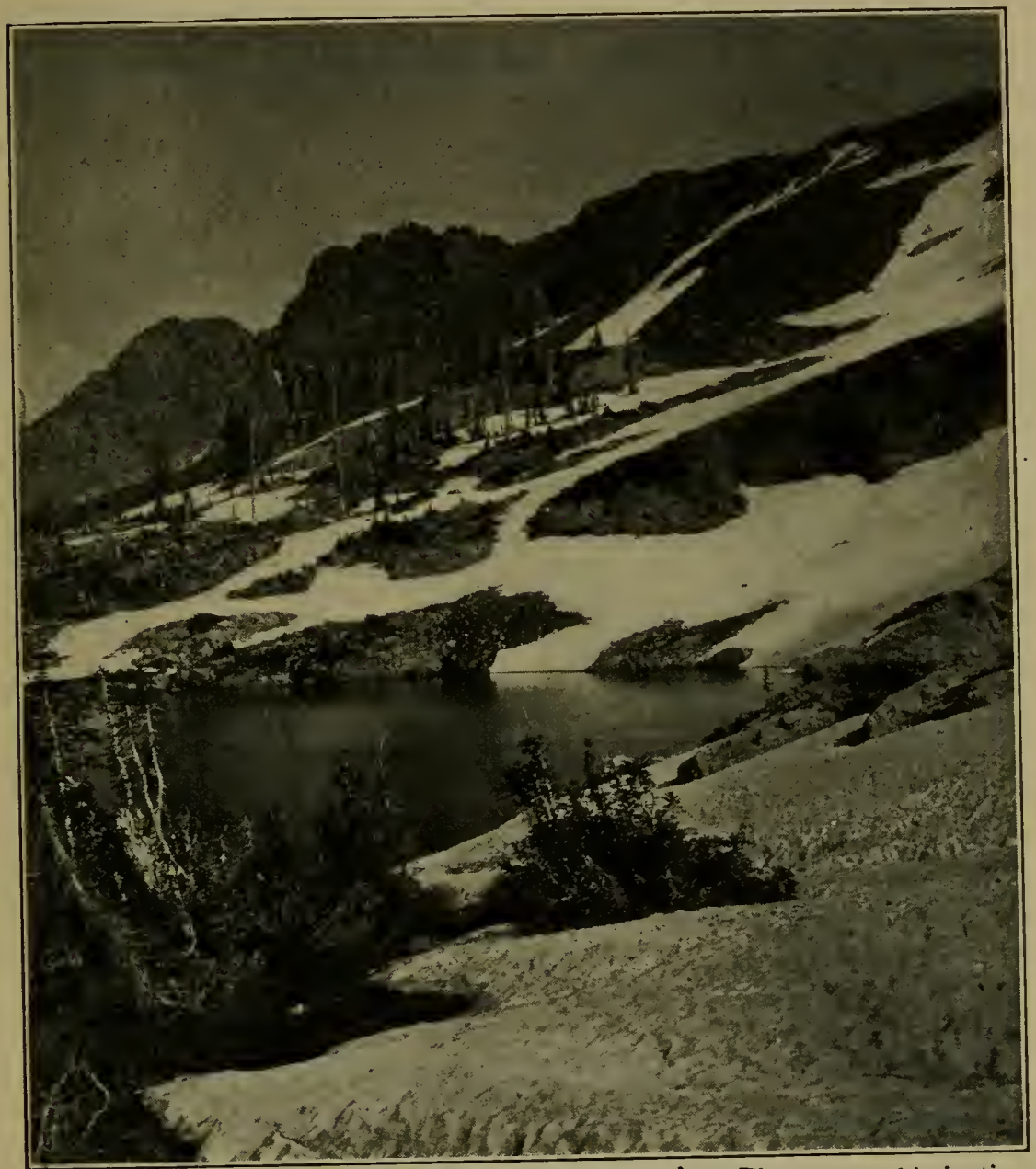

FIG. 17. Midsummer snow in the tops of the mountains. The source of irrigation water. This water is very pure. 
King found that eleven successive extractions of soil with water removed more than eleven times the quantity of some constituents that was extracted the first time. The continuous solubility of soils is well established, and it has, no doubt, an important bearing on the permanent production of crops.

Whenever, therefore, irrigation water is applied to the soil, a part of the soil is dissolved, providing that the substances dissolved by the previous irrigation have been somewhat thoroughly removed by plant roots or by drainage. Naturally, not all soil constituents are extracted at the same rate by successive applications of water. Approximately the same quantity of potash goes into solution from extraction to extraction, while a very large part of the nitrates is extracted during the first application of water, leaving little for the later ones; unless, indeed, during the interval between irrigations, nitrates have been added or cultural treatments have permitted a very rapid rate of nitrification.

53. Absorption by soils.-The solution of soil constituents occurs most readily at the surfaces of the soil grains. The dissolved substances, under the influence of somewhat obscure manifestations of the laws of attraction, are held in high concentration very near the surfaces, and the outward movement through the waterfilm of the dissolved materials is very slow. This property of firmly holding certain soluble substances near the surfaces of the soil particles, known as absorption, is of tremendous importance in conserving the fertility of agricultural soils, whether under humid or arid conditions. The first water added to a soil, as has already been explained, is held as thin films around the soil grains. Drainage through the soil occurs only after these films have acquired a cer- 
tain definite thickness. Water added beyond this point fills the capillary tubes and under the influence of gravity moves downward into the country drainage. As this gravitational water moves downward, the soil-water film clinging closely around the soil grains is not materially affected. A small part of the outer film may be carried downward, but the inner part, near the surfaces of the soil grains, where the dissolved soil constituents are held in greatest concentration, probably does not move at all with the gravitational water. Enough is carried along, however, to affect materially the composition of the drainage water. In one of the Utah experiments, water was applied to a very loose gravelly soil, scarcely 2 feet deep, and underlaid with a cobble rock formation of unknown depth. Underground collecting chambers were constructed to collect the drainage water. So gravelly was the land that within half an hour after water had been applied, it drained through into the lysimeters. As an average of one season's test, the following results were obtained:

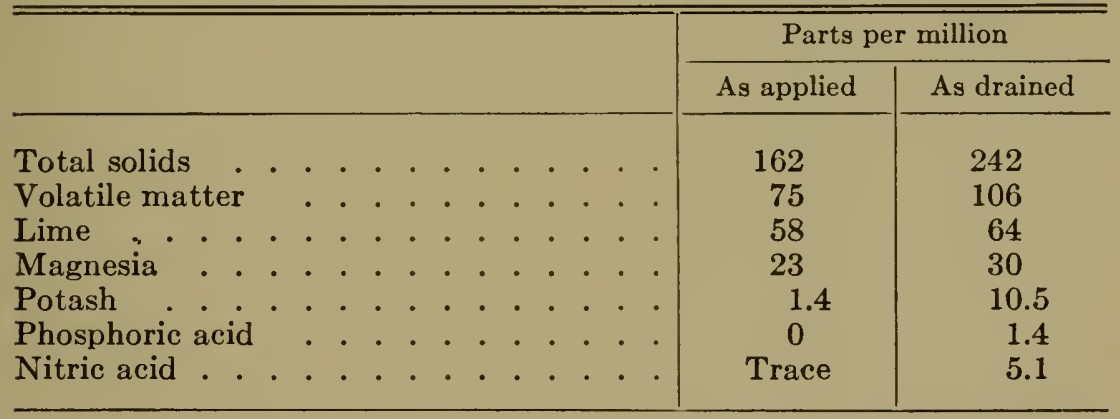

It will be noted from these figures that, even under conditions of easy and rapid drainage, much valuable material is washed out of the soil. Nevertheless, as will be shown, the parts of total solids in 1,000,000 parts of 
the drainage water were not much higher than in many of the streams and rivers used for irrigation. The lime and magnesia were not washed out to any great extent, but the potash, phosphoric acid and nitric acid, the three most important constituents of the soil, were proportionally much more abundant in the drainage water than in the original irrigation water. Analyses of drainage waters in various countries lead to similar results. Hilgard, in a collection of analyses of drainage water from European countries, has shown that the parts of total solids in 1,000,000 parts of water range from 140 to 721 , with an average of 352.6 , which is somewhat higher than the 242 found in the above Utah experiment.

54. Composition of drainage water.-It may be said safely that the concentration of drainage water under normal conditions is not extraordinarily high, but hovers in the neighborhood of 200 to 400 parts of total solids in 1,000,000 parts of water. Under abnormal conditions, these figures may be much larger. If, for instance, the soil is rich in organic matter, as after heavy manuring, the drainage water may show a high proportion of organic matter; if the soil is of an alkali nature, the drainage water frequently contains tremendously large quantities of soluble matter. In one of the reclamation experiments of the United States Bureau of Soils at Billings, Montana, the drainage water from an alkali tract, which had been underdrained for the purpose of removing the alkali, contained from 250 to 9,000 parts of dissolved matter in $1,000,000$ parts of water; in the drainage water from a similar tract located near Salt Lake City, were found 10,710 to 20,346 parts of dissolved matter in $1,000,000$ parts of water. These are extraordinary concentrations of drainage water which occur only when the soils are 
abnormally rich in soluble constituents. Normal soils, by the power of absorption, retain most of the soluble materials, so that the concentration of the drainage water is kept low, as above given.

55. Concentration of soil moisture.-Results of striking interest are obtained when the possible concentrations of soil water are calculated. If it be assumed that a soil with .1 per cent of soluble matter under ordinary laboratory methods contains an average of 20 per cent of moisture to a depth of 10 feet, which is the approximate condition of an irrigated clay loam immediately after a 5 -inch irrigation, and if all the soluble matter goes into solution in the water thus added, the soil solution will have a concentration of about 5,000 parts of dissolved matter for every $1,000,000$ parts of water. This is far in excess of the composition of any drainage water from such soils under normal field conditions. Moreover, as evaporation goes on, this concentration must increase considerably. Arid soils usually contain more than .1 per cent of soluble matter; if .5 per cent is held by the soil, for instance, the concentration under the above assumptions will be 25,000 parts of dissolved substance for every $1,000,000$ parts of water-a concentration larger than that of the drainage water from the above mentioned alkali reclamation tract near Salt Lake City. Little is known, as yet, about the exact concentration of soluble matter in the film held about the soil grains; but it must be comparatively high. In such solutions the feeding roots of plants are bathed.

56. Loss by drainage.-The repeated application of water to soils, in quantities sufficient to drain through, results disastrously, because, even though the quantity of soluble matter taken out each time is small, in the end the 
total is considerable. The evidence of this is found in the lean and washed-out soils of humid districts, where the rainfall is large enough to permit steady drainage without the counterbalancing effects of a tropical warmth. In arid districts, likewise, where over-irrigation has prevailed, soils have been permanently injured by the loss of plant-food-carried off in the drainage.

The loss of plant-food is only one of the many injurious effects of the excessive use of water. In arid districts the drainage water, resulting from over-irrigation, frequently accumulates in some lower-lying closed basin, such as in the lowest part of a valley. At this point the ground water rises higher and higher as excessive irrigation is practised on the higher land, until the water-table is so near the surface that water may be lifted from it to the surface by capillary attraction. When this condition has been reached, continuous evaporation from the soil surface occurs. The soluble matters contained by the water which is left behind increase, first, the concentration of the ground water, and secondly, as evaporation goes on, fill the upper layers of soil with soluble salts, often with a formation of an alkali crust. Over-irrigation thus becomes one of the chief sources of the dreaded alkali.

The disastrous results of the excessive use of water prevail over large areas in almost every irrigated section of the world. Leaky canals have permitted large quantities of water to soak through great areas of fertile soils, until, heavily charged with precious plant-food, they have accumulated in lower basins. Farmers, anxious to protect themselves against the drought, and believing that the more water used the more certain would be the crop, have so over-irrigated their lands as to permit a more or less constant drainage into subsoil and lower-lying places. 
In view of this danger, the irrigation farmer must so control the application of water to the soil that no more is added than is necessary to produce the maximum film around the soil grains. Drainage must, as a rule, be avoided. A knowledge of the depth and character of the soil and devices for measuring water make this easily done.

57. Upward leaching.-In yet another manner is the nature of the soil materially influenced by irrigation. If water is applied in moderation, and according to the best principles of irrigation, the soil-water film is simply thickened to a distance greater or smaller, according to the quantity applied. The water thus added is in part lost by evaporation at the top soil, and in part is taken from the soil through the plant roots. While the plant roots often penetrate the soil to a depth of 8 to 10 feet or more, yet the greatest abundance of plant roots is found in the upper soil. 'Under heavy irrigation, especially, when plants are not obliged to drive their roots deeply in search of water, the greatest root-development is usually found in the upper 3 feet or so of the soil. However, even these surface roots draw water from much greater depths; for, as has already been explained, the removal of water in an upper soil results in a slow capillary flow of water from below, to re-establish equilibrium. As the water moves upward, to replace that removed by the roots, it carries with it some of the materials dissolved from the lower soil layers.

Under wise irrigation, therefore, there is a gradual movement of the soluble soil constituents toward the surface, where the soil moisture often becomes so concentrated that the salts crystallize out and form layers of alkali. When irrigation is again applied, these soluble matters are in part washed downward; but, owing to the 
laws of absorption, they are held very near to the surfaces of the soil grains and are not easily dislodged by the gravitational water passing through the first foot. The downward movement of water is comparatively rapid and largely gravitational; the upward movement comparatively slow and capillary. Therefore, in irrigated soils, fairly rich in soluble matters, the tendency is to concentrate the soluble materials in or near the top soil.

Arid soils are frequently 50 to 70 feet deep and at times that distance from the ground water. The irrigation water in such soils, if wisely applied, moves downward 10 to 15 feet. It is only, then, within this limit that the soluble matters are moved upward. If the soil is rich in soluble matters, this concentration may result in injury to the plants; if, as is the usual case, the percentage of soluble matters is low, no injury results, but the plantfoods from lower depths are made easily available to plants. Even where the soil is rich in soluble materials, the farmer can, by judicious irrigation, and by the proper cultivation of the soil, keep the soluble substances so well distributed that no damage can result to the growing crop.

58. Salinity of river waters.-The natural waters used in irrigation are never quite pure, for no natural water is free from dissolved substances. Even rain-water dissolves from the air considerable quantities of nitrates and other substances. When the water that falls upon the land as rain or snow moves toward the rivers by seeping through the soil or by flowing over the ground, it succeeds in dissolving, during its descent, relatively large quantities of soil materials. The more deeply such water soaks into the soil before it finally reappears as a spring, or the longer it flows over the soil, the higher will be its concen- 
tration of dissolved substances. This is well shown by any of the analyses made of river water taken at different distances from the river head. For instance, in the following rivers the salinity or the parts of soluble matter in $1,000,000$ parts of water was as follows:

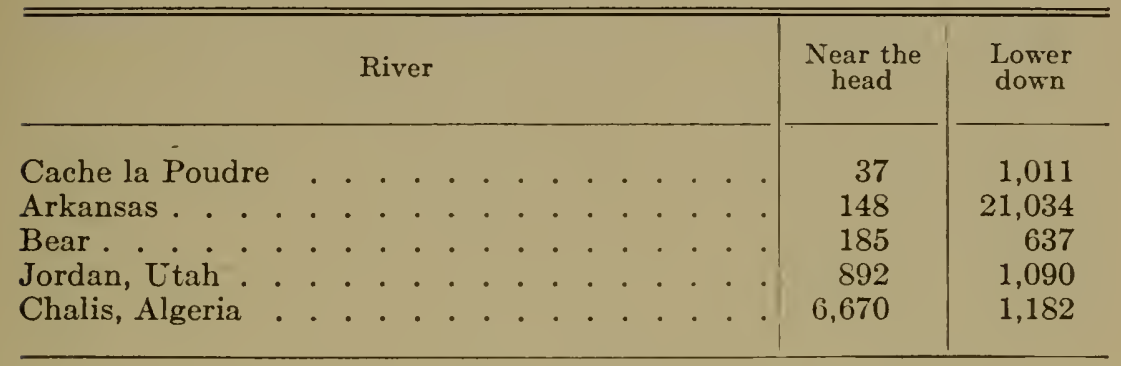

The Chalis River, Algeria, is an exception to the rule because tributaries, carrying relatively pure water, enter and dilute the main river near its lower end.

The quantity of dissolved substances in natural water, that is, the salinity, varies from exceedingly small quantities, as in rain-water, to almost saturated solutions, as in the waters of the Dead Sea and the Great Salt Lake. The following table, based upon the classical work on "The Data of Geochemistry," by F. W. Clarke, shows the proportions of dissolved substances found in some of the river waters of the world. No such table, however elaborately constructed, can be wholly accurate. At best, only a few of the rivers of the world have been subjected to chemical analysis, and even the rivers that have been most thoroughly studied, have not been analysed at all seasons of the year for a sufficient number of years to make the averages absolute in their values. 
Dissolved Substances in River Waters

(Parts per million)

\begin{tabular}{|c|c|c|c|}
\hline \multirow{2}{*}{ Locality } & \multicolumn{2}{|c|}{ Range } & \multirow{2}{*}{ Remarks } \\
\hline & Min. & Max. & \\
\hline \multicolumn{4}{|l|}{ United States- } \\
\hline Atlantic Slope & 15 & 140 & Nearly all under 100 \\
\hline Mississippi Basin & 90 & 2,323 & One-half under 300 \\
\hline Southwestern rivers & 321 & 2,384 & Three-fourths above 700 \\
\hline Northwestern rivers & 31 & 1,481 & Nearly all under 100 \\
\hline Great Basin (no outlet) & 185 & 1,090 & \\
\hline California.. & 119 & 2,412 & Nearly half under 200 \\
\hline \multicolumn{4}{|l|}{ Canada- } \\
\hline St. Lawrence Basin. & 1 & 298 & \\
\hline Saskatchewan Basin & 115 & 551 & \\
\hline \multicolumn{4}{|l|}{ Europe- } \\
\hline Great Britain . . & 31 & 286 & \\
\hline Western . . . . . & 134 & 254 & \\
\hline Eastern . . . . & 49 & 447 & \\
\hline Rhine . . . . . & 126 & 299 & \\
\hline Elbe . . . . . . & 13 & 221 & \\
\hline \multicolumn{4}{|l|}{ South America- } \\
\hline Amazon . . . & 37 & 59 & \\
\hline Southern . . . . & 40 & 9,185 & \\
\hline Nile.... . . . & 130 & 174 & \\
\hline India and Java . . . & 86 & 122 & \\
\hline
\end{tabular}

It will be observed that, in the United States, the waters of highest average purity, that is, of lowest concentration, are those on the Atlantic Coast; those of the Mississippi Basin and of the great Northwest come next; the waters of the southwestern rivers, including the Colorado, are still higher in their average content of soluble matter; while those of the California rivers stand between those of the Mississippi River and those of the Southwest. The rivers of the Great Basin, which, after a short journey from the mountain headwaters, reach the interior lake into which their load is deposited, are less concentrated than the rivers of the Southwest and more like those of the Mississippi River Basin. 
The concentration of river waters, at least in the United States, appears to vary with the rainfall. In humid districts, where the soils are more thoroughly water-washed, and where the run-off is large, the quantity of dissolved material is small. In arid districts, with soils richer in soluble matter, the concentration of the river waters increases. While the annual rainfall is not the only factor determining the concentration of river waters, yet it determines, in large measure, the quantity of soluble substances. The same general law may be observed in the data dealing with the Canadian rivers. In the St. Lawrence Basin, the proportion of dissolved substances in the river waters is considerably smaller than in the Saskatchewan Basin, which is more of a semiarid character. Similarly, the data from the river waters of Europe shows a variation with the general climatic conditions, especially with the rainfall.

The Nile, famous in irrigation history, does not carry a great abundance of soluble material. It stands in this respect between the waters of the Mississippi and those of the Great Basin. The data of the above table, which are representative of the rivers of the world, show that the quantity of dissolved substances in river waters is not extraordinarily large. In most cases, the waters of even long rivers in arid districts are less concentrated than the ordinary drainage water of agricultural fields.

The river waters of humid regions, with low total concentration, are comparatively rich in carbonates; those of arid regions, on the other hand, with high concentration, contain more sulfates and chlorides than carbonates. This is explained when it is recalled that, under humid conditions, the native vegetation grows abundantly and the proportion of soil humus is much larger than 
under more arid conditions. Water passing through such humid soils naturally takes up from the humus much carbon dioxide.

59. Salinity of lake waters.-The waters of the great lakes of the world, from which irrigation waters are frequently taken, vary as largely as do the river waters. The water of mountain lakes that are fed directly by the melting snows contains little dissolved matter. For example, the water of Lake Tahoe, in Nevada, contains only 73 parts of dissolved substances to $1,000,000$ parts of water; whereas, the water of Sevier Lake, in Utah, contains 86,400 parts, and, in the water of the Great Salt Lake there are nearly 300,000 parts of dissolved substances. Ocean water, as another example, contains about 39,000 parts of dissolved substances in 1,000,000 parts of water. Naturally the lakes that contain the most concentrated solutions are in almost every instance those of interior basins with no outlet to the ocean. The water runs into these basins and as it is gradually evaporated it leaves behind its load of soluble materials to concentrate the remaining water. In the course of time, such waters become saturated with certain substances which then crystallize out. This is the case with the Great Salt Lake and many other well-known interior lakes of western United States and other arid parts of the world.

60. Salinity of mineral springs.-The most heavily charged waters, however, save those of interior basin lakes, issue as mineral springs in many parts of the world. The high degree of salinity of such waters seems to be due, as already suggested, to the fact that the percolated water has passed over subterranean layers of soluble material which is brought up in solution when the spring issues from the soil. The salinity of such waters varies 
from extreme purity to a concentration comparable with saturated waters of inland lakes.

61. Soil moisture and natural waters compared.-As shown above, the soil solution of a clayey loam containing about .1 per cent of soluble matter will contain in the neighborhood of 5,000 parts of dissolved matter for 1,000 ,000 parts of water. This is considerably higher than the concentration of the larger number of river waters, or even of mineral springs. In the arid regions, the soluble matter of soils often exceeds .1 per cent, and the concentration of the soil solution, after irrigation, is probably higher than 5,000. Moreover, if the top soil is not thoroughly stirred, evaporation from the soil surface goes on very rapidly and the soil solution becomes so concentrated that, before the next irrigation, the concentration must be nearly twice what it is immediately after an irrigation. The effect of varying quantities of dissolved substances in irrigation water on the growth of plants will be discussed in the chapter on alkali. It is of very great importance to the irrigation farmer.

62. Ash constituents added by irrigation water.When the quantities of water used in irrigation are so large that there is a constant drainage through the soil, the only probable effect of the water on the soil is the washing out of certain soil constitutents. When water is added in moderation, so that the soil is filled to a certain depth, but not in sufficient quantity to drain through, the soluble matters contained by the water must of necessity remain in the soil, except as they may be utilized by the plant. Under existing practices 2 acre-feet of water represent a very moderate annual irrigation. On sufficiently deep soils, if the single applications are not too large, this quantity of water does not cause material 
drainage. It is then possible to calculate the probable quantities of soluble salts deposited in the soil to a depth of 10 to 15 feet during one season's irrigation. In the arid regions, 250 parts of dissolved substances in 1,000,000 parts of water are accounted unusually low, unless obnoxious substances are admixed. Such a water, applied to the soil to a depth of 2 feet throughout the season, allowing for no drainage, would leave in an acre of soil throughout the season, approximately 1,300 pounds of solid matter. This repeated, year after year, would naturally run into large amounts, although some would, undoubtedly, be taken up by the plants in their growth and used for the elaboration of plant tissues.

At the Utah Station, a large number of analyses were made of crops grown under irrigation, and it was found that in wheat kernels the ash content was about 2.5 per cent and, in wheat straw, about 10 per cent. A thirtybushel wheat crop would then abstract from the soil about 345 pounds of mineral matter, or a little more than one-fourth of the total quantity added by irrigation. Lucern contained about 8.5 per cent of ash materials, in which case a crop of 10,000 pounds would contain approximately 850 pounds, or a little more than two-thirds of the materials left by the irrigation water. None of the crops ordinarily grown under irrigation takes up the quantity of soluble substances added to the soil by 2 acre-feet of water, providing drainage is prevented. It must be remembered, in this connection, that irrigation waters do not always contain all the essential plant-foods, or in the right proportion. While a water may add to the soil more solid matter than the crop needs, the individual constituents may be wholly or in part absent, and must be supplied by the soil. 
Under more modern and improved methods of irrigation, first-class crops are frequently raised with 1 or $11 / 2$ acre-feet of water. In such cases, the crop more nearly takes up the substances added to the soil by irrigation water. On the other hand, the water used for irrigation ordinarily contains more than 250 parts of dissolved substances in 1,000,000 parts of water. If the salinity is 500 , 2 acre-feet of water would add to one acre, 2,600 pounds of solid substances, and waters richer in mineral matters would leave in the soil tremendous quantities of solid matters. It is readily seen, therefore, how profoundly irrigation water may affect soils under irrigation. Should the irrigation water be heavily charged with substances deleterious to soil or crop, immediate and irreparable damage may be done. Little definite information concerning the whole subject is as yet available. It is quite evident, however, that the methods of irrigation must be varied with regard to the composition of the water used.

63. Use of concentrated waters.-An irrigation water of medium concentration may be used safely in moderation, although it should be so used as to leave as little as possible of its constituents in the soil. When concentrated waters are used, excessive quantities are applied to force drainage, so that the concentration of the free water in the soil after irrigation is never above that of the water used. This is the good reason behind the practice of farmers, in districts where the soils or waters are heavy in alkali, to use more water throughout the season than in districts where the soils are freer from alkali and the water of low concentration. This principle is frequently the essential one in building up a district which of necesity must depend upon highly mineralized water for its supply of irrigation water. 
64. Need of water surveys.-The substances contained by the water may in themselves be harmless; but, since they are applied to the soil from year to year in such large quantities, they undoubtedly often fill many of the capillary soil spaces or are deposited on the surfaces of the soil grains, and thus affect the chemical composition and the granular condition of the soil. This subject has as yet been poorly investigated, but is worthy of careful investigation, so that irrigation practices may be rationalized from the point of view of the varying composition of irrigation water. Systematic chemical surveys of irrigation waters should be made in connection with the study of the soils to which the waters are to be applied. Only when such data are abundantly at hand will it be possible to formulate for each section irrigation practices that will be permanently satisfactory. In the present stage of irrigation progress, it has become very important to know the composition of irrigation waters. As irrigation becomes older more problems will arise, many of which can be solved only by a more thorough knowledge of the waters used on irrigated soils. Water surveys are as legitimate in irrigated districts as are soil surveys.

65. Composition of natural waters.-While the total quantity of soluble matter found in a given volume of irrigation water is of great importance, the composition of such soluble matter is of equal importance. In soils are found the great majority of the chemical elements and particularly those that are essential in plant-growth. In the following table may be found the composition of a number of natural waters selected from the data given by Clarke. 


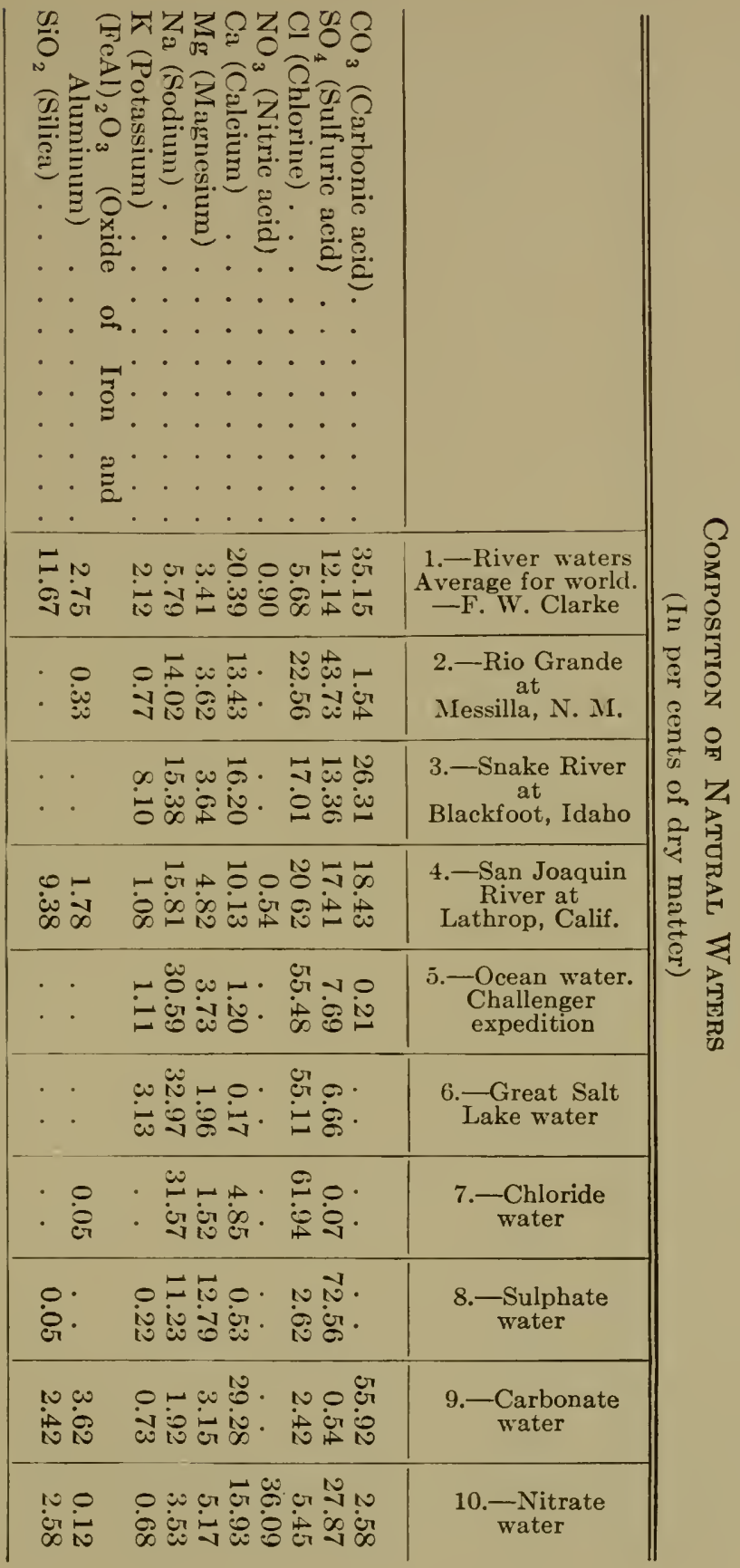


The first column shows the average composition (rarer elements being excluded) of river waters for the world. All the elements necessary for plant-growth are present. The carbonic acid, combined chiefly with calcium, is in largest abundance. Sulfuric acid, in combination with calcium, magnesium, sodium and possibly potassium, is also present in large abundance. Chlorine is third in abundance. Even nitric acid, vitally important for plantgrowth, is present in small quantities. In the three following columns are analyses of the waters of three great rivers of western America, used largely for irrigation purposes. All the necessary plant-foods are present, but in very different proportions, which, undoubtedly, will affect, differently, the conditions of plant-growth. In column 5 is the average composition of ocean waters as determined by the Challenger expedition. It differs materially from the analysis in column 1 which is a world average for river water. The carbonic acid has practically disappeared, no doubt precipitated by the lime, and the sodium and chlorine have increased tremendously. In column 6 is an analysis of the water of the Great Salt Lake, which is a body of water practically saturated with common salt. It resembles ocean water, but carbonic acid is totally absent; the proportion of calcium and magnesium lower; of potassium higher.

66. Classification of natural waters.-Considering the composition of the soluble materials held by natural waters, especially those used in irrigation, they may be classified as follows: Those rich in chloride of sodium are called chloride waters; those rich in sulfates, especially of sodium and calcium, are sulfate waters; those rich in carbonates, especially of sodium, are carbonate waters; those rich in borates are borate waters; those rich in free 
acids, are acid waters. This classification may be extended to cover any water as soon as its predominating constituent is known. The above are the leading classes. A typical analysis of a water in several of the above classes will be found in the last four columns of the preceding table.

This classification of natural waters is very useful in irrigation practice, and especially important in considering the alkali question. For the purposes of this chapter it is sufficient to make clear that practically all known natural waters, unless rain-water and water coming immediately from the melted snow be excepted, contain varying quantities of all the essential elements of plantgrowth. Moreover, the variations in the proportions of the constituents of water are so great that while the waters may be roughly classified as chloride, sulfate or carbonate waters, there is a host of intermediate kinds which overlap two or more groups. For an exact understanding of the chemical behavior of an irrigation water on the soil or crop, an analysis of the water in question must be available.

67. Plant-food value of irrigation water.-The information found in the preceding table makes possible some interesting calculations. The quantity of plant nutrients, such as nitrogen, potassium, phosphorus and lime removed from an acre of soil by some of the common crops, has been computed by Warington. His results, obtained under humid conditions, do not differ greatly from those that might be obtained under irrigated conditions, and, until data from irrigated crops are obtained, may be used with approximate accuracy. A crop of wheat yielding thirty bushels to the acre requires at least about thirty pounds of potash, ten pounds of lime, twenty pounds of phosphoric 
acid and forty-eight pounds of nitrogen. By using the smallest percentage, 22 per cent of potash, in the above table, 2 acre-feet of water would yield a little less than six pounds of potash, a quantity entirely insufficient for the production of a crop. By using the averages of some of the other waters in the table, the potash added by 2 acrefeet is ample to supply the crop needs. Any of the waters in the table, save No. 6 , with only 17 per cent lime, would supply amply the needs of the crop for lime. In most waters, the nitric acid is present in natural waters in very small quantities, but it is not likely that the quantity of water ordinarily used in irrigation throughout a season would be sufficient to supply the crop needs. Phosphoric acid is also present in small quantities and seldom can supply, thoroughly, the crop needs. While, therefore, the total soluble material contained by ordinary water appears to be quite sufficient in quantity to supply the total needs of the plant, the specific substances required for successful plant-growth are fully met only in a few waters. With moderate irrigations and waters of average composition, plants must draw upon the soil for at least some of the constituents needed in their growthnotably for phosphoric acid, nitrogen and potash. Waters in which these substances are present in larger proportions may supply all the needs of the crop for mineral matters.

The property of the soil to retain certain ingredients of the water that may be passing through it is of importance in this connection. Lime, magnesia, potash (notably in clay soils), chlorine, and practically all the ingredients of irrigation water, are partly absorbed by the soil through which the water passes. The substances that are absorbed and the degree of absorption are determined by the com- 
position of the soil and of the water. To establish equilibrium between the soil and the water, in conformity with chemical and physical laws, substances dissolved in the irrigation water are absorbed and held by the soil, or corresponding substances are taken from the soil to enrich the drainage water. Because of this soil power of absorption, the water that drains from the soil is propor-

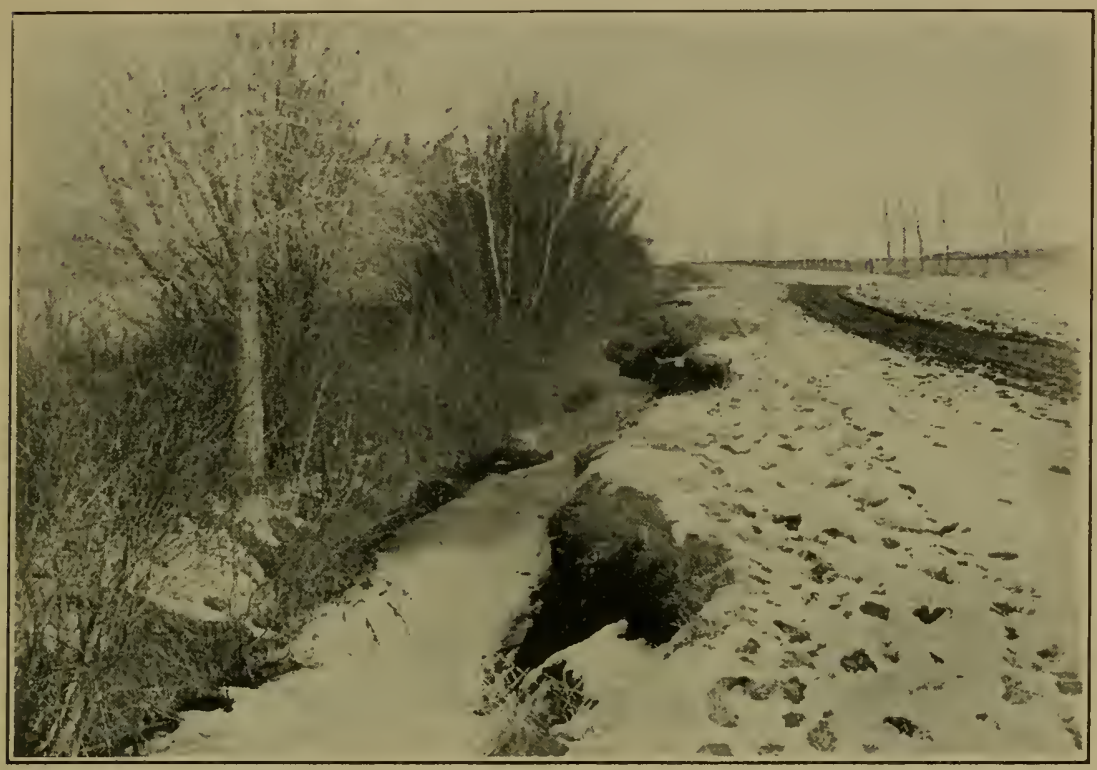

FIG. 18. Badly corroded ditch due to excessive fall. On a larger scale this is the action of swift rivers.

tionally of a much different composition from the water which was originally added to the soil. This is brought out by the analysis on page 77 .

68. Suspended matter in river waters.-By far the larger part of river waters carry not only large quantities of dissolved substances; they carry, also, considerable loads of suspended solid matter. This suspended material is naturally derived from the washing effect of 
the snow-water, rain-water and floods, chiefly among the highlands, near the headwaters of the river course. Note the following table:

\section{Suspended Matter in River Waters}

(Parts per million)

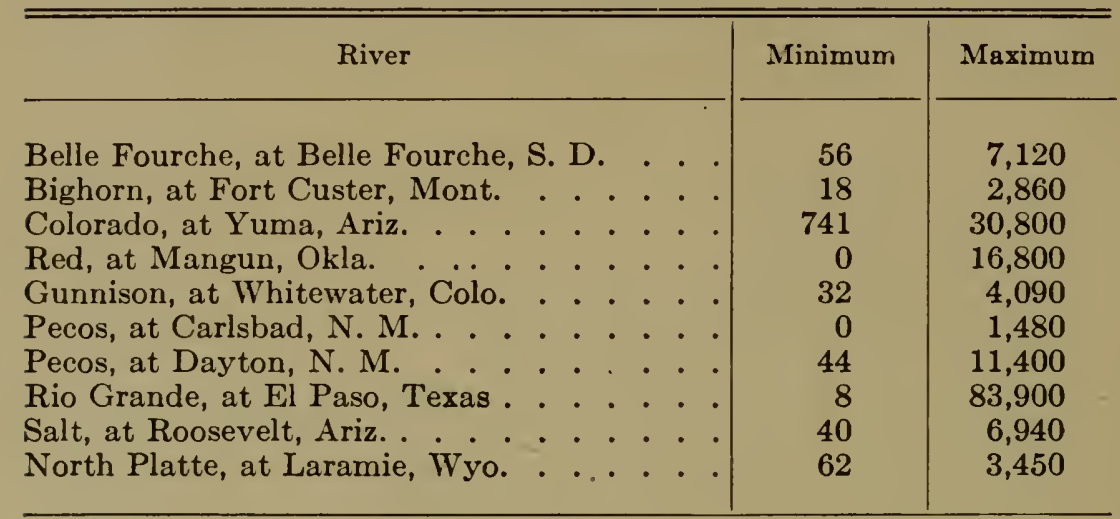

The quantity of suspended matter as shown in the above table is very variable and frequently very large. Rivers rising in well-forested districts, or those that travel only a short distance before they empty into the lake or main river, are often comparatively free from suspended matter. The Colorado and the Rio Grande Rivers carry more suspended matter than any other of the great rivers of the United States. As shown above, as high as 84,000 parts of suspended matter in $1,000,000$ parts of water-nearly 8.5 per cent-have been found in the water of the Rio Grande at El Paso, Texas. The Colorado at Yuma, Arizona, has carried nearly 31,000 parts, or more than 3 per cent, of suspended matter in 1,000,000 parts of water. When the immense volumes of water in such rivers are considered, it is readily understood that quantities of suspended matter almost beyond human comprehension, are carried from the highlands tributary to the river, 


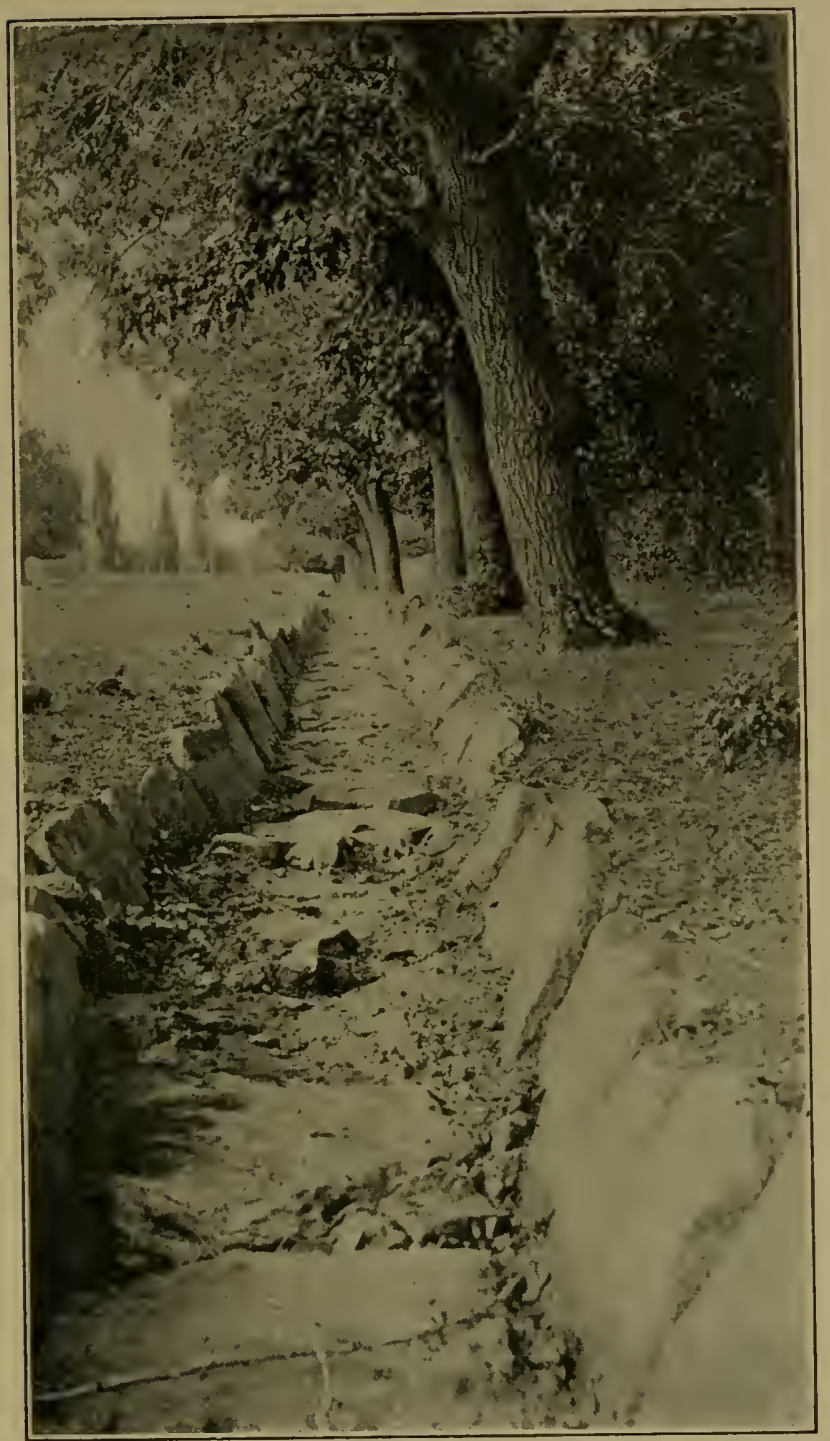

FIG. 19. Walled ditch to prevent erosion of easily "washed" soil.

during each season's flow. Large rivers, all over the world, carry similar loads of suspended matter. Famous examples are the Nile, the Danube, the Rhine and many other 
historical rivers, a large number of which are partially diverted for irrigation purposes. (Figs. 18, 19.)

69. Seasonal variation of suspended matter.-The suspended matter carried by a river varies in quantity from month to month. This is well shown in the following table, constructed from the records of the Green River, at Jensen, Utah, during the years 1905 and 1906.

Suspended Matter Carried by the Green River, at Jensen, Utah, Each Month During the Year 1905-06.

(In parts per million)

\begin{tabular}{|c|c|c|c|}
\hline April & $.2,278$ & October & \\
\hline May & . 917 & November & \\
\hline June & 415 & December & \\
\hline July & 91 & January . & 17 \\
\hline August & - 613 & February & 28 \\
\hline September & $.4,749$ & March & . $.3,170$ \\
\hline
\end{tabular}

In March and April, during the time of the heavy spring rains, the loads of sediment were very large; as also in September and October, when the fall rains occurred. During the summer months of June, July and August, when only occasional showers fell, the suspended matter was low; and in November, December, January and February, when the ground was largely covered with snow, it was even smaller.

During the seasons of the year when the lands around the headwaters of the rivers are not covered with snow and ice, the quantity of suspended matter carried by a river varies directly with the time and quantity of precipitation. A sudden flood will render the river turbid with suspended matter, and the longer seasonal floods of spring and fall are characterized by long periods of muddy water. In a part of the western United States where the growing season is rainless, the water is clearer during the 


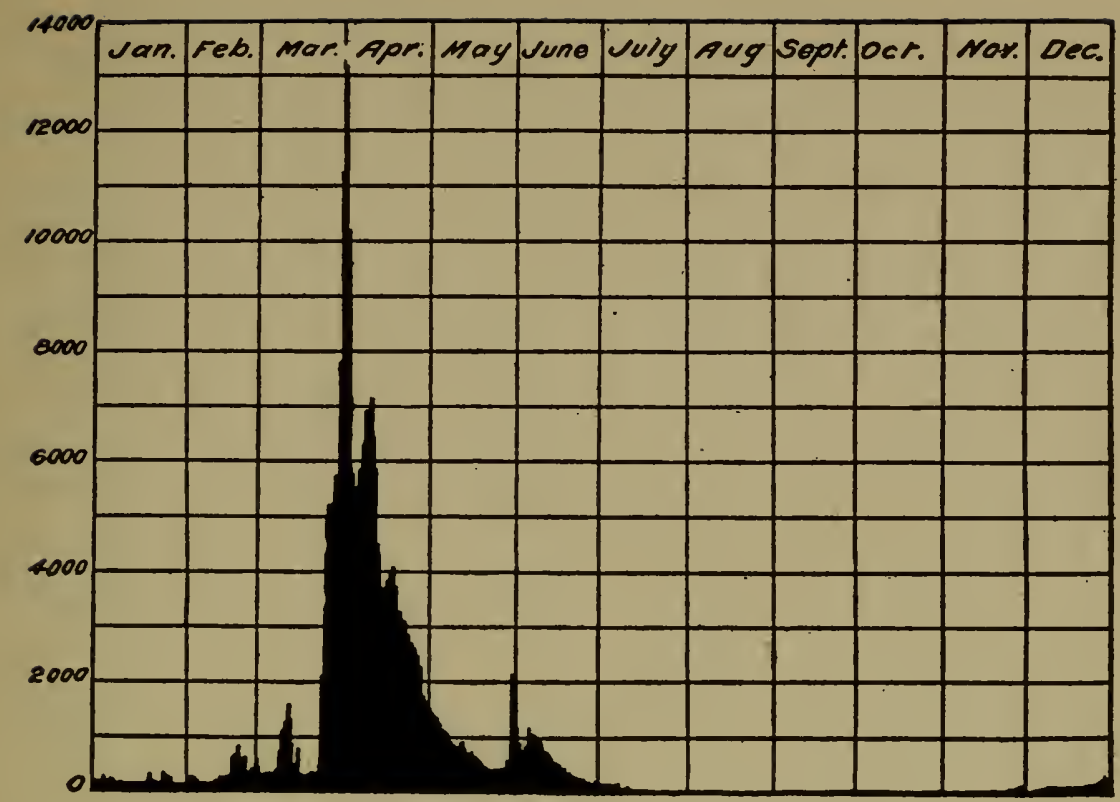

FIG. 20. Daily discharge of Malheur River (second-feet).

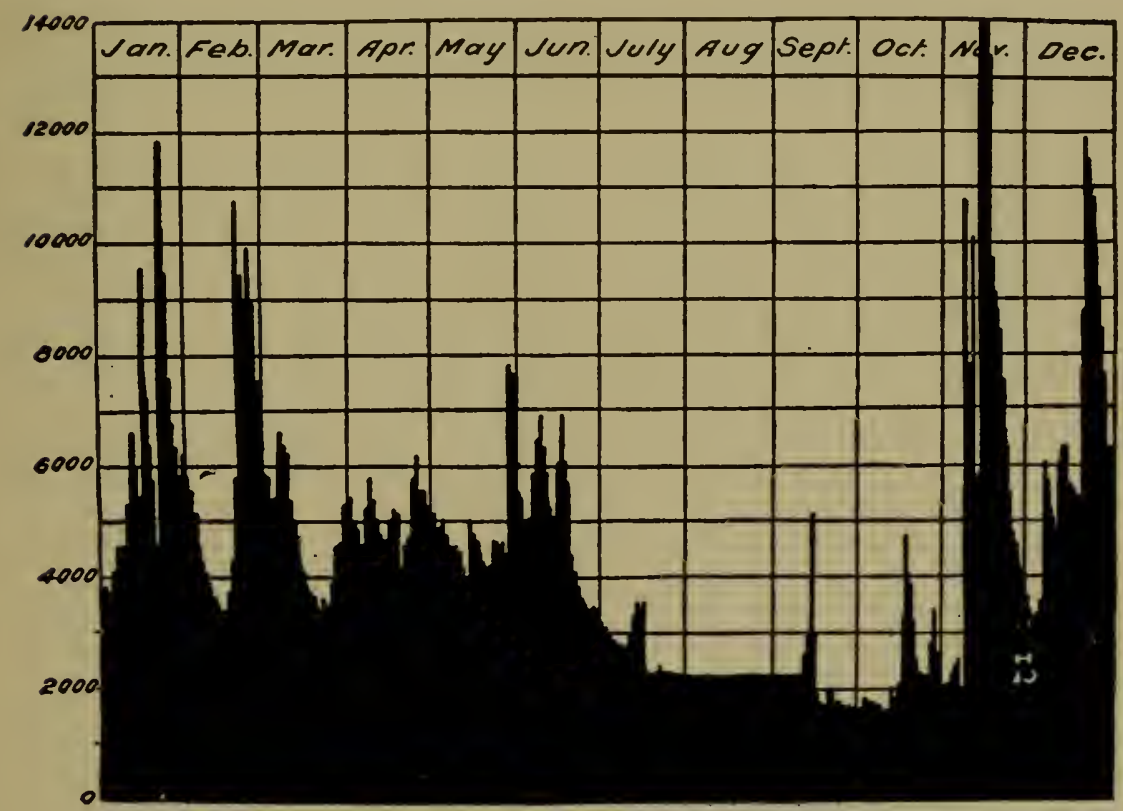

FIG. 21. Daily discharge of Mackenzie River (second-feet). 
irrigation season than either just before or after. In other parts, where summer rains prevail, the irrigation water is often heavily loaded with suspended matter. (Figs. 20, 21.)

70. Suspended matter added to soil by irrigation.Considerable quantities of sediment may be added to the soil during a season's irrigation. If 2 acre-feet of water are used annually for the production of crops, a calculation may be made similar to that which was made concerning the soluble matter added to the soil. During the time of summer floods, few waters contain less than 1,000 parts of suspended matter in $1,000,000$ parts of water. If this were continued throughout the season, it would mean an addition to each acre of land of over 5,000 pounds of sediment. The southwestern rivers, which carry, ordinarily, throughout the season much more sediment than this, add to each acre during each irrigating season an extremely large total quantity. It has been reported from Arizona that, frequently, the sediment of one season's irrigations covers the land to a thickness of 4 to 6 inches. In rivers with less sediment, these effects are not so visible, but wherever irrigation is practised, especially in arid districts, a large quantity of solid matter is deposited on and in the soil. This, continued year after year, will certainly affect the productive power of the soil.

71. Suspended matters derived from surface soils.The suspended matters in river waters come chiefly from the surface washings of the lands near the headquarters of the rivers. The character of the suspended matters carried by rivers varies, therefore, with the surface nature of the soils from which the sediments are derived. If the contributing soils are sandy, the suspended matter will 
be sandy; if the soils are loamy or clayey, the sediments will be correspondingly more rich in clayey materials. Usually, however, only the silty or finer particles reach the lower portions of the river where the irrigation canals are taken out. The coarser or more sandy particles are deposited in the first quiet places of the river and do not, ordinarily, reach the lower lands, except, perhaps, in times of high water, when even the sand deposits of earlier years may be torn up and whirled down to the irrigated districts.

The top or surface soil is always most vigorously affected by sunshine, air, water and biological agencies; therefore the top soil is the most fertile part of the soil. It is this fertile soil layer that is washed into the rivers, finally perhaps to be deposited on the farmers' fields. Eventually, then, the farmer covers his own land with the fertile surface soil of the mountain slopes and upland valleys.

72. Composition of river sediments.-River sediments have been analysed in the United States, in Europe and in Egypt. The results show that river muds are somewhat richer in the essential plant-foods than the ordinary fertile soils which the water serves. It has been estimated by Forbes that the market value of the fertilizing constituents in three samples of Salt River mud, to the acrefoot of water, varied from $\$ 7.98$ to $\$ 25.51$. These figures should be given respectful consideration by the farmer who does not content himself with using one acre-foot of water. When the fertilizing value of these sediments is considered in connection with the fertilizing value of the dissolved materials, one of the great advantages of irrigation is made evident. Under many of the rivers of the irrigated section, proper methods of irrigation should 
make the draft of the plant upon the soil so small as to extend greatly the productive power of the soil.

73. Physical effects of sediments.-The physical effects of the addition of river silts to the soil are not, however, always uniformly beneficial. On a sandy soil, the river silts usually bind the soil together and make it more firm, of better water-holding power and of easier

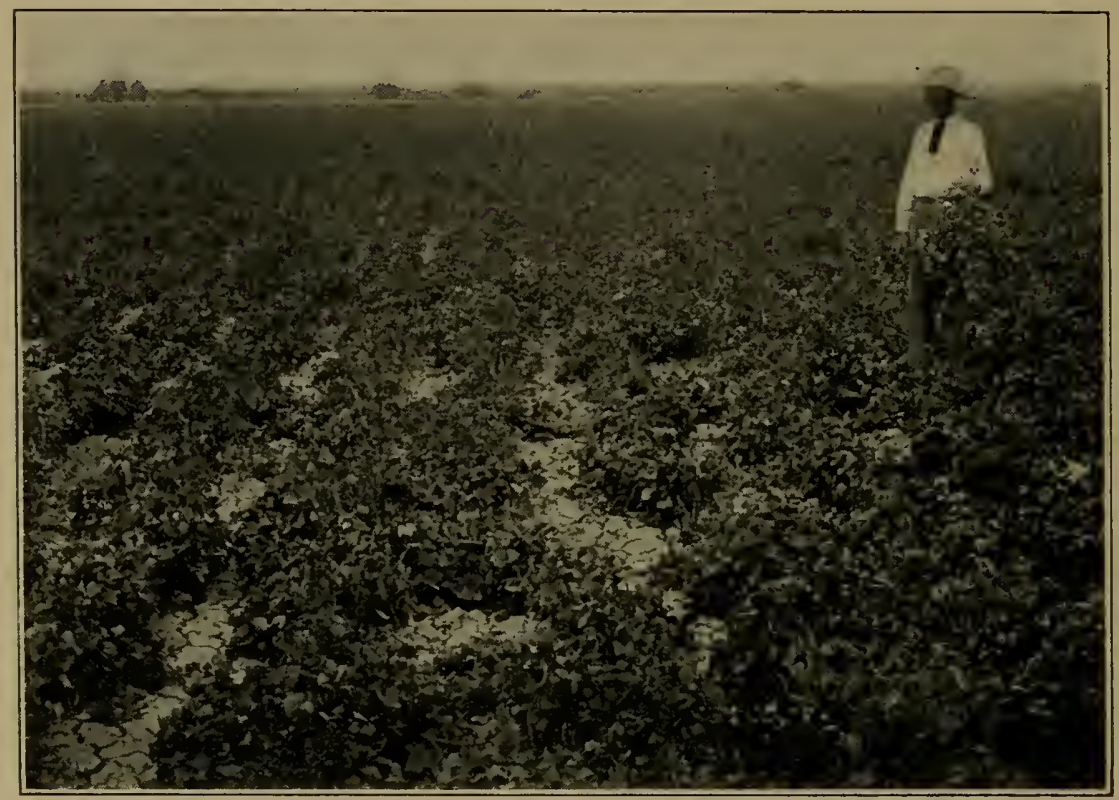

FIG. 22. Deposit in field of suspended matter from irrigation water.

cultivation. On a heavy clay, if the river sediment is of a loamy character, the clay is mellowed and lightened and, therefore, improved. However, if the silt is very fine or of a clayey nature, its application to a clay soil or even to a loam soil might be disadvantageous, because of the finer texture that it would produce. Herein lies the danger in using irrigation water that carries considerable quantities of suspended matter. River mud is usually 
of a very fine texture. When dry, it crusts and forms a hard covering, which does not readily admit water or air into the soil. This necessarily interferes seriously with plant-growth. One season's irrigation is not greatly injurious, but if repeated year after year, unless proper cultural treatments are employed it may result disastrously.

Another danger, of less importance, resulting from the use of water containing much suspended matter, is that occasionally the finely suspended matter clings closely around the roots of the plant, and, as it dries and contracts, injures the plant mechanically; or it may produce a type of sun-scald, not yet clearly understood. It is not wise to apply to young plants during a period of high temperature an abundance of water heavily charged with suspended matter. (Fig. 22.)

74. Cultural treatment of sediments.-It is not, however, a very difficult problem to meet and overcome this condition. The annual silt deposit should be plowed into the soil thoroughly each fall or spring, and, to keep the top soil open, thorough cultivation should be practised throughout the growing season. It has been observed that fields of wheat, irrigated with water rich in mud, have produced unusually large crops wherever the sediment was plowed in from year to year, and the soil thoroughly disked or harrowed in the spring after the highwater irrigation, with its load of silt, had been applied. The young wheat is not injured materially by such early harrowing, and the advantages resulting from the breaking of the silt crust are shown in unusually large crops. On the other hand, an alfalfa field, cultivated in the oldfashioned way, that is, which receives no cultural help throughout the season, is soon made to suffer severely 
by the accumulation of the annual silt deposits, which effectually shut out air from the soil and make it almost impossible for water to penetrate into the lower soil layers. If this one danger be avoided, the suspended matter in irrigation waters may be made a source of wealth to the irrigation farmer.

75. Effect of sediments on crop yields.-Forbes has made some interesting experiments on the effects of the river silt on the production of crops in Arizona. Similar, but not so carefully made, observations have been made in other sections of the world. The general conclusion seems to be that wherever water, carrying sediments, is applied without attention being given the silt deposits, the crop-yields tend to decrease. Whenever, however, the physical disadvantages discussed above are offset by proper tillage, great financial advantages result from the fertile matter carried by the irrigation waters. In fact, the fertile suspended matters, carried at the irrigation season, should increase materially the value of waterrights from such sources. The tremendous value of the overflow of the Nile, heavy with suspended matter brought from the African highlands, is a familiar historical fact. In India, South Africa, Europe and the United States, there are districts in which the lands have higher values because of the quantities of sediment carried by the irrigation streams.

The irrigation farmer deals with a much more complicated problem than does his brother who depends simply upon the natural precipitation for the moisture supply. To the irrigation farmer the soil is one factor, the rainfall another, and the water that he uses may be almost as important a factor as the soil itself.

76. Water and soil life.-Soil moisture also exerts a 
distinct effect on the living organisms in the soil. The detailed relations that exist between soil life and varying soil moisture are yet to be determined, and will furnish another and most important chapter in irrigation practice. Very few investigations have been made on this phase of irrigation, although the field is full of promise.

It is well known that bacteria and other forms, of low life flourish best when in the presence of an abundance of water, and the statement is commonly made that the greatest effects of bacterial life are obtained when an excess of water is available. While these findings are generally true, it must be observed that few studies of bacterial activity have been made under an environment similar to that which prevails in the soil. Low forms of life, like higher ones, require various foods in addition to water; and these substances must be in solution at a certain concentration. Under irrigation, as already shown, the concentration of the soil solution may be varied considerably. When over-irrigation is practised, the soil solution is kept very dilute; when no irrigation is practised, during rainless summers, it may be kept very concentrated. This phase of the subject, in relation to soil life, is yet to be studied.

Stewart and Greaves have studied, at the Utah Station, the effect of varying applications of water on the nitrifying organisms. Series of field plats were grown to different crops. Each series received irrigation from 25 inches to none. The soil was ideally adapted to rapid bacterial action. The work was continued over eight years, so that the conclusions may be accepted with considerable assurance of their truth. It was found that the nitric nitrogen content never exceeded 300 pounds to a depth of 10 feet. The application of irrigation water 
had a distinctly beneficial effect upon the formation of nitric nitrogen. The greatest total production was observed when 15 inches of water were applied. The greatest production to the inch of water was found, however, when the minimum quantity of water was used. The use of the maximum quantity of water, 25 inches, decreased the total yield, and gave the smallest yield of nitrates per inch of water used. A medium quantity of water appeared best, therefore, for the activity of the nitrifying organisms.

In the same investigations, it was found that the concentration of the soil solution, in nitrates, was always greater as more irrigation water was used.

In view of the tremendously great importance of soil life in the maintenance of soil fertility, it should be carefully studied under the conditions of irrigation.

\section{REFERENCES}

Cameron, F. K. The Soil Solution. Chemical Publishing Company, Easton, Pa. (1911).

Cameron, F. K., and Gallagher, F. E. Moisture Content and Physical Condition of Soils. United States Department of Agriculture, Bureau of Soils, Bulletin No. 50 (1908).

Cameron, F. K., and Bell, James M. The Mineral Constituents of the Soil Solution. United States Department of Agriculture, Bureau of Soils, Bulletin No. 30 (1905).

Clarke, F. W. The Data of Geochemistry. Second edition. United States Geological Survey, Bulletin No. 491 (1911).

Collins, W. D. The Quality of the Surface Waters of Illinois. United States Geological Survey, Water Supply Paper No. 239 (1910).

Cushman, A. S. The Effect of Water on Rock Powders. United States Department of Agriculture, Bureau of Chemistry, Bulletin No. 92 (1905).

DoLe, R. B. Analyses of Waters East of the 100th Meridian. United States Geological Survey, Water Supply Paper No. 236 (1909). 
Fonbes, R. H. The River Irrigating Waters of Arizona. Arizona Experiment Station, Bulletin No. 44 (1902).

Forbes, R. H. Irrigating Sediments and Their Effects Upon Crops. Arizona Experiment Station, Bulletin No. 53 (1906).

Hare, R. F., and Mrtchell, S. R. Composition of Some New Mexico Waters. New Mexico Experiment Station, Bulletin No. 83 (1912).

Hilgard, E. W. Soils. Chapters VII and XVIII (pp. 327-333). The Macmillan Company (1906).

KING, F. H. Investigations in Soil Management. United States Department of Agriculture, Bureau of Soils, Bulletin No. 25 (1905).

KING, F. H. Investigations in Soil Management. Madison, Wis. (1904).

Patten, H. E. Heat Transference in Soils. United States Department of Agriculture, Bureau of Soils, Bulletin No. 59 (1909).

Stabler, Herman. Some Stream Waters of the Western United States. United States Geological Survey, Water Supply Paper No. 274 (1911).

Stewart, Robert, and Greaves, J. E. Study of the Production and Movement of Nitric Nitrogen in an Irrigated Soil. Utah Experiment Station, Bulletin No. 106 (1909).

Stewart, Robert, and Greaves, J. E. Production and Movement of Nitric Nitrogen in Soil. Centralblatt für Bakteriologie, Band 34, p. 115 (1912).

Widtsoe, J. A., and Stewart, Robert. The Dry-Farm Soils of Utah. Utah Experiment Station, Bulletin No. 122 (1913).

Winkle, W. Van, and Eaton, F. M. The Quality of the Surface Waters of California. United States Geological Survey, Water Supply Paper No. 237 (1910). 


\section{CHAPTER VI}

CONDITIONS DETERMINING THE USE OF SOIL MOISTURE BY PLANTS

THE discussion in the preceding chapters has taken no account of the effect on plants of soil moisture. Yet, the plant is a most important factor, for it uses immense quantities of water throughout the season, and the rate of use is very difficult to control. It becomes necessary, therefore, to investigate the relationship of the plant to the water added to the soil in irrigation. The relationship is of particular importance, because, under irrigation, the farmer may apply different quantities of water, at stated times, throughout the growing season. That is, under irrigation a soil-moisture control is possible, which is not possessed by any other system of agriculture.

The essential question in agriculture is always, "To what extent can the farmer control the conditions of plant-production?" Where water is the critical factor, as in irrigation, it is of first importance to know how the absorption of water from the soil by plants may be controlled. Once this is known, systems of farming may be planned whereby the scanty water supply may be made to reclaim the largest possible area of land, or to produce the largest yield of high-quality crops.

This chapter is devoted to a discussion of the conditions that determine the rate at which water is taken from the soil by plants. The rate at which water is used is ordinarily different from the total quantity used by the 
plant throughout the season. A rapidly growing plant, for example, may use daily a very large quantity of water but only for a relatively short time, while a more slowly growing plant, using daily a smal er quantity of water, but for a longer period of time, may in the end use much more water. The rate at which a plant uses water refers invariably to the quantity used per hour, day or any other unit of time, during certain periods of its growth, and is not invariably a measure of the total water-needs of the crop.

77. Absorption of water by roots.-The roots are the organs of water-absorption. Practically no water is taken into the plants by the stems or leaves even under conditions of heavy rainfall. In the absorption of water from the soil, the young roots are most active, and, of these, only certain parts are actively engaged in waterabsorption. At the tips of the young roots are numerous fine hairs, known as root-hairs, clustering near the tip of the root. These are the organs of the plant that absorb soil water. As the root-hairs grow older, they lose their power of water-absorption; in fact, they are active only when they are in actual process of growth. Water-absorption, therefore, occurs near the tips of the growing roots, and, whenever the plant ceases to grow, water-absorption also ceases.

The root-hairs are filled with a solution of various substances, as yet poorly understood, which play an important part in the absorption from the soil of water and plant-food. Owing to their minuteness, the roothairs are in most cases immersed in the moisture film that surrounds the soil particles, and the soil moisture is taken directly into the roots from this film by the process of osmosis. Without entering into a discussion of the com- 
plicated movement of water from the soil into the plant, it may be said that the concentration of the solution in the root-hairs is higher than that of the soil-water solution. The water tends, therefore, to move from the soil into the roots to make the solutions inside and outside of the roots of the same concentration. If it should occur that the solutions inside and outside the root-hairs were of the same concentration, that is to say, if they contained the same substances in the same proportional amounts, there would be no further inward movement of water. Moreover, if the soil moisture should become stronger than the water within the root-hairs, water would tend to pass from the plant into the soil. This is the condition that prevails in the alkali lands of the West, and is often the cause of the death of plants growing on such lands.

78. Transpiration.-There is a constant movement of water, holding in solution the indispensable plant nutrients, after it has entered the root-hairs, through the roots, stems and into the leaves. At the leaf surfaces evaporation occurs, and, there, much of the water taken from the soil passes into the air as invisible water vapor. The rapidity of this current is often considerable. Ordinarily it varies from 1 to 6 feet an hour, although observations on record show that the movement often reaches the rate of 18 feet an hour. In an actively growing plant it does not then take long for the water in the soil to find its way to the uppermost parts of the plant and to be evaporated from the leaf surfaces. This movement of water from the soil, through the plant, into the air, is the process known as transpiration. If the current of water passing through the plant is stopped for any considerable length of time, the plant is injured and death often results. Transpira- 
tion appears to be a process wholly necessary to plant life. Our question is, To what extent may it be reduced without injuring plant-growth?

79. The initial percentage of soil moisture.-The most important factor in determining the rate of loss of soil water is the average percentage of water found in the soil at the beginning, known as the initial percentage. All other conditions being the same, the loss of water from two plants during a definite period of time varies as the initial percentage. The following table, selected from a great number of experiments on this subject made at the Utah Station, illustrates the law:

\begin{tabular}{cc|c|c}
\hline Length of period & $\begin{array}{c}\text { Average per cent } \\
\text { of water at } \\
\text { beginning }\end{array}$ & $\begin{array}{c}\text { Pounds of water } \\
\text { lost per } \\
\text { square foot }\end{array}$ \\
\hline Ten days. . . . . . . . . . . . & 21.84 \\
Ten days. . . . . . . . . . . & 13.18 & 25.05 \\
Difference .......... & 8.66 & 10.51 \\
\hline
\end{tabular}

The soil which contained at the beginning of the experiment 21.84 per cent of water, lost during ten days more than twenty-five pounds of water to the square foot; whereas the soil that contained 13.18 per cent of water at the beginning of the period lost only about ten and onehalf pounds of water to the square foot. It seems very clear that the rate of loss of water from a soil increases as the initial percentage of water in the soil increases; that is, the higher the initial percentage of water, the greater the loss; the lower the initial percentage, the smaller the loss.

The reason for this effect of the initial percentage can be fairly well understood. The fine root-hairs come into 
contact with a comparatively small area of the soil-water film. As water is drawn into the plant, there must be a flow of water toward the point of contact between the active roots and the soil-moisture film. If the film is thick, the water will move with some freedom and the plant, in a given time and with the expenditure of a given amount of energy, will absorb a larger quantity of water than would be possible if the film were thin and offered greater resistance to the moving water. The same principle has been shown to hold generally, as when water evaporates directly from the surface of the soil. The percentage of water in the soil is a fair measure of the thickness of the soil-water film, and the rate of loss of water from the soil increases, therefore, as the initial percentage of moisture in the soil increases. This is the same as saying that the more water contained by the soil to a given depth, the more is lost in a given time by plant- and sun-action.

This important law seems to imply that plants are not able to regulate the quantity of water taken up by roots; but rather that, assuming all other factors to be uniform, the rate of transpiration varies only with the ease with which water may be obtained. If this be true, plants may easily waste water if too much is found in the zone of root-growth; unless, indeed, the rate of growth is proportional to the use of water-a condition which does not exist. Here is evidently, then, because of the inability of the plant to regulate its consumption of soil moisture, a danger which the farmer must carefully heed. While the plant cannot possibly be prevented from taking more water from moist than from dry soils, yet, the farmer may so reduce the percentage of soil moisture that the plant is not always absorbing water at its maximum capacity. Manifestly, in spite of all that can be done, 
immediately after an irrigation, when the soil is moist, the plant will of necessity use much more moisture per unit of time than later when the soil is not so moist.

A question of importance in this connection is this: If two fields contain respectively 20 per cent and 10 per cent of water, will the loss of soil moisture during any definite period be twice as great from the one field as from the other? From the data in our possession, it may be answered that the losses are proportionally larger from the wettest soils. This may be seen from the table on page 111. The difference in the moisture per cent is only 8.66 but the difference in the pounds of water lost to the square foot during the same period was 14.54. That is to say, the wetter the soil became, the more rapid did the proportional loss of moisture become. This important phase of the law of the initial percentage might have been foretold by recalling that the thinner the soil-moisture film, the more firmly is it held by the soil. Under the point of lento-capillarity, plants can absorb the soil moisture only with the greatest difficulty; above this point, the absorption goes on much more rapidly. Preliminary experiments seem to show that, if the lento-capillary water of a soil be subtracted from the percentage of water held by each of two or more soils, and the cube roots be taken of the remainders, that is, of the water in true capillary condition, an approximately correct measure of the relative ease with which plants can abstract water from the soil is obtained.

The law of the initial percentage teaches the important doctrine that moderate irrigations are in all probability more economical than heavy ones; and it may explain why heavy irrigations, as will be shown later, do not yield proportional increases of dry matter. 
80. Distribution of water in the soil.-The distribution of water in the soil is likewise important in determining the rate at which plants use water.

\begin{tabular}{c|c|c|c}
\hline \hline Length of period & $\begin{array}{c}\text { Per cent } \\
\text { of water in } \\
\text { first foot }\end{array}$ & $\begin{array}{c}\text { Average per cent } \\
\text { of water to } \\
\text { depth of } 8 \text { feet }\end{array}$ & $\begin{array}{c}\text { Pounds of water } \\
\text { lost per } \\
\text { square foot }\end{array}$ \\
\hline Ten days . . . . & 23.68 & 17.69 & 18.24 \\
Ten days . . . & 17.25 & 16.85 & 13.55 \\
\hline Difference. . . & 6.43 & 0.84 & 4.69 \\
\hline
\end{tabular}

As shown in the above table, two soils may each contain approximately an average of 17 per cent of water to a depth of 8 feet, but in the first the percentage of moisture in the first foot is over 23 per cent, while in the second the percentage of moisture in the first foot is about 17 per cent. That is, the distribution of water is not the same in the two soils. In such a case, more water is lost from the soil in which the water is heaped up near the surface. The more evenly the water is distributed to the full depth of root-action, the more slowly does the plant consume the water during any given period of time. The data in the table show that during a period of ten days, where the top soil was wettest, 4.69 pounds more were lost to the square foot than where the water was more evenly distributed throughout the soil.

The greater water loss from soils, otherwise alike, that contain a large proportion of water in the first foot, may be explained in part by the greater root-development in the upper layers of the soil. Roots are well developed in arid soils to a depth of 10 or more feet, but the larger part of the small roots are developed within the upper 3 or 4 feet. Moreover, when the top soil is abundantly rich in 
water, direct evaporation from the soil occurs much more freely.

To prevent the accumulation of water in the upper foot, and the consequently greater loss of soil moisture, the land should be plowed deeply, so that the irrigation water may move easily and rapidly to the lower soil layers. For the same reason, the soil should be kept moist enough to permit water to descend quickly. The limiting of root-development in the upper foot by deep cultivation may also be advantageous. Whatever device the farmer may employ to distribute water uniformly to comparatively great depths, and to prevent the excessive development of roots in the upper soil layers, will tend to reduce the rate at which plants will absorb water from the soil. Under the law of distribution, as explained in Chapter III, the proportion of water is normally greater in the upper than in the lower soil layers; yet, by proper cultural treatments, it is possible to effect the most complete distribution in the shortest time, and thus to conserve the water.

81. The effect of time.-Closely connected with the law of the initial percentage, and derived from it, is the further law that as time goes on, the rate of loss of soil moisture becomes smaller and smaller. In the beginning, when the soil is moist, much water is lost. After the first day, there is a smaller quantity of water in the soil, and the rate of loss will be a trifle smaller, and so on, day after day, until a period is reached which finds the soil so dry that the plant can no longer draw water from it. On a shallow soil, during two weeks after irrigation, more than 31 per cent, or nearly one-third, of the total loss of water occurred during the first three days after irrigation; 29 per cent the next four days; 23 per cent the next three 
days; and 17 per cent the last four days of the two-week period. Similar proportional figures were found for longer periods. On a deep soil, of good water-holding power, during fourteen days after irrigation, 62 per cent of the total loss occurred during the first seven days, and only 38 per cent during the second week. Such figures, which might be multiplied by drawing from many experiments on the subject, show that methods designed to conserve soil moisture should be put into operation as soon as possible after irrigation. Especially to prevent direct evaporation, the soil should be cultivated as soon as possible after irrigation-in fact, as soon as the soil is dry enough to support the cultivator without injuring the structure of the soil.

82. The depth of soil.- The deeper the soil, the average percentage of soil moisture being the same, the larger is the loss of water in a given period of time. This law. is easily understood. If two soils weighing 100 pounds to the cubic foot are 1 and 2 feet deep respectively, and both contain an average of 20 per cent of moisture, they will contain respectively to the square foot of surface, and to their full depth, twenty and forty pounds of water. During the first day, each soil will lose, say, two pounds of water. There will remain, at the beginning of the second day, in the shallow soil, eighteen pounds, and in the deep soil, thirty-eight pounds of water, or 18 per cent and 19 per cent-the deeper soil having a higher percentage of moisture. During the second day, then, in accordance with the law of the initial percentage, the deeper soil will lose more water than will the shallow soil. The difference will become more marked with each passing day. Other factors enter in, as the fuller development of plant roots in deep soil, but, assuming all other factors to be the same, 
the deeper the soil the more rapidly will the soil lose its moisture. It does not follow from this law that the deep soil will dry out more rapidly than a shallow one. On the contrary, since, in the case above suggested, there is only half as much water in the shallow soil as in the deep soil, the shallow soil, with a smaller rate of loss, will dry out very much more quickly than will the deep soil with a larger rate of loss. This must be understood and remembered by the farmer who is dealing with shallow soils.

Various kinds of shallow soils occur in the irrigated district. In some cases a hardpan has been formed a few feet below the surface, which does not readily disintegrate under the influence of irrigation. This leaves a comparatively shallow soil in which to store moisture, which dries out quickly and must be irrigated frequently. Many soils are underlaid at a depth of a few feet with coarse, loose gravel, through which water percolates and is lost. Such shallow soils must be treated as are soils with hardpan near the surface. However, where an impervious hardpan underlays the soil, if too much water be applied, there is greater danger of water-logging; whereas, on soils underlaid with loose gravel there is little such danger, for the excess moisture percolates downward and is lost. From another point of view, also, this is important. On shallow soils of any kind, a given quantity of water cannot distribute itself over considerable depths. As a consequence, the percentage of soil moisture is higher, which causes a more rapid loss of soil moisture. From the point of view of the conservation of soil moisture, such soils are, therefore, less economical than deep ones.

83. Physical composition of soils.-The rate of loss of soil moisture from cropped fields varies with the physical composition of the soil. In a fine soil, a given quantity of 
water will be spread over a much larger surface of soil particles and the film, therefore, will be thinner; hence, the water will be absorbed at a slower rate than from a coarsegrained soil, which exposes a smaller surface and over which the same quantity of water forms a much thicker film. It may be demonstrated that, with a given quantity of water, the thickness of the film that forms over soil particles varies as the radius of the soil grains. That is, if in a given soil the particles are twice as large in diameter as in another, a given quantity of water added to these soils will form a film twice as thick in the coarse soil as in the fine one. Consequently, plants growing on fine-grained soils will use water at a lower rate than those growing on coarse-grained soils. In other words, under conditions otherwise uniform, the more clay a soil contains the less rapidly does the plant draw water from it.

84. Chemical composition of soils.-The chemical composition of the soil also determines the rate at which plants take moisture from the soil. This factor is of especial importance because it is within the power of the farmer to change, at least in a small way, the chemical composition of the soil, by proper methods of tillage, or by the direct addition to the soil of manure or commercial fertilizers. As explained in Chapter V, the chemical substances of which the soil is composed are gradually dissolved by the soil moisture. The soil solution of different soils varies, therefore, with the composition of the soil and the quantity of water added. The root-hairs, through which soil moisture is absorbed, lie immersed in the soil solution. The rate at which water is taken from the soil by these plant roots depends largely upon the relative strength of the solution inside and outside of the root- 
hairs. In general, the stronger the soil solution the less rapidly will plants take water from the soil with a given rate of growth. This is not an invariable law, however, since it depends, in part, on the nature of the soil materials that go into solution. If the soil solution is acid, the rate of absorption by plants is accelerated; if alkaline, it is retarded. In the vast majority of cases, soils are alkaline rather than acid. Especially in arid regions is the occurrence of acid soils infrequent.

The soil solutions of fertile soils are usually more concentrated than those of less fertile soils. It follows, therefore that, the more fertile a soil is, the less rapidly does the plant absorb the soil moisture with a given rate of growth. This law, which has been demonstrated in a number of interesting experiments, teaches the farmer the great importance of keeping the soil in a most fertile condition. Bouyoucos has made some interesting observations on this subject. As above stated, the more concentrated the soil solution is, the less rapidly do plants take moisture from the soil. Yet this concentration need not always be due to plant-food, for Bouyoucos has shown that an innocuous soluble substance, such as common salt or sodium sulfate, if added to the soil, decreases the rate at which the plants take water from the soil. This is important because of the fact that in a great many irrigated soils of the country, resulting from the peculiar climatic conditions, are found considerable quantities of common salt, and soluble salts of magnesium, calcium and other elements which are not needed as plant-foods. These accumulations, ordinarily known as alkali, when present in large quantities, are a serious menace to successful agriculture. The above law seems to show, however, that the presence of such materials in the soil may 
be of distinct value in diminishing the rate of loss of water from the soil. Consequently it follows, also, that on alkali soils the rate at which water is transpired is smaller than on soils that are free from alkali. This may, in a small measure, account for the fact that even cropped alkali lands remain rather moist throughout the season.

If all this be true, however, it is within the power of the farmer so to maintain the soluble material in the soil as to permit the plant to draw water from the soil at the slowest possible rate. By proper methods of cultivation whereby plant-food is set free, by the application of commercial fertilizers, of manure, or by innocuous salts, such as the abundant sodium sulfate, it is possible to maintain the soil solution in a high degree of concentration and thereby secure for the plant the necessary foods at a very slow rate. This fundamentally important factor in the economical use of water by plants, has received in the past practically no attention, but is now becoming more generally recognized.

85. Plowing.-Among the cultural processes that have for their purpose the reduction of the rate of loss of water from the soil, none is more important than the ancient art of plowing, which is the fundamental practice in all agriculture. From the point of view of the irrigation farmer, and the saving of soil moisture, plowing has distinct advantages. First, it permits the easier descent of water into the soil and consequently a more rapid and more uniform distribution throughout the soil. This results in a smaller rate of loss. Second, thorough and careful plowing at the right time of the year, preferably in the fall, gives every soil activity new freedom, thereby releasing more plant-food and rendering the soil solution more 
concentrated. Thorough and careful plowing results in a diminished rate of loss of water from cropped soils.

86. Cultivation.-The frequent cultivation of the soil, as discussed in Chapter III, has for its purpose the reduction of the direct evaporation of water from the soil. It has, however, a number of other beneficial effects of high importance to the irrigation farmer. For example, cultivation diminishes the rate at which plants take water from the soil, and further, as will be shown later, it even diminishes the quantity of water required to produce a given quantity of dry matter. Cultivation is essential in irrigation agriculture because it diminishes the direct evaporation from the soil and because it reduces the quantity of water transpired by plants. It is a practice that should be observed faithfully by the farmer throughout the season. After every rainfall and after every irrigation, just as far as possible from spring until fall, the soil should be carefully stirred by the farmer. The cost of such treatment will be more than paid for in the greater yields of crops, and in the greater producing power of water.

87. Manuring.- - It is quite evident, from what has been said already, that manuring, or the adding to the soil of plant-foods, under a given rate of growth will tend to reduce evaporation. This is another argument in behalf of manuring - a practice which, unfortunately, has not been carefully observed by the irrigation farmers of America. As time goes on and water becomes more precious, and the population of the arid region increases, the art of manuring, whether with natural or artificial fertilizers, will acquire a greater and greater importance.

88. Vigor of plant.- The rate of loss of soil moisture due to plants depends very largely upon the vigor of the 
plant itself. A sickly plant evidently does not require, nor can it use, so large quantities of water as a strong, healthy plant. Many farmers fail to understand this simple and almost self-evident law, and therefore apply to a crop poorly developed fully as much water as is applied to one which is growing vigorously.

89. Root-system.--Another factor of importance in determining the rate of loss of soil water due to plants is the development of the roct-system. If the roots have been developed near the surface, more water will be used from the top soil than if the roots have been more evenly distributed throughout the soil, and the energy expended in lifting the water from the lower depths is increased. To drive the roots downward, water should not be applied too early in the season, nor should it be applied in such quantities as to make it unnecessary for the lower roots to continue their work. Only when the roots fill the soil to the greatest depth in the most thorough manner, will the soil moisture be used most economically.

90. Age of plants.-The age of a plant naturally determines, largely, the rate at which soil moisture is absorbed. A plant increases very rapidly in dry weight, up to the time of flowering. After this time the increase is slight, and finally diminishes. The rate at which plants use water varies somewhat in the same way. There is a steady increase in the rate at which plants use water from early spring up to flowering; after which there is a diminution, until, when the plant is old, it uses water at a very low rate. A similar relation exists between growth and water-use of biennial crops such as sugar beets. The effect of the age of plants on the rate of loss of soil water is well shown in the following table: 
Pounds of Water Lost Daily Per Square Foot

(Rate increases to flowering, then decreases.)

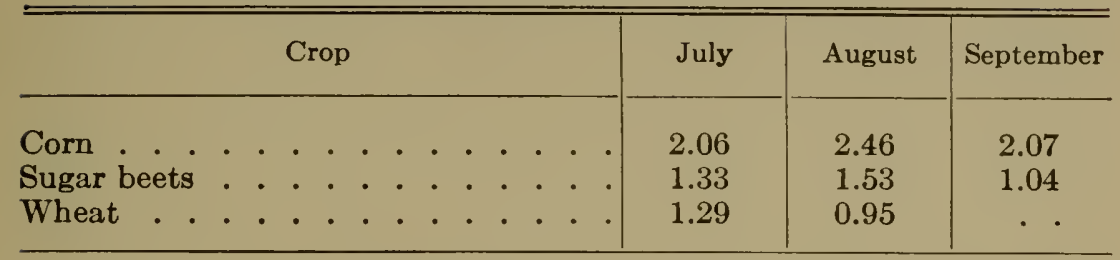

It is to be remembered that, in this table, the initial percentages are not in all cases the same, so that the different crops cannot be compared as to their power to abstract water. The only legitimate use of the table is to compare the quantities of water for each crop that were lost in July, August and September-the months of the growing season. In the case of corn, the greatest loss came in August; while in July and September, the loss was practically the same. In the case of sugar beets, the greatest loss also came in August; the next in July, and the smallest in September. In the case of wheat, the largest loss came in July and the smallest in August. These variations are readily explained by remembering that, under the climatic conditions prevailing, the wheat matured in July and was harvested in August, thus corresponding with the rates of loss as shown above; while the corn and sugar beets continued their vigorous growth into September. The time of most rapid growth is usually the time of greatest daily water use.

91. The kind of crop.-The kind of crop also influences, materially, the rate at which water is taken from the soil. No two crops appear to be exactly alike in their power to absorb soil moisture. Much work is yet to be done on this subject before really definite results can be given. Meanwhile, some general laws have been observed which can safely be stated, at least until further knowledge is 
gathered. It appears that crops which mature early use water more rapidly than those which have a longer growing period. For example, under the conditions prevailing in the irrigated sections of the United States, wheat and oats use daily more water than corn, beets or potatoes, although in the aggregate, wheat and oats use much less water than do the longer-growing crops. Wheat, oats and similar crops hasten on to maturity and, in so doing, use water at a very rapid rate. Corn, potatoes and sugar beets continue their steady growth throughout the season, and the rate at which they use water is considerably smaller. Lucern, which is cut from two to four or even more times during the season, behaves pretty much as if it were a series of quickly growing crops.

The rate at which various crops use water may be roughly estimated by the degree to which soils are dried out during long periods without irrigation by the respective crops. Experiments show that, from this point of view, lucern comes first, followed, in order, by wheat, oats, corn, sugar beets and potatoes. This is practically the order obtained in direct experimentation. More information is needed regarding the relative powers of different crops to abstract soil moisture.

92. The seasons.-The farmer may, in a measure, control most of the factors already discussed, but he is helpless when it comes to controlling the varying seasons. No one factor is so powerful in influencing crop-growth as are the seasons, and with this factor the farmer must always reckon. The average temperature throughout the season is of first importance in determining plantgrowth, and therefore, in a large measure, the rate at which the plant uses water. With a high average temperature, plant-growth is rapid and the daily loss of soil 
moisture is great. Sunshine is next in importance. The more abundant the sunshine throughout the growing season, the more favorably affected is plant-growth, and the more rapid is the loss of the soil moisture. Third in importance is the relative humidity of the air. The drier the air, the more rapidly does water evaporate from the plant, and, therefore, the more steadily does water move through the plant from the soil. Following these three factors-temperature, sunshine and humidity-are winds and all manner of air movements. These dry out the soil and increase the rate at which water passes through the plant to supply the more rapid evaporation from the plant. Winds are always a serious factor of water-loss, largely beyond the control of the farmer. Rains, especially slight ones, during the growing season are a menace, for they keep the top soil moist and make possible a rapid direct evaporation; however, they tend to diminish transpiration, from the reduction in the relative humidity which follows them. These factors, fundamental in determining the season, determine largely the evaporation of water from the soil itself. Experiments have shown that the rate of loss of soil moisture due to plant-action is frequently varied as a result of the seasons.

The factors of water-loss discussed in this chapter are those of most importance to the irrigation farmer. Many of them may be controlled more or less perfectly and, therefore, they should be well understood.

\section{REFERENCES}

Bouroucos, George J. Transpiration of Wheat Seedlings as Affected by Soils, by Solutions of Different Densities, and by Various Chemical Compounds. Proceedings of the American Society of Agronomy, Vol. III, pp. 130-191 (1911). 
Briggs, Lyman J., and Shadtz, H. L. The Water Requirements of Plants. United States Department of Agriculture, Bureau of Plant Industry, Bulletins Nos. 284 and 285 (1913).

Buergerstein, A. Die Transpiration der Pflanzen (1904).

Widtsoe, J. A., and McLadghlin, W. W. The Movement of Water in Irrigated Soils. Utah Experiment Station, Bulletin No. 115 (1912).

Widtsoe, J. A. Factors Influencing Evaporation and Transpiration. Utah Experiment Station, Bulletin No. 105 (1909).

Utah Station StafF. Irrigation Investigations. Utah Experiment Station, Bulletin No. 80 (1902). 


\section{CHAPTER VII}

\section{THE WATER-COST OF DRY MATTER}

THE steady transpiration stream of water, passing from the soil through all growing plants to be evaporated at the leaves, is responsible for the largest loss of soil moisture. This loss is, also, the most difficult to control; for, as shown in previous chapters, direct evaporation from the soil may be largely prevented by simply stirring the top soil, but many complex factors are involved in the loss of water by transpiration. Many experiments have been made to determine the relative quantities of water lost by evaporation and transpiration. While no absolute numbers of general application have been obtained, yet, when the land is not cultivated to prevent evaporation, one and one-half times as much water evaporates ordinarily from the vigorous, growing plant as from the soil. When the soil is well tilled, and direct evaporation thus reduced, the water lost by transpiration is often five to ten times greater than the quantity lost by evaporation from the corresponding area of soil.

This great loss of soil moisture by transpiration is a matter of much concern to the farmer, who pursues his work in the hope of reaping the largest harvest from the land, water and labor employed. Especially, where water is scarce or irrigation is practised, the important question is whether the increased yield is in proportion to the quantity of water passing through the crop by transpiration. If the yield increases in proportion to the 
increase in transpiration, there will be no need to reduce transpiration. If, on the other hand, the water-cost of the crop is partly independent of the transpiration stream, it may become necessary to decrease or increase transpiration to a point at which the largest yield of dry matter is produced with the smallest quantity of water. Only when this is done does irrigation give its greatest returns.

93. Carbon assimilation.-Practically one-half of a plant consists of the element carbon. From 2 to 10 per cent consists of mineral matter, taken from the soil, and brought into the plant in the process of transpiration. The remainder of the plant consists of the elements of water combined with carbon and mineral matter to form the variety of plant constituents.

The carbon, constituting one-half or more of the dry plant, is obtained by the plant from the air through leafaction. The gas carbon dioxid constitutes about three parts in 10,000 parts of air. As the air washes against the leaves of plants, this gas finds its way into the leaves of green plants through small openings, known as stomata, or breathing pores, which occur in great abundance, especially on the lower side of the leaves. The stomata are delicately adjusted valves which as they open and close are entrances to relatively large open spaces within the leaves themselves. When the carbon dioxid enters the leaves through the breathing pores, it is rapidly absorbed by the juices of the leaves and immediately decomposed into the element carbon and the element oxygen. The oxygen is returned to the atmosphere, while the carbon is retained and combined with water and other substances with the formation of sugars, starches and other valuable plant constituents. This process of carbon assimilation continues without intermission in green plants during the 
time of bright daylight or of sunshine. Chlorophyll, the green coloring matter of higher plants, and sunshine are indispensable for this wonderful decomposition and new composition.

A simple calculation will show how actively the leaves of the plant must be at work decomposing carbon dioxid and building up the new compounds derived from the assimilated carbon. It is not uncommon in the irrigated section that an acre of well-developed lucern yields, in one season, 10,000 pounds of dry matter. One-half, or 5,000 pounds, of this crop consists of the element carbon, obtained from the gas carbon dioxid of the air by the countless leaves that have swayed back and forth in the air throughout the growing season. Each tiny leaf has done but a small part of the work, but the total gives a lively appreciation of the tremendous activity of plant leaves.

94. Plant age and carbon assimilation.- The rate at which this assimilation of carbon, or "growth," takes place varies with the maturity of the plant. To illustrate, at the Utah Station careful measurements were made of the total acre weight of dry matter in a crop of lucern from May 4 to August 24, covering practically the whole of the growing season. In early May, when the plant was well established, the weekly gain of dry matter was something over 300 pounds to the acre; this increased steadily until just before the time of flowering, when it was nearly 800 pounds, after which it gradually decreased until late in July, when there was a loss instead of gain. This represents a general law of plant-growth. At the beginning of the growing season the daily or weekly gains of the crop are small, but they increase steadily and rather rapidly, providing the conditions of growth are favorable, 
until the maximum rate of increase occurs about the time of flowering. After flowering, as seed-formation sets in, the rate of growth becomes smaller, for, from that time on, the main energies of the plant are no longer directed to the increase in dry matter, but concern themselves more largely with the elaboration of the food materials already gathered into seed to be used for the perpetuation of the species.

Evidently, since water is unquestionably necessary in plant-growth, the needs of the plant for water probably increase about as the rate of growth increases. From earliest spring the water-need of a plant increases, until it reaches a maximum about the time of flowering, after which it gradually diminishes. This supposition, as will later be shown, is confirmed by actual field experiments.

95. Conditions of growth.-Many factors influence, to some degree, the rate of growth of a crop. Most of them are uncontrollable and, therefore, of little importance to the farmer. Those that concern him most, especially under arid conditions are (1) heat, (2) light, (3) oxygen, (4) mineral food and (5) moisture supply. With given vitality and inherent qualities, these factors will act vigorously upon the assimilation of carbon. If the temperature is too low, the life activities of the plant become slower and may finally cease. The higher the temperature, within a rather large range, the more rapidly does growth go on. Light, especially sunlight, is another powerful factor in furthering the assimilation of carbon. Oxygen is a prime factor in plant-growth, for without it the processes of oxidation, corresponding to breathing in the higher animals, cannot proceed; and, without this function, plant life cannot long persist. There must be, therefore, an abundance of fresh air playing about the 
plant. Mineral food, though taken up in small quantities, is indispensable to plant-growth. Through the action of the mineral foods, the most complicated processes of the plant are initiated and completed. Finally, carbon assimilation and growth cannot proceed unless there is a sufficient supply of moisture in the soil. The heat and light factors cannot well be controlled by the farmer; the mineral food can be controlled in part, but under conditions of irrigation the moisture environment of plant roots may be rather easily controlled. It is of first importance, therefore, to the irrigation farmer, to know in what way variation in the moisture supply will affect the total production of dry matter of the crop he is growing.

96. The transpiration ratio.-Dry matter is that part of a plant which remains when all the water has been driven off by heat near the temperature of boiling water. It is the only part of a plant of real value to the farmer in disposing of his crops for purposes of food, clothing or shelter, for the water contained in vegetable substances is of little more value than water drawn from a stream. The quantity of dry matter produced is, moreover, the best agricultural measure of the sum of the activities of a crop during the growing season.

The water-cost of the dry matter of plants may be expressed in various ways. The simplest and most easily understood, for the purposes of this chapter, is to speak of the number of pounds of water used in the production of one pound of dry matter. This method of expressing the water-cost of dry matter has been adopted by most investigators of the subject, and it is, therefore, well established.

The pounds of water required for one pound of dry matter, may, however, be determined in two ways. Water 
is taken up by the roots, passed through the plant and evaporated at the leaves throughout the season. The pounds of water thus actually passing through the plant for each pound of dry matter produced, give the transpiration ratio. Under agricultural conditions, however, as water passes through the plant, some water is also evaporated from the soil surrounding the plant. This

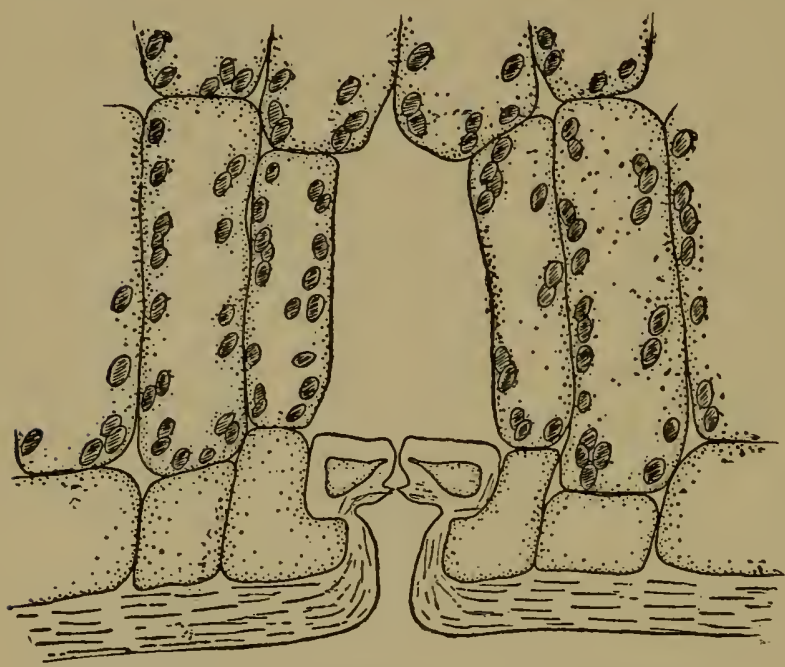

FIG. 23. Stomatal apparatus in carnation leaf through which transpiration occurs. direct loss from the soil surface, if completely checked, would seriously hinder plant-growth. The pounds of water passing through the plant and evaporating from the soil belonging to the plant, for each pound of dry matter produced, give the evapotranspiration ratio. Students of this subject have not always carefully distinguished between these ratios; consequently, in modern agricultural books, the two ratios are found in the same tables as meaning the same thing. Of the two ratios, the evapo-transpiration ratio is more nearly the measure of the true agricultural needs of the plant.

In the earlier investigations of the water-cost of dry matter it was dimly thought that, possibly, under all conditions, an invariable relationship existed between the quantities of water transpired and of dry matter pro- 
duced-that the transpiration ratio would always be the same. If the increase in dry matter were thus always proportional to the quantity of water transpired, it would simplify greatly many important problems of agriculture. Such a definite relationship, however, was not found, and it is now well known that every agricultural practice influences not only the assimilation of carbon but, also, transpiration, though not always to the same degree or in the same direction. Transpiration and the production of dry matter are only in part interdependent; to a much larger degree they are independent of each other. This is a fundamental thesis of irrigation agriculture.

Many investigators have determined the number of pounds of water required for the production of one pound of dry matter of various crops on a variety of soils and in several countries of the world. Some of these determinations are collected in the following table:

\begin{tabular}{|c|c|c|c|c|c|c|c|c|}
\hline & & \multicolumn{4}{|c|}{ Transpiration ratio } & \multicolumn{3}{|c|}{$\begin{array}{c}\text { Evapo-transpiration } \\
\text { ratio }\end{array}$} \\
\hline & & 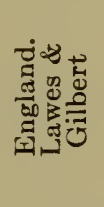 & 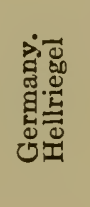 & 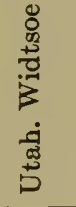 & 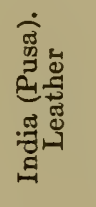 & 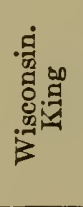 & 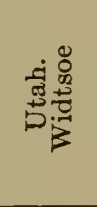 & 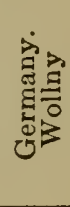 \\
\hline Wheat & . . & 247 & 338 & 546 & 850 & & 1,017 & \\
\hline Barley & $\therefore$ & 257 & &. & 680 & 464 & . & 774 \\
\hline Oats. &... & & 376 & & 870 & 504 & & 665 \\
\hline Corn & . & & & 386 & 450 & 270 & 552 & 233 \\
\hline Clover & & 269 & 310 & & & 577 & & \\
\hline Peas. & $\therefore$ & 259 & 273 & 843 & 830 & 477 & 1,118 & 416 \\
\hline
\end{tabular}

It may be noted that the transpiration ratios are lower in England and Germany, under humid conditions, than in Utah and India, under arid conditions. This is a general 
rule. Further, the transpiration ratios vary considerably, even under similar conditions of humidity or aridity, varying from 247 to 870 pounds of water for one pound of dry matter. As would be expected, the evapo-transpiration ratios are higher than the transpiration ratios. The variation among the evapo-transpiration ratios is also large, varying from 270 to 1,118 pounds of water for one pound of dry matter.

The data in the above table may well be used to show the average limits of the magnitudes of the transpiration and evapo-transpiration ratios on good soils of the standard crops in different parts of the world; for, of the thousands of determinations, not included in the table, nearly all fall within the limits here given. Yet, in a given locality, the transpiration ratio is not even approximately constant, unless the many factors concerned in plant-growth and in evaporation are constant. The variability of the watercost of dry matter is well brought out in the following table, which shows the range of transpiration ratios for certain standard crops in India and in Utah:

Transpiration Ratio

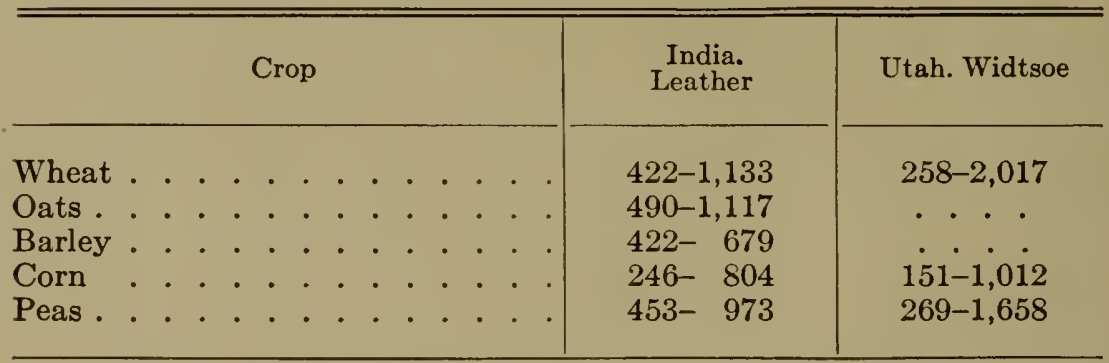

For wheat, the range was in India from 422 to 1,133 pounds of water, and in Utah from 258 to 2,017 pounds of water for each pound of dry matter produced. Other 
crops varied in very much the same manner. Whether countries or various fields of the same crop in the same country are compared, the water-cost of dry matter will vary widely.

Meanwhile, under conditions of normal fertility and a favorable growing season, the transpiration ratios fall

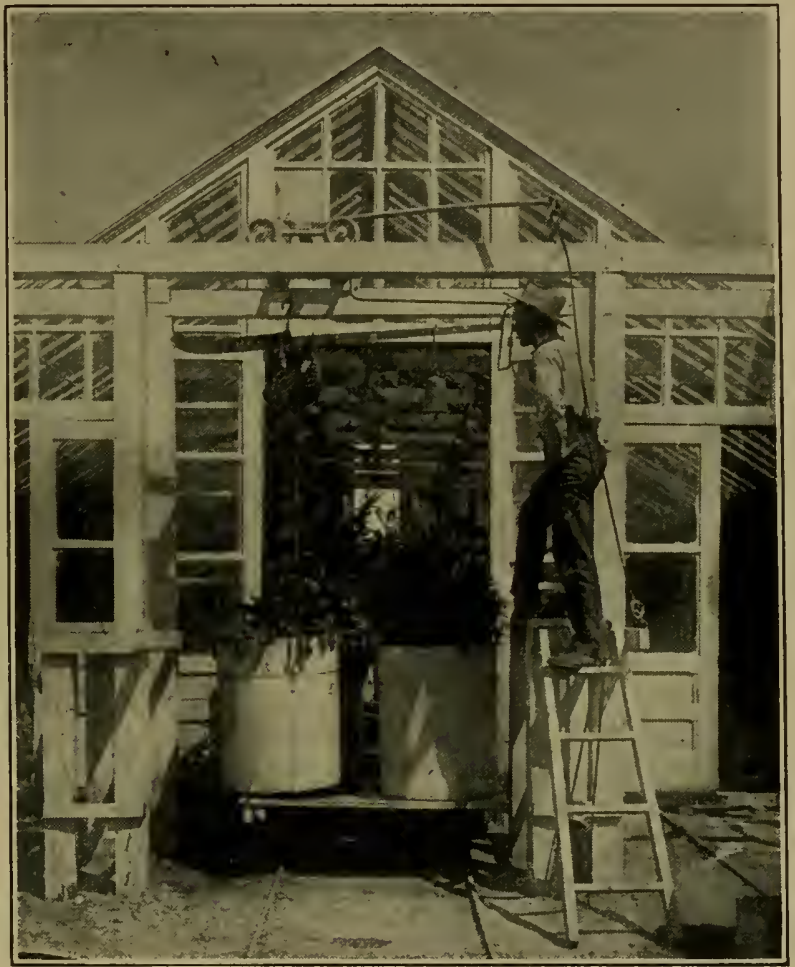

FIG. 24. Determining the transpiration ratio.

within rather definite limits. In fact, under normal conditions, the evapo-transpiration ratio varies from 250 to 1,000 pounds of water for each pound of dry matter. This gives a basis for an estimate of the quantity of water required for the production of a good crop of wheat or other standard crops. For example, a crop of wheat 
yielding thirty bushels of grain to the acre, if 250 pounds of water are required for one pound of dry matter, would require throughout the season 5 acre-inches of water; if 500 is the transpiration ratio, 10 inches would be required, and if 1,000 is the transpiration ratio 20 inches would be required. A fair crop of wheat requires annually, considering the quantity that evaporates directly from the surface, from 5 to 20 inches throughout the season. This then gives a fairly safe basis on which to establish a duty of water.

97. The seasons.-The seasons, including sunshine, temperature, relative humidity and all other climatic factors, are of first importance in determining the acreyield of crops. In fact, for the production of dry matter, the seasons overshadow any other one natural factor, and usually is as important as the cultural operations. In irrigated sections, where water is added at will, the influence of the season is usually underestimated, for on a good and well-tilled soil, even though the season is unfavorable, the application of a sufficient quantity of water makes the crop sure. Nevertheless, in the irrigated sections, as elsewhere, the seasons determine the average crop-yields for the season, whether they shall go high or fall low.

The seasons also determine in large measure the quantity of water used in the production of one pound of dry matter. At the Utah Station, in a series of experiments covering several years, it was found that, under conditions otherwise nearly identical, the transpiration ratio for wheat varied from season to season, the range being from 280 to 577 . In 1902, the transpiration ratio for wheat was 402 ; in 1903, 284; in 1904, 577; in 1905, 280, and in 1908, 357. Leather, working under East Indian 
conditions, obtained similar results. The transpiration ratio of wheat varied from season to season from 507 to 883 , and of corn from 332 to 477 . Both the Utah and the Indian experiments showed, for all crops investigated, a similar seasonal variation in the water-cost of dry matter. Whenever the season is favorable for the production of much dry matter, the water-cost is reduced; that is, a good season produces not only a large yield, but produces it with a relatively small quantity of water. A poor, backward season not only produces a small quantity of dry matter, but produces it at a high water-cost. The variation in the water-cost of dry matter, with the seasons, is much less than that of the total yield, as determined by the seasons. The water-cost is, however, influenced materially by the general seasonal conditions.

98. The soil.-The vital relation of the soil to crops would naturally suggest that the quantity of water required to produce one pound of dry matter would be partly determined by the nature of the soil. This has been conclusively demonstrated by many elaborate investigations. Pagnoul, working in France, found that the transpiration ratio of fescue grass on a fertile soil was 555 ; on an infertile soil, 1,190. In the Utah experiments, the transpiration ratio for corn was 386 on College loam, 408 on Sanpete clay, 561 on sand, and 601 on clay. Similar variations, some much larger, were observed with other crops on similar soils. For corn, the transpiration ratio varied, according to the soil used, from 432 to 579 ; for wheat, from 466 to 849 . Similar results could be quoted in great abundance to substantiate the statement that the nature of the soil is a determining factor in the relative quantity of water used by the plant for the production of a given quantity of dry matter. 
The physical and the chemical properties, as well as the depth of the soil, are of importance in determining the water-cost of dry matter. The deeper the soil is, the smaller is the transpiration ratio. This is to be expected, for the deeper the soil the more complete will the rootdevelopment be; and the more extensive the root-system is, the more easily may water and the mineral foods be obtained. Thus, carbon assimilation and all the other vital functions of the plant are stimulated into action. Leather grew crops in jars of different sizes, and, almost invariably, found that the crops grown in large jars were produced at the smallest water-cost. While the depth of the soil is an incidental factor, it may at times be of considerable importance. There is, throughout the irrigated region, a tendency to use very large quantities of seed. Unless the soil is deep and easily penetrated, the mass of roots, resulting from the large quantity of seed, may not find sufficient space in which to develop properly. The resulting crowding and overcrowding lead to immense numbers of stunted individual plants, that do not always possess the vigor to use water to the best advantage. This is of particular importance wherever hardpan is near the surface, or where a heavy clay underlies the top soil. Moderate quantities of seed should be sown, even under irrigation.

The relation of the physical composition of a soil to the water-cost of the plant grown has not been thoroughly investigated. It was observed, however, long ago, that in the use of water, a loam soil is more economical than a sand soil. It seems that, with given conditions of fertility, the finer the soil the smaller is the transpiration ratio. Soils rich in clay or fine sand are naturally more economical of water than are those containing coarse 
sand or poor in clay. However, the fertility of the soil, as expressed in plant-food content, or in good structure, seems to be of more importance than the texture of the soil. Any fertile soil, of whatever texture, will produce dry matter at about the same cost of water, providing all other factors are approximately the same.

99. Mineral food or soil fertility.-The fertility of a soil, especially as measured in mineral food, is a large determining factor in the water-cost of dry matter. It has been shown in Chapter VI that transpiration is affected by the dissolved mineral constituents of the soil. The actual quantity of water required to produce one pound of dry matter is, likewise, materially influenced by the mineral plant-food in the soil. In practically every investigation, from the first to the latest, soils rated as fertile, because of their large annual yields, invariably yielded dry matter at a lower water-cost than less fertile soils. This law, that crops grown on fertile soils are produced at a lower cost than those grown on an infertile soil, has been especially brought out by the diminished water-cost of crops grown on soils to which commercial fertilizers have been applied. The Utah experiments showed that, on moderately fertile soils, the transpiration ratio could be varied from 247 to 639 by applying very small quantities of commercial fertilizers. On two very infertile soils, the transpiration ratio due to fertilizers was reduced, in the case of the sand from 1,012 to 459 , and in the case of the clay from 1,331 to 445 . Soils of high fertility, however, did not respond to the application of fertilizers so far as the water-cost of dry matter was concerned. Leather, working under Indian conditions, came to the conclusion that suitable manures enable plants to economize water in the production of dry matter As 
an average of many experiments, crops were produced on unmanured soils with a transpiration ratio of 782 ; and on manured soils with a transpiration ratio of 572 . Bouyoucos has concluded, from a series of carefully conducted tests, that the greater the concentration of the soil solution, that is, the more substances it holds in solution, the smaller the transpiration ratio. Fertile soils are usually more soluble than infertile ones, and the soil solution of fertile soils is usually more concentrated. The same investigator has also shown that as the soil solution becomes richer in soil constituents, the cell sap of the plant becomes more concentrated, and that this may be the reason that less water enters the plant daily when the concentration of the soil solution is high.

Different substances influence the transpiration ratio differently. Acids, for instance, tend to accelerate transpiration, and to increase the transpiration ratio. Alkalies have the opposite effect. This is of importance to the irrigated sections, since under arid conditions alkaline, rather than acid, soils are naturally produced. Lime, phosphoric acid, potash and nitrates tend, especially, to reduce the water-cost of dry matter. Of first importance are the nitrates. The richer the soil is in nitrates, the more surely will the water-cost of the crop be reduced. This law appears and reappears in investigations on all manner of soils, from all parts of the world. The maintenance of an abundance of nitrates in the soil is undoubtedly of prime importance in reducing the water needs of crops. Increasing the concentration of the soil solution reduces the transpiration ratio only when the substances held in solution in the soil moisture are true plant-foods. Bouyoucos showed that a solution of common salt, or sodium sulfate, or other substances, not direct plant- 
foods, reduced the rate of transpiration, but did not diminish the water-cost of the resulting dry matter. It does not follow, therefore, that on alkali soils, such as occur frequently in the arid West, crops may be produced at a lower water-cost than on soils containing less soluble matter. Whether or not water is saved depends entirely upon the composition of the alkali. In places, the alkali consists largely of nitrates, potassium salts and other plantfoods; but, ordinarily, alkali lands contain the chlorides, sulfates and carbonates of sodium and other substances of a non-nutrient character. Crops grown on the usual alkali lands are not only injured by the high concentration of the soil solution, but they are produced at an excessive cost of water.

The irrigation farmer who wishes to make the best use of a limited quantity of water must keep steadily in mind the necessity of maintaining the soil, constantly, in a very fertile condition.

100. Cultural operations. - It is well understood that thorough plowing, frequent cultivation and other correct cultural operations accelerate soil solubility and favor bacterial activity in the soil. Nitrification, the conversion of the soil nitrogen into nitrates, is especially fostered by proper soil tillage. This treatment given soils should, therefore, affect quite distinctly the water-cost of crops. Few experiments have been made on this subject, but those available bear out this belief. At the Utah Station, a number of pots containing soils of varying degrees of fertility were sown to corn. Half of the pots were properly cultivated, and the others received no cultivation, throughout the growing season. The transpiration ratio was invariably smaller on the cultivated than on the non-cultivated soils. On College loam, the ratios 
on the cultivated and on the non-cultivated pots were 252 and 603 ; on a sandy clay, 428 and 535 , and on an infertile clay, 582 and 750 . It so happened that the College loam was a self-mulching soil, on which ordinary cultivation did not lessen direct evaporation. The favorable effect of cultivation was shown, however, in the great reduction in the water-cost of dry matter resulting from simple tillage. On every hand the proper cultivation of the soil is shown to be a means of economizing water. It prevents the direct evaporation of water from the soil; it reduces the transpiration, and it makes it possible to produce dry matter at a low water-cost. There is much truth in the statement of the irrigation farmer that cultivation may take the place of water. Within certain limits, it may be said that tillage is water. Water is indispensable for the production of crops, but the need for water may be tremendously reduced if the upper layer of soil is thoroughly cultivated.

All other correct treatments of the soil have pretty much the same effect. At the Utah Station, a series of soils were cropped every year for three years, while another similar series, receiving identical treatment, were left bare for three years. The fourth year, all the soils were planted to corn. The soils that had lain fallow for three years invariably produced dry matter at a lower watercost than did those which has been cropped. The transpiration ratios for the fallow and the cropped soils were, on the College loam, 573 and 659 ; on Sanpete clay 550 and 889 , on clay 1,739 and 7,466 . Irrigated soils are cropped every year, and fallowing is scarcely ever practised under irrigation. In fact, none of the established systems of irrigation-farming include the fallow year. Under dry-farm conditions, on the other hand, fallow- 
ing is almost indispensable. Fallowing may be replaced by crops such as corn or sugar beets, which receive cultivation throughout the season and thereby set free plantfood for the following crop. It is probable, however, that, even under conditions of irrigation, as in the West, where land is plentiful and water scarce, it may in the end be profitable to observe the occasional clean fallow of the land. The resting period not only helps to destroy weeds, plentiful under irrigation, but enables the soil to resume a natural physical condition, to set free plantfood and to start again a favorable bacterial flora. The value of fallowing is well shown is another of the Utah experiments. One series of soils had been cropped steadily for four years; another series had been cropped only three out of four years, and still another series had been cropped only one year out of four. These three series of soils were left exposed to the elements for three years; that is, they received a three-years' fallow. They were then all sown to corn, which grew and flourished well. The transpiration ratios, determined for each series of soils, were almost identical. This shows that the three years of fallow had restored the three soils to an approximate equality of fertility, so far as water-consumption was concerned, although at the beginning of the period, they had been left widely different by the various treatments they had received. The fallow period, objectionable chiefly because of the chance it gives the organic matter to be oxidized by the air, has great advantages in restoring the soil to a condition where crops may be produced at a low water-cost.

101. The vigor of the plant.-Whenever the seasons, the nature of the soil, the available plant-food, the treatment of the soil, the factors above discussed, favor vigor- 
ous plant-growth, they also tend to diminish the quantity of water required for the production of one pound of dry matter. That is, so far as these factors are concerned, as the plant becomes more and more thrifty the smaller becomes the transpiration ratio. The more vigorous a plant is, the more economically can it use the water at its disposal.

102. Varying quantities of water.-Of greatest importance in the consideration of the economical use of water by plants is the effect of varying, quantities of water. Under irrigation, much or little water may be applied at the will of the farmer. Upon the proper manipulation of this characteristic factor, irrigation agriculture will stand or fall. It is, therefore, of prime importance to know how the production of crops is affected when the quantity of water applied is varied.

Many experiments on this subject have been made lately, but not enough to set forth fully the principles involved. Most of the leading students of water in relation to agriculture have lived in humid countries, where the only important control of soil water is the conservation of the rain-or snow-water-in the soil upon which it falls. Only in recent years has serious attention been given to the subject from the direct point of view of irrigation. Moreover, most of the experiments on this subject, many of high value, have been made in pots, under conditions not strictly comparable with the conditions of practical irrigation. Usually, the soils have been maintained at definite degrees of wetness. To maintain these conditions, water was added to the pots every day or every few days, so that it could be said, at the end of the experiment, that the soil had been kept practically at that degree of saturation throughout the whole experi- 
mental period. Under irrigation, the method is quite different, for the water is applied at relatively long intervals, and when the available soil moisture has been largely removed by the growing crop. The saturation of the soil falls, therefore, from high to low, between successive irrigations.

All experiments on the subject, whether in pots or in the field, show that, as a general rule, the more water offered the plant, within practical limits, during the growing season, the larger the total yield of dry matter. The increase in dry matter due to the increase in soil-saturation falls upon every part of the plant-roots, stems and leaves. Von Seelhorst and Tucker, among the early experimenters in this domain, showed, in a series of carefully conducted tests, that the whole oat plant-heads, straw and rootsincreased as the water in the soil increased. In the pots containing a low percentage of water, 591 grams of the whole plant were obtained; in the pot with a medium percentage of water, 725 grams, and in the pots with a high percentage of water, 922 grams. In most experiments, only the parts of the plants harvested by the farmer are considered, so that this experiment is of special importance. The increase in the total yield of dry matter does not, however, continue indefinitely, as the soil-saturation increases. Mayer, who was one of the first to study the effect of varying quantities of water, found that for rye, wheat, barley and oats, the yield increased with the increase in soil-saturation up to a certain point, after which there was a strong diminution in the yield of dry matter. Experiments made elsewhere bear out this conclusion. As a further general rule, then, increasing the soil moisture increases the production of dry matter only within certain definite limits. If too much water is applied to the 
soil during the season, there is a diminution instead of an increase in the yield obtained.

This question, however, remains: As the dry matter increases with the increase in soil saturation, does the water-cost of each pound of dry matter remain the same? This matter has been investigated with considerable care and with concordant results. Wilms found that with a little water the transpiration ratio for potatoes was 39 ; with more water, 50 ; and with much water, 61 . The Utah experiments showed invariably that with wheat, sugar beets, corn, potatoes, alfalfa and all other crops tested, as the quantity of water used was increased and the yield thereby increased, the water-cost also became larger. The general law is that, within the limits of practical irrigation, the transpiration ratio increases as the quantity of water added to the soil increases; that is, that the water-cost of crops becomes larger as more water is used in irrigation. Lyon and a number of his co-workers, notably Morgan and Harris, as well as other students, have confirmed this law, until it may be accepted as being securely established. This is a matter of tremendous importance. By using more water, the irrigation farmer obtains a larger yield, but less for each unit of water used. The question will always be, With how much water will he get the largest possible returns from the use of his land, water and labor?

The only field experiments of any magnitude conducted with a view of testing the effect of various quantities of water on the production of dry matter and on the water-cost of dry matter are those of the Utah Station. Other experiments, not reduced to dry matter, will be noted in later chapters. In the following table the yields of dry matter in pounds to the acre, with varying 
quantities of water and on a deep fertile soil, are shown for four of the standard crops. The results are averages of a large number of experiments, and may be accepted as being tolerably accurate for the climate of the intermountain region.

Yields of Dry Matter in Pounds per Acre with Varying Quantities of Water

\begin{tabular}{|c|c|c|c|c|}
\hline $\begin{array}{l}\text { Inches of } \\
\text { water applied }\end{array}$ & Wheat & Corn & Sugar beets & Potatoes \\
\hline 5.0 & 4,969 & . . . & 6,080 & 2,310 \\
\hline 7.5 & 5,545 & 10,757 & & 2,730 \\
\hline 10.0 & 5,684 & 12,762 & 8,053 & 2,925 \\
\hline 15.0 & 6,279 & 13,092 & 8,636 & 3,405 \\
\hline 20.0 & & 13,856 & 10,076 & 4,005 \\
\hline 25.0 & 6,672 & 14,606 & . . . & \\
\hline 30.0 &.$\quad$. & 15,294 & 10,271 & 3,660 \\
\hline 35.0 & 7,229 & . . & & . . . \\
\hline 50.0 & 7,999 & & 11,528 & $* 3,795$ \\
\hline 55.0 & . . . & 12,637 & . . & . . \\
\hline
\end{tabular}

*45 inches.

An examination of the above table will show that as the quantity of irrigation water was increased throughout the season, the yield of wheat increased without interruption; the corn increased up to 30 inches, but fell at 55 inches; the sugar beets and the potatoes increased without interruption. This is in accordance with the law above stated that, as water is increased the general tendency of the yield of crops is to increase. The soil was deep and porous, into which even very large quantities of water sank to great depths. Thus, the soil was never oversaturated, but with large irrigations the soil-water film continued longer to be of maximum thickness than with small irrigations. Even under these favorable conditions, the yield of corn diminished after 30 inches of water had 
been applied, and the yields of other crops, not given in the table, likewise diminished after certain limits had been reached. Undoubtedly, had more water been used than the maximum in the above table, or if the soil had been shallower or less fertile, there would have been a strong falling off in the yields of all the crops.

In the following table the evapo-transpiration ratios of the above yields under varying applications are given:

Pounds of Water Required to Produce One Pound ó Dry MatTer with Varying Quantities of Water

(Evapo-transpiration ratio)

\begin{tabular}{|c|c|c|c|c|c|}
\hline $\begin{array}{l}\text { Inches } \\
\text { of water } \\
\text { applied }\end{array}$ & Wheat & Corn & Alfalfa & Sugar beets & Potatoes \\
\hline 5.0 & 856 & $\cdot \cdot$ & . & 569 & 1,136 \\
\hline 7.5 & 869 & 276 & . . & . . & 1,136 \\
\hline 10.0 & 948 & 275 & 621 & 571 & 1,255 \\
\hline 15.0 & 1,038 & 356 & 977 & 663 & 1,411 \\
\hline 20.0 & . . & 416 & 946 & 682 & 1,466 \\
\hline 25.0 & 1,317 & 474 & 1,052 & & . . \\
\hline 30.0 & & 527 & 1,253 & 889 & 2,242 \\
\hline 35.0 & 1,530 & . . & . . & . . & . \\
\hline 45.0 & . . & . . & . & & 3,060 \\
\hline 50.0 & 1,809 & $\therefore$ & 1,480 & 1,186 & \\
\hline 55.0 & . . & 1,087 & . & • & 3,292 \\
\hline
\end{tabular}

Without exception, when small quantities of water are applied, the water-cost is low; as larger quantities are applied, the water-cost becomes greater and greater. By increasing the total quantity of water throughout the season, the evapo-transpiration ratio or the pounds of water for one pound of dry matter increased for wheat from 850 to 1,809 ; for corn, from 255 to 1,087 ; for alfalfa, from 641 to 1,480 ; for sugar beets, from 569 to 1,186 , and for potatoes, from 1,136 to 3,292 . While, therefore, there is a distinct increase in dry matter as more water is 


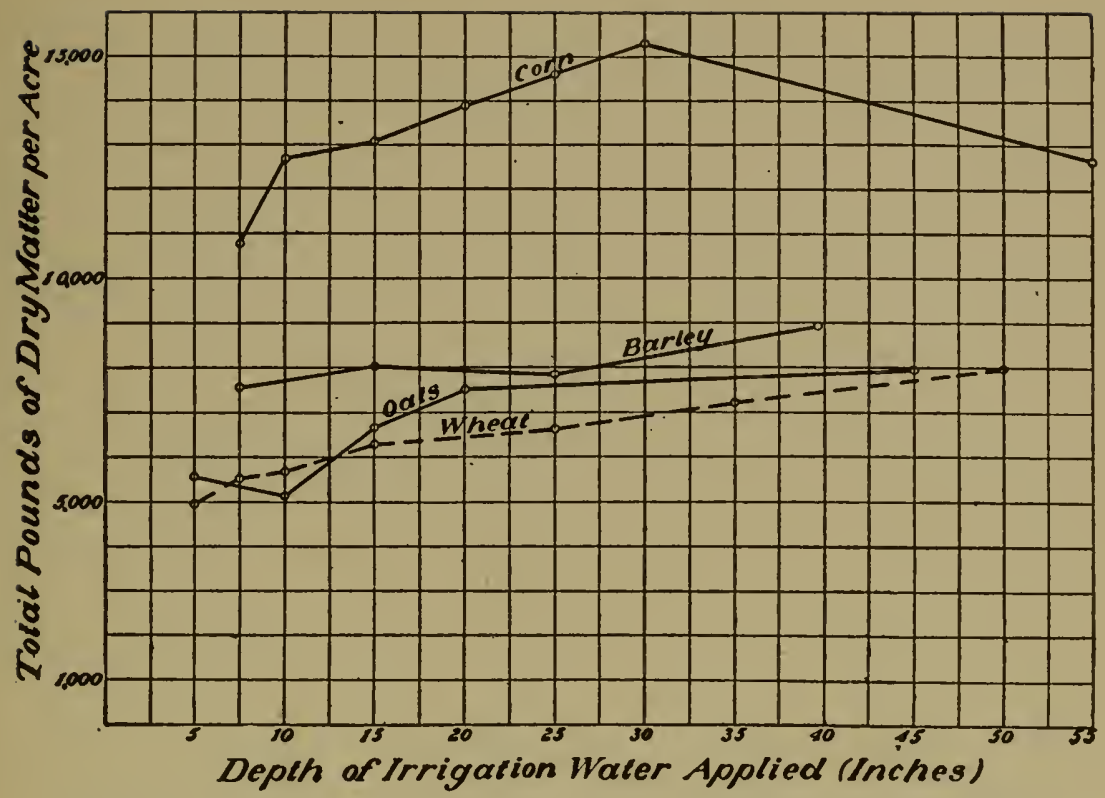

Fig. 25. Yield of dry matter of cereals with varying quantities of water.

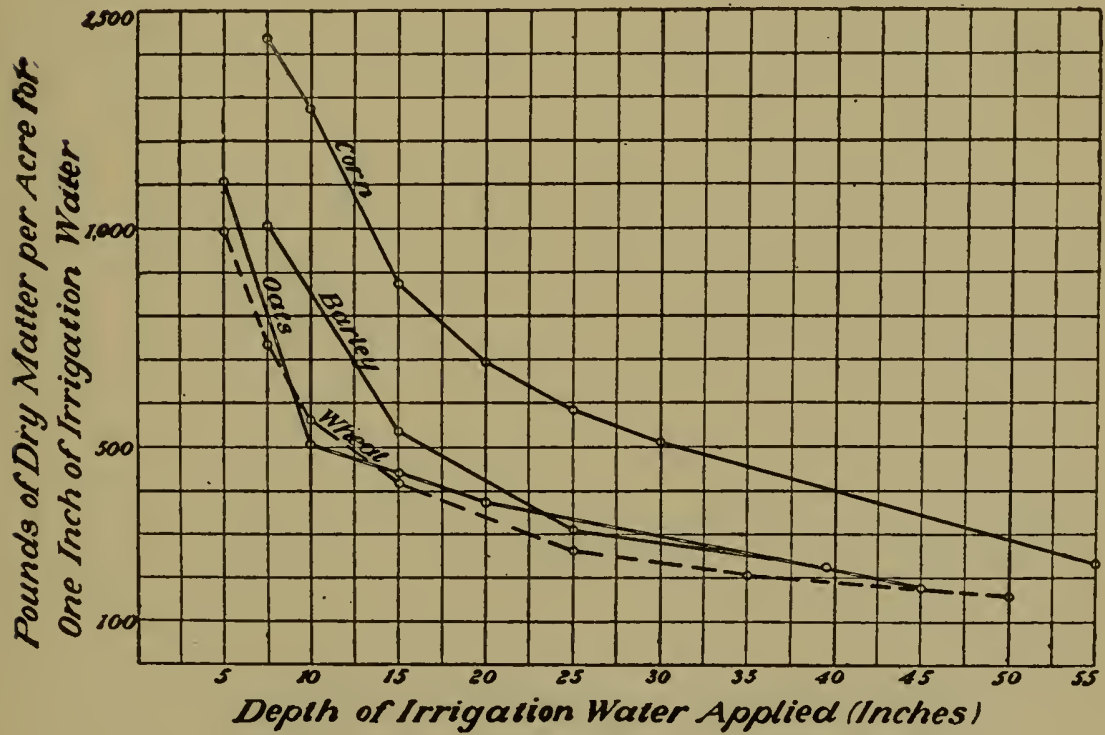

Fig. 26. Yield of dry matter of cereals per inch of irrigation water. 
applied, this increase is obtained at a distinctly higher water-cost. Moderate irrigations are always most economical.

The same figures are presented in a more practical manner in the following table, in which are shown the yields in pounds of dry matter to the acre for each inch of irrigation water under varying total irrigations:

Pounds of Dry Matter per Acre per Inch of Irrigation Water

\begin{tabular}{|c|c|c|c|c|c|}
\hline $\begin{array}{l}\text { Inches } \\
\text { of water } \\
\text { applied }\end{array}$ & Wheat & Corn & Alfalfa & Sugar beets & Potatoes \\
\hline 5.0 & 994 & & & 1,216 & 462 \\
\hline 7.5 & 739 & 1,434 & & & 364 \\
\hline 10.0 & 568 & 1,276 & 909 & 805 & 293 \\
\hline 15.0 & 419 & 873 & 463 & 576 & 227 \\
\hline 20.0 & & 693 & 418 & 504 & 200 \\
\hline 25.0 & 267 & 584 & 344 & & \\
\hline 30.0 & & 510 & & 342 & 122 \\
\hline 35.0 & 207 & . . & 271 & . & \\
\hline 45.0 & & & & & 84 \\
\hline 50.0 & 160 & & 199 & 231 & \\
\hline 55.0 & . . & 230 & . . & $\cdot$ & \\
\hline
\end{tabular}

It is clear from the data of this table that, so far as water is concerned, it is more profitable to use small than large quantities of water. As the total seasonal quantity of water increased, the acre-yield of dry matter, for each inch of irrigation water, varied for wheat from 994 to 160 pounds; for corn, from 1,434 to 230 pounds; for alfalfa, from 909 to 199 pounds; for sugar beets, from 1,216 to 231 pounds, and for potatoes from 462 to 84 pounds. These are tremendous reductions with increasing applications of water, which of necessity must be considered in the establishment of a consistent practice of irrigation, having as its purpose the reclamation of the largest pos- 
sible area in the arid regions. However true it may be, in the humid regions, that the acre-yield is the all-important thing, in arid regions the yield to the acre-inch or to the unit of water is equally important. For each crop and given conditions, a point must be determined at which the highest possible returns may be obtained from the land, water and labor employed. (Figs. 25, 26.)

103. Maximum yield with given quantity of water.The relation of varying quantities of water to the yields of crops may be expressed also by showing the producing power of a definite quantity of water, say 30 acre-inches, when spread over $1,2,4$ or 6 acres. This is done in the following table:

Pounds of Dry Matter Produced by 30 Acre-Inches of Water

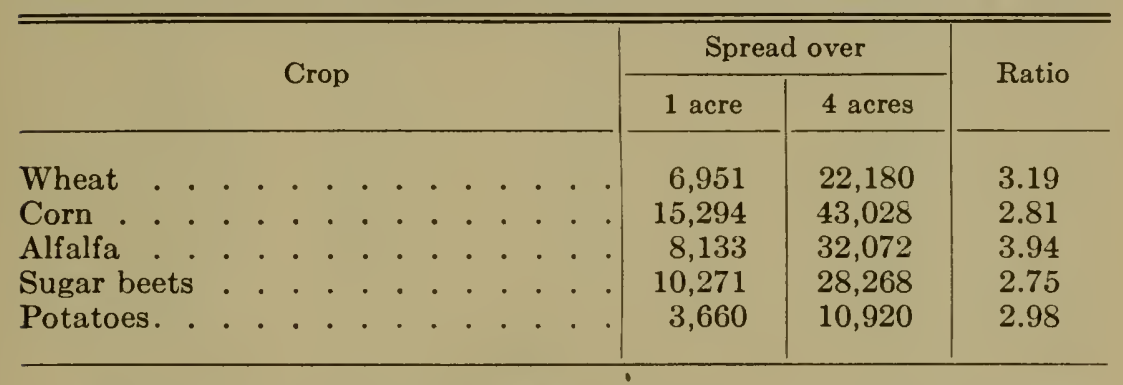

When 30 acre-inches were made to cover 4 acres instead of 1 acre, the yield was increased for wheat nearly three-fold, for alfalfa nearly four-fold, for sugar beets nearly three-fold and for potatoes nearly three-fold. When it is considered that the development of the arid regions will depend upon the settlement of a dense population, requiring food, clothing and shelter, it is evident that irrigation water, the limiting factor of the prosperity of the region, must be made to produce the largest quantities of materials for food, clothing and shelter. The acre-yield, the criterion of humid regions, will retreat 


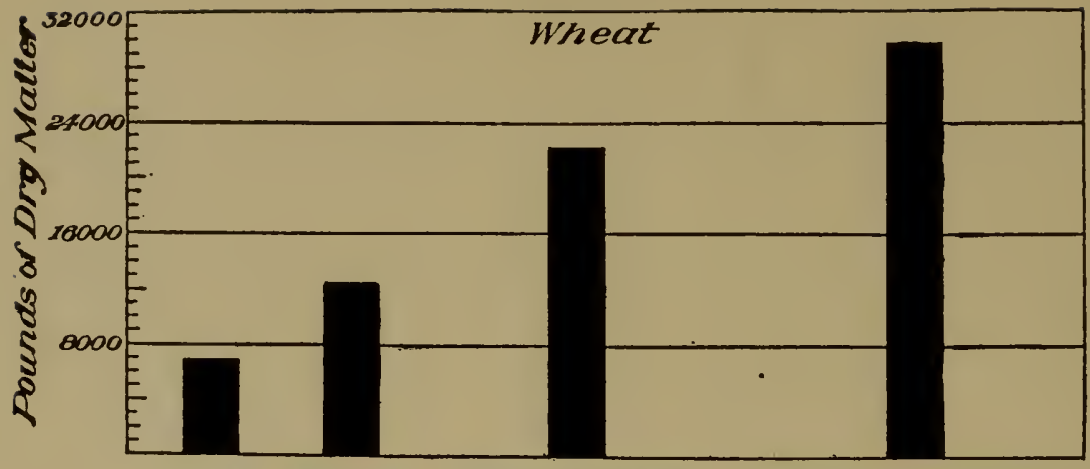

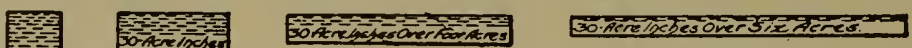

FIG. 27. Crop-producing power of 30 acre-inches (wheat)
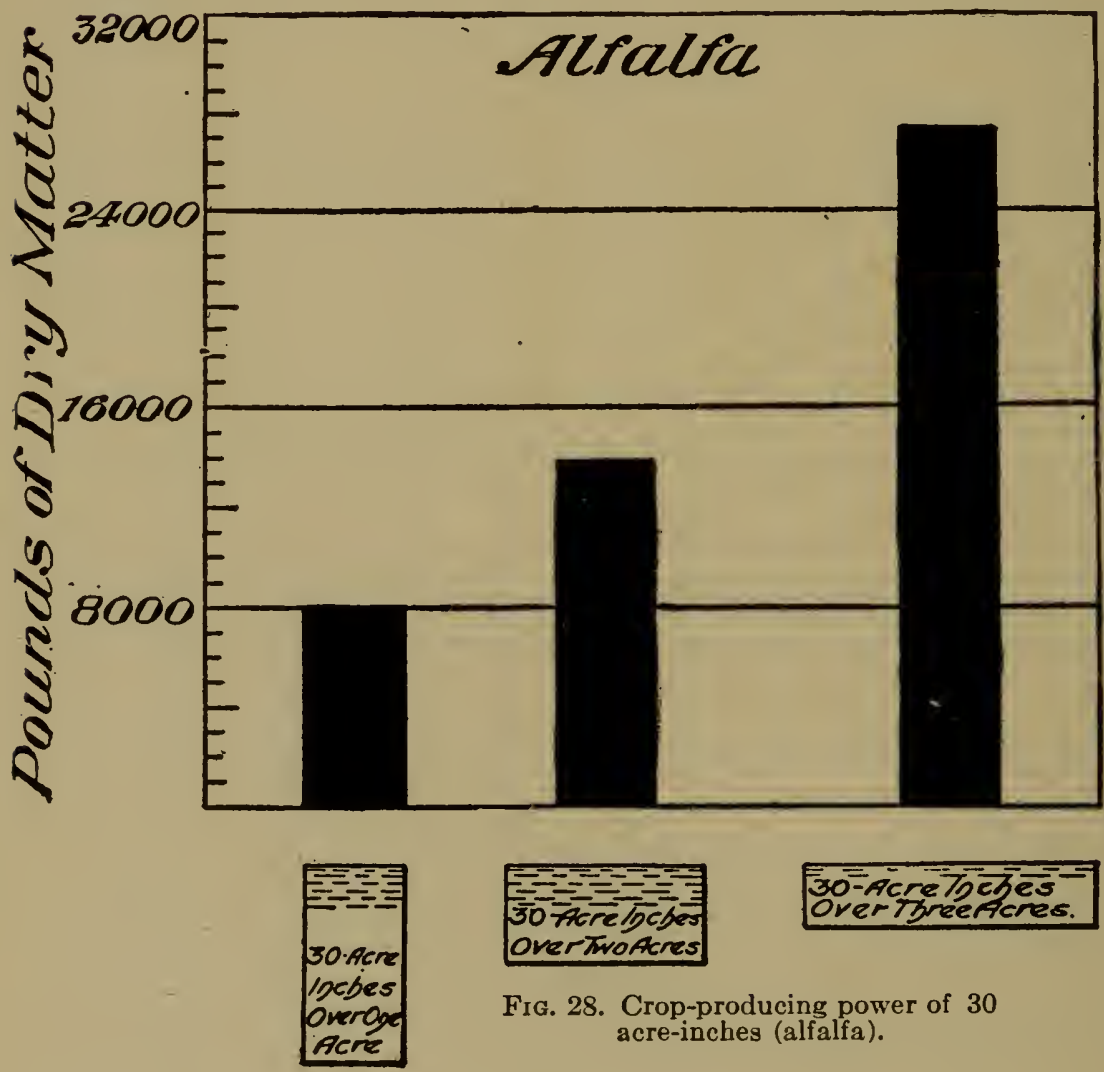

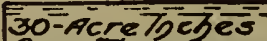
Overthreefcres.

Fig. 28. Crop-producing power of 30 acre-inches (alfalfa). 
before the acre-inch yield, the criterion of irrigated regions. The understanding of this principle must be brought into the practices of the people, and must reshape the irrigation laws of the states and federal government, if the greatest prosperity shall be won for the West. In the day to come, it is probable that no farmer, though he own an abundance of water, will be allowed to use more

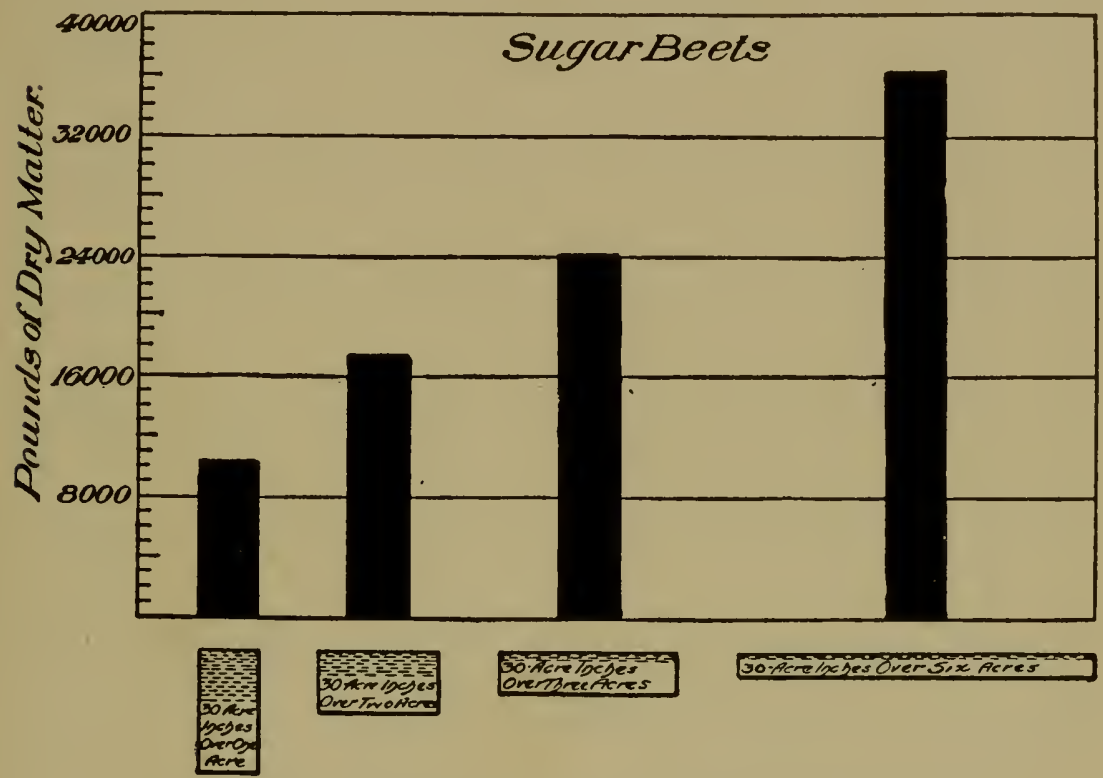

FIG. 29. Crop-producing power of 30 acre-inches (sugar beets)

than the quantity determined upon by the state as being the best.

The evils of over-irrigation are many. In addition to those mentioned, it is shown in this chapter that the large acre-use of water may diminish the actual yield an acre, and invariably does make the crop more expensive from the point of view of the water used for each unit of dry matter. The permanence of irrigation-farming depends on the moderate use of water. (Figs. 27-29.) 
104. The nature of the crop.- The nature of the plant is a factor in the economical production of dry matter. Little is as yet known as to the special properties of the plant that affect the water-cost of dry matter; but, it is certain that plants differ in their water requirements. A number of interesting results have, indeed, been obtained, as for example, Montgomery's observation that narrowleaved corn uses less water to produce a pound of dry matter than does corn with wider leaves. Attempts have often been made to classify crops in accordance with their water needs, but seldom under irrigated conditions.

Some crops always yield largely, others lightly. This differing power is inherent in the crops, and is generally beyond the farmers' control, for the variations in yield due to cultural methods are within rather narrow limits. The results of the Utah work has made possible the arrangements of the crops in the order of their acreyield of dry matter, as in the following table:

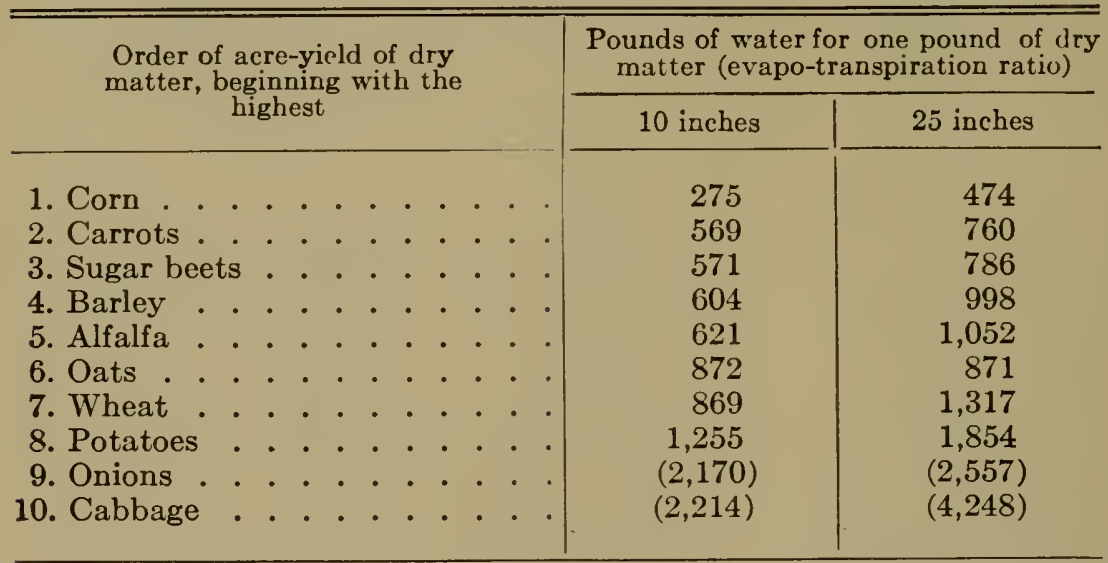

With light, medium and heavy irrigations, the order was practically the same. Corn yielded the largest quantity of dry matter to the acre; Italian rye grass, the smallest. 
To the irrigation farmer, a large yield, however, is of interest only if it is produced with little water. In the second and third columns of the preceding table, therefore, are shown the pounds of water required for one pound of dry matter, or the evapo-transpiration ratio, when 10 and when 25 inches were used. The uniform variation is remarkable. There was a steady diminution in the evapo-transpiration ratio, from corn to the lowest yielder. In the case of the two exceptions, oats and wheat, and corn and carrots, the yields were almost identical. Only under the 25-inch heading was there a notable exceptionthat of oats. The variation, however, is so regular, over so large a range of crops, that it may be suggested, as a law, that the water-cost of dry matter varies inversely as the inherent power of the plant to produce dry matter per acre. That is, the crop that yields most largely produces the yield at the lowest water-cost. It may be observed in this connection that the crops that yield most heavily with the least expenditure of water are those of the longest growing period.

Summary.-The factors that determine the watercost of dry matter fall into two classes: First, those like the season, nature of the soil, mineral food, tillage, vigor of plant and nature of plant, that favor the production of dry matter, and at the same time diminish the rate of transpiration and reduce the water-cost of dry matter; and, second, those, like the varying quantity of water, that favor the production of dry matter, but at the same time accelerate transpiration and increase the water-cost of dry matter. All these factors are of great importance in the establishment of practices for the economical production of dry matter, but, the last, the varying quantity of water, because it is under the easy 
control of the irrigation farmer, and, because its effects are large, is of greatest importance.

\section{REFERENCES}

Bouyoucos, G. J. Transpiration of Wheat Seedlings as Affected by Soils, by Solutions of Different Densities, and-by Various Chemical Compounds. Proceedings of the American Society of Agronomy, Vol. III, p. 130 (1911).

Briggs, Lyman J., and Shantz, H. L. The Water Requirements of Plants. United States Department of Agriculture, Bureau of Plant Industry, Bulletins Nos. 284 and 285 (1913).

Fortier, Samuel. Soil Moisture in Relation to Crop-Yield. Montana Experiment Station, Ninth Annual Report (1902).

HarRIS, F. S. Effects of Varying Soil-Moisture Content on Certain Properties of the Soil and on the Growth of Wheat. Cornell University, Doctor's Thesis (1911).

Harris, F. S. Long versus Short Periods of Transpiration in Plants Used as Indicators of Soil Fertility. Proceedings of the American Society of Agronomy, Vol. III (1910).

Khankhaje, P.S. Some Factors Which Influence the Water Requirements of Plants. Journal American Society of Agronomy, Vol. VI, p. 1 (1914).

KING, F. H. The Physics of Agriculture. Second edition (1901).

Leather, J. W. Water Requirements of Crops in India. Agricultural Institute, Pusa, Memoirs of the Department of Agriculture in India, Part I, Vol. I, No. 8, (1910); Part II, Vol. I, No. 10 (1911).

Mayer, A. Ueber den Einfluss Kleineren oder Grösseren Mengen von Wasser auf die Entwickelung einiger Kulturpflanzen. Journal für Landwirtschaft, Band 46, S. 167 (1898).

Montgomery, E. G. Correlation Studies of Corn. Nebraska Experiment Station, Twenty-fourth Annual Report, p. 109, especially p. 150 (1911).

Montgomery, E. G., and Kiesselbach, J. A. The Relation of Climatic Factors to the Water Used by the Corn Plant. Nebraska Experiment Station, Twenty-fourth Annual Report, p. 91 (1911). 
Morgan, J. O. The Effect of Soil Moisture and Temperature on the Availability of Plant Nutrients in the Soil. Proceedings of the American Society of Agronomy, Vol. III, p. 191 (1911). Seelhorst, C. Von, and Tucker, G. M. Der Einfluss, welcher der Wassergehalt u. s. w. auf die Ausbilding der Haferpflanze, Journal für Landwirtschaft, Band 46, 52 (1898).

Widtsoe, J. A. The Chemical Life History of Lucern. Part I. Utah Experiment Station, Bulletin No. 48 (1896).

Widtsoe, J. A. Factors Influencing Transpiration and Evaporation.

Utah Experiment Station, Bulletin No. 105 (1905).

Widtsoe, J. A. Dry-Farming. Chapter IX (1911).

Widtsoe, J. A. The Production of Dry Matter with Different Quantities of Irrigation Water. Utah Experiment Station, Bulletin No. 116 (1912).

Willard, R. E., and Humbert, E. P. Soil Moisture. New Mexico Experiment Station, Bulletin No. 86 (1913). 


\section{CHAPTER VIII}

\section{CROP DEVELOPMENT UNDER IRRIGATION}

The total yield of a crop is, usually, of first importance; but, frequently, a particular part of the plant commands a much higher value than some other part. Thus, the seed of wheat, oats, barley, rye, corn and the other grains, has a much higher value than the straw; and the tops of sugar beets have comparatively little value, while the roots bring high money returns. For such plants, it is as important to regulate the proportion of plant parts as to produce a large yield of the whole plant. The whole crop of alfalfa and the hay crops generally, is sold, but the nutritive value of the hay, per pound, depends on the relative proportion of the stalks and leaves, since the leaves are much more nutritious than are the stalks. The farmer prefers leafy plants, and it is important to know under what conditions of irrigation the largest proportion of leaves may be obtained.

In yet another way is this matter important. The grains, the grasses and many other crops are harvested only for the parts above ground. The roots are left in the ground to decay and have no direct money value. The substances elaborated in the plant are rather easily moved from place to place, and, under certain cultural treatments, it is conceivable that much of the nutritive material of the plant may move into the roots and remain there when the plant is harvested. The farmer needs to know, therefore, under what conditions of irrigation the 
largest possible proportion of the material formed in the plants may be retained in above-ground parts which are harvested. In the case of root crops, the reverse is desired. The roots possess the highest value, the tops the smallest and therefore the largest possible proportion of the plant constituents should be found in the roots at the time of harvest.

Moreover, it is of interest and often of importance to know in what way the general growth of the plant is affected by varying methods of irrigation. To understand thoroughly the principles underlying the art of irrigation, it is not sufficient to know how much crop by weight is produced by given quantities of water applied in given ways, but it is equally important to know in what way the various parts of the plant are affected in their growth by such variations in irrigation.

105. Response to irrigation.-The plant responds quickly to irrigation. In irrigation, water is applied at infrequent intervals. At first the soil is very wet; then it gradually dries, until it reaches the lento-capillary point or even the wilting point; then it is again wet, again dry, and so on throughout the season.

All the life processes of plants growing on irrigated land become very active as soon as water is applied to the soil. Under conditions of irrigation, therefore, the plant is somewhat intermittent in its growth. Assimilation and all other processes favoring growth are especially rapid after each irrigation, gradually diminishing in intensity and almost ceasing before the next irrigation.

In the Utah experiments, for instance, it was found that during the first week after irrigation of peas, more than 500 pounds of dry matter were added to the weight, and of oats, more than 700 pounds of dry matter were 
added to the acre. Such large gains, could not, of course, continue for any length of time without resulting in total yields far above the maximum for the crops in question.

Many of the effects of irrigation are more clearly understood if it is kept in mind that the crop responds readily to the application of water.

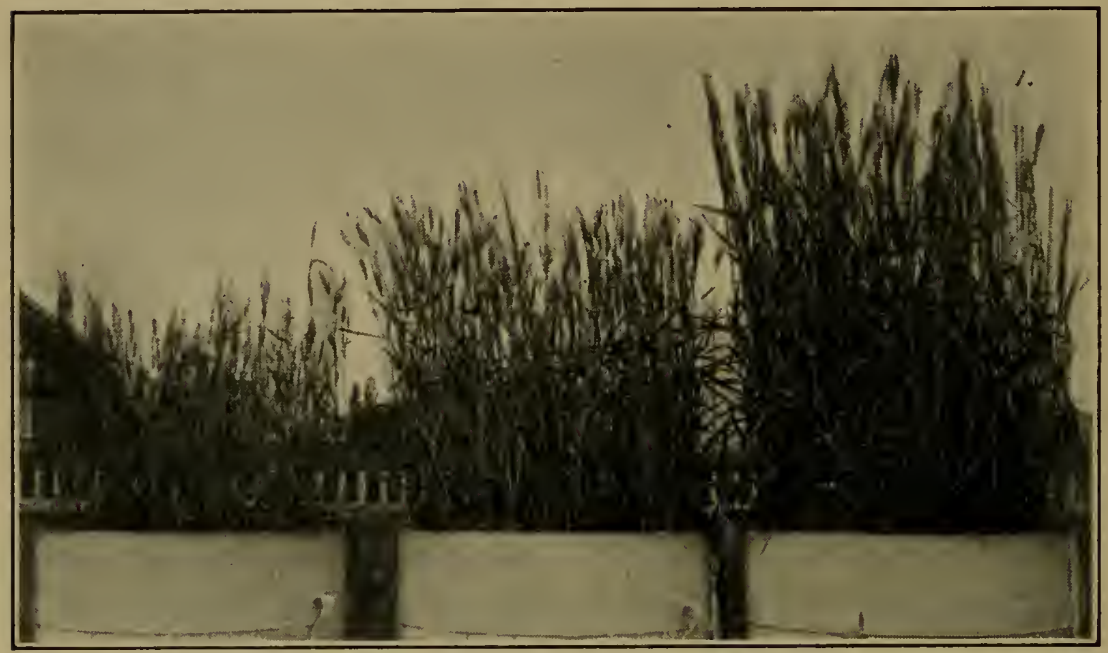

Frg. 30. Effect of little, medium and much water on wheat.

106. Proportion of roots.-The vigor and general condition of the plant depend largely upon the development of the root-system. In the early stages of growth, the plant uses most of the materials gathered from the air and soil for the development of large and numerous roots, which, radiating through the soil, may readily absorb water and plant-food. When the roots are well developed, carbon-assimilation by the leaves is hastened, and growth is rapid. Later in the life of the plant, rootgrowth becomes slower and slower, and the energies of the plant are more largely directed to the development of the parts above ground. When at last the stems are well 
developed and a sufficient quantity of materials has been stored in the various plant organs, growth diminishes, flowers and, later, seeds are developed. This is the natural course of plant-growth. It is indispensable that in the beginning the plant be given every possible chance to develop its root-system.

It has long been known that a dry soil is more completely filled with roots than is a wet one. Under dryfarm conditions, for instance, wheat roots penetrate heavy clay soils to a depth of 8 feet or more. No special attention was at first given to this observation, because, under the humid conditions prevailing in the earlier investigations of agriculture, there seemed to be no practical method of regulating the quantity of water in the soil during the growing season. The rain came as it willed, irrespective of the needs of the farmer. During the last few years, however, this matter has been given quantitative investigation. Von Seelhorst and Tucker found that, of the whole oat plant, including the underand above-ground parts, when little water was used, about 13 per cent was contained in the roots; when much water was used, about 7.5 per cent was found in the roots. With barley, wheat, peas, and other similar crops, it has likewise been shown that the total and relative weights of roots are largest when little water is used. In the Utah work, it was found that the proportion of sugar beets or potatoes to the parts above ground was not greatly affected by the quantity of water used. In fact, the tendency seems to be that specialized roots and tubers increase slightly in proportion to the whole plant as the quantity of water is increased. It may, however, be stated, as a law fairly well established, that the roots of plants, at least of annual plants, always form 
a larger proportion of the whole plant when the soil is kept somewhat dry throughout the growing season. The roots seem to go in search of water and food, when little is at hand, thus increasing the root-development. It does not follow that the actual weight of roots produced in dry soil is much larger than when produced in wet soil. The experiments conducted on the subject indicate that the total weight is somewhat larger in dry than in wet soil; but, the differences are not great and do not approximate the differences in the proportions of roots in the whole plant.

Gain has conducted a number of especially valuable experiments on this subject and has come to the conclusion that, whenever little water is added, the main or primary roots are large and well developed, while the side or secondary roots are small and poorly developed. If much water is used, the main roots are smaller and the side roots become relatively larger. That is, with little water a much larger volume of soil is reached by the rootsystem than when much water is used.

The lesson to the irrigation farmer is clear. A plant with a small root-system, poorly developed, cannot make as good use of the water added to the soil, or of the food in the soil, as can a vigorous plant. It is important, therefore, that as early as possible the root-system be made large and well developed. When this has been accomplished, water may be added in considerable quantities without the fear that plant roots are unable to make proper use of it. As intimated above, to develop a large root-system it is necessary to keep the soil only moderately wet in early spring. In districts where the winter precipitation is fairly large, deep irrigated soils are fairly well stored with moisture in the spring, at the time of 
seeding. If irrigation is applied very early to such lands, the root-system is likely to be retarded in its growth, and the final crop-yield may be greatly reduced. On soils practically saturated, at planting time, from the winter rains and snows, the first irrigation should be postponed as long as possible so that a strong root-system can be developed to use fully the water applied plentifully later in the season. This doctrine has been confirmed by many experiments under true irrigated conditions. For instance, in districts where the winter precipitation is so high (say 8 inches during the six months of fall and winter) that the soil to a depth of 10 to 12 feet is approximately saturated, no benefits result from irrigation immediately after sowing; and the effect of the first irrigation becomes greater as it is removed in time from the date of seeding.

Naturally, however, where the climatic conditions are such that at seeding time the soil is not well filled with water, thorough irrigation immediately before or after planting would do much to insure a proper germination of the seeds and a more rapid development of the rootsystem. Even when this is done, the longer the first irrigation is postponed, the better it will be for the crop, which then can better develop its root-system. Let it not be forgotten by the irrigation farmer that, in a relatively dry soil, roots will develop faster and will go more vigorously in search of water and food.

107. Proportion of leaves and stems.-The part of the plant above ground is also definitely affected by the quantity of water applied. As the water applied to the soil increases, the whole plant becomes longer. This is true with all the common crops, such as wheat, oats, barley, rye, beans and buckwheat. Every farmer has observed that in fields to which water is added abundantly 
the grain and hay stand high, and often the grain crops become so tall that they fall over and give a great deal of trouble at harvest time. Similarly, it is commonly observed that with little water the crops are short. Under dry-farming conditions, where the rainfall is small, the wheat is usually so short that instead of binders, which cannot be used, headers are employed which simply cut off the heads of the grain leaving the high straw standing. Further, as irrigation water is increased, the clusters of seed-bearing heads increase in number. The general appearance of the plant, therefore, depends on the quantity of water added to the soil during the growing season.

Of chief importance is the effect of varying quantities of water upon the stooling of the grains, that is, the number of seed-producing stalks from one seed. The more water is used, the more profuse becomes the stooling; the less water is used, the less stooling occurs. This is of particular importance wherever the seed is the chief product at the harvesting.

In practically every experiment conducted on this subject, however, it has been found that, while the length of the plant and the number of seed-bearing stalks increase as the water increases, there is a limit to this correlation. The increase due to the increased irrigation continues only up to a definite limit, beyond which, if more water is added, a diminution occurs and the plant becomes shorter, the seed-bearing stalks less developed and with fewer seeds, and growth is arrested. A medium quantity of water would therefore be better than a very large quantity to produce large plants with many seeds.

The nature of the leaves is influenced by the application of water. With little water the leaves of the grains are distinctly green and firm; with much water, they are 
pale green and soft. In the case of corn, it has been shown, also, that with little water the leaves are narrow and pointed, whereas with much water they are wide and more rounded, and their screw-like turning increases. Wilms showed that, in the case of potatoes, a small amount of water produced a thick leaf containing long cells and few stomata or breathing pores per square inch, while much water produced thinner leaves containing short cells and many more stomata per unit of surface. That is, in color, form, consistency, cell-structure, and other properties, both the leaves and the stems respond definitely to varying quantities of water. This emphasizes the power of the irrigation farmer, by merely varying the quantity of water applied to plants, to change the color of the plant, the stiffness of the stalks, the shape of the leaves, and many other similar properties. Every part of the plant is changed to correspond with the water at the disposal of the plant.

Of more direct interest, however, to the farmer, than the size and shape, is the relative proportion of leaves, stalks or other parts of a crop. The leaves of plants, whether large or small, are usually of higher nutritive value than the stalks. It is desirable therefore, when a crop is grown for forage to secure the largest proportion of leaves. The few available investigations make it clear that the proportional parts of leaves and stalks are distinctly affected by the quantity of water used in irrigation. In the Utah experiments, with wheat, oats and peas, the proportion of leaves in the whole plant became higher and higher as the water was increased, whereas with potatoes the reverse occurred. When the leaves and stalks alone were compared, it was found that, as with potatoes, the less water used the leafier were the plants. 
In general, much water produces at first leafy plants; if more is added, the proportion is diminished. Crops grown for forage, in which a high proportion of leaves is desirable, may profitably be given larger quantities of water than crops that are grown more largely for some other part of the plant.

108. Proportion of heads and grain.-The grain crops are grown primarily for seed. The value of the straw is small in comparison with that of the seed. The grain farmer desires therefore to convert as much as possible of the plant into seed at the time of harvest. Up to a definite limit, the clusters of seed-bearing heads increase with the quantity of water used. The number of seeds in each head of wheat, or ear of corn increases, likewise, as the quantity of water is increased. Even the beard in the bearded varieties, becomes longer or shorter as much or little water is applied. The seedbearing part of plants, like the roots, stalks and leaves, is sensitive to the water applied to the soil.

Many reported experiments deal with the proportions of the heads in grain crops as influenced by varying quantities of water. In the Utah experiments it was found that as the total quantity of irrigation water was increased the proportion of heads in the plant above ground decreased with wheat, from 38 to 25 per cent; with oats, from 59 to 49 per cent; with peas, from 67 to 48 per cent. In every case it was distinctly shown that the more water applied, the smaller the proportion of the heads in the whole plant. Therefore, while the size and number of heads seem to be increased as the total quantity of water increases, it is equally clear that the stems and leaves are increased more markedly. This leads to a decreasing proportion of heads in the whole 
plant as the water applied increases throughout the season.

This correlation has been demonstrated by a great number of investigators, although in few cases only under true irrigated conditions. Hellriegel was one of the first to investigate this subject and to announce the law that the proportion of seed to the straw in all ordinary crops becomes smaller as the available water in the soil during the growing season increases. Mayer, working in Holland, investigated rye, wheat, barley and oats, and found invariably that the more water he offered the plants, the smaller became the proportion of the grain yielded by the crops. French and English investigators have confirmed this conclusion. At the Utah Station, in a long series of experiments under irrigated conditions, the percentage of seed in the harvests of wheat, oats, barley and corn was very carefully determined. In the following table some of the results obtained are shown:

\begin{tabular}{|c|c|c|c|c|}
\hline \multirow{2}{*}{$\begin{array}{l}\text { Depth of } \\
\text { water applied } \\
\text { (inches) }\end{array}$} & \multicolumn{4}{|c|}{ Percentage of grain in harvest of } \\
\hline & Wheat & Oats & Barley & Corn \\
\hline $5.0-7.5$ & 44.45 & 64.54 & 50.74 & 51.69 \\
\hline 15.0 & 40.83 & 62.55 & 47.09 & 47.92 \\
\hline $25.0-35.0$ & 38.65 & & 38.27 & 43.55 \\
\hline $45.0-50.0$ & 32.89 & 57.63 & & \\
\hline
\end{tabular}

In the first column is given the depth, in inches, of the water applied throughout the growing season; in the following columns, for each crop, the percentage of grain in the total harvest. The smallest quantity of water applied was 5 inches, and the largest 50 inches. The smallest quantity used should meet, fairly, ordinary crop needs, and the largest quantity used is not very far above that 


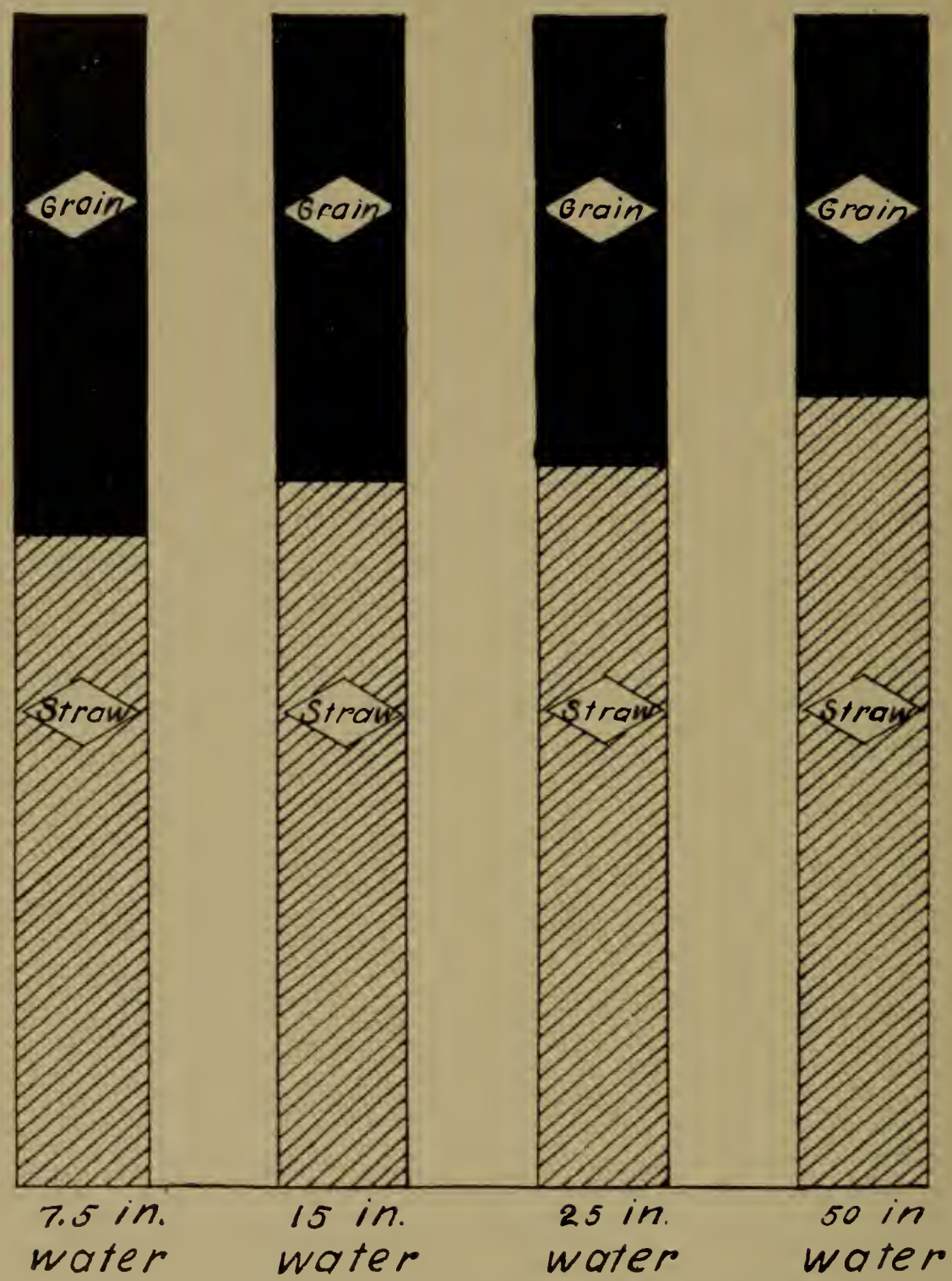

FIG. 31. Proportion of grain and straw with varying irrigations (wheat). 
actually used, though wastefully, in many of the irrigated sections.

With the smallest quantity of water, nearly 45 per cent of the total wheat crop was seed; as the water was increased, the percentage became smaller and smaller, until, with 50 inches, the percentage of seed in the crop was less than 33 per cent. In a similar manner, the seed in oats fell from 64 to 57 per cent as the water was increased; in barley, from nearly 51 to a little over 38 per cent; and in corn, from nearly 52 to about 43 per cent.

That is, under irrigated field conditions, the law which has been so frequently determined in pot experiments has been fully confirmed: namely, as the water available to plants increases, the proportion of seed in the plants decreases. This is naturally of the deepest significance to the irrigation farmer, for not only does the total yield of the crop per unit of water decrease largely as more water is used, but the proportion of the more valuable parts of the plant decreases also. The meaning of this is that, if the yield per acre-inch of water of the whole wheat crop is diminished as more water is used, the yield of grain is even more largely decreased. The grain farmer cannot, therefore, by any process of reasoning convince himself that it is desirable to use very large quantities of water for the production of his crops. (Fig. 31.)

It may be said, in this connection, that the prevailing idea that grain grown with little water is not so full and plump as that produced with more water, is erroneous. This phase of the matter will be discussed in Chapter XI.

109. Other plant parts.-The development of crops under the influence of irrigation as here outlined is fairly 
well established and may be safely accepted, yet it is not to be forgotten that much work must yet be done with the various crops before a full knowledge of the subject is in our possession. We may say with a certainty that the leaves, stems, seeds and roots of crops are influenced definitely by varying the quantity of irrigation water. We do not know definitely, however, how the yield of fruit is affected by varying quantities of water, although in view of the high value of the fruit crop, this is a particularly important need. It is probably true that the production of fruit depends upon the time at which water is applied rather than upon the total quantity of water. However, from early springtime each tree sends forth its leaves, and the materials elaborated by the leaves are distributed throughout the whole tree-to develop roots, trunk and branches, and to produce fruit. Undoubtedly, the quantity of water applied plays an important part in determining how these elaborated materials shall be used in the tree. In so large a structure as a well-matured fruit tree it must be of great importance to know how the materials gathered from the soil and air may be driven into the fruit, without injuring the well-being of trunk, branches and roots of the tree. That the fruit crop is as sensitive as other crops to the effects of varying quantities of water is well shown in several experiments. For instance, Jones and Colver, in a study of the composition of irrigated and non-irrigated fruits, conducted under the auspices of the Idaho Experiment Station, and using fruit grown under the somewhat humid conditions of northern Idaho, found that the proportion of seeds, skins and other wastes of fruits was high or low as the fruit was or was not irrigated. The following table gives some of the results: 


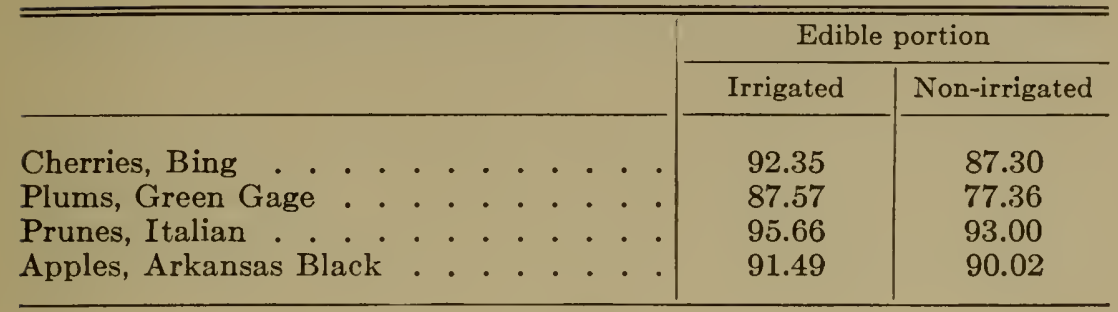

It was further observed that the various parts of the waste varied with the water used. As our knowledge of this matter grows, it will no doubt be possible, under conditions of irrigation, to control largely the output of fruit from a given orchard.

A similar problem is connected with the production of the tomato, which is grown in tremendously large quantities in districts where the canning factories operate. It is of prime importance to obtain the largest yield by weight of tomatoes, considering both quality, size and shape. To make the vines small and the tomatoes large is a question of very great importance. The same may be said of the cantaloupe industry, which assumes large proportions in certain sections of the irrigated West. The agricultural investigators of the irrigated regions must take these matters in hand at an early date, to discover the laws that control the production of the various parts of all the crops that are commonly grown under irrigation.

The length of season also has an important bearing upon the economy of the water used. By varying the quantity of water used, it is possible, at least in a small measure, to lengthen out or shorten the season. As is well known, the more water is at the disposal of the plant, the longer growth continues. If the soil moisture is high in early spring, there is a tendency for the plant to pre- 
pare for a long wet season, and if this same environment is continued throughout the season, the plant continues the vegetative processes much longer than if the moisture from the earliest period is relatively low. In general, we may lay down the law that the more water used, the longer the growing season of the plant; the smaller the quantity of water used, the shorter its growing season. This may often find important applications. For instance, wherever early and late frosts prevail, the moderate use of water will hasten maturity; and, in hot, dry districts, the moderate use of water will prevent an unnecessarily long vegetative period with rapid evaporation.

\section{REFERENCES}

HaRRIS, F. S. The Irrigation and Manuring of Corn. Utah Experiment Station, Bulletin No. - (1914).

Widtsoe, J. A. The Effect of Varying Quantities of Irrigation Water on the Production of Dry Matter. Utah Experiment Station, Bulletin No. 116 (1912).

Widtsoe, J. A., and Stewart, Robert. The Effect of Irrigation on the Growth and Composition of Plants and Different Periods of Development. Utah Experiment Station, Bulletin No. 116 (1912). 


\section{CHAPTER IX}

\section{THE TIME OF IRRIGATION}

UNDER ideal conditions of irrigation, a plentiful supply of water would always be at the disposition of the farmer. In practice, such a condition seldom exists. The flow of water in the rivers from which the canals are taken, varies from season to season, and, unless the water is stored in reservoirs, there is not, throughout the season, a uniform supply of water. In the spring, the flow is beyond the capacities of the canals; in midsummer and later it is often insufficient for the needs of the system. Different crops have different water requirements, both as to total quantity and periodic application. Young plants use less water than do the larger and stronger plants some weeks older; and the mature plant, the life activities of which have ceased, has very little need of water. The life history of the plant determines, largely, the best time of irrigation. It seldom happens, however, that the periodic natural flow of water coincides with the periodic crop requirements. The problem of applying the best quantity of water at the proper time, which will determine the principles of canal management, is one of the most complex in irrigation practice.

110. The ideal principle.-It may be laid down as an ideal principle, that, so far as possible, the same percentage of moisture should be maintained in the soil throughout the growing season, irrespective of the age of the plant. That is, the soil-water film should be kept 
at the same thickness while the plant is growing. The young plant requires less water per day than the older plant, but the ease with which the water may be obtained should be practically the same for young and older plants, as long as they are growing vigorously. Such a condition of uniform water content in the soil is practically impossible unless water is added daily to the soil to replace that lost by evaporation and transpiration. The intermittent nature of irrigation, fundamentally characteristic, implies a period of high moisture percentage immediately after an irrigation, gradually diminishing until, just before the following irrigation, the soil is often very dry. Nevertheless, the irrigation farmer must attempt to apply irrigation water in such a way as to leave the plant in an approximately uniform moisture environment throughout the season. Therefore, irrigation must be more abundant and frequent at periods of high transpiration. So far as the soil is concerned, the intermittent nature of irrigation is highly favorable in producing a condition favorable to plant-growth.

The discussion of the time of applying irrigation water may be surveyed as follows:

1. Irrigation when crop is not growing.

(a) Fall irrigation.

(b) Winter irrigation.

(c) Early spring irrigation.

2. Irrigation when crop is growing.

(a) For germination.

(b) Use of early spring floods.

(c) Irrigation at different periods of crop growth.

(x) Annuals.

(y) Biennials.

(z) Perennials. 
111. Fall irrigation.-Fall irrigation means irrigation after harvest, but before winter sets in. After harvest, water still flows down the river channels and ordinarily goes to waste. This late water may be used to saturate the soil, and thus be held over until the following growing season. In districts where the fall and winter percipitation is insufficient to saturate the soil, fall irrigation is especially desirable.

An average soil of the arid regions, under field conditions, is saturated when it contains about 18 per cent of water to a depth of 10 feet. This is equivalent, approximately, to a depth of 3 feet of water. Under wise systems of cropping, about 12 per cent of water is left in the soil to a depth of 10 feet at the time of harvest. At the following seed time, the soil should again be in a saturated condition. The difference between 12 per cent and 18 per cent, or practically 1 foot of water, should, therefore, be furnished by the natural precipitation, or by fall, winter or spring irrigation.

Over a large area of the inter-mountain country, the precipitation comes chiefly in the fall and winter or early spring, that is, between harvest and seed time. In this district, fall and winter irrigation have little value, if the land is so treated as to permit the storage in the soil of the rain- and snow-water-unless the total seasonal precipitation is low, when irrigation during the fall season may be very helpful. In other sections, much of the rainfall comes in late spring, summer or early fall, that is, during the growing season. This water does not remain stored in the soil during the winter for the use of next season's crop, and under this condition, fall irrigation is highly profitable.

It is of great advantage to have the soil saturated 
at planting time, for (1) it makes possible a quicker and more complete germination, and (2) it delays the time of the first irrigation, and the plant is enabled to establish a strong root-system. It is, also, decidedly advantageous to keep the soil well saturated with water throughout the dormant season. Water added in the fall distributes itself in the usual way throughout the soil to a considerable depth. The soil-water film then remains long in intimate contact with the soil particles; plantfood is dissolved and well distributed throughout the water until, at planting time, the soil-water is heavily charged with dissolved plant-food and is a very nutritious medium for plant-growth.

Water applied during the growing season is immediately drawn upon by the plant, and does not remain in the soil long enough to permit of extensive solution or distribution of soil nutrients in the soil-moisture film. Only the portions of the soil-water film that lie nearest to the soil particles become rich in plant-food. This may be the one explanation of the repeated observation that a given quantity of water applied in irrigations at intervals of one, two, three or even four weeks may often yield a larger crop than when applied in smaller and more frequent irrigations. Water applied too frequently or in small quantities is pumped out of the soil so rapidly that there is little chance for solution of plant-food. With longer intervals and larger irrigations, more plantfood may be dissolved and used in plant-production.

At any rate, water applied in the fall and winter season has the opportunity throughout the long months of the dormant season to dissolve from the soil such materials as will be of value in plant-growth. Such soil solution is of tremendous value in establishing the young plant dur- 
ing the earlier periods of growth. Water stored in the soil at the time of planting is invariably more valuable, unit for unit, than water applied directly at the time of, or immediately after planting.

Fall irrigation may be applied to bare lands at any time after harvest. The common practice is to apply the water as soon as may be convenient after harvest without previous plowing, and to allow the soil to remain unplowed until the following spring. Another practice is to plow soon after harvest and then to apply water. When the soil "washes" easily, this latter practice is not always successful; moreover, plowed land is irrigated with difficulty. The structure of some soils is easily injured by the work of making the water cover the plowed land, thus affecting the crop of the following year. On orchards, fall irrigation should not be applied too early. The soil should be allowed to become dry in the early fall, so that the trees may ripen their wood for the winter's rest. Then fall irrigation may be applied in safety. If water is applied to trees before growth has ceased, a late new growth is started, which usually results in winter-killing. Naturally, this applies only to deciduous trees. Citrus trees are irrigated during the whole year, if necessary.

Generally, when fall irrigation is applied late enough it results only in good. Lands are not ordinarily cultivated after fall irrigations, because, over the larger part of the irrigated territory, the fall rains usually leave the top soil in a condition to be puddled if subjected to tillage. However, a soil that has been fall-irrigated should be carefully cultivated in the spring, just as soon as the top soil is in the proper condition. It is never wise to use tillage implements on soils that are too wet. Early spring cultivation always means cultivation performed on a 
soil sufficiently dry to support the tools without danger to the soil structure.

Fall irrigation has been tried extensively in places where the winter rainfall is light, and almost invariably with great success. Wherever the winter precipitation is high, it is probably unnecessary and possibly inadvisable to practise fall irrigation. Meanwhile, the use of the water which ordinarily goes to waste in the fall may be the means of making the summer flow cover a larger area of land than would otherwise be possible.

112. Winter irrigation.-Winter irrigation means the application of water to the soil during the winter proper. It is seldom practised where the winters are closed in by snow or where the top soil is frozen for weeks or months. It is true that an unsaturated soil, when frozen, is of a granular structure, and that through such a frozen soil water penetrates to considerable depths. However, water applied to frozen soils stands on the soil and often freezes into sheets of ice. On bare soils this does little harm and little good. A possible advantage is that when the warmer weather melts the ice and opens the soils, the water that has not run off soaks rapidly into the soil. On lands bearing grass or lucern, great injury is done when sheets of ice are formed over the surface of the fields, and winter irrigation should never be practised on such fields where freezing weather characterizes the winters.

Winter irrigation is and should be practised chiefly where the winters are mild and open. In such districts, winter irrigation is really a later fall irrigation. All the arguments in favor of fall irrigation hold for such winter irrigation.

Excellent studies have been made of the value of winter or late fall irrigation in supplementing the rain- 
fall and increasing the duty of irrigation water through the growing season. The most notable of these studies was made in 1898 and 1899 by McClatchie, in an Arizona valley where the annual rainfall averages about 11 inches, and is so distributed as to be heaviest from July to September and from December to February. Deciduous trees shed their leaves in November; the buds start in February, and the leaves are generally out by the end of March. Heavy frosts often occur in December and January. The orchard used for the experiments contained chiefly peaches and apricots planted in 1892. In 1898, the orchard was irrigated in September. Then, from January 2 to March 1, 1899, the orchard received eight irrigations. It was then plowed and harrowed. From March 31 to June 24, 1899, no further irrigation was applied and no rain fell during that time. In spite of the lack of irrigation the growth of the trees and the yield of fruit were excellent. On December 16, 1899, the winter irrigations began again and 3 acre-feet of water were applied between that date and March 5, 1900. During the following eight months no irrigation water was applied, and the rainfall during that period was only about $2 \frac{1}{2}$ inches, distributed among five rains. At the end of the eight months the trees were in fine condition and the yield of fruit was excellent. The season was the driest and hottest on the records of the state.

This classical experiment demonstrates conclusively the high crop-producing value of fall and winter irrigation, correctly applied in districts where such irrigation is at all practical. It reëmphasizes also the doctrine that, when the soil is used as a storage reservoir, it is not necessary that much water be added during the growing season of the crop. 
McClatchie observed that, as a result of heavy winter irrigations, the tree roots grew while there was no visible growth above the ground. The strengthened roots then made possible rather rapid growth above ground at a later period. Roots were found plentifully to a depth of 16 feet and one was followed to a depth of 20 feet. Available moisture was observed to a depth of 20 to 25 feet. The major use of water by the trees was in the spring and early summer. In the later summer the trees were somewhat sluggish so far as the use of water was concerned. As a result of his investigations, McClatchie advised the use of winter irrigation, and not to exceed one summer irrigation, for the successful production of fruit in that section of Arizona.

It must not be believed, however, that under fall and winter irrigation plants are given less moisture than when the water is added in summer. More likely the liberal use of water in fall and winter, when few farmers use it, means that really more water is thus used for the production of dry matter. In the experiment above cited, it was found that approximately 48 inches of water were received throughout the season. This was used by the orchard proper, by the cover-crop for the maintenance of soil fertility, and by evaporation. Whether in winter or summer, water should be used sparingly.

Winter and fall irrigations are two excellent methods whereby the waters which now largely go to waste may be so conserved as to increase the duty of the summer flow. In time, as more reservoirs are built and all the fall and winter waters are held back in these reservoirs, fall and winter irrigation will not be so important; but even under these future ideal conditions, it may be found desirable to irrigate the soil in the fall, so that, in the 
spring, there may be an abundance of water, heavily charged with the valuable constituents of the soil, for the use of the young plant.

113. Early spring irrigation.-This refers to irrigation made soon after the winter breaks, either before or after planting, but nearly always before the plant is really in need of additional water. When spring appears, the melting mountain snows increase greatly the river flow, culminating in the period of high water and spring floods. Unless reservoir provisions are made these great quantities of water flow away unused and it is an increasingly important question whether this spring flow may be diverted profitably upon cultivated lands.

If the soil has been well filled with water during fall and winter, either by late irrigation or by heavy winter precipitation, it is probably useless to expect that spring irrigations will benefit crops. The early application of water may rather be detrimental in such places, as it tends to wash down, beyond the reach of plant roots, the rich soil solution formed during the winter.

On the other hand, wherever the winters are dry, or where fall and winter irrigation cannot well be practised, the application of water in the early spring may be beneficial in stimulating early crop-growth. In fact, in localities where the soil in spring is in a condition too dry for germination, it is indispensable that water be applied to the soil about the time of planting, if any crop at all is to be obtained. In such districts, water is often applied to the soil some time before the planting season. After the water has distributed itself throughout the soil, the top soil is loosened to prevent evaporation and to furnish a good seed-bed. Usually, however, the seed is sown in the relatively dry soil and a rather heavy irrigation is 
applied afterward. In either case, germination is encouraged.

Our present knowledge leads to the belief that spring irrigation should be practised only where it is absolutely indispensable. The value of early irrigation depends upon the quantity of water in the soil in the early spring. It is much better, wherever conditions permit, to irrigate in the fall, and to conserve in the soil as much as possible of the natural precipitation, so that the seed may be planted without irrigation and the first irrigation may be postponed until early growth is well started, and late spring or early summer weather has set in.

This matter was tried out at the Utah Station with the result that the longer the spring irrigation was postponed, the more valuable it became in increasing the crop-yield. Under the prevailing conditions, there was a liberal fall, winter and early spring precipitation, so that at planting time the soils were usually saturated with water. To irrigate such soils does little good, and possibly results in harm. Only where germination will be delayed or be incomplete without irrigation should the early application of water be practised. It is of prime importance, for obtaining the best results, that the soil be well filled with moisture at the time of planting.

114. Irrigation during growth.-The time to irrigate crops during their growth should measurably determine the rotation of water from irrigation systems and it bears, therefore, directly upon the question of canal management.

In the spring, when the root-system is being developed, the growth above ground is slow. With each day, however, the rate of growth increases, until buds and flowers appear. At that time the rate of plant-growth is most 
rapid; and this rapid growth, or increase in weight, continues during the whole time of early flowering. When seed-formation begins, the rate of growth diminishes; and after the seeds have been formed, it is even smaller than in the earlier stages.

The water transpired by crops is generally, though not always, in proportion to the rate of growth. Water lost by evaporation from the soil increases and decreases largely in the same proportion, because the time, temperature and other conditions that determine the rate of plant-growth also determine the rate of direct evaporation.

Such a coincident variation would mean that little water needs be applied in the earlier periods of plantgrowth, but that, as the rate of growth increases, the rate of adding water must be increased until the period of seed-formation approaches, when the supply may again be diminished. In practice, it is exceedingly difficult even to approximate this ideal system of irrigation, for the stream flow in most localities decreases rapidly from early spring until the time of maximum water needs is reached. At that time of high requirements and low supply it is difficult for the farmer to supply his crops with the best quantity of water at the right time. Under reservoir conditions, the ideal requirements are more nearly met. Nevertheless, under any conditions, the farmer must attempt, as nearly as may be possible, to give his crops most water at the time when the crops need water most. This time, in turn, depends on the crops grown under the system. By a wise diversity of crops, a small stream in early or late summer may be made to served a large area well.

115. Time of irrigating short-season crops.-Wheat and the other small grains, peas, beans and similar short- 
season crops, after having been planted in a soil well filled with moisture, should be allowed to grow as long as possible without irrigation. The early irrigation of such crops is only slightly advantageous, and the results seldom pay for the labor and cost of water. By postponing the first irrigation, the root-system may be more fully developed, so that the best use may be made of the water when it is applied. Such crops, grown for seed, seldom need irrigation before the time of flowering or seed-formation, when one or two moderate irrigations may be applied with decided advantage.

At the Utah Station it was found that, when a given quantity of water was used, the total weight of the crop was not greatly affected by varying the time of irrigation; the effects were felt in the yields of grain produced. When irrigation was performed early, before flowering, more straw and less seed were produced; when irrigation came late, less straw and more seed resulted. The sum of straw and seed was, in both cases, practically the same. That is, late irrigations make possible the transfer of nutritive materials from the roots and stalks to the heads, there to be permanently elaborated into seed materials.

After the seeds are well formed there is seldom any advantage in irrigation. Certain varieties of grain, peas and beans have an extended growing season, and to such it may be necessary to apply water some time before flowering, and perhaps once after seed-formation is well under way. Even to the crops that mature early, it may often be profitable to add water at the time the seeds are forming most rapidly, for it may help fill them more completely.

116. Time of irrigating long-season crops.-Sugar beets, potatoes, corn and similar crops should also be 
planted in well-saturated soil. The first irrigation should be postponed, for the reasons already given, until the plants really show need of water. From the time of the first irrigation, water must be applied to these longgrowing crops at regular intervals throughout the growing season. Sugar beets, carrots, corn and like crops, planted usually in May, need the greater quantity of water in July and first half of August. From the first of September and during autumn, little, if any, water should be applied, even if the harvest does not occur until October or November. Sugar beets are seldom benefited by irrigation after the first of September.

Under the conditions of the inter-mountain country and on deep clayey or loamy soils, 5 inches of water is a fairly large single application. An irrigation of this degree every two or three weeks throughout the season, from the time of the first irrigation until the first week in September, is quite sufficient to maintain the soil in a first-class condition for the needs of beets and other longseason crops. Usually, a much smaller quantity of water at each irrigation will suffice to produce a bountiful harvest of root crops. It is doubtful, however, if more than three weeks should elapse between irrigations, where water is fairly abundant, for if the soil dries out too much the plant may be injured permanently. When 15 acreinches are applied throughout the season it is well to apply them in four or five irrigations. The deeper the soil, and the more thorough the surface-cultivation, the fewer need be the applications. During the hot season, they will naturally be closer together than in the early or late summer. In one series of experiments, the highest yield of carrots, a long-season crop, was obtained with seven irrigations; the highest yield of sugar beets was obtained 
with six irrigations. Excellent crops of carrots were, however, obtained with four irrigations, and of sugar beets, with only two irrigations. Each district must work out the problem for itself, keeping well in mind that root crops must be made to wait as long as possible for the first irrigation and that thereafter, until early fall, they should receive rather regular irrigations.

Lucern, or alfalfa, should be watered with reference to the number and times of cuttings. Over the irrigated district three cuttings of lucern are ordinarily obtained annually. The first irrigation should be applied when the crop goes into flower, which is the time of the greatest rate of growth. The next irrigation may be applied just before or after the first cutting. This second irrigation is intended, primarily, for the use of the second crop, and its chief effect is to stimulate the early growth of the second cutting. It matters little whether the crop be irrigated immediately before or after the cutting. It is possible that an irrigation before cutting permits the water to be distributed more thoroughly in the soil, before the growth of the second cutting begins. On the other hand, the longer the interval between the irrigation and the cutting of the first crop, the larger the loss by evaporation. Each cutting of lucern could well receive an irrigation at the time of flowering and another at the time of cutting, excepting the third crop, which is usually cut so late as to require no further irrigation, unless it be the fall irrigation which is practised for the benefit of next crop.

Hay crops that yield only one cutting a year should be treated very much as is the first cutting of lucern. The one irrigation should be applied at the time of flowering or seed time. If the aftermath is to be used, one or more small applications may be applied throughout the 
season, to maintain the late growth. Pastures which in the irrigated section are maintained during the whole season require small but regular applications of water from spring to fall.

The time to apply water to fruit trees depends on both fruit- and bud-formation. The fruit-buds are formed the year preceding the bearing of the fruit. At the time that these are formed, usually in late midsummer, when the fruit is still small and immature, the crop should be plentifully supplied with water. Fruit trees require a moderate amount of water in the spring and early summer with an increasing quantity as the summer advances and the fruit develops. Late fall irrigation of orchards, after the season's wood has ripened, is beneficial to the succeeding crop, except in places where the winter precipitation is very heavy.

117. Night vs. day irrigation.-Water is usually allowed to run through the canals with equal volume by day and by night. The night water, so far as is known, is quite as valuable as the day water in crop-production. However, night irrigation naturally is more difficult to perform. Sanborn and others have experimented on the relative value of night and day irrigation. Their results lead to the conclusion that there is no material difference in results between night and day irrigation. Where the water supply is small, it must be husbanded carefully, and the farmer then uses it both day and night.

\section{REFERENCES}

Harris, F. S. Studies in Soil Moisture and Fertility.

Harris, F. S. Long versus Short Periods of Transpiration in Plants Used as Indicators of Soil Fertility. Proceedings of the American Society of Agronomy, Vol. II, p. 93 (1910). 
McClatchie, Alfred J. Winter Irrigation of Deciduous Orchards. Arizona Experiment Station, Bulletin No. 37 (1901); also United States Department of Agriculture, Farmers' Bulletin No. 144 (1901).

McDowell, R. H. Irrigation. Nevada Experiment Station, Bulletin No. 25 (1894).

Richman, E. S. United States Horticultural Department Bulletin No. 20 (1893).

Sanborn, J. W. Night versus Day Irrigation. Utah Experiment Station, Bulletin No. 21 (1893).

Welch, J. S. Irrigation Practice. Idaho Experiment Station, Bulletin No. 74 (1914).

Widtsoe, J. A., and Merrill, L. A. Methods for Increasing the Crop-Producing Power of Irrigation Water. Utah Experiment Station, Bulletin No. 118 (1912). 


\section{CHAPTER X}

\section{THE METHOD OF IRRIGATION}

THE method of irrigation determines greatly the duty of water and the profitableness of irrigation. The considerable labor which always attends the application of water to land is one of the big charges to be made against irrigation, and one that must be made as low as possible. Besides, the method of irrigation frequently affects, directly, the degree to which plants may use the water applied.

There are only two general methods of applying irrigation water; first, irrigation above ground and, second, irrigation below ground. Each of the two methods appears under several variations and possesses a special advantage. In practice, the method of applying water above ground is the only one in general use.

118. Sub-surface irrigation.-The application of irrigation water from below, or sub-surface irrigation, has the advantage that water so applied is not subjected to such direct evaporation from the surface as of necessity accompanies surface irrigation. When water is scarce, it is especially of great importance to reduce such evaporation. For this purpose, sub-irrigation seems to be the method that should be employed.

It should, however, be kept in mind that the successive wetting and drying of the top soil, which accompanies surface irrigation, benefits crops and enables them to produce dry matter with least water, and often. this 
benefit overshadows the loss by evaporation. In the Utah work, some attention was given to the effect of irrigation above ground with respect to the transpiration ratio. In every case, much larger quantities of water were evaporated when the water was applied to the surface of the soil than when applied by sub-irrigation, but a pound of water applied to the surface produced as much dry matter as when applied below the surface. It may be that the value of sub-irrigation has been considerably exaggerated because the diminution of evaporation only has been considered.

Aside from these theoretical considerations, sub-irrigation has not received wide acceptance, due to certain intrinsic difficulties, which seem insurmountable. Subirrigation implies underground water channels, opened at various places for the escape of water to the crop. These underground channels are usually pipes of iron or concrete or wood. Machines are on the market which, as they move along, open the soil to the requisite depth and at the same time lay a concrete pipe of the desired dimension. The cost of installing such a system is very great and adds immensely to the initial cost of irrigation. With the present prices of land, water and crops, it is not good business to install sub-irrigation systems, unless it be in a few favored localities where conditions of labor and markets are just right.

It may be urged that such a system once installed and out of sight requires little further attention; whereas surface irrigations require a large annual cost for the upkeep of ditches and the actual spreading of water over the land. This advantage is, however, more apparent than real. Leaks are often sprung in the underground systems which are located with difficulty and remedied at large 
expense. Still worse, plant roots, always in search of water, are gradually directed to the openings in the underground pipes, and fill them so completely that the flow of water is either greatly diminished, or entirely stopped. For this reason every sub-irrigation system has either been abandoned or has been maintained only in spite of the

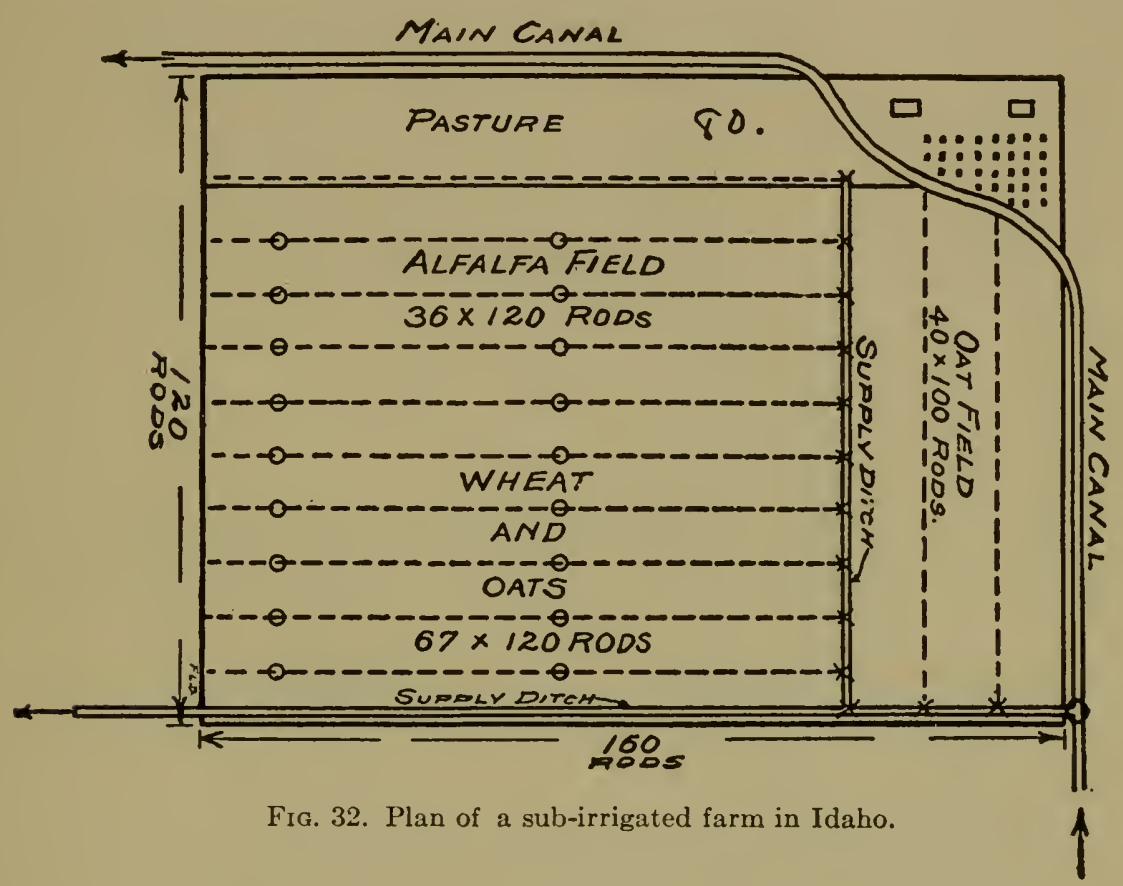

great cost of keeping the water outlets free from plant roots. The best that can be said about sub-irrigation is that the method has not yet been perfected, and that it offers a fine field for the agricultural inventor.

One kind of sub-irrigation of extremely limited application has proved successful. In certain localities are found somewhat sandy soils, 1 to 5 feet in depth, underlaid by an almost impervious clay. Ditches are dug at intervals of $1 / 2$ to $3 / 4$ mile. The water flowing through these 
ditches sinks until it reaches the clay bottom, along which it travels for great distances within reach of plant roots. Some of the finest fields in western America are supplied with water by this inexpensive process of natural lateral seepage. Clearly, this method is so limited in extent that

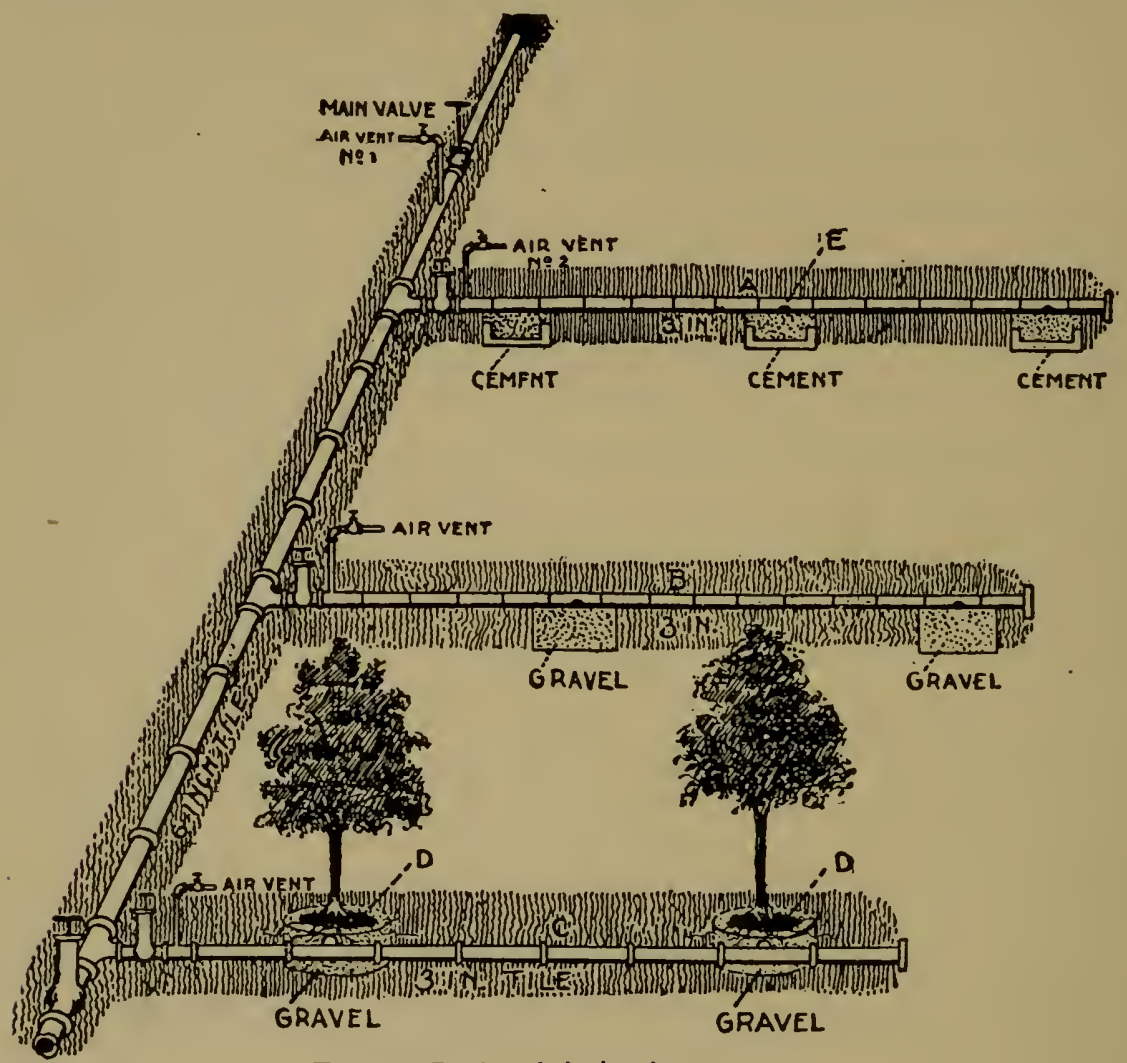

FIG. 33. Lee's sub-irrigation system.

it deserves only a passing notice. Yet it should be kept in mind, so that, whenever the conditions appear to be suitable, attempts may be made to irrigate crops by natural sub-irrigation. (Figs. 32, 33.)

Except in greenhouses and under natural systems, subirrigation may be eliminated from consideration. 
119. Surface irrigation.-Surface irrigation is the method generally adopted in all irrigated countries. There is a great variety of methods of surface irrigation, most of which are scarcely worth consideration, because they either fail to recognize the natural laws underlying irrigation, or their cost of installation is beyond practicability.

The approved methods of surface irrigation may be classified under two heads: first, the flooding method; second, the furrowing method. By the flooding method, all the soil is covered by the water applied; by the furrowing method, the water is guided in furrows or channels which traverse the whole field, but the water covers only a part of the soil surface. Both flooding and furrowing are used extensively in all irrigated regions. In one locality flooding may be the general method; in another, furrowing. The adoption of one or the other of these methods depends sometimes upon careful trials, but more often upon custom following the first practices.

The chief factors determining the choice between flooding and furrowing, are: (1) the nature of the soil, (2) the contour of the land, (3) the head of the water stream, (4) the quantity of water available, and (5) the nature of the crop.

If the soil is light and "washes"-a condition existing over large areas of the irrigated section-furrowing is the only really practicable method. On such soils, the soil-washing due to flooding often results in large channels, gullies or "washes" being cut in the soil. On heavier soils, flooding may be practised safely, as far as erosion is concerned. Many soils, after haring been wetted, bake and form a hard crust, which is injurious to the soil and to the plant. On such soils the furrowing method is advisa- 
ble, for by that method only a part of the surface is covered with water, and that part may be covered with loose earth by cultivation soon after irrigation. Other soils, after having been wetted, as they dry, fall apart, forming natural mulches. On these soils, flooding is quite safe.

On relatively level land, either flooding or furrowing may be adopted. Flooding is best done when the slope of the land is not great, especially if the soil tends to "wash" easily. On steeper lands, furrowing must be employed. The heavier the soil, the steeper may be the inclination; the lighter the soil, the gentler must be the inclination. On the relatively steep slopes, frequently used for orchards, furrowing, alone, is employed, and the sharp descents are overcome by carrying the furrows back and forth around the slopes with any desired fall. While no definite rule can be laid down as to the permissible inclination of lands under irrigation, yet a farmer soon learns by experience the practice best suited to his land. Farm irrigation systems should be laid out with reference to the contour of the land and, therefore, the irrigation farmer should first secure contour maps of the land which he intends to bring under irrigation.

By the "head" is understood the volume of water supplied to the unit of time. Under some systems of canal management, farmers are given large streams of water for short times; under other systems, small streams are available for longer periods. The total quantity of water, at the end of the period, may in either case be practically the same. A high head of water pushes rapidly over the land. Loose, sandy soils that absorb water rapidly must be irrigated with a high head of water, especially under the flooding method, or the water may all be drawn into 
the soil, before the lower end of the field is reached. Under the flooding method, a high head of water may be used on nearly all soils, but a low head is suitable only for heavier soils. It follows that the furrowing method is best adapted where the head of water is low; the flooding method where the head is high. This deduction has found practical expression over the whole irrigated area.

If irrigation water is abundant, and a high head may consequently be secured, the flooding method is usually employed. If water is scarce, the main consideration is to make the total supply cover the largest number of acres, and the furrowing method is ordinarily employed, since by this method a small quantity of water may be made to cover much land. It has been shown that the productive power of water decreases as the total quantity applied to a given area is increased. That is, with each additional inch of water, less dry matter is produced. Consequently, where water is scarce, it is more profitable to spread the small quantity of water over a large area of land. To do this, the furrow method is indispensable. In irrigation practice, therefore, although the reason is not always understood, the furrowing method is invariably used wherever the supply of water is low.

The nature of the crop determines, also, the method of irrigation. Some plants are more sensitive than others to contact with water. It is believed by many that the sugar beet is injured whenever irrigation water is allowed to come into contact with it, especially if the day is hot. This may be true at times, but this danger is much exaggerated. Only when water stands against a plant for some time is injury really likely, and, then, injury comes either when the water is so hot as to cause sun-scald or so cold as to chill the plant. In either case, the process 
of growth is retarded. Much work yet needs to be done on this subject.

The various modifications of the flooding method may be grouped into (1) flooding open fields, and (2) flooding closed fields. Open fields are those not surrounded by levees. Closed fields are those completely surrounded by levees, making a compartment into which water is admitted.

120. Permanent ditches.-A permanent system of ditches, having in view immediate and probably future

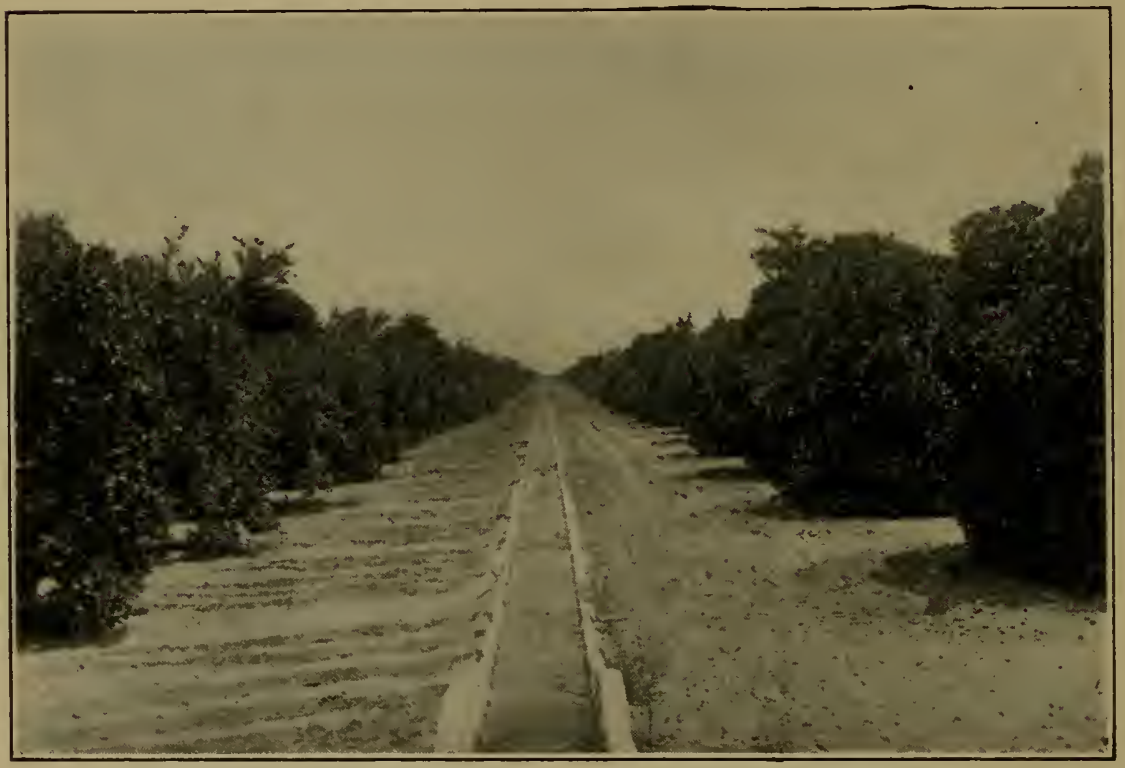

FIG. 34. A permanent ditch in an orange grove (Redlands).

needs, should be constructed on every farm, to connect the canal with the field to be irrigated. The ditches should be placed so as to interfere as little as possible with regular agricultural operations, and they should conform either to the contour of the land, or to some well defined plan for dividing the farm into fields. The laying out and 
construction of permanent ditches is the first big thing in irrigation agriculture. Great waste has occurred and is occurring because of carelessness in this matter.

The ditches, once decided upon, should be built in a permanent fashion, so that they will not need to be

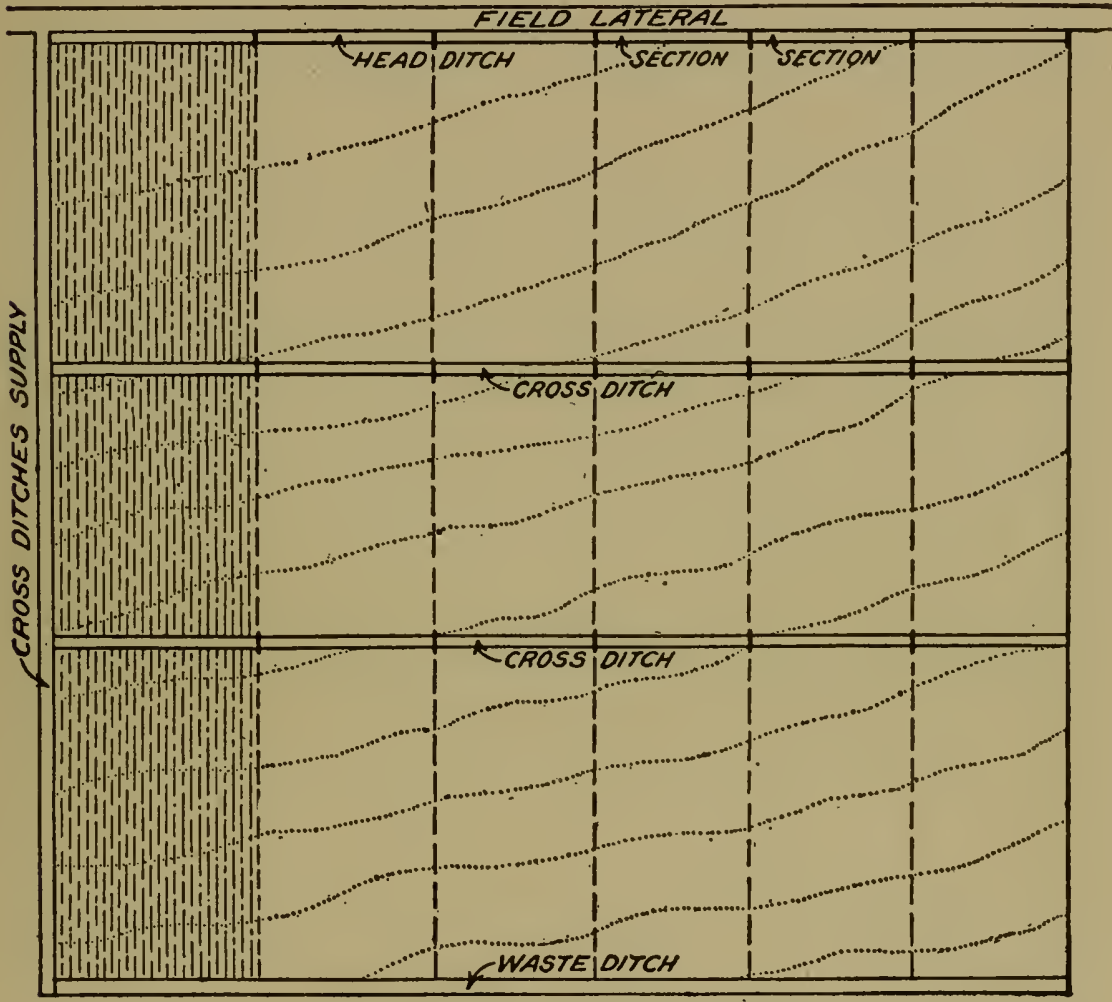

FIG. 35. Plan of field-ditch irrigation.

repaired greatly from year to year. In the older and more prosperous irrigated sections, ditches are often made of concrete and are consequently practically indestructible. The best illustration of this kind of ditch is found in California, notably in the Riverside district, where the orange groves require that water be made to do its highest duty. 


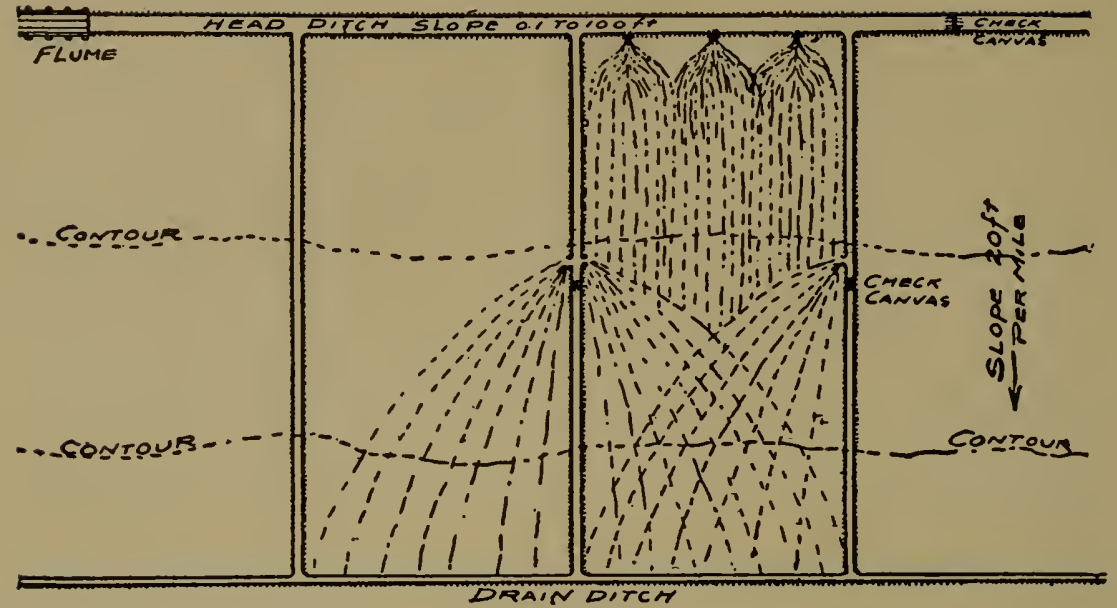

FIG. 36. Flooding from ditches running down the steepest slope.

The main permanent ditches if made of concrete, are frequently put underground, out of sight and out of the way. The water is allowed to escape through stand-pipes into the temporary ditches of the farm. The beauty and often the prosperity of the irrigated farm depend upon the permanent ditches. (Fig. 34.)

121. Field-ditch or field-lateral method.-This method,

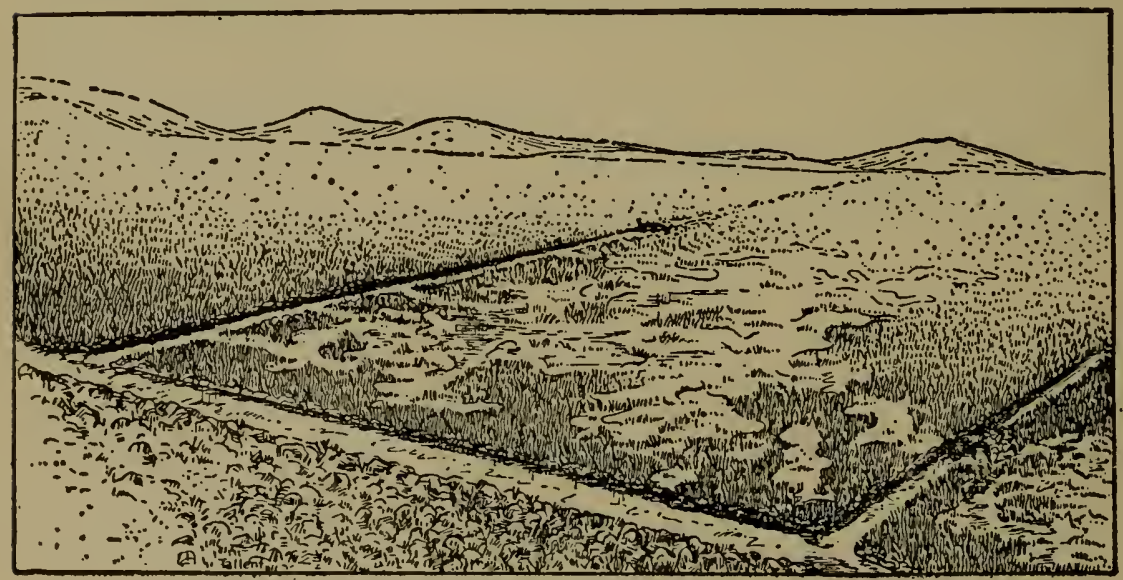

FIG. 37. Flooding from field ditch. 
which is the most largely used method of open field-flooding, is especially adapted to level lands with gentle slopes. By this method, the water is taken out of the main ditches at various intervals, and as it flows over the field, is distributed properly over the field by small temporary ditches or furrows. These small laterals follow the high

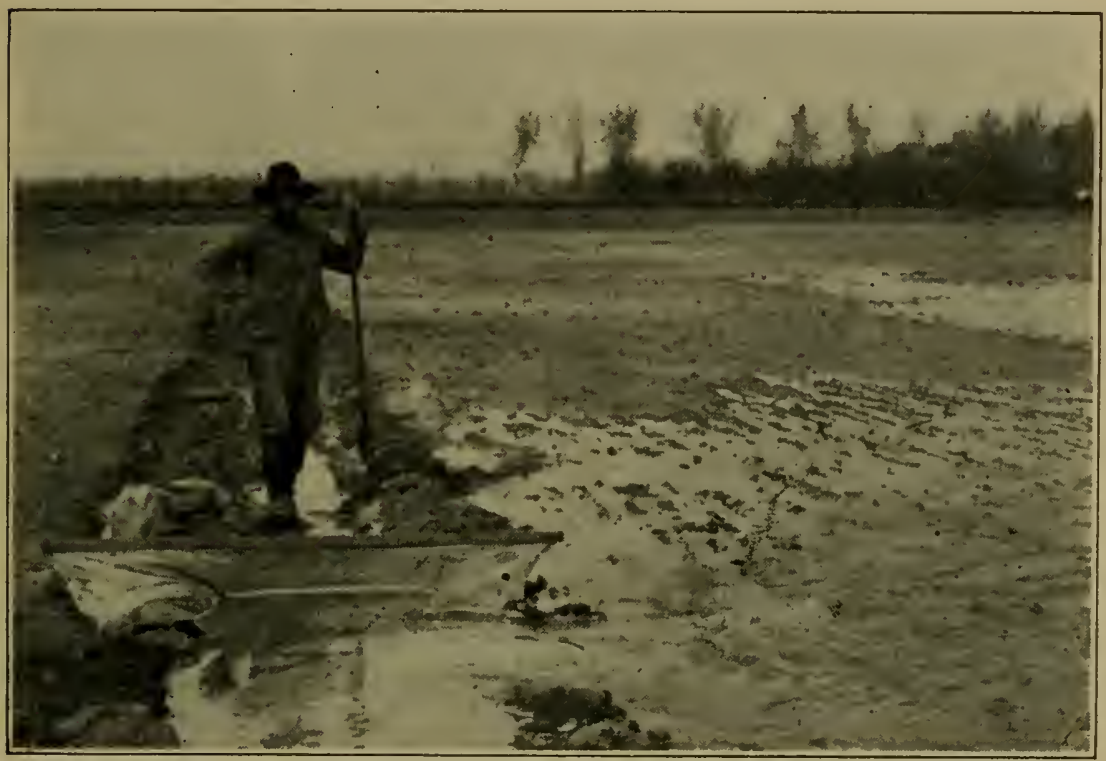

FIG. 38. Flooding with aid of canvas dam.

places of the field, and the water overflowing their banks covers the field.

For instance, wheat is planted in the usual way, without reference to the field ditches which are made after the wheat has germinated and is a few inches high. The small laterals are made with a small horse-plow made for the purpose, or they are made by the irrigator with a hoe. The field ditches of lucern and similar permanent crops, once made, remain from year to year, except that they may be deepened a little from season to season. These 


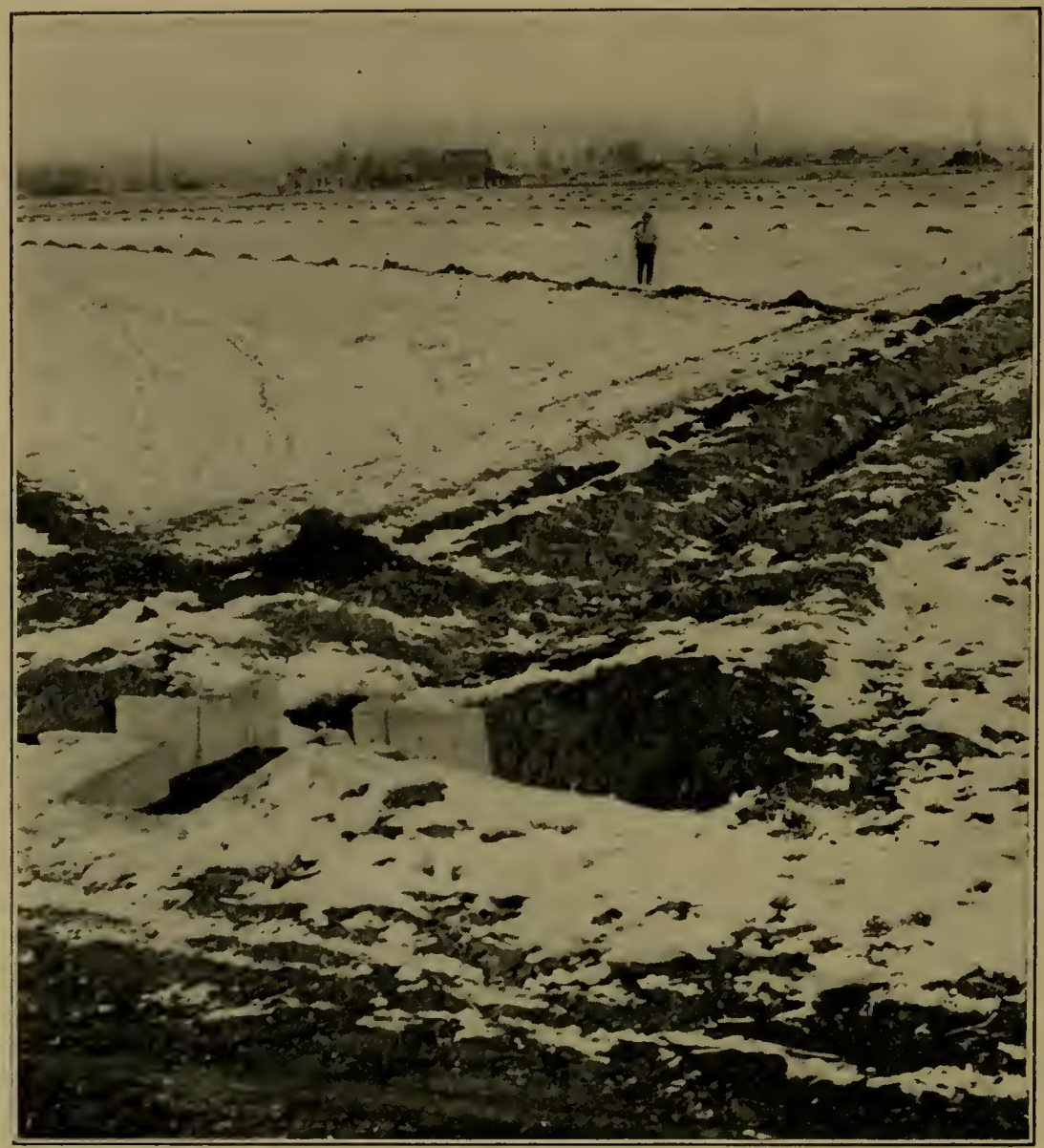

Fig. 39. Laterals made in field and dammed with small piles of manure for next year's irrigation.

field ditches, however, whether in wheat or alfalfa, are so small as to be of no hindrance in the cultural operations of the farm.

The essential feature of this method of irrigation is the guiding of the water over the land through numberless furrows or small ditches. This is hard and slow work. One man can cover daily only a few acres at most by this method. The greatest advantage of the field-ditch method 
is that the first cost of preparing the land for irrigation is small; the top soil is not disturbed, and the field is not cut up by levees that make ordinary farming operations difficult. The disadvantages are that the necessary field labor is hard; the field ditches must be made over from year to year; and, finally, it is difficult to secure an even distribution. It is clear, however, from the great extension of this method that the advantages overshadow the disadvantages. This is the method employed by the Mormon pioneers when they founded irrigation in the Salt Lake Valley and is still one of the safest methods of irrigation in Utah, Idaho, Wyoming, Colorado and some of the other irrigated states. Practically all manner of crops, except those planted and cultivated in rows, can be irrigated by this method. In spite of its disadvantages, immense yields, the largest on record, have been secured by this method of irrigation. (Figs. 35-39.)

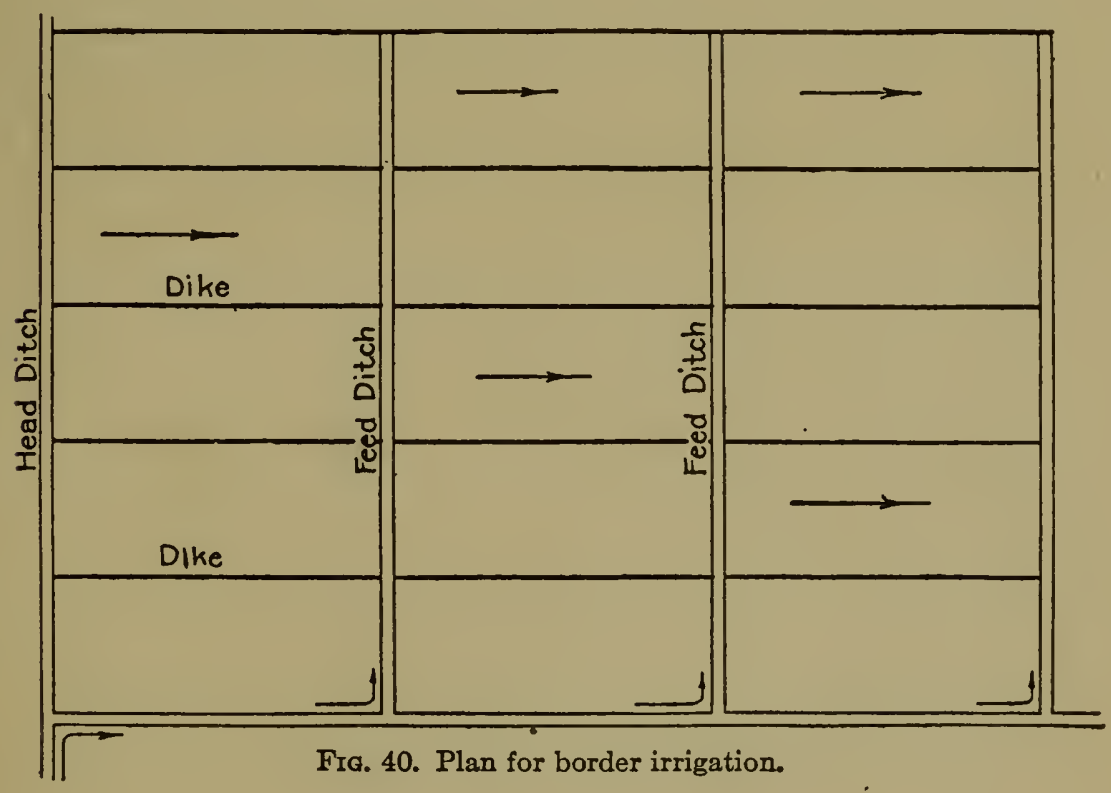


122. The border method.-The border method of irrigation is an open-field method. By this method the field is divided by low flat ridges of earth into long narrow strips, the lower ends of which are open. The ridges are spaced about 50 feet apart and are frequently 800 feet long. Water is guided over the land by field ditches. This modification of the field-ditch method has for its purpose the better control of the water. The ridges prevent the water from spreading beyond the distance determined

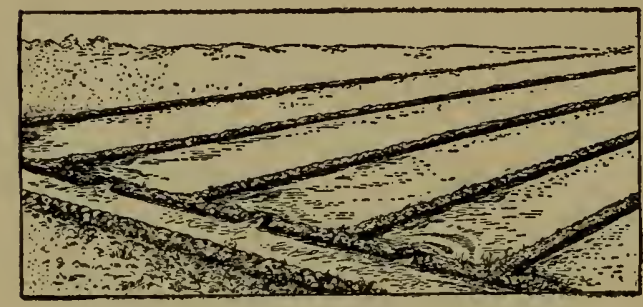

FIG. 41. Border method of irrigation. between the ridges. This enables the irrigator to watch the water more closely. When the water reaches the lower end of the strip, it may be shut off and another strip attacked. The advantages and disadvantages are, practically, those explained for the field-ditch method, except that the lateral ridges make the handling of the water somewhat easier. In cultural operations the ridges are in the way. (Figs. 40, 41.)

123. The check method.-This is the most important of the closed-field variation of applying water by the flooding method. The field is laid off into compartments or checks wholly surrounded by levees. The water is admitted at the upper end and completely fills the compartments until, in many cases, it overflows at the lowest point of the levee. This method of irrigation has been practised from the earliest antiquity. The irrigated countries of Europe, Asia and Africa employ this method very largely.

Evidently it is adapted only to comparatively level 


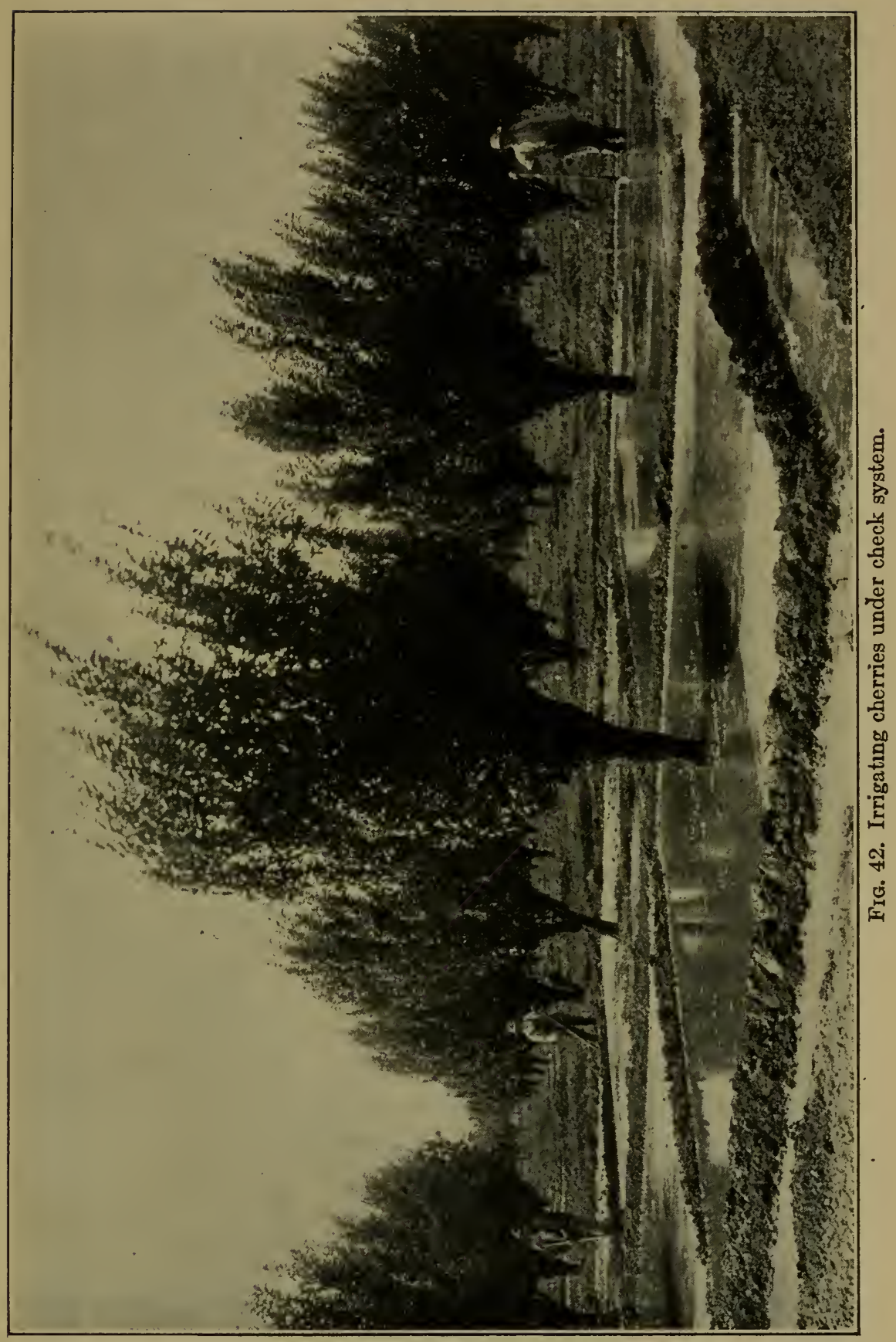


land; if the slope is great, the lower levee must be made too high for practical purposes. A large head is always necessary; for, if the head is small, the land, especially if sandy, is likely to absorb the water so fast at the upper

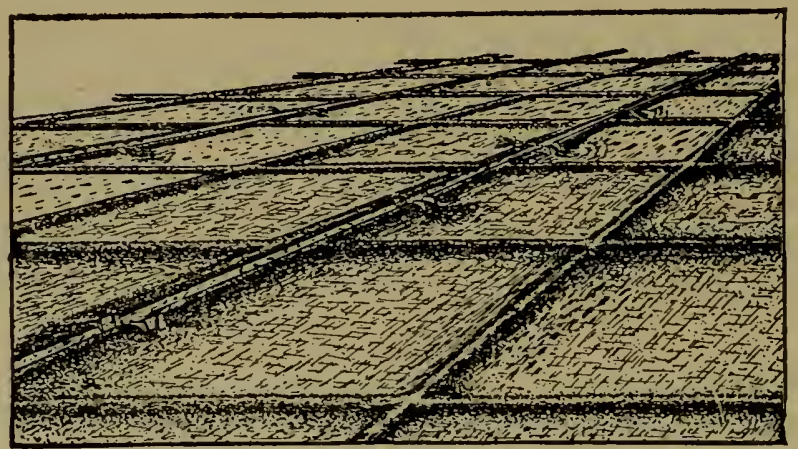

FIG. 43. Rectangular check method of irrigation.

end that the lower end receives only a small part of the water intended to cover the whole check. The flow of water should be from 5 to 10 second-feet in order to make the method thoroughly successful. In the older countries, the checks are usually small. In America, the checks are often very large-from 10 to 20 or more acres. The check method of irrigation, to be really successful, must be practised with small checks, at the most from 1 to 3 acres in area.

The compartments may be laid off in various ways. If the land does not slope too much, the whole farm is laid off into square or rectangular checks, into which the water is admitted in succession. Where the land is uneven, or the slope steep, the checks are made to conform to the contour of the land. In either case, water must be admitted at the highest point and be brought rapidly into the compartment so that the ground may be covered thoroughly and in a short time. At times a depression is 
made in the lower levee over which the excess of water passes into the next lower check.

The check method of irrigation has some advantages. Once the checks or the levees have been well constructed, one man may irrigate 7 to 15 acres a day. The cost of preparing the land for irrigation, after the first year, when the levees are made, is very small. The quantity of water applied can be very accurately gauged and evenly distributed by this method. For crops such as rice, which demand that the soil be kept moist or even submerged for long periods throughout the year, the check method of irrigation is indispensable. Such crops are few, and the check method is, in fact, used more extensively

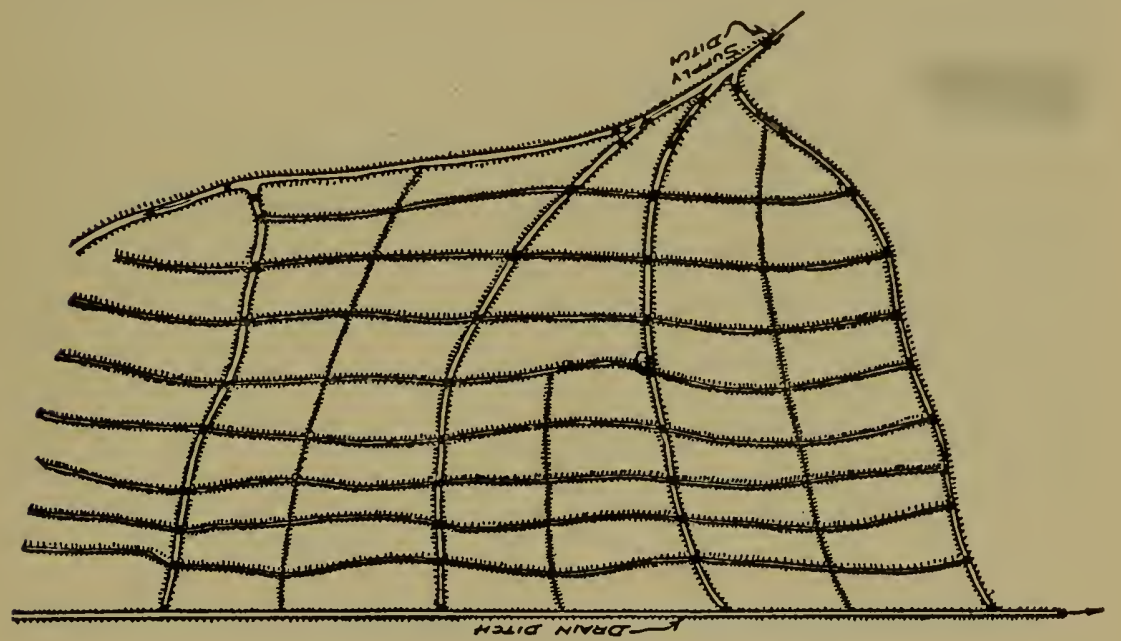

FIG. 44. Contour check method of irrigation.

for other crops. The check method of irrigation also has many disadvantages. The levees cost from $\$ 7$ to $\$ 20$ an acre, under American conditions, where the compartments are large. The cultural operations of the farm are delayed and the machinery damaged by passing back and forth over the high levees. In any case, they are in the way 
and are a disagreeable feature on the farm. The farmer finds it difficult to change to new and possibly better cropping systems, without going to the large expense of leveling the old levees and throwing up new ones. If the soil bakes, this method should not be employed at all, since water covers, for some time, the whole area. It is impossible by this method to keep water from touching

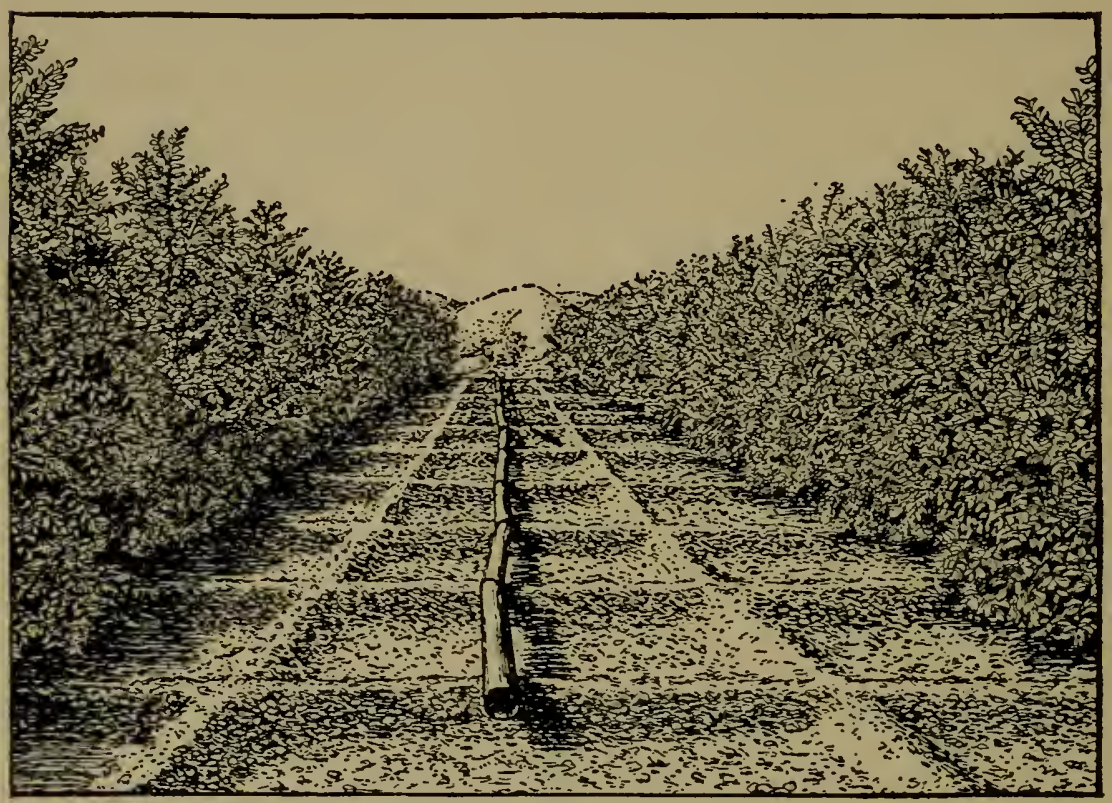

FIG. 45. Filling checks with detachable pipes.

the crop. The relatively large quantities of water that must be used by this method tend to keep the roots very near the surface, and the crop will be more intensely affected by adverse conditions of heat or cold.

The check method is, next to the field-ditch method, the most important method of applying water to crops; yet, its disadvantages overshadow its advantages, and it is a method which, in all probability, will gradually pass 
out of general use, and be retained only where crop, soil or other conditions make it necessary. (Figs. 42-45.)

124. The basin method.-The basin method is practically identical with the check method. It refers to checks in orchards with a tree in the center of each, and with temporary levees. Earth is heaped around the tree trunks to keep the water away from the

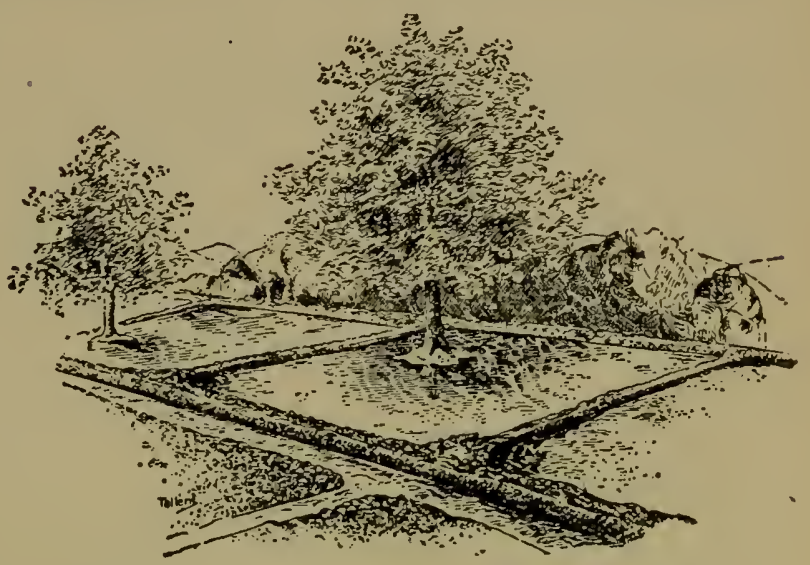

Frg. 46. Orchard irrigation by basin method. bark. This method is used especially in mild climates where fall or winter irrigation is practised. The use of this method is also rapidly decreasing, and is likely soon to pass out of practice. The advantages and disadvantages of this method of irrigation are those discussed under the check method. (Figs. 46-48.)

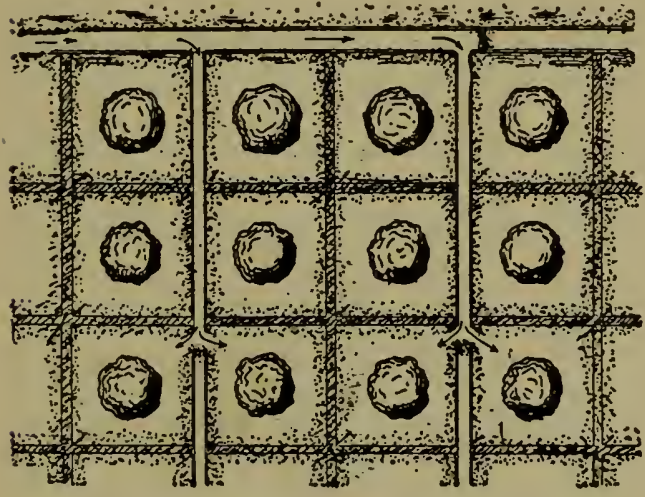

FIG. 47. Orchard irrigation by basin method.

125. The furrow method.-In this method of irrigation, small furrows leading from the supply ditch traverse the fields to be irrigated. Water flows down the furrows and is absorbed by the soil. Next to the method of flood- 
ing by field ditches, this is the most common method of irrigation, and it promises, at least in America, to supersede all other methods.

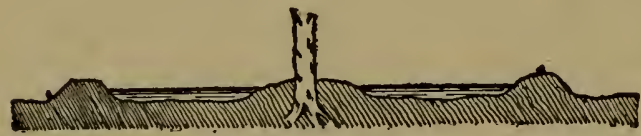

Fra. 48. Grading of interior of basins to prevent water from coming in contact with trees.
(Figs. 49, 50.)

After the crop has been planted, small furrows leading from the supply ditch at the head of the field are made to cover the field by some of the many kinds of markers or furrowers. This process of furrowing the land is known as "marking" or

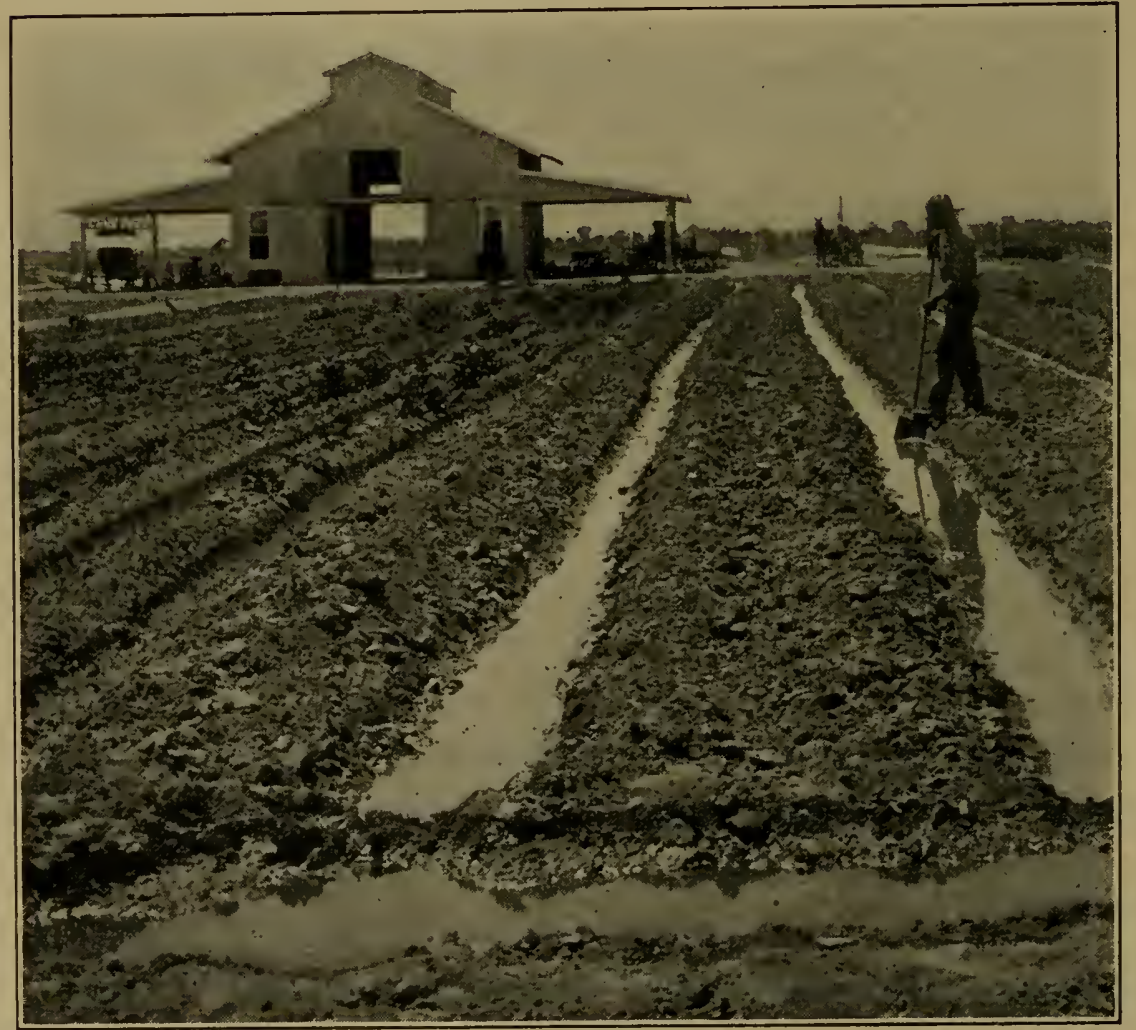

FIg. 49. Furrow irrigation. 
"laying off" the land. (Fig. 52.) The furrows are made at right angles to the supply ditch, or, if the land is irregular in contour, they are made to follow the contour lines. This is done, especially, in orchards where trees grow

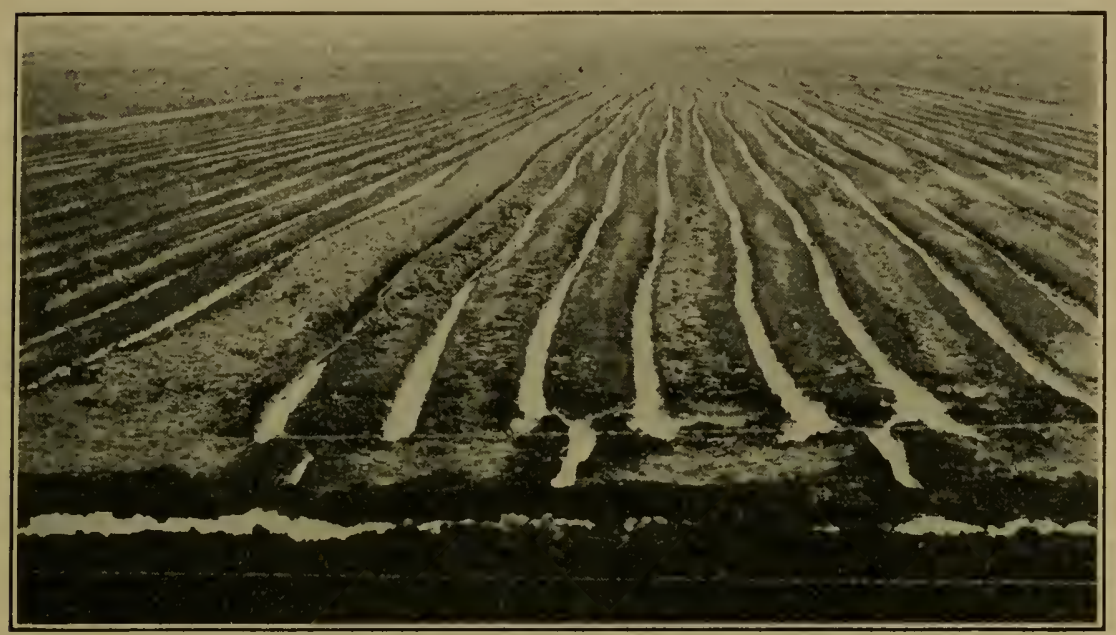

Frg. 50. Furrow irrigation of young alfalfa.

on the hillsides. It is not an uncommon sight in such districts to see thirty or forty furrows filled with water zigzagging down a hillside.

The furrows are made from year to year, except in the case of alfalfa and other perennial crops. Alfalfa, when irrigated by this method, is furrowed the first year, and the permanent furrows are only deepened or cleaned out from year to year. The disadvantage of the permanent furrows is that as the mower travels across them the rider is shaken up considerably and the machine is injured. In wheat fields, furrows are laid off soon after the wheat is planted, when it is about 3 or 4 inches high. Fields of sugar beets, potatoes and similar crops are furrowed just before the first irrigation. One furrow is ordinarily made between every two rows of plants, although on some soils 
the distance between furrows is greater. In orchards, the furrows are usually made at the time of the first irrigation. When the trees are young, one furrow is made on each side of each row, perhaps 2 feet or a little more away from the tree. As the tree becomes older and the root-system

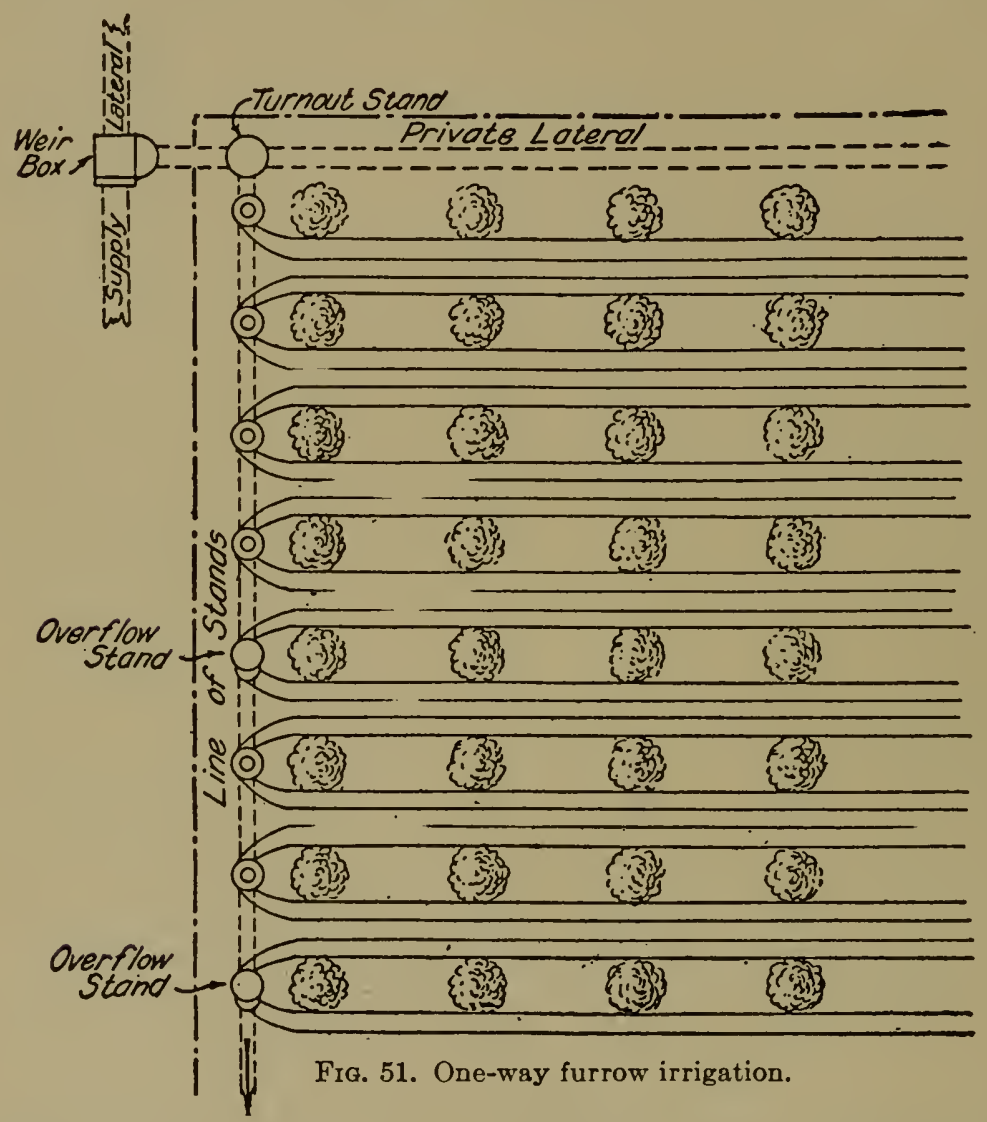

expands, the furrow is moved away from the tree until, as the tree approaches maturity and more water is needed, three or four furrows may be made between two rows of trees. The principle in spacing the furrows is that the furrows shall be so close together that the water soaking from the furrows into the soil will meet and thoroughly 
saturate the soil below the surface. In orchards where trees are 16 to 20 feet apart, one furrow cannot do this and several furrows are employed. The reason for using only one furrow when the tree is young is that the roots have not spread sufficiently to make use of water that might be applied half way between the rows of trees; and, moreover, the young tree needs little water. Fewer and

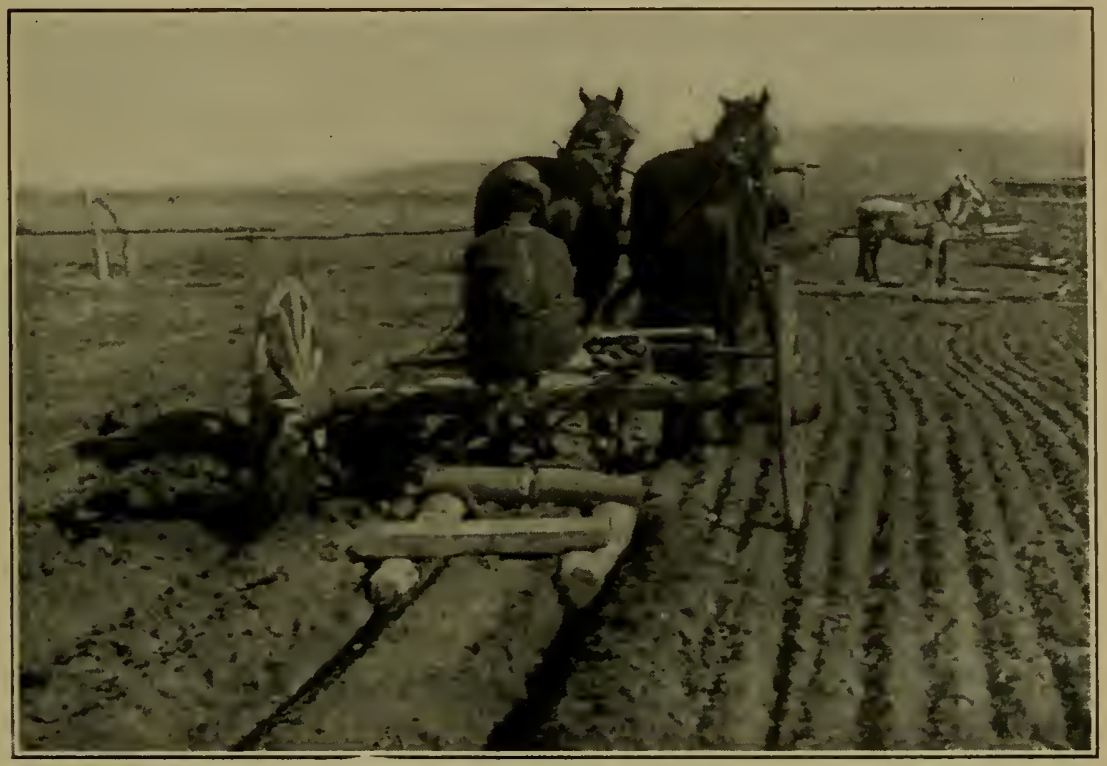

Fig. 52. Furrowing land.

deeper furrows are now generally used in the irrigation of orchards and other crops. Fortier and others have shown that the deep furrow has a decided advantage over the shallow furrow. (Figs. 51, 53-55.)

The furrow method is in many ways an ideal method of irrigation. It enables the farmer to control the quantity of water added to a soil. It makes it possible to spread a small quantity of water over a relatively large area of land. It prevents the washing and consequent destruc- 
tion of the light soils characteristic of arid regions. It reduces evaporation; tends to prevent over-irrigation, and, because of the ease with which the furrow may be covered, soon after irrigation, the rise of alkali is delayed. There is little disturbance of the top soil, and baking is

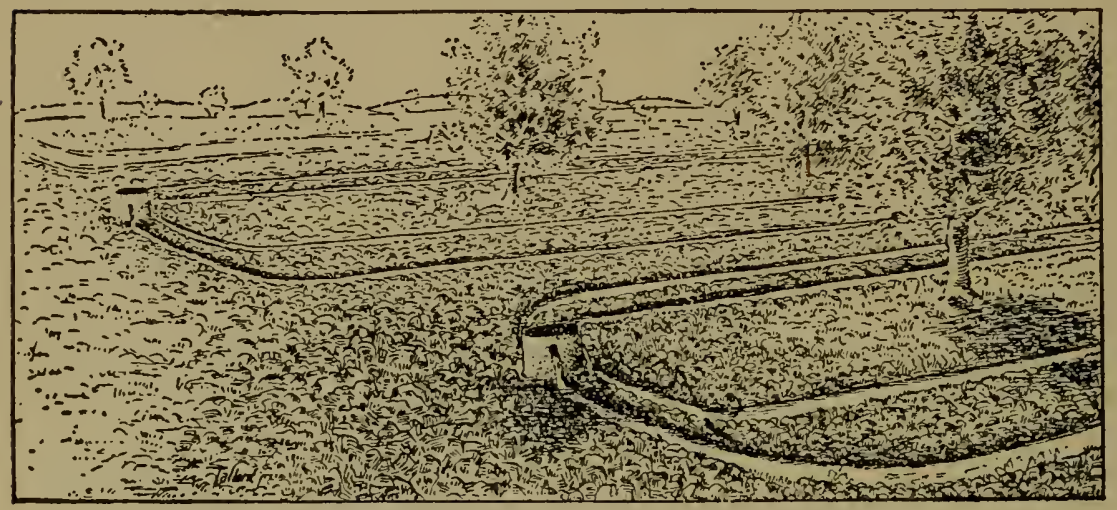

FIG. 53. Standpipe supplying furrows with water.

largely eliminated. The system once laid off requires little attention; one man can irrigate a large number of acres in one day. The method is inexpensive.

The furrow method of irrigation also has some disadvantages. Large heads of water cannot be used in the small furrows. It may be desirable, especially in the spring, to apply quickly a large quantity of water to a given field. This is practically impossible with the furrow method of irrigation. It is difficult to admit the same quantity of water to each of the many furrows. Special attention must, therefore, be given to establishing checks in the supply ditch at suitable intervals, to force, as nearly as may be, the same quantity of water into each furrow. Tubes or lath boxes, connecting the furrows with the supply ditch, are helpful in establishing a steady flow in each furrow. (Fig. 56.) The uniform use of water 
throughout the length of the furrow is very difficult. On sandy soils, especially, the upper end of the furrow absorbs so much water that little is left for the lower end. In fact, when the furrow is long, it frequently happens that the water disappears before the lower end is reached. The best way to overcome this difficulty is probably to shorten the furrows, and to have a series of temporary supply ditches for each series of furrows.

Finally, the soil is benefited by being occasionally covered with water. The Utah work showed that, with a given quantity of water, as large yields were invariably obtained when the water was applied by flooding as by furrowing, in spite of the greater loss by evaporation

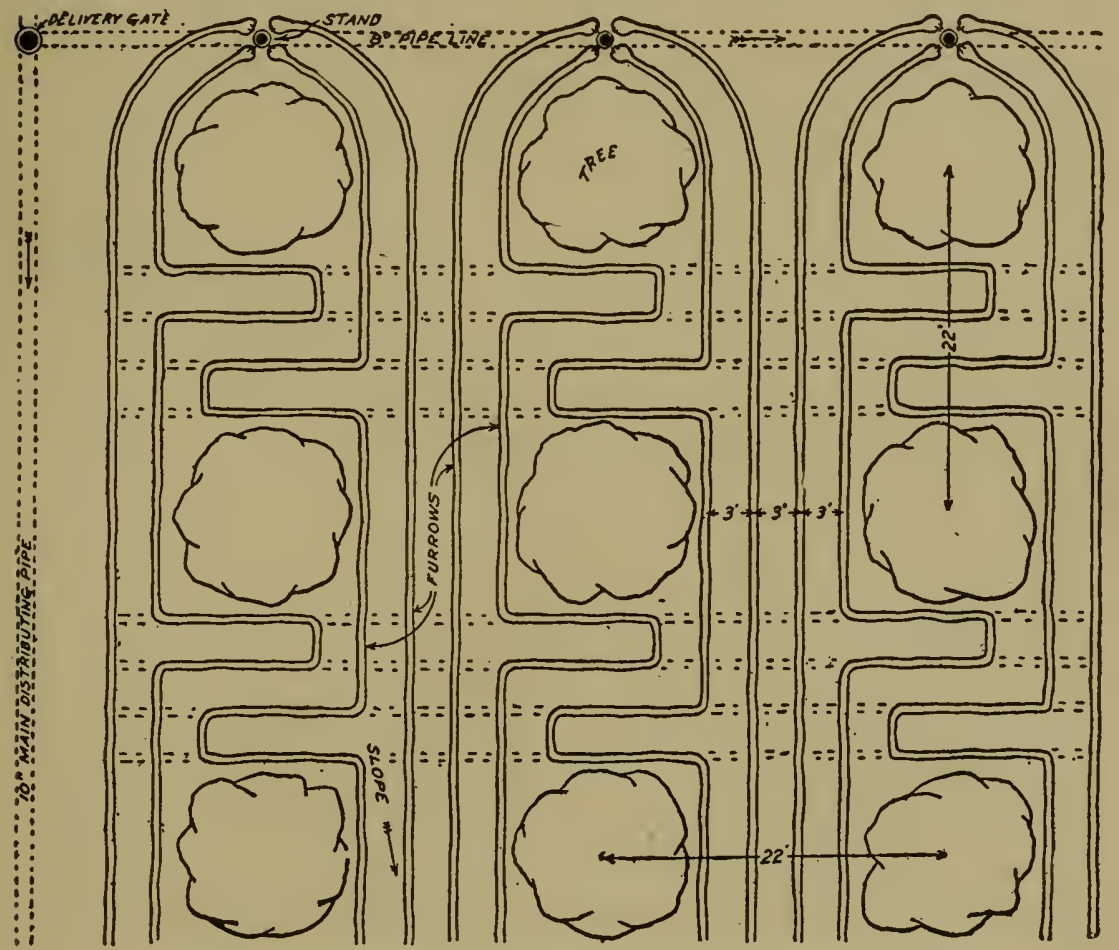

FIG. 54. Zigzag furrows to insure uniform distribution over soil. 
under the flooding method. It may be well, therefore, to allow the water to overflow occasionally even under the
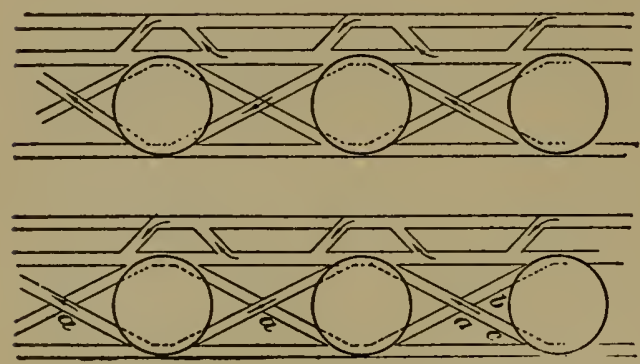

Fig. 55. Another type of zigzag furrows. furrow method of irrigation. The same effect may be obtained in part by placing the furrows differently from year to year. Meanwhile, the furrow method, with a given quantity of water, will yield as heavily as will the flooding method, and may yield more.

126. Summary.--In brief, there are, in practice, only two great methods of irrigation: (1) flooding by field ditches, and (2) furrowing. The field-ditch method is in reality a furrowing method, in which the water overflows the banks of the furrows. On certain soils and under certain conditions the fieldditch method will be found most serviceable; on others, the furrowing method. The closed field

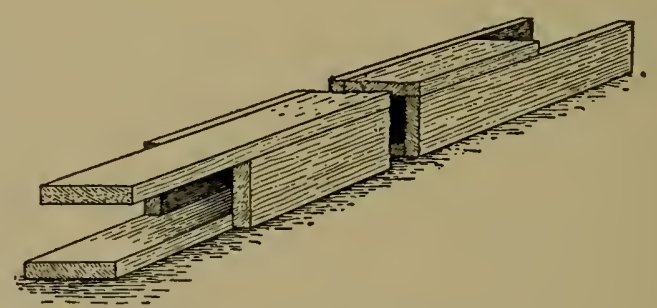

FIG. 56. Lath-box for distributing water to furrows from head ditch.

methods are likely to vanish quite rapidly because of the large expense of installation and the want of elasticity in the system. The method of irrigation by furrows will probably triumph as the great method of applying water to soils for the production of crops. At the present time the field-ditch and the furrowing methods are in chief use. 


\section{REFERENCES}

Fortier, Samdel. Methods of Applying Water to Crops. United States Department of Agriculture, Yearbook for 1909, p. 293. Fortier, Samuel, and Beckett, S. H. Evaporation from Irrigated Soils. United States Department of Agriculture, Office of Experiment Stations, Bulletin No. 248 (1912).

Loughridge, R. H. Distribution of Water in the Soil in Furrow Irrigation. United States Department of Agriculture, Office of Experiment Stations, Bulletin No. 203 (1908).

Mead, Elwood, et al. Preparing Land for Irrigation and Methods of Applying Water. United States Department of Agriculture, Office of Experiment Stations, Bulletin No. 145 (1904).

Wickson, E. J. Irrigation Among Fruit-Growers on the Pacific Coast. United States Department of Agriculture, Office of Experiment Stations, Bulletin No. 108 (1902).

Widtsoe, J. A. Factors Influencing Evaporation and Transpiration. Utah Experiment Station, Bulletin No. 105 (1909).

Widtsoe, J. A., and Merrill, L. A. Methods for Increasing the Crop-Producing Power of Irrigation Water. Utah Experiment Station, Bulletin No. 116 (1912). 


\section{CHAPTER XI \\ CROP COMPOSITION}

Crops have been valued almost entirely by weight. A bushel of wheat has been a bushel of wheat, providing it weighed sixty pounds. Of late years it has been determined that the quality may be as important as the quantity in determining the value of a crop as a food for man or beast. The time is undoubtedly near when crops will be judged in the markets by quality as well as by quantity.

Many agricultural industries already make significant use of quality valuation. Sugar-beet factories purchase beets at a given price a ton, but the price is conditioned on the sugar content, and the contracts with the farmers always specify a minimum percentage of sugar. Potatoes, when made into starch are valued on the basis of starch content. Grains are graded by quality. Fruits are classed according to color, size and other characteristics. Many other crops are likewise valued according to composition as well as to actual weight.

As knowledge concerning food and its relation to the animal body becomes popularized, there will be an increasing demand for foods of definite composition which will affect the world markets until a scale of prices based on weight and composition shall be established for each crop. In that day, the irrigation farmer will have a great advantage, for the regular variation of plant composition with the quantity of water applied makes it possible under the controlled water supply of irrigation to regulate in a 
measure the quality of the crops produced. Irrigation, or the artificial application of water to crops, requires added labor. It is, therefore, only upon the basis of certain and larger yields, and better quality of the crops produced, that irrigated areas may compete in the open markets with other sections of the world.

The relation between irrigation and crop composition has been studied by several investigators. In general, it has been shown that many irrigated crops may be made to possess a composition superior to that of crops grown under the natural rainfall. Yet, it must be admitted that we know the merest outlines of the subject. There is here a great and important field open for investigation by those who are interested in developing a science of irrigation

127. Groups of plant constituents.-Every plant contains five great groups of substances and each has a definite food value and bears important relationships to the soil on which the plant has been grown. These are: (1) water, (2) ash or mineral matter, (3) nitrogenous substances, (4) fats, and (5) carbohydrates.

128. Water.-During the life of the plant, large quantities of water are passed rapidly from the soil into the plant, and from the plant leaves into the air. As has been shown, hundreds of pounds of water are thus passed through the plant for the production of one pound of dry matter. That the vital processes of the plant may proceed unhindered, the cells of the green plant must be fully filled with water. The more water is in the soil, the more completely are the plant cells filled with water. That is, on a moist soil, under conditions of abundant irrigation, the green plant probably contains a larger proportion of water than on dry soils, where the quantity of irrigation 
water applied is small. This effect is felt most in the stalks of plants. In the leaves, which naturally contain less water than do the stalks, the effect of varying quantities of water is not so apparent; but the water content of every part of the plant is somewhat affected by the water supply. The underground parts of plants, such as potatoes and sugar beets, contain usually a slightly larger percentage of moisture, when grown on land abundantly irrigated.

Since most crops are not sold green, this effect of irrigation has little commercial value. True, in the case of fruits, tomatoes and similar crops, which are usually disposed of in an undried condition, the increased percentage of water in crops grown with much water may make considerable difference in the final weight. Potatoes and sugar beets, when irrigated heavily and late, may weigh more per acre, but the increased yield is obtained only at the sacrifice of quality. In most cases the difference is so small as to be negligible.

The water content of hay, grain and other crops that are sold after thorough curing or ripening, is not influenced by the irrigation during growth. However, hay, cured under the dry conditions of the arid region, contains less water and is to that extent more valuable than hay cured in the humid regions. Likewise, the water content of wheat and similar crops that ripen before harvesting is only slightly influenced by the degree of irrigation; but the dry conditions of the arid region tend to yield crops containing less water than when grown under humid conditions. In short, irrigated crops of the arid region, that are dried before being placed on the market, are more valuable, pound for pound, than those grown in humid regions, for the reason that under humid conditions the 
drying-out cannot be so complete. Stewart has shown that this difference may have very noticeable financial results when large shipments of grain are made from the arid regions.

129. Ash.-The ash, or incombustible portion of plants, represents, roughly, the food taken from the soil by the plant. It is, therefore, important in considering the maintenance of soil fertility. The effect of much or little soil moisture upon the quantity of ash taken up by the plant has been investigated by many students. In general, the percentage of ash in the dry substance becomes larger as the quantity of irrigation water or the soil moisture increases. The following table shows some typical results under irrigated conditions:

\begin{tabular}{|c|c|c|c|c|c|c|}
\hline \multirow{2}{*}{\multicolumn{2}{|c|}{$\begin{array}{l}\text { Degree of } \\
\text { irrigation }\end{array}$}} & \multicolumn{5}{|c|}{ Percentage of ash in dry matter of } \\
\hline & & $\begin{array}{c}\text { Oat } \\
\text { leaves }\end{array}$ & $\begin{array}{l}\text { Oat } \\
\text { stalks }\end{array}$ & $\begin{array}{l}\text { Oat } \\
\text { heads }\end{array}$ & $\begin{array}{l}\text { Sugar } \\
\text { beets }\end{array}$ & $\begin{array}{l}\text { Potato } \\
\text { tubers }\end{array}$ \\
\hline Large . . & & 21.10 & 8.68 & 6.38 & 6.15 & 3.36 \\
\hline Medium . & 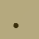 & 19.57 & 7.72 & 6.03 & 6.02 & 3.89 \\
\hline Small . . & . & 17.13 & 7.27 & 5.29 & 6.18 & 4.39 \\
\hline
\end{tabular}

As the supply of water increases, there is usually a very marked increase in the percentage of ash in the leaves, a smaller increase in the stalks, and a yet smaller increase in the underground parts of the plant. This relative variation among the plant parts seems to be a general rule, although observations are on record showing a decrease in the percentage of ash in the underground parts as the irrigations are made larger.

Tollens and others have shown that, in general, this law of increase is true for each ash constituent as for the total ash. Lime is taken up very abundantly by the plant 
as the supply of water increases; and potassium, phosphorus, and other important plant-foods are likewise taken up in larger proportion to the dry matter as the supply of water is increased.

This law, that the percentage of ash in plants increases as the irrigation water is increased, means, apparently, that more plant-food is used to produce a unit of dry matter as more water is used in irrigation. This is one of the strongest arguments yet found against the excessive use of water. The farmer who uses a small quantity of water in crop-production not only obtains a larger amount of dry matter for each unit of water used, but also uses a smaller quantity of plant-food for each unit of dry matter. The waste due to over-irrigation is, therefore, at least twofold: it diminishes the yield of dry matter to the unit of water used, and it increases the soil-fertility cost per unit of dry matter. This must be a fundamental consideration in the establishment of a permanent system of agriculture under irrigation.

130. Protein.-Protein is the term commonly applied to all organic plant substances containing nitrogen. These nitrogenous plant constituents are of greatest importance in the maintenance of animal life. When organized into proteid forms, they form the basis of blood, muscles and all other primary tissues of the animal body. In fact, as a food for animals, the value of a crop may be well measured by its percentage of nitrogenous substances. The compounds containing nitrogen are not, however, all of equal value. Some furnish merely body heat, while others enter into the fundamental structures of the body. In the investigations of the effect of irrigation on plant composition, attention has been given mainly to the group of substances under the name "protein," and little knowl- 
edge exists concerning the variations of the individual compounds occurring under this general head.

The percentage of protein in plants is very sensitive to irrigation. The more water used, the smaller is the percentage of protein in the resulting plant. This is almost invariably true. In the following table is given the percentage of protein in several crops, when small, medium or large quantities of water were used in the production of the crop.

Percentage of Protein in Dry Matter with Varying Degrees OF IRRIGATION

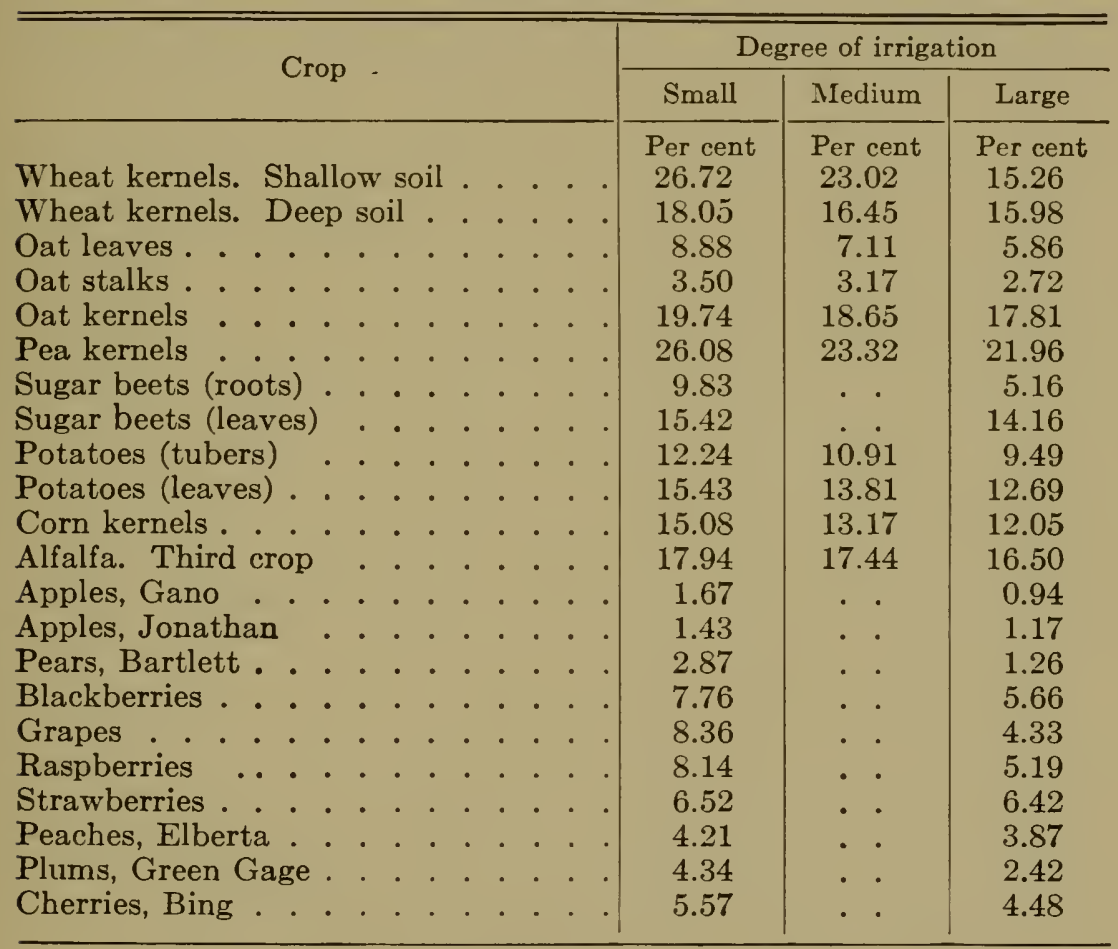

Every crop in the table, even apples, pears and small fruits, shows a diminishing percentage of protein with an increasing volume of irrigation water. The law is 
undoubtedly of very wide application. In the above table, the percentage of protein in plant parts is also given. In general, the percentage of protein is diminished in every part of the plant when the irrigation is increased. The little existing knowledge indicates that the proteid parts of protein, used in the production of blood and muscle, are affected by varying irrigations, even more strongly than is the protein, and in the same direction. Some little work has also been done upon protein digestibility as affected by irrigation; and it seems safe to assert that when crops are grown with increasing quantities of water there is a decreasing percentage of digestible, nitrogenous substances in the plant. It is clear, therefore, that plants and plant parts are more valuable as animal foods, pound for pound, when grown with little water.

The quantity of nitrogen taken up by a crop is not, however, largely affected by irrigation. Whether the crop has received much or little irrigation water during the period of growth, the total quantity of protein that it contains per acre is approximately the same. For most crops the tendency is for the total yield of protein to increase with much irrigation, though the percentage decreases.

The compounds of nitrogen from which protein is made, are taken, as is the ash previously discussed, by the roots from the soil. It would be expected, therefore, that the protein should vary as does the ash content. Instead, the variation is the opposite. Nitrogen is present in the soil in relatively small amounts, and, in its soluble and available forms, in even smaller amounts. Nitrification and similar processes which convert the organic nitrogen into forms available to plants go on at 
a slow rate. In the spring and early summer when the demand of the young plant for protoplasmic material is greatest, the relatively small quantities of available nitrogen in the soil, accumulated since the last harvest, are eagerly and quickly absorbed. From then on, the small supply of nitrogen is that made available by nitrification and similar processes. Moreover, after the protoplasmic materials have once been made, it is doubtful if the plant's demand for nitrogen continues unabated.

The protein in the plant is thus obtained in the early stages of growth. Carbon assimilation, however, continues until the period of ripening, and the more water used the more dry matter produced. In any case, after the first periods of growth, dry matter is formed more rapidly than protein. Consequently, the percentage of protein in the dry matter decreases as the plant grows older and as more water is used. This seems to be the simplest explanation of the important law that the larger the irrigation, the smaller the percentage of protein in the dry matter produced by plants.

Whatever explanation may be found for this law, the fact remains that the decreasing percentage of protein with increasing irrigation is another strong argument in favor of the use of little water in the production of crops under irrigation.

131. Fat.-The quantity of fat in plants, except in the few crops especially grown for their fat content, is so small as to be of little consequence. Little is known of the effect of irrigation on the content of fat in plants. The more water used in irrigation, the larger, usually, the percentage of fat in the plant. This, however, is subject to revision as more knowledge concerning the matter is obtained. 
132. Carbohydrates.- The substances included in this group are used in the animal body for the production of heat and the formation of fat. The carbohydrates are very important foods; but, since they are quite abundant, they are of less value than the protein. The elements constituting the carbohydrates are drawn from the water of the soil and the carbon dioxide of the air, both of which are more easily supplied than the ash or the nitrogen, the essential element in protein. For agricultural purposes it is necessary to consider under the head of carbohydrates the sugars, starches, and the woody substances or crude fiber. It has been well established that the percentage of total carbohydrates in a plant increases as the quantity of irrigation water increases. That is, the percentage of the sum of all the carbohydrates varies in the opposite direction from protein, as the quantity of irrigation water is varied.

133. Sugars.-The sugars are many. The best known is beet or cane sugar. As a general though not an invariable rule, the percentage of sugar in a crop decreases as irrigation water increases. In the following table are presented a number of data secured by Jones and Palmer, in a study of fruits grown in Idaho. In the one column is the composition of irrigated, in the other of non-irrigated fruits. The locality in which these fruits grew receives a rather large rainfall, and the conditions are not those prevailing under true arid conditions. The non-irrigated crops may, therefore, really be compared to those that have received a small irrigation, and the irrigated crops to those that have received a heavy irrigation: 
Percentage of Total Sugar and Acids in Dry Matter

\begin{tabular}{|c|c|c|c|c|c|c|c|}
\hline \multirow{2}{*}{\multicolumn{2}{|c|}{ Crop }} & & & \multicolumn{2}{|c|}{ Total sugar } & \multicolumn{2}{|c|}{ Acids (as $\mathrm{H}_{2} \mathrm{SO}_{4}$ ) } \\
\hline & & & & Irrigated & Non- & Irrigated & Non- \\
\hline Cherries, Bing . . & & & & 49.10 & 53.08 & 3.48 & 2.55 \\
\hline Peaches, Crawford & & & & 59.91 & 65.12 & 3.63 & 3.90 \\
\hline Plums, Green Gage & & & & 48.20 & 35.17 & 4.05 & 7.05 \\
\hline Prunes, Italian & & & & 37.28 & 48.31 & 4.12 & 3.63 \\
\hline Apples, Gano . & & & & 63.55 & 61.70 & 1.97 & 1.50 \\
\hline Apples, Jonathan & & & . & 64.05 & 63.25 & 2.30 & 2.32 \\
\hline Blackberries . & & & . & 43.72 & 23.85 & 3.22 & 5.28 \\
\hline Dewberries . . & & . & . & 37.37 & 34.52 & 3.05 & 7.18 \\
\hline Grapes, Delaware & & & . & 45.41 & 43.26 & 2.79 & 3.16 \\
\hline Loganberries . . & & & . & 38.89 & 30.22 & 8.19 & 13.47 \\
\hline Strawberries & & . & . & 42.69 & 36.35 & 5.88 & 4.95 \\
\hline
\end{tabular}

Cherries, peaches, and prunes contained most sugar and least acids when receiving small irrigations. That is, these fruits became more sour as more water was used, On the other hand, plums, apples, grapes, loganberries and strawberries became sweeter as the irrigation water. was increased. Much work is yet to be done before we shall know the full truth regarding this matter. Meanwhile, from practical experience it is safe to predict that it will be found that the moderate irrigation of fruit orchards will produce the sweetest fruit.

Investigations have been made, also, on the effect of irrigation on the percentage of sugar in sugar beets. Up to a certain low limit the percentage of sugar increases as irrigation increases. When excessively large quantities of water are used, there may be a decided increase in sugar. With small and medium applications the differences in the percentages of sugar are relatively small. This is shown in the following table, which contains average results of many years' experimentation by the Utah Station: 


\begin{tabular}{c|c|c}
\hline \hline $\begin{array}{c}\text { Inches of irrigation } \\
\text { water applied }\end{array}$ & $\begin{array}{c}\text { Per cent sugar } \\
\text { in juice }\end{array}$ & $\begin{array}{c}\text { Per cent purity } \\
\text { in juice }\end{array}$ \\
\cline { 2 - 3 } 10 & 15.33 & 80.46 \\
20 & 15.13 & 81.09 \\
35 & 15.41 & 79.54 \\
\hline
\end{tabular}

When the water used was increased from 10 to 35 inches, there was increase of less than one-tenth of 1 per cent of sugar and a difference of only about 1 per cent in the purity of the juice. Moderate irrigations are undoubtedly quite as satisfactory as larger ones in producing beets with a high percentage of sugar. Potatoes and other crops yielding much sugar, contain the highest percentages of sugar when medium quantities of water are used. In general, sweeter crops are produced by moderate than by either very small or very large irrigations.

134. Starch.--Starch, one of the important foods of man, is found generally in plants. In potatoes, sugar beets and similar crops it is a chief constituent. In the dry matter of sugar beets the percentage of starch increases very rapidly with the increase in irrigation. That is, where large quantities of water are applied to sugar beets, much of the sugar is rapidly converted into starch. This is another argument against the use of large quantities of water in irrigation. In the dry matter of potatoes, grown largely for starch, the percentage of increase in starch, due to increasing irrigation, is much slower. In general, the starch content increases as irrigation increases.

135. Woodiness.-The woody material or crude fiber of plants, made up largely of cellulose, is of little value as a food. It is influenced very strongly by irrigation water. As the irrigation water applied to a crop increases 
the crude fiber remains practically constant in the leaves, increases rapidly in the stalks, and increases slowly in the underground parts. In hay crops the increase is not great so long as moderate quantities of water are applied, but when excessive quantities are applied, the crude fiber in all crops increases very rapidly. Woody crops are usually the result of over-irrigation.

136. Color and flavor.-It is the general experience that lightly irrigated crops have the best color. Apples or peaches, grown with moderate quantities of water, are highly colored, while those receiving large quantities of water are of a paler color. Under conditions otherwise the same, the difference is not great, unless an excessive quantity of irrigation water be applied. The flavor of fruits is usually better when medium quantities of water are used. In some crops, as wine grapes, this is of great importance. The flavor of the grape is transferred to the wine, and often determines the value of the beverage. When the irrigation water used is insufficient to produce a commercial crop, it often happens that small quantities of splendidly flavored fruit are obtained. In practice, the best' color and flavor are obtained when moderate quantities of water are used in irrigation.

137. Flour.-The composition of the wheat kernel is strongly affected by irrigation. Much water produces a soft wheat; little water a hard wheat. High protein wheat is obtained with small irrigations; low protein wheat with large irrigations. This difference in the composition of the original kernel is transferred to all milling products of the wheat-bran, shorts and flour. For instance, in flour made from wheat grown with much water, there was 12.63 per cent of protein; with a medium amount of water, 12.92 per cent, and with no irrigation water, 13.62 
per cent. Similar variations were found in all the essential characters of the flour. Unquestionably, since millers demand hard and high protein wheat, the time is near when grain grown with much irrigation water will not be considered for flour-production on the markets of the world. Irrigated sections that still produce grain for flour should govern their irrigation practices in accordance with the needs of millers.

138. Cooking value.-While very little definite information on the subject exists, it is fairly certain that the cooking value of fruits, vegetables and other crops is affected by the quantity of water used in irrigation. In one reported experiment, it seemed that potatoes grown with a medium quantity of water were whiter and mealier than were those grown with more water. Similarly, the flavor of vegetables is changed by the quantity of water used in irrigation. This is a very interesting field for investigation, especially by those interested in the food branch of home economics.

139. Effect of cultural treatment.-It is evident from this discussion that the more moisture there is in the soil the higher the percentage of ash, carbohydrates and crude fiber, and the lower the percentage of protein. Any cultural treatment which results in maintaining more moisture in the soil during the growing period would, therefore, have the same effect as if more water had been added to the soil. The thorough cultivation of the soil to prevent evaporation conserves the moisture in the soil. In the Utah work, it was found that the percentage of protein was lower in crops grown on well-cultivated soils than in those grown on soils receiving little or no cultivation., Under the furrow method of irrigation, the percentage of protein in the resulting crop was somewhat 
higher than under the flooding method. However, the composition of the crop showed the greatest sensitiveness to cultural methods in the matter of the time of applying irrigation water. Some of the results obtained are shown in the following table:

\begin{tabular}{c|l|c}
\hline \hline $\begin{array}{c}\text { Inches of } \\
\text { irrigation water } \\
\text { applied }\end{array}$ & \multicolumn{1}{|c|}{ Time of application } & $\begin{array}{c}\text { Per cent protein } \\
\text { in dry matter } \\
\text { of grain }\end{array}$ \\
\hline 3.5 & At usual time. & 21.75 \\
3.5 & Later at time of "filling out." & 18.84 \\
7.5 & Two irrigations $(5.0 ; 2.5)$ & 17.81 \\
7.5 & Two irrigations $(2.5 ; 5.0)$ & 16.65 \\
7.5 & Two irrigations $(3.75 ; 3.75)$ & 16.21 \\
10.0 & Two irrigations $(7.5 ; 2.5)$ & 17.17 \\
10.0 & Two irrigations $(2.5 ; 7.5)$ & 16.40 \\
10.0 & Two irrigations $(5.0 ; 5.0)$ & 16.01 \\
\hline
\end{tabular}

Clearly, the response of the composition of the crop to the time of application is greatest when the total quantity of water used is small. It seems to be the invariable rule that when the greater part of the water is applied early in the season, the percentage of protein is highest. On the other hand, when the distribution is such that the percentage of moisture remains constant throughout the growing season, the percentage of protein falls. When water is so applied that a high moisture period is followed by a low moisture period, the protein percentage increases. A more complete examination of this subject might go far in determining the time at which water should be applied. It offers an alluring field of experimentation for those engaged in irrigation study.

The time at which grain is planted also helps to determine the composition of grain. When planted in 
the fall, it grows partly in the fall, freezes down, and then grows again early in the spring, before the spring wheat is planted. Fall wheat has, therefore, a longer growing period than has spring wheat, and there is more water available for fall than for spring wheat. Consequently winter wheat contains a smaller percentage of protein than does spring wheat. In an experiment continued eight years, it was found that fall-sown wheat contained 15.75 per cent of protein, whereas spring-sown wheat contained 16.85 per cent of protein. Similar differences have invariably been found when contrasting springgrown and fall-grown grain.

\section{REFERENCES}

Jones, J. S., and Colver, C. W. The Composition of Irrigated and Non-Irrigated Fruits. Idaho Experiment Station, Bulletin No. 75 (1912).

Le Clenc, J. A. A Comparison of Irrigated and Non-Irrigated Wheat. United States Department of Agriculture, Yearbook for 1906, p. 199.

Lewis, C. J., Kraus, E. J., and Rees, R. W. Orchard Irrigation Studies in the Rogue River Valley. Oregon Experiment Station, Bulletin No. 113 (1912).

Stewart, Robert and Hirst, C. T. Comparative Value of Irrigation and Dry-Farming Wheat for Flour-Production. Journal of Industrial and Engineering Chemistry, Vol. IV, No. 4, April, 1912.

Tollens, B. The Ash Constitutents of Plants. Experiment Station Record, Vol. XIII, Nos. 3 and 4.

Widtsoe, J. A., and Stewart, Robert. The Chemical Composition of Crops as Affected by Different Quantities of Irrigation Water. Utah Experiment Station, Bulletin No. $120^{\prime}$ (1912).

Widtsoe, J. A., and Stewart, Robert. The Effect of Irrigation on the Growth and Composition of Plants at Different Periods of Development. Utah Experiment Station, Bulletin No. 119 (1912). 


\section{CHAPTER XII \\ THE USE OF THE RAINFALL}

RAIN falls upon the whole surface of the earth Where there is much rain, the country is called humid; where there is little rain, the country is called arid. Humidity and aridity are conditions that depend, primarily, upon the water that falls from the heavens as rain or snow, although where water-dissipating factors, such as winds and shallow soils, are small, a low rainfall may be more effective than a high rainfall where these factors are large. Growing plants require large quantities of water. Some of this necessary water evaporates directly from the soil; another part evaporates from the leaves of the plant; some water may be lost, also, by seepage through the soil. Unless there is enough water in the soil, it is impossible for plants to thrive and to yield sufficient returns to the farmer. Irrigation is the art whereby the deficiency in the natural rainfall, whether large or small, is supplied by water, artificially added, so that regular, abundant crops may be obtained.

140. Irrigation supplementary to rainfall.-Such a definition of irrigation makes it evident that the quantity of water to be used in irrigation depends on the degree of the natural precipitation. The higher the annual rainfall that may be retained in the soil for crop use, the smaller the quantity of water required in irrigation. The lower the annual rainfall that may be so retained, the higher the irrigation requirement. This is a somewhat new 
thought in irrigation practice. Modern irrigation was founded in a very arid country, with almost rainless summers, at a time when there was no science of agriculture, and by men who had had no previous irrigation experience. The practice of irrigation was, therefore, founded on the assumption that irrigation was a primary art, practically independent of the natural precipitation. As practical irrigation experience was gathered it became clear that any rainfall, even a small one, if conserved in the soil, has crop-producing power, and that irrigation is always a supplementary art. Irrigation is and always should be supplementary to the rainfall. Consequently, the first big irrigation problem is to conserve the rainfall in the soil for crop use, so that the available irrigation water may be made to cover as much ground as possible. The beginning of irrigation wisdom is the conservation of the natural precipitation for the use of crops.

141. Crop-producing power of rainfall.-The theoretical productive power of the natural precipitation shows that even a low annual rainfall, properly conserved, may produce fair crops without irrigation. It has been shown previously that to produce one pound of dry matter on a fertile soil under arid conditions, more than 750 pounds of water are seldom required. If 750 pounds of water are required to produce one pound of dry matter, one bushel of wheat will require for its production 90,000 pounds, or forty-five tons, of water. On this basis, each acre-inch of water-weighing about 113 tons-should produce about two and one-half bushels of wheat. An annual precipitation of 10 inches, if fully conserved, should then produce twenty-five bushels of wheat per acre, which is a high average crop. 
142. Results of dry-farming.-This theoretical demonstration has been well borne out by the results of the modern art of dry-farming. Dry-farming, as a system of agriculture, attempts to produce profitable crops without irrigation on soils that receive an annual rainfall of between 10 and 20 inches. Where there are high winds or other water-dissipating factors, a rainfall of from 20 to 30 inches a year also requires dry-farming methods. The two-thirds of the area of the earth's surface receiving annually less than 20 inches of rain, are the so-called arid and semi-arid regions of the earth on which irrigation has been held, until lately, to be a necessity for successful crop-production. Yet, successful dry-farming, during the last few years, has been practised on great areas that receive between 10 and 20 inches of rainfall annually. This confirms the accuracy of the theoretical deduction of the crop-producing power of the rainfall.

143. Crop value of rainfall in irrigation.-Experiments have also been performed to discover what proportion of a crop grown under irrigation may properly be credited to the natural precipitation. In the Utah work, the same crop was planted on two neighboring plots. One was irrigated; the other dry-farmed. Both plots yielded crops, and it was assumed that the yield on the plot receiving no irrigation was the same as the part of the yield under irrigation, due to the natural precipitation. Some of the results thus obtained are given in the following table. In reading the table, it should be remembered that the average precipitation under which the work was done was in the neighborhood of 15 inches a year. The soils were deep and of splendid water-holding power, and had been carefully tilled according to the best dry-farm methods, so as to conserve the natural precipitation. 
Percent of a Crop Raised with About $71 / 2$ Inches of Irrigation, Due to the Natural Precipitation

\begin{tabular}{|c|c|}
\hline $\begin{array}{l}\text { Wheat (grain) } \\
\text { Wheat (straw) } \\
\text { Oats (grain) } \\
\text { Oats (straw) } \\
\text { Corn (grain) } \\
\text { Corn (stover) } \\
\text { Alfalfa (all crops) } \\
\text { Potatoes }\end{array}$ & $\begin{array}{l}\text { Per cent } \\
83.99 \\
86.42 \\
85.67 \\
98.19 \\
81.14 \\
83.03 \\
77.18 \\
66.89\end{array}$ \\
\hline
\end{tabular}

The results show that between 80 and 90 per cent of the yield of grain of wheat, oats and corn, grown with about $71 / 2$ inches of irrigation water, was really produced by the natural precipitation. Even larger proportions of straw and stover were so produced. With the same degree of irrigation, 77 per cent of a crop of alfalfa, and 67 per cent of a crop of potatoes, were produced by the natural precipitation.

Bark and Welch carried on similar experiments on the Gooding Experiment Station, Idaho, with Blue Stem, Sonora and Little Club wheats. As an average of three years of work with these wheats it was found that of a crop raised with about 6 inches of irrigation water, about 75 per cent of the yield should be credited to the natural precipitation. This confirms the Utah work. True, on different soils, the same precipitation would produce different results, and these figures are probably maximum because of the excellent treatment given the soil and crops. However, a considerable proportion, usually from 40 to 70 per cent, roughly one-half, of the crop obtained under irrigation may be safely credited to the natural precipitation, wherever the rainfall is over 12 inches annually and proper methods of cultivation are practised. On the other hand, when the rainfall is not conserved, the 
yields under irrigation are greatly reduced. As the rainfall is more carefully conserved, the area that may be served by the available irrigation water will be greatly increased. (Fig. 57.)

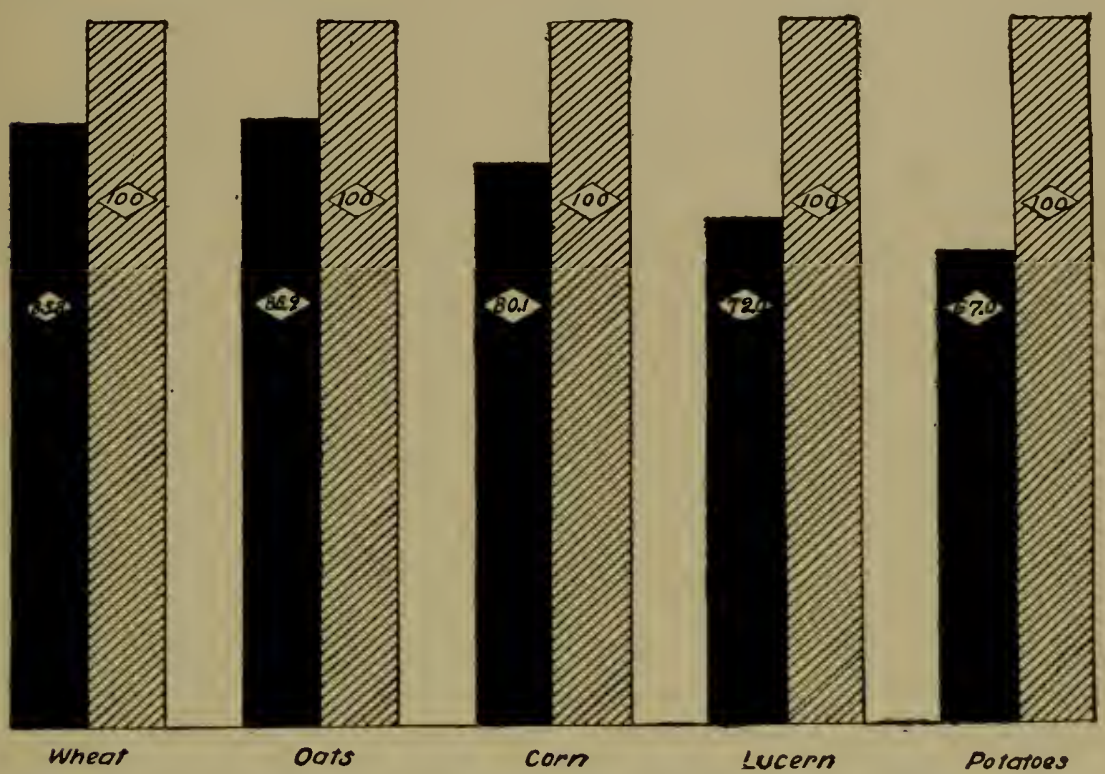

FIG. 57. Yield of crops due to rainfall. Shaded areas, yields with irrigation; black areas, yields without irrigation.

144. Conserving the rainfall.-The high crop-producing value of the rainfall in irrigation practice makes it important to understand the best methods whereby the natural precipitation may be conserved. (1) The top soil must be kept in a loose condition, so that the water may enter the soil easily and completely as it falls from the heavens. (2) The soil must be so treated by thorough cultivation that the water which enters the soil will be kept there until needed by the plant. These are the two chief considerations of the irrigation farmer who desires to get the greatest possible returns from the rainfall.

145. Distribution of rainfall.-The methods to be 
employed in water conservation vary with the seasonal distribution of the rainfall. The rainfall varies not only from place to place, but varies also in its seasonal distribution. Thus, on the Pacific seaboard, west of the Sierra Nevadas and the Cascades, the wet season extends from October to March, with a practically rainless summer. This is the Pacific type of distribution. Under the subPacific type, which extends over eastern Washington, Nevada and Utah, the maximum rainfall is shifted toward the early spring, but the summers are still quite rainless. Under the Arizona type, fully developed in Arizona and New Mexico, about 35 per cent of all the rain falls in July and August, and May and June are generally the rainless months. Under the Rocky Mountain foothills type, most rain falls from April to June. Finally, under the Plains type, embracing the larger part of the Dakotas, Nebraska, Oklahoma and Texas, the heaviest rains come during May to July, when crops are growing. Moving eastward from the Pacific Coast to the Great Plains, the major rains are shifted from midwinter to midsummer. Moreover, in many places snow lies long on the ground in the winter, while in other places there is no snowfall. The methods of conserving the rainfall in the soil must be varied somewhat with regard to the prevailing type of precipitation. Whether rains come in winter or summer they must be stored in the soil for some time. Especially where the rains come in the winter, they must be held in the soil until the growing season arrives.

146. Storing water in the soil.-Well-plowed soil is in a good condition to store water from the rains and snows. In the western United States, where the summers and falls are somewhat rainless, and the chief precipitation comes in winter or early spring, fall plowing is commonly 
resorted to for the purpose of enabling the rains to enter the soil. Fall plowing is practised as early as convenient, and the soil is frequently left in the rough throughout the winter. The fall, winter and spring rains are quickly absorbed by such land and stored to considerable depths, as already explained in Chapter III. Where the chief precipitation comes in late spring and summer, it is sufficient to plow in early spring and to keep the soil loose during the time of precipitation by tilling after each rain.

147. Cultivation.- The purpose, effect and method of cultivation have been discussed in Chapter IV. It is the best known method for retaining the natural precipitation in the soil. It is just as important that the soil be carefully cultivated after a rain as after an irrigation. In the spring the land should be properly harrowed and cultivated, so that the moisture gathered during the winter may not evaporate.

148. Proportion of rainfall conserved.-In the intermountain country, where the precipitation comes in winter or early spring, it has been found that, by fall plowing and spring cultivation, from 60 to 90 per cent of the precipitation between harvest and spring is found stored in the soil in the spring. In the region where the rainfall comes largely in spring and summer it has been found that it is possible to store in the soil during the summer season from 40 to 60 per cent of all the moisture that falls at that time. Water so stored in the soil is of great value in producing crops; especially valuable is the water stored in the soil during winter, for it has been in very intimate contact with the soil particles and is heavily charged with plant-foods.

149. Relation of irrigation- and dry-farming.-There is no opposition between dry-farming and irrigation- 
farming. They are twin sisters. Upon them rests the responsibility of reclaiming the two-thirds of the earth which receive an annual rainfall of less than 20 inches. Newell estimates that under a perfected system of water storage, it is probable that not more than one-tenth of this vast arid region will be reclaimed by irrigation. The remaining nine-tenths must be reclaimed, if at all, by the methods of dry-farming. On the irrigated lands will be the great cities and the bulk of the population, but surrounding them will be the great dry-farm empires, the products of which will help support the people on the irrigated tracts. Since, in any country, the supply of irrigation water is adequate to cover only a small fraction of the arid lands, it is important to learn every method whereby irrigation water may be made to render a high duty and to cover more land. The most promising method for accomplishing this result is the introduction into irrigation practices of methods whereby the natural precipitation may be conserved in the soil. That is, thorough and deep plowing in the fall, and frequent and deep cultivation, should be made part and parcel of irrigation practices. When, in connection with this thorough tillage, irrigation water is applied in smaller quantities, so that larger returns may be obtained for each unit of water, it is not unlikely that the irrigated area may be increased three- or fourfold. From the beginning, therefore, the irrigation farmer should familiarize himself with the methods of dry-farming and apply them so far as may be possible in the development of a high duty of the available irrigation water.

150. Dry-farm homesteads.-The dry-farming areas are often at considerable distances from large water supplies, although small springs or streams or subterranean waters are usually within reach. In some cases water 
must be hauled many miles to the dry-farms. The dryfarmer can do his work most effectively if he can build his homestead on the dry-farm and live there with his family. To do this he needs to have a small irrigated garden around his home, with some trees for shade and fruit. A clear understanding of the possibilities of irrigation water, combined with dry-farming methods, will make it possible to establish on the great majority of the dryfarms throughout the country small homesteads, where grass, and flowers and trees may be enjoyed. If, then, dry-farming methods are of value in extending the irrigated area, the possibilities of small water supplies in irrigation will do much to make dry-farming more attractive to those who practise it.

Dry-farming and irrigation will go hand in hand in redeeming the waste places of the earth. Both depend primarily upon the natural precipitation.

\section{REFERENCES}

Campbell, H. W. Soil Culture Manual. Soil Culture Company. Dry-Farming Congress, Reports of.

Fortier, Samuex. The Use of Small Water Supplies for Irrigation. United States Department of Agriculture, Yearbook for 1907, p. 409.

Hilgard, E. W., and Lovghridge, R. H. Endurance of Drought in Soils of the Arid Region. California Experiment Station, Bulletin No. 121; also (fuller), Report for 1897-8, p. 40 (1900).

MacDonald, Wm. Dry-Farming. Century Company (1910).

MeAd, Elwood. The Relation between Irrigation and Dry-Farming. United States Department of Agriculture, Yearbook for 1905, p. 423.

MerriLl, L. A. Seven Years' Experiments in Dry-Farming. Utah Experiment Station, Bulletin No. 112 (1911).

Shaw, Thomas. Dry Land Farming (1912).

Widtsoe, J. A. Dry-Farming. The Macmillan Company (1911). 


\section{CHAPTER XIII \\ IRRIGATION OF CEREALS}

WHEN land is brought under irrigation, the small grains form the first of the staple crops. This follows from the nature of the cereals. They furnish breadstuffs to man, and their by-products are excellent concentrated foods for farm animals. A ready market always awaits the small grains, and they bring, therefore, sure and quick returns to the farmer who is just beginning the conquest of an irrigated farm. The small grains mature at the time of large water supply, and for that reason, need less attention during the drier period of the growing season. Land is easily prepared for small grains and the cultural operations are simple. After more profitable crops have been established under the irrigation system, the small grains fit well into the rotations necessary for the maintenance of soil fertility. Finally, small grains may be grown with limited capital, which is all-important to the average new settler.

In the beginning of irrigation in the United States, the small grains formed the bulk of the crops that were raised. Extensive grain-growing under irrigation is, however, gradually ceasing, because special crops, such as sugar beets and fruits, yield larger acre returns than the grains, and, moreover, because it has been shown that the small grains are particularly well adapted for growth under dry-farming methods on the non-irrigated lands. Then, the increasing demand by millers for hard wheats 
will gradually diminish the market value of the softer wheats produced by irrigation.

Undoubtedly, small grains, especially wheat, as a major crop, will gradually be driven from the irrigated to the non-irrigated lands, although they will always be important crops, since they fit well into rotations. Wherever an irrigation enterprise is begun, it will be found profitable to grow, for some years, extensive crops of the small grains.

151. Spring vs. fall wheat.-Wheat may be considered as a type of the small grains. Formerly, under irrigation practice, spring grains were sown almost entirely. With the advance of dry-farming, which is characterized by fall sowing, irrigated grain is often planted in the fall. The advantage of fall planting is that grain so sown makes better use of the fall and winter precipitation, gets an early start in the spring, and matures earlier. Moreover, less water is required to bring the fall grain to maturity and to a high yield. In harmony with the spirit of economizing irrigation water, the sowing of fall grain should be made a general practice in irrigated sections.

152. Quantity of wheat to sow.-The quantity of seed to sow must be varied with the quantity of irrigation water available throughout the season. Under dryfarming, on lands that receive an annual precipitation of 12 to 15 inches, twenty-five to thirty pounds of wheat are used to the acre. Under irrigation, with the same annual rainfall, one to three bushels of seed or more are often used. It is not wise to use too much seed, for the numerous plants that result demand a large supply of water, if they are to be brought to maturity; and, if by chance the water supply should be cut off or diminished, the excessive number of plants would speedily exhaust the soil moisture 
and become seriously injured. A common experience on dry-farms, where too much seed has been used, is to find a splendid stand of young grain in the spring, and failure at harvest time. Under irrigation, as under dry-farming, the number of plants must be proportional to the probable water supply. If the number of plants is in excess of the probable water supply, the yield will be unsatisfactory. It is always better to sow limited quantities of seed, for by stooling there is an automatic adaptation of the wheat plant to the water in the soil. Experiment has shown that where little seed has been sown, and the water has been sufficient, the harvest is as great as if more seed has been sown. No material change in the acre-yield has occurred even when the seed sown to the acre varied from four to twelve pecks. One bushel or less is probably as satisfactory as larger quantities, except on very rich soils with an abundance of water.

153. Method of sowing wheat.-Wheat and the other small grains should always be planted in rows by some one of the many press drills. This enables the farmer to control the quantity of seed used, and the depth and regularity of planting. Under irrigation, the yield is influenced by the distance between the drill rows. Experiments on this subject indicate that the yield is increased when the same quantity of seed to the acre is planted in rows twice as far apart. This may be due to the greater chance, under such conditions, of a large lateral development of the roots.

The direction of the drill rows may be of considerable importance. On comparatively level land, the drill rows may help guide the irrigation water from place to place. On rolling land and steep hillsides the drill rows may be run with the contour lines, i. e., across the inclination. 
By this method, the rows become checks to the descending water, and washing or unnecessarily rapid flooding of the land is prevented.

154. Cultivation of wheat.-As explained in Chapter IV, cultivation, properly performed, may largely take the place of irrigation. On clayey soils there is a tendency for a crust to form after each irrigation, which should be broken to prevent serious injury to the plants. The present system of planting grains in rows very near each other makes it difficult and probably unprofitable to give such crops inter-row culture. However, wheat fields may safely be cultivated while the plants are young-from 8 to 12 inches high-by harrowing with an ordinary spiketooth harrow with the teeth set backward, so that few plants will be torn out. The corrugated roller is sometimes used to break the crust, but the harrow is probably better, since it does not compress the soil. As the grain becomes older it shades the ground very completely, and, consequently, baking of the soil is not so common later in the season.

155. Method of irrigating wheat.-Water may be applied to wheat by any of the standard methods of irrigation. In the beginning of American irrigation, flooding was almost the only method employed. Only gradually, to meet compelling conditions, was the furrow method thought out and adopted and, even today, flooding is the most general method of irrigating wheat and other small grains: The flooding of grain is accomplished ordinarily by the field-ditch method. From the main supply ditch, smaller ditches, often following the high lines or ridges, are taken out to the field. From these again, small temporary field ditches or mere furrows are made, from which the water overflows to cover the land. Occasionally, but 
only where there is an abundance of water, the small grains are irrigated by the check or basin system. The furrow method of irrigating the small grains is rapidly coming into use, and promises to displace the more extensively used flooding methods. Under the flooding method, much labor is required to apply the water to the land, but little labor to prepare the land for irrigation. Under the furrow method little labor is needed to apply the water, but the land must be carefully prepared before the method can be employed.

The method to be chosen depends on the soil and the scarcity of water. Lands with a baking tendency, sown

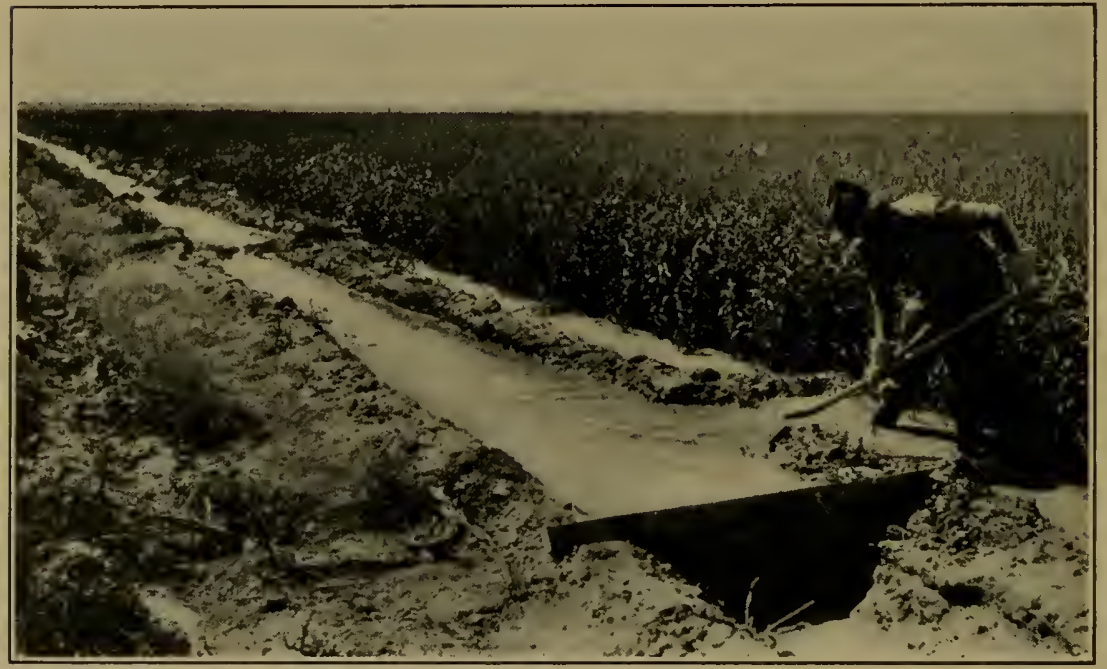

FIG. 58. Irrigating wheat.

to grain, as already suggested, are cultivated with difficulty. When the furrow method is employed on such lands, only the soil touched by the water in the furrows bakes, and cultivation is not so necessary. Other lands wash easily. They are usually of very fine texture, and are rich either in calcium sulphate with other somewhat 
soluble substances or are derived from volcanic ash. Even a small stream of water, with a slight fall, running on such soils, unless watched with extreme care, may quickly cut deep ravines and destroy the field. On such soils, therefore, the furrow method, which permits of a better con-

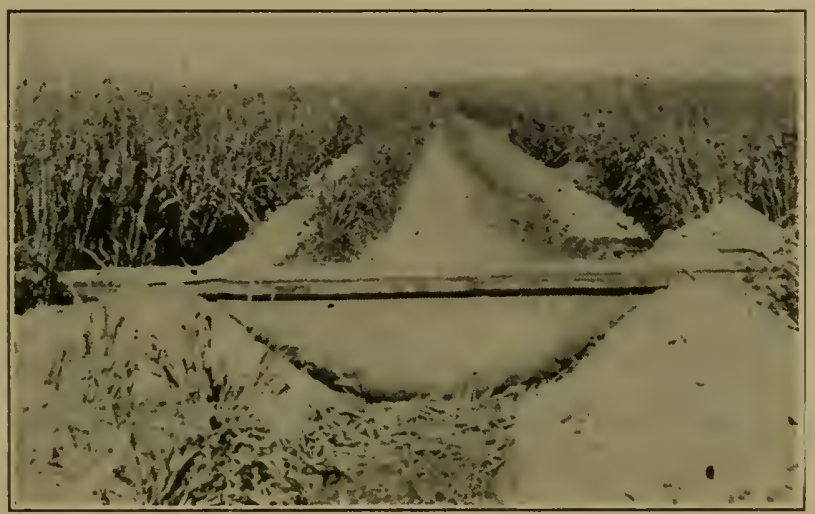

FIG. 59. Canvas dam to check water.

trol of water, is gradually becoming the only method. Limited supplies of irrigation water also demand the furrow method, for it is evident that, with a given quantity of water, more land may be covered by the furrow than by the flooding method. It has been explained that the yield of a crop to a unit of water is greater when small quantities are used and a larger total yield will be obtained when the small available quantity of water is spread over a large area.

Finally, under the best flooding system it is difficult to secure an even distribution of water over ordinary lands, which are not absolutely level. The furrow method permits of a more even, though not by any means perfectly even distribution. This has been another determining factor in the acceptance of furrow irrigation for small grains. 
The furrows are usually made after seeding but before the plants come up, by the use of special implements described in Chapter XX. Shallow furrows, usually 5 inches deep and from 6 inches to 3 feet apart, are ordinarily employed. Their length varies from 150 to 600 feet, depending on the slope, the nature of the soil and various other conditions. Long furrows are of doubtful value, for the upper end of the furrow receives water for a longer time than does the lower end, and, consequently, in long furrows the upper end may be over-irrigated when the lower end has received just enough. Shorter furrows obviate this danger, at least in part. (Figs. 58,59 .)

156. Time of irrigating wheat.-The time of irrigation, one of the most important factors in the economical use of water, depends in part upon the distribution of the rainfall throughout the year. Land for spring grain is especially suitable for fall and winter irrigation. Such lands, when plowed in the early fall and given a good soaking in the fall, will contain much stored water in the spring to germinate the seed and to maintain the young plants far into the early summer. However, fall and winter irrigation is to be considered only when the natural winter precipitation is insufficient to saturate the soil to a depth of 8 to 10 feet. It is especially in districts where the precipitation comes largely in spring and the growing season, and where the winter and fall are dry, that irrigation during the dormant season is of much value.

When the soil enters the spring in a somewhat dry condition, it becomes necessary to provide by irrigation the water needed for germinating the seed. This may be accomplished by applying a thorough irrigation to the soil before seeding, after which the land is plowed, then sown to the crop. The objection to this method is 
the delay occasioned by the necessary interval between irrigation and plowing. For that reason, the soil is frequently plowed early in the spring, irrespective of dryness, the seed planted in the dry soil, and then irrigated. The water thus added immediately favors germination and furnishes also a supply of water for the young plant. Both of these methods of early irrigation are giving satisfactory results.

After germination and first growth, irrigation should be delayed as long as possible. When water is needed, the grains, which normally are of a light green color, become darker green, and in protracted dryness the lower leaves become definitely yellow. If the soil becomes too dry, the crop may be permanently injured; in fact, the soil below the surface should remain fairly moist throughout the growing season. If the seed has been planted in wellsaturated soil, since young plants require little moisture, several weeks will elapse before irrigation will be necessary.

During the early stages of growth, the plant devotes its energies to the preparatory work of gathering carbon from the air and mineral matters from the soils, and of combining these into organic forms. The period of most rapid growth comes shortly before or at the time of flowering. At the time of "boot," that is, when the heads just begin to show, it is well to apply water, and again, if needs be, at the time of seed-formation. It is most important, however, that the soil be not dry at the time of flowering; for, if there is an abundance of water at that time, a ready transfer of nutritive materials from stalks and leaves to the heads is made possible. Moreover, water applied when the seeds are "filling out" will result in increased grains at the expense of the straw.

It may be that the answer to the question concerning 
the right time of applying water to grain is to keep the soil approximately at the same moisture content throughout the season, until ripening sets in. Some authorities have declared that plants need a high soil-moisture percentage at one period and a smaller one at another period and so on throughout the season. This may be correct, but in practice the farmer will make no mistake in maintaining the soil in approximately the same correct moisture condition throughout the season. More water will be transpired, and the irrigations therefore heavier or more frequent at the time of most rapid growth, that is, about the time of flowering.

It is seldom necessary to give wheat more than three irrigations except, possibly, in the hot climate of Arizona and similar regions. In fact, two irrigations are usual, and one irrigation ordinarily ample wherever the annual precipitation is between 12 and 15 inches. Where the annual precipitation is large, little water will be required; where it is small, much water must be added by irrigation. Bark found that under a rainfall of about 18 inches, the water used for grains by farmers during the months of May to August inclusive, was as follows: May, 7.86 per cent; June, 52.34 per cent; July, 36.14 per cent; August, 3.66 per cent; total, 100 per cent. In the mountain country, where grain is sown in April, there is little need of irrigation after late June or earliest July. Fallsown grain, with proper tillage, needs probably only one heavy irrigation, or at the most two light irrigations. McLaughlin recommends that wherever weeds have been troublesome the grain fields be irrigated after harvest, to germinate the weed seeds, and later to plow the plants under. Thus, the soil is fertilized and the weeds destroyed.

157. Quantity of water for wheat.-The quantity of 
water to be used for wheat and the small grains depends upon many factors. Less water is required on clayey than on sandy or gravelly soils. Deep soils require less water than shallow soils, or soils underlaid by gravel or hardpan. Bark, working in Idaho, found that, in actual practice, grains received on medium clays and sandy loams about 18 inches of water, while on sands or gravelly soil nearly 36 inches were used. More water is necessary

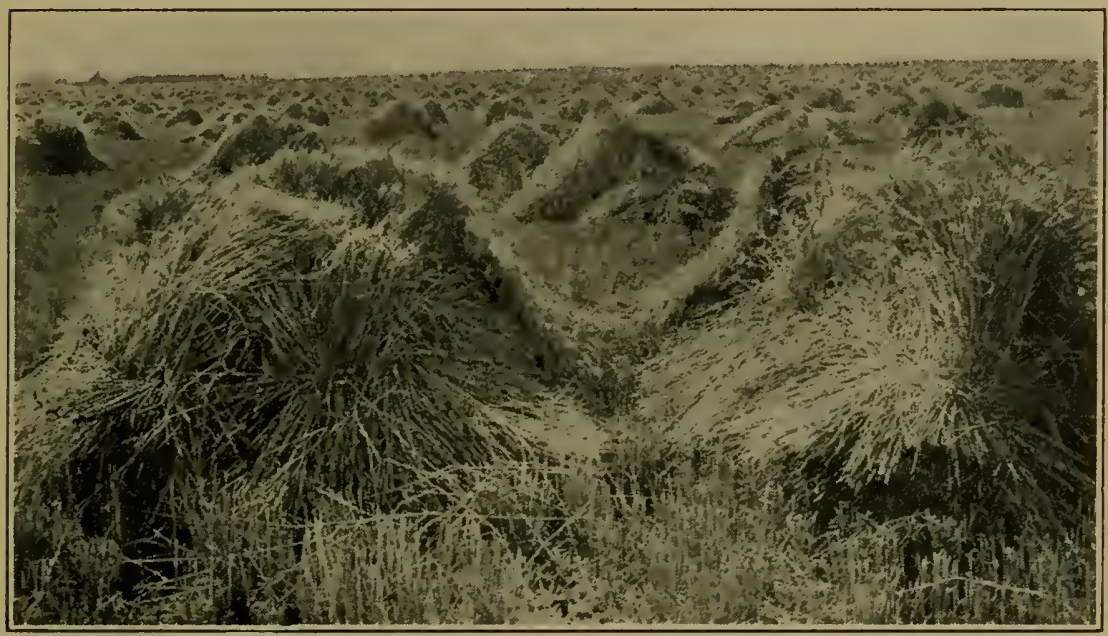

FIG. 60. Irrigated wheat in Montana.

on new than on old land. A high temperature, a low relative humidity and a steady wind increase the water requirements of crops. All these and others previously discussed, must be considered in deciding on the quantity of water to be used.

The fundamental law to be considered in determining the quantity of water used in the production of wheat and of other crops is that, as more water is applied to a field the smaller is the relative yield of grain and of straw. Undoubtedly, as water is applied, the total yield increases 
steadily to a limit, beyond which there is an actual decrease; but, as the increase goes on, there is a steady diminution in the yield per unit of water applied. This is shown in the following table, taken from the Utah results:

Yields of Wheat with Varying Quantities of Irrigation WATER

\begin{tabular}{c|c|c|c|c}
\hline \hline $\begin{array}{c}\text { Inches } \\
\text { of irrigation } \\
\text { water applied }\end{array}$ & $\begin{array}{c}\text { Bushels of } \\
\text { grain } \\
\text { to the acre }\end{array}$ & $\begin{array}{c}\text { Pounds of } \\
\text { straw } \\
\text { to the acre }\end{array}$ & $\begin{array}{c}\text { Pounds of } \\
\text { straw for } \\
\text { each bushel } \\
\text { of grain }\end{array}$ & $\begin{array}{c}\text { Bushels of } \\
\text { wheat for } \\
\text { each inch } \\
\text { of water }\end{array}$ \\
\cline { 1 - 2 } 5.0 & 37.81 & 2,986 & 79 & 7.56 \\
7.5 & 41.54 & 3,301 & 75 & 6.39 \\
10.0 & 43.53 & 3,452 & 79 & 4.35 \\
15.0 & 45.71 & 3,954 & 87 & 3.05 \\
25.0 & 46.46 & 4,311 & 93 & 1.86 \\
35.0 & 48.55 & 4,755 & 98 & 1.39 \\
50.0 & 49.38 & 5,332 & 108 & 0.99 \\
\hline
\end{tabular}

The quantity of water applied to wheat varied from 5 to 50 inches, but the yield varied from about thirtyeight bushels to a little over forty-nine bushels-an increase of not quite twelve bushels of wheat for an increase of nearly 45 inches of water. In the last column of the table, it is shown that the yield per inch of irrigation water fell from about seven and one-half bushels with 5 inches of water, to about one bushel with 50 inches of water. This variation in yield, due to increasing applications of water, has been confirmed by practically every investigator who has carried on accurate work under field conditions. Moreover, the greater the quantity of water used, the smaller the proportion of seed in the whole plant. See the fourth column of the above table. (Fig. 63.)

Not only is it possible to diminish beyond serious consideration the acre-inch yield by increasing irrigations, but it is possible by excessive irrigation to cause an actual 
decrease in the total yield. Further, an excess of water delays ripening, and thus subjects the grain to the dangers of late growth when the fall frosts are at hand. When too much water is used, the plant becomes converted into a pumping system, having for its purpose the ridding of the soil of the injurious excess of moisture. Such over-irrigation is, naturally, less likely to occur on porous than on compact soils; but, on the other hand, the excess of water

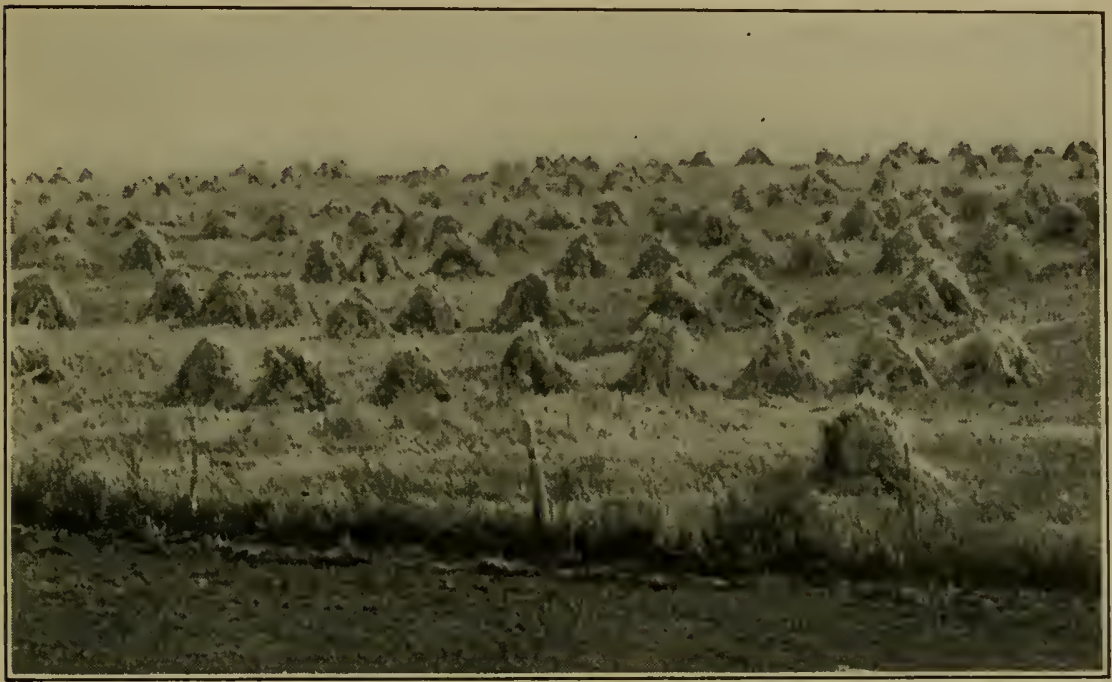

Fig. 61. Irrigated oats in Montana.

applied to porous soils moves downward more easily to raise the standing water table. Fortunately for the pioneers who laid the foundations of irrigation, and who were not well acquainted with the dangers of over-irrigation, the small grains endure fairly well an excess of water. Wheat can probably endure over-irrigation better than either oats or barley. However, the practice is unwise; and the ridiculously large quantities of water often applied in the hope of large yields are a serious menace to the permanence of irrigation agriculture. 
The quantity of water which produces the largest yield of grain to the acre is seldom the most economical quantity to apply. In the irrigated region, the acre of land and the acre-foot of water must both be given attention; and, since the acre-foot of water usually has a higher value than the acre of land, the emphasis should be placed upon the producing power of a given volume of water. The possibility of wheat-production with 30 acre-inches of water-the quantity often assigned by irrigation engineers-based on the preceding table, may be shown as follows:

\begin{tabular}{l|c|c|c|c|c}
\hline \hline & \multicolumn{4}{|c}{30 acre-inches spread over } \\
\cline { 2 - 6 } & 1 acre & 2 acres & 3 acres & 4 acres & 6 acres \\
\hline Grain ........ & 47.51 & 91.42 & 130.59 & 166.16 & 226.16 \\
Straw ........ & 4,532 & 2,908 & 10,256 & 13,204 & 17,916 \\
\hline
\end{tabular}

By spreading 30 acre-inches over 6 acres instead of over 1 , the total yield of wheat was increased from fortyseven bushels to 226 bushels. In the final establishment of empires on irrigated soils this fundamental relationship between water and crop-yield, must of necessity be taken into consideration. (Fig. 64.)

The best knowledge of the day makes it safe to say that, on deep soils, $71 / 2$ inches of water in two good irrigations, should be ample for the production of a crop of wheat. On shallow, gravelly soils, as high as 18 inches may be used in four or five irrigations. On many soils one good irrigation of 4 to 5 inches would be sufficient to carry the crop to a large yield of grain of higher quality than if more water were used. Everything considered, an average of 1 acre-foot should be ample for the production of wheat on fertile, well-tilled soils. 
If 12 acre-inches be taken as the quantity of water amply sufficient for the needs of wheat, the subjoined table shows that 1 second-foot, during a sixty-day irrigation period, will cover 120 acres; during a forty-fiveday irrigation period, 90 acres. If $7 \frac{1}{2}$ inches be the depth of water applied, the duty of a second-foot will vary as shown below from 60 to 192 acres. In many places in the West, the duty of water for grain has been raised to 200 acres or more. For instance, under the famous Bear River Canal of Utah, where irrigation practices have been worked out to great perfection, Wheelon reports that there is a gradually decreasing duty of water for grain and for all other crops. At the present time the duty of water there approximates 170 acres for grain with a prospect of a rapid increase.

Duty in Acres of Second-Foot of Water Contindousty FLOWING

\begin{tabular}{|c|c|c|}
\hline $\begin{array}{c}\text { Depth of water } \\
\text { applied }\end{array}$ & $\begin{array}{c}\text { Length of irrigation } \\
\text { season }\end{array}$ & Duty \\
\hline $\begin{array}{l}7.5 \text { inches } \\
7.5\end{array}$ & 45 days & $\begin{array}{l}144 \text { acres } \\
192\end{array}$ \\
\hline 12.0 “ & 45 “ & 90 \\
\hline 12.0 & 60 & 120 “ \\
\hline 18.0 “ & 45 “ & 60 \\
\hline 18.0 & 60 “ & 80 \\
\hline
\end{tabular}

158. Oats.-Oats is another of the staple crops of the irrigated section. It has almost always been sown in the spring, but the development of dry-farming has led to the introduction of winter varieties. It is very probable that oats, like wheat, will, in the future be grown chiefly under dry-farming, although the crop will find an important 
place in the rotations for maintaining the fertility of irrigated land.

In general, oats and wheat may be treated alike. The quantity of seed should be carefully regulated with respect to the available water. The cultivation, methods and

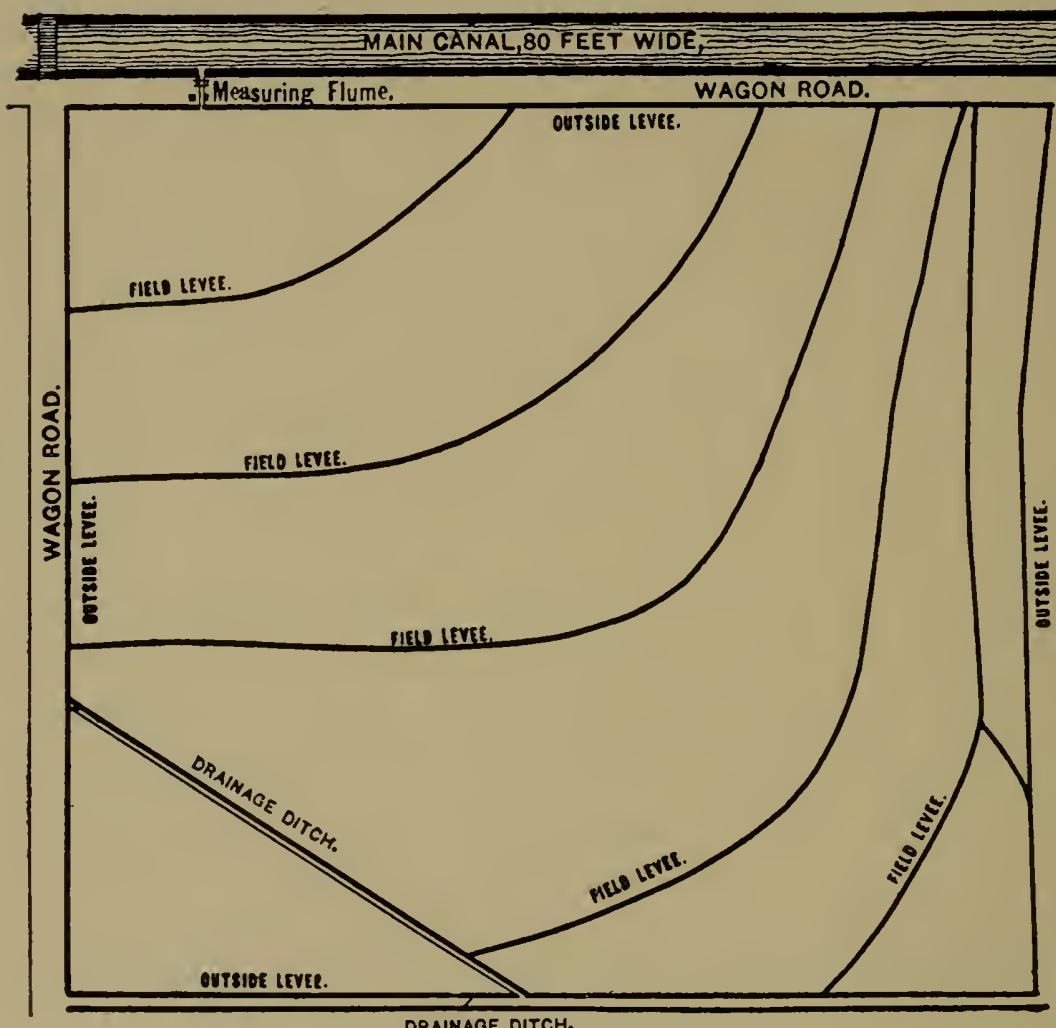

FIG. 62. Plan of rice irrigation.

time of irrigation are practically the same as those discussed under wheat. The duty of water for oats is about the same as for wheat, although oats is rather more sensitive than wheat to over-irrigation. Oats of high quality may be grown abundantly by the moderate application of water. We are quite safe in saying that the 
duty of water for oats should not be any lower than for wheat.

159. Barley.-Barley is also a valuable crop for irrigated lands. Excellent malting barley is produced under irrigation, and, in fact, irrigated barley appears to be the best for malting. The irrigation of barley conforms with the irrigation of wheat or oats. Barley is even more sensitive than oats to over-irrigation, and water should, therefore, be applied to barley with great care. In the Utah work it was found that the total yield of barley did not increase, or decrease, after a depth of $71 / 2$ inches of water had been applied. In the Wyoming work, little increase was found after 16 to 20 inches had been applied However, it has been demonstrated that the malting value of barley decreases when too much water is applied in irrigation. The duty of water for barley should not be lower than for oats or wheat.

160. Rye.-Rye is seldom grown under irrigation, for it does so well under dry-farming that there is no good reason for using costly irrigation water in its production.

Wheat, oats, barley and rye behave very much the same in their relation to water. The chief difference is in the sensitiveness to water. Wheat endures more water than oats, and oats more than barley, and barley probably more than rye; but, practically, the effect of irrigation on these crops is the same. All of them have a larger proportion of straw in the whole plant, if grown with much water.

161. Corn.-Corn, the great American crop, thrives and yields heavily under irrigation. It produces more dry matter for the water used than practically any other crop, and, when drought comes, it survives and produces fair yields. Dry-farm corn seldom fails. The importance of the corn crop to the irrigated region will increase rapidly 
as its behavior under irrigation becomes better understood, and as dairying and other forms of animal husbandry develop on irrigated lands.

Corn differs from the small grains in its longer growing, hence longer irrigating, period. The details of preparing the land, seeding and general cultural practices are

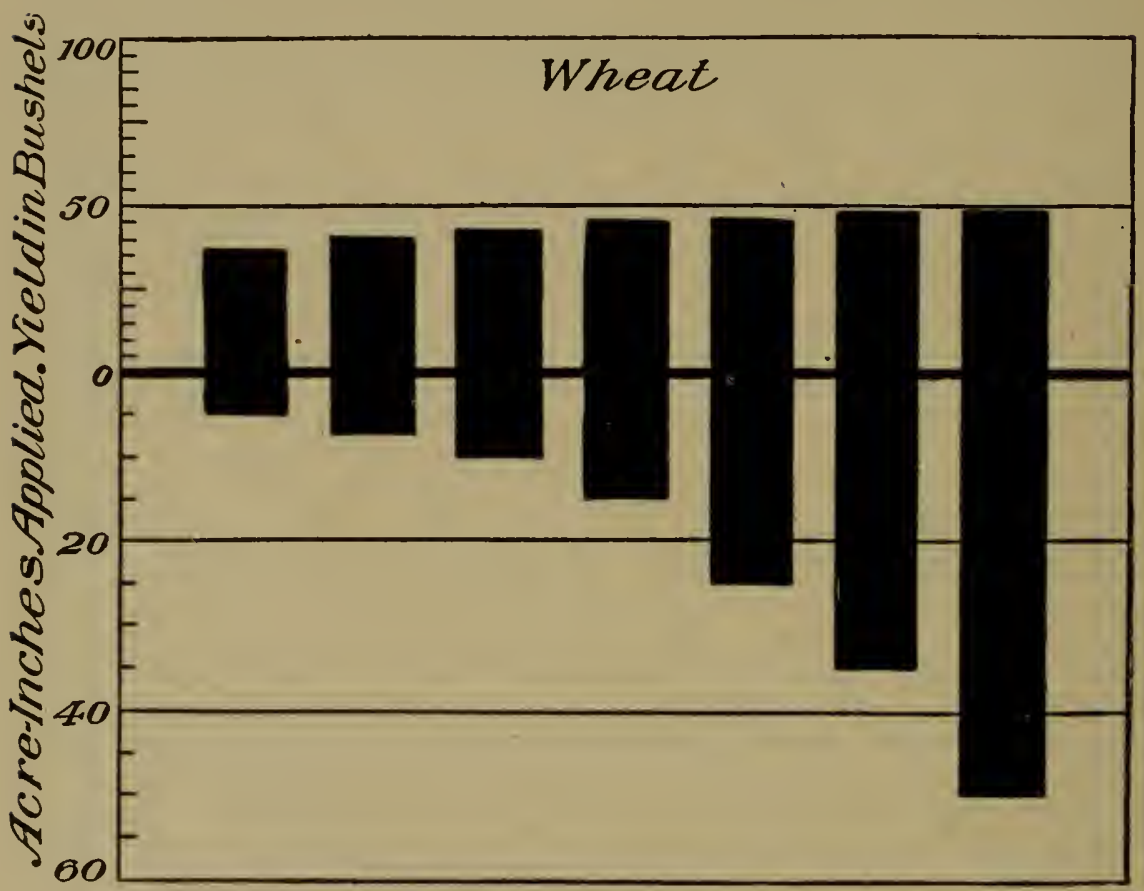

FIG. 63. Yield vs. water (wheat).

those followed in humid districts. Drill or row culture is the only allowable method of sowing corn under irrigated conditions.

Cultivation is as essential in corn-growing under irrigation as under humid conditions. The soil should be cultivated immediately after each irrigation, as soon as the soil is dry enough to permit the hoe to be safely used. Moreover, it is well to cultivate the corn at least 
twice to four times between irrigations. By this method the water-cost of the crop may be greatly reduced. Moreover, thorough cultivation yields a corn crop having a much higher feeding value than one which has received less thorough cultivation.

Irrigation water is invariably applied to corn in furrows, although the flooding methods may be used. Since
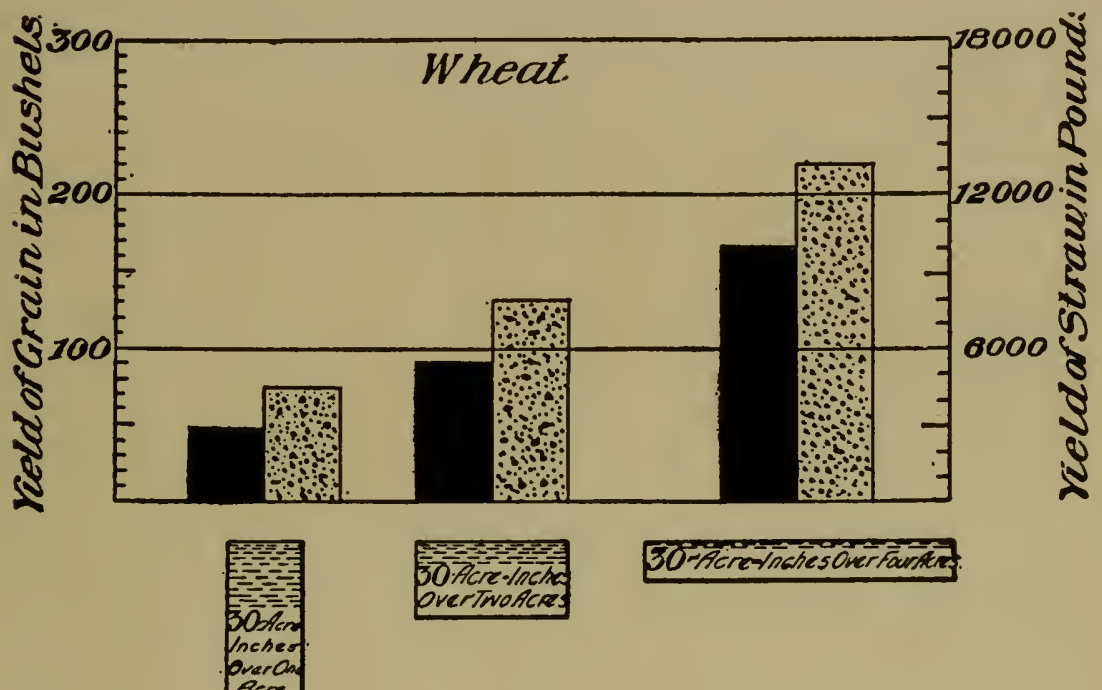

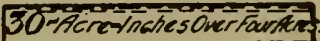

FIG. 64. Producing power of 30 acre-inches (wheat).

corn is inter-tilled, it is much more convenient and satisfactory to irrigate by the furrow method and, further, the corn plant should not be in contact with water. The furrow is dug half way between the rows. For reasons already discussed the furrows should not be made too long.

Corn land may well be irrigated in the fall and winter, if the natural precipitation during those seasons is not sufficient to saturate the soil thoroughly. The soil should 
be well stored with moisture at the time of seeding, and when this is not the case it may be necessary, as in the case of wheat, to give the soil a thorough soaking before planting.

162. Time to irrigate corn.-Corn is planted later than the small grains and during its early growth is, therefore, subjected to a higher temperature and more rapid evaporation. However, the young plant draws little water from the soil, and the first irrigation after seeding should be light and should come as late as possible. As the plant continues its growth the irrigations may be increased in quantity and frequency. The May planting of corn means that July and the first half of August are the periods of most rapid growth and during which most irrigation is needed. After August 15, less water is required; in fact, it is questionable if water should be applied to corn after the period of August 15 to September 1. As in the case of the small grains, the key to the successful production of irrigated corn seems to be to keep the soil in a uniform moisture condition throughout the season. It is manifestly impossible under irrigated conditions to keep the soil exactly at the same percentage of moisture; but, by proper cultivation and irrigations at correct intervals, the soil may be maintained throughout the season at a favorable moisture percentage. Excessively dry and wet periods should never follow each other.

Corn, like the small grains, should have at its disposal an abundance of water at the time of seed-formation. When the seed is ripening, little water is required; in fact, in the later periods of growth, water must be withheld from the plant, so that ripening may not be delayed. If little water is available during the season, two irrigations are probably sufficient, and two are better than one. In one 
series of Utah experiments it was found that $71 / 2$ inches applied in one irrigation yielded nearly ninety-two bushels of corn; whereas, the same quantity of water applied in two equal irrigations yielded nearly 102 bushels of corn. When the two irrigations were used, there was a larger proportion of seed in the whole plant, indicating that an application of water was made possible at the time of seed-formation, and nutritive materials were probably transferred to the ears at the expense of the stover. An annual precipitation of 12 to 15 inches coming largely in the fall and spring would indicate that three irrigations throughout the season should be sufficient to mature a good crop of corn. True, many farmers apply water more frequently than this, but the greater number of irrigations is of doubtful value. Fewer irrigations, with many cultivations, would in the end be more satisfactory. When four or five irrigations are applied, about 10 per cent of the total water should be added in June; 50 per cent in July; 30 to 40 per cent in August, and about 10 per cent in September. When only two irrigations are applied, perhaps 60 per cent of the total should come early in July.

163. Quantity of water for corn.-Corn is not a waterloving crop. It will use large quantities of water if available, but it does not demand an abundance of water to produce a good yield. As with other crops, the soil determines chiefly the quantity of water used by the corn crop. On shallow, gravelly and new soils, more water is necessary than on the deep, clayey, well-tilled soils. The climatic factors that increase evaporation increase the water-use of the crop.

Corn, like all other crops, is subject to the law that the increase in yield is not proportional to the increasing water supplied by irrigation. The more water is used, 
though the total yield be slightly larger, the less the yield to the unit of water. The following table, taken from the Utah work, will illustrate this statement:

Yields of Corn with Varying Quantities of Irrigation Water

\begin{tabular}{c|c|c|c|c}
\hline \hline $\begin{array}{c}\text { Inches } \\
\text { of irrigation } \\
\text { water applied }\end{array}$ & $\begin{array}{c}\text { Bushels of } \\
\text { grain } \\
\text { to the acre }\end{array}$ & $\begin{array}{c}\text { Pounds of } \\
\text { stover } \\
\text { to the acze }\end{array}$ & $\begin{array}{c}\text { Pounds of } \\
\text { stover to } \\
\text { one bushel } \\
\text { of corn }\end{array}$ & $\begin{array}{c}\text { Bushels of } \\
\text { grain for } \\
\text { each inch } \\
\text { of water }\end{array}$ \\
\cline { 2 - 3 } 7.5 & 79.14 & 7,189 & 91 & 6.07 \\
10.0 & 89.52 & 6,007 & 67 & 5.80 \\
15.0 & 93.93 & 8,279 & 88 & 4.57 \\
20.0 & 91.58 & 8,692 & 95 & 3.59 \\
25.0 & 99.16 & 9.492 & 96 & 3.25 \\
30.0 & 97.12 & 10,390 & 107 & 2.73 \\
55.0 & 96.78 & 10,258 & 106 & 1.43 \\
\hline
\end{tabular}

The depth of irrigation varied from $71 / 2$ to 55 acreinches, but the acre yield increased only from eighty to ninety-seven bushels of grain, and the stover showed a similarly small increase. The bushels of grain per inch of irrigation water were six, when $71 / 2$ inches of water were used; and only 1.43, when 55 inches were used-a decrease of three-fourths. Invariably, also, as more water was used, the proportion of stover to grain increased. (Fig. 65.)

Thirty acre-inches have been allowed, frequently, by state engineers as the proper quantity of water to be used by farmers. It may be calculated from the above table that, when 30 acre-inches are applied to 1 acre, about ninety-seven bushels of corn are obtained; when spread over 4 acres, more than 316 bushels of corn are produced. This possible crop-producing power of water must be considered in building irrigated empires. The best knowledge of the day indicates that 12 to 15 acre-inches are ordinarily a very satisfactory depth of water for the produc- 
tion of good crops of corn. The longer growing season of corn makes necessary more irrigations and possibly a larger quantity of water than for wheat. Where the rainfall is less than 12 inches, or on unfavorable soils, or under conditions of very high evaporation, it may be necessary to increase this quantity of water to 18 inches. It is more likely, however, that on deep soils, properly cultivated, the depth of water necessary to produce proper crops of corn may be reduced to 10 or even $7 \frac{1}{2}$ inches of water.

If it be assumed that the length of the irrigating season for corn is ninety days, the duty of a second-foot should not be greatly different from that of wheat. One

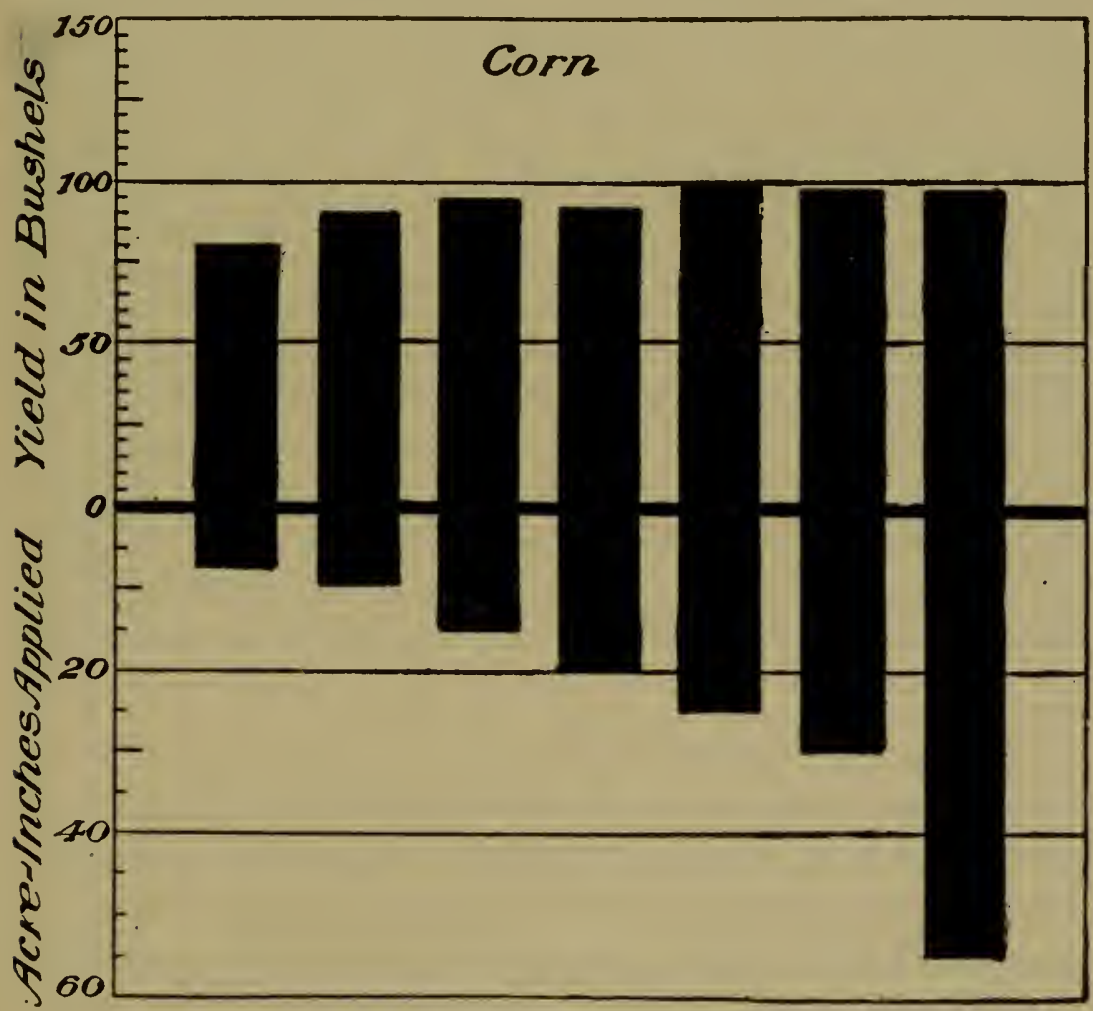

Fig. 65. Yield vs. water (corn). 
second-foot, flowing for ninety days, will cover 180 acres to a depth of 12 inches. This corresponds closely to the duty of water as given for wheat. As in the case of the small grains, the duty for corn is steadily increasing.

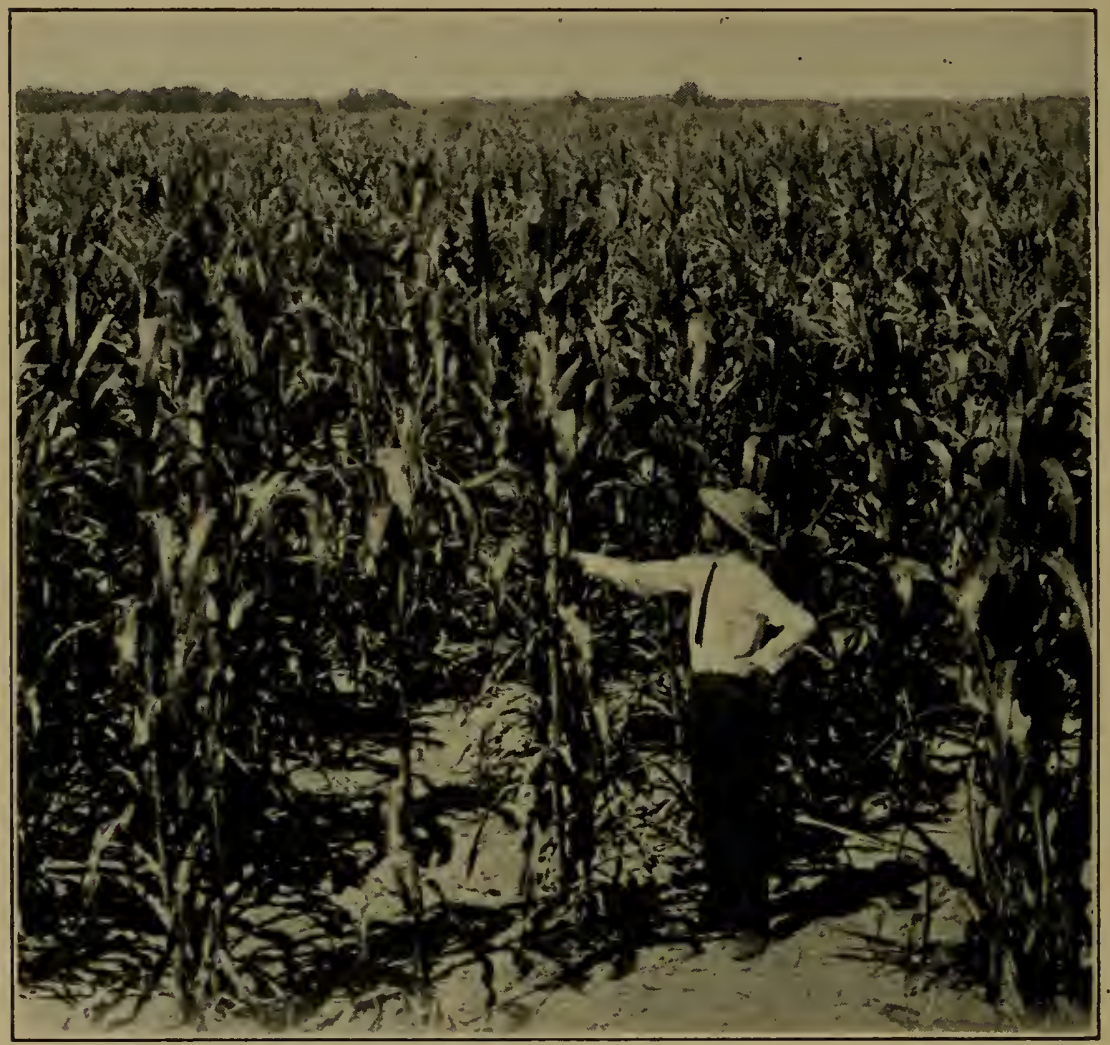

FIG. 66. Irrigated corn in Arizona.

164. Rice.-Rice is a semi-tropical plant, best developed in moist climates. Certain varieties of upland rice thrive in dry climates, but these are practically unknown in the United States. The rice of commerce requires moist conditions, and, therefore, heavy irrigation. It is grown chiefly on the delta and marsh lands of the South 
Atlantic States, the alluvial lands along the Mississippi, and in southwest Louisiana and southeast Texas. Upland rice may be grown wherever corn does well, and by methods similar to those used in the culture of summer oats.

Rice fields are divided by field levees into tracts of varying sizes, depending on the slope of the land and the depth of water to be applied. When the water is to stand over the field from 6 to 12 inches deep, the levees are made from 12 to 18 inches high; they should, in fact, be just high enough to retain the water at the depth decided on. If the levees are too large, the resulting vegetation on them is a source of annoyance. The method of irrigation is necessarily the method of checks.

Immediately after seeding, the land is flooded for a few days. When the plants are 6 to 10 inches high, they receive the first irrigation. From that time the water is made to stand on the land to a depth of 3 to 6 inches until the grain is in the dough, or about two weeks before harvest, when the water is drained off and the crop left to ripen. The irrigation water is nearly always pumped from lower levels into the checks, and the ground water is very near the surface, so that it is not a difficult matter to keep water standing on the soil for any desired length of time. The length of the irrigation season varies from two to three months, with an average of about seventy days.

It might be supposed, from the fact that rice fields are thus covered with standing water, that large quantities of water are necessary for rice-production. The careful investigations of the Office of Experiment Stations show that only from 12 to 18 inches of water above the rainfall are really used by the plant. In one series of experiments, 
about 29 acre-inches of water were applied throughout the season to the field, including the rainfall; the evaporation was about 16 inches, leaving 13 inches that were actually used by the plant. This is not greatly different from the quantity of water actually supplied, by irrigation, to other cereals.

The rice industry is very old in the United States. For many years it had languished, but of recent years has, appeared to show signs of new growth. It is probable that the study of varieties of rice suitable for growth on the great irrigated areas of the country, where less water must. be used, may develop another highly profitable branch of industry for the irrigated region. (Fig. 62.)

\section{REFERENCES}

BARK, Don H. Duty of Water; Investigations (1910-12). Ninth Biennial Report, State Engineer of Idaho (1912).

Bond, Frank, and Keeney, George H. Irrigation of Rice in the United States. United States Department of Agriculture, Office of Experiment Stations, Bulletin No. 113 (1902).

Harris, F. S. The Irrigation and Manuring of Corn. Utah Experiment Station, Bulletin (1914).

Humbert, Eugene P. Wheat-growing Under Irrigation. New Mexico Experiment Station, Bulletin No. 84 (1912).

Hunt, Thomas F. The Cereals in America. Orange Judd Company (1904).

McLadghlin, W. W. Irrigation of Grain. United States Department of Agriculture, Farmers' Bulletin No. 399 (1910).

McLadghlin, W. W., and Morgan, E. R. Irrigation Investigation during 1905-6. Utah Experiment Station, Bulletin No. 99 (1906).

Nowell, Herbert T. Irrigation of Barley. Wyoming Experiment Station, Bulletin No. 77 (1908).

TEeLE, R. P. Review of Ten Years of Irrigation Investigations. United States Department of Agriculture, Office of Experiment Stations, Annual Report for 1908 (separate). 
WeLCH, J. S. Irrigation Practice. Idaho Experiment Station, Bulletin No. 74 (1914).

Widtsoe, J. A., and Merrill, L. A. Methods for Increasing the Crop-producing Power of Irrigation Water. Utah Experiment Station, Bulletin No. 118 (1912).

Widtsoe, J. A., and Merrill, L. A. The Yields of Crops with Different Quantities of Irrigation Water. Utah Experiment Station, Bulletin No. 117 (1912). 


\section{CHAPTER XIV}

\section{ALFALFA AND OTHER FORAGE CROPS AND PASTURES}

A Permanent, modern system of agriculture cannot be developed without the aid of live-stock husbandry. Consequently, forage crops and pastures are of high importance in irrigation agriculture. However, no forage crops of any kind should be shipped out of the district where they are raised, for the plant-food contained in hays, especially alfalfa hay, is often worth more than the money actually received for the hay. Irrigationfarmers, dealing with a new and largely undeveloped system of agriculture, on very fertile soils, are tempted to pay little or no attention to the permanence of the system. In the sections recently reclaimed by irrigation, there is, however, the most unusual opportunity known in the history of agriculture, to apply our vast, new agricultural knowledge on lands which never before have been under cultivation. It should be possible by the wise use of our knowledge to build, under irrigation, a system of agriculture excelling all others in profitableness and increasing fertility. A first principle in accomplishing this is that the irrigated sections must send out only such products as have been manufactured from the rougher crops-butter, cheese, sugar and meats-and which contain the minimum quantities of plant nutrients.

165. Alfalfa, or lucern. - This wonderful crop has been the foundation of successful irrigation agriculture 
in the United States. If corn is the king, then alfalfa is the queen of American crops. Alfalfa is of high antiquity, and the watchful care of unnumbered generations of farmers has resulted in a crop of extremely high agricultural value. It thrives best in arid and semi-arid climates, and under irrigation in such climates reaches its highest perfection. Differences in altitude or average temperature do not affect it much, so that over the whole irrigated section, from the high mountain valleys to the seacoast and from the cold mountain country to the burning sands of the low desert, alfalfa thrives and yields heavily. It is an excellent preparatory crop for infertile or new land. In cases without number it has been found that lands on which grain would not at first grow would support alfalfa, and that, after some years in this crop, the lands would produce grains or any other crop. It is a host for nitrogen-gathering forms of life and, therefore, increases the fertility of the soil. It is a most palatable food for all domestic animals, which thrive upon it. Its tonnage is large, averaging about five tons to the acre. It is reported that in Arizona and similar districts, exceptional yields of seven tons or more are obtained. With proper tillage, an alfalfa field lasts long. Even with the improper tillage given the early alfalfa fields of the West, there are fields, forty to fifty years old, that are still yielding large harvests. When the alfalfa field is disked or harrowed annually, it should continue for generations to produce undiminished yields.

Alfalfa requires abundant sunshine, and prefers a high summer temperature. It does best on rich, deep, welldrained soil. Hardpan or ground water near the surface is undesirable, as it tends to prevent the descent of the tap-root. Especially is such interference objectionable 
when it comes after the plant has developed roots deeply in the soil. It is not an ideal dry-farm crop except where the ground water is within reach, so that the roots may draw water from below. It is essentially an irrigated crop, and thrives best where the conditions of soil, temperature, relative humidity and sunshine are of an arid character.

There is nothing unusual in the preparation of land for alfalfa. It requires a smooth surface preferably with a slope of from 10 to 20 feet to the mile. It should be sown in drill rows on land well stored with water. It is difficult to obtain a stand on raw land. Oats may be sown with it as a nurse crop. During the first two years of its life it needs careful culture. By that time it is well established and can then receive the regular treatment given the matured alfalfa fields. Water should then be kept off the land until it is actually needed, so that the plant roots may be trained to strike deeply.

166. Cultivation of alfalfa.-Cultivation of alfalfa fields to prevent the evaporation of water is very possible. Each fall the alfalfa field is gone over with a disk or a harrow, which loosens the top soil to prevent evaporation, and, at the same time, leaves the soil so that it may easily absorb water and be acted on by atmospheric agencies. Meanwhile, the thoroughness with which the older plant shades the ground tends greatly to diminish evaporation.

It is a very common practice, after the last cutting, to turn cattle and horses into the alfalfa field, to make use of the late growth. When pastures are scarce, and hay not abundant, this may be justifiable, but, considering the effect upon the field, it is of doubtful value. The tramping of the animals makes the soil hard and if there are fall rains, the top soil may become puddled and thus 
the alfalfa seriously injured. If such pasturing is not followed by disking, there may be a great diminution in the value of the field. Occasionally, stock is turned into the field after each cutting. The practice must be wholly abandoned. It is also important that stock be kept off the field soon after an irrigation. The top soil of alfalfa, as of the grains, must be kept in an ideal condition for plantgrowth.

167. Method of irrigating alfalfa.-Water may be applied to the alfalfa field either by flooding or furrowing. If water is abundant, flooding is generally the method employed. Check or border irrigation has been used on a large scale with alfalfa fields.

The border method uses sections of the field, about 15 feet wide, of varying width up to 900 feet long. The border levees are about 7 feet wide and 1 foot high, and covered with alfalfa. Water is run down in a large sheet between these levees. The check method completely incloses large fields of alfalfa with levees, into which the water is run until it covers the whole field to a certain depth. In the inter-mountain region, on the smaller fields, where the flooding method is followed, water is applied by the field-ditch method. From the supply ditch, a transverse ditch is run to the field, from which the water is spread over the soil by means of small field furrows that do not interfere materially with the plant or its harvesting.

Recently the furrow method promises to displace the flooding method for irrigating lucern fields. Where the soil tends to run together, or where it bakes hard after irrigation, the furrow method is especially employed. Where the supply of water is limited, it has been found advisable also to employ the furrow method. In furrowing, 
the land, immediately after seeding, is "laid off," "marked" or furrowed. The furrows thus made become permanent, and last usually as long as the field is used. They may become partly filled from year to year with the sediment carried by irrigation water, but this is removed by the annual cleaning. The method of applying water by furrows is the same for alfalfa as for other crops. (Fig. 67.)

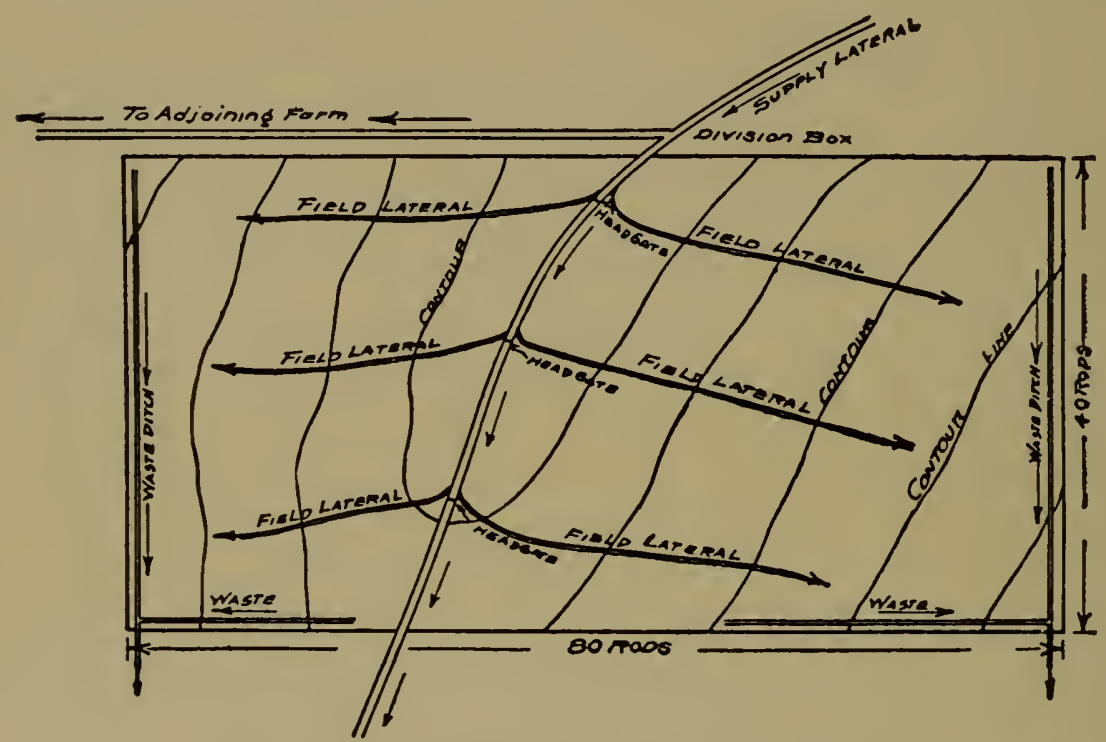

FIG. 67. Plan of irrigating an alfalfa field in Colorado.

Perhaps 5 per cent of the total irrigated area of alfalfa is sub-irrigated by natural means, as already explained.

168. Time to irrigate alfalfa. - If the fall and winter rainfall is insufficient to saturate the soil, fall or winter irrigation of alfalfa, especially if the winters are mild and open, has been found quite satisfactory. It is imperative, however, that water applied to alfalfa in the fall or winter be made to soak into the soil, for if water stands on the soil, in winter, the crop will probably be injured. Water should not be applied in the fall until some time after 
the last harvest, when the plants are dormant. Open, dry winters are not conducive to good alfalfa yields. A soil of low water content in winter is not so satisfactory for alfalfa as one that is near field saturation. However, too much water is equally harmful, and may cause winterkilling. Free water, found in the upper foot or two of the soil, freezes in seasons of high cold, and serious injury is done the plants. The alternate freezing and thawing of some winters is even more injurious to the crop. If

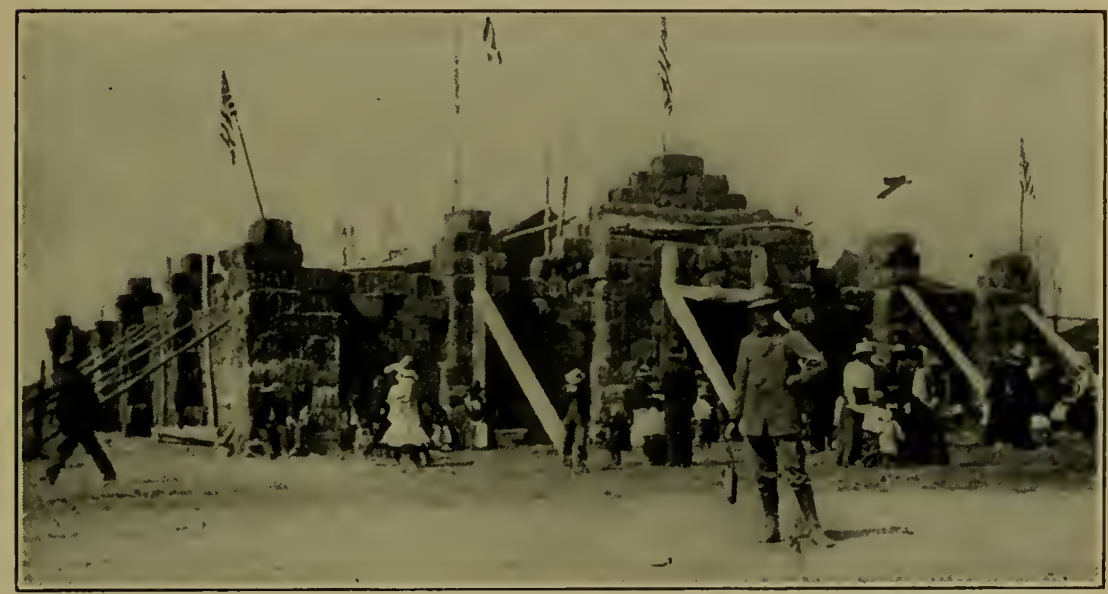

Fra. 68. Temporary county fair building constructed of baled alfalfa hay. In a pioneer section.

water is allowed to form ice over the surface, the alfalfa plants are fatally injured. The soil should not be too wet in the spring, for the low temperature of the soil induced by the presence of much water will tend to retard the early and important spring growth.

After the spring growth has begun, the first irrigation should be postponed for some weeks, although it is not so important to do this with alfalfa as with the annual crops that are irrigated late in order to drive their root-systems downward. Where wheat is planted in April, the first 


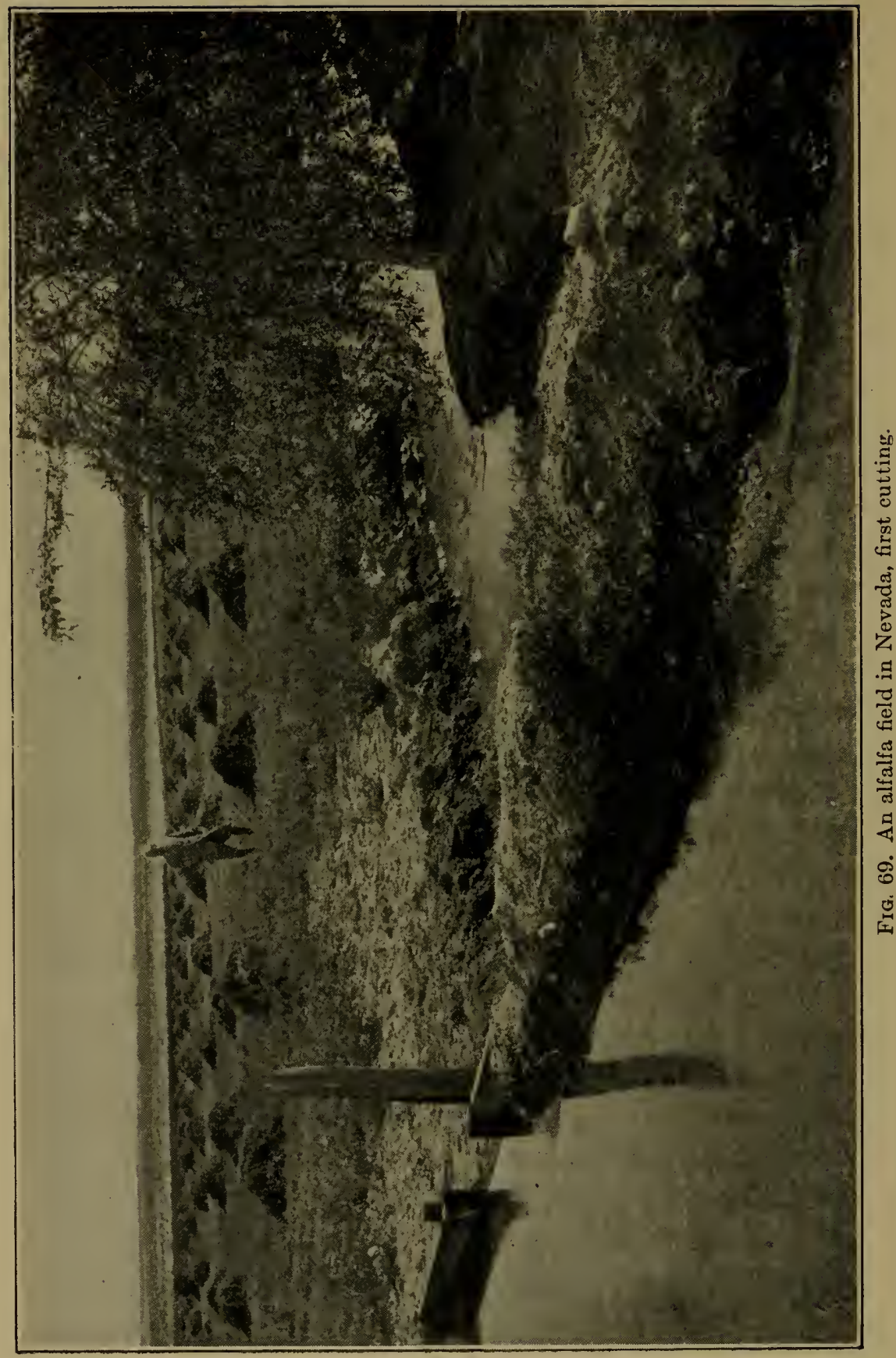


irrigation of lucern usually comes the first or second week in June and occasionally as late as the third or fourth week in June. Little water in the soil at the time of first growth makes it necessary to apply water even earlier.

It is sufficient, under conditions of deep soil and moderate evaporation, to give the crop one irrigation for each cutting; two or even three light irrigations for each cutting are not objectionable. 'The best present practice is to apply water a few days before cutting and again soon after cutting - nearly two irrigations for each cutting.

If one irrigation for each cutting is used, it is always a question whether to apply it before or after cutting. If water is applied just before the cutting of alfalfa, when the land is covered with a heavy growth, there is more trouble to cover the land properly with water. On the other hand, the water becomes well distributed throughout the soil in time to serve the second cutting to the best advantage. If the water is applied immediately after cutting, there is less trouble in applying it to the clean field, but it will take longer time before the plant can make as good use of the water as it could if it were already distributed throughout the soil. In the Utah work, no appreciable difference in total seasonal yield was found whether the irrigation was applied just before or just after cutting. Heavy soils bake more readily if water is applied after cutting.

Bark has determined the time at which alfalfa is irrigated by a large number of Idaho farmers and the percentage of the season's irrigation applied each month. The following table shows some of the results:

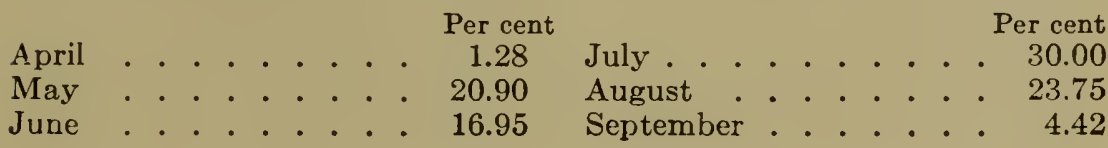


It may be observed that 1.28 per cent of the total quantity applied during the seaon, was added in April. That undoubtedly was due to the lack of water in the soil at that time. The May irrigation, likewise, was doubtlessly applied to lands not well saturated with moisture in the spring. The bulk of the irrigation came in July and August, during the time of the second and third cuttings.

169. Quantity of water for alfalfa.-The growing season for alfalfa is longer than for the small grains, but to offset this it uses less water for each pound of dry matter. Nevertheless, the heavier acre-yield of alfalfa makes necessary more irrigation for alfalfa than for the cereals. The law connecting yield of alfalfa with the quantity of water used is the same as that developed for other crops. In the following table are given the results of experiments on the water requirements of alfalfa conducted by Fortier in Montana:

Yields of Cured Alfalfa Hay with Varying Quantities of IRRIGATION WATER

\begin{tabular}{c|c|c}
\hline \hline $\begin{array}{c}\text { Inches of irrigation } \\
\text { water supplied }\end{array}$ & Pounds per acre & $\begin{array}{c}\text { Pounds per inch } \\
\text { of water }\end{array}$ \\
\cline { 2 - 3 } 6 & 9,220 & 1,537 \\
12 & 8,840 & 737 \\
18 & 7,500 & 416 \\
24 & 12,700 & 529 \\
30 & 14,400 & 480 \\
36 & 15,360 & 426 \\
\hline
\end{tabular}

The depth of irrigation water varied from 6 to 36 inches; the total yield of well-cured alfalfa hay, from 9,000 to 15,000 pounds. As shown in the third column of the table, the yield did not keep pace with the increase 
in the irrigation water for the harvest of cured alfalfa hay, for each inch of irrigation water fell from 1,500 pounds when 6 inches of water were used, to 400 pounds when 36 inches of water were used. The maximum yield did not coincide with the economic yield. The results obtained by Fortier have been corroborated by the Utah Station. Some of the data obtained are found in the following table:

Yields of Cured Alfalfa Hay with Varying Quantities of IRRIGATION WATER

\begin{tabular}{c|c|c}
\hline \hline $\begin{array}{c}\text { Inches of irrigation } \\
\text { water supplied }\end{array}$ & Pounds per acre & $\begin{array}{c}\text { Pounds per inch } \\
\text { of water }\end{array}$ \\
\cline { 2 - 3 } 10 & 9,884 & 988 \\
15 & 7,546 & 503 \\
20 & 9,097 & 455 \\
25 & 9,354 & 374 \\
30 & 8,840 & 295 \\
50 & 10,813 & 216 \\
\hline
\end{tabular}

The irrigation water applied was increased from 10 to 50 inches, and the yield of cured alfalfa hay increased from 9,800 to 10,800 pounds. That is, the yield of cured alfalfa for each inch of water fell from 988 pounds to 216 pounds as the irrigation water was increased five-fold. Bark, working in Idaho, found the same law to hold. (Fig. 70.)

While alfalfa does not respond proportionally to the application of large quantities of water, yet it can endure fairly large irrigations, providing the soil is fertile and not too heavy. In water-logged soils, the yield of alfalfa is invariably lessened. Alfalfa, not properly cared for by harrowing or disking, does not respond well in its yield to the water used. This is partıcularly important in districts 


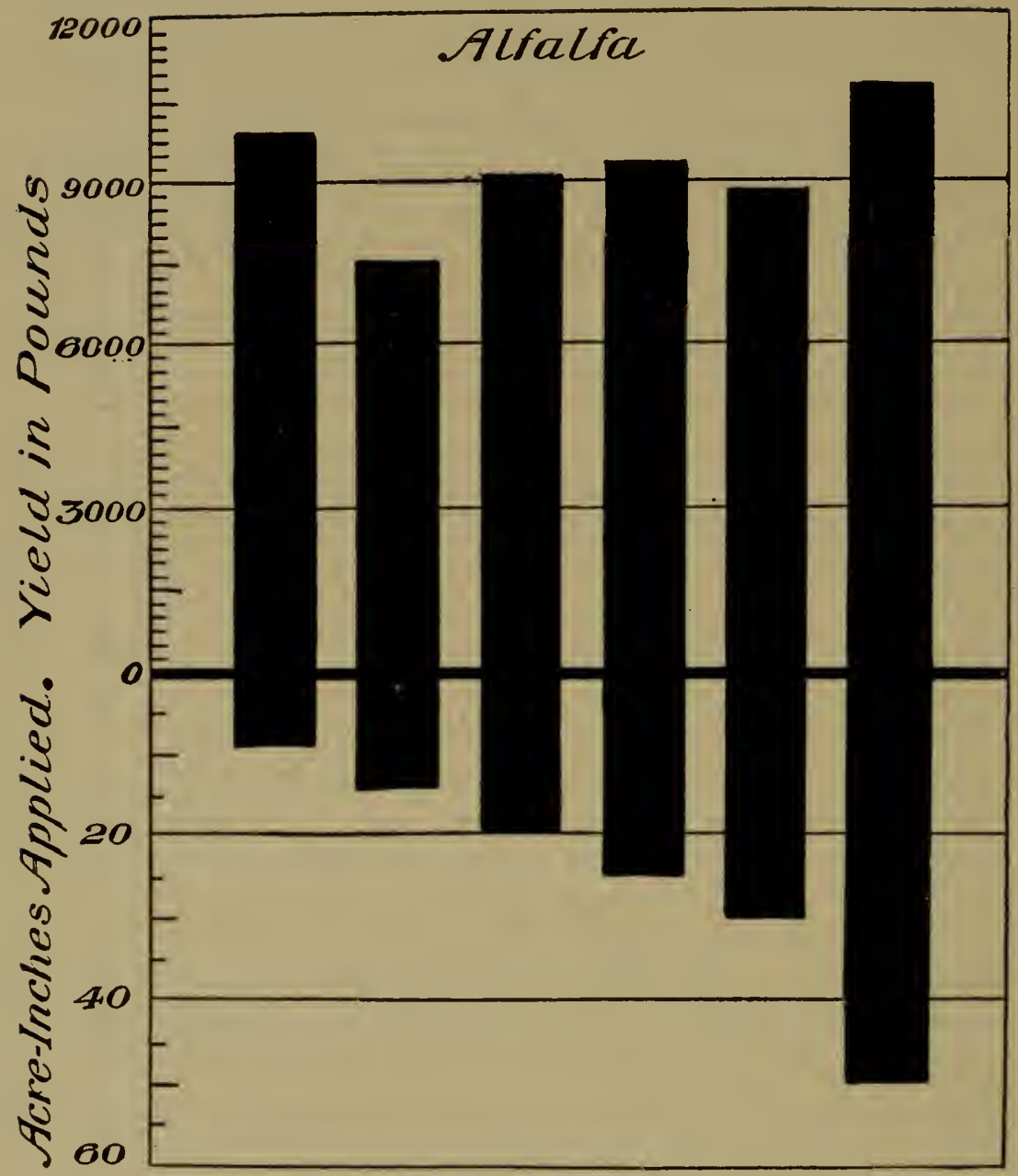

Fig. 70. Yield vs. water (alfalfa).

the irrigation water of which deposits much silt over the soil.

A small quantity of water will give a fair yield of alfalfa hay; good returns are obtained with 12 to 18 or even 24 inches of water. In general, on alfalfa fields, about one and one-half times as much water may be safely used as is given to corn and the small grains. On deep soils, alfalfa 
will take more water and give good returns. The abundance of water must always be considered in determining the water to be used on alfalfa fields, for it will determine whether the acre yield or the acre-inch yield is of first importance. Fortier's results show that 30 acre-inches, used on one acre, produce about 14,400 pounds of alfalfa hay; on five acres, about 64,100 pounds. It is probably safe to say that, on the fertile soils of the West, not more than 18 inches of water need be applied to alfalfa, providing the crop is given good cultivation. On soils that are infertile, shallow, very sandy or underlaid by hardpan, more can probably be well used. This depth of water refers to districts which receive an annual rainfall of 12 to 15 inches. Where less rain falls, more water must probably be added in irrigation; where more, less need be applied.

The irrigation season for alfalfa covers approximately 120 days-June to September, inclusive. During this period one second-foot will cover 240 acres to a depth of 12 inches; 150 acres to a depth of 18 inches; 120 acres to a depth of 24 inches. The best managed irrigation systems have a duty of water for alfalfa of about 150 acres, which is increasing.

Irrigated alfalfa hay is of high quality. The quantity of water used in producing alfalfa determines, in a large measure, the quality of the hay. The more water used, the more woody the hay becomes, and the less valuable, therefore, for feeding purposes. The less water used, the richer the hay becomes, per pound, in the blood- and muscle-forming elements. All in all, as with other crops so with alfalfa-it must be grown with a moderate quantity of water.

170. Alfalfa seed.-The present large demand for alfalfa seed is likely to continue as long as new lands are being 
brought under irrigation. The conditions determining the production of alfalfa seed are not well understood, but the chief secret seems to be the use of little water. The first cutting is harvested as usual for hay; the second cutting is allowed to go to seed with little irrigation-none if the first cutting has been well irrigated; after the harvest, water is added to obtain, if possible, a small third crop. The use of much water diminishes the yield of seed, and also retards the production of the seed until too late in the fall. Morgan, working in Utah, obtained the highest yield of seed when about 8 inches were used. Either less or more resulted in smaller yields of seed. In other localities, some other quantity might be found to be best, but it is never large. Another method of producing alfalfa seed is to clip the first growth of alfalfa about the time of the first irrigation, or a little earlier, and then to allow the first crop to go to seed. By many, this is held to be by far the most successful method of producing alfalfa seed. The whole matter needs much careful experimental study before definite rules can be laid down.

171. Hay-making crops.-The standard hay-making crops may all be produced under irrigation. With the growth of irrigation there will be an increasing demand for a variety of hay-making crops. While nearly all haymaking crops will thrive under irrigation, they do so with varying degrees of success, depending upon their adaptability to the soil and climatic conditions of the irrigated region. Usually, some years of adaptation precede the best results from any crop introduced into the irrigated region.

The Utah work included studies of timothy, orchardgrass, brome-grass, and Italian rye-grass, all of which are typical hay-making crops. These were planted as 
usual, took root and grew well. Plenty of water was added in the spring to cause an early start and to imitate a cool, moist spring; after which water was held off for several weeks, until near the time of cutting. Any of the wellestablished methods of applying water may be used. From 5 to 100 inches were used in the experiments. In every case there was a smaller yield with 100 inches than with 5 inches. In some cases, smaller yields were obtained with 10 to 15 inches than with 5 inches. The evidence of the available experimental work is that these grasses tolerate only small quantities of water. The following table shows some of the results obtained in the Utah work:

Yield in Pounds Per Acre

\begin{tabular}{|c|c|c|c|c|}
\hline $\begin{array}{c}\text { Irrigation } \\
\text { water used } \\
\text { in acre-inches }\end{array}$ & Timothy & Orchard-grass & Brome-grass & $\begin{array}{l}\text { Italian } \\
\text { rye-grass }\end{array}$ \\
\hline 5.0 & & 2,526 & & \\
\hline 7.5 & 3,982 & & 4,480 & 2,357 \\
\hline 10.0 & & 2,829 & 4.957 & \\
\hline 15.0 & 3,844 & 2,685 & & 2,218 \\
\hline 30.0 & 6,054 & & 3,821 & \\
\hline 40.0 & . . & 4,042 & . . & \\
\hline 45.0 & & & & \\
\hline 60.0 & 8,406 & 5,270 & 4,757 & 3,201 \\
\hline 100.0 & 2,214 & 1,192 & 3,068 & 2,357 \\
\hline
\end{tabular}

Since the roots of these plants do not penetrate the soil deeply, the frequent application of water may be justified, but the total quantity need not be great. Timothy appears to endure much water better than the other crops. One crop only is obtained from these grasses, and they are, therefore, much like the small grains in their water requirements. Ordinarily it is sufficient to give these crops one good irrigation before cutting. From 5 to 10 inches of water should be sufficient to produce the one 
crop of hay. On infertile or sandy soils from 10 to 15 inches should be ample. Where the aftermath is pastured, the field may be irrigated lightly once or twice during the hot months of July and August, when good pasturage results until late in the fall.

These and other grasses, especially the native grasses, are often grown on the large ranches of the West. One crop is ordinarily harvested and the aftermath pastured. As early as possible in the spring, these fields are covered

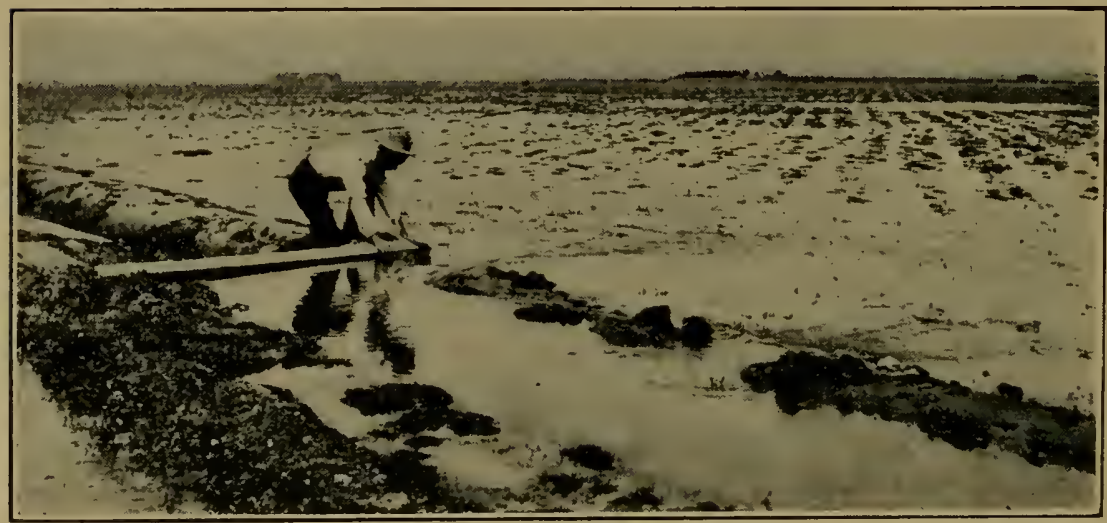

FIG. 71. Flooding pasture land.

with immense quantities of water, which often stand for days, 1 to 2 feet deep. It is believed that under such conditions the frost is taken out of the soil, and a larger quantity of hay is obtained. The experiments at our service indicate that all hay crops are injured by an excess of water, and that the best yields are obtained only by moderate irrigations. The immoderate use of water on such ranches should be discontinued, for it is an absolutely senseless practice. The hay-making grasses, whether tame or wild, should not be given too much water if large yields are desired. 
172. Red clover.-Red clover, and the other clovers, should be irrigated much as is the first cutting of alfalfa, or the grasses above discussed. All the standard forage crops are subject to the laws already laid down. It is probable that from 12 to 15 inches would meet amply the requirements of practically any one of the standard hay crops. The longer the growing period of the crop the larger will be the necessary quantity of water. When

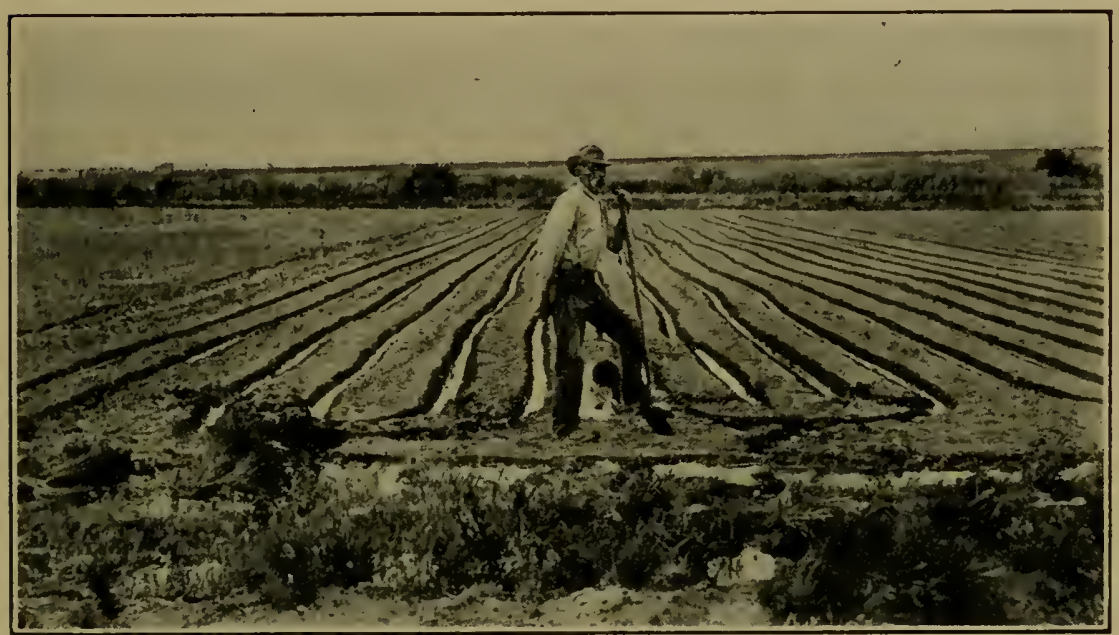

Fig. 72. Irrigating young alfalfa.

vetches and peas are grown for hay they are to be treated as indicated for peas in Chapter XV.

173. Pastures and meadows.-Many natural meadows are supplied with water from below. In fact, in the irrigated section, the term meadow is generally applied to natural pastures where no irrigation is needed. These sometimes become dry in the summer, and must then be irrigated. The time and quantity of application depend entirely upon the prevailing conditions. No rules can be laid down. 
The chief pastures of the irrigated region are those that are irrigated throughout the season; and these pastures are the finest known to agriculture. They may be kept green and luxuriant throughout the season, and, therefore, will support many times the head of live-stock possible on unirrigated pastures of humid regions. As livestock husbandry develops under irrigation, pastures will rapidly increase.

There is as yet no unity in the practice of selecting mixtures of grasses for irrigated pastures. All the standard pasture grasses are used in a variety of combinations under irrigation. Thus, in various combinations according to soil, climate and individual views, the following are used on the irrigated pastures of the West: Kentucky blue-grass, perennial rye-grass, meadow fescue, red clover, red-top, orchard-grass, white clover, alfalfa, meadow oatgrass, brome-grass, Rhode Island bent, timothy, alsike, and many of the native grasses, which, as they become better known, will become important factors in the reclamation of the West. The proper mixture, culture and irrigation of these plants will give a constant, free, luxuriant pasturage that should bring dairying and related branches of live-stock husbandry to their highest possible development.

All pastures should receive fairly heavy irrigations in the spring, and if they are used throughout the season should be irrigated during the whole summer. Pastures that are well established on deep soils, should not be irrigated, after the irrigation season begins, oftener than every two weeks, and then to a depth of 3 to 4 inches. If the pastures are on gravelly or shallow lands, water must be applied perhaps as often as once a week, but in such cases less water should be applied at each irrigation. 
The irrigation season for pastures is approximately the same as for corn or potatoes. The largest need for water is in July and August, when the hot weather causes the most rapid evaporation. Irrigated pastures must not be allowed to become very dry, for it is difficult for the pasture to recover in a season from a set-back due to a period of extreme dryness. On the other hand, the fallacy of over-irrigation should be avoided. Pastures do not need much more water than do the hay crops. The long growing season, the shallow root-system and the variety of plants in the pasturage mixture, make it difficult to foretell the best quantity of water for pastures. With our present knowledge, however, it is safe to say that from 12 to 24 inches of water should be ample to main-

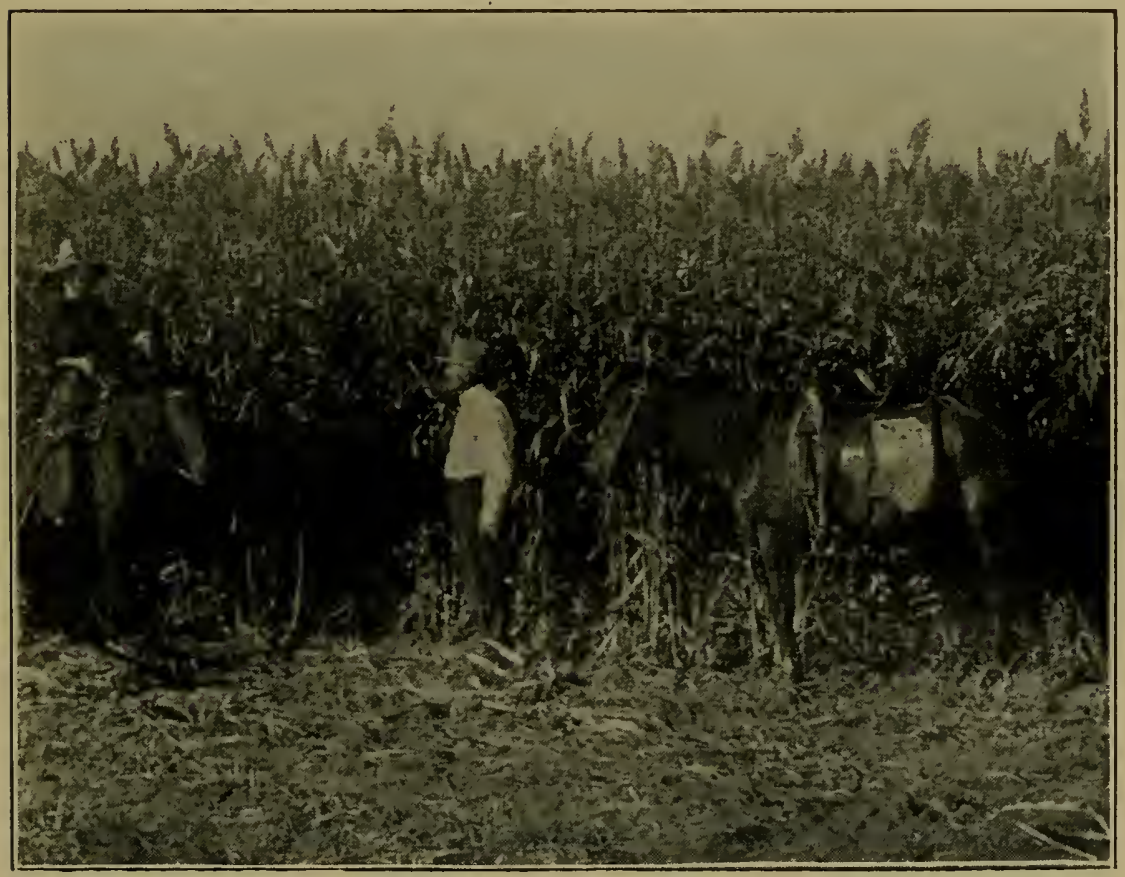

Frg. 73. Irrigated cane in Kansas. 
tain any well-planted pasture in a luxuriant condition throughout the season. This is a wide limit, and it is probable that the best quantity lies near 18 inches.

Irrigated pastures should not be grazed in early spring or immediately after an irrigation, when the soil is soft, because the plants may then be materially injured. Meadows and pastures should be frequently disked or harrowed, so that the top soil may be kept in a somewhat loose condition. Such treatment will diminish the quantity of water required throughout the season. Under the most favorable conditions, the constant tramping of animals on pastures will compact the top soil and thereby increase evaporation, decrease the rate of water penetration and increase the quantity of water required for the growth of the plants. The key to pasture maintenance seems to be the relatively frequent applications of small quantities of water to prevent any period of excessive dryness.

\section{REFERENCES}

BARK, Don H. Duty of Water; Investigations (1910-12). Ninth Biennial Report, State Engineer of Idaho (1912).

Coburn, F. D. The Book of Alfalfa. Orange Judd Company (1902).

Evans, M. W. Timothy Production on Irrigated Lands in the Northwestern States. United States Department of Agriculture, Farmers' Bulletin No. 502 (1912).

Fortier, SAMUel. Irrigation of Alfalfa. United States Department of Agriculture, Farmers' Bulletin No. 375 (1909).

McLadghlin, W. W., and Morgan, E. R. Report on Irrigation Investigations during 1905-06. Utah Experiment Station, Bulletin No. 99 (1906).

Ousn, W. H. American Irrigation-Farming. A. C. McClurg Company (1913)。 
TEele, R. P. Review of Ten Years of Irrigation Investigations. United States Department of Agriculture, 'Office of Experiment Stations, Annual Report for 1908 (separate).

Welch, J. S. Irrigation Practice. Idaho Experiment Station, Bulletin No. 74 (1914).

Westgate, J. M., McKee, Roland, and Evans, M. W. Alfalfa Seed-Production. United States Department of Agriculture, Farmers' Bulletin No. 495 (1912).

Widtsoe, J. A., and Merrill, L. A. The Yields of Crops with Different Quantities of Irrigation Water. Utah Experiment Station, Bulletin No. 117 (1912).

Widtsoe, J. A., and Merrill, L. A. Methods for Increasing the Crop-producing Power of Irrigation Water. Utah Experiment Station, Bulletin No. 118 (1912).

Wilcox, Lucius M. Irrigation Farming. Orange Judd Company (1902).

Wing, Jos. E. Alfalfa Farming in America. Sanders Publishing Company (1909). 


\section{CHAPTER XV}

\section{SUGAR BEETS, POTATOES AND MISCELLANEOUS CROPS}

AMONG the most satisfactory irrigated crops are those that pass through some process of manufacture before they are placed upon the market. Thus, sugar beets reach the consumer as sugar; potatoes, often as starch; hay as butter or cheese; fiber crops as twine and rope; oil crops as oil, and so on. It must be the great endeavor of irrigation agriculture, the initial cost of which is often larger than that of humid agriculture, to foster crops that may be manufactured. Not only do such crops make it possible to maintain more easily the fertility of the soil, but they represent steady prices and ready markets.

174. Sugar beets.-The most typical irrigated crop, in view of the development of irrigated commonwealths, is the sugar beet. All fairly fertile soils may produce sugar beets, providing proper methods of culture and irrigation are followed. Sugar beets endure alkali better than most crops; they yield fairly well even on the shallow, sandy or gravelly soils of the mesas. A clay loam of good depth is preferable, if it can be obtained. Sugar beets respond well to an arid climate and to dry summers.

Sugar beets require careful soil preparation and an even sowing and thinning. It is a common practice, apparently to assure uniform and rapid germination, to roll the soil after the seed has been placed in the ground. 


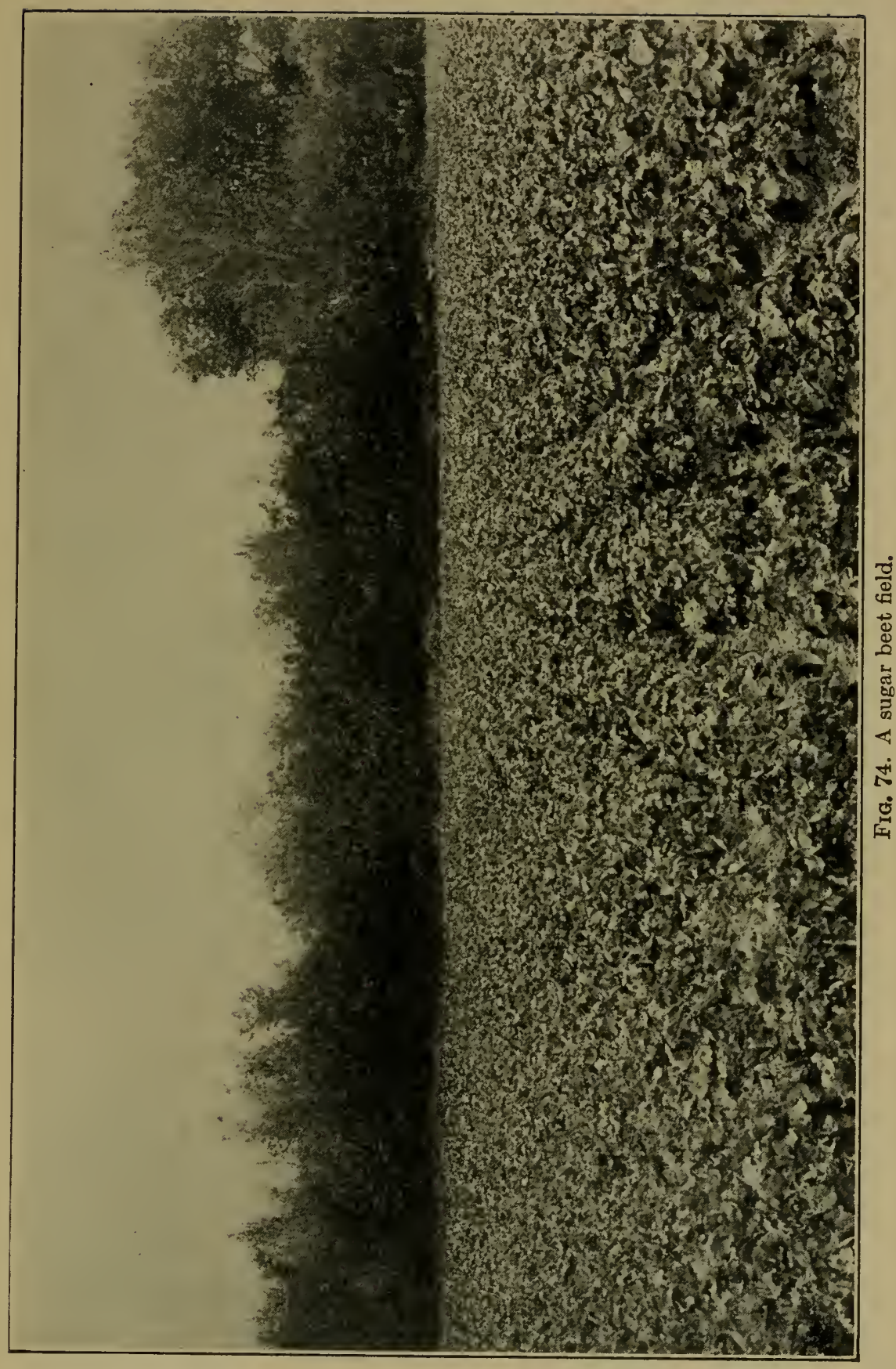


Rolling of the top soil, however, invariably causes a loss of soil moisture, and it may be necessary for the beetgrowing sections to revise their practice in this particular. If the soil is rolled, it should be followed immediately, if possible, with a harrow to stir the top soil. Sugar beets are always planted in rows, to permit of easy cultivation

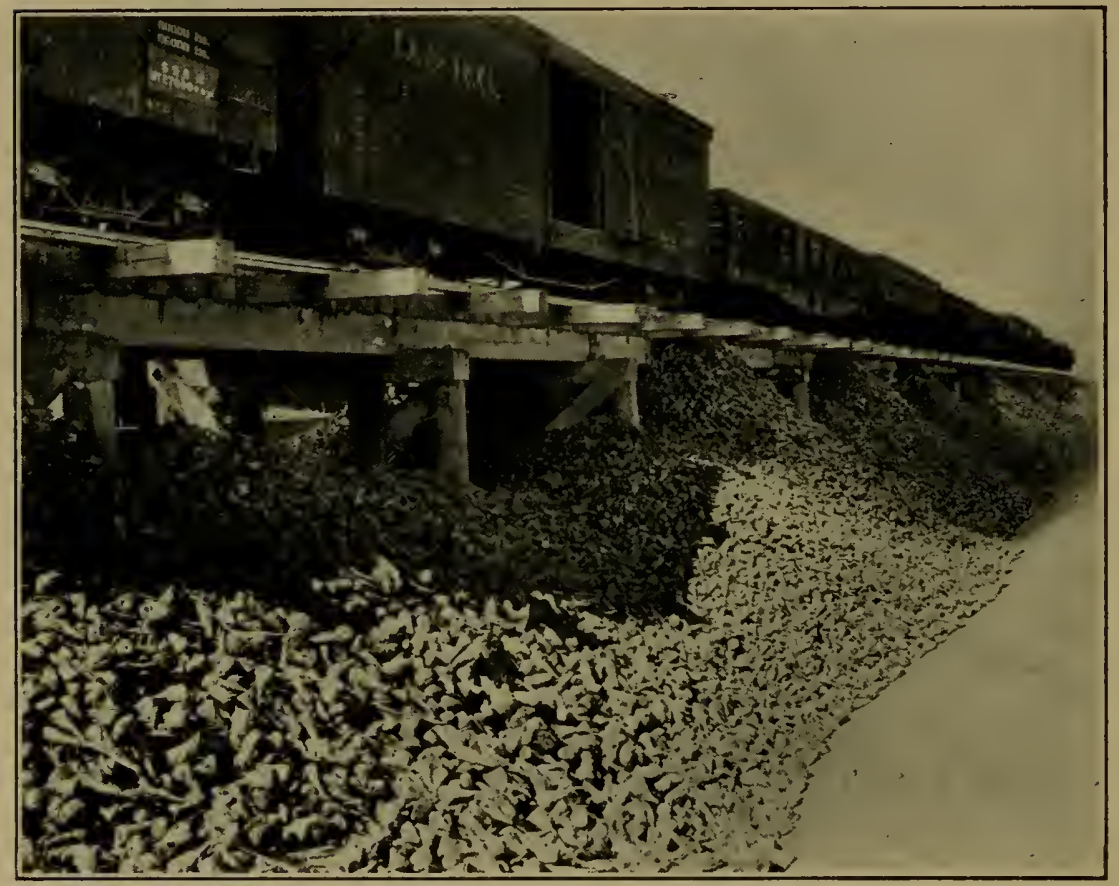

FIG. 75. Unloading sugar beets in factory bins.

between the rows, which is usually done by horse power. Cultivation, an essential factor in sugar-beet-growing under irrigation, should be practised after each irrigation and two to four times between successive irrigations. As with other inter-tilled crops, the more frequent and thorough the cultivation of the soil, the smaller the quantity of water required for the production of the crop, and the better the quality of the crop. 
175. Method of irrigating sugar beets.-The careful leveling of the land before sowing adapts sugar beet fields to the furrow method of irrigation, although either furrowing or flooding may be practised. In earlier days, the field ditch method of flooding was used for sugar beet fields, and in California, today, many of the beet fields are irrigated by the border method of flooding. By the flooding method, serious injury often results from contact between the water and the heavy leaves of the beets. Especially on hot days, immediately after an irrigation, is a kind of sun-scald induced by too much water on the ground near the leaves. Once a crop is set back by such sun-scald, it recovers slowly. This trouble is largely obviated when the furrow method is employed. All in all, the furrow method of irrigation gives the most satisfactory results in sugar beet culture and is rapidly displacing the flooding method. The rows are usually about 3 feet apart, with the furrows half way between. If the soil sub-irrigates easily, the furrow may come between every other row. Cross ditches are run at the head of the field and every 300 to 500 feet to intercept the water from above and to supply the adjoining lower section of the field. The quantity of water allowed to run down each furrow is small, except when a high head is used for the special purpose of covering the field quickly. As with corn and the other crops already discussed, it is well not to make the rows too long. The ideal of every method of irrigation is to distribute the water equally over the whole field, so that each plant may receive the same quantity of water. This is best accomplished by the furrow method of irrigation.

One of the main difficulties in all furrow irrigation is to secure a uniform application of water in the different 
furrows. Many soils "wash" easily, and if connections are made with the main supply ditch by simply hoeing out a small opening, the water is likely to make the opening larger, or by shifting, even to close it, so that the water does not for any length of time flow down the furrows as intended by the irrigator. In many sugar beet fields and orchards, small boxes, made of lath or lath-like boards, about an inch square on the ends and 24 to 30 inches long, are placed at the head of each furrow-opening, connecting the furrow with the head supply ditch, and establishing a permanent opening into each furrow, not easily disturbed by the moving water. These boxes can be placed a little higher or lower with very little effort, so that practically the same quantity of water may enter each furrow. With devices of this kind it is possible for one man to irrigate a very large tract in a very short time.

Roeding determined the relative yields obtained when the same quantity of water was applied to a sugar beet field by the open furrow and by the lath-box furrow. When lath boxes were used to carry the water into the furrows, thus providing a slower and more regulated flow, 16.47 tons of beets were produced to the acre. When the furrow opened directly through the earth into the supply ditch, making it difficult to control the quantity and even distribution of water, the yield of beets per acre fell to 13.72 tons. This emphasizes the value of an even distribution of water over the sugar beet field, and naturally over fields of any other crop. The sub-irrigation of sugar beets has been found feasible only in a few localities where the lands are naturally sub-irrigated. It has not been found profitable to install subterranean channels for water, with outlets at various intervals, for irrigation purposes.

176. Time to irrigate sugar beets.-The beet crop is 
greatly benefited by winter irrigation. The land is bare in fall and winter so that irrigation cannot injure the crop, and the soil is invariably benefited by late irrigations, providing the natural rainfall of fall, winter and spring is not sufficient to saturate the soil to the full depth of root-action. Where the winters are dry, winter irrigation of sugar beets has been found very profitable.

There should be water enough in the soil in the spring to germinate the plants without further irrigation. If, at the time of seeding, there is not sufficient water in the soil to insure rapid and complete germination, it becomes necessary to apply water just before or after seeding. Whether such irrigation for germination should be before or after seeding is still undecided. In some sections the general practice is to irrigate before seeding; in other sections, excellent results are obtained by irrigations after seeding.

The first irrigation should be postponed as long as possible after planting, as early irrigations bring the root-system to the surface and produce a turnip-shaped beet with a heavy growth of leaves, which in turn means a large, wasteful use of water later in the season. The sugar beet makes its most rapid growth after late spring and early summer, so that the crop has little need of water early in the season. Evaporation is great from the large leaf surface, and the leaves occasionally wilt slightly toward the end of a hot day. This may occur on soils well supplied with water, and implies only that water cannot be drawn from the soil as rapidly as it is evaporated from the leaves. If, in the morning, there is no evidence of wilting, no fear need be had about the condition of the crop, and the next irrigation need not be hurried along; 
but, if the beets are wilted in the morning, it is a fairly sure sign that irrigation is necessary.

On the deep, fertile soils of the West two to four irrigations should be sufficient for the season. On porous, gravelly soils, more water will be necessary. Many of the sugar factories advise two irrigations; few advise more than three. In liberal practice, three to five irrigations should be ample. The final irrigation should occur at least four to six weeks before harvest; that is, from September 1 to September 15, so that the beets may have ample time to ripen in the cool weather of fall, and be ready for the factory. Water applied late causes late growth, with a decided fall in the sugar content, and often in the yield. The great length of the growing season makes it probably better to apply a small total quantity of water in several irrigations than in one. Many irrigations tend to give an increase in the yield; but more than four or five seldom pay in added yield for the increased cost of irrigation. Where the annual rainfall is from 12 to 15 inches, most of which falls in winter and early spring, there is little or no need of irrigation in June. In July, when the growth is rapid, two irrigations; in August, not more than two, and in September, at the most one irrigation should be applied. The Utah work indicates that, of the total quantity of water to be applied throughout a season, about 45 per cent should be added in July; 35 per cent in August, and about 20 per cent in June and September. A small total quantity during the season eliminates irrigations in June and September. Clay loams should not be irrigated oftener than every two weeks. The number of irrigations in a season depends, after all, upon the total quantity to be used. With a heavy annual rainfall, little irrigation, therefore few applications; with light 
rainfall, more irrigation and more frequent applications. Beets, like all long-season crops, require water during the hot months of rapid growth, when the water runs low. Under reservoir conditions, this makes little difference, since water can be sent to the farms at the time of greatest need; but, where canals are taken directly from the rivers, it is often difficult to supply a large acreage of longseason crops with all the water needed in July and August.

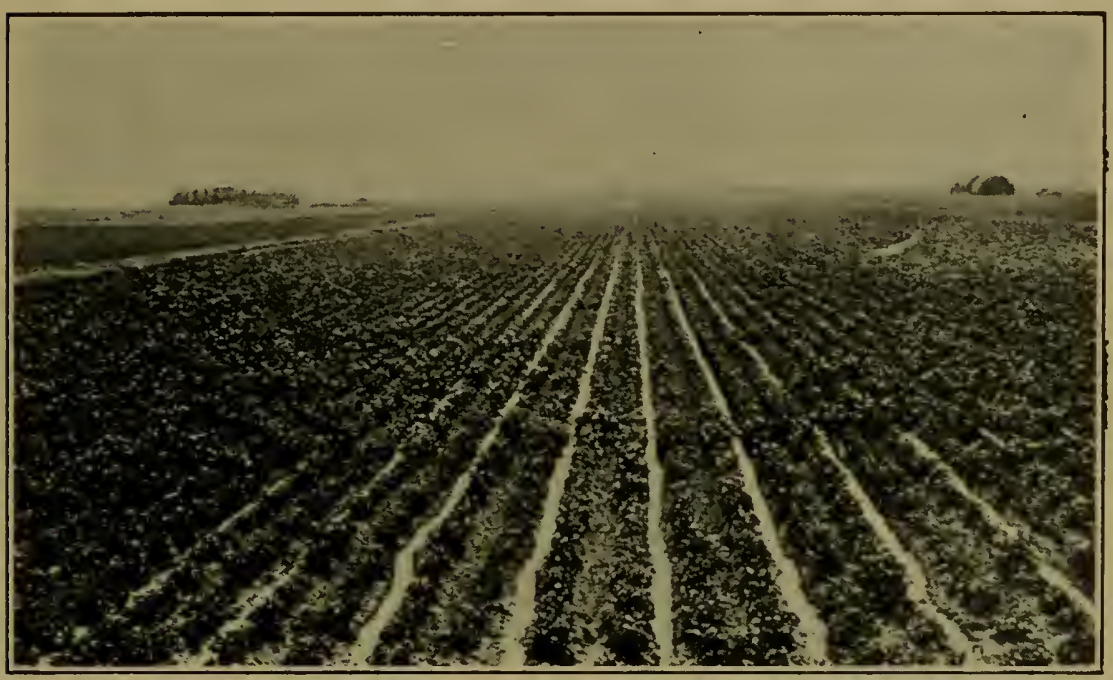

FIG. 76. Irrigating potatoes.

177. Quantity of water for beets.-Whether $2 \frac{1}{2}, 5$ or $71 / 2$ inches of water are to be applied at each irrigation, depends on climatic, soil and cultural conditions. The plant should be allowed to drain thoroughly the water from the soil. Then, a quantity of water should be added to bring the soil moisture up to the full field capacity. Ordinarily, 4 to 6 inches are used at each irrigation, but in the hot summer months of low water, 2 to 3 inches only are applied. It is inadvisable at any time to apply in one irrigation very large quantities, as for instance, 1 foot. 
The sugar beet, like the other crops hitherto studied, is subject to the law that the increased yield due to the increase of irrigation is not proportional to the added quantity of water. Roeding found, as shown in the following table, that during the season of $1905-06$, on a clayey loam of good depth, as the water was increased from 6 to 18 inches, or three-fold, the yield increased only from approximately ten tons to nearly thirteen tons to the acre. The Utah results, as also shown in the following table, are practically the same.

Yields of Sdgar Beets with Varying Qdantities of IRRIGATION WATER

\begin{tabular}{c|c|c}
\hline \hline $\begin{array}{c}\text { Inches of irrigation } \\
\text { water applied }\end{array}$ & Tons per acre & $\begin{array}{c}\text { Tons per inch } \\
\text { of water }\end{array}$ \\
\cline { 2 - 3 } Roeding's results- & & \\
6.1 & 9.7 & 1.59 \\
10.0 & 10.8 & 1.08 \\
16.8 & 11.8 & 0.70 \\
18.4 & 12.8 & 0.70 \\
Utah results- & 13.8 & \\
5.0 & 18.6 & 1.76 \\
10.0 & 19.5 & 1.30 \\
15.0 & 21.3 & 1.06 \\
20.0 & 20.8 & 0.69 \\
30.0 & 24.5 & 0.49 \\
50.0 & &
\end{tabular}

Water was applied from 5 inches to 50 inches, or tenfold. The yield under this treatment increased from 13.8 tons to 24.5 tons, or not quite double. Within these limits the yield per inch of irrigation water fell from 2.76 to 0.49 tons of sugar beets. (Fig. 77.)

By understanding this law, the possibility of 30 acreinches may well be illustrated. If 30 acre-inches are made to cover 1 acre, the yield is 20.82 tons of sugar beets; 2 
acres, 38.90 tons; 3 acres, 55.89 tons; 4 acres, 64.89 tons; 6 acres, 82.68 tons. Whether, in consideration of the scarcity of water and the abundance of land, it would be preferable to grow twenty-one tons of sugar beets on 1 acre with 30 inches, or eighty-three tons on 6 acres, with the same quantity of water, is a thing that each community must determine for itself. However, it is questionable if sugar beets should receive during any season more than 18 inches of water, representing three heavy irrigations,

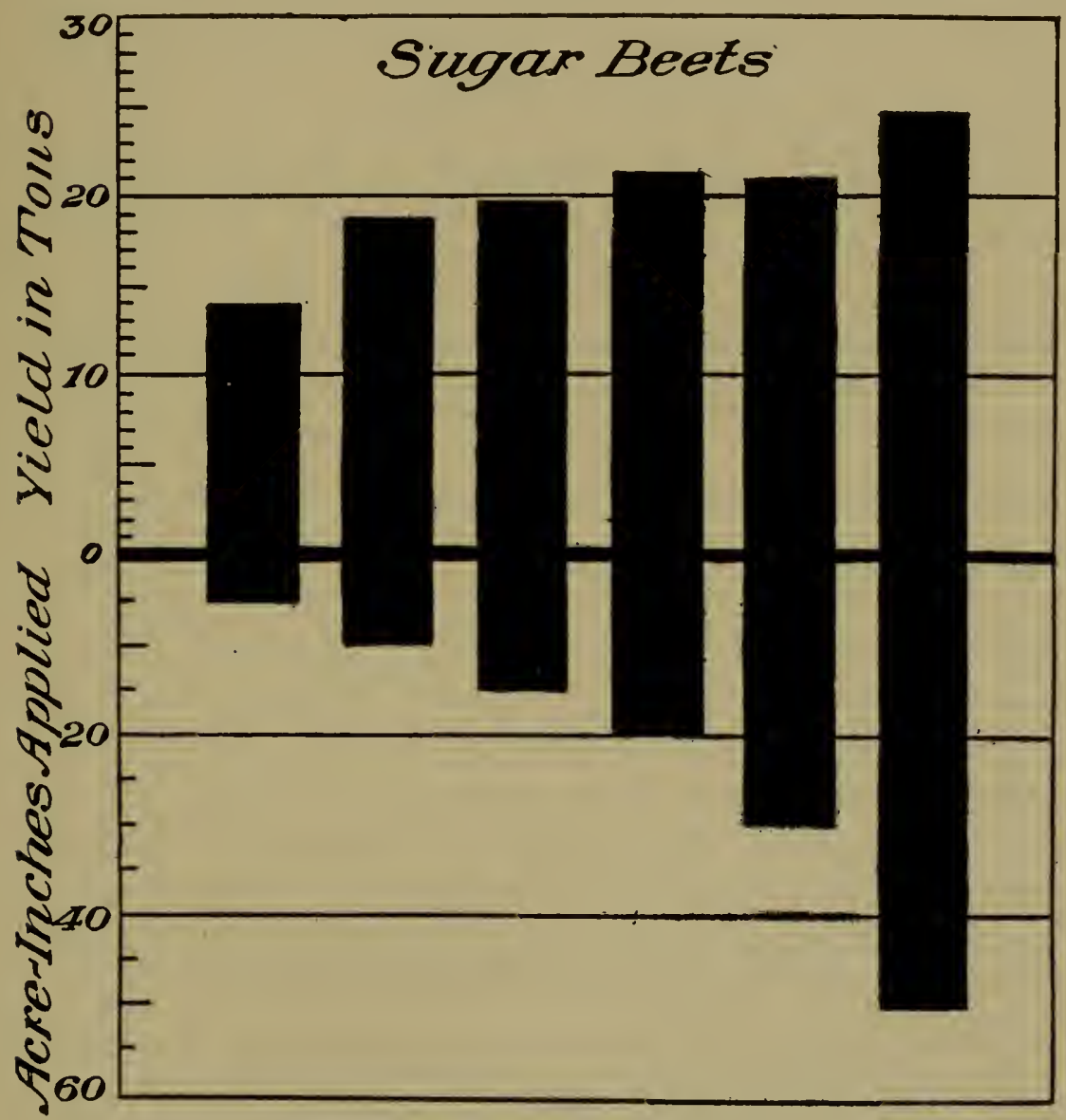

FIG. 77. Yield vs. water (sugar beets) 
or four lighter irrigations, or six light irrigations. Within existing practice, sugar beets receive from 15 to 24 inches of water, according to the prevailing water conditions, except in the newer districts where water is abundant, when even more is used. The development of more rational methods will reduce the quantity now used.

The irrigation season for sugar beets seldom exceeds ninety days. If a depth of 15 inches of water is applied during this season, a second-foot of water will have a duty of 144 acres; if 18 inches are applied, a duty of 120 acres, and if 24 inches are applied, a duty of 90 acres. The present practice makes the duty of water for sugar beets about 150 acres, with a rapid upward tendency.

As explained in Chapter XI, the percentages of sucrose and purity are highest when medium quantities of water are used in sugar beet production. The quality of sugar beets is especially improved when water is withheld several weeks before harvest. The ripening and increase in sugar and purity go on until very late in the fall. Water is often applied late, in the hope that the yield may be increased. This seldom occurs, and when an increased yield is obtained, it seldom pays for the labor of irrigation; moreover, it causes a decided loss to the sugar factory, which depends upon the sugar content for its profitable operation. Sugar beets bought on the basis of sugar are not subjected to late irrigations.

The shape of the sugar beet is materially improved when moderate quantities of water are used. An early irrigation produces turnip-shaped beets, and late or heavy irrigations produce forked or irregular beets.

178. Carrots.-Carrots are grown practically as are sugar beets, though less attention is given to quality and more to the total acre yield. Irrigation studies of this 
crop show that carrots are subject to the laws that prevail with other crops. As shown in the following table, when the water applied increased from $3 \frac{3}{4}$ inches to 60 inches, the total yield increased only from 7.3 tons to 34.2 tons per acre; the yield per inch of irrigation water diminished from 4.35 tons to 0.57. However, carrots seemed to respond more readily than did sugar beets to large quantities of water. The total quantity of water to be used throughout the season is about the same as that recommended for sugar beets.

Total Yield of Carrots with Varying Quantities of IRRIGATION WATER

\begin{tabular}{c|c|c}
\hline \hline $\begin{array}{c}\text { Inches of irrigation } \\
\text { water applied }\end{array}$ & Total yield in tons & $\begin{array}{c}\text { Total yield } \\
\text { per inch of water }\end{array}$ \\
\cline { 2 - 3 } 3.75 & 17.3 & 4.35 \\
7.50 & 16.6 & 2.22 \\
15.00 & 24.8 & 1.65 \\
25.00 & 23.4 & 0.94 \\
35.00 & 28.5 & 0.82 \\
60.00 & 34.2 & 0.57 \\
\hline
\end{tabular}

179. Other root crops.-Root crops are becoming of greater importance as the live-stock business increases. Turnips, beets, mangels, parsnips, radishes and all similar crops, when grown as field crops, may be treated practically as sugar beets and carrots. When grown in gardens they are sown more closely, and the water requirements are somewhat higher. They are always irrigated in furrows and precautions are taken not to bring water in actual contact with the growing plant, especially during hot weather. Beets are usually irrigated every two weeks; radishes and early spring crops require little total water, but most of it very early; turnips get along with little 
water-considerably less than sugar beets. Little exact knowledge has been gained concerning the irrigation of these crops. Practical experience, however, teaches that much water delays the time of ripening; it is usually sufficient to irrigate the garden every two or three weeks; water should be taken off as soon as ripening should commence; it is always dangerous to maintain water on these crops in the fall; and the total water required is not greatly different from that required for sugar beets.

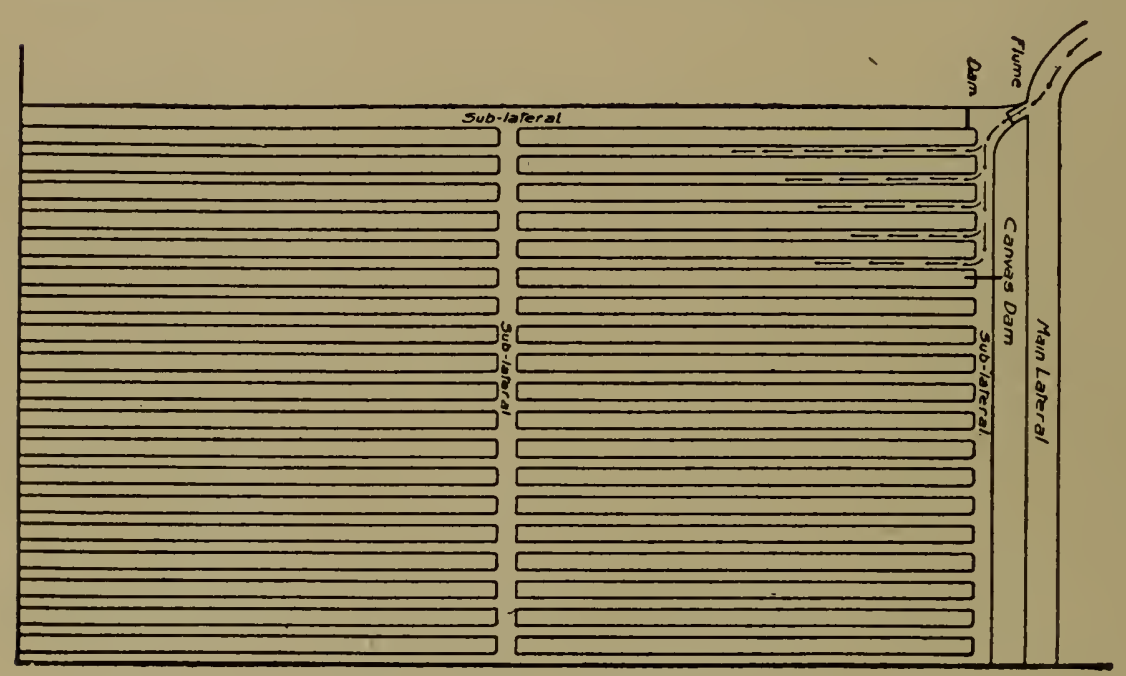

FIG. 78. Plan of potato irrigation.

180. Potatoes.-Potatoes are one of the important irrigated crops. In its water requirements the potato is much like the sugar beet. It is a long-season crop, requiring thorough cultivation. It is deep-rooted and prefers deep soil, and does best on land previously grown to alfalfa.

Potatoes should be irrigated by the furrow method, although both furrowing and flooding methods are used. Water is usually allowed to run down between all the 
rows, although on soils with good lateral seepage it may be sufficient to irrigate every other row. Occasionally, every other row only is irrigated at the first irrigation, and every row thereafter. (Figs. 76-79.)

Potatoes need a good supply of water in the soil at planting time. If the soil is too dry, it may be necessary to irrigate the crop, which may be accomplished by

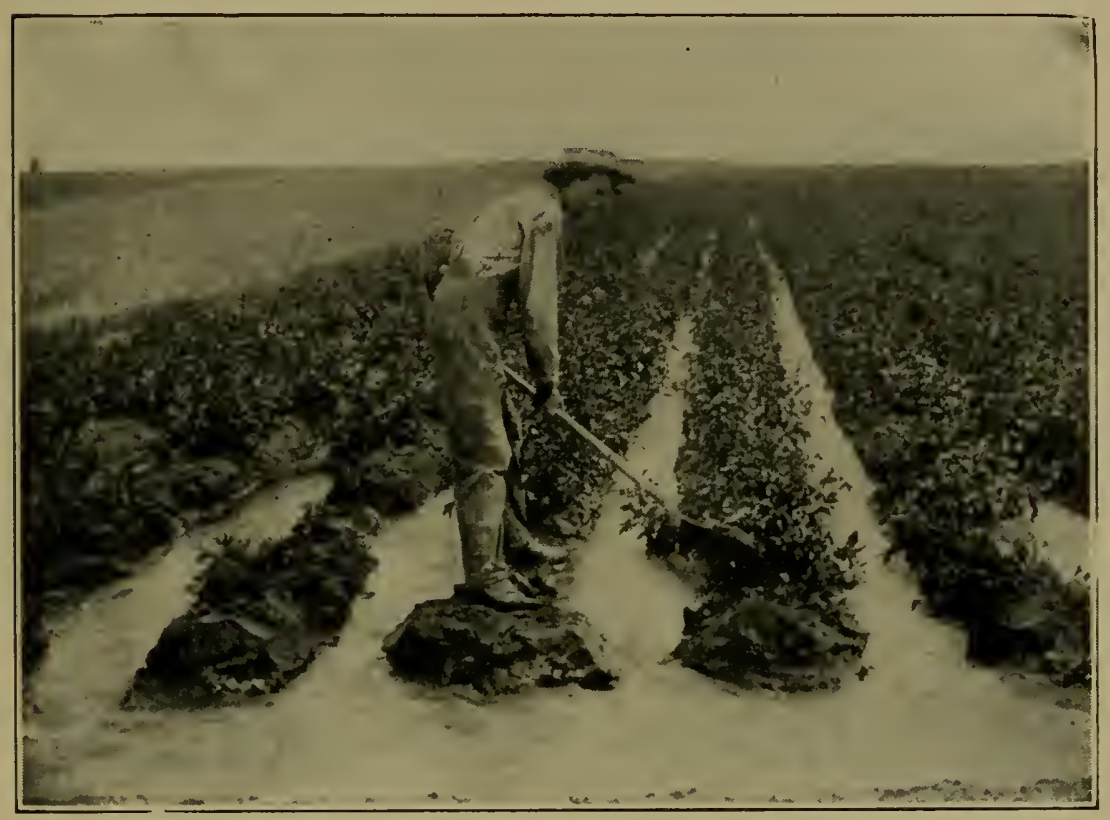

FIG. 79. Irrigating potatoes at Greeley, Colo.

applying water just before or after planting. Little water is needed by potatoes during the first period of growth, providing there is a plentiful supply in the soil at the time of planting. Potatoes planted about the first of May seldom need irrigation before July 1 ; and from then on irrigation should be practised only as the plants need it. One of the surest signs of water need is the darkening of the foliage. If water, especially cold water, is applied too 
frequently, growth is seriously retarded. It is well to secure a good growth early, and to develop early a deep root-system that may endure the heat of midsummer. It is seldom advisable to irrigate oftener than every two weeks, and every three or four weeks frequently gives satisfactory results. Irrigation should cease about the middle of August, leaving about sixty days for the ripening of the potatoes. Potatoes are seriously injured by over-irrigation. The first visible effect of too much water is a light green color acquired by the leaves. The Utah Station conducted experiments on the effect of varying quantities of water on the yield of potatoes. Some of the results obtained are found in the following table:

\begin{tabular}{c|c|c|c}
\hline \hline $\begin{array}{c}\text { Inches of } \\
\text { irrigation water } \\
\text { applied }\end{array}$ & $\begin{array}{c}\text { Yield in } \\
\text { bushels } \\
\text { per acre }\end{array}$ & $\begin{array}{c}\text { Bushels } \\
\text { per inch of } \\
\text { irrigation water }\end{array}$ & $\begin{array}{c}\text { Percentage of } \\
\text { marketable } \\
\text { potatoes }\end{array}$ \\
\cline { 2 - 3 } 5.0 & 154 & 30.8 & 74.80 \\
7.5 & 182 & 24.3 & 74.70 \\
10.0 & 195 & 19.5 & 77.94 \\
15.0 & 227 & 15.1 & 82.12 \\
20.0 & 267 & 13.4 & 80.62 \\
30.0 & 244 & 8.1 & 79.81 \\
45.0 & 253 & 5.6 & 79.50 \\
60.0 & 304 & 5.1 & 76.90 \\
\hline
\end{tabular}

The total quantity of water used varied from 5 to 60 inches, or twelvefold. The yield of potatoes increased meanwhile from 154 bushels to 304 bushels, or not quite double. The yield to the inch of irrigation water fell, as the water was increased, from 30.8 bushels to 5.1 bushels or about one-sixth. As shown in the last column of the above table, the percentage of marketable potatoes in the total crop increased, with the increase in water, up to medium quantities, after which it fell definitely. Clearly, the law 
connecting yield with irrigation is the same for potatoes as for other crops. However, the yield of potatoes is more nearly proportional to the water used than are sugar beets or the other root crops. This may be due to the fact that the potato is an enlarged stem. Following the Utah results, when 30 acre-inches were applied to 1 acre, 195 bushels of potatoes were obtained; when spread over 6 acres, 691 bushels were obtained. (Fig. 84.)

The quality of potatoes is also definitely affected by the quantity of water used. Medium quantities produce starchy potatoes; if too little or too much water is used, the percentage of starch is materially lowered.

It is probable that the duty of water for potatoes should not be greatly different from that for sugar beets. From 15 to 24 inches should represent an ample quantity of water for the production of a good crop of potatoes, wherever the annual rainfall is in the neighborhood of 15 inches, and where the soils are deep and well cultivated. It has been found possible in the arid regions to raise large crops of first-class potatoes without irrigation, and it is probable that the duty of water for potatoes will be greatly increased as fuller knowledge is obtained.

181. Peas and beans.-Peas and beans are becoming important irrigated crops. They are especially valuable because, like lucern, they grow well on raw soils that are unwilling to yield the ordinary crops when first brought under cultivation. Of late years these crops have become valuable in the hog and sheep industry. The sheep eat the vines and the hogs the seeds. Large quantities of the proper varieties of peas are also canned, and in that condition shipped all over the earth.

Peas and beans may be grown either as garden or field crops. They are characterized by a rather short 
growing season, and in that particular are comparable with the small grains and the grasses. They should be sown in rows, between which cultivation should be practised as long as possible. Large yields may be obtained with small quantities of water, providing they are carefully cultivated after each irrigation, and several times between successive irrigations.

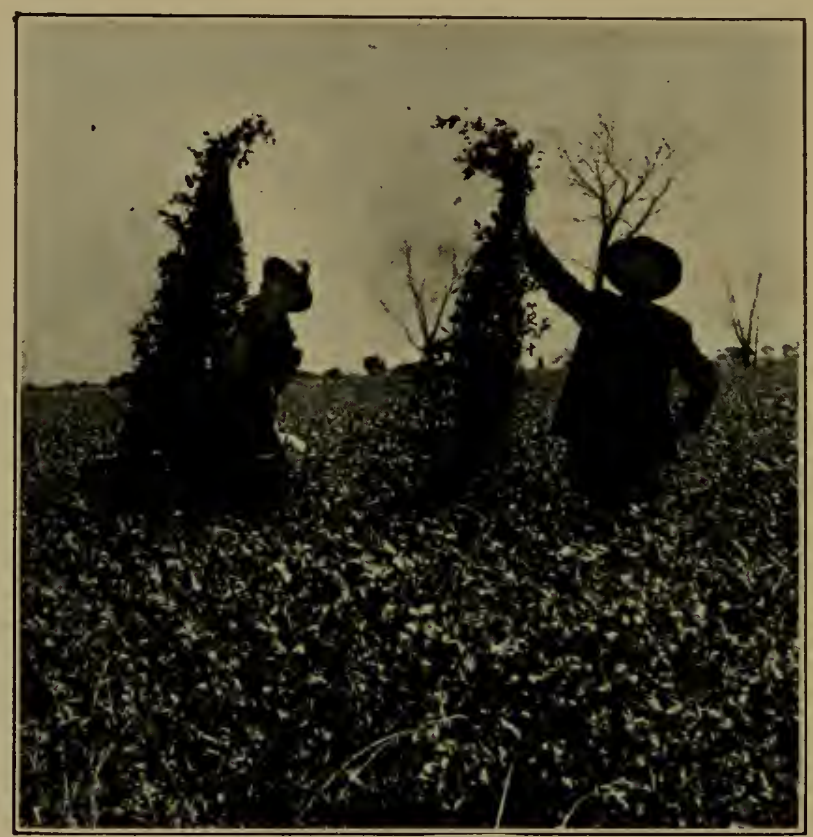

FIG. 80. Irrigated field peas.

The furrow method of irrigation is almost invariably used. The furrows are about 3 feet apart, and, to avoid sun-scald, so filled that water does not touch the plants.

These crops should be planted in moist soils, and, if the soil is dry, it may be necessary to irrigate them either by adding water just before or after seeding. After seeding they need little water until the soil becomes somewhat dry. However, they are rapid growers and water 
must be applied whenever needed, so that they may suffer no set-back because of intense dry spells. Peas and beans finish most of their growth in spring and early summer, when there is usually an abundance of water. Just before and at the time of blooming the largest quantity of water is required. When the pods are pretty well formed little water is required, and soon afterward irrigation may be stopped altogether. In fact, a somewhat dry soil, after the pods are well formed, helps in the formation of the seed. Peas, which require less water than beans, when grown for seed require only one irrigation; when grown for fodder, two or three irrigations may be applied. It is often profitable to grow two crops of peas. One is harvested early in July and the other in early fall.

The Wyoming Station has conducted experiments on the quantity of water used by peas. Some of the results obtained are shown in the following table:

\begin{tabular}{c|c|c|c}
\hline \hline $\begin{array}{c}\text { Total inches of } \\
\text { irrigation water } \\
\text { applied }\end{array}$ & $\begin{array}{c}\text { Total tons of } \\
\text { forage } \\
\text { per acre }\end{array}$ & $\begin{array}{c}\text { Total yield of } \\
\text { peas per acre. } \\
\text { Bushels }\end{array}$ & $\begin{array}{c}\text { Per cent } \\
\text { of peas } \\
\text { in forage }\end{array}$ \\
\cline { 1 - 3 } 22.92 & 4.20 & 19.21 & 14 \\
20.09 & 2.84 & 34.75 & 37 \\
17.73 & 1.77 & 16.56 & 28 \\
9.13 & 1.74 & 11.17 & 19 \\
5.02 & 1.27 & 6.04 & 14 \\
. & 0.66 & 3.00 & 14 \\
\hline
\end{tabular}

The quantity of water used varied from none to 22.92 inches. The acre yield of forage varied from .66 tons to 4.20 tons. The total acre yield of peas varied from three bushels to nineteen bushels. The percentage of peas in the whole crop varied from 14 to 37 . The yield did not increase so rapidly as the water increased. The 
percentage of seed increased with the water, which is distinctly different from the behavior of the grains, in which the proportion of seed decreases with an increase in water. From 10 to 15 inches of water are probably ample for the production of peas or beans under present methods. This depth will be decreased as irrigation practices are perfected.

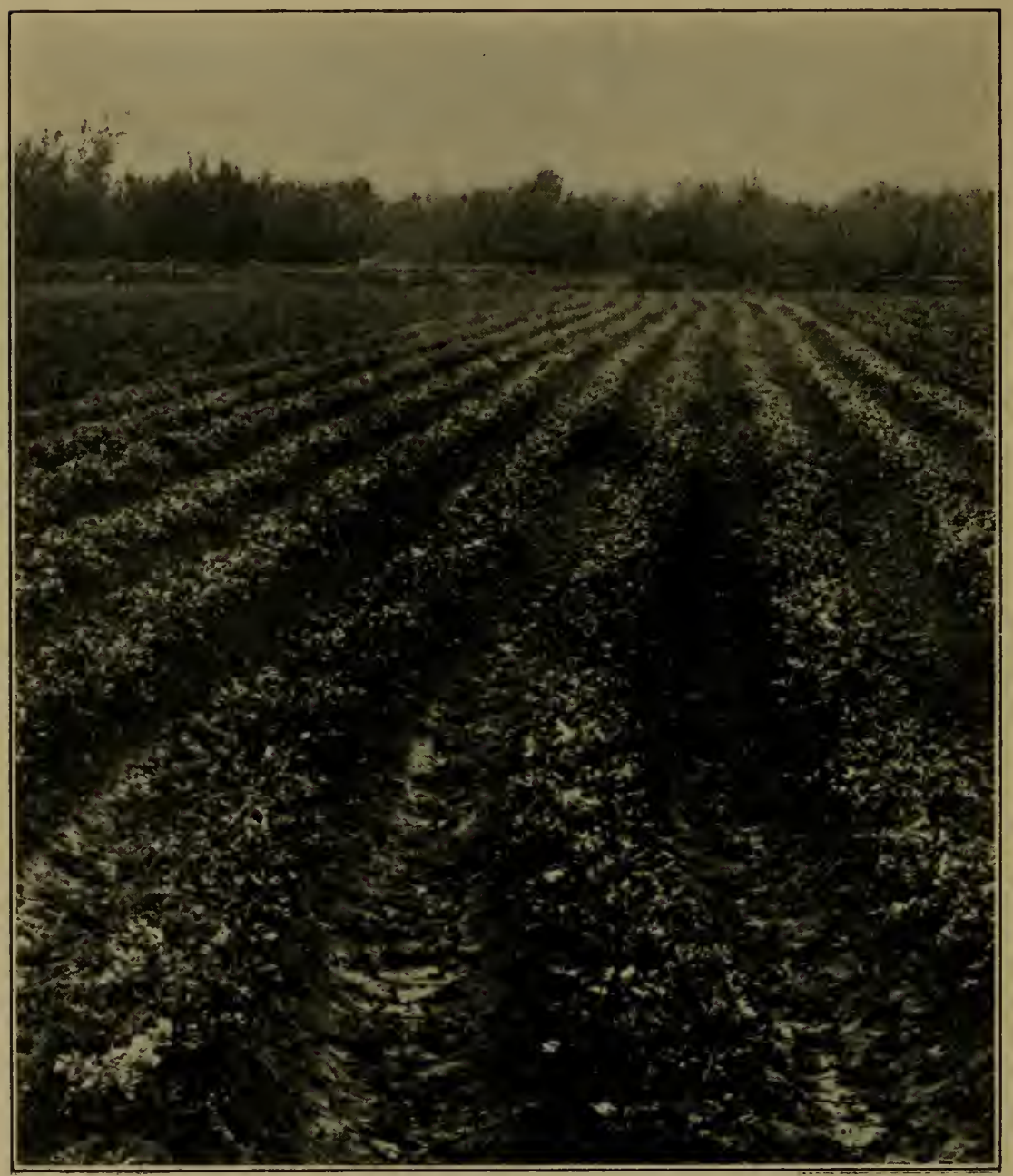

Fị. 81. Irrigated celery. 


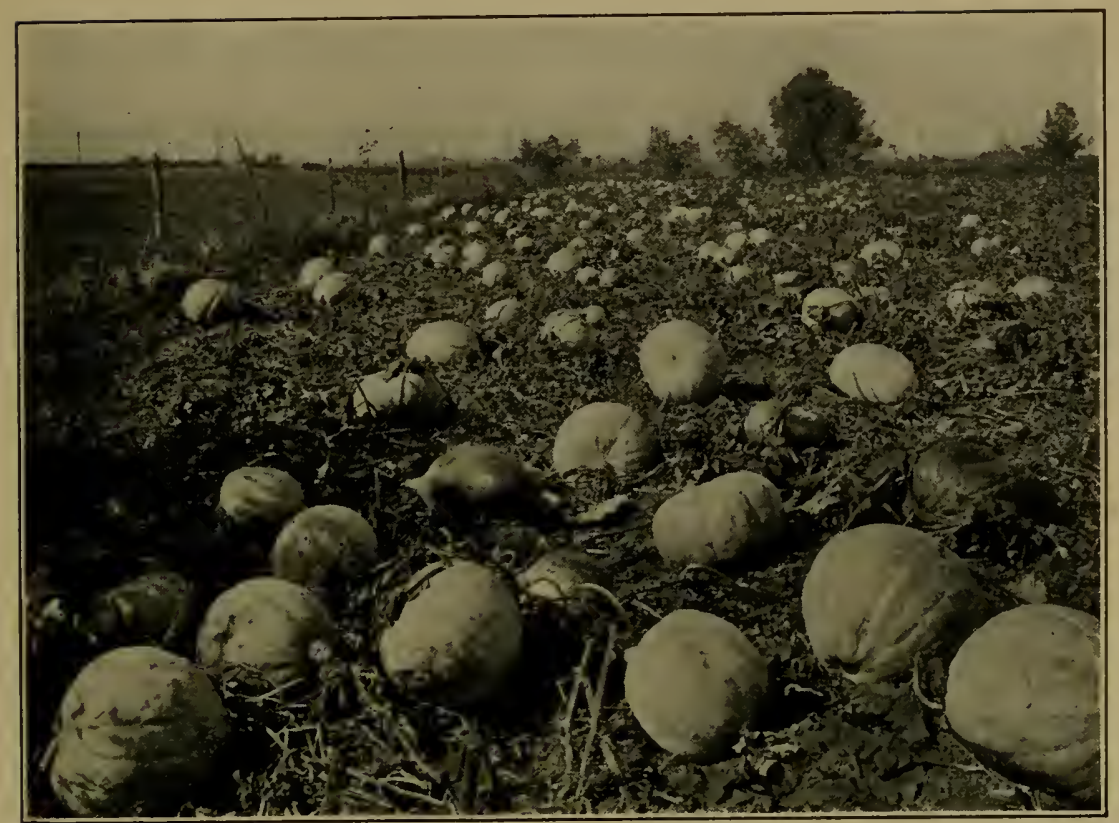

FIG. 82. Irrigated pumpkins.

182. Fiber crops.-The strength of irrigation agriculture will increase as the crops grown are related to manufacturing industries. The fiber crops are, therefore, important. Hemp grows exceedingly well under irrigation; and, from the irrigated crop, fiber of the highest quality has been made. It is always grown in rows and irrigated by furrows. Since it attains great growth it requires considerable water. Flax is likewise of easy culture under irrigation. It must always be irrigated by furrows, since it is subject to sun-scald. It requires little water; in fact, it has been grown on dry-farms with great success. Cotton has been grown under irrigation for more than fifty years, and in quantities sufficient to supply a cotton-mill, which was established at that time. In more recent days cottongrowing has been established successfully in the Imperial Valley of California and in southern Arizona. It is irri- 
gated by the furrow method. It uses little water. The soil should be moist at planting, and the crop usually receives but one irrigation after planting.

183. Hops.- Hops is another valuable crop, which is grown to a limited extent under irrigation. In the humid hop-growing sections, supplementary irrigation is a very common practice. Hops are easily grown, and are irrigated by either the furrow or the flooding method. Water is applied every three or four weeks. The heaviest irrigations are given as the buds appear. No irrigation is applied after August 15, when the crop is about to ripen.

184. Tomatoes, cantaloupes, etc.-These and similar crops do excellently well under irrigation. Tomatoes, especially, have become a very important crop as canning factories have been established. The plants are set out in rows in the usual way, and the water is applied invariably by the furrow method. If careful cultivation is applied to the irrigated field, the tomato plant does not demand an excessively large quantity of water. Too much water encourages too great a growth of vines, and interferes with ripening. The first irrigation is postponed as long as possible after planting, and, when the irrigation season begins, three irrigations are usually sufficient for the season. Heavy irrigation at the time of ripening tends to increase the weight. of the crop, and farmers who supply the canning factories, therefore, apply at that time large quantities of water; so large, indeed, that growth is stopped and the ripening fruit is well filled with water. In other places, at the time of ripening, water is refused the plant entirely, leaving excellent fruit, although the total weight is not so great. During picking it is a common practice to apply water largely, with the result that the yield is increased. The cultivation of tomatoes throughout the 
season is really as important as the irrigation. The total quantity of water required for tomatoes is seldom in excess of 18 inches. Occasionally, good crops are produced with less water.

Watermelons, cantaloupe, squash, pumpkin, eggplant and similar crops grow well under irrigated conditions. Of these crops the cantaloupe is especially important. The watermelon needs little water, and practically none after it is half grown. Two or three irrigations in a season seem to be enough. Cantaloupes require a little more water.

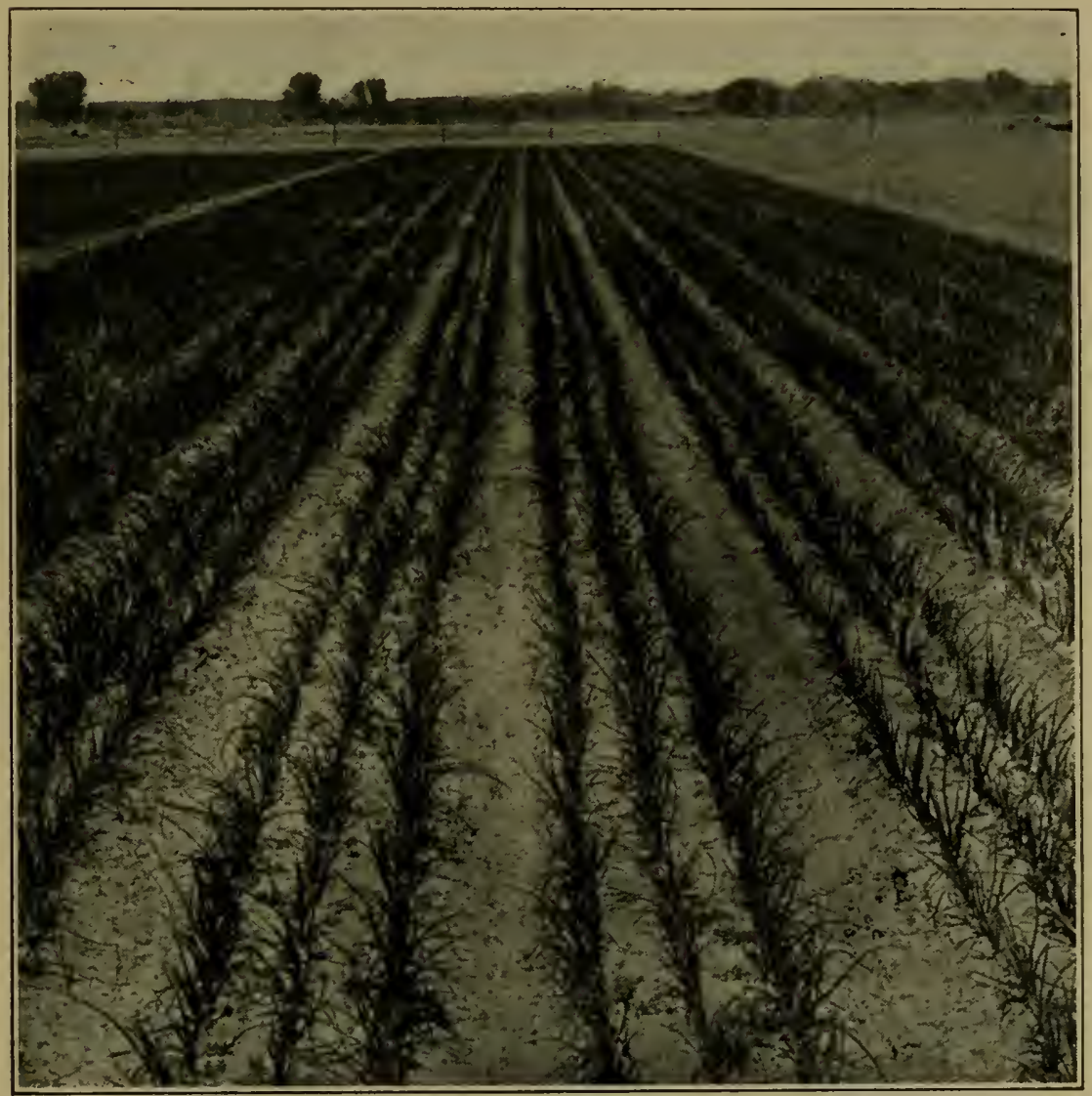

FIG. 83. Irrigated onions in Arizona. 
After flowering, and during fruiting, more water is required than before. Cultivation is the main consideration in the culture of both watermelon and cantaloupe. To obtain crops of high quality, water should be limited at the time of ripening. Pumpkins and squash should be irrigated very much as the watermelon. No exact records are available, but the evidence points to 10 to 12 inches of water as ample for most of these crops.

185. Cabbage, cauliflower, etc.-These typical garden crops, sometimes grown as field crops, use fairly large quantities of water. The Utah Station has made some experiments as to the effect of varying quantities of water. Some of the results are shown in the following table:

Yields of Cabbage with Varying Quantities of IrRigation WATER

\begin{tabular}{c|c|c}
\hline \hline $\begin{array}{c}\text { Inches of } \\
\text { irrigation water } \\
\text { applied }\end{array}$ & Tons per acre & $\begin{array}{c}\text { Tons per acre-inch } \\
\text { of water }\end{array}$ \\
\cline { 2 - 3 } 12.5 & 9.2 & .74 \\
20.0 & 9.2 & .46 \\
25.0 & 8.2 & .32 \\
40.0 & 10.2 & .26 \\
70.0 & 11.6 & .17 \\
\hline
\end{tabular}

As the total quantity of water increased there was a relatively small increase in yield. In ordinary practice these crops receive small irrigations weekly, or somewhat larger irrigations every other week. The most important thing in their culture is to keep the soil from becoming too dry during the growing period. However, no water should be added after the heads are half formed as it may cause a splitting of the heads. Cauliflower should be treated much the same as cabbage. Lettuce, spinach and 
SUGAR BEETS, POTATOES, ETC.

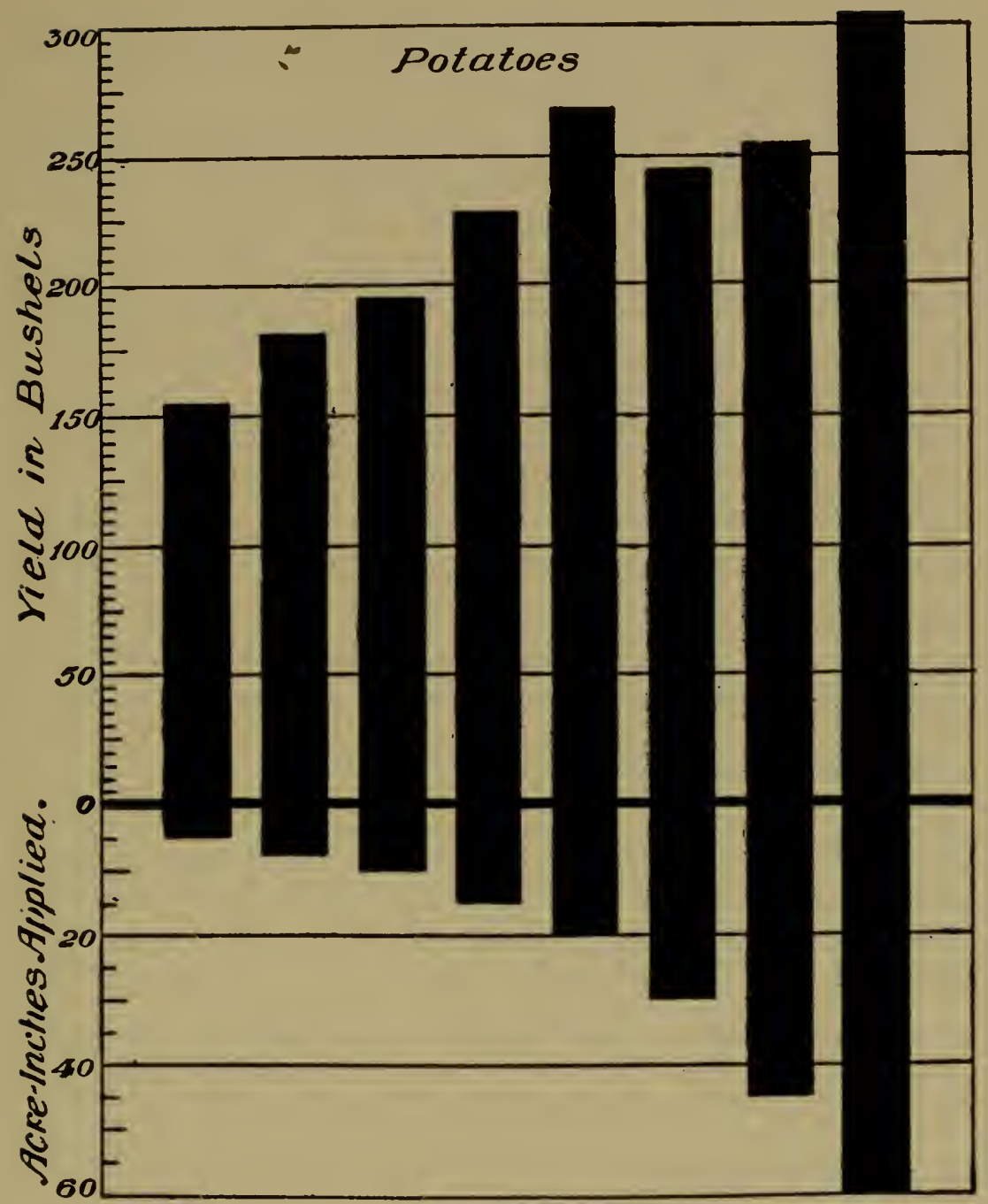

FIG. 84. Yield vs. water (potatoes).

parsley are crops that feed near the surface and require rather small frequent irrigations. The total quantity of water required by these crops is small.

186. Asparagus and celery.-These are important and valuable irrigated crops. Asparagus needs water chiefly during the cutting season, after which watering 
once a month is ample. Celery is a water-loving crop, although if sufficient is added to keep the soil in a moist condition, the yield is just as well as if excessive quantities were added, and the quality is better.

187. Onions and miscellaneous crops.-Onions should be planted in a soil well filled with moisture. A month may then elapse before the first irrigation. This crop may be irrigated either by the furrow or the flooding method. Usually frequent small irrigations are better than infrequent large ones. In middle summer, when growth is rapid, it may need much water. When the tops fall, irrigation should cease. Maturity may be hastened by withholding water when the crop is half grown. The Utah Station has tested the effect of varying quantities of water on the yield of onions as shown in the following table:

Yields of Onions with Varying QUantities of Irrigation WATER

\begin{tabular}{c|c|c}
\hline $\begin{array}{c}\text { Inches of } \\
\text { irrigation water } \\
\text { applied }\end{array}$ & Tons per acre & $\begin{array}{c}\text { Yields per acre-inch } \\
\text { of water }\end{array}$ \\
\hline 15 & 10.8 & .71 \\
20 & 11.0 & .55 \\
30 & 16.2 & .55 \\
65 & 16.2 & .27 \\
\hline
\end{tabular}

The law that the yield does not increase in proportion to the water applied holds with onions as with other crops.

Rhubarb requires frequent irrigations during cutting time. With good wettings in midsummer, the bidd-formation for the next year is furthered.

Tobacco, peanuts and a host of other crops grown in the world may be brought under successful cultivation 
in the irrigated section. These and other crops should be grown under irrigation as under humid conditions. Practically all of them may be grown successfully from the first by remembering a few general principles: The soil should contain much moisture at the time of planting. The crops should always be planted in rows. As a general rule it is best to irrigate in furrows. Irrigation should be delayed until the plant has established its rootsystem well and until it really calls for water. Irrigation should occur every two or three weeks. Water should be applied liberally at the time of flowering. Where the rainfall is from 12 to 15 inches annually, a quantity of

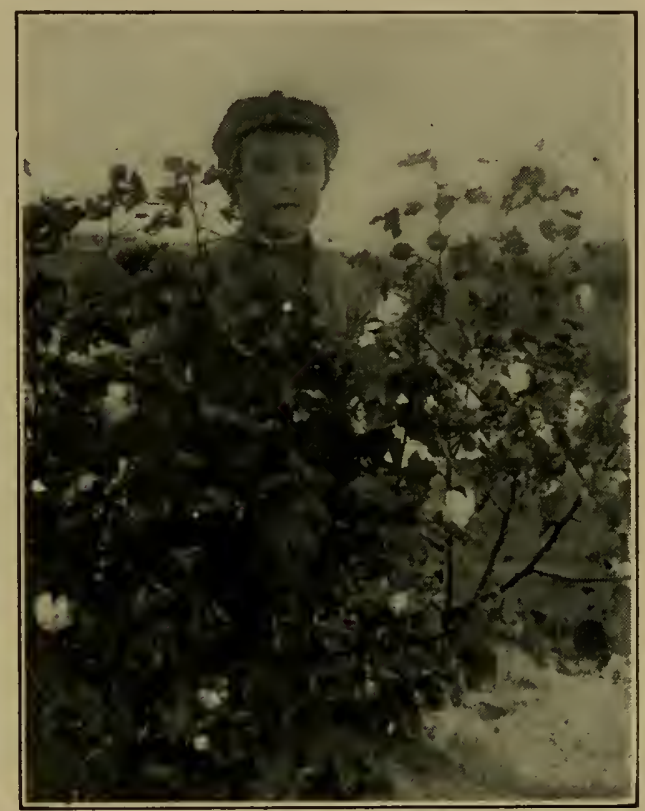

FiG. 85. Irrigated Egyptian cotton. irrigation water for the season, from 15 to 24 inches, is more than enough to make sure of a good yield for any crop. More than that is likely to cause deterioration of quality and diminution in yield. Less than that often produces the best yield. The crops that grow throughout the season are watered more than those which have short growing seasons. Crops that are leafy require more water than those of small leaf surface. Crops planted closely together use more water than those planted far apart. All in all, more depends ordinarily upon the soil than upon irriga- 
tion in making any new crop successful. If the soil is of the right kind, and irrigation is practised in moderation, more depends upon the careful, persistent cultivation of the soil than upon the water or the soil. The irrigation farmer needs to remember over and over that irrigation is simply the supplementing of the natural rainfall, and

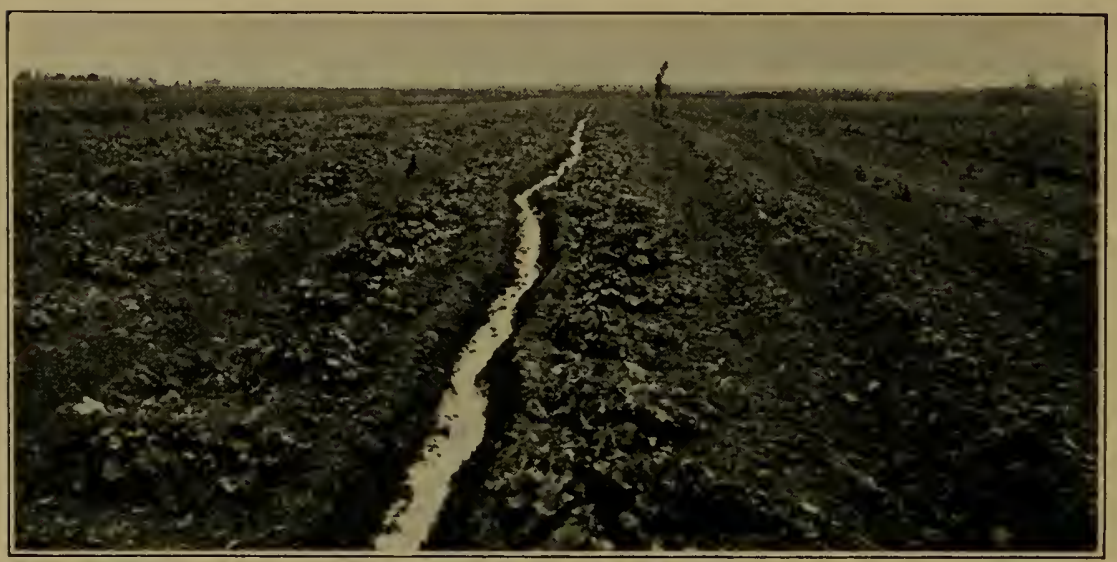

FIG. 86. Irrigating cantaloupes.

that any crop grown under natural rainfall may be grown with irrigation providing soil and climatic conditions are suitable for the crop.

\section{REFERENCES}

Clark, J. Max. Potato Culture near Greeley, Colorado. United States Department of Agriculture, Yearbook for 1904.

Coit, J. Eliot, and Packard, Walter E. Imperial Valley Settlers'

Crop Manual. California Experiment Station, Bulletin No. 210 (1911).

Corbet, L. C. Suggestions to Potato Growers on Irrigated Lands. United States Department of Agriculture, Bureau of Plant Industry, Circular No. 90 (1912).

GrubB, E H. Potato Culture on Irrigated Farms of the West. United States Department of Agriculture, Farmers' Bulletin No. 386 (1910). 
Grdbi, E. H., and Guilford, W. S. The Potato. Doubleday, Page \& Co. (1912).

McLaughtin, W. W., and Morgan, E. R. Report on Irrigation Investigations during 1905-06. Utah Experiment Station, Bulletin No. 99 (1906).

Nowell, Herbert T. Duty of Water on Field Pease. Wyoming Experiment Station, Bulletin No. 72 (1906).

Roeding, F. W. Irrigation of Sugar Beets. United States Department of Agriculture, Farmers' Bulletin No. 392 (1910).

Teele, R. P. Review of Ten Years of Irrigation Investigations. United States Department of Agriculture, Office of Experiment Stations, Annual Report for 1908 (separate).

Townsend, C. O. Sugar-Beet Growing under Irrigation. United States Department of Agriculture, Farmers' Bulletin No. 567 (1914).

Welch, J. S. Irrigation Practice. Idaho Experiment Station, Bulletin No. 78 (1914).

Wickson, E. J. Irrigation in Field and Garden. United States Department of Agriculture, Farmers' Bulletin No. 138 (1901). Widtsoe, J. A., and Merrill, L. A. The Yields of Crops with Different Quantities of Irrigation Water. Utah Experiment Station, Bulletin No. 117 (1912).

Widtsoe, J. A., and Merrill, L. A. Methods for Increasing the Producing Power of Irrigation Water. Utah Experiment Station, Bulletin No. 118 (1912). 


\section{CHAPTER XVI}

\section{FRUIT TREES, OTHER TREES AND SHRUBS}

THE pioneers of irrigation planted practically every known fruit tree in the early years of their possession of the West, and demonstrated that all would grow to maturity and bear excellent fruit. Apples, pears, peaches, quinces, figs, dates, oranges, lemons, nuts, strawberries and all the small fruits, and a host of others, have been shown to thrive under irrigation. The people of the earth are consuming more and more fruit, and a greater demand is being made for fruit of definite color, quality and other desirable properties. The control that irrigation makes possible, together with the favorable climate and soil of the arid region, enables the farmer to produce fruit of the quality demanded by the markets. Fruit-growing is becoming a great irrigation industry, and as time goes on, fruit from the irrigated farms will be sent over the whole earth.

188. Fruit-growing.-Fruit-growing differs in many essentials from the production of other farm crops. First, there is a high initial expense in preparing the land and in purchasing and planting the young trees. Then, only after many years of careful supervision, entailing much labor, is the first crop obtained. Finally, for many years, the trees live and yield harvests, during which the consequences of the mistakes made in the beginning are made evident to the farmer. Therefore, from the first, extreme care must be used in fruit-growing. 
The methods of planting and maintaining trees are not essentially different in irrigated and humid districts. Irrigation is the one chief difference, and irrigation is not the least important in producing and maintaining orchards that justify the great expenditure of -means that must be made upon them. In orchards, moreover, the greatest irrigation science has been applied, and in them the highest duty of water has been obtained.

Orchards lend themselves well to thorough cultivation, which may be one reason for the high duty of water in fruit-farming. It is of extreme importance that cultivation be practised as thoroughly as possible in orchards. The soil must be stirred immediately after each irrigation, and several times between successive irrigations. Both in spring, fall and early growing season should the cultivator be at work in the orchard if the farmer expects the greatest profit.

189. Method of orchard irrigation.--Orchards may be irrigated by any of the methods already discussed. In early irrigation days, the flooding method was most generally employed in orchards, and even today this method is extensively used in California and some other localities. When the flooding method is used today, earth ridges are formed half way between the rows of trees, making a set of squares with a tree in the middle of each. These are filled with water as described in Chapter X. The trees themselves are protected from direct contact with the water by earth heaped around the trunks. This method has the advantage that it covers the whole surface of soil and insures a uniform penetration of water, which has a beneficial effect upon the soil and soil organisms. However, much work attends the throwing up of the ridges and the orchard is made unsightly and difficult 
to cultivate by the ridges. In other places the check method of flooding is used. The whole orchard is surrounded by ridges or checks, and water is allowed to flow into the basin thus formed. This method is now seldom used. The only flooding method of today, besides the basin method, is the equivalent of the field ditch method, whereby water taken from the head ditch by smaller ditches, is led by small ditches, filled to overflowing, over the whole orchard.

The furrow method is the commonly adopted method of all orchard irrigation. By this method a permanent ditch is built at the head of the orchard. This may be a flume or pipe made of wood or concrete. At various intervals there are openings in the ditch or flume to lead the water into the orchard; or if a pipe has been laid underground, there are standpipes through which the water pours out. From this head ditch the water is led by furrows through the orchard. A head ditch carrying about 2 second-feet is about right for most orchard work.

In the furrow irrigation of orchards it is very difficult to admit to each furrow the same quantity of water. For that reason small lath boxes, already described, are employed to connect the head ditch with each furrow. Instead of the lath boxes, small permanent pipes are often placed at the head of the furrows. The length of the furrows on sandy or gravelly soils should usually be less than 500 feet, and on clayey, heavy soils, seldom more than 600 feet. The shorter the furrow, within practical limits, the more probable is the equal distribution of water at the head and end of the furrow. The grade of furrows preferred in orchard irrigation is a fall of 3 to 4 inches to each 100 feet. If the land is steeper than this, the furrows must be carried around the land in a zigzag 
fashion. This is a very common orchard practice in notable orchard districts, as for instance, the Hood River Valley of Oregon.

Under good systems of orcharding, almonds, pears, peaches, cherries, apricots and oranges are spaced about 24 feet apart; apples about 30 feet; walnuts about 38 feet; and other trees in like proportion. This wide spacing makes necessary several furrows for irrigation between the rows of trees, if the soil is to be saturated thoroughly. Young trees have light water requirements, and one furrow, not too far from the row of trees is then usually sufficient. Older trees with wide-spreading roots make it necessary to move the furrows farther away. As time goes on, several furrows are made between the rows of trees, so that the farmer is certain that the roots, wherever they may be, are given an ample supply of water. However, if the furrows are carried too near the trees at the beginning of growth, the roots may strike upward and remain near the surface. For that reason, the furrow is placed at some distance even from the young tree, so that the roots will be made to grow downward in search of the moisture soaking down from the furrow. By this method it is possible to establish deep root-systems, which are of first importance in producing trees that may endure ooccasional droughts and always make the best use of the water stored in the soil by rains or irrigation.

Small furrows, carrying little water, are usually placed about $2 \frac{1}{2}$ feet apart. Deeper ones carrying more water are placed 3 to 4 feet apart. Some orchardists place the furrows 7 or 8 feet apart but make them very deep, and depend on lateral seepage to moisten all the soil. On average arid soils it is possible that a distance of 7 or 8 feet apart for deep furrows is really better than the 
distance of 3 or 4 feet more commonly used. On sandy soils it is safe to place the furrows farther apart than on clayey soils; but deep, widely spaced furrows are the best. Shallow furrows were formerly used extensively, but of late it has been demonstrated, especially by Fortier, that deep furrows are by far the better.

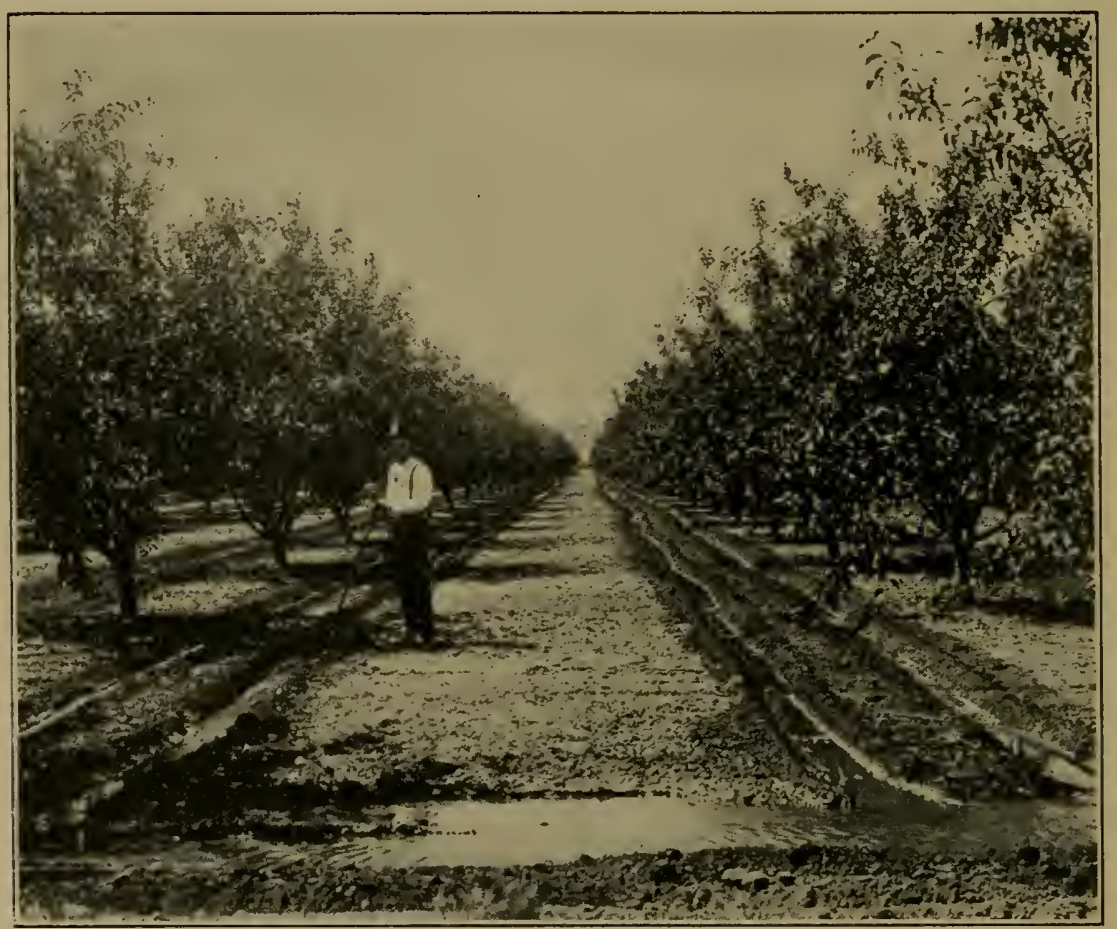

FIG. 87. Irrigating an apple orchard.

When furrows are run in one direction between the rows of trees it follows that there is a space in the row between the trees that is left quite dry. For that reason cross furrows are sometimes run between the trees at right angles to the main furrows so that the land may be more uniformly wetted. To cover the whole orchard uniformly, the furrows are often zigzagged across the orchard instead 
of following the rows. While this system does moisten the land uniformly, it is complicated and involves considerable expense. Straight furrows running between the rows, with occasional cross furrows, is the more satisfactory system.

After each irrigation, the furrow is covered to diminish evaporation. The furrows, therefore, are temporary and must be made before each irrigation. It is difficult to control the water thoroughly even under the furrow method of irrigation. Some water, of course, always reaches the end of the furrows and is allowed to flow into a cross ditch at the end of the furrows which acts as head ditch to the furrows below, or this water may be taken on to fields of lucern or other crops. (Fig. 87; also Figs. 4156.)

190.- Time of orchard irrigation.-Fall and winter irrigation is very advantageous in the maintenance of orchards. In the colder parts of the arid regions, where the ground, during winter, is frozen and well covered with snow, fall irrigation alone is practised. The wood of the trees is allowed to ripen thoroughly before fall irrigation. If water is applied too early, so that new growth starts, the trees are in danger of winter-killing. In the warmer parts of the arid region, with mild, open winters, as in Arizona, winter irrigation is of greatest benefit. Lands that receive little precipitation in the winter are especially benefited by winter irrigation. Districts in which the precipitation comes largely in the fall, winter or early spring, are not so greatly benefited by fall or winter irrigation. In such places the added water may simply cause seepage, which is not desirable.

Unless the soil is dry in the spring, there is no need of spring irrigation. As a general rule, trees must not be 
irrigated, or very cautiously, when they are in bloom; for such early irrigation is said to interfere with the setting of the fruit. The proof of this has not yet been made. As the hot season advances, water is needed, but the first irrigation should be postponed until really needed by the orchard. In Washington, where the season begins early and there is a high annual rainfall, the first irrigation comes in late April or early May, followed by three or four irrigations, from twenty to thirty days apart. In the drier parts of the arid region, where spring comes later, the first irrigation can be postponed until June or even July. In the Hood River Valley of Oregon, soils well saturated in the spring need no further irrigation until about July 15. In Colorado, water is applied to an orchard from two to five times a season. In Idaho, where the first irrigation comes about June 15, three irrigations in a season are said to be sufficient. The Utah practice is the same as that of Idaho. As an average, two to four summer irrigations, of 3 to 7 acre-inches each, and one fall irrigation should be sufficient for deciduous fruits. This means that if irrigation begins in June there will be one irrigation every three or four weeks throughout the summer season.

Orchard soils should not be allowed to dry out too much, for an excessive dryness in early or middle summer will injure the tree for the whole season. On the other hand, over-irrigation tends to decrease fruit-production and delay the ripening of the fruit. The farmer, therefore, must remember not to check the growth of the fruit tree by too little irrigation, nor to irrigate so heavily that the formation of buds is decreased and ripening delayed. Fruit trees make little growth after July 15, when the fruit-buds for the following year are being made. Excessive irrigations at this time, which force continued 
growth, tend to retard the development of fruit-buds for the ensuing year. Fruit-buds seem to develop more rapidly when growth is slow, due perhaps to the fact that rapid growth consumes the supply of stored food, which is necessary in constructing wood or buds. It is the general opinion that young peach orchards should not be watered after August 1, and that apples or pears should not ordinarily be watered after August 15. Withholding water, from these dates, enables the trees to ripen their fruit properly, and to produce fruit of high color and fine quality. If the soil is well stored with moisture early in August, the trees are not likely to suffer if no further irrigations are applied. A light green color and dead edges of the leaves and the shriveling of the young fruit are evidences that the soil moisture supply is so low that the root-hairs are drying up. No harm comes to a tree that has been irrigated well up to the middle of August, even if the soil becomes very dry thereafter, although occasionally, under such conditions, the leaves become yellow and fall before frost comes. This, however, does not injure the tree, and need not worry the farmer.

Citrous trees are really evergreens. They make their chief growth in autumn, when the deciduous tree rests. Citrous trees are always active. Transpiration goes on practically the whole year and such trees must, therefore, be provided with water in summer and winter. This increases the total water requirements and also the number of times that irrigation should be applied. Common practice seems to be that, whereas deciduous fruits are irrigated three or four times during the season, citrous trees must be irrigated at intervals of about a month each, leaving the wet season to take care of the trees 
without further irrigation. Each irrigation in California is in the neighborhood of 3 acre-inches.

191. Quantity of water for orchards.-There is little exact data on the right quantity of water to use in orchard irrigation. Orchards need less water than a vigorous field of alfalfa. - Pears can stand more water than apples; apples more than peaches; citrus trees most; the olive

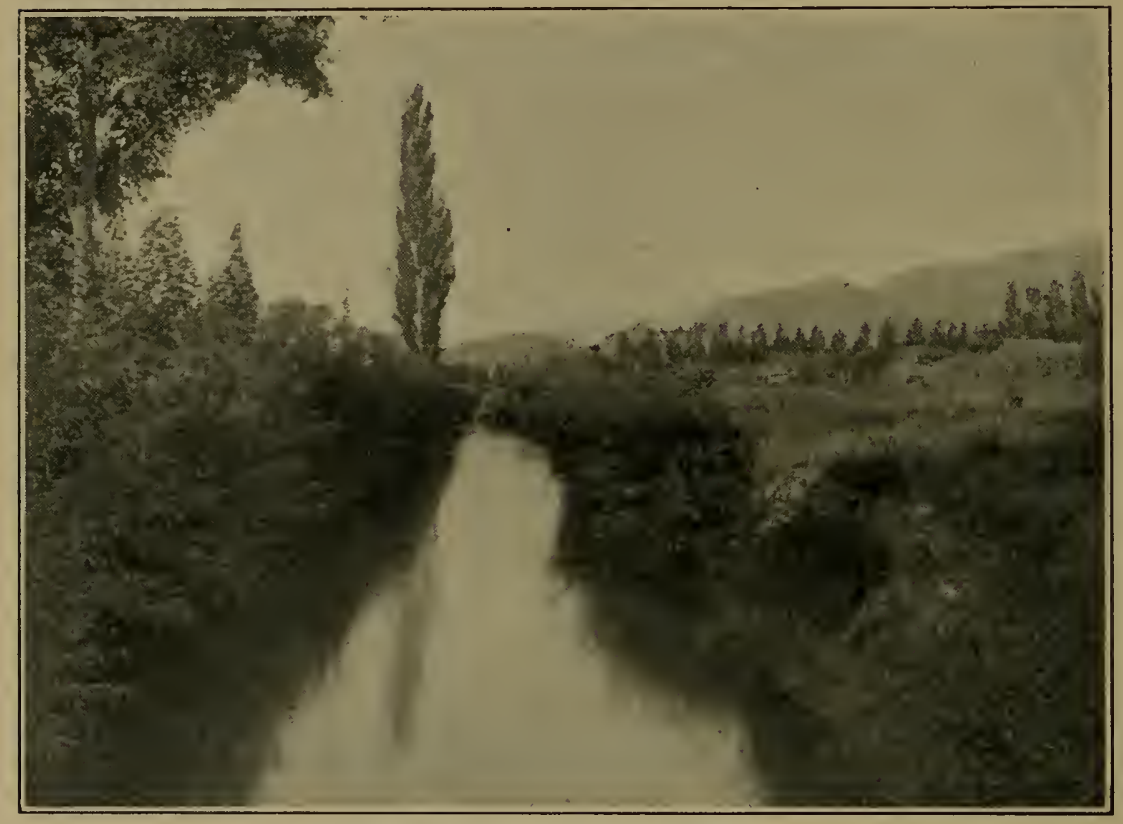

FIG. 88. On the upper canal.

endures very little water. The true water requirements depend on many factors, such as climate, soil, and age and nature of crop. A tree may grow with a very small quantity of water which, however, may be insufficient to produce fruit.

The actual duty of water in orchard irrigation varies from 60 acres to 400 acres for 1 second-foot of water. Fortier states the well-known truth that where most 
water is available, most water is used. For instance, in Wyoming, in well-watered sections, the duty of water is 70 acres per second-foot; in California, where water is scarce, the duty is 400 acres per second-foot. Yet, in the latter place citrus trees with long growing periods are largely grown, and the climate is hotter than in Wyoming. The whole question of the quantity of water needed for orchards needs careful investigation. It is probably safe to say that from 12 to 24 inches is an ample seasonal depth of water for orchard crops. More than 6 acreinches is seldom needed in any one month, even under low rainfall and high evaporation. That means, for an irrigation season of two months, 12 inches, and of three months, the usual limit, 18 inches. The long-season citrus fruits seldom need more than 3 acre-inches of water per month, although according to Wickson, citrus trees require 50 per cent more water for each crop than do deciduous trees. Wickson declares, however, that 20 acre-inches are ordinarily sufficient, annually, for the irrigation of citrus trees, and that 10 inches are frequently sufficient.

192. Other conditions of orchard irrigation.-In young orchards, and occasionally in old orchards, inter-culture is often practised. Corn, potatoes, beets, squash and various vegetables or small fruits are planted between the rows of trees. Moreover, to maintain the fertility of the land, cover-crops are occasionally planted between the rows of older trees. Inter-tillage in orchards invariably means a higher water requirement than does clean culture. The increase corresponds to the degree of interculture.

The great danger in orchard irrigation is over-irrigation. Only by moderate irrigation can the root-system 
be so developed as to take care of the tree in seasons of drought. If too much water be used, the rising ground water will kill the roots and thus the trees. Trees that have been planted on soils with a water table near the surface do not send their roots into the water and are not injured; but, when the roots have gone deeply into the soil and then are immersed in the rising water, the tree is sooner or later killed. Irrigation cannot take the place of pruning, cultivation and other approved horticultural practices. When these are attended to, relatively small quantities of water will produce large yields of excellent fruit. The orchardist must keep in mind, most of all, that if the soil itself is deep it is a splendid water reservoir, in which may be stored large quantities of water without making connection with the standing water.

There is often a great hurry to make the young tree grow as rapidly as possible above ground, when, in fact, the main thing is to make the young tree develop a deep, vigorous root system. The young tree, during the first year or two, does not really use much water; and, if the land to be planted to trees is irrigated abundantly before planting, and then thoroughly cultivated, there will be little need of irrigation during the first year. The second is the critical year for the orchard. During this year it should be irrigated sparingly, but cultivated well. If too much growth is then encouraged, the trees may easily be winter-killed, and if the roots are given the wrong habit of growth, the orchard may be injured permanently. With each year more water is needed, until maturity is reached.

At the town of Hanksville, Utah, the dam supplying the irrigation canal broke, and the people, disheartened, 


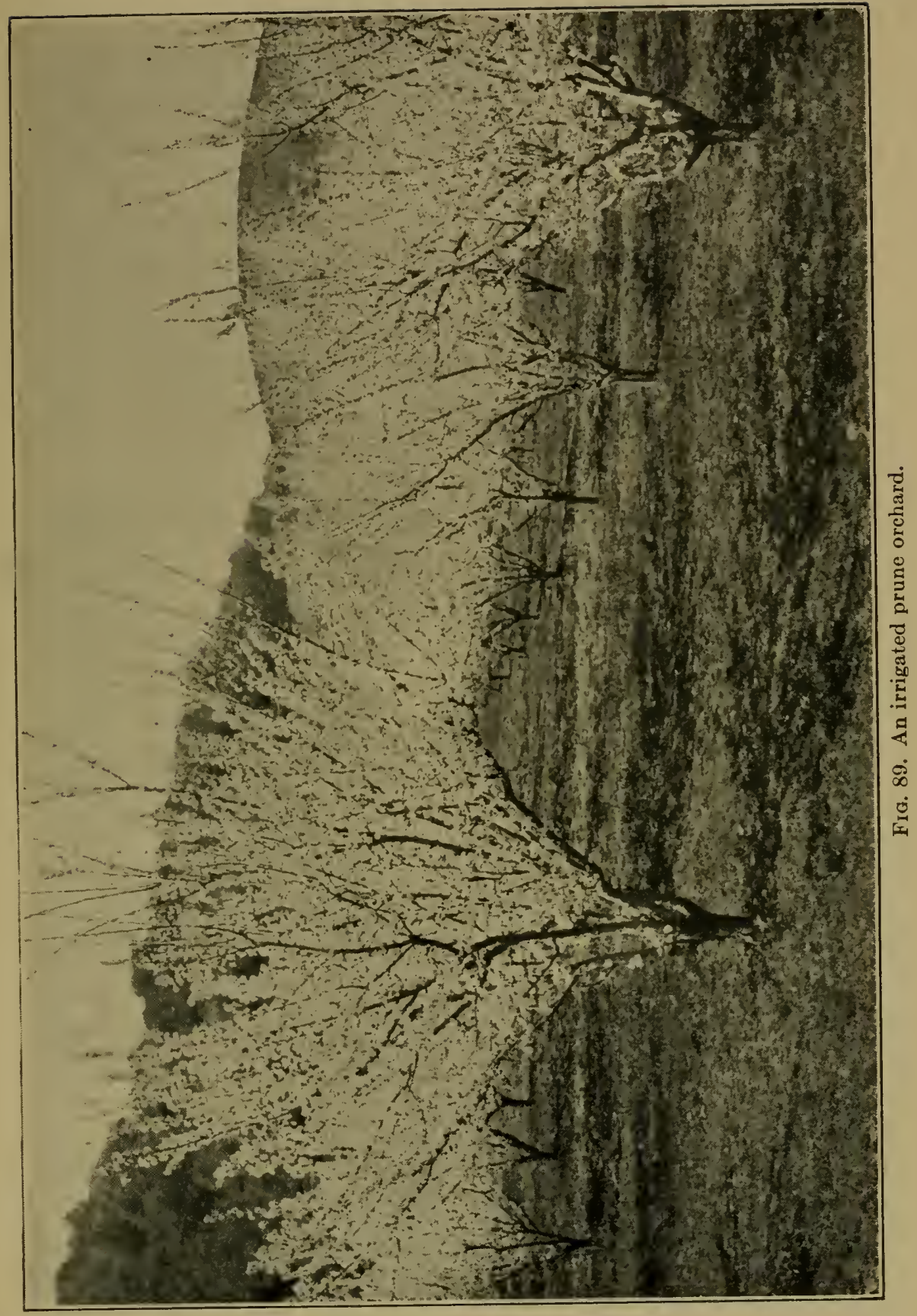


abandoned their homes and their orchards. Five years later, every tree that had grown along the ditch banks and had, therefore, developed shallow root-systems, was dead. Every tree that stood at considerable distance from the ditch banks and had, therefore, been compelled to strike its roots deeply, was in a most excellent condition and carrying small quantities of fruit. These and similar experiences demonstrate the very great importance of a deep root-system in sections where drought or the driest year may come at any time, through climatic variations or some accident like the breaking of a dam.

The quality of irrigated fruit is greatly affected by irrigation. Lewis states that irrigation makes larger, more elongated, more angular, brighter and more attractive fruit. Moderate irrigations reduce the windfalls, and produce fruit of high color, fine flavor and good shipping quality. Fruit raised by moderate irrigations is preferred for drying or canning. Walnuts slip more easily from the skin if water has been applied in medium quantities. Over-irrigation is always an injurious practice in fruit-production.

193. Nursery stock.-Nursery stock must be grown in soil kept as far as may be possible at a uniform degree of moisture. Nursery stock does not well resist sudden shocks of any kind.

194. Small fruits.-The small fruits, such as dewberries, raspberries, currants, blackberries, strawberries, loganberries and gooseberries, are grown readily under irrigation, and most of them require very little water. Cranberries also have been known to yield well under irrigation in especially constructed basins.

There should be an abundance of water at planting, and some water should be kept in the soil throughout the 
growing season. Little water should be applied at flowering time and much water at fruiting time. The wood should be allowed to ripen for the fall in comparatively dry soil. Ordinarily, irrigation should be stopped about August 1. Then, in late October or early November, another irrigation may be given, to help produce a better crop the following year. The small fruits should all be irrigated in furrows, and the water should not be allowed to touch the plant. In general, the principles that have been developed with regard to other crops hold with these.

195. Grape-vines.-The grape cannot stand much water. In fact, grape-vines grow without irrigation over a large part of the arid regions where the annual rainfall is 10 to 15 inches. The excessive use of water is the chief cause of the troubles of the vine-growers. Excessive irrigation causes mildew and similar troubles, and injures the shipping qualities of the grapes. In California, water is withheld from grape-vines even to the point where the leaves begin to fall. Very superior fruit of high sugar content and excellent flavor results. Irrigation is done by furrows. The furrows should be run midway between the rows; for, if they are too near, mildew may set in, and the vines will trail in the mud. In vineyard culture, the rule is to water well when watering and to cultivate several times before the next irrigation. Coit, speaking of conditions in the Imperial Valley, suggests that the last irrigation should be given at the commencement of the ripening period, and that irrigation during the last stages of ripening is dangerous. The grape-vine must be so grown as to have deep roots, which can be done only by the consistent use of moderate quantities of irrigation water. 
196. Plants for ornament and comfort.-Shade trees, shrubs, flowers - as windbreaks, along the streets or in the gardens - are all grown easily under irrigation. They require, generally, the same treatment as other crops. Such crops should be watered regularly. During the

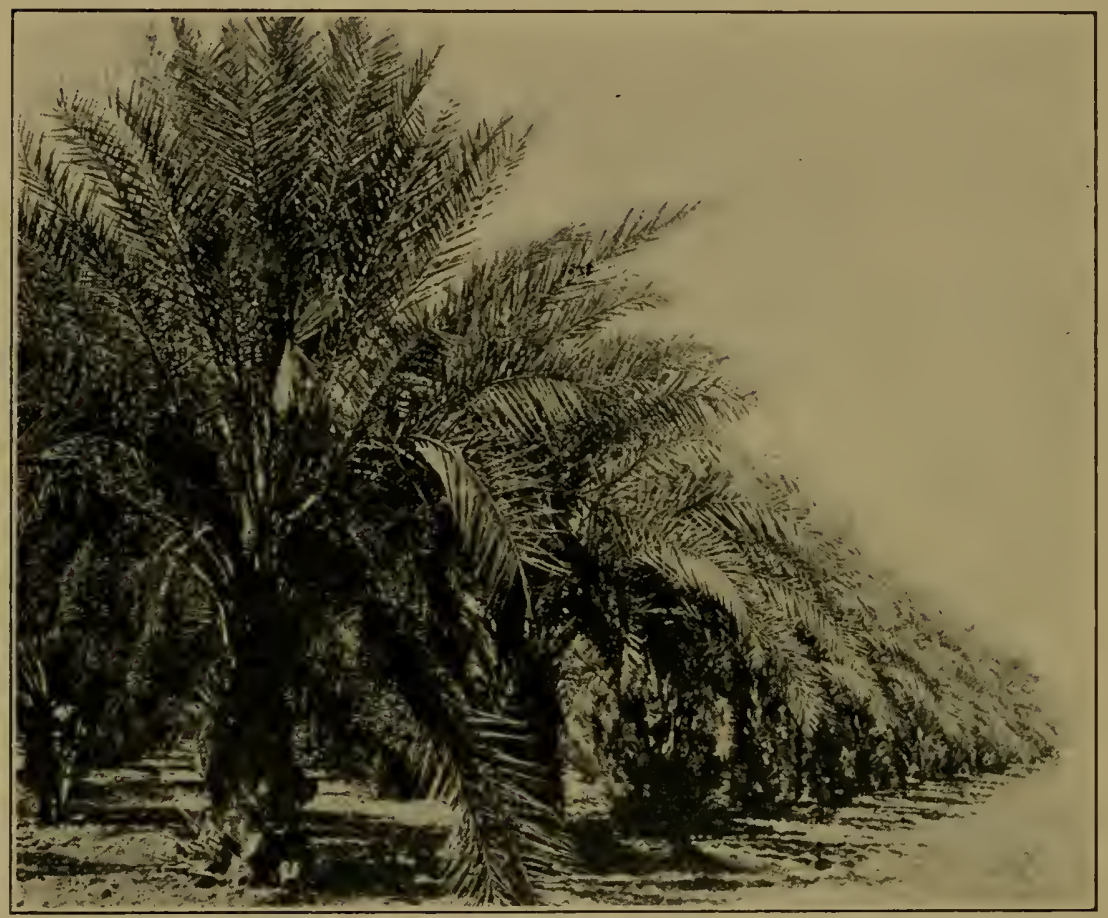

FIG. 90. An irrigated date palm orchard in Arizona.

season, more water can be given them than crops grown for commercial purposes. Forest trees are seldom grown except for ornamental purposes. In a few sections of the country, where the settlements are far from the railroad and coal mines, trees, notably the poplars, are grown to furnish fuel for the farmers. Trees for this purpose are grown along the ditch banks, and receive only such water as they absorb directly from the water seeping through 
the ditch bank. When such trees are grown in plantations, the quantity of water applied and the manner of application are practically as for orchards, except that more water may be applied, since the main purpose is to produce the largest possible wood growth.

Practically every tree, shrub and flower known to man, which can endure the soil and climatic conditions of the irrigated area, may be grown under irrigation. Irrigation is nothing more than supplementary rainfall. Wherever rainfall is desirable for plants, irrigation is desirable also:

\section{REFERENCES}

CoIT, J. Euıot. Olive Culture and Oil Manufacture. Arizona Experiment Station, Bulletin No. 62 (1909).

Cort, J. Eliot, and PACKARD, W. E. Imperial Valley Settlers' Crop Manual. California Experiment Station, Bulletin No. 210 (1911).

Etcheverry, B. A. Practical Information on Irrigation for British Columbia Fruit Growers. British Columbia Department of Agriculture, Bulletin No. 44 (1912).

Fortier, Samuel. Irrigation of Orchards. United States Department of Agriculture, Farmers' Bulletin No. 404 (1910).

Fortier, Samuel. Guide to Irrigation Practice on the Pacific Coast. National Irrigation Congress, Bulletin No. 4 (1907).

Herrick, R. S., and Bennetr, E. R. The Colorado Raspberry Industry. Colorado Experiment Station, Bulletin No. 171 (1910).

Lewis, C. J., Kraus, E. J., and Rees, R. W. Orchard Irrigation Studies in the Rogue River Valley. Oregon Experiment Station, Bulletin No. 13 (1912).

Longyear, B. O. Strawberry Growing in Colorado. Colorado Experiment Station, Bulletin No. 140 (1909).

McClatchie, A. J. Winter Irrigation of Deciduous Orchards. Arizona Experiment Station, Bulletin No. 37 (1901).

Paddock, Wendell, and Whipple. O. B. Fruit Growing in Arid Regions. Chapter XIII. The Macmillan Company (1910). 
Smith, Ralph E. Walnut Culture in California. California Experiment Station, Bulletin No. 231 (1912).

Whipple, O. B. Grape Growing. Colorado Experiment Station, Bulletin No. 141 (1909).

Wickson, E. J. Irrigation in Fruit Growing. United States Department of Agriculture, Farmers' Bulletin No. 116 (1900).

Wickson, E. J. Irrigation among Fruit Growers of the Pacific Coast. United States Department of Agriculture, Office of Experiment Stations, Bulletin No. 108 (1902). 


\section{CHAPTER XVII}

\section{THE DUTY, MEASUREMENT AND DIVISION OF WATER}

IN the foregoing chapters have been elucidated the known laws governing the relationship that exists between soils, plants and water. Results obtained under wellcontrolled laboratory or experimental field conditions may often differ from those obtained in general field practice. This chapter, therefore, discusses the practical duty of water and the methods of measuring and distributing irrigation water, so that ideal conditions may be approached.

197. The duty of water.-The duty of water, a term long since coined, means the quantity of water needed to mature crops. It may be expressed in various ways. Sometimes the duty of water is expressed as the number of pounds of water required to produce one pound of the dry matter of the crop; under other conditions, as the depth of water over the field, required during the growing season, to produce the crop. More commonly, however, the duty of water is expressed as the number of acres that may be irrigated by a definite quantity of water, say a second-foot, flowing continuously throughout the growing season. In Canada, the United States, India, Australia and other irrigated countries, this is by far the most common method of expressing the duty of water. The reason for this popularity seems to be that irrigation canals are generally taken directly from 
streams having a continuous flow during the irrigation season.

Various units for measuring water are used in different parts of the country, such as the miner's inch, but the only one in modern general use is the cusec or second-foot, which means 1 cubic foot of water passing a given point

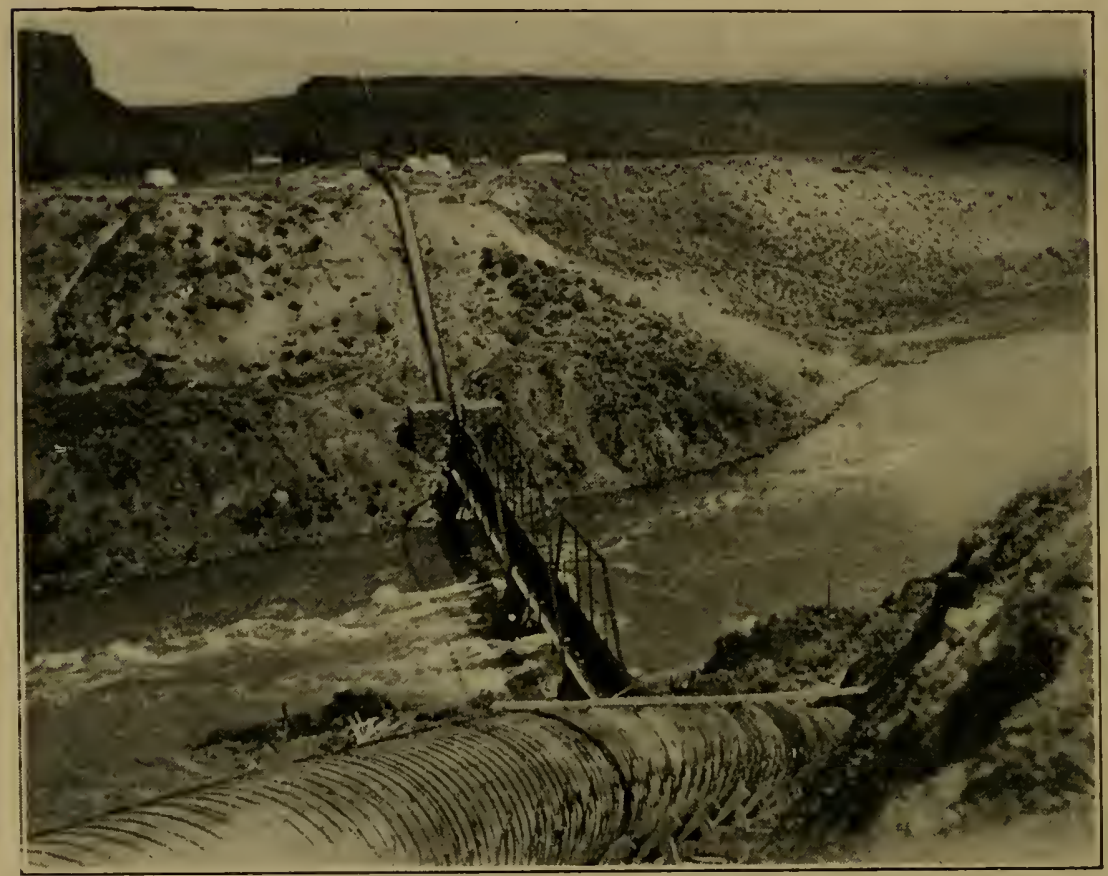

FIG. 91. Canal crossing river in an inverted syphon.

each second of time. The duty of a given stream would then be the number of acres irrigated per second-foot, flowing continuously during the season. This duty may easily be converted into acre-inches or acre-feet of water. One second-foot, flowing for twenty-four hours, will cover 1 acre to a depth of nearly 2 feet. If the time is known during which a second-foot of water has been nlowing over a given area, it is but a moment's calcula- 
tion to determine the depth to which the land has been covered.

The time during which a given volume of water flows is of first importance in determining the duty of the stream. A canal carrying 10 second-feet of water may be filled from May 1 to November 1; and during that time may irrigate 1,000 acres of land. The quantity of water

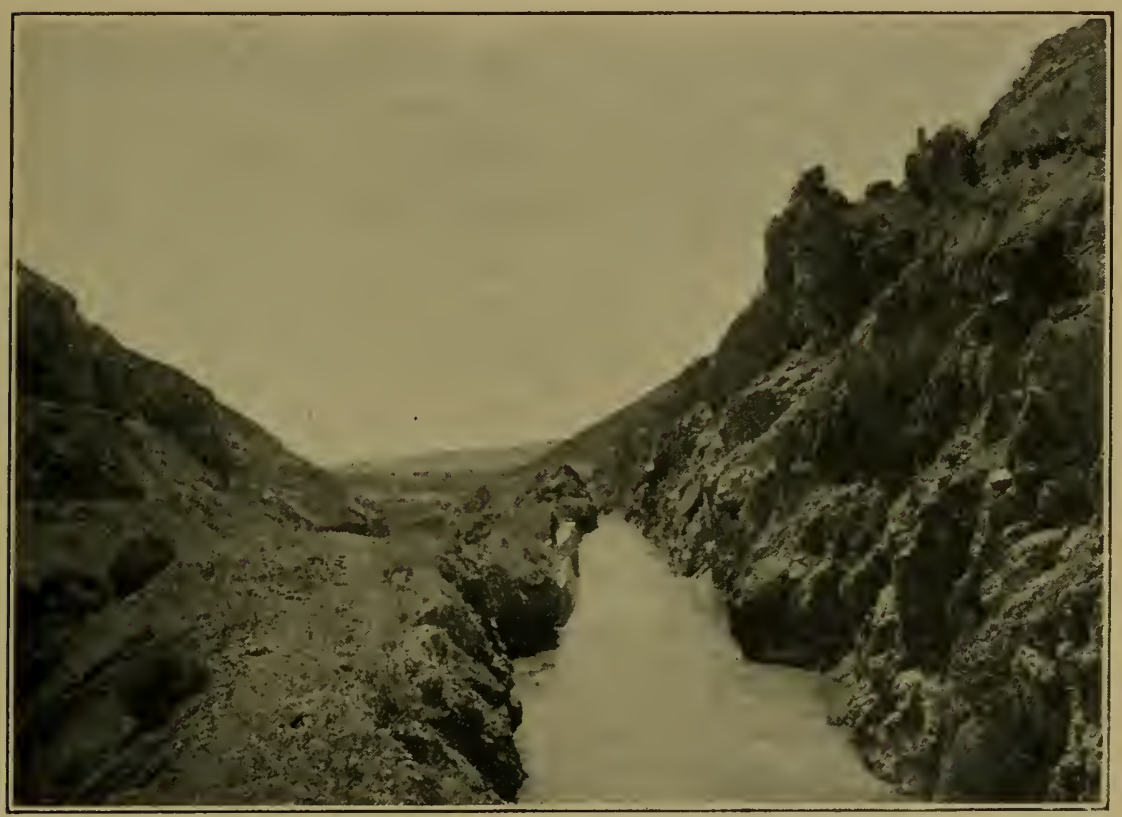

FIG. 92. Looking down the Bear River Canal.

passing through the canal during the six months in question would cover the 1,000 acres to a depth of nearly 39 inches. In fact, however, the water was used for irrigation purposes only about seventy-five days out of the six months and the actual depth of water given the crop was only about 18 inches. The duty of water expressed as the area covered by a given volume of water, flowing continuously, may, therefore, become very misleading 
unless it is carefully specified that the water was used during a certain number of days.

Canals taken directly out of the river usually carry water from early spring until late fall, but the water so delivered before and after the irrigation season should not be charged to the duty of water. When the waters are held back in reservoirs, water is of course allowed to flow through the canal only during the irrigation season.

The relationships existing among the quantity of flowing water, the number of acres to be irrigated and the depth to which the land will be covered may be shown in simple formulas:

$A=$ Area to be irrigated.

$\mathrm{D}=$ Duty of water, that is the acres matured by 1 second-foot flowing continuously for a definite period.

$\mathrm{B}=$ The time in days 1 second-foot flows to mature crop.

$\mathrm{S}=$ The depth in inches of the given volume of water over the area irrigated.

$\mathrm{F}=$ The discharge of second-feet necessary to irrigate the given area $\mathrm{A}$, with the duty $\mathrm{D}$.

The following relationship may then be established:

$$
\begin{aligned}
& \mathrm{S}=\frac{\mathrm{B}}{\mathrm{D}} \times 23.8 . \\
& \mathrm{F}=\frac{\mathrm{A}}{\mathrm{D}}=\frac{\mathrm{AS}}{\mathrm{B} \times 23.8}
\end{aligned}
$$

198. Classes of duty.-The theoretical duty of water is never quite realized in practice. The term "duty of water" does not refer to the theoretical deductions in laboratory experiments, but refers invariably to the watercost of crops under practical conditions. It is, therefore, 
a term which cannot, under present conditions, be fixed. As time goes on, and irrigation practices are improved, there will be an increasingly high duty of water obtained in the irrigated section.

The absolute duty of water means the sum of the water applied to the plant in irrigation and the water supplied from the soil moisture and by rains during the growing season. This duty is usually expressed as the depth in

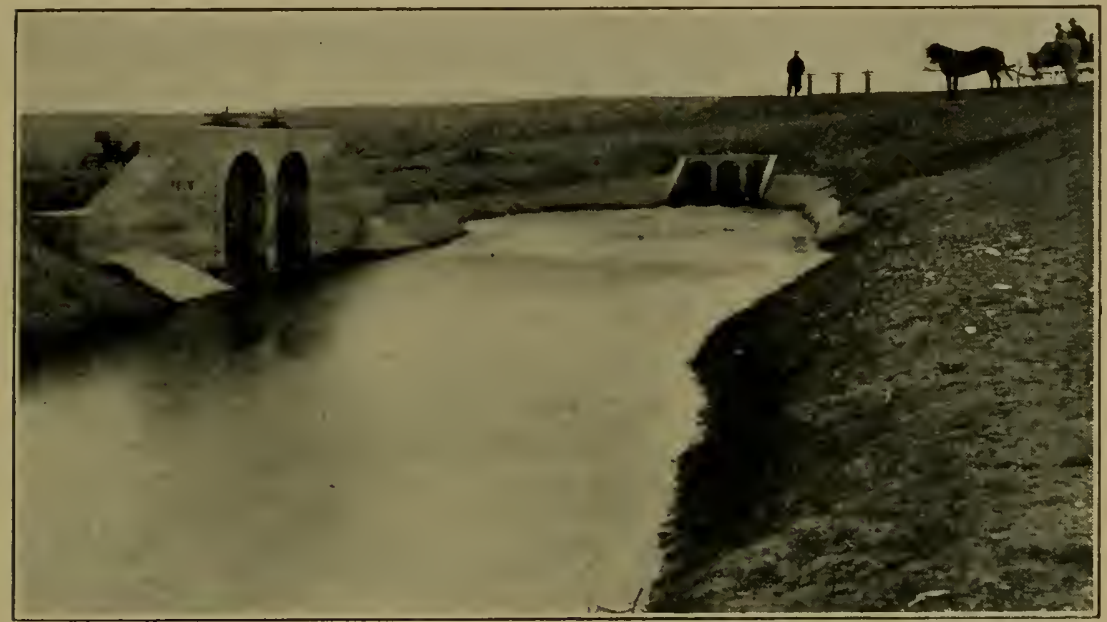

FIG. 93. Lateral outtake from large canal.

inches over the land. For instance, in a certain experiment, 6.4 inches of water were taken from the soil; 15.3 inches were added by irrigation, making a total of 21.7 inches, the absolute duty.

The net duty of water means the area of land covered by the water received by the farmer at the farm headgate. It is practically identical with the absolute duty, except that the water stored in the soil and the rains during the summer are not taken into account.

The gross duty of water means the area of land served by the water at the intake of the canal, or occasionally 
at the intake of the large lateral. It is the duty for the whole system and is of primary interest to the engineers who design irrigation systems. In transit from the head of the main canal to the farm where the water is applied to the crops, large volumes of water are lost by evaporation and seepage, and the duty of water for the system does not at all represent the actual water requirement of the crops grown under the system. The net duty is therefore of prime value to the farmer whose chief interest is in the water actually received by him at his farm.

199. Determination of duty of water difficult.-The duty of water under any irrigation system is always difficult to determine. The soil, climate, methods and time of application and many other factors do much to increase or decrease the area that may be served by a given quantity of water. The reservoirs and canals themselves, whether lined or unlined, whether passing over gravelly strata or clay beds, determine in large degree the gross duty under the system. After all such factors have been taken into consideration, there remains, as a disturbing factor, the law that the more water is added to a crop, the smaller the yield to the unit of water. This law of increasing water-cost brings always to the front the question of whether much water shall be used to obtain the largest possible yield an acre, or whether moderate quantities shall be used to obtain the largest yield from each acrefoot of water. There is a depth of water for each set of land, crop and water conditions, which produces the greatest profits. When water is added above or below this point the profitableness decreases. This point of optimum duty will, as our knowledge increases, be determined for different crops and irrigation projects.

An example will illustrate what is meant by this point 
of highest profitableness or optimum duty. A beet field is supplying beets to the factory at a contract price of $\$ 5$ a ton. The total cost of producing the beets, including interest on the investment, may be assumed to be $\$ 60$ an acre. The following table may then be constructed on the basis of the crop yields in the Utah experiments on the effect of varying quantities of water on the growth of crops:

\begin{tabular}{|c|c|c|c|c|c|c|c|c|c|}
\hline $\begin{array}{c}30 \text { acre } \\
\text { inches } \\
\text { spread } \\
\text { over }\end{array}$ & & 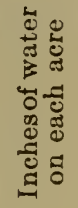 & 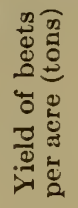 & 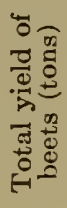 & 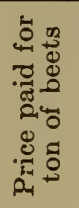 & 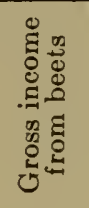 & 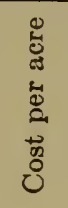 & 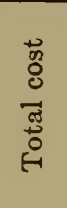 & 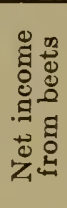 \\
\hline 1 acre & . & 30.0 & 21.0 & 21 & $\$ 5$ & $\$ 105$ & $\$ 60$ & $\$ 60$ & $\$ 45$ \\
\hline 2 acres & . & 15.0 & 19.5 & 39 & 5 & 195 & 60 & 120 & 75 \\
\hline 3 acres & . & 10.0 & 18.6 & 56 & 5 & 280 & 60 & 180 & 100 \\
\hline 4 acres & . & 7.5 & 16.3 & 65 & 5 & 325 & 60 & 240 & 85 \\
\hline
\end{tabular}

Under the above conditions, the largest net income, $\$ 100$, was obtained when 30 acre-inches were spread over 3 acres. When spread over less or more land than this the net income decreased. Similar results must be determined for all of the standard crops, so that for any set of conditions the most profitable depth of water may be known.

In different sections of the irrigated regions, 1 secondfoot of water serves from 25 to over 300 acres, with an average near 75 to 100 acres. This great variation is partly due to the differences in rainfall. Wherever the rainfall is high, less irrigation water is required to mature crops. This is not the main cause of the varying duty of water, for the highest duty is usually found where the rainfall is light, as in southern California. Differences 
in the duty of water lie rather in the practices of the farmer, who usually feels that the more he irrigates his crops, the greater will be his reward. Every irrigation farmer is something of a water hog. His safety lies in the irrigation canal, especially in the lateral which leads to his farm. One of his main efforts is to secure the largest possible quantity of water for his land. As a consequence, the varying duty of water can ordinarily be correlated with the quantity of water available in various localities. Wherever water is abundant, the duty is low; wherever limited, the duty is high. At the upper end of the canal the duty is less than at the lower end, for the farmer at the head has the first chance and uses all he can get, usually to the detriment of his crop.

200. Duty of water in Africa.-Egyptian irrigation antedates written history. The early Egyptians gave careful attention to the development of a permanent system of irrigation. The modern government of Egypt has likewise given very careful attention to irrigation and some of the largest modern irrigation projects have been constructed in Egypt.

The climate of Egypt is very arid. According to Sir William Willcox, the average annual rainfall at Alexandria is about 9 inches, at Cairo about $1 \frac{1}{4}$ inches, and at Assuan practically no rain falls. Under such a dry climete, the water requirements of crops should be very high, and the duty of water very low. As reported by Willcox, during an irrigation season of about seventy-five days, 1 second-foot has a duty for cotion and other dry crops of 115 acres; for rice, 60 acres. This is not far from the average results obtained in other countries where much more rain falls. Nevertheless, the methods of irrigation practised in Egypt tend to waste considerable portions of 
water, and make it unlikely that the duty as above given represents the most economical use of water. When the Nile overflows, water is conducted into large basins and allowed to stand there until the silt carried by the river water is deposited and the soil itself has become thoroughly saturated with water. Afterwards the surface water is allowed to flow back into the Nile. This makes it certain that plants do not use all the water actually applied to the soil. Moreover, the above results represent the gross duty of water in Egypt. Few studies have been made of the net duty, but since the gross duty varies little from that obtained in other sections of the world, it is likely that the net duty is not greatly different from that obtained in other parts of the world.

Some investigations have been made also on the duty of water in southern Africa. According to Mawson, the duty of water in South Africa, under an annual rainfall of 20 to 35 inches, is, for grain, 115 acres; for vegetables, 100 to 180 acres; for cereal crops, 140 to 200 acres; for sugar-cane, 50 to 70 acres; for fruit trees, 200 to 300 acres. In the Cape Colony, the duty of water has been found to vary from 150 to 285 acres, although two crops were raised on the land. In the Transvaal, not quite 24 acre-inches of water are applied to land for the production of crops.

201. Duty of water in Asia.-In Asia, as in Egypt, irrigation has been practised from before written history. The best example of Asiatic irrigation is India. More systematic irrigation work has probably been done recently in India than in any other part of the world, unless it be the recent irrigation progress in western United States and western Canada.

The rainfall of India varies greatly, from the highest in the world to a condition of extreme aridity. Over the 
Ganges delta, the average annual rainfall varies from 60 to 70 inches, whereas over the Northwest Provinces it is in the neighborhood of 25 inches.

The duty of water in India has been investigated under government supervision, and much has been published

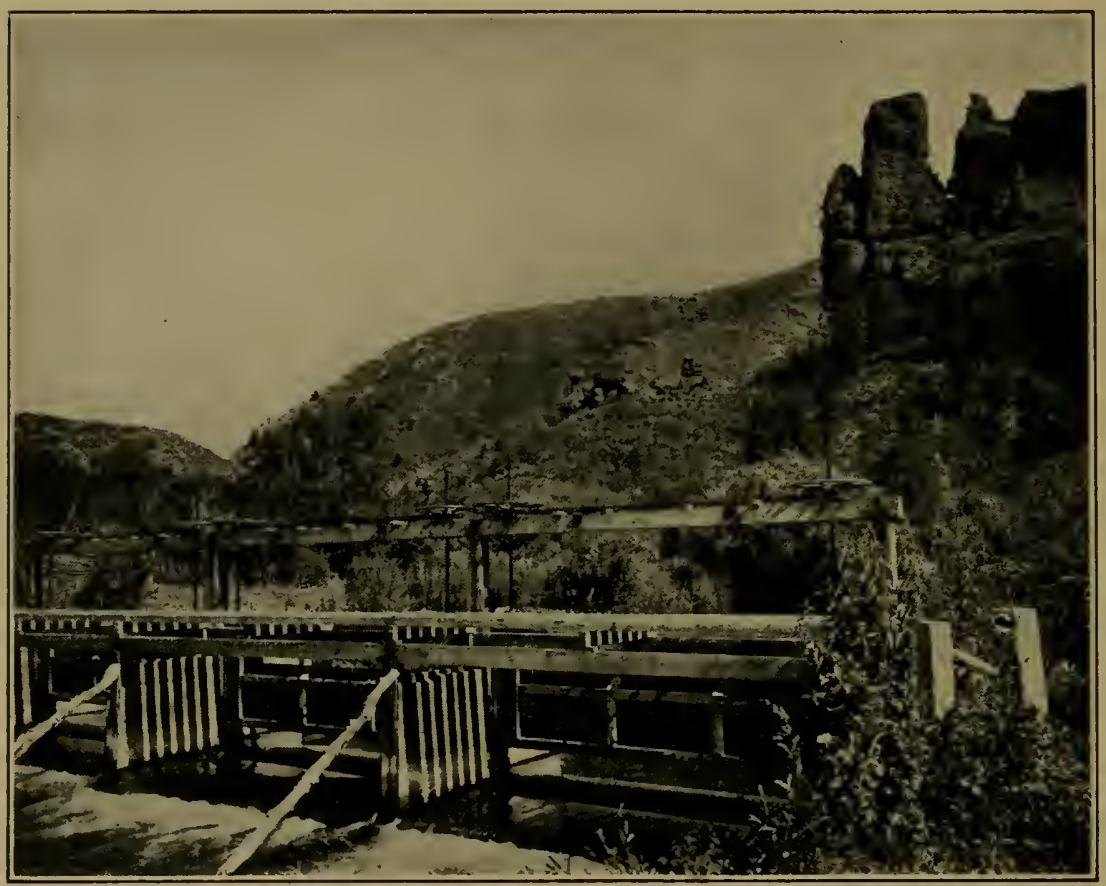

FIG. 94. Headgate of a canal.

concerning it. R. B. Buckley, the chief authority on East Indian irrigation, states that the gross duty of water during the wet season-from June to October-varies from about 80 to 170 acres to the second-foot. During the cold season-from November to March-the duty of water varies from about 90 to 200 acres to the second-foot of water. The duty of water varies greatly, even under the same canal, if different sections are considered. In India, as elsewhere, it seems to be true that the more 
water available, the more used. Moreover, varying seepage in different localities causes a varying gross duty of water. In one exhaustive study of the duty of water, it was found that under a given system, 20 acre-inches were actually used for the production of crops; while in another place four irrigations of $2 \frac{1}{2}$ acre-inches each, or a total of 10 acre-inches, produced abundant crops of wheat. Kennedy, who carried on experiments under the BarriDoab Canal, found that wheat, barley, coffee, Indian corn and cotton required during the season 10.6 inches of water; and sugar-cane 25.7 inches. These results show that the water requirements of crops in India are practically identical with those in America and other countries of the world.

The loss of water from the main Indian canals varies from 20 to 75 per cent and, consequently, the net duty of water in India is much greater than the gross duty. In one series of investigations it was found that even the laterals from the main canal served a much larger area than the whole canal, per second-foot of water, the difference rising occasionally to 30 or 40 per cent.

Under several of the Indian canals, 160 acres have been adopted as the duty of water for 1 second-foot under the whole system. This compares very favorably with present practices in the United States.

202. Duty of water in Europe.-Irrigation is generally practised in Europe, especially in France, Spain and Italy. In these latter countries, irrigation goes back many hundreds of years, and the methods now followed are based upon the experience of centuries. True, in southern Europe, irrigation is not a matter of life and death, as in the more arid sections of the world, but it has done and is doing much to increase the wealth and prosperity of 
southern Europe, for, without irrigation, some of the most fertile sections of southern Europe would be of mediocre producing power.

The duty of water under European canals does not differ greatly from that observed under canals of other countries. In France, the duty has been found to vary from about 40 to nearly 200 acres to the second-foot of water. The lower duty of water prevails where water meadows are maintained, which are not a true form of irrigation agriculture. Under the carefully managed canals of France the duty ranges from 100 to nearly 200 acres to the second-foot of water. In Italy, the duty of water varies from about 40 to 100 or more acres per second-foot, and occasionally reaches 300 acres where Indian corn and similar crops are raised. In Spain, where economy in the use of water has been carried to a high degree, an average duty, under twenty canals, was found to be 172 acres to the second-foot of water. As an average of one series of measurements under the chief canals of France, Italy and Spain, 1 second-foot of water serves 239 acres of the standard crops of those countries. Generally speaking, therefore, the duty of water in southern Europe is somewhat higher than in Egypt, India or the United States.

203. Duty of water in South America.-Few data exist concerning the duty of irrigation water in South America. In prehistoric times, large irrigation projects existed in South America, the remains of which give testimony of the excellence of South American irrigation in earlier days. In northern Peru, which is practically rainless, it is reported that the duty of water is 160 acres to the second-foot of water; and in northern Chili, which is also practically rainless, the duty is about 190 acres to the second-foot of water. These figures are averages, for 
special districts. It is not likely that any unusually high duty of water prevails in South America.

204. Duty of water in Australia.-Irrigation on a large scale is just beginning to be developed in Australia. The methods there adopted are based upon the best practices of the world, notably upon those of the United States. The duty of water, as it is developed in Australia, does not differ materially from that of North America. Many of the projects are comparatively new and the duty is low, but will become higher as more complete irrigation practices are adopted.

205. Duty of water in North America.-The chief irrigated section of North America covers western Canada and the western United States. These two districts are so similar in climatic and soil conditions that whatever is true of one is generally true of the other. Some excellent duty of water experiments have been made for this section, by the United States Department of Agriculture under the direction first of Elwood Mead and later of Samuel Fortier. The gross duty of water was determined for a number of representative canals in all of the western states. As a general result, Teele declares that "It appears that $3 \frac{1}{2}$ to 4 acre-feet are required at the heads of unlined earth canals. This can be taken safely as a basis for computation." This means that the duty of water for 1 second-foot, flowing for 60 days, varies from 34 to 27 acres; flowing for 120 days, from 68 to 54 acres, and flowing for 180 days, from 102 to 80 acres. This gross duty for western North America does not represent, even approximately, the net duty of water, for the irrigation investigations of the United States Department of Agriculture have shown for a series of representative canals that nearly 60 per cent of the water is lost between the 
headgate of the canal and the laterals, and undoubtedly much of the remaining 40 per cent is lost between the heads of the laterals and the farms. Observations were also made by the government investigators on the quantities of water actually applied to crops, with average results as follows: Alfalfa, 32 inches; wheat, 18 inches; barley, 16 inches; potatoes, 28 inches; sugar beets, 25 inches, with an average for these crops of about 23 acreinches. For an irrigation season of about ninety days, this would mean a net duty of 100 acres. This is much larger than the gross duty as above given. The losses from the canals are always large, averaging 5.77 per cent per mile; and Fortier declares that perhaps less than onethird of the water diverted by the canals is actually used by the crops.

206. Bear River Canal experience.-One of the most notable canals in western America is the Bear River Canal, which began its actual operations in 1891. Its first duty of water was 40 acres for six months for each second-foot of water, or a depth of 4.2 feet during the six months. In 1903, after twelve years of experience, it was obvious that too much water was being used. The ground water table was rising rapidly near the surface, alkali was becoming visible in certain low sections, and, all in all, the evils from over-irrigation were observed. Careful measurements were then made of the water delivered, and attempts were made to increase the duty of water. For four years thereafter, 6,000 measurements were made at the head of the canal, at the heads of the laterals, and at the gates to the individual farms. According to Wheelon, it was found in 1903 that a duty of 67 acres per second-foot prevailed. In 1904, this had been raised to 120 acres, and in 1905 to 138 acres. These 
duties were calculated from the measurements taken at the heads of the laterals and are smaller than would be the case were measurements made at the farms themselves. During these years of increasing duty, cropyields were equally good, and crop quality was improved. The increasing duty of water under this system is still going on, with the result that farming conditions are being greatly improved. This is the history of all the larger canals in America that have received competent and constant supervision. The duty of water is steadily increasing throughout the whole of western America.

207. Idaho results. - A series of recent investigations in Idaho further brings out the present duty of water in western America. Bark measured the quantities of water used by 168 Idaho farmers. Most of these farmers had been farming only a few years, and since the duty of water is always lowest at the beginning of irrigation prac. tice, the measurements represent maximum use. The irrigation season for grain varied from thirty-six to fortysix days, and for alfalfa from ninety-six to one hundred and twenty-two days. It was found that the crops received on an average practically 2 feet, or 24 inches of water, which, for an irrigation season of four months, would be equivalent to about 120 acres to the second-foot of water. Where water was plentiful, much was used; where water was scarce, little was used. Moreover, it was found that the entire need for water fell on the four months, May to August inclusive. It is likely that for all ordinary crops the irrigation season seldom exceeds four months and in many cases is covered by two months.

208. Miscellaneous results.-H. M. Wilson, a high authority on irrigation matters, presents the following as the duty of water for 1 second-foot of water: In western 
United States it varies from 60 to 300 acres; where water is most abundant it varies from 60 to 120 acres; where water is less plentiful it varies from 100 to 150 acres, occasionally rising to 200 acres; where water is very scarce, as in southern California, it rises to 300 acres. There are records to show that the duty of water has reached even 1,000 acres to the second-foot of water, but such figures are as yet exceptional and need not be given serious consideration as part of present-day practical irrigation agriculture.

Elwood Mead, one of the world's chief irrigation authorities, declares that the duty of water in the United States is on the average quite as high as in the older countries, but predicts that the duty will be doubled as more perfected methods of agriculture are adopted.

F. H. Newell, the illustrious director of the Reclamation Service of the United States, believes that for good farming an average of 12 acre-inches for each acre, during the irrigation season, should be enough, except for alfalfa and certain similar crops. This, for a four month's irrigation, is a duty of 206 acres. Newell further states that the duty of water often reaches 250 to 500 acres to the second-foot of water.

209. The Utah results.-The careful studies of the Utah Station on the water requirements of crops indicate that, when the natural precipitation is properly conserved, even 6 acre-inches an acre will produce fairly good yields of all the ordinary crops. If more water be applied the yield is smaller in proportion. The Utah results would lead to the belief that where the annual rainfall is from 12 to 15 inches a depth of water from 10 to 20 inches is best for ordinary farm crops, and that the best quantity lies-nearer the smaller figure. A depth of 12 inches prob- 
ably represents the average requirement of ordinary farm crops, providing the water is measured at the intake to the farm. Should this be increased to 20 inches it would still be much less than the quantity ordinarily applied. A depth of 12 acre-inches equals a duty of 120 acres per second-foot for sixty days, or 180 acres for ninety days, or 240 acres for one hundred and twenty days. These figures probably approximate the normal duty for western America, under present conditions.

The new duty of water must be based upon all the knowledge in the possession of man. The water in the streams must be used to cover the largest possible area so that more men may be giveñ employment and more families maintained upon the irrigated lands.

\section{THE MEASUREMENT OF WATER}

210. Need of measuring water-Farmers keep accounts of the area of land under cultivation, the yields of crops per acre and the money received for each bushel of grain or ton of alfalfa, but often fail to keep track of the quantity of water used in irrigation. The whole discussion of the preceding chapters is, however, based on the thesis that irrigation water may be and should be measured. Especially is this necessary where water is more valuable than the land, and where it is, therefore, more important for the farmer to obtain a large yield to the acre-foot of water than to the acre of land. Moreover, if water, from the beginning of irrigation, had been measured, less land would have become water-logged or subjected to the rise of alkali. Finally, there will always be disputes about water-rights, and after water-rights are established the rulings of the courts must be literally obeyed, so that 
peace may prevail in irrigation communities. What the surveyor does in promoting peace as he establishes boundary lines for fences between farms, the modern irrigation engineer does as he determines the quantities of water each farmer and his neighbor are receiving from the canal or river.

In the beginning of irrigation in this country, when the pioneers were few and had an abundance of water, it is evident that there was not so much need for the measurement of water as at the present time. As more settlers

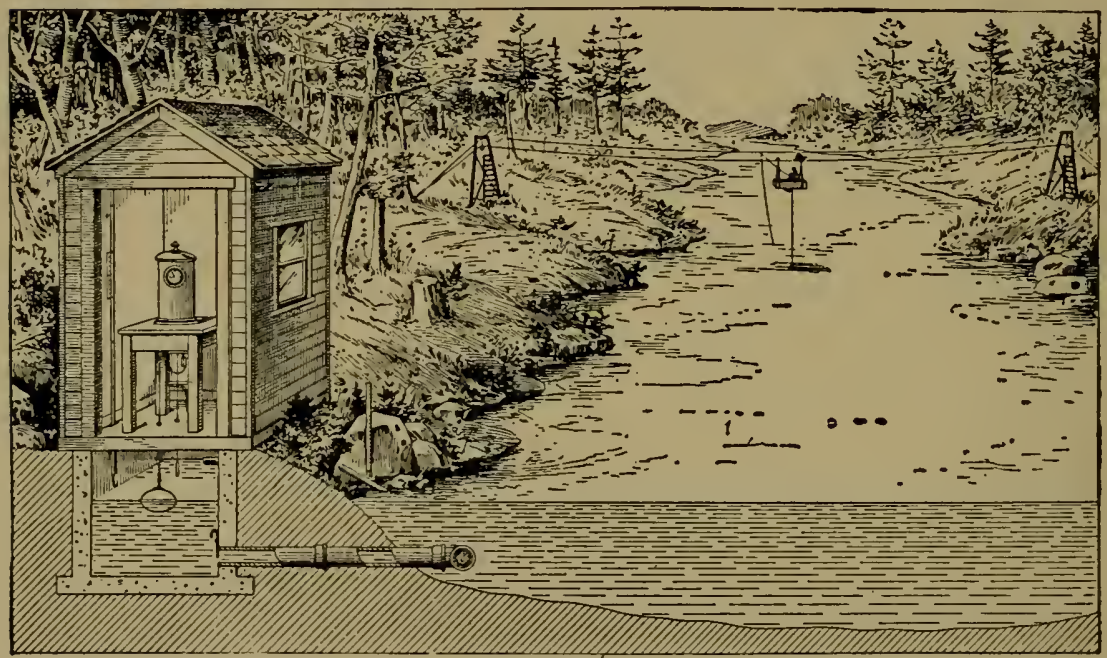

FIG. 95. A cable measuring station with automatic gauge.

arrived, all the waters were taken up, and there came a crying need for suitable devices for measuring and dividing water. A perfected system of irrigation agriculture cannot come until measurements are made of the flowing water in the natural river channels, in the main canals, in the laterals and at the headgate of each farm. In fact, the measurement of water is the great irrigation need of the day, in the face of which all other needs vanish. All that 
has been done in the gathering of information concerning the relations of soils and crops to water is practically useless unless the knowledge be applied under conditions of carefully measured water.

211. Who shall measure the water?-The company controlling the irrigation system should conduct measurements and deliver to each farmer at his own headgate and at certain periods a definite number of cubic feet of water. The complexity of irrigation agriculture, however, makes it evident that a new kind of irrigation engineer must arrive who must stand between the canal corporation and the farmers drawing water from the canal. He must know enough engineering to measure, divide and distribute water and to keep up the system of canals and laterals, and enough of agriculture to define the quantity of water for different soils and crops. A big step onward will be taken when canal owners and farmers insist upon such a trained water-master. However, in this matter of water-measurement the farmer must be independent. He should understand the simple ways of measuring water accurately. Even when the canal management delivers definite quantities of water, it becomes the business of the farmer to distribute this water correctly on the fields of the farm, and this can be done only by employing satisfactory measuring devices.

212. Classes of measurement.-Only under the few canals of moderate capacity and early water-right, or from ample reservoirs, can the farmer depend on receiving the same quantity of water from year to year. In most districts the total quantity of water taken in by an irrigation system depends upon the quantity of water flowing in the river which, in turn, depends upon the varying seasons. Except for certain primary water-rights, or 
small canals or canals drawn from reservoirs, they who take water out of a river have right only to a definite proportion of the total flow. In a dry as in a wet year this proportion remains the same. For instance, if there

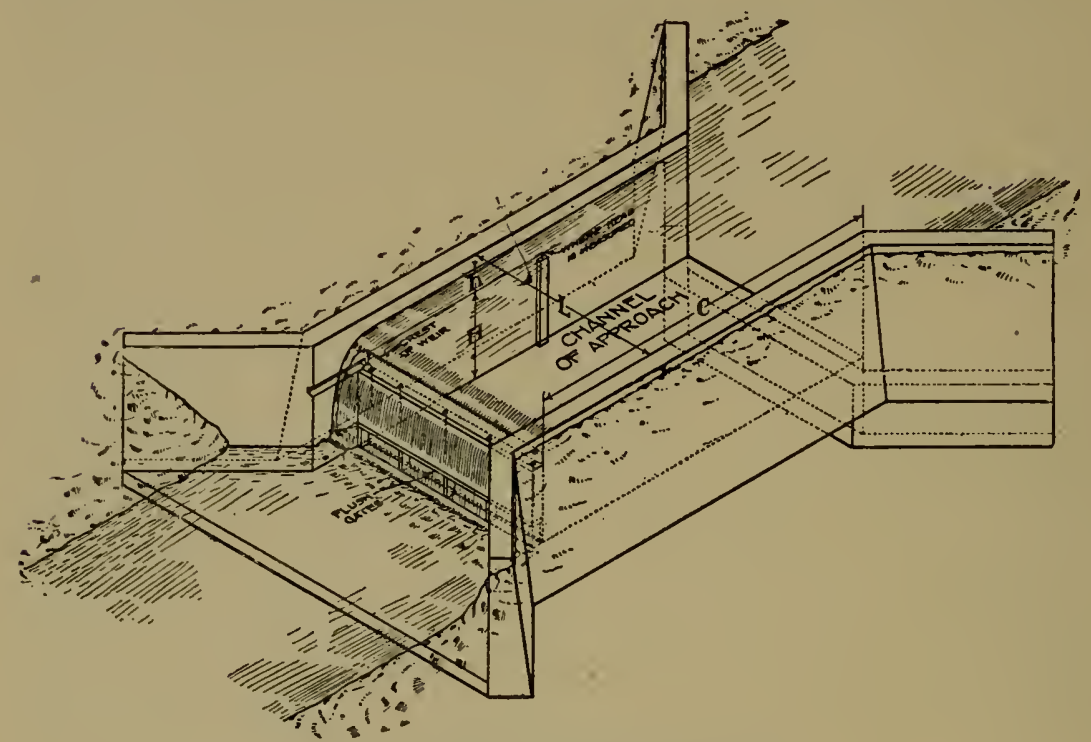

FIG. 96. Lyman rectangular weir.

are 500 shares in such a canal company, each share will receive $\frac{1}{500}$ of the total flow in the canal whether the flow be large or small.

There are, therefore, two classes of measuring devices: (1) Divisors, for the purpose of dividing streams into halves, quarters or other fractions, independently of the volume; (2) modules, for the purpose of measuring the absolute volumes of water that flow through canals or ditches. The divisors can be made satisfactorily only after proper and satisfactory modules have been established.

A great variety of water-measuring devices exists. In the beginning of modern irrigation there were no 
special methods for measuring water. Ordinary gates, placed at the heads of the laterals, were raised or lowered by the water-master to send volumes of water, equal to the eye, down the laterals to farmers owning practically the same water-rights. Later, with the increasing value of water, better measuring devices have been adopted.

The simplest devices for measuring the quantity of water flowing in a channel are those known as weirs or overfalls. A board is placed as a check across the stream. Into the board is cut a notch through which the water flows. The weir method of measuring water has been investigated long and carefully, with the result that in some form it may now be used safely and easily by the farmer. The chief objection to the use of weirs in irrigation is the tendency of the weir to become filled with silt if the water carries sediment. When this occurs, the measurements are less reliable and the weirs must, therefore, be cleaned frequently.

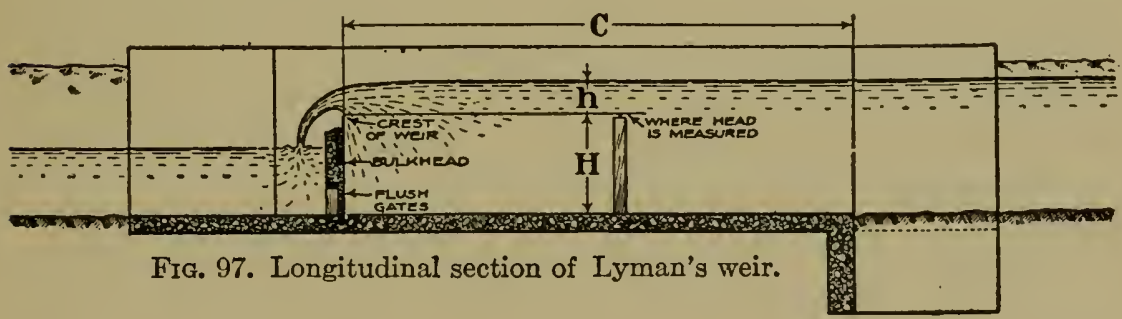

Three kinds of weirs are used successfully for water measurement. First, the rectangular weir, which is best known and most certain, for it has received most study by engineers. It is not, however, the simplest, because the water flowing over the weir contracts at the bottom and sides, and this contraction varies as the depth of the 
water or the length of the weir increases. The necessary corrections for this variation complicates the use of the rectangular weir. Many irrigation engineers, however, well acquainted with irrigation, insist that for practical purposes no weir has taken the place of the rectangular weir. Second, the trapezoidal weir, which has largely replaced the rectangular weir in irrigation. The trapezoidal is like the rectangular weir, except that the sides of the notch slope away slightly, making a trapezoidal, instead of a rectangular, opening through which the water flows. The sloping sides are intended to correct automatically the loss of water due to the contraction. Over a trapezoidal weir 2 feet long, all else being equal, twice as much water is supposed to flow as over one 1 foot long. This is not true of the rectangular weir. The first trapezoidal weir with this purpose in view was devised by the Italian engineer Cippoletti, and the weir has been named the Cippoletti weir by L. G. Carpenter, of Colorado, who was first to call the attention of the American public to this form of weir. In America, Canada, Australia and other countries it is practically the only weir used by the irrigator. Third, the triangular weir, the notch of which is in the form of a triangle. Its chief advantage is that only the depth of water flowing over the triangle needs to be measured. Very satisfactory results are obtained by the use of the triangular weir, and it is likely to increase in favor: With our present knowledge, triangular weirs seem suitable chiefly for small streams.

Recently, Lyman has given careful and exhaustive study to this subject, with the result that he has devised methods whereby water may be correctly and easily measured in flowing streams, without the use of weirs. (Figs. 96, 97.) 
213. The Cippoletti weir.-The sides of the notch of the Cippoletti weir slope outward at the rate of 1 inch horizontally, to 4 inches vertically. The notch of the weir is always made with a beveled edge of $30^{\circ}$ or more down stream so that the water always flows over a sharp edge. To maintain the sharp edge, the weir should be faced on the inside, or up stream, with iron strips, placed even with the beveled edge. The distance from the bottom of the weir box to the top of the crest should be at least two times the depth of the water flowing over the crest. The weir should be installed where the approach of the water is straight, long and level. As the water passes over the crest, it should flow very slowly, not more

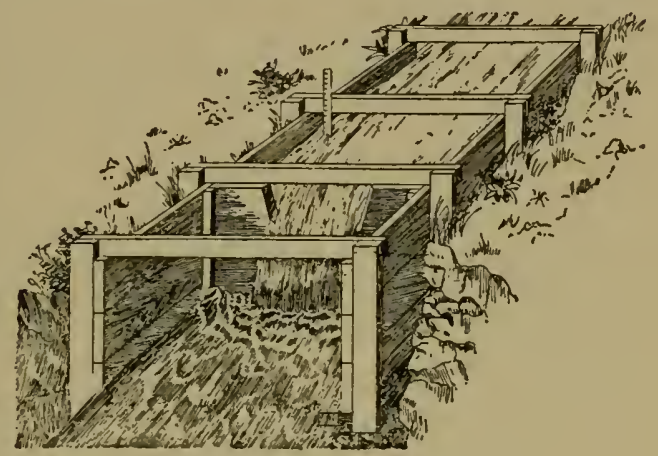

FIG. 98. Cippoletti weir. than 6 inches a second for a weir 6 feet wide. The weir must be placed at right angles to the stream, with the crest absolutely horizontal. Provision should also be made for washing out the accumulating sediment by making the weir movable, so that it may be raised from time to time. In many rivers or large canals the weirs are movable and are kept above the stream except when measurements are taken. Below the weir, where the water falls over the crest, there should be sufficient depth, so that the water below the weir does not interfere with the flow over the crest. There should always be a free circulation of air under the jet of water falling over the weir. When a weir of known crest length has once been installed, it is necessary to determine only the depth of water above the $\mathrm{w}$ 
crest, some distance back from the weir itself, where the overfall has not yet begun to curve the water downward. Then, by the use of tables (See Appendix B), the quantity of water in cubic feet a second passing over the weir

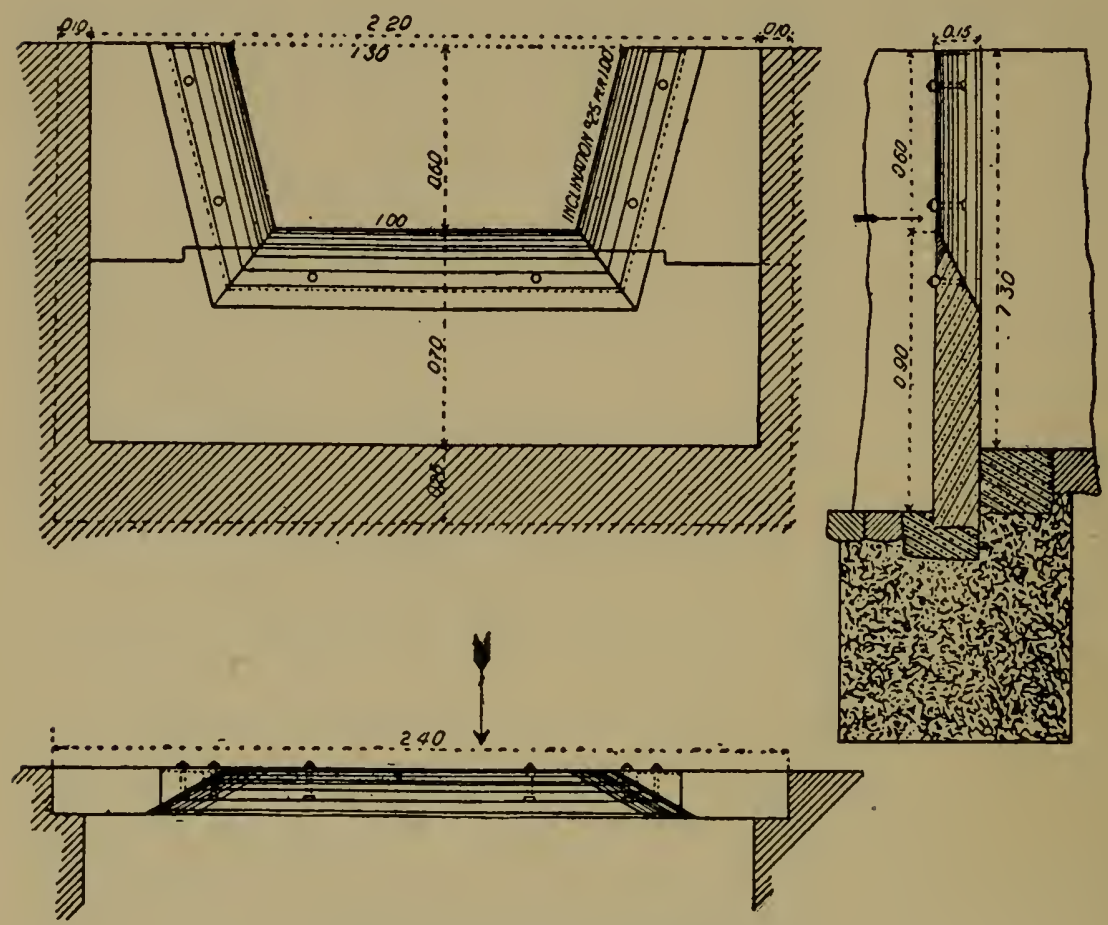

FIG. 99. Details of Cippoletti weir.

may be determined. Moreover, by use of these tables the size of the weir necessary for a given flow of water may be found. (Figs. 98, 99.)

However, even the use of tables is somewhat unsatisfactory and inconvenient for the farmer actually at work in the field. For that reason, plates have been devised, that may be screwed to the side of the weir box, which show by inspection the number of cubic feet of water passing over the weir every second of time. (See Fig. 100.) 
Naturally, a different plate must be made for each length of weir. Once such plates are installed, however, the labor of reading weirs is reduced to a minimum. The whole question of weir measurements is now being critically examined at the Colorado Experiment Station, in coöperation with the United States Department of Agriculture. The weir in some form will undoubtedly be the standard measuring device of the irrigation world.

214. Divisors. - With the Cippoletti weir, the division of water may be performed easily and accurately. Since the slanting sides of the Cippoletti weir allow for the contraction of the water, the quantity of water flowing over any portion of the crest is approximately equal to that flowing over any other similar portion. Therefore, by placing a partition below the weir to divide the crest into certain proportional parts, the stream itself is divided into similar proportional parts. A beveled board or a sharp-edged partition of some kind is placed at right angles to the crest and so low as not to interfere with the free circulation of air around the jet of water. If the weir crest is 3 feet long and a partition is placed 1 foot from one end of the crest, the water is divided into two parts,

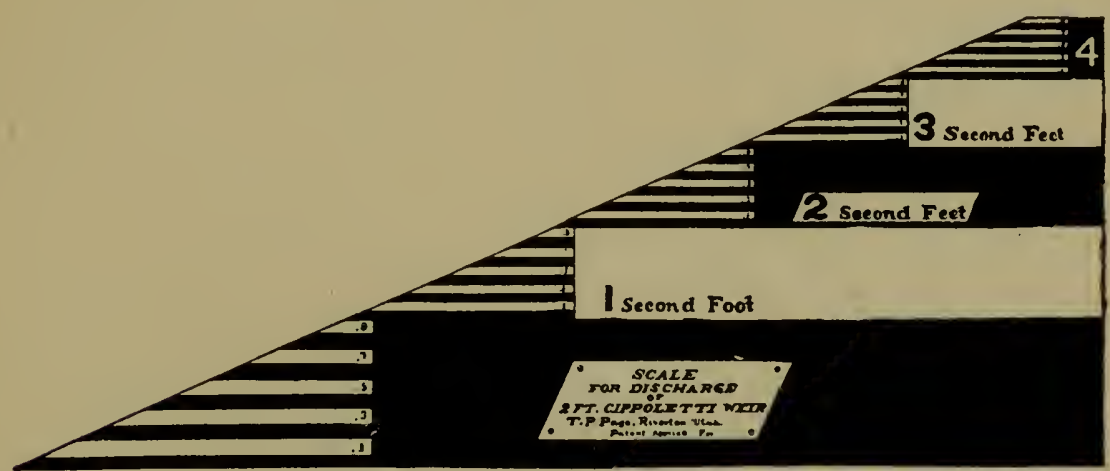

FIG. 100. Scale to be screwed on side of Cippoletti weir. This shows at a glance the quantity of water passing over the weir. 
one containing one-third and the other two-thirds of the whole stream. If the partition is placed $11 / 2$ feet from the end of the crest, the flow is divided into two equal streams. This extremely simple method of dividing water seems to give general satisfaction. It is frequently desirable to

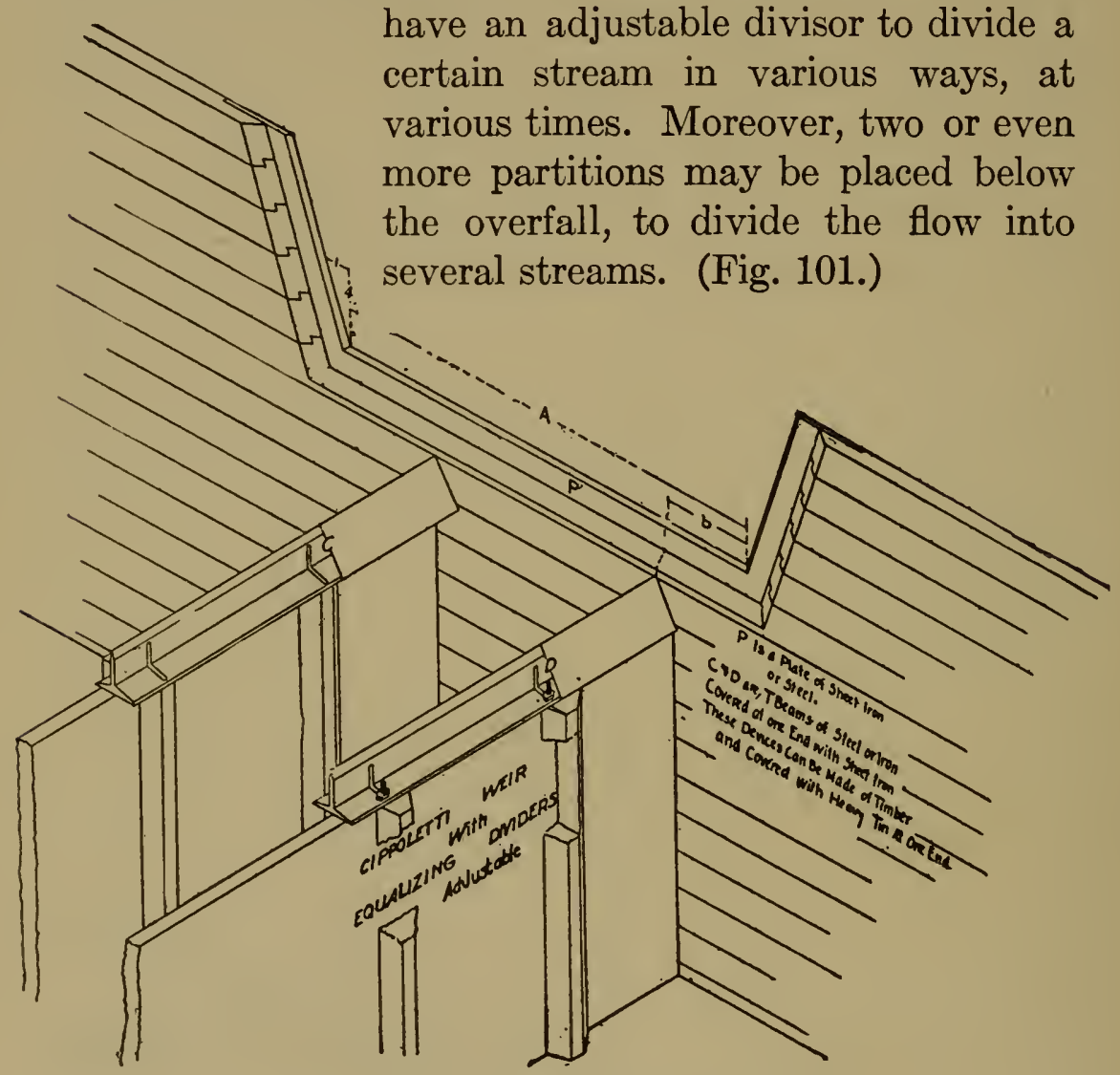

FIG. 101. Divisor attached to Cippoletti weir.

Frequently, it is necessary to divert a constant quantity of water from a large canal. For this purpose the automatic weir suggested by Winsor probably gives the best satisfaction. A board with a long, shallow notch in it to act as a spillway is placed lengthwise in the stream 


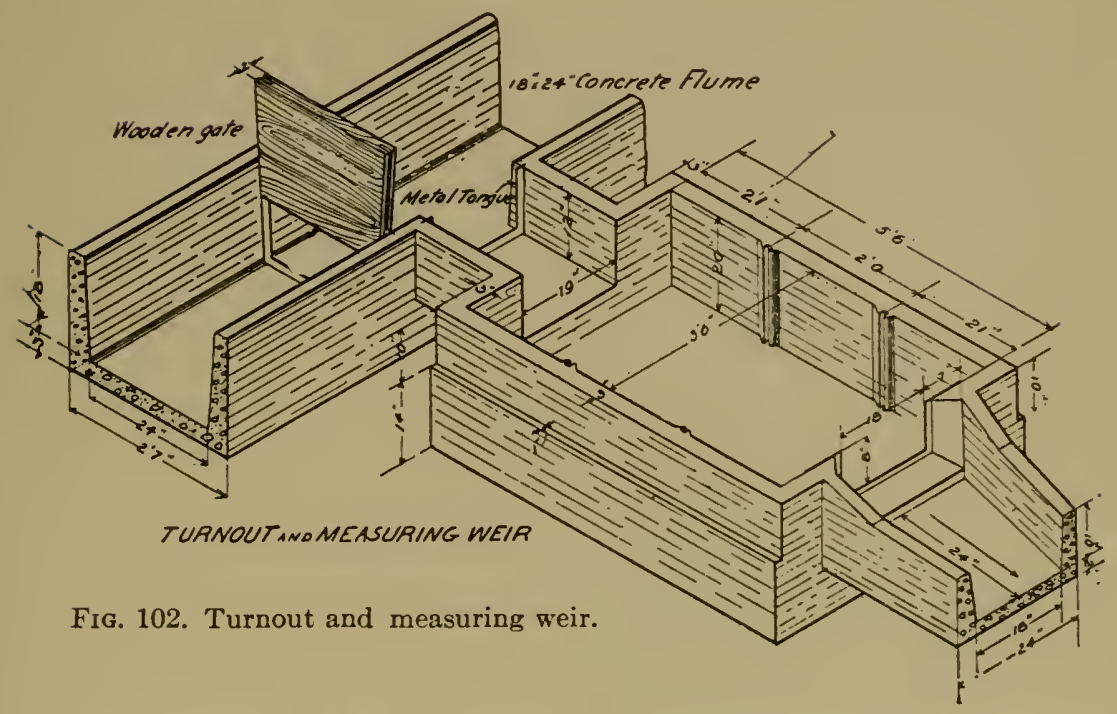

near the head of the secondary ditch to divert a part of the water flowing in the main ditch. At the proper distance down the secondary ditch an ordinary Cippoletti weir is placed. The board containing the spillway notch is raised or lowered in accordance with the quantity of water to pass over the weir. This device maintains the water flowing over the weir at practically the same height, irrespective of the quantity of water in the main channel. (Figs. 102, 103.)

THE DISTRIBUTION OF WATER

\section{Meaning of the distribution of water.- After the duty of water has been decided upon, and the quantity of}

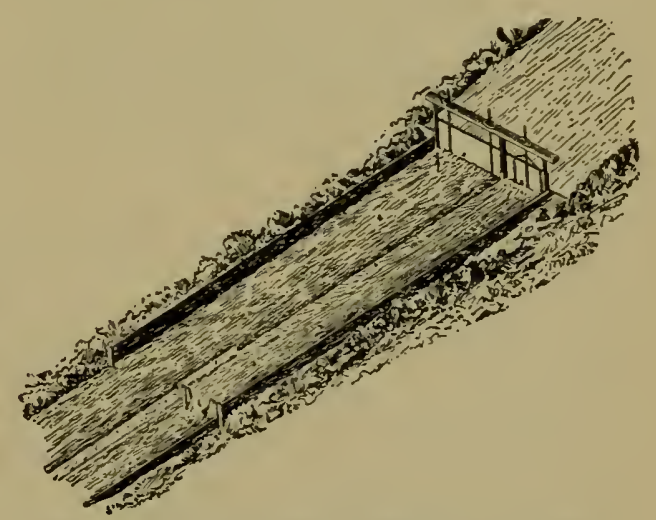

FIG. 103. Device for diverting a constant quantity of water. 
water flowing into the canal and its laterals has been carefully measured, there yet remains the perplexing and important problem of the proper distribution of the canal or reservoir water to the numerous farms of various sizes, growing different crops. Each irrigator must receive water in a quantity proportional to his interests in the canal, and at such a time as will each year insure him a good crop. The irrigator, the owner of the water-right, knows only one test of the efficiency of the canal management-does he have an ample supply of water whenever needed by his crops? The success of an irrigation enterprise depends on the success with which this test is answered; that is, upon the system of distribution of water under the canal.

216. Methods of distribution.-There are three general methods of distributing irrigation water among farmers. First, a continuous flow of water to the farm during the whole irrigating season. Second, an intermittent flow, which means that the farmer gets a certain flow of water for a definite length of time at certain intervals. Third, the delivery of water to the farmer as he applies for it.

Under reservoirs, with an ample supply of stored water, any one of these three methods may be used. Where canals are taken directly from the rivers the first two methods may be used but the third method is practically impossible.

The method chosen for the distribution of water may affect greatly the duty of water under the system, for it may determine the crops to be grown and the areas to be devoted to each.

217. Continuous flow.-Irrigation is not successful unless the head or volume of the irrigation stream is sufficiently large to cover quickly a suitable area of land. 

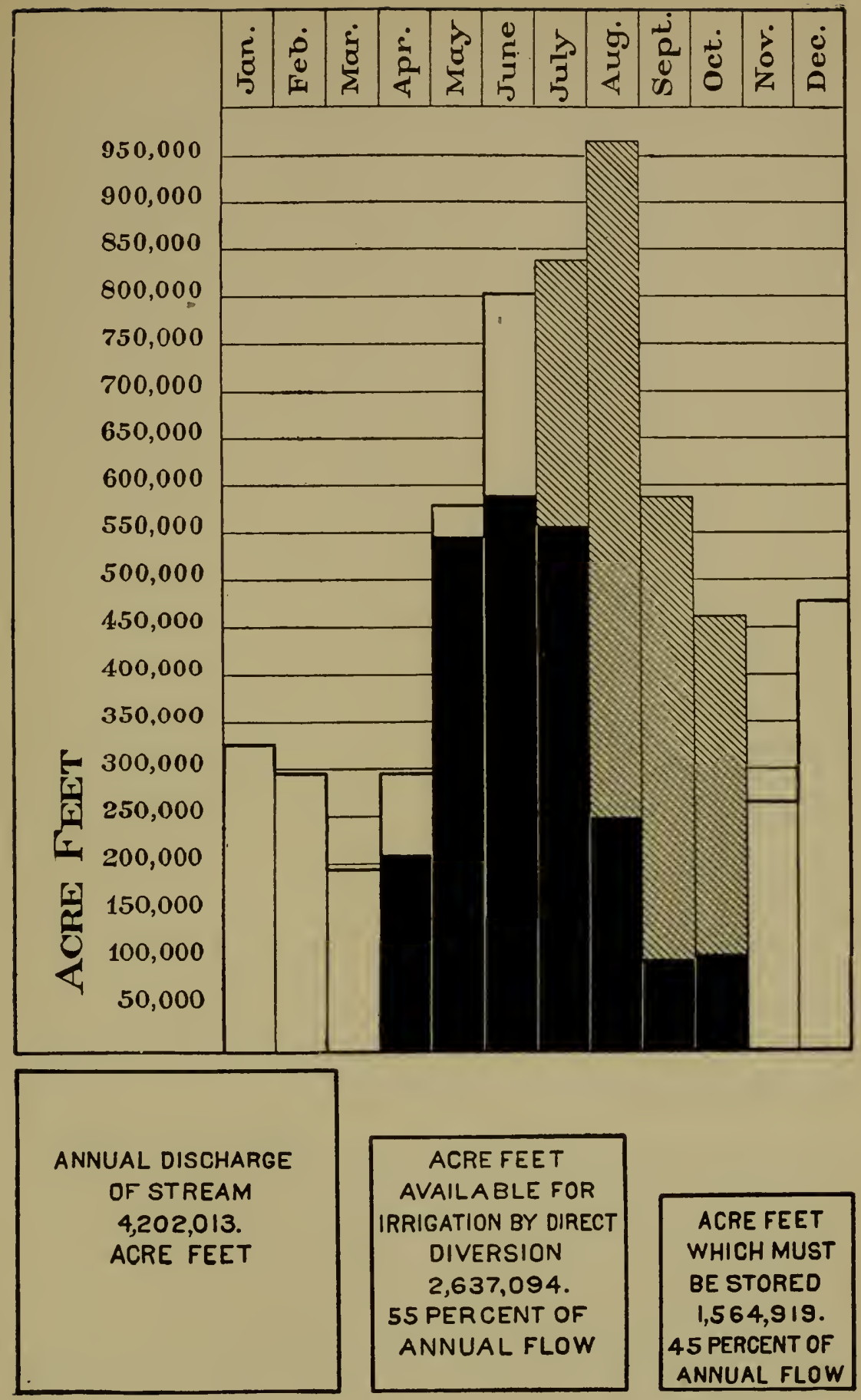

FIG. 104. The need of storing water in reservoirs. (Yakima River.)

(359) 
If the volume is very small, too large a proportion of the water is lost by evaporation during the long time required to cover the land with water. The method of continuous flow, which means that a stream of the same volume enters the farm from the beginning to the end of the irrigation season is successful only if the stream has a sufficient head, say from 1 to 2 second-feet. If smaller than this the method of continuous flow is not usually satisfactory. A large farm of from 100 to 300 acres may utilize so large a continuous stream. On small farms with small water supplies, the method of continuous flow is utterly unsatisfactory. A chief objection, even on large farms, to the method of continuous flow, is that, under it, irrigation must always be going on. The method of continuous flow is of real value only when the farm is a miniature complete irrigation system, representing the diversity of crops and conditions under the whole canal system; for only when this condition exists can the water be used to advantage from the beginning to the end of the season.

There is always more land than water in the irrigated sections. A man having a continuous stream of water throughout the season would probably plant one-half of his farm to grains and other early-maturing crops, and the other half to potatoes, beets or other late-maturing crops. In the early season the water would be used chiefly on the early crops; in the later season on the later crops. By such methods, the continuous flow may be made to cover larger areas than can the intermittent method. In practice, the distribution of water by continuous flow is carried on as follows: Ten second-feet are carried by a canal for the use of 1,500 acres divided into several farms. Laterals are made to each farm, in which is carried the proper proportion of water for that farm. Thus, a farm of 150 acres, 
one-tenth of the total area, would receive a continuous flow throughout the season of one-tenth of the total flow, or 1 second-foot. A farm of 50 acres, under this system, would receive a continuous flow of one-third of a secondfoot. The system is exceedingly simple after the laterals and dividing contrivances have once been established. The burden of the method falls upon the farmer who must use the water every day and night throughout the season.

218. Continuous rotation.-The method of distributing water by rotation is by far the most satisfactory. In America, it was introduced by the irrigation pioneers, and since that time has been tried out thoroughly in every section of the country. It is the standard method of water distribution in Asia, Africa, Europe and Australia. Every great irrigation enterprise has either adopted the method of rotation or is planning to adopt it.

By the method of continuous rotation the farmer receives a stream carrying a rather large head or volume of water for a certain definite number of hours, after which no water is at his disposal until his turn comes again, when a similar stream is received for the same length of time. The relatively large streams of water thus supplied give the small farmers the advantage of the larger farmers, of applying the water to the land in the shortest possible time. Moreover, the farmer is relieved of the strain of constant irrigation. During the time that the stream is at the farmer's disposal, he can give himself wholly to the work of irrigation; when that work is done, he may turn to some other farm operation. Experience has shown this to be most satisfactory to the farmer.

This method tends to eliminate the waste of water. Under the method of continuous flow, the steady care of 
the water becomes so burdensome that much of the water is often allowed to go to waste. The method of rotation, on the other hand, develops a spirit of using water carefully, since the time during which it is available for the farmer is relatively short and the work must be done at that time or not at all until the next turn. The farmer under the rotation method receives the water schedule early in the spring, and knows in advance the dates on which he will receive water. He may then plan much of his work for summer, and because of this system can make his days more pleasant and profitable. Perhaps the greatest argument for the method of rotation is that it gives the small farmer an equal chance with the large farmer. Under the method of continuous flow the farmer owning 10 acres would be obliged to spend as much, or possibly more, time in irrigation as would the man who owned 100 or more acres. Under the method of continuous rotation, the small farmer works as hard as the large farmer, during a time in proportion to the acreage that he possesses.

The application of the method of rotation is simple and varies only slightly under varying conditions. In the main canal, particularly if it is taken directly from the river, water flows continuously; and the chief laterals likewise carry continuous flows of water. The laterals are divided and sub-divided into smaller streams, until the quantity of water flowing continuously in each meets the requirements of the area of land under the stream, in accordance with the duty of water prevailing under the system. Let it be assumed that the duty of water under a canal system is 100 acres to the second-foot, during the irrigation season, and that at each application a depth of water not more than 4 inches should be applied. A certain 
lateral under this system carries 2 second-feet of water continuously, and is, therefore, to be reserved for 200 acres. This means that the whole 200 acres could be covered by this stream, to a depth of 4 inches, every sixteen and two-thirds days. In other words, each farm under this lateral would receive its allotment of water every sixteen and two-third days. If the 200 acres under this lateral consist of six farms of 5, 10,20, 25, 40 and 100 acres respectively, it may easily be calculated that they. would receive water every sixteen and two-third days as follows:

Area of farm
5 acres
10 "
20 “"
25 “"
40 “"
$\frac{100}{200}$ “

Length of irrigation period (every $162 / 3$ days, or 400 hours)

10 hours

20 "

40 "

50 " "

80 "

200 “

$\overline{400}$ “

If the stream were larger, the time for each farm would be correspondingly decreased. Such a system may be followed easily by the water-master and is readily understood by the farmer.

Another application of the rotation method is to fill the main laterals in rotation. One or a few laterals are given all the water of the canal for a certain number of days; then another set of laterals, and so on, until the rotation has been accomplished. This system is not so satisfactory to the farmer as the preceding one, because a whole district is for a time without water, when the neighboring district has an abundance. Under the first system all districts under the canal are at all times doing some irrigating, and the presence of the water gives the farmer a sense of security. 
Still another application of the method of rotation is found where city lots are watered for the purpose of maintaining home gardens, which usually, because of less careful cultivation, require water very frequently. Under this method the flow of water is divided into many small streams that make it possible to irrigate every week or every two weeks.

Each farmer, under the rotation method of distribution, is notified at the beginning of the irrigation season of the size of the stream allotted, and the time and frequency of its use. The farmer is sometimes permitted to turn the water into his own ditch at the hour assigned, but the better plan is to allow a regularly employed watermaster or ditch-tender to open or close all gates and to divert water to or from farms. The farmers under a lateral frequently organize, and as a company manage the water from the lateral, exactly as the laterals are managed by the canal company. When this is done, the responsibility for the ultimate distribution of the water rests upon the group of farmers living under the lateral. Such lateral organizations are proving very satisfactory, and it may be that they will increase until the canal managements will need to exercise no further jurisdiction over the distribution of water after it has once been turned into the laterals. Such a lateral organization determines for itself the method of water distribution to be used.

219. Distribution on application.-This method means that water flows to a farm only at the request of the farmer. The method is practicable only under reservoirs, or canals that are always filled with water. Under reservoirs the farmer may be said to own a definite quantity of stored water upon which he may draw as he chooses, 
just as he does with his money in the bank. The chief objection to this method of distribution is that if many farmers should call for water at the same time, more water might be demanded than the canals could carry. When this method is used under ordinary diversion canals, it is generally for the purpose of compelling the most economical use of water. The tendency of the irrigator to use too much water is increased whenever a continuous flow of water is supplied, or under methods of rotation, when water is given for longer periods than is actually needed. If the irrigator feels that he has a limited quantity of water in the system, on which he may draw at will, he is more likely to practice greater irrigation economy, and the surplus water may then be applied beneficially elsewhere. The method of distributing water on the application of the farmer is an ideal system, but of extremely limited application. Even under reservoir conditions it will probably be found that the rotation method will in the end give the greatest satisfaction.

220. Organization for distribution.-The proper distribution of water from great canals can be accomplished only by an organization for the purpose. In the early irrigation days, when water was relatively plentiful and the population small, little attention was given to supervision. Each man drew what he needed from the coöperative canal. The increasing value of water has made the the proper distribution of water more and more important. Large canals that serve 3,000 to 20,000 acres, especially, are justified in exercising very careful supervision of the distribution of the water. It should be insisted upon by those who have the best interests of the system at heart. Experience points to the conclusion that the success of an irrigation system is in direct proportion to the super- 
vision given to the distribution of the water and to the maintenance of the system.

Some sort of supervision exists under practically all canals, but it is exceedingly varied. Under the Davis and Weber Counties Canal in Utah, serving 12,000 acres, divided among 520 farmers, four men only are employed to distribute the water equitably. Under the Farmers' Canal in Montana, serving 15,000 acres, owned by sixty farmers, two men on part time supervise the distribution of the water. On the other hand, the Gage Canal in California, serving only 9,000 acres, finds it profitable to maintain a chief engineer and six other men for the proper distribution of the water flowing through the canal and for the maintenance of the system itself. The same force of men can usually supervise the distribution of the water during the irrigation season and maintain the system itself.

The head of the organization for water distribution and canal maintenance, called, possibly, the manager or superintendent, should be an irrigation engineer. $\mathrm{He}$ should be, however, an engineer of a new type - one who understands enough of engineering to maintain in a high state of excellence the dams, canals, laterals and gates of the irrigation system, and who understands enough of modern irrigation agriculture to direct the use of the water for the production of crops under the canal system. To such a man belongs justly the title of irrigation engineer. If one canal company does not feel itself wealthy enough to maintain such a trained superintendent, it is often possible for adjoining canal systems to employ the same superintendent who can be assisted by water-masters from the respective systems. Much money could be saved in legal and engineering services if such permanent expert help were employed. 
This chief worker should be assisted by water-masters to whom various duties could be assigned. Some, taking the place of the old ditch-rider, should supervise the admission of the right quantity of water from the main canal into each lateral; others could well be used to supervise the up-keep of the main canal and its laterals. Ditch-tenders, as assistants to the water-masters, should be employed, if necessary, to supervise the farmers' ditches drawing water from the laterals. The water-masters and the ditch-tenders should be somewhat trained for their work. Especially should they understand water units, the relation between soils, crops and water, and the common methods of measuring and dividing water. Moreover, they should be experienced in the practice of irrigation so that the farmers' side may be understood by them.

Where the farmers under a lateral have formed a lateral organization they could well employ their own watermaster, who, like the company water-masters, should be trained for the work. The day of the untrained man for water-distribution has passed. The superintendent, watermasters and ditch-tenders, must know their work, and must especially be familiar with the use of water in irrigation. Then will the work be done well.

The cost of such supervision of the distribution of water and of the maintenance of the system, including the keeping of records, is not great. According to Adams, for thirteen of the best-known canals in western America, it varies from 9 cents to $\$ 1.30$ an acre, with an average of $41 \frac{1}{2}$ cents an acre, a year. This is not at all prohibitive if one considers that by the unwise or dishonest distribution of water crop failures or crop diminutions may easily occur. 
221. Regulations and records.-Irrigation under the best conditions is complex. If the best results are to be obtained from an irrigation system, careful regulations must be established and published, and careful records must be kept. It is a common fault that the farmers are not kept in full touch with the plans under which the system is operated, including the duty, measurement and distribution of water. Full information concerning the rules of the system, including its relation to the farmer, should be printed and distributed to every farmer under the system. The greater the publicity given the operations of the canal management, whether consisting of farmers or capitalists, the less friction will accompany the work.

The records of the system should be as orderly as those of the best commercial establishments. Water has a definite cash value; and it should be traced as carefully as is any other valuable commodity. At regular intervals the flow of water into the main canal and into each of the laterals, and as far as possible on to the farms, should be carefully measured. Excellent type records may be found in Bulletin No. 229 of the Office of Experiment Stations, United States Department of Agriculture, entitled "Delivery of Water to Irrigators," by Frank Adams. The superintendent, water-masters and ditch-tenders should all be taught to make such records, and should be charged with the duty of making such permanent records. In avoiding the characteristic irrigation disputes, such records would be of inestimable value. The keeping of accurate records by irrigation systems would also help greatly to increase the duty of water. Both crop and water records should be kept. The want of record-keeping is largely responsible for our faulty irrigation methods. 


\section{REFERENCES}

Adams, Frank. Delivery of Water to Irrigators. United States Department of Agriculture, Office of Experiment Stations, Bulletin No. 229 (1910).

BARK, Don H. Duty of Water Investigations. Ninth Biennial Report of the State Engineer of Idaho, 1911-12.

Buckley, Robert Burton. Facts, Figures and Formulæ for Irrigation Engineers (1908).

Buckley, Robert Burton. The Irrigation Works of India. Second edition (1905).

Carpenter, L. G. On the Measurement and Division of Water. Fourth edition. Colorado Experiment Station, Bulletin No. 150 (1910).

Cone, V. M. Hydraulic Laboratory for Irrigation Investigations. Fort Collins, Colorado. Engineering News, Vol. LXX, No. 10, p. $66 \dot{2}$ (1913).

Cone, V. M., Trimble, R. E., and Jones, P. S. Frictional Resistance in Artificial Waterways. Colorado Experiment Station, Bulletin No. 194 (1914).

FLYNN, P. J. Irrigation Canals, etc. (1892).

Horton, Robert E. Weir Experiments, Coefficients and Formulæ. United States Geological Survey, Water Supply Papers, No. 200 (1907).

Lyman, Richard R. Why Irrigation Water Should be Measured. Bulletin International Irrigation Congress, Vol. I, p. 63 (1912).

Lyman, RICHaRd R. Measurement of Flowing Streams. Utah Engineering Experiment Station, University of Utah, Bulletin No. 5 (1912).

Lyman, Richard R. Measurement of the Flow of Streams. Proceedings of American Society of Civil Engineers, Vol. XXXIX, p. 1913 (1913).

MEAD, Elwood. Irrigation in northern Italy. United States Department of Agriculture, Office of Experiment Stations, Bulletins Nos. 144 (1904) and 190 (1907).

MEAD, Elwood. Irrigation Institutions. The Macmillan Company (1903).

Newell, F. H. Irrigation. Crowell \& Co. (1906). 
Tannatt, E. Tappan, and Kneale, R. D. Measurement of Water.

Montana Experiment Station, Bulletin No. 72 (1908).

Teele, R. P. Review of Ten Years of Irrigation Investigations.

United States Department of Agriculture, Office of Experiment Stations, Annual Report (1908).

Teele, R. P. The State Engineer and His Relation to Irrigation.

United States Department of Agriculture, Office of Experiment Stations, Bulletin No. 168 (1906).

United States Reclamation Service. Operation and Maintenance Use-Book (1913).

Widtsoe, J. A., and Merrill, L. A. The Yields of Crops with Various Quantities of Irrigation Water. Utah Experiment Station, Bulletin No. 117 (1912).

Willcox, William. The Nile Reservoir Dam at Assuan (1903).

Willcox, William. The Nile in 1904. 1904 (E. \& F. N. Spon.)

Wilson, Herbert M. Irrigation in India. United States Geological Survey, Water Supply and Irrigation Papers, No. 87 (1903).

Wilson, Herbert M. Manual of Irrigation Engineering. Third edition (1899). Wiley \& Sons.

Winsor, L. M. Measurement and Distribution of Water. Utah Experiment Station, Circular No. 6 (1912). 


\section{$v$ \\ CHAPTER XVIII \\ OVER-IRRIGATION AND ALKALI}

Over-IRRIGAtTon and alkali are the two chief evils that endanger irrigation as a permanent system of agriculture. These result from the unwise use of water and from peculiar soil conditions that may be aggravated by excessive irrigation.

222. Seepage from reservoirs and canals.-Soil is a porous mass. Water added to the soil forms a film around the soil particles which thickens as more water is added, until the film becomes so thick that the liquid water slides through the capillary spaces to the greater depths of the soil. When the annual rainfall is from 20 to 30 inches, approximately one-half of it seeps through the soil beyond the reach of plants. Under a high rainfall more is lost. This seepage continues until the water reaches an impervious layer of rock, clay or other substance, where a permanent water table is formed; and the more water is added from above, the thicker becomes the water table. It does not necessarily stand still, but usually flows gradually in some direction depending upon the inclination of the impervious bottom. According to the most recent estimates there is such a layer of water 100 feet thick, on the average, under the whole surface of the earth.

Much of this subterranean water is derived from the rainfall directly; much water seeps also from the river beds, which are covered with water practically the whole 
year. There is always a possibility, also, of seepage from reservoirs for the storage of water. If the reservoirs are well silted large losses will not occur. A reservoir from which a depth of water of not more than 2 feet is lost annually is said to be practically impervious. The smaller the reservoir, the better silted it is, and, therefore, the smaller the loss of water from it. From canals, also, there are large losses of water by seepage. For instance, the United States Irrigation Investigations have found that, as an average for all canals investigated, the loss by seepage was 5.77 per cent of the total water carried, for every mile of canal. The aggregate loss of water by seepage from canals must, therefore, be tremendous. Individual canals differ, however, greatly in this respect. In the government investigations, the losses from canals varied from none to 60 per cent of the total quantity of water carried, for each mile of canal. If a canal passes over a rocky ledge, much water may be lost through cracks and crevices. Canals passing over gravelly soils lose most; over sandy soils, nearly as much, and over heavy clay soils, least water. New canals always lose more water by seepage than do old ones, because silting and settling has not been fully established. Small canals lose proportionately more than large ones, and canals not used in the winter lose less than those filled with water throughout the year, although at the time of opening the canals in the spring, before silting has gone on, the loss is greater.

On the average, 30 per cent of the water taken in at the head-gates of irrigation canals is lost by seepage from the canals themselves. In comparison with this great loss all other losses are small. The loss of water by evaporation, for instance, is ordinarily less than 15 per cent of the loss due to seepage. Carpenter concluded that the water lost 
from canals in one day is sometimes equivalent to a depth of 20 feet and is seldom less than 3 inches over the whole canal surface.

The laterals of canals are subject to similar losses. Every irrigation farmer knows that though the flow into the lateral at the head-gate may be ample, frequently not enough water reaches the farm. Practically, another third of the water taken in at the head-gate is gone before it reaches the farmer.

223. Loss from excessive irrigation.-Water is lost by seepage on the farm itself, for the common practice is to irrigate land too heavily. When more than 5 inches of water are added to the soil in any one irrigation, there is usually a loss by seepage; yet, on a great many farms, twice that much water is applied at one irrigation, providing it is available and the soil can be made to absorb it. Evil follows such excessive irrigations, especially if they succeed each other at short intervals. Farmers who misunderstand the use of water usually apply as much as possible, as frequently as possible, and urge upon the canal managers the necessity of having free access to water. An irrigation applied to the soil before the plant roots have had time to remove the water added in the previous irrigation retards the growth of the crop, and soaks down the soil to increase the standing water table. The loss of water due to excessive use of the water on the farm is often very large. It may safely be estimated that onehalf of the water taken in at the head-gate of the canal is lost by percolation from canals, ditches and excessive irrigation. This is an awful waste when the great cost of irrigation structures and the vast areas of arid land are considered. The old idea that irrigation should take the place of tillage must be fought vigorously. 
224. Ground water.-The seepage losses from reservoirs, canals, laterals and farms increase the depth of the ground water. Consequently, in irrigated sections, where such losses go on uninterruptedly, water rises slowly but steadily until wells that were dug 50 to 100 feet deep to reach water, now have the water table within 3 to 10 feet from the surface. This great layer of ground water flows along the impervious layer upon which it rests, usually

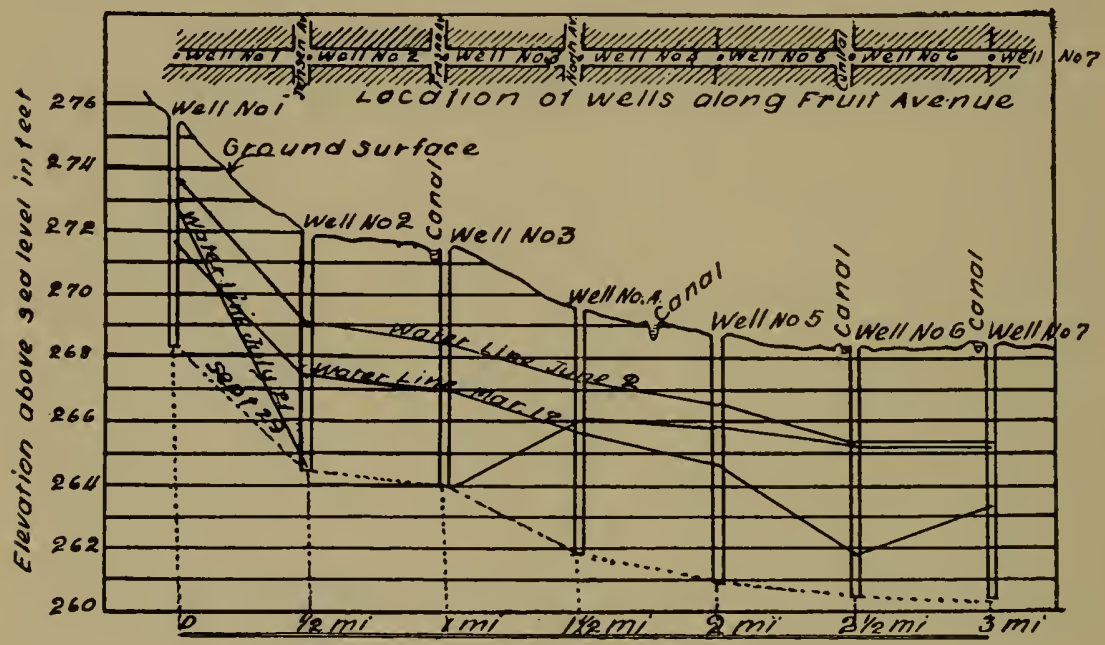

FIG. 105. Rise of ground water from irrigation.

slowly, but sometimes rapidly. Carpenter found in one place that the underground movement of water reached a rate of 1 mile an hour. According to the underground structure of clay deposits, hardpan or bedrock, this water comes out somewhere, usually in the lower-lying lands, to form springs, bogs and water-logged lands. The first irrigation settlements were often made on the lower lands, where the natural seepage made green spots of grass or clumps of trees, that looked inviting to the pioneers. As the higher-lying irrigation canals were taken out, the seepage from them soon converted these green spots, 
the natural drainage outlets of the district, into waterlogged lands which had to be abandoned. In that way the danger of seepage has from the beginning been called to the attention of the irrigation communities.

True, the water that seeps from the canals and the farms is not wholly lost. Some finds its way into the lower canals or rivers and is used elsewhere. The "lost rivers" of the West are examples of this condition. The Sevier River of Utah flows full near its head, and gradually disappears until it is nearly dry; but, lower down, the water reappears and the river flows full again. Where the underflow can be caught, canals have been built for the purpose. Moreover, the underground waters of the country, especially in the arid West, will be used more and more as irrigation by pumping becomes better understood. Under the best of conditions, however, much of the water that disappears by seepage is permanently lost. Seepage must be reduced to the minimum.

225. Comparison with humid areas.-The danger from unnecessary seepage, due to excessive irrigation and canal losses, is certainly great; but, the area of resulting waterlogged lands is not nearly so great in proportion to the land surface as are the water-logged lands of humid regions. According to the last government census, the swamp and marsh lands east of the Rocky Mountains, subject to reclamation, cover an area of 77,000,000 acresnearly equal to the combined area of Illinois, Indiana and Ohio. This area of swamp and marsh land varies roughly with the rainfall, which is another proof of the doctrine that such lands are determined by the quantity of water brought upon the soil surface. The water-logged lands of the irrigated regions form a very small fraction of the cultivable land, and it lies within the power of the irri- 
gator to reduce this area by wiser methods of conducting and using water.

226. Lined ditches-a remedy.-The chief danger of seepage will remain with the canals and laterals, for it is

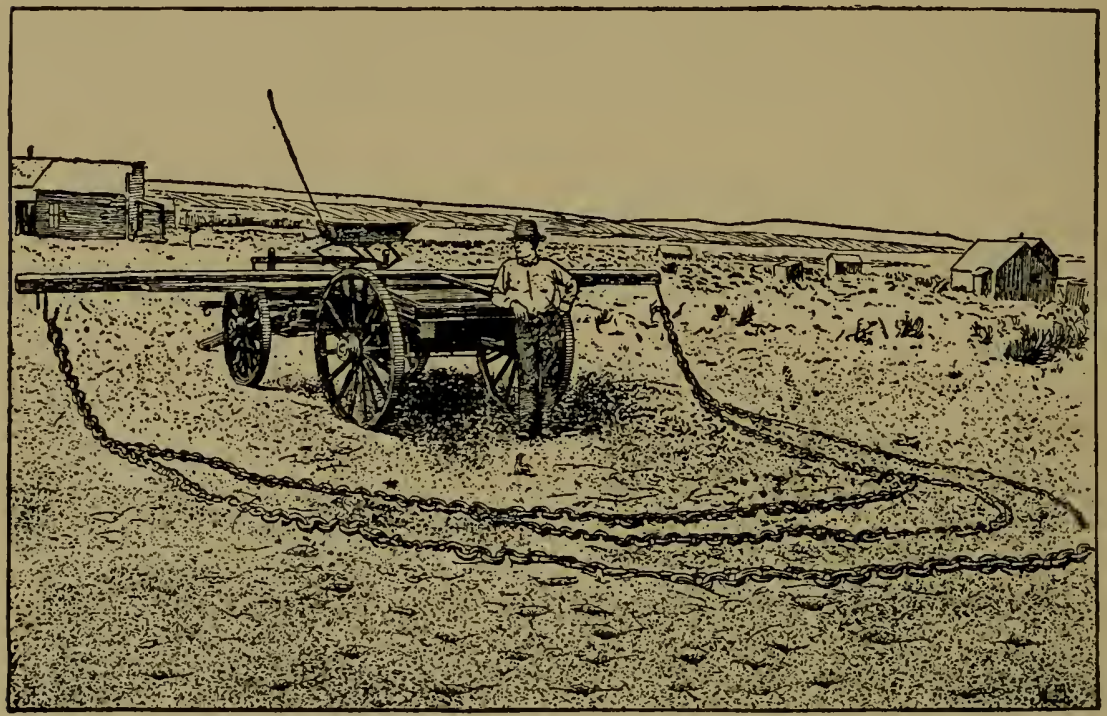

Fig. 106. Chain puddler. Used in making canals watertight.

relatively easy to control the quantity of water used on the land. The first obvious remedy against seepage is, therefore, to make the ditches more impervious. A canal carrying clear water will not of itself become impervious, but a canal carrying muddy water will receive the settlings, often to such a degree as to reduce or even to stop the seepage. Moreover, the leaks due to layers of gravel, sand or open rock, over which canals pass, should be stopped by the application of clay or some other impervious material. Very often, it is advisable to line the whole canal with impervious materials or to build flumes or pipes to take the place of the canal. The first expense seems large, but the annual saving of water and the 
reduction of the area of lower water-logged lands justify the expenditure. The many materials used for this purpose are discussed in special books on the subject.

The oldest method of lining ditches is by masonry, the first cost of which is not, by any means, the most expensive, but requires relatively skilled labor, and later considerable upkeep. Cement concrete, though it is most expensive, is becoming the favorite material for lining ditches, for under good supervision, it can be installed rapidly and with ordinarily available labor. The great objection to cement concrete linings is that in cold districts it is likely to break unless carefully covered with earth or sand. Meanwhile large, cement-lined canals, even in districts of very cold winters, are giving excellent satisfaction.

Crude mineral oil is also a favorite material for lining irrigation ditches. It is heated and while still hot is sprinkled with an ordinary road sprinkler over the bottom and sides of the canal. It is then harrowed in, usually with a chain puddler. This treatment reduces, largely, the seepage. The older method of puddling thoroughly the bottom and sides of the canal with clay is often the

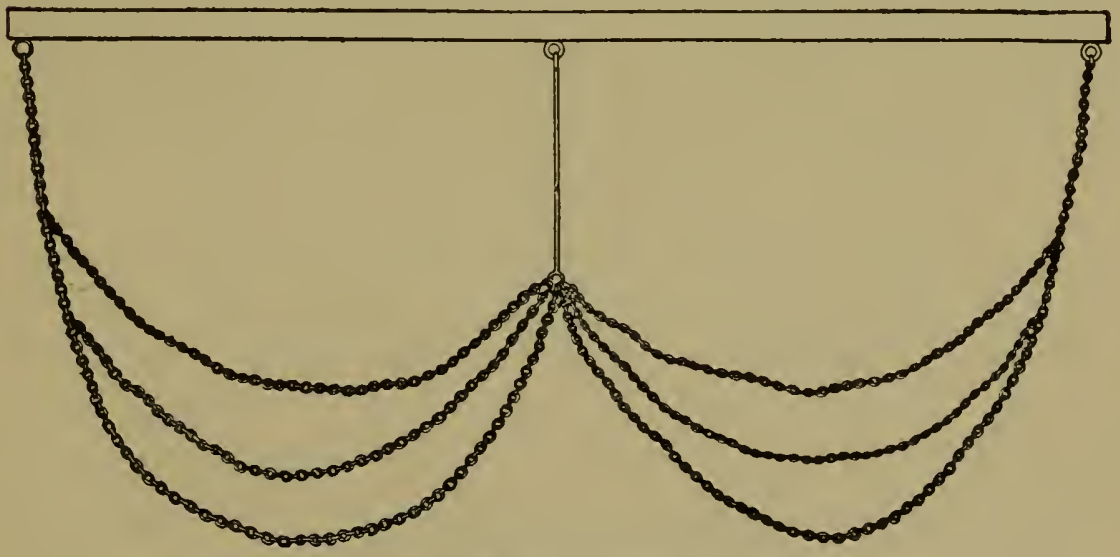

FIG. 107. Modified chain puddler. 
cheapest and most satisfactory where the materials are near at hand, but the effects are never permanent as with masonry or concrete linings. Finally, silting a canal is often recommended. Clay or clayey materials, thrown into the water at various places, settle wherever the grade

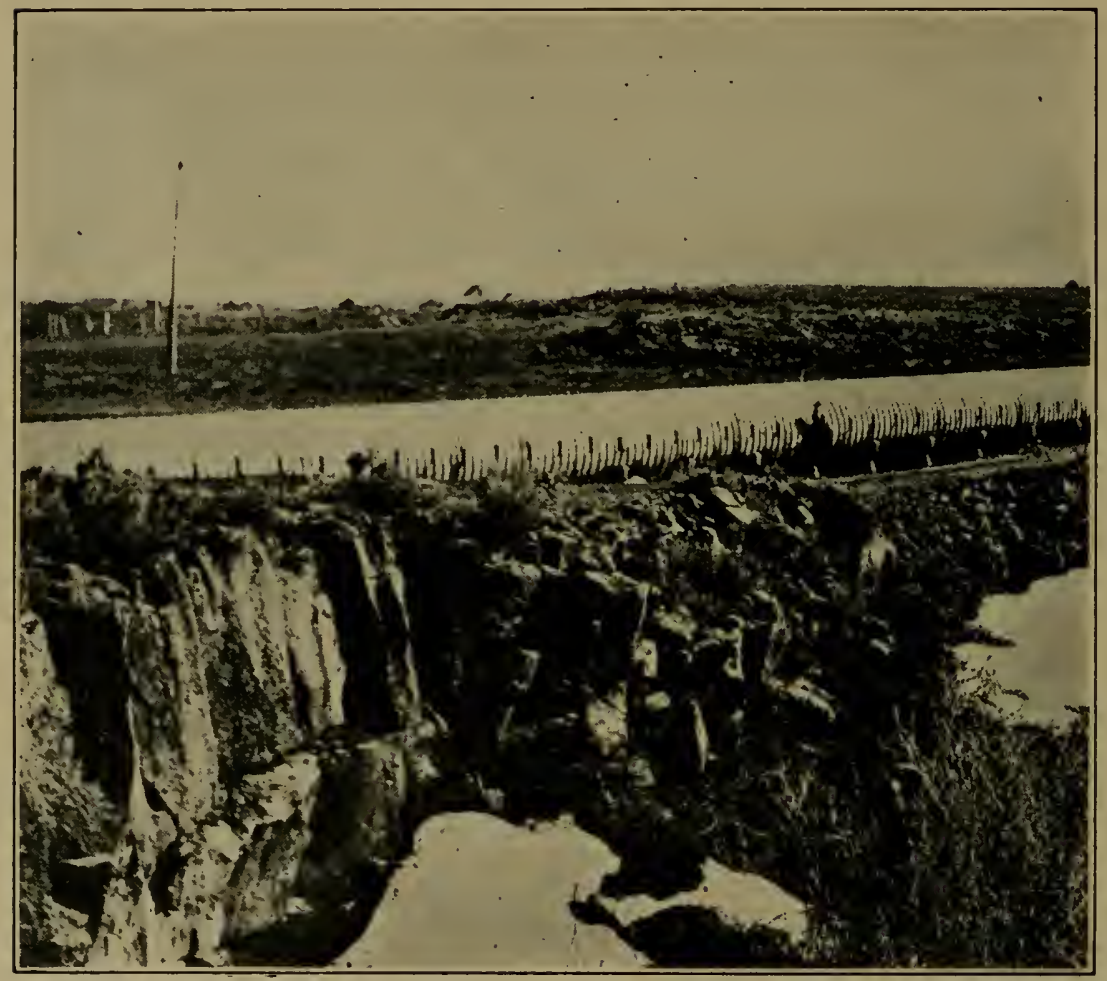

FIG. 108. Wooden stave pipe carrying irrigation water.

is not too steep. Afterwards, the silt deposits are puddled by the chain puddler. This is a very cheap and often an effective method of preventing seepage. (Figs. 106, 107.)

In California, whole canals have been lined with cement concrete, and the definite attempt to reduce seepage by first-class canal linings has become established. In other states, also, large canals are rapidly being lined. One of 
the most notable is the main canal of the Davis and Weber Counties Canal Company of Utah, which is lined with

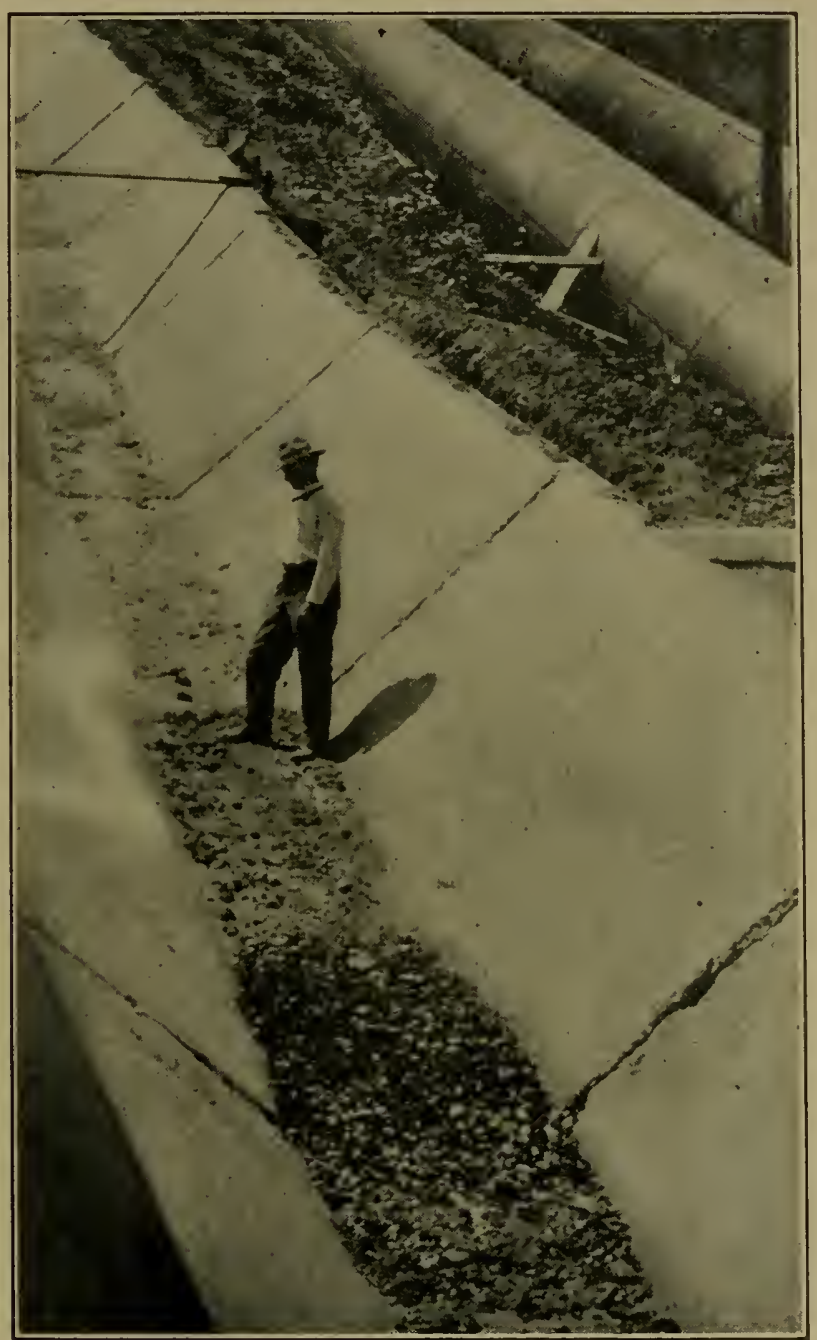

Fig. 109. Lateral lined with concrete.

cement for 10 miles. The work, authorized by farmers owning the canal, was done under the direction of some of the best engineers of the country. 


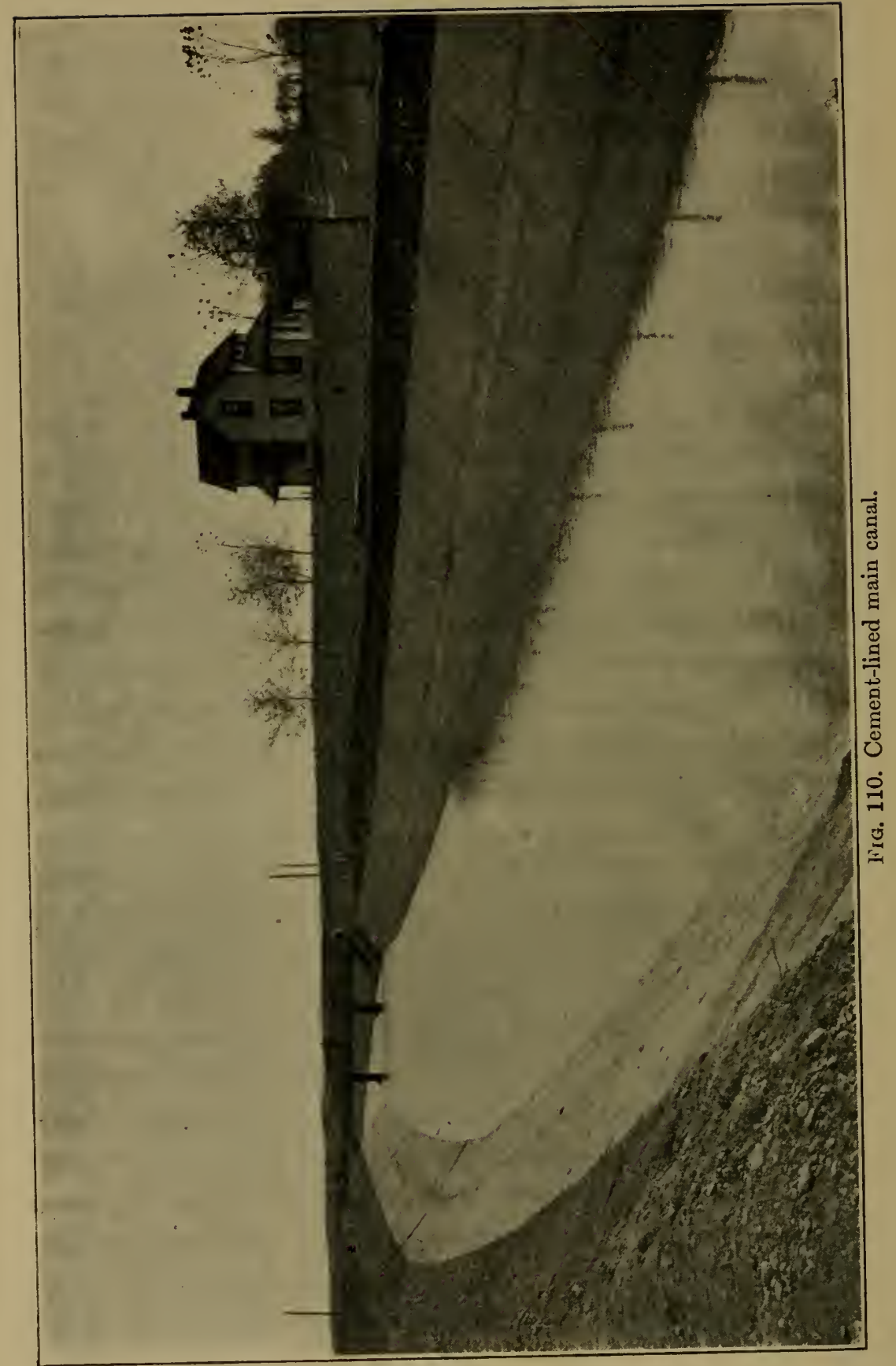


Machines and molds for lining farm ditches are on the market and may be obtained at relatively small cost. Pipes are often most desirable for the smaller ditches, since they eliminate direct loss by evaporation, and also the growth of grass or algæ near the ditch banks. Smith has shown that tile may be made of cement at prices so low as to make the method available for the farm irrigation system. The good irrigation farmer should make the ditches under his control as impervious as is possible.

227. The economical use of water-a remedy.-The common custom of allowing water to run in irrigation canals during the whole year, when it is really needed only a few months of the year, is responsible for much seepage and positive injury to the lower-lying lands. Water, whether taken from reservoir or river, should be allowed in the canals only during the seasons of the year of actual use. Moreover, on the farm, it should be used economically, in harmony with the principles already elaborated in this volume. By the more economical use of water in these two directions the danger of water-logging will be greatly reduced.

228. Drainage - the final remedy.-Even in the arid region, where no irrigation is practised, there will be some low-lying wet lands resulting from the natural rainfall seeping through the soil from the highlands and the river beds. When irrigation is established and practised, even under the best conditions, the area of wet land will be somewhat larger than it was before. Naturally, the best and final remedy for this condition is underdrainage. Underdrainage has been well tried out during the last hundred years in Europe and in the eastern United States, and has been found to be a great and helpful factor in making agriculture successful. In spite of the apparent 
paradox, underdrainage on a small scale must be a necessary complement of irrigation. The sooner, therefore, that underdrainage is established, in places where it is necessary, the better it will be for the development of the irrigated region. The low-lying, water-logged lands are fertile, and, when drained, require very little irrigation. Many excellent experiments have been made on

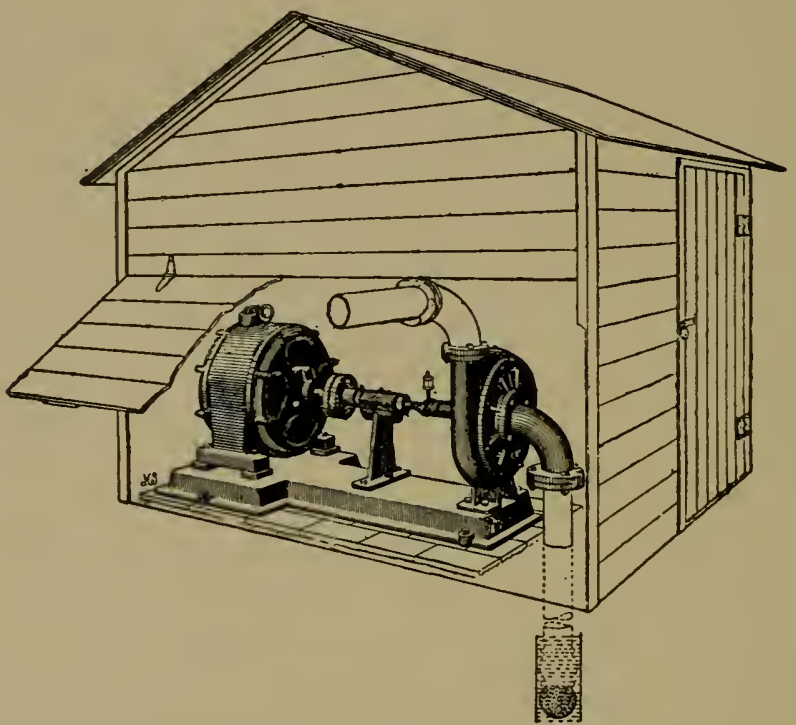

FIG. 111. Pumping plant. (Lifts water 37 feet and irrigates 70 acres. (Montana.)

the underdrainage of lands in the irrigated region, and the practice has been found to be wholly successful and in cost to be well within the farmer's reach.

The methods for underdrainage under irrigated conditions are only slightly different for those prevailing under humid conditions. Usually an upper main drain is constructed, transverse to the flow from the upper canal, so as to intercept the water seeping from above. (See Fig. 112.) Where the subsoil rests on a hardpan, blasting 
the impervious layer is often sufficient to improve the drainage and to send the obnoxious standing water downward. It has also been proposed that water-logged lands may be drained by pumping, the pumped water to be lifted to reclaim lands yet without water. Drainage water of the right composition, that is, free from alkali, can well be so used, especially in view of the fact that the next great development in irrigation, so far as sources of water are concerned, will be the use of subsoil water by pumping. In Europe, the practice of pumping water for the purpose of relieving the land from excessive moisture and of using the pumped water, prevails largely.

Without question, underdrainage will become an established practice in the irrigation region as it is in the humid region.

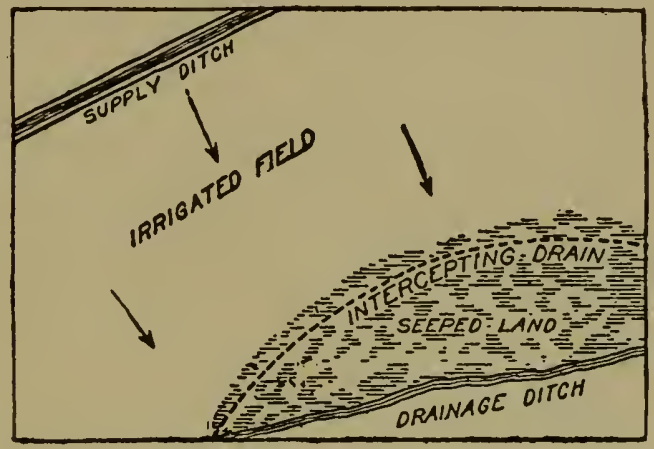

Frg. 112. Drainage of irrigated lands by intercepting drains.

The excellent drainage investigations of the Office of Experiment Stations of the United States Department of Agriculture have collected a great deal of information concerning the right methods of draining irrigated lands.

229. Alkali defined.-Soluble substances are being continuously formed in all soils from the progressive decomposition of the soil particles. Under high rainfall most of these soluble materials are washed into the country drainage, and finally into the ocean. It has been suggested that the salinity of the ocean is at least in part due to the accumulation of salts lost by soils. Under low rainfall, which penetrates only a few feet of soil, the soluble 
constituents remain in the soil and accumulate as the years go by. This is one of the characteristic differences between the soils of arid and humid regions. These accumulations often become so large as to be injurious, and then are called alkali. Alkali means the water-soluble materials in the soil, especially when the quantity is so large as to be injurious to plant-growth.

Much alkali is of early geological origin. In early geological times, as now, large accumulations of soluble soil materials occurred in lakes similar to the Great Salt Lake or the Dead Sea. When these prehistoric interior lakes dried up, there were left behind great deposits of the salts held in full or partial solution in the lake water. In time these layers of saline materials were covered by silt and other materials derived from soils, and thus conserved until the present day. When such lands are irrigated the water dissolves the soluble salts which may become very injurious.

Ordinarily, alkali appears as an incrustation on the soil surface, even on native soils, where conditions are favorable to the accumulation of soluble matter. As often, however, alkali does not appear as an incrustation, but is held in the concentrated soil solution, with equally injurious effects.

230. Seepage and alkali.-Soils tend, naturally, to retain their soluble matters, especially those of value in plant-growth; but, when a continuous excess of water passes through the soil, the soluble substances are given up and pass into the country drainage. When such seepage water, heavily charged with salts, appears in some lowlying place and is evaporated, the alkali is left behind, either on the surface or in the remaining soil water itself. In either case, the soil becomes increasingly less suitable 
for plant-production. By over-irrigation, water is lost, plant-food is lost, the upper lands are impoverished and the lower lands made useless.

The whole process is well illustrated on a large scale by the inland salt lakes, found in abundance over the arid region, such as the Great Salt Lake. This lake is,fed by the seepage from the neighboring territory, and by rivers flowing directly into it. It has no outlet. Water is lost from the lake chiefly by evaporation, and the soluble substances carried by the water entering the lake are accumulated in the lake water. As a result, the water has become so saturated that crystallization is going on. On a smaller scale, in every valley bottom with poor drainage, the process is being repeated. Large areas have thus been and are being made alkaline.

231. Upward leaching.-Another phase of the alkali question does not concern itself with seepage. Arid soils are rich in soluble matters, which, when evenly distributed throughout the soil, are advantageous in plant-growth. If by any chance the soluble substances of the upper 6 to 10 feet of the soil are partly concentrated near the surface, plant injury is almost sure to follow. Such concentration frequently occurs under irrigation. Water, added to the soil in moderation moves downward only a few feet, but in its descent dissolves some of the water-soluble soil constituents. By transpiration and evaporation the water thus added moves upward and carries with it the substances dissolved in its descent. At the soil surface, the water evaporates and the salts are left behind. As this is continued, the soluble soil constituents tend to accumulate at or near the surface. This process has been named upward leaching. It is a condition that need not cause permanent injury, for it may be controlled. 
The process has gone on in nature for many ages; the salts have each year been washed down to a depth ordinarily reached by the rainfall and returned to the surface during the warmer season. Arid soils are often underlaid at a certain depth by layers of salts which indicate the

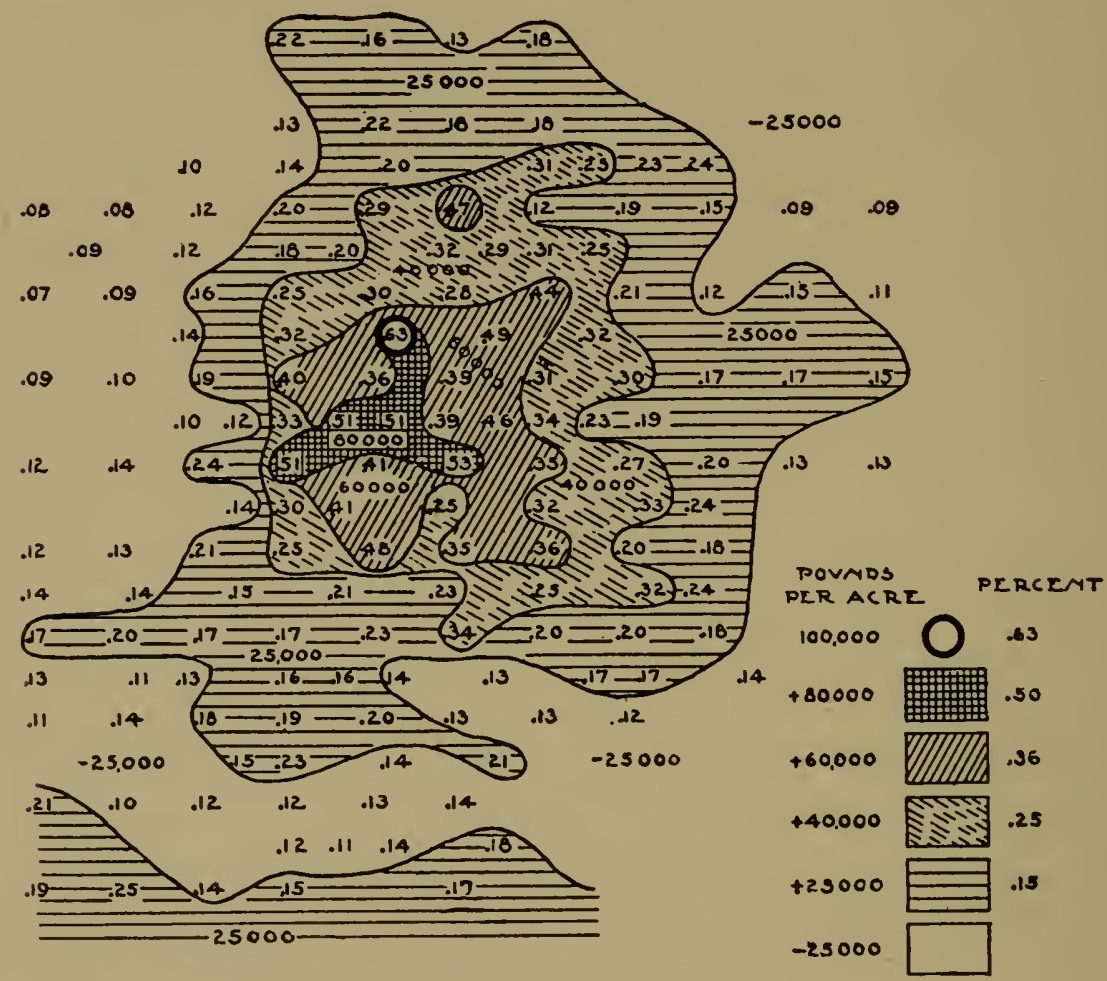

FIG. 113. Structure of an alkali spot.

annual penetration of the rainfall throughout the ages before man began to cultivate the soil. (Fig. 113.)

Upward leaching may be prevented by preventing evaporation from the soil surface. The tillage methods recommended for the conservation of water are those that will prevent the accumulation of alkali at the soil surface. 
232. Use of saline water--Another source of alkali is the use of water charged with large quantities of soluble salts. As shown in Chapter V, all natural waters contain certain quantities of dissolved substances. Only when the proportion of such soluble salts is too large does there appear to be any danger in the use of such waters. In fact, saline waters have usually been undervalued for purposes of irrigation.

Plants can tolerate large quantities of soluble salts in irrigation water providing they are of the right mixture. Thus Kearney and Cameron found that seventy parts of magnesium sulphate in 1,000,000 parts of water represented the highest concentration in which plant-roots could survive; yet, in the presence of a concentrated solution of calcium sulfate, 33,600 parts of magnesium sulphate in 1,000,000 parts of water could be tolerated. Gypsum and common salt are both antidotes for magnesium sulfate; magnesium carbonate is an antidote for sodium carbonate and sodium chloride, raising their limit two to four times; lime is an antidote for magnesium and sodium, in the form of sulfates, carbonates or chlorides, raising the limit of these dangerous salts hundreds of times. Kearney found that the native irrigationists of northern Africa raised successfully many of the ordinary crops with water containing 8,000 parts of soluble salts for each 1,000,000 parts of water. Hilgard, as a result of his long life of experimentation on such subjects, holds that from 1,200 to 1,700 parts of soluble matters in each $1,000,000$ parts of water represent the highest limit of endurance for ordinary plants. This, however, is much lower than that observed by Kearney in northern Africa, or observed by other students in other parts of the world. The concentration of water that may be used for irrigation 
purposes depends primarily upon the proportions of the salts in the water. The poisonous action of irrigation water is not the sum of the poisonous actions of its various constituents; for, as observed, the effect of any compound is qualified by the presence of other compounds. The whole subject is in a confused state and needs extensive investigation.

The real danger in the use of saline waters for irrigation, whether they contain 1,000 or 8,000 parts of soluble matter to $1,000,000$ parts of water, is in the residue of salts from the evaporated matter. For example, if an irrigation water contains 1,000 parts of soluble matter in each 1,000,000 parts of water, and if 18 inches of this water are used over an acre each year, 4,000 pounds of alkali an acre are added each year. As this is repeated year after year, the accumulation of salts becomes so great as to render the land unfit for farming. To overcome this difficulty it is necessary, when saline waters are employed in irrigation, to reverse the usual rule, and to use quantities of water so large that drainage is assured. The excess of salt is then washed into the country drainage, and alkali accumulations are prevented. Such handling of saline waters is, however, dangerous in that the excess of water, heavily alkaline, may appear on the lower lands, there to cause injury. Before saline waters are used for irrigation, they should be investigated carefully as to their composition and their probable effect on the land.

233. Alkali deposits.-The great deposits of alkali or alkali impregnated soils and rocks common to arid countries are another source of alkali. These deposits, yet to be studied exhaustively, are associated with the geological history of the country. In early geological 
days, salt lakes, similar to the Great Salt Lake, were no doubt formed, which were dried by the changing climate, leaving great masses of salt, that were later covered by washings from the hills. In other cases, silt and other

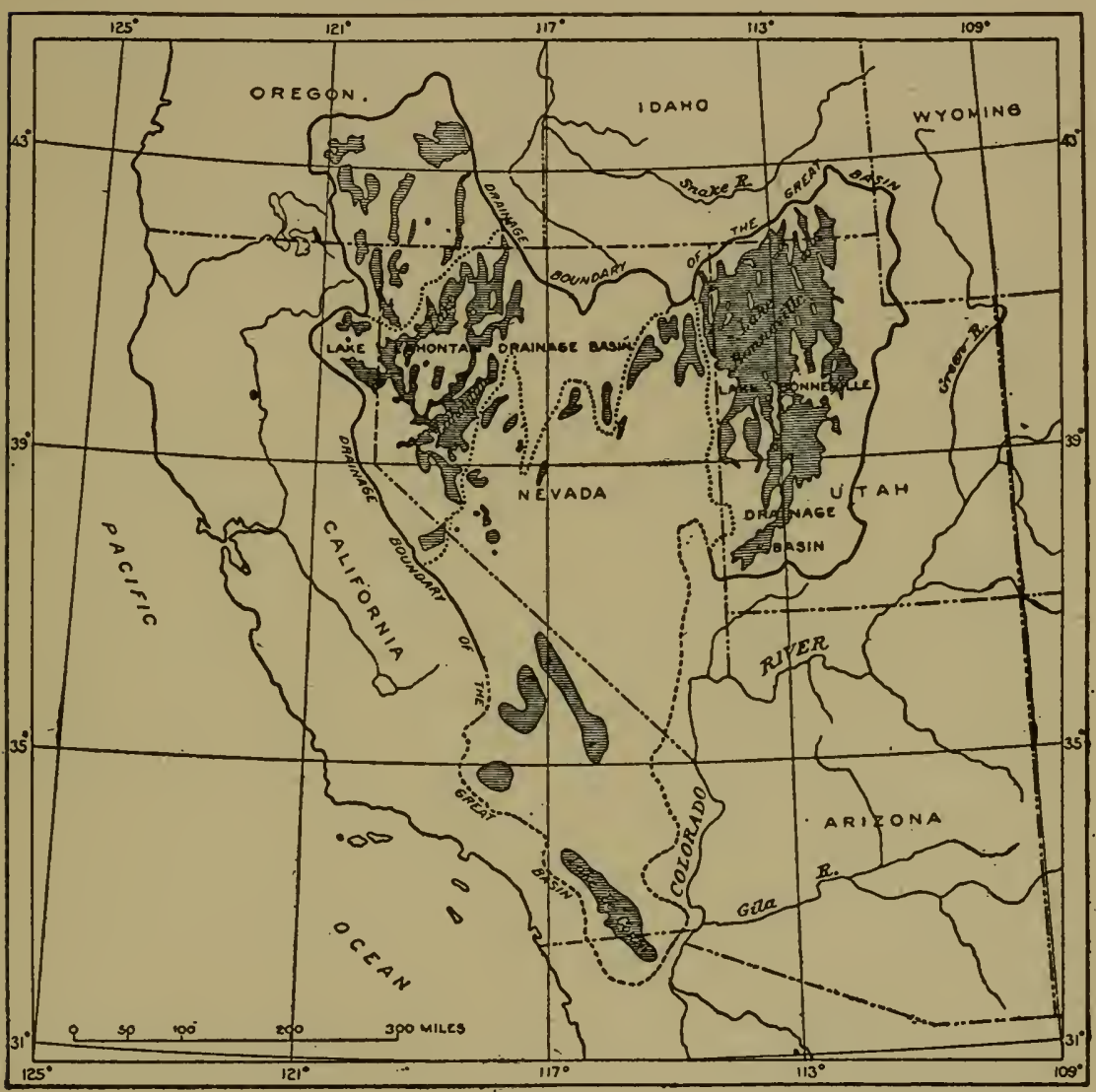

FIG. 114. Quaternary Lakes of the Great Basin. Sources of alkali deposits.

soils of early geological days were deposited in the presence of salt or brackish water. These in time became hardened into rocks. Consequently, over much of western America there are great exposures of shales and sandstones containing large percentages of water-soluble substances. 
On the soils derived from many of these deposits, plantgrowth is difficult or impossible, and they are therefore easily recognized.

Water passing through these alkali deposits of early times and dissolving the salts, carries alkali to otherwise alkali-free sections. This is a chief source of alkali, next in importance to over-irrigation, although it has been largely overlooked by students of alkali. Knight and Slosson, of Wyoming, have shown that great numbers of such deposits occur in Wyoming; other students of western conditions have discovered similar deposits in various districts; and Stewart and Peterson, of Utah, have recently confirmed the wide distribution of such alkali deposits. Once the existence of such deposits is recognized in the neighborhood, precautions against them may be taken, and they need not then be a menace. (Fig. 114.)

234. Kinds of alkali.-Since alkali is simply the soluble matter of soils accumulated to an injurious degree, it follows that alkali may contain any or all of the constituents of rocks and soils. The numerous existing analyses show that in alkali there is a preponderance of the bases, sodium, calcium and magnesium, combined with hydrochloric, sulfuric, carbonic and nitric acids. In other words, the chlorides, sulfates, carbonates and nitrates of sodium, calcium and magnesium are the chief constituents of ordinary alkali. In addition to these dominant constituents there are a great many others, as potassium salts, phosphates and other indispensable plant-foods. Alkali may be said to be the cream of soil fertility, so concentrated as to cause plant indigestion. The following table gives partial analyses of four samples of alkali crust: 
Percentage Composition of Alkali Crusts

\begin{tabular}{|c|c|c|c|c|c|}
\hline & $\begin{array}{l}\text { New } \\
\text { Mexico }\end{array}$ & Wyoming & Utah & Colorado & Utah \\
\hline $\begin{array}{l}\text { Sodium carbonate (sal- } \\
\text { soda) } \\
\text { Sodium chloride (common }\end{array}$ & Trace & Trace & 2.0 & . $\cdot$ & $\cdot$ \\
\hline $\begin{array}{l}\text { Sodium sulfate } \\
\text { ber's salt) }\end{array}$ & 70.4 & 39.7 & 3.2 & & 88.6 \\
\hline $\begin{array}{l}\text { Sodium nitrate (niter) } \\
\text { Magnesium sulfate (Ep- }\end{array}$ & Trace & Trace & Trace & 40.8 & . . \\
\hline $\begin{array}{l}\text { som salts) } \\
\text { Calcium sulfate (gyp- } \\
\text { sum) }\end{array}$ & 11.8 & 42.4 & 90.3 & 30.5 & . . \\
\hline
\end{tabular}

In the first sample from New Mexico, sodium sulfate, or Glauber's salt, predominates; in the second, from Wyoming, magnesium sulfate, or Epsom salts, is most prominent; in the third, from Utah, calcium sulfate, or gypsum, predominates; in the fourth, from Colorado, sodium nitrate, or niter, predominates, and in the fifth, from Utah, sodium chloride, or common salt, predominates.

Between the extreme compositions shown in the above table, all possible variations occur. It is impossible to lay down any rule for the composition of alkali, unless the source is known. The following analysis of a California sample also shows the complex composition of alkali:

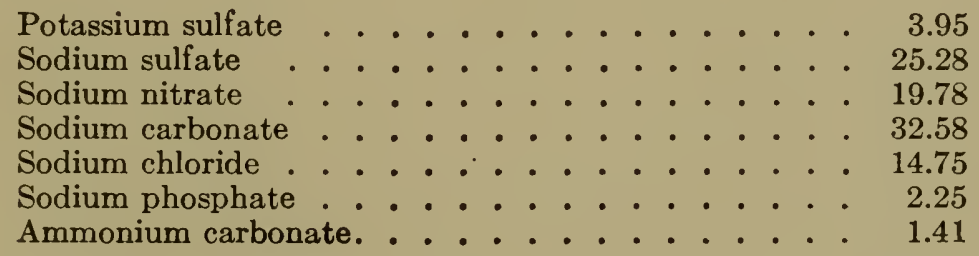

Total . . . . . . . . . . 100.00 
Ordinarily, alkali is classified as white, black or brown. Black alkali appears as a black, shiny mass, or as black spots, over the soil. White alkali has a clean, white appearance like that of salt. Experience has demonstrated that black is far more injurious than white alkali, for it is corrosive and girdles the tissues of the plant near the soil surface and thus destroys the plant itself. White alkali is relatively harmless, and injures plants only as it

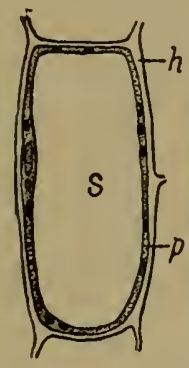

1

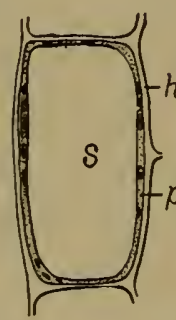

2

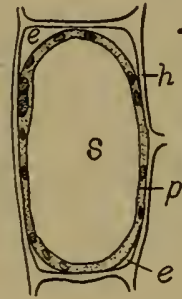

3

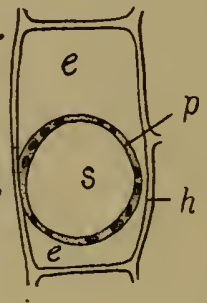

4 is present in too large an abundance. Black or brown alkali is composed chiefly of the carbonate or nitrate of sodium, with perhaps some

common salt.

FIG. 115. Effect of a strong solution of potassium nitrate on protoplasm.

The carbonate dissolves the plant tissues with the formation of a black mass; it moreover destroys the tilth of the soil by destroying its structure. The nitrate forms brown spots; it also makes soils mushy; but, when the soils containing nitrates dry out, a very characteristic crumbly soil results. The white alkali is composed of the sulfates and chlorides of sodium, calcium and magnesium.

235. Tolerance for alkali.-The tolerance for alkali of plants depends on five factors: (1) the main salt, (2) the concentration, (3) the associated salt, (4) the age of the plant, and (5) the plant itself. Kearney and Cameron, experimenting with seedlings of various plants, have shown that various salts affect growth variously. Sodium carbonate is the most injurious constituent of alkali, 
followed by sodium chloride, followed by sodium sulfate, followed by magnesium sulfate. This is the general order of tolerance of these four important salts, frequent constituents of alkali.

The injury from each salt depends upon the mixtures of salts in the alkali. The action of magnesium sulfate is almost wholly destroyed, if there is mixed with it a quantity of calcium sulfate. In fact, calcium sulfate is the great neutralizer of the dangerous substances of

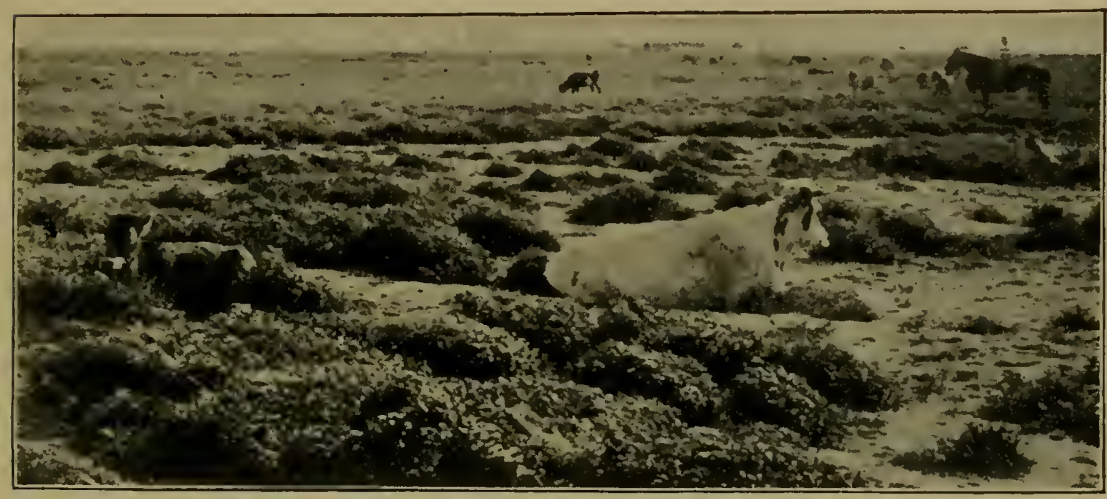

Fig. 116. Vegetation on alkali lands. California.

ordinary alkali. The salts found in alkali do not show any specific effect upon the wilting coefficient. Any of the alkali salts, present in large quantity, tends to increase the water-cost of dry matter. Evaporation from alkali soils is always reduced. In general, while alkali tends to reduce the direct evaporation from the soil, it also tends to increase the water-cost of dry matter.

The concentration of alkali in the soil that will injure plants has not been finally determined. Most work on the subject has been done by Hilgard and Loughridge of the University of California. Loughridge has tabulated the highest quantity of alkali salts endured by various 
crops, as based upon many years of observation at the California stations. In the following table will be found the information given by Loughridge, adapted slightly:

Highest Quantity of Alkali Salts Endured by Various Crops Fruit Trees

\begin{tabular}{|c|c|c|}
\hline $\begin{array}{l}\text { Per cent of } \\
\text { sodium sulfate (Glau- } \\
\text { ber's salt) in soil }\end{array}$ & $\begin{array}{l}\text { Per cent of sodium } \\
\text { chloride (common salt) } \\
\text { in soil }\end{array}$ & $\begin{array}{l}\text { Per cent of } \\
\text { sodium carbonate (sal- } \\
\text { soda) in soil }\end{array}$ \\
\hline 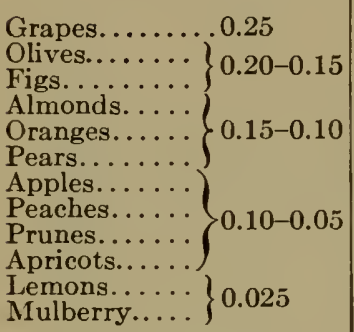 & 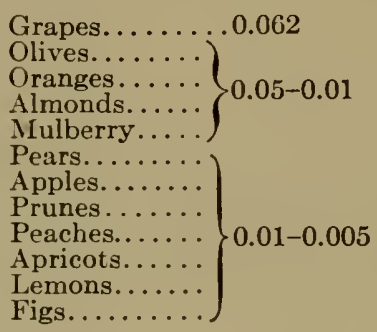 & 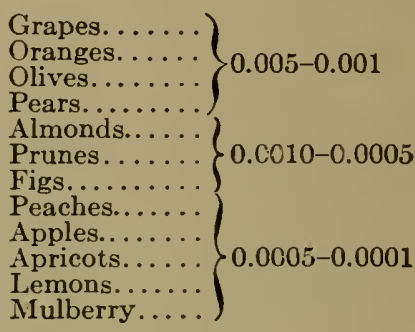 \\
\hline
\end{tabular}

Small Cultures

\begin{tabular}{|c|c|c|}
\hline $\begin{array}{l}\text { Per cent of } \\
\text { sodium sulfate (Glau- } \\
\text { ber's salt) in soil }\end{array}$ & $\begin{array}{l}\text { Per cent of sodium } \\
\text { chloride (common salt) } \\
\text { in soil }\end{array}$ & $\begin{array}{l}\text { Per cent of } \\
\text { sodium carbonate (sal- } \\
\text { soda) in soil }\end{array}$ \\
\hline 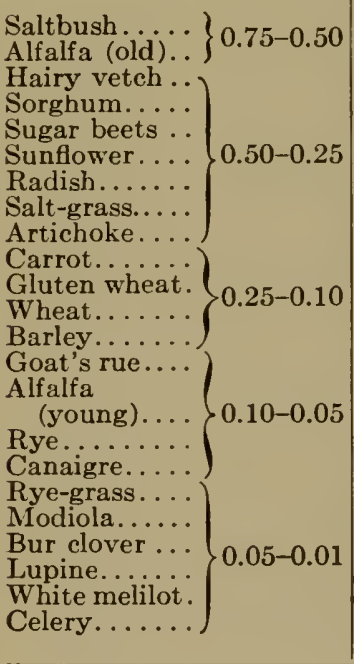 & 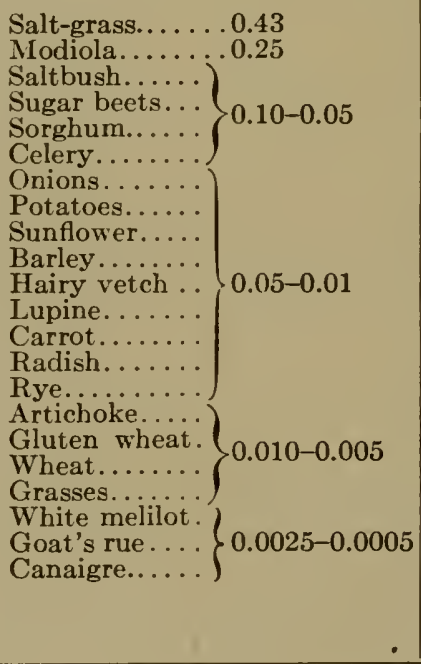 & 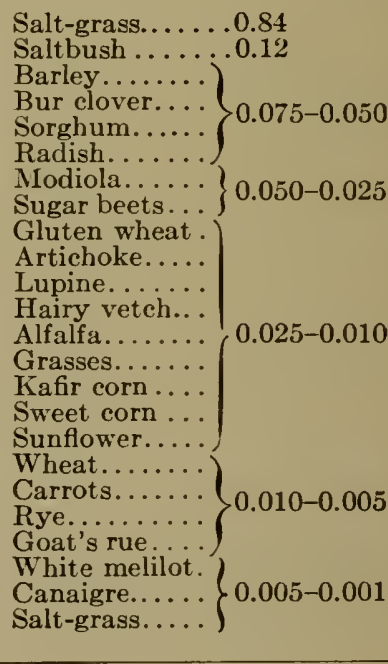 \\
\hline
\end{tabular}


For fruit trees, the tolerance of Glauber salts varies from 0.25 to 0.025 of 1 per cent; of common salt from 0.062 to 0.005 of 1 per cent; of sal-soda from 0.005 to 0.0001 of 1 per cent. For the small cultures, tolerance of Glauber's salt, as of salt and sal-soda, is increased considerably. However, the variation for various crops in the table is so great as to make it practically impossible to lay down any definite rules that may be generally used in agriculture. Loughridge concludes that, in general, for fruit trees, the maximum tolerance of alkali in the soil ranges from 0.28 per cent to 0.04 per cent; for small cultures, excluding the salt bushes, from 1.0 per cent to 0.06 per cent.

The experience of the Bureau of Soils is perhaps the best for formulating limits of the tolerance of plants for alkali. The staff of the Bureau of Soils has investigated practically every important alkali area of the United States. They have had ample opportunity to correlate the growth on the soil with the alkali content. It has been found that on land containing, to a depth of 6 feet, up to 0.2 per cent of total alkali, none of the common crops are injured, unless carbonates greatly predominate, or unless most of the salt is concentrated in the upper part of the first foot. On land containing from 0.2 per cent to 0.4 of total alkali, or from 0.05 to 0.1 per cent of black alkali, or 0.5 per cent of sodium chloride, or 1 per cent of sodium sulfate, all but the most sensitive crops will grow. Near the higher limits, all but the most resistant crops show signs of distress. A grade of land containing from .4 to .6 per cent of total alkali and from .1 to .2 of black alkali contains a little too much for common crops. Pastures usually grow on such land. Where the land contains from .6 to 1 per cent of total alkali it is 
almost worthless for general or fruit farming. In spite, however, of these well-established limits, it is known that even with 3 per cent of alkali in the upper 6 feet, crops may occasionally be grown successfully. Much depends, as already said, upon the crop, the nature of the alkali, the nature of the soil, methods of irrigation, and tillage.

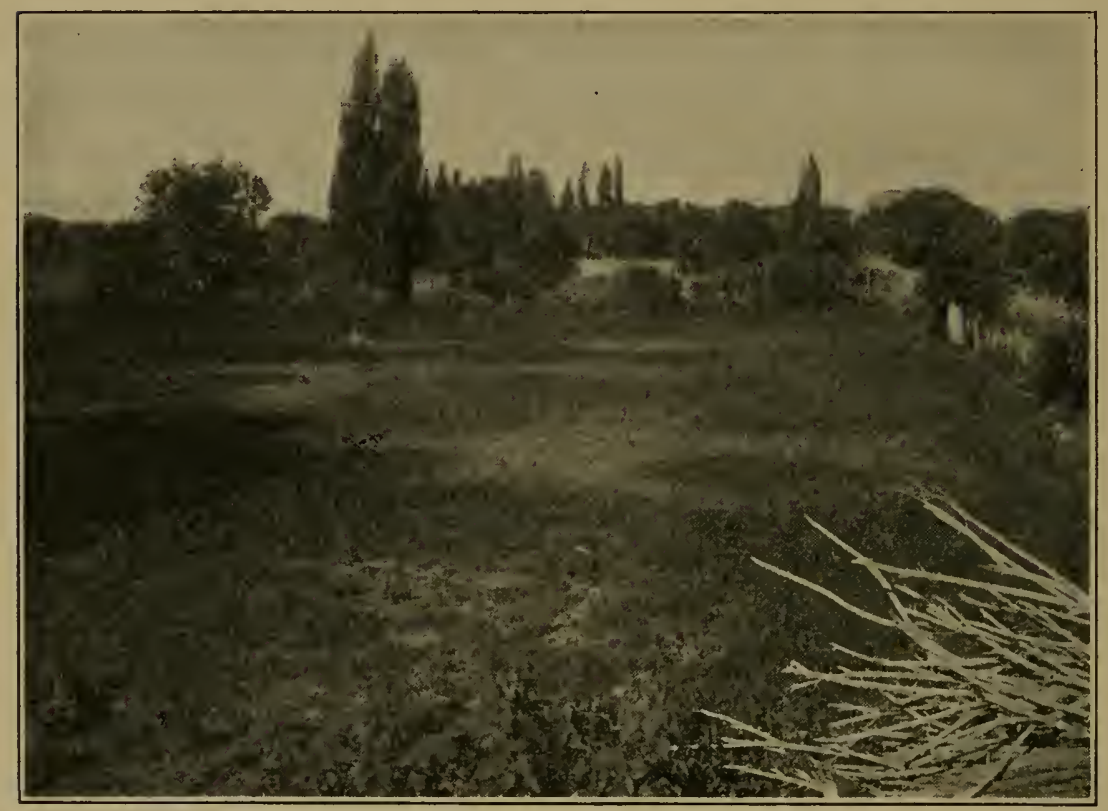

FIG. 117. Alkali spots on irrigated pasture.

The crop itself determines, fundamentally, the tolerance for alkali. Certain fruits and small crops endure large quantities of alkali, while others are very sensitive to it. When properly cultivated, kafir corn, sorghum, sugar beets, and barley are excellent alkali-resistant crops. The date palm, in its resistance to alkali, stands at the very head of cultivated crops. However, the area over which this plant may be grown at present is relatively small. 
The age of the crop also determines largely the tolerance of alkali. Germinating crops can stand only small quantities of alkali; but as they become older and the rootsystem better established the tolerance increases. Therefore, it is advisable to wash the alkali far down into the subsoil at the time of seeding, so that germination and first growth may occur without hindrance. The quality of crops is often reduced by the presence of alkali. Headden found that the quality of beets was largely interfered with by the presence of nitrates in the soil.

All in all, the subject of the tolerance of plants for alkali is in considerable confusion. This exceedingly difficult subject needs to be worked over, with new experiments and devices before the last word concerning it can be spoken.

236. Cropping against alkali.-Apparently the simplest method of utilizing alkali lands is to grow upon them alkali-resistant plants. Many native plants thrive on alkali lands, and are relatively sure indicators of alkali conditions. Greasewood, shad-scale, salt-weeds and saltbushes thrive best on lands that are fairly rich in alkali. While these plants usually grow on alkali soils they often do well on alkali-free soils, and are not therefore invariable indicators of alkali. Unfortunately, most of the native alkali-resistant plants have little agricultural value. They are usually unpalatable and of low digestibility and feeding value. There are a number of cultivated plants that also endure alkali. Among these is the Australian salt-bush, tried out in California, which yields well and makes a fairly palatable forage. Sweet clover, which is almost a weed in many localities, grows remarkably well on certain classes of alkali land, and, if cut early, forms a palatable stock-feed. Lucern once started on 
alkali land, does fairly well, as do also sugar beets, sorghum, kafir corn, rye, the date palm, grape-vines and many other crops which yield annual crops of fair size in the presence of relatively large quantities of alkali.

The theory of reclaiming alkali lands by cropping is that each crop absorbs from the soil considerable quantities of alkali, and as cropping is continued year after year, there is diminution in the alkali content of the soil corresponding to the quantities removed by the crops. The Australian salt-bush, containing about 20 per cent of ash, may yield five tons an acre, which means each crop removes from the soil about one ton of alkali. This, continued for several years, would tend to make an alkali soil better capable of producing' ordinary crops.

On alkali soils, deep-rooted plants do better than shallow-rooted plants, and leafy plants do better than those giving less shade. Legumes do not resist alkali well, while the sunflower family does exceedingly well in the presence of alkali. The fiber plants, such as flax, are sensitive to alkali. Much information is yet needed concerning alkali-resistant plants; the conditions under which they thrive best, and the degree to which they are able to remove alkali. Much new work can profitably be done on this branch of the subject of alkali.

237. Chemical treatment for alkali.-The suggestion has been made repeatedly that something might be added to the soil to neutralize alkali. The chemical nature of the constituents of alkali makes it difficult to make them insoluble or to change them into something less obnoxious. The conclusion has been reached, after much experimentation, that only sodium carbonate may be corrected, practically, by chemical treatment. Hilgard demonstrated many years ago, on the California experimental 
farms, that calcium sulfate, or gypsum, added to a soil containing sodium carbonate, changed the carbonate to a sulfate; that is, gypsum changed black alkali to white alkali. Twice as much gypsum as there is sodium carbonate in the soil, should in time be worked into the soil thoroughly. To add 200 to 400 pounds of gypsum an acre annually, is better than to attempt to add the full quantity all at once. After each treatment the soil should be irrigated. This is an excellent corrective for black alkali; and it is, indeed, the only known chemical corrective for alkali.

238. Scraping the surface.-Another method of combating alkali is to allow evaporation to go on until the alkali has crusted the soil surface, and then to scrape off this crust and to remove it permanently from the soil. By this method, hundreds of pounds of alkali per acre may be removed from the soil; but not enough is carried off really to improve the soil, and the labor involved is so large as to make the whole process of doubtful value.

239. Tillage against alkali.-Alkali is most injurious if concentrated near the surface. If distributed evenly throughout the soil relatively large quantities of alkali may be endured by plants. This condition may be secured, measurably, by reducing evaporation and thereby preventing the rise of alkali. This is a very effective method of preventing damage from alkali. Orchards seriously injured by alkali have frequently been restored to a profitable condition by thorough cultivation. The common custom is to plow under the crust, irrigate thoroughly, and follow this by a thorough cultivation as often as needs be throughout the season. Alkali lands should also be cultivated in the spring, when evaporation is likely to go on rapidly. 
240. Washing out alkali.-In the attempt to remove alkali, lands are often flooded with a large quantity of water flowing under a high head. The theory has been that the rapidly moving water passing over the soil will dissolve the alkali and carry it off. This, however, has been found to be ineffective, for, the moment the water dissolves the alkali, it sinks into the soil and only the pure water runs off the surface.

A better method is to apply irrigations so large that the water seeps into the country drainage. When this can be done it is very satisfactory, but only on naturally well-drained lands, or on open soils, can it be made effective. Occasionally, the soil is underlaid by a hardpan, and it is found helpful to make holes through this impervious layer to connect with the more permeable soil. In any case, when much water is used on alkali land, irrigation should be followed by careful cultivation.

241. Underdrainage the final remedy.-The only really satisfactory treatment for alkali is one that removes the alkali permanently from the soil. This is accomplished best by underdrainage, since few soils permit of natural drainage.

The feasibility of underdrainage has been demonstrated in all parts of the world, and the only considerations, with respect to alkali lands, are the cost of installation and the disposition of the drainage water. The cost is no higher in irrigated than in humid regions; and irrigated lands are fully as valuable as those in humid regions. The disposition of the drainage water depends on local conditions, and must be carefully determined upon, for the drainage from alkali lands is unfit for agricultural uses. Drainage from such lands need not, however, be continuously great, for lands, underdrained for the re- 
moval of alkali, are not necessarily swampy; on the contrary, they may be perfectly dry in their natural condition.

If underdrainage is used as the final remedy for alkali, very heavy applications of water must be applied for some time, until the alkali is thoroughly washed out and carried off through the drains. This is a dangerous procedure, for valuable plant-foods are taken out with the alkali. The washing of the soil should be stopped, therefore, as soon as the main alkali condition has been corrected.

The possibility of removing alkali by underdrainage has been well demonstrated by the Bureau of Soils of the United States Department of Agriculture. The pioneer experiment was made on land located west of Salt Lake City, toward the Great Salt Lake. The farm, when located, was covered with a glistening coat of white alkali. The soils of the district are generally heavily impregnated with alkali, chiefly common salt, from the concentrated water of the Great Salt Lake, which has either overflowed in the past, or has moved through the subsoil. From $2 \frac{1}{2}$ to 5 per cent of alkali was found in the soil at the time the experiments began, and ground water stood about 4 feet from the surface. Tile pipe was laid in the usual manner, at a cost of about $\$ 16$ an acre. In 1903 , the year after the laying of the tile, the land was thoroughly flooded, and from August, 1904, it was again flooded thoroughly, at various intervals, until 1906, when the land was returned in a good agricultural condition to the owner. Since that time a thrifty crop of alfalfa has grown upon it, as proof that the alkali condition has been permanently corrected. From September, 1902, to October, 1904, the water added was equal to a little more 
than 10 feet in depth over the whole area. This quantity of water carried off 5,317 tons of salt, and reduced the alkali content to 13 per cent of what it was at the beginning of the experiment. Not only was this tract of 40 acres reclaimed by this treatment, but the beneficial effects of the drainage were felt in the adjoining fields.

At Fresno, California, where the predominating type of alkali was a mixture of the chloride and the carbonate of sodium, a hopelessly alkaline tract was restored by tile drainage in less than one year to permanent fertility. At Billings, Montana, where the prevailing type of alkali was sodium sulphate, similar reclamation work was accomplished in two years. These three experiments, at Salt Lake City, Fresno, and Billings, representing the three chief types of alkali, demonstrate the feasibility of reclaiming alkali lands by underdrainage, provided there is a sufficient fall of the land and a suitable outlet.

Alkali may attack and injure the materials of which the drains are made. When glazed pipe is used, the danger is small; but if concrete or cement pipe is laid, the danger is large, for alkali uniting with the calcium hydroxide of the cement tends to disintegrate concrete. In the destructive action on concrete, sodium sulfate stands first, followed by magnesium sulfate and then by sodium carbonate. Sodium chloride has a small but definitely injurious effect.

Alkali lands represent only a small proportion of the total irrigated area. Cautious irrigation of the higherlying lands will prevent the increase of this area, and underdrainage will reduce it considerably. With our present knowledge, there is no reason why the "alkali plague" should be feared. Vigorous measures should be taken, however, if the alkali trouble is approaching. 


\section{REFERENCES}

Bonsteel, JAY A. Marsh and Swamp Lands. United States

Department of Agriculture, Bureau of Soils, Circular No. 69 (1912).

Brown, Charles F. Drainage of Irrigated Lands. United States Department of Agriculture, Farmers' Bulletin No. 371 (1909). Brown, Charles F., and Hart, R. A. The Reclamation of Seeped and Alkali Lands. Utah Experiment Station, Bulletin No. 111 (1910).

Burke, Edmund, and Pinckney, Reuben M. The Destruction of Hydraulic Cements by the Action of Alkali Salts. Bulletin No. 81 (1910).

Carpenter, L. G. Seepage or Return Waters from Irrigation. Colorado Experiment Station, Bulletin No. 33 (1896).

Carpenter, L. G. The Loss of Water from Reservoirs by Seepage and Evaporation. Colorado Experiment Station, Bulletin No. 45 (1898).

Carpenter, L. G. Losses from Canals from Filtration or Seepage. Colorado Experiment Station, Bulletin No. 48 (1898).

Dorsey, Clarence W. Alkali Soils of the United States (contains United States literature). United States Department of Agriculture, Bureau of Soils, Bulletin No. 35 (1906).

Dorsey, Clarence W. Reclamation of Alkali Land in Salt Lake Valley, Utah. United States Department of Agriculture, Bureau of Soils, Bulletin No. 43 (1907).

Dorsey, Clarence W. Reclamation of Alkali Soils at Billings, Moniana. United States Department of Agriculture, Bureau of Soils, Bulletin No. 44 (1907).

Elliot, C. G. Development of Methods of Drainage for Irrigated Lands. United States Department of Agriculture, Office of Experiment Stations, Annual Report for 1910.

Elliot, C. G. Drainage of Farm Lands. United States Department of Agriculture, Farmers' Bulletin No. 187 (1904).

Etcheverry, B. A. Increasing the Duty of Water. California Experiment Station, Circular No. 114 (1914).

Fleming, B. P. Seepage Investigations. Wyoming Experiment Station, Bulletin No. 61 (1904).

Fitterer, J. E. Reclamation by Drainage. Wyoming Experiment Station, Bulletin No. 90 (1911). 
Fuller, Myron L. Summary of the Controlling Factors of Artesian Flows. United States Geological Survey, Bulletin No. 319 (1908).

Fuller, Myron L. Underground Waters for Farm Use. United States Geological Survey, Water Supply Papers Nọ. 255 (1910).

Fortier, Samuel, and Cone, Victor M. Drainage of Irrigated Lands in the San Joaquin Valley, California. United States Department of Agriculture, Office of Experiment Stations, Bulletin No. 217 (1909).

Headden, W. P. The Fixation of Nitrogen in Some Colorado Soils.

Colorado Experiment Station, Bulletins Nos. 155, 178 and 186 (1913).

Hfiadden, W. P. Deterioration in the Quality of Sugar Beets, Due to Nitrates Formed in the Soil. Colorado Experiment Station, Bulletin No. 183 (1912).

Headden, W. P. Destruction of Concrete by Alkali. Colorado Experiment Station, Bulletin No. 132 (1908).

Hilgard, E. W. Soils. The Macmillan Company (1906).

Kearney, Thomas H. The Wilting Coefficient for Plants in Alkali Soils. United States Department of Agriculture, Bureau of Plant Industry, Circular No. 109 (1913).

Kearney, Thomas H., and Harter, L. L. Comparative Tolerance of Various Plants for the Salts Common in Alkali Soils. United States Department of Agriculture, Bureau of Plant Industry, Bulletin No. 113 (1907).

Loughridge, R. H. Tolerance of Eucalyptus for Alkali. California Experiment Station, Bulletin No. 225 (1911).

Machie, W. W. Reclamation of White-Ash Lands Affected with Alkali at Fresno California. United States Department of Agriculture, Bureau of Soils, Bulletin No. 42 (1907).

Mead, Elwood. Report of Irrigation and Drainage Investigations, 1904. United States Department of Agriculture, Office of Experiment Stations, Annual Report for 1904.

Mead, Elwood, and Etcheverry, B. A. Lining of Ditches and Reservoirs to Prevent Seepage Losses. California Experiment Station, Bulletin No. 188 (1907).

Means, Thomas H. Reclamation of Alkali Lands in Egypt. United States Department of Agriculture, Bureau of Soils, Bulletin No. 21 (1903). 
Schlichter, Charles S. The Rate of Movement of Underground Waters. United States Geological Survey, Water Supply Papers, No. 140 (1905).

Sмiтh, G. E. P. Cement Pipe for Small Irrigating Systems and Other Purposes. Arizona Experiment Station, Bulletin No. 55 (1907).

Stewart, Robert, and Greaves, J. E. The Movement of Nitric Nitrogen in Soil and Nitrogen Fixation. Utah Experiment Station, Bulletin No. 115 (1911).

Tannatt, E. Tappan, Anderson, A. P., and Kneale, R. D. Seepage and Drainage. Montana Experiment Station, Bulletin No. 65 (1907), and No. 76 (1909).

Tannatt, E. Tappan, and Burke, Edmund. The Effect of Alkali on Portland Cement. Montana Experiment Station, Bulletin No. 68 (1908).

Teele, R. P. Review of Ten Years of Irrigation Investigations. United States Department of Agriculture, Office of Experiment Stations, Annual Report for 1908 (separate).

Teele, R. P. Losses of Irrigation Water and Their Prevention. United States Department of Agriculture, Office of Experiment Stations, Annual Report for 1907.

Talmage, J. E. The Great Salt Lake, Present and Past (1900).

True, Rodney H., and Bartlett, Harley, Harris. Absorption and Secretion of Salts by Roots as Influenced by Cultural Solutions. United States Department of Agriculture, Bureau of Plant Industry, Bulletin No. 231 (1912).

Widtsoe, J. A., and Stewart, Robert. The Soil of the Southern Utah Experiment Station. Utah Experiment Station, Bulletin No. 121 (1913).

Woodward, S. M. Land Drainage by Means of Pumps. United States Department of Agriculture, Office of Experiment Stations, Bulletin No. 243 (1911).

Wright, J. O. Swamp and Overflowed Lands in the United States. United States Department of Agriculture, Office of Experiment Stations, Circular No. 76 (1907). 


\section{CHAPTER XIX}

\section{IRRIGATION IN HUMID CLIMATES}

IRRIGATION should always be practised to supplement the natural rainfall. Where there is much rainfall, either during the growing season, or in the winter, that can be stored, less irrigation is needed than where the rainfall is low. Wherever the rainfall is not high enough to yield maximum crops, however, irrigation is desirable; and wherever the rainfall does not come regularly during the season or from season to season, irrigation ensures steady yields. Only over a small part of the earth's surface is the rainfall large enough or regular enough to insure the highest or steady yields. The so-called humid regions are often subject to droughts, and the soils of such sections are usually unresistant to drought. The great centers of population, with their splendid markets, usually located in humid sections, make it especially desirable that large and steady yields be obtained by the neighboring farmers, particularly the truck-gardeners. For these reasons, irrigation promises to become a large practice under humid conditions.

Irrigation in humid climates is not new. Much of the European irrigation is done under a relatively high rainfall. Water meadows have been known for centuries in England, and many have existed for a half-century or more in New England. The practice of irrigation under humid conditions has only recently, however, been considered seriously and extensively. 
242. Dry seasons.- It is an elementary fact of weather science that neither the total annual rainfall nor its distribution is exactly the same from year to year. The average of many years does not, perhaps, vary greatly, but from year to year there is a considerable difference. This constitutes the main reason for irrigation in humid districts. For instance, Williams has compiled the following table from the United States Weather Bureau, covering ten years, from 1899 to 1909, showing the average annual rainfall, the number of droughts or periods of fifteen days with less than 1 inch of rainfall, for five points in the United States, representing five great divisions of the country. In the first column is shown the point at which the observation was made; in the second column, the average annual rainfall in inches; in the third column, the number of fifteen-day periods or over with less than 1 inch of rain, or periods of drought; in the fourth column, the number of days when irrigation was required, meaning the number of days beyond the fifteen days during which less than 1 inch rainfall was received.

\begin{tabular}{l|c|c|c}
\hline \hline \multicolumn{1}{c|}{ Stations } & $\begin{array}{c}\text { Average } \\
\text { annual } \\
\text { rainfall }\end{array}$ & $\begin{array}{c}\text { Number of 15-day } \\
\text { periods or over } \\
\text { with less than } \\
\text { 1 inch of rain }\end{array}$ & $\begin{array}{c}\text { Number of days } \\
\text { when irrigation } \\
\text { was required }\end{array}$ \\
\hline Ames, Iowa . . . . & 30.39 & 23 & 190 \\
Oshkosh, Wis. . . . & 29.78 & 27 & 292 \\
Vineland, N. J. . . . & 47.47 & 46 & 352 \\
Columbia, S. C. . . . & 47.55 & 62 & 568 \\
Selma, Ala. . . . . & 50.75 & 60 & 724 \\
\hline
\end{tabular}

It may be noted in the above table that at Ames, Iowa, with an average rainfall of over 30 inches, there were, in ten years, twenty-three periods of drought, with 190 days when irrigation would have been beneficial. At 
Oshkosh, Wisconsin, with a rainfall of practically 30 inches per year, there were twenty-seven such. periods of drought, sixteen of which came in the spring and early summer, and one of which lasted fifty-nine days. At Vineland, New Jersey, with a rainfall of 47 inches, there were forty-six such droughts, and 362 days during which irrigation would have been helpful. At Columbia, South

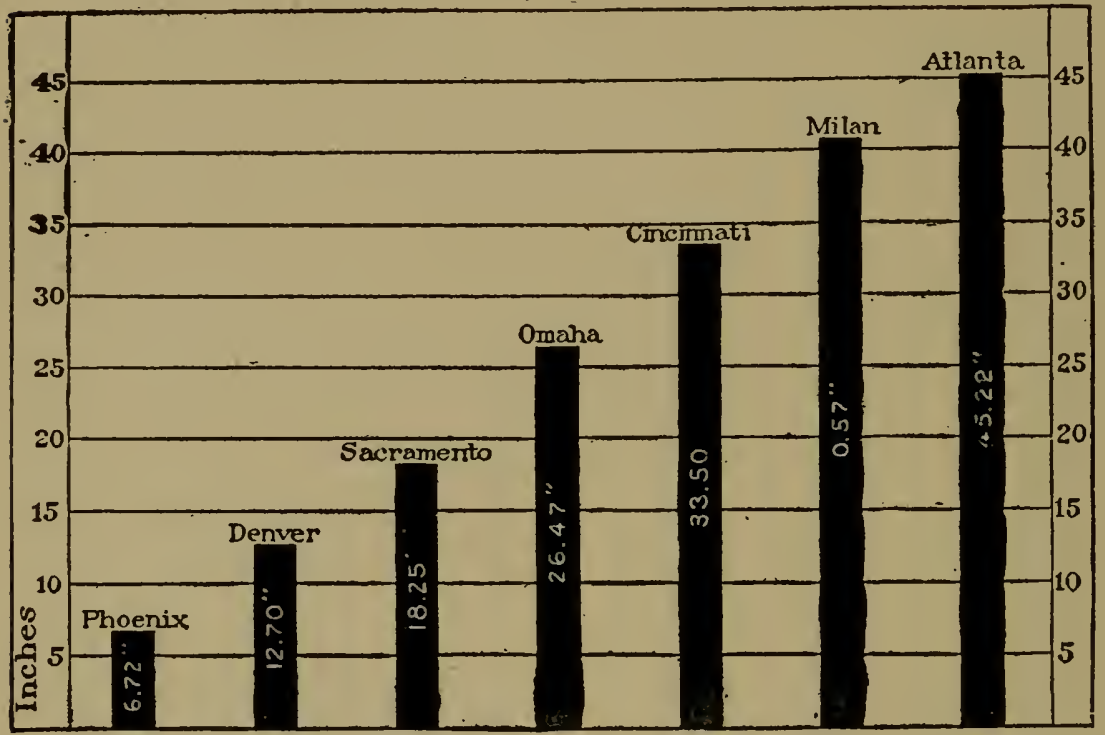

FIG. 118. The annual rainfall of Milan (famous for its irrigation), compared with that of humid and arid districts in the United States.

Carolina, of the sixty-two droughts occurring in the ten years, twenty-seven lasted from twenty to thirty days, four from forty to fifty days, and one lasted sixty-one days, showing the frequent occurrence of rather long droughts in that section of the country. At Selma, Alabama, with over 50 inches of rainfall, sixty periods of drought occurred, with 724 days needing irrigation.

The facts of this table are only representative of a vast mass of information of a similar character gathered by the 
Weather Bureau. No part of the country, no matter what its total annual rainfall may be, is wholly free from periods of drought. Occasionally, these periods are so long and so severe as to cause almost the absolute failure of crops with all the evils attending crop failure. It is to protect the farmer against such periods of drought that irrigation in humid regions is advisable.

243. Results of irrigation in humid regions. - Irrigation in humid regions, as already suggested, is not a new practice; it has simply failed to arouse any large interest among the people living under humid conditions. In recent years, considerable experimental work has been conducted in various parts of the humid regions of the United States, having in view the determination of

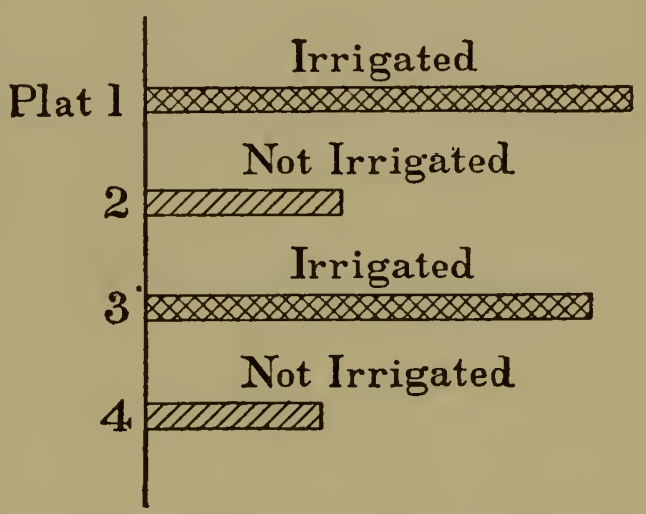

FIG. 119. Comparative yields of strawberries, irrigated and unirrigated. (Connecticut, 1895.)

the advantage resulting from the use of irrigation water in localities that may safely be classed as humid.

Bowie investigated about 125 irrigated meadows, in four counties, in the state of Pennsylvania, the average yields of which were contrasted with similar unirrigated meadows in the same localities. The average of the 125 observations showed that irrigation just doubled the yield. In other states, similar investigations of meadows have been made, with practically the same results. In the eastern United States, irrigation doubles the harvests from ordinary meadows. 
Waters conducted experiments under Missouri conditions, and, while the work was not continued long enough to give averages for a variety of climatic conditions, it was found that a great increase in the yield resulted from the application of irrigation water. Asparagus, grown without irrigation, was thin and covered with rust; when irrigated it was plump and free from rust. Yield and quality were increased by irrigation. Onions and corn both yielded larger crops under irrigation.

Crane, working under Sơuth Dakota conditions, found that every crop he investigated yielded twice as much when irrigation water was applied. His studies were almost entirely with artesian water, and the increase in crop-yields proved abundantly that whenever such waters can be obtained they may be used with great profit.

Voorhees carried on extensive investigations, chiefly during the years 1898 and 1899, to discover if the use of irrigation water influenced materially the yield of crops in New Jersey. He found, as expected, that the season is the important factor in determining the value of irrigation. If the growing season was an abundantly wet one, irrigation had less effect than when the season was relatively dry. The averages of the results obtained by Voorhees for the two years in question are exceedingly instructive.

Blackberries, several varieties of which were tried, showed an increase, due to irrigation, of nearly 77 per cent of the yield without irrigation. Raspberries, represented by several varieties, increased over 37 per cent, varying from 70 per cent to a loss when the natural precipitation was high. Currants, represented by a number of varieties, increased over 28 per cent, varying from 91 to a loss. Gooseberries, represented by a number of varieties, increased 3.3 per cent, varying from 109 per cent 
to a loss. That is, every experiment undertaken by Voorhees yielded average large returns, for small fruits, by the application of irrigation water. Phelps, working in Connecticut, in 1895, obtained similar results. Strawberries grown under irrigation in Connecticut yielded a harvest 159 per cent greater than that obtained without irrigation.

King conducted a long series of similar experiments under Wisconsin conditions, and his results confirm, in every particular, the conclusions of other investigators. King found that irrigation increased the yield of potatoes 46 per cent; cabbage, 12 per cent; corn, 55 per cent; and clover, barley, strawberries, and many other crops under experimentation showed large increases under irrigation. Maxwell studied, for a number of years, sugar-cane irrigation in the Hawaiian Islands, under an annual precipitation of about 47 inches. During the year 1897-98 the yield of sugar was increased nearly 1,500 per cent by irrigation.

It may be that these large increases from irrigation are partly due to the fact that under irrigation much closer planting is allowed without drying out the soil. However that may be, the increase is really due to the fact that there is no shortage of water during the growing period. It has been amply demonstrated that the artificial application of water on humid lands does increase the harvests. Whether the increase and certainty of crop-yield will pay for the cost of building the irrigation system and of applying the water must be worked out by each farmer in accordance with the conditions that surround him. Field crops which yield a small acre return may not pay for irrigation, but truck crops, yielding large acre returns, will often pay in one season for the instal- 
lation of the irrigation plant and leave a margin besides. Irrigation in humid climates probably always pays, unless exceptional difficulties are encountered in securing and distributing water. One drought, unprovided against, frequently causes a loss that would pay for the irrigation system and much else.

244. Methods of applying water.-The methods of applying water in humid regions are those in general use

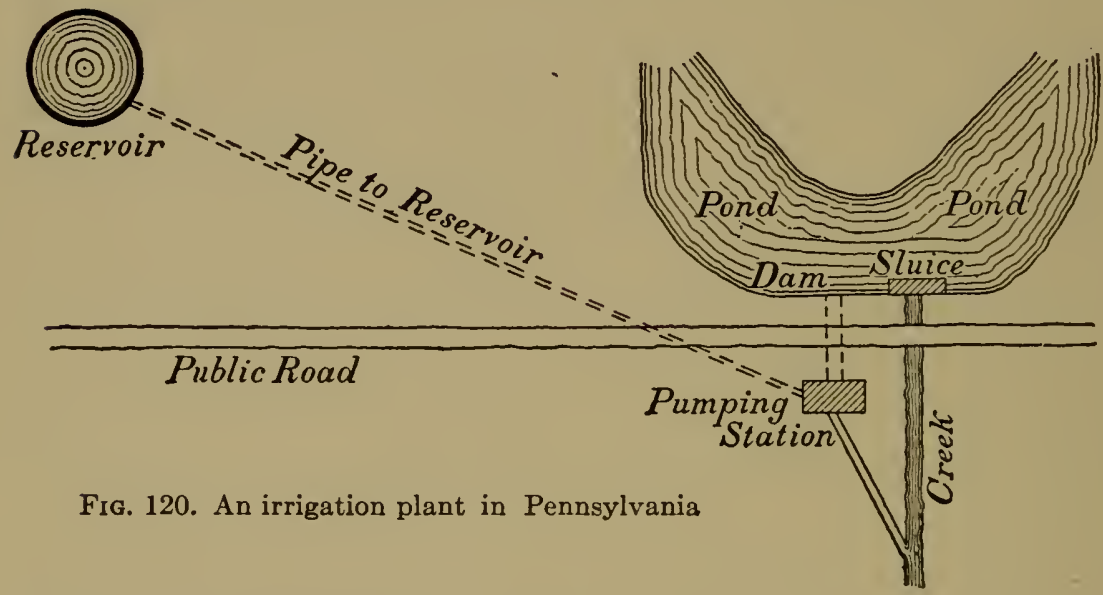

everywhere. Furrowing is probably best, except where the soil is very clayey, or where meadows are flooded with water. In humid regions, on many relatively small tracts devoted to irrigation, specialized crops are usually grown, yielding high acre returns. Under such conditions it is often feasible to install special irrigation devices, such as sprinkling from permanently fixed pipes or from the nozzles of movable hose. Such methods are wasteful of investment, labor and water and are practically out of the question for large areas. Sub-irrigation also is advocated under humid conditions, but the arguments already urged against sub-irrigation, unless natural, hold under humid condi- 
tions. There should be no differentiation in the irrigation practices of humid and arid regions. In both regions there should be an adaptation of the general principles to the special needs of the community.

245. The duty of water.-Since irrigation is merely supplementary to the rainfall, less irrigation water is ordinarily required in humid regions than in arid regions. One to 3 inches of water applied at each irrigation is common under humid conditions, and is apparently abundant. In arid regions, on the other hand, 3 to 5 inches, or even more, are applied at each irrigation. In the humid regions, plants are likely to be somewhat shallow-rooted, owing to the abundance of moisture in the early growing season. This makes it unnecessary for the roots to move deeply in the soil and therefore more frequent irrigation is probably necessary than in arid regions. However, the application of water every ten or fifteen days should be sufficient. In general, the duty of water in humid regions should be higher than in arid regions, but this does not always follow, for it is reported that to irrigate sugar cane, under humid conditions, a depth of water equivalent to 40 to 100 inches is used throughout the season, which is much more than is necessary in the arid regions. It is probable that, in humid as in arid regions, the tendency will be to use too much water. Over-irrigation is just as objectionable in humid as in arid climates, and for the reasons already stated in previous chapters.

246. Sources of water.-The humid region abounds in creeks, ponds, rivers and underground water, all of which are suitable for irrigation. However, water-rights in the East, where irrigation has received little attention, are more complicated, and frequently it is more difficult 
there than in the West to claim water for agricultural purposes. Consequently irrigation in the humid regions, at least in the beginning, must be more of individual effort and less of community action. Independent, small plants must be established, which, in time, may lead to coöperation. Meanwhile, many natural waters may be impounded; springs may be enlarged, water may be lifted by the stream current from the rivers, windmills and other engines may be made to lift water from wells, and artesian waters may be developed. Since underground water is more available under humid conditions than under arid conditions, the pumping plant may become a chief dependence on the irrigated farms of the East. Such pumping plants need be in operation only at the very time that water is needed for the farms.

247. Water-conservation methods.-In the humid regions, the farmer has depended on the rainfall and has given little attention to cultural methods for conserving water. Beyond question, humid agriculture would be greatly improved if the farmers should adopt the simple methods of dry-farming for storing and retaining the water that falls upon the soil, by proper plowing, surface tillage and other methods. This, alone, would eliminate many of the droughts that trouble the humid regions. Irrigation, then, would need to be called less frequently into service. Before the droughts of the world shall finally cease to vex man, it is necessary for both dryfarming and irrigation methods to be adopted in the humid regions of the world.

248. Value of sewage water.-Sewage irrigation, while not necessarily practised under a high rainfall, is closely associated with irrigation in humid regions for the reason that most of the larger cities, boasting the largest quan- 
tity of sewage, are, as yet, located under a considerable rainfall. The materials dissolved or suspended in irrigation water are often, as shown in Chapter $\mathrm{V}$, of high value as plant-food. Of all known waters, however, sewage water is usually of the highest value in crop-growth, since its chief constituent, human waste, approaches in composition the more valuable portions of plants.

It has been roughly calculated that each person, living in a city, wastes annually eight pounds of nitrogen, three pounds of potassium, two pounds of phosphorus, not counting the organic matter of which these three fundamentally important elements are parts. When these quantities are multiplied by the millions residing in many of the large cities, the sewage which passes into the rivers and oceans, rises to tremendous value. The large cities cause the largest single losses, but the smaller cities of the country are now installing sewage systems, and all should give some attention to the conservation of sewage waste. Sewage can best be put to use by its application in irrigation.

249. The use of sewage.-In many countries, sewage water is used for plant-production. The most famous example is that of Craigentinny meadows, receiving sewage from Edinburgh. According to Storer and King, one hundred years ago, when sewage irrigation began on these fields, they were originally a waste. With the aid of sewage irrigation they have produced continuously since that time large crops of grass, with a profit far above that of the best fields of the country. Similarly, near Milan in Italy, sewage is let into great canals that lead to great meadows. These have produced remarkably, as a result of the application of the heavily fertilized water. China, and the Orient generally, are perhaps the greatest examples of the 
wise use of human waste in crop-production. In these countries, modern sewage systems have not been installed, but the human waste is carried in specially provided receptacles to the farms. It is not likely that this method will be adopted under civilized conditions; human waste will continue to be thrown into sewage systems, but, as among the Chinese and other nations that have established a permanent system of agriculture, the sewage

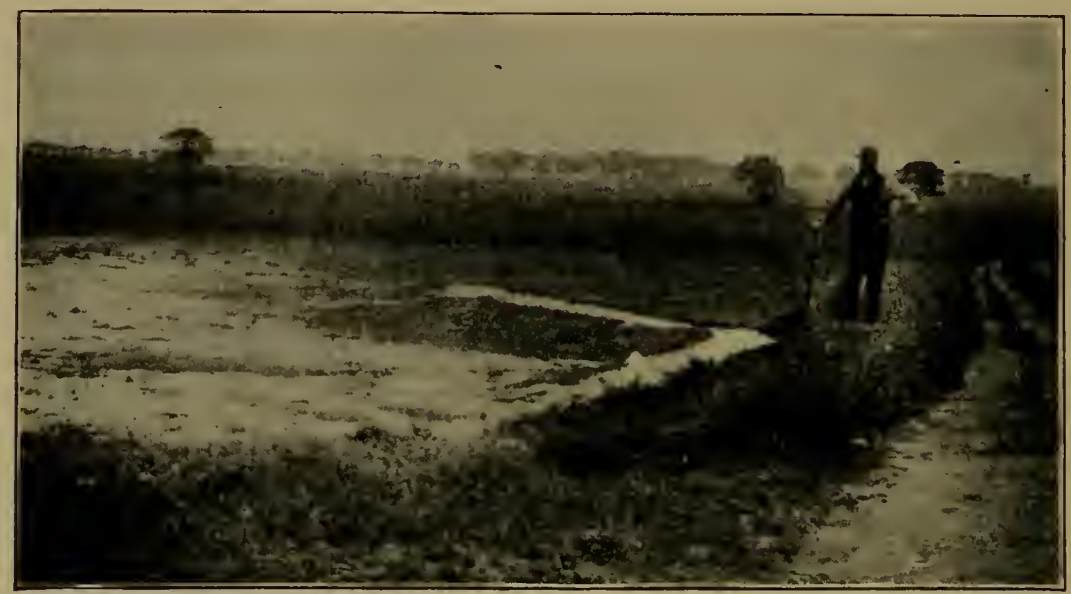

FIG. 121. Distribution of water on Craigentinny Meadows, Edinburgh.

water thus produced must be used for the production of crops.

It has been argued that, for health reasons, sewage should not be so used, for disease germs might be carried by sewage water to the herbage and thence to domestic animals and finally to human beings. The fact that sewage irrigation has been practised for centuries with no evidence of such evil effects leads to the belief that the danger does not exist. Sewage, if properly applied to a soil which is properly tilled, is thoroughly oxidized and becomes innocuous. Plants, themselves, would not be 
likely to take up disease germs. Every open water channel, especially in settled sections, contains to some degree the substances of ordinary sewage, yet none hesitate to use such water for irrigation purposes. The matter could well be subjected to experimental inquiry, before extensive sewage irrigation is undertaken.

It is ordinarily quite difficult to make the best use of sewage water, because the outlets of sewage systems are usually in low places, and the main problem is that of lifting water to fields. However, in many places it is possible to take out the river water some distance below the outlet of the system and there to apply it to fields. In other places, the sewage might be run into reservoirs and then be pumped to the fields.

250. Factory and mill waste.-While, in general, sewage waters are admirably adapted to the production of vegetable matter, yet it must not be forgotten that certain kinds of waste are detrimental to plant growth. For instance, the sewage or waste from certain factories and mills is injurious. In the West, it has been found frequently that waters coming from gold and silver mills contain poisonous elements. Copper mills have likewise been shown to contaminate water to such a degree that its irrigation value is greatly reduced. Attention should be given, even in the open country, to the possible contamination of water by substances which are injurious to plants and animals.

\section{REFERENCES}

BowIE, Adg. J., Jr. Irrigation in the North Atlantic States. United States Department of Agriculture, Office of Experiment Stations, Bulletin No. 167 (1906)

KING, F. H. Irrigation in Humid Climates. United States Department of Agriculture, Farmers' Bulletin No. 46 (1896).

AA 
KING, F. H. Farmers of Forty Centuries. Mrs. F. H. King, Madison, Wisconsin (1911).

Maxwell, Walter. Irrigation in Hawaii. United States Department of Agriculture, Office of Experiment Stations, Bulletin No. 90 (1900).

Mead, Elwood. Irrigation Investigations in Humid Sections of the United States in 1903. United States Department of Agriculture, Office of Experiment Stations, Bulletin No. 148 (1904).

Phelps, C. S., and Voorhees, Edward B. Notes on Irrigation in Connecticut and New Jersey. United States Department of Agriculture, Office of Experiment Stations, Bulletin No. 36 (1897).

Voorhees, Edward B. Irrigation in New Jersey. United States Department of Agriculture, Office of Experiment Stations, Bulletin No. 87 (1900).

Williams, Milo B. Possibilities and Needs of Supplemental Irrigation in the Humid Regions. United States Department of Agriculture, Yearbook for 1911.

Yoder, P. A. Poison in Water from a Gold and Silver Mill. Utah Experiment Station, Bulletin No. 81 (1903). 


\section{CHAPTER XX}

\section{IRRIGATION TOOLS AND DEVICES}

FARMING under irrigation may and does use practically every approved farm tool found desirable under humid conditions. Every refinement known to agriculture may be practised with profit by the farmer under the ditch. Plowing at the correct time, to the best depth and by the accepted methods, lies at the foundation of successful irrigation-farming and humid-farming. To plant correctly; to supply the plants with sufficient food; to remove weeds, and to harvest wisely - are all practices to be observed as carefully by the irrigation-farmer as by the rainfallfarmer.

The special tools and devices for irrigation farming are those only that are used directly for the distribution upon the land of water from the canal and the conservation of it in the soil.

251. Clearing and breaking the land.-The pioneer irrigationist will usually find his new farm unbroken. It is either covered by sage-brush or similar plants or in the firm sod of the plains. Sod land may be easily broken by a breaking plow, many forms of which are found on the market.

Sage-brush land is, however, much more difficult to clear. One of the most effective methods is to drag over the land two parallel railroad irons which pull up most of the sage-brush. The remaining clumps must be grubbed out by hand. Sometimes the railroad irons are joined in a 
$\mathrm{V}$-shape, and shod on the outside with iron cutting-edges. Such an iron "snow-plow" is also very effective in clearing sage-brush from the land. The most effective method, when it can be used, is to burn off the brush. In the intermountain country with dry summers, the brush often becomes very dry in late summer, and on a day when a light wind is blowing it may be possible to remove the brush from a large area. The obvious dangers that accompany fire must always be considered. Many machines are on the market for removing sage-brush;
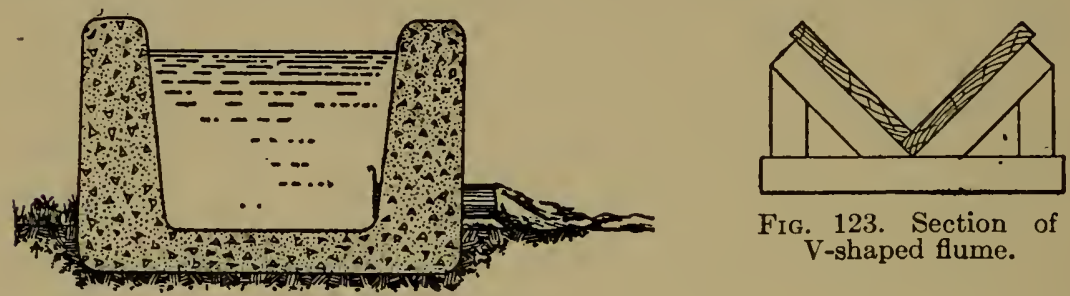

FIG. 123 . Section of

Fig. 122. Section of cement flume.

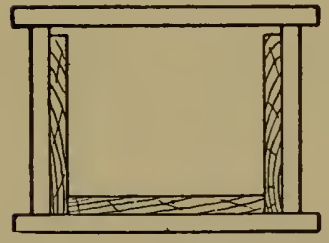

FIG. 124. Wooden flume.

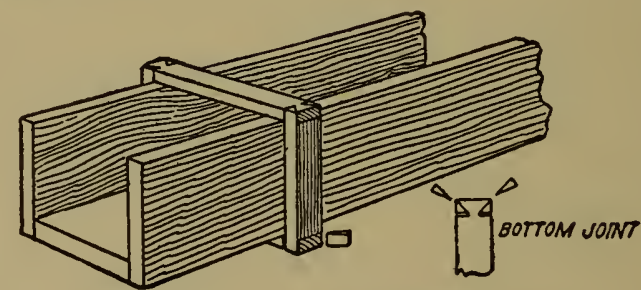

FIG. 125. Section of rectangular flume.

none are wholly satisfactory, and as the country is taken up, there will be no further need for them.

252. Laying out the farm.--Once the land has been cleared, the farm should be laid out with reference to the crops to be grown, rotations to be followed, and the most effective methods of applying water. The characteristic feature of farming under irrigation makes it of first importance that the lay-out be made with direct reference to the location of the irrigation ditches that must cover 
the farm. This should be done with extreme care, for any mistakes made in the placing of irrigation ditches will mean loss in time and money when a new system is built.

In general, water should be delivered from the supply lateral at the highest point of the farm. This makes it possible to distribute water over the whole farm. In earlier days, all the farm ditches were carried along ridges or high lines of the farm. This method

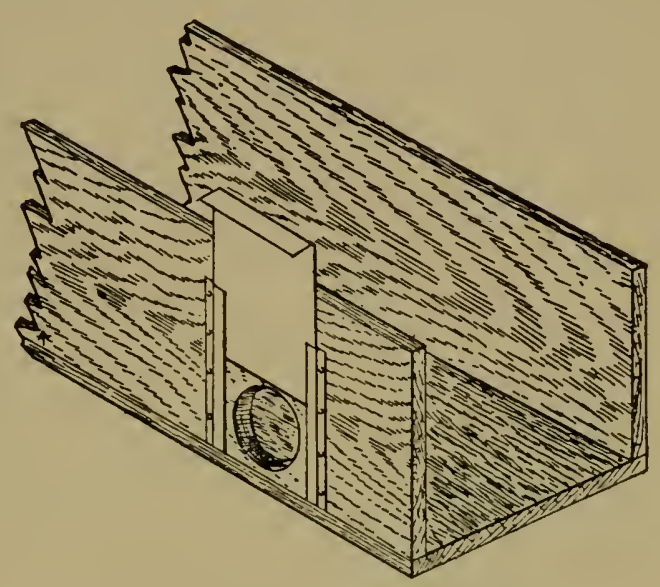

FIg. 126. Flume with lateral gate. led to the formation of irregular and somewhat unsightly fields, awkward to fit into a system of rotation. While it is indispensable that the farm ditches follow, in a general way, the contour lines of the farm, yet an irrigated farm may be laid off into regular, rectangular fields by the use of special devices to carry the water across depressions of the land.

The most common method of securing straight ditches on the farm is the use of earthen levees, to carry the

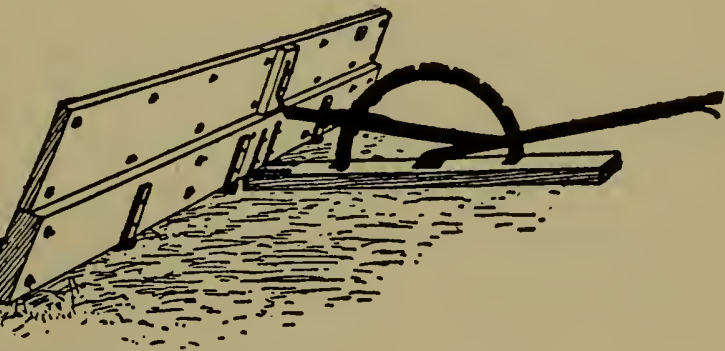

Fig. 127. Buck scraper. 


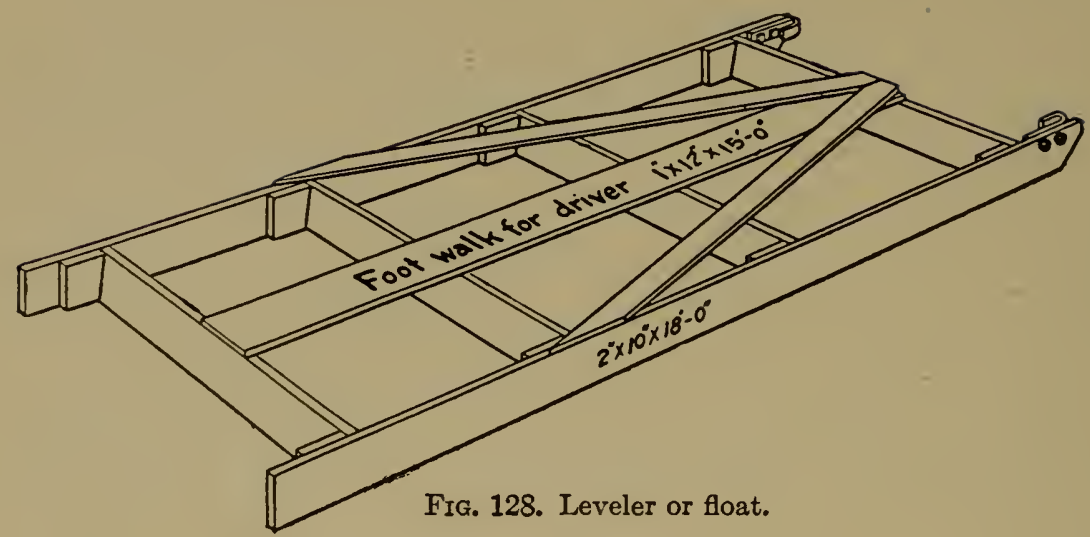

water across the low places. Earthen levees cost little and may be made by the farmer, and, although subject to frequent washouts during the first two or three years, give no further trouble after they are once established. A more desirable method, when it can be afforded, is the flume or the pipe to carry water across low places. Triangular and rectangular flumes are used. Wooden flumes

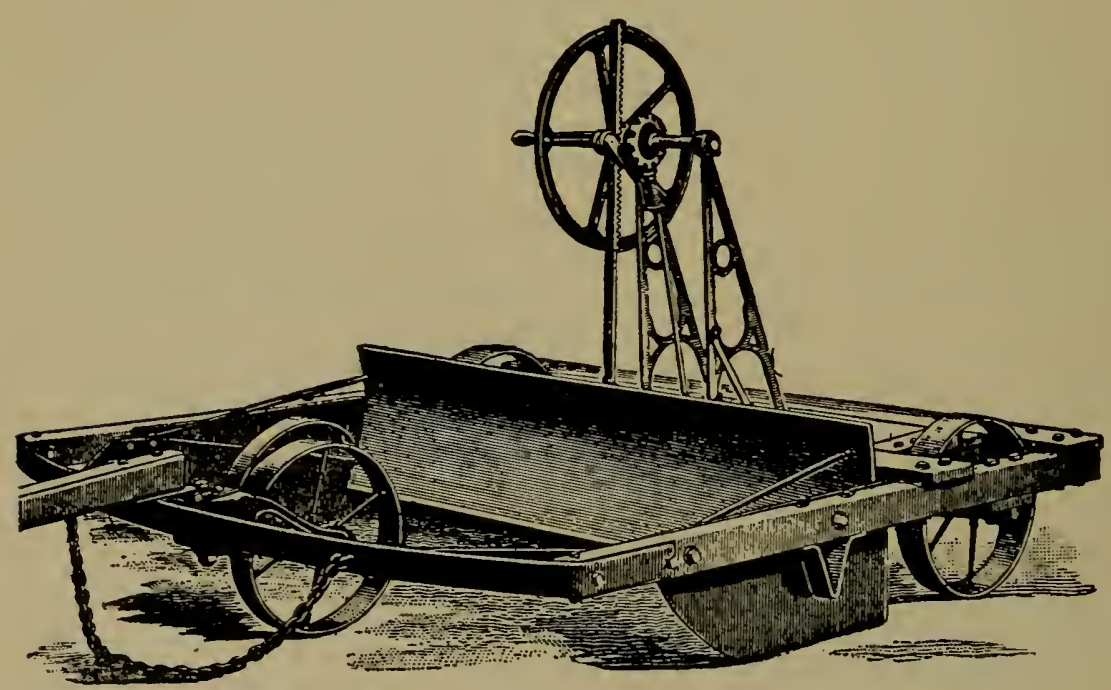

FIG. 129. Shuart grader. 
give very good satisfaction while they last, but are not so permanent as the concrete flumes which are now being constructed extensively. Recently, also, galvanized iron pipes or concrete pipes are used with success for carrying water over the farm.

The second guiding principle in laying out the ditches on the farm should be that they be as inconspicuous as possible and out of the way of the regular operations on the farm. For that reason the ditches are often made to follow the fences separating the farm fields, and are even buried underground as pipes, with openings at proper places to supply the smaller laterals. (Figs. 122-125.)

253. Leveling the land.-Natural land is seldom of even or regular sur-

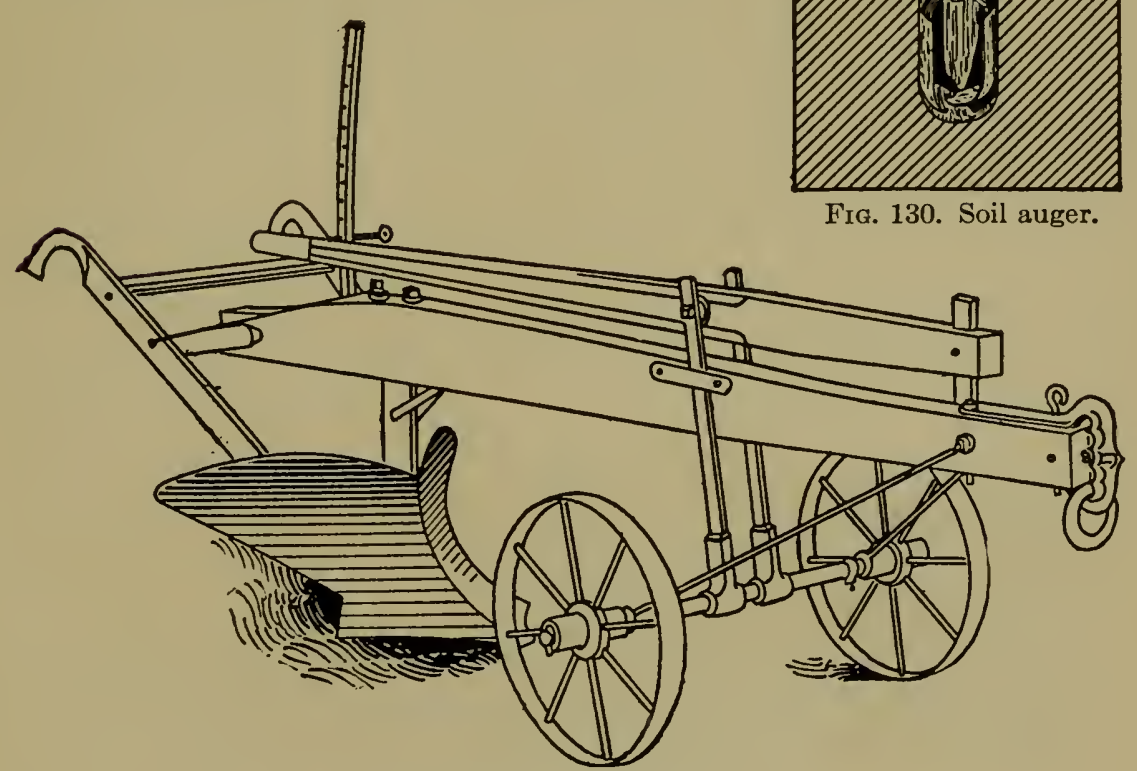

Fig. 131. Lateral plow. 


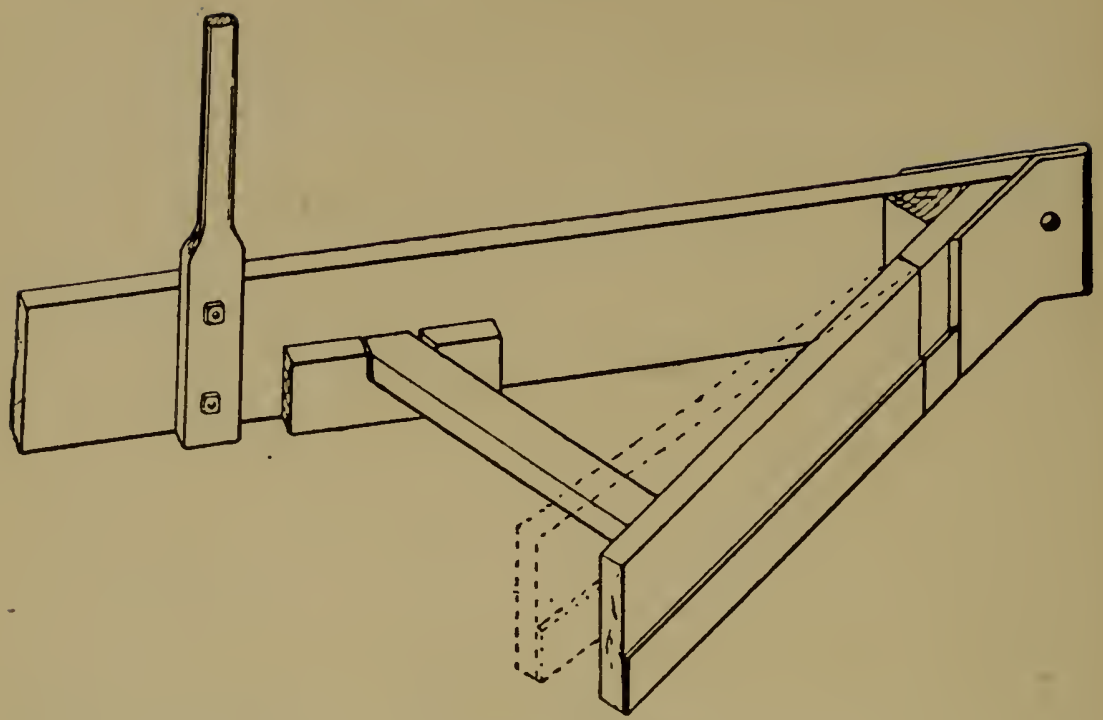

Fig. 132. V-crowder.

face. Slight elevations and depressions cover it. The more even the land is, however, the more easily and uniformly may irrigation water be applied. Water applied to uneven land accumulates in the lower places and over-irrigates the plants there growing, while the plants on the higher places receive little or no water. Consequently, the yieid of the crop is reduced. Moreover, such irrigation re-

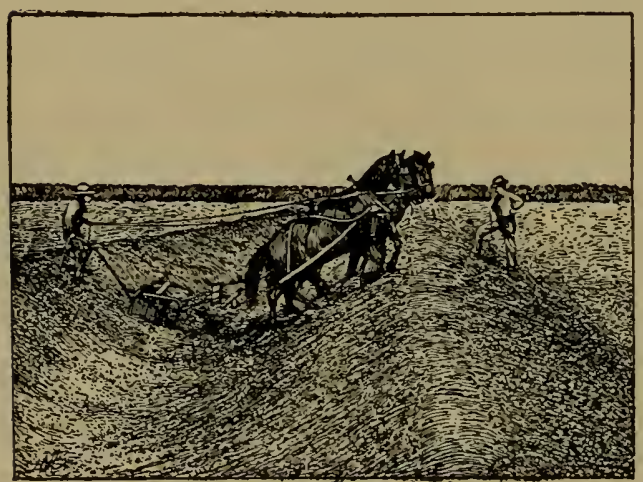

FIG. 133, Building a ditch. quires much labor, and is unsightly. As soon as the layout of the farm has been decided upon, steps should be taken to grade or level the land. The work once done properly need not be done again, 


\section{TYPICAL FORMS of FARM DITCHES}

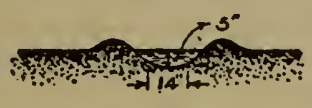

No.l.

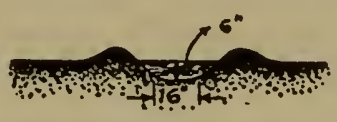

No.2.

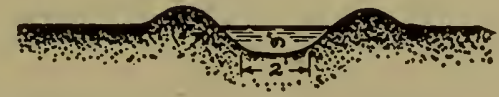

No.3.

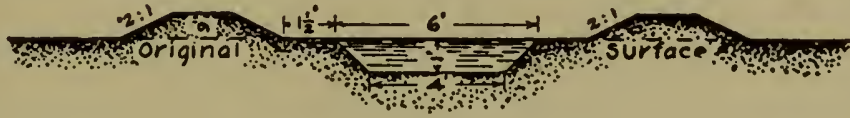

No.4.

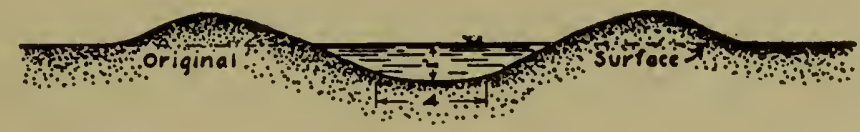

Ariother form. of No. 4 .

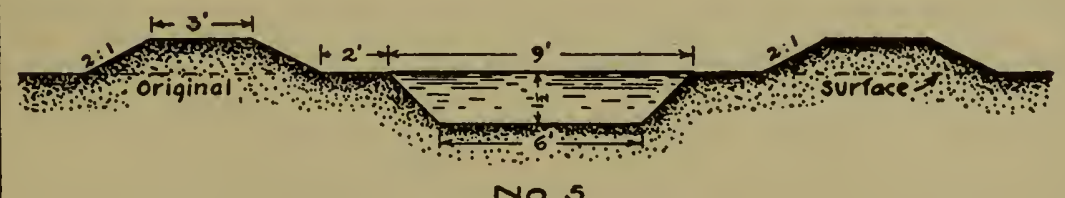

No.s.

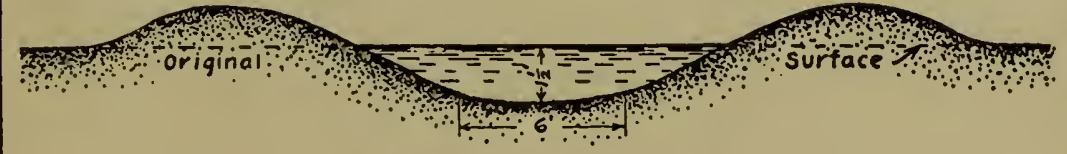

Another form of No.s.

FIG. 134. Typical forms of farm ditches. 
and from the first irrigation may be done in the best manner.

Land may be leveled by any of the many machines on the market. The regular scrapers or graders may be used

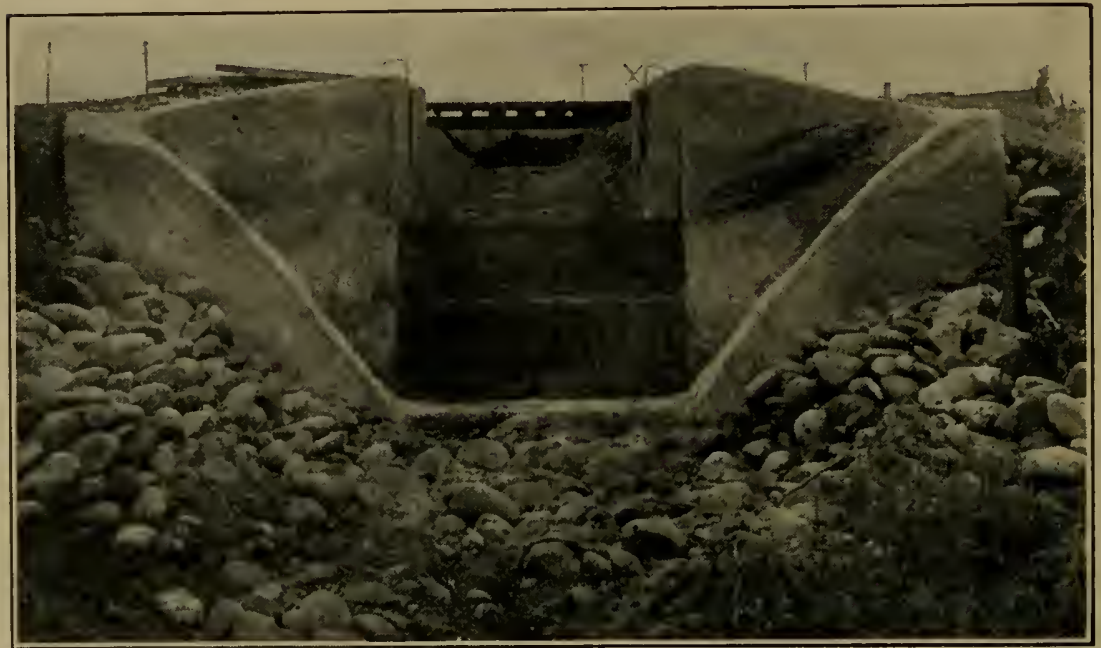

FIG. 135. Concrete drop in ditch.

for reducing the high points, and plank-levelers or floats may be used for the final grading. (Figs. 127-129.) In cutting down the high places, it is well to know something of the subsoil. If the top soil is underlaid near the surface with a lifeless clay it may not be wise to carry the grading too low, or especially, to scatter the clay on the lowerlying land. In such cases, slight grading through successive years may be more satisfactory. For studying the subsoil, a soil auger is very useful. (Fig. 130.)

254. Making farm ditches.-After the layout of the farm has been decided upon, the main supply ditches placed, and the land leveled, the farmer may construct the necessary laterals or farm ditches, fed by the larger supply ditches. The location of the farm ditches must be 
determined by the layout and contour of the farm. All ditches, whether large or small, must follow, in general, the ridges of the land.

Farm ditches may be made by any machine that will make a furrow in the ground. The first modern irrigation ditch in America was made by an ordinary moldboard plow, the furrow from which was cleaned out with shovels. Thousands of small farm ditches have been made in that way since that first day of irrigation. The lateral plow or winged shovel plow is now more frequently used in ditch-

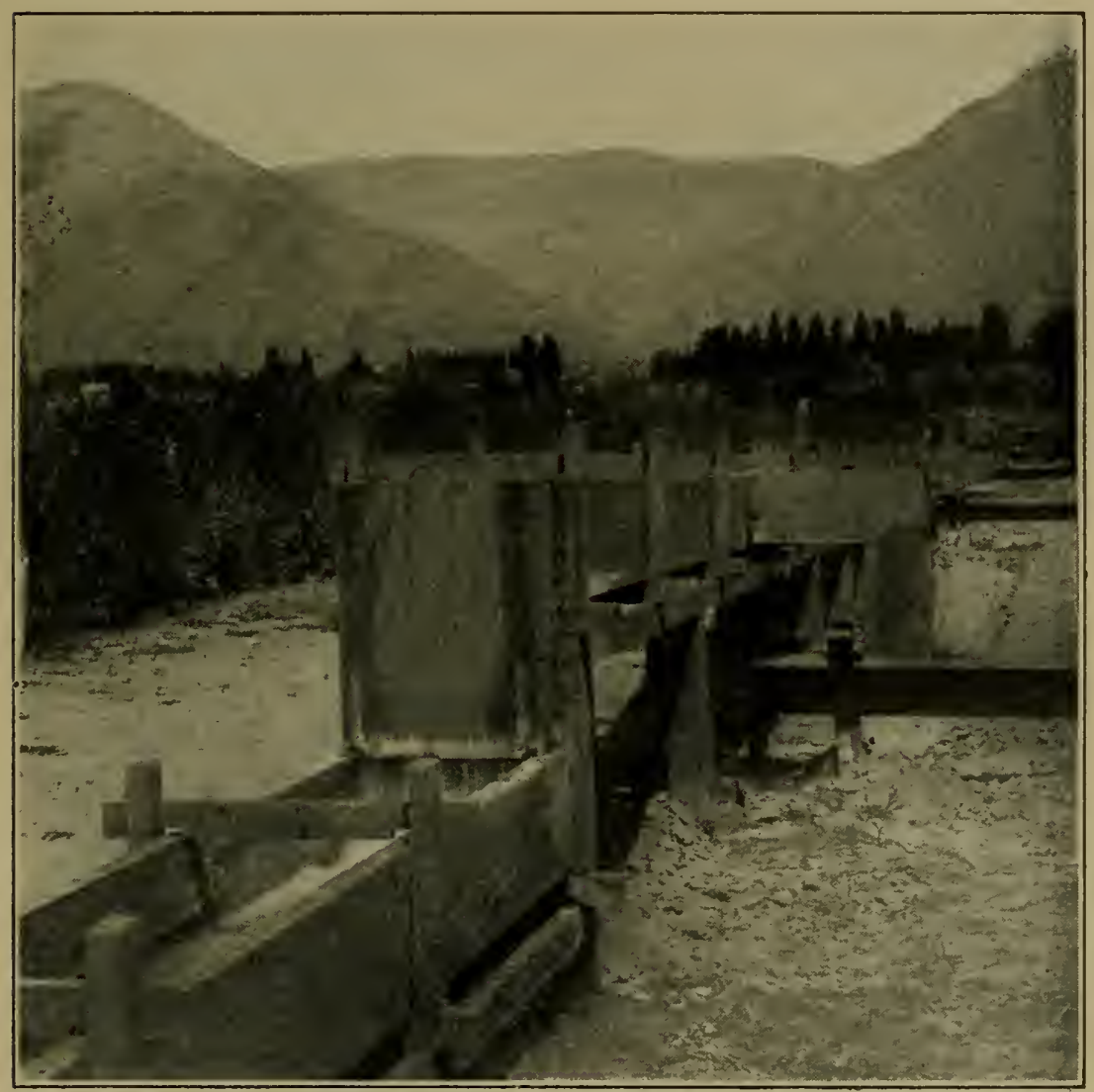

FIG, 136. Drop in flume. 
making. (Fig. 131.) The adjustable crowder, as shown in Fig. 132, is extensively used in removing the loose dirt

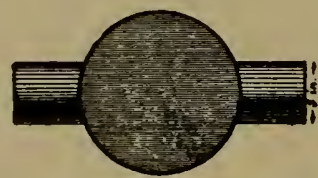

FIG. 137. Distributor for hose.

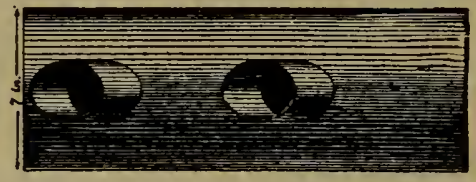

from the plow furrow. If the ditch is large, the scraper is used for that purpose.

Farm ditches must be constructed with reference to the quantity of water required by the land that they are to serve. The quantity of water that may be carried by a ditch depends fully as much upon its fall or grade as

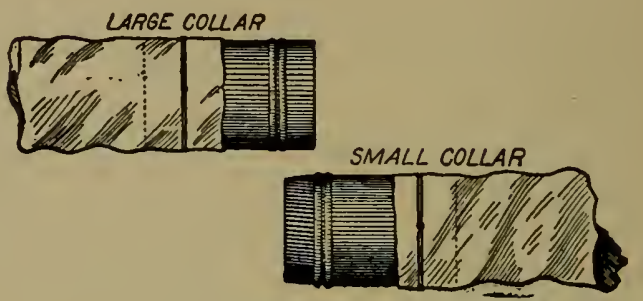

FIG. 138. Attaching hose to distributor. upon its width and depth. The smaller the volume carried by a ditch, the greater the grade
of flow. In a small ditch capable
of carrying about $1 \frac{1}{3}$ second-
feet of water, a fall of 2
inches to the rod 


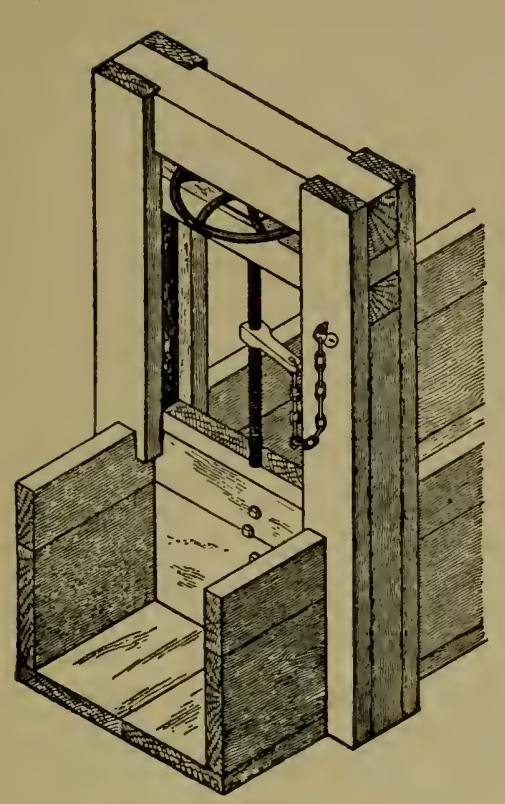

would produce a velocity of 2 feet a second, while in a ditch capable of carrying about 24 second-feet, the fall required to give the same velocity would be only $1 / 4$ inch to the rod. The nature of the soil determines chiefly the grade that may be adopted for farm ditches. In fine sand or silt a mean velocity of 1

FIG. 140. Lateral headgate.

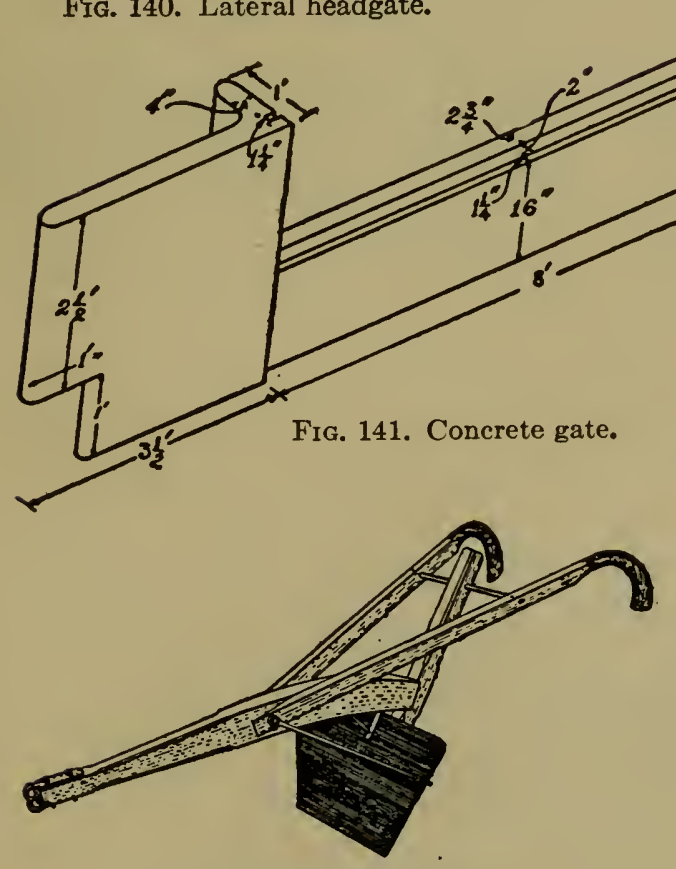

Fig. 142. Dammer.

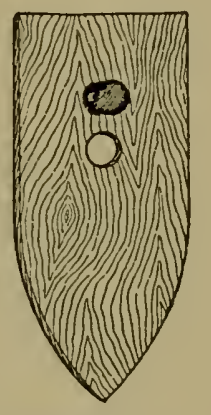

Frg. 143. Board dam. 


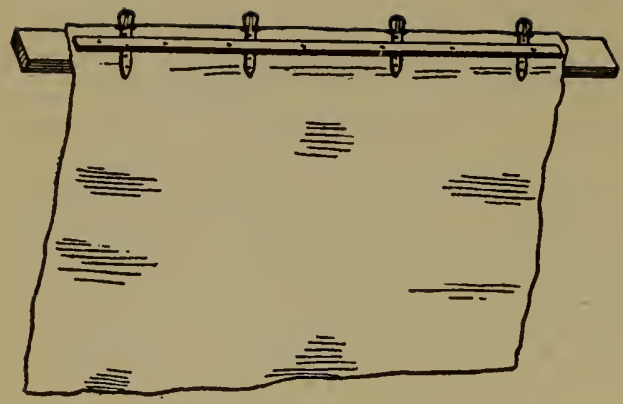

FIG. 144. Canvas dam.
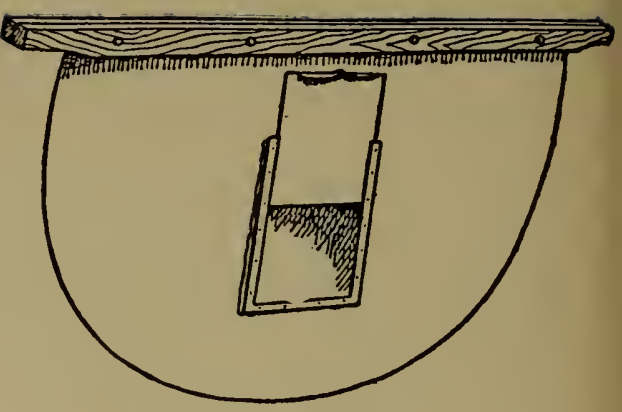

Fig. 146. Metal dam.

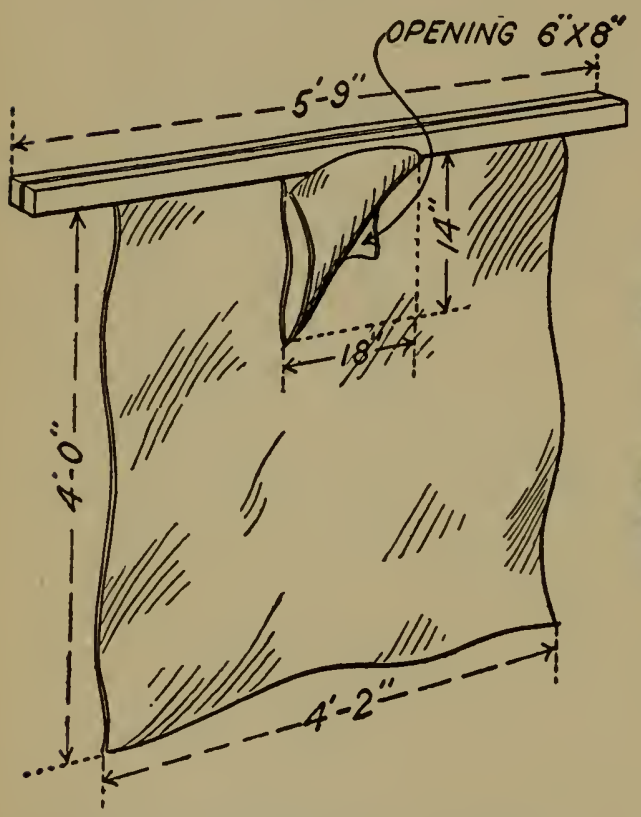

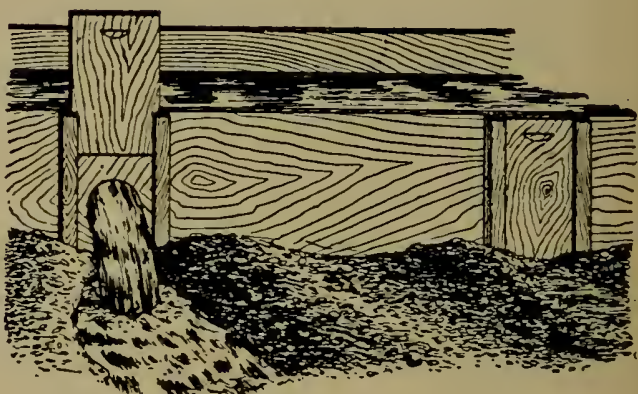

Fig. 147. Distribution of water from flume to furrows.

FIG. 145. Canvas dam with opening.

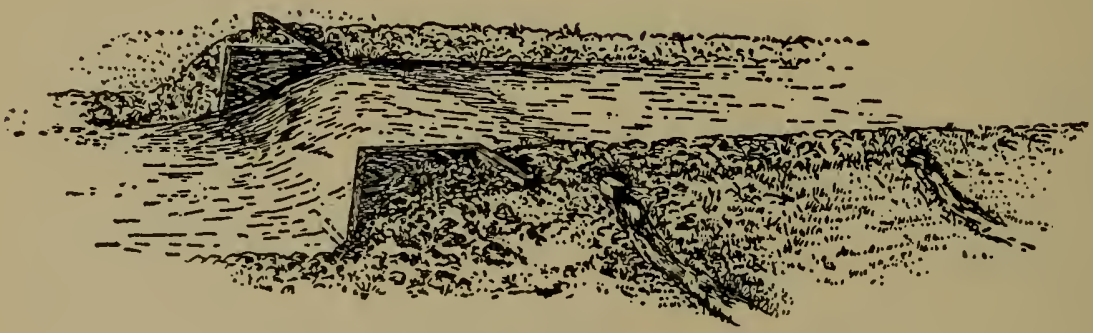

FIG. 148. Distribution through wooden tubes. 
foot per second is often the maximum, while in clay, a velocity of 3 feet per second may be adopted. Some soils "wash" so easily that a very small velocity only may be used. The farmer must learn for himself the nature of his soil and the ditch grades that may be safely adopted. In ordinary materials a velocity of 2 to $2 \frac{1}{2}$ feet a second are considered safe. Naturally the

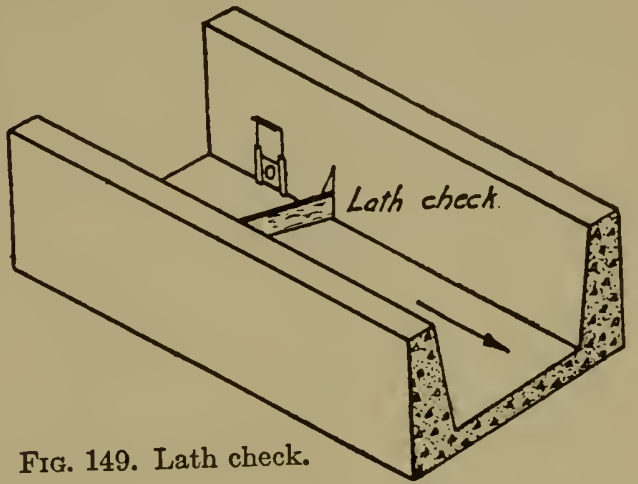
grade of the ditch can not exceed that of the land.

Fortier has figured the flow of water in each of five types of farm ditches (Fig. 134) which cover ordinary farm conditions. His results follow.
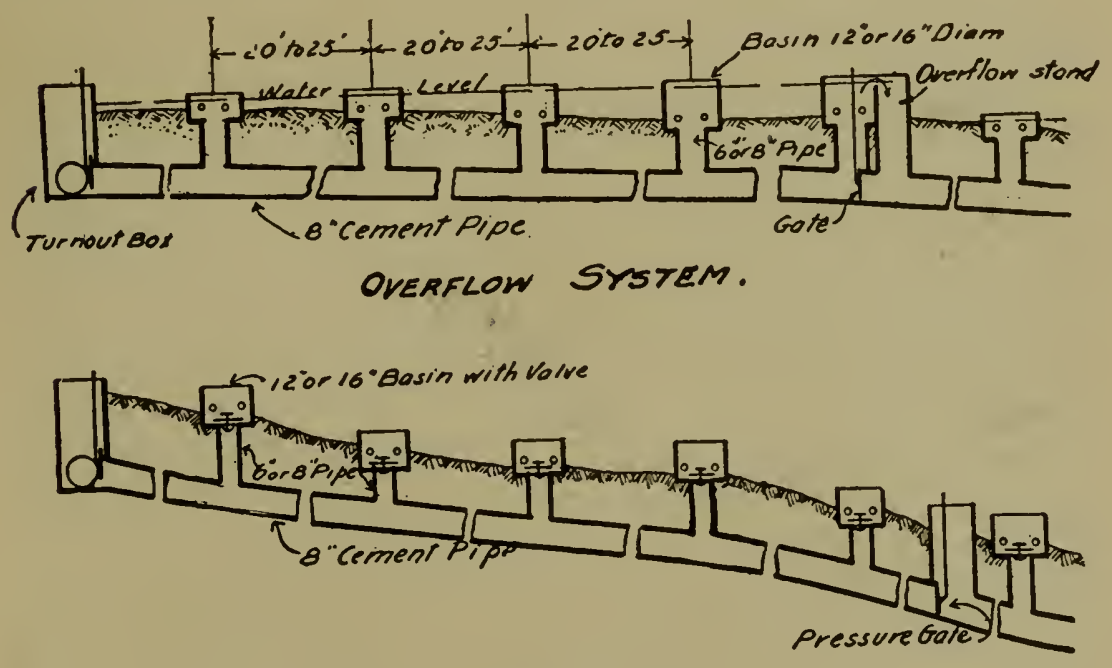

PREssure STSTEM.

FIG. 150. Conducting water down inclines in concrete pipes. 
Mean Velocity and Discharge of Ditches with Different Grades

Farm Ditch No. 1

\begin{tabular}{|c|c|c|c|c|}
\hline \multicolumn{3}{|c|}{ Grade } & \multirow{2}{*}{$\begin{array}{l}\text { Mean velocity } \\
\text { in feet per } \\
\text { second }\end{array}$} & \multirow{2}{*}{$\begin{array}{l}\text { Discharge in } \\
\text { cubic feet } \\
\text { per second }\end{array}$} \\
\hline $\begin{array}{l}\text { Inches } \\
\text { per rod }\end{array}$ & $\begin{array}{l}\text { Feet per } \\
100 \text { feet }\end{array}$ & $\begin{array}{l}\text { Feet per } \\
\text { mile }\end{array}$ & & \\
\hline $1 / 2$ & .25 & 13.33 & 1.01 & .67 \\
\hline $3 / 4$ & .38 & 20.00 & 1.23 & .81 \\
\hline 1 & .51 & 26.67 & 1.42 & .93 \\
\hline $11 / 4$ & .63 & 33.33 & 1.59 & 1.05 \\
\hline $11 / 2$ & .76 & 40.00 & 1.75 & 1.16 \\
\hline 2 & 1.01 & 53.33 & 2.04 & 1.35 \\
\hline $21 / 2$ & 1.26 & 66.67 & 2.28 & 1.50 \\
\hline 3 & 1.51 & 80.00 & 2.50 & 1.64 \\
\hline $31 / 2$ & 1.77 & 93.33 & 2.70 & 1.78 \\
\hline
\end{tabular}

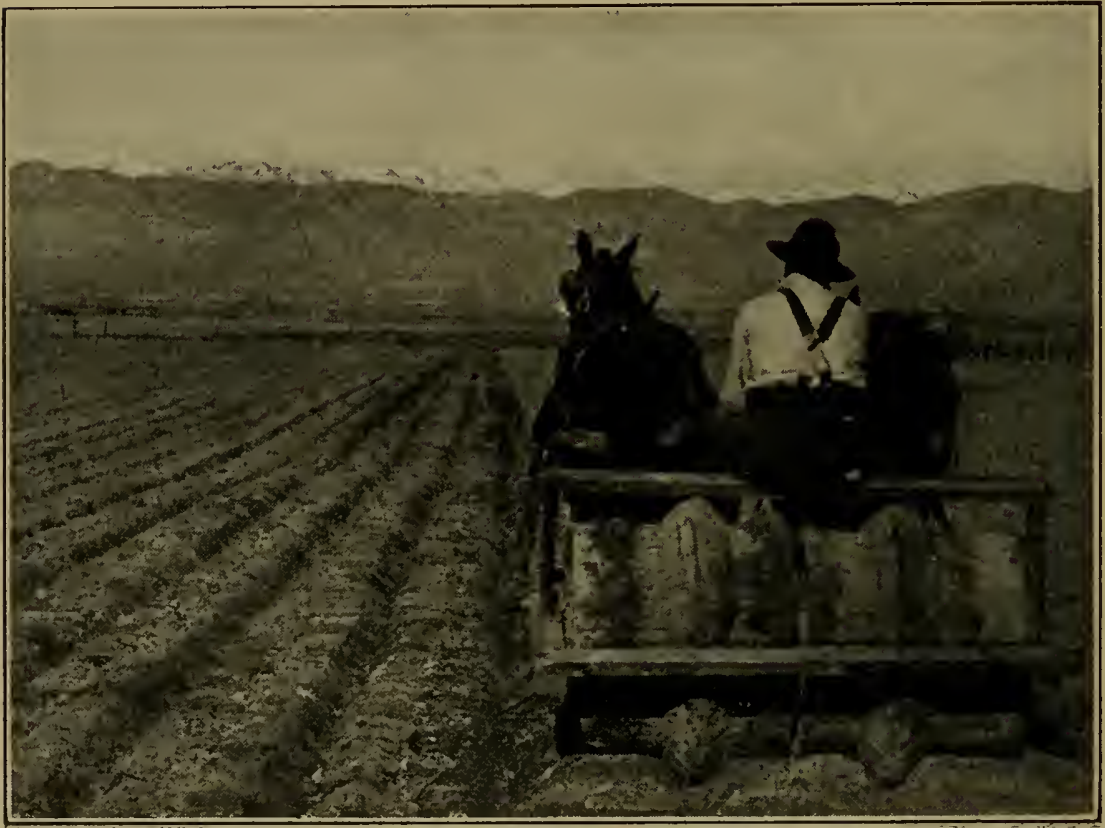

Fig. 151. Roller furrower. 
Mean Velocity and Discharge of Ditches with Different Grades, Continued

Farm Ditch No. 2

\begin{tabular}{|c|c|c|c|c|}
\hline \multicolumn{3}{|c|}{ Grade } & \multirow{2}{*}{$\begin{array}{l}\text { Mean velocity } \\
\text { in feet per } \\
\text { second }\end{array}$} & \multirow{2}{*}{$\begin{array}{l}\text { Discharge in } \\
\text { cubic feet } \\
\text { per second }\end{array}$} \\
\hline $\begin{array}{l}\text { Inches } \\
\text { per rod }\end{array}$ & $\begin{array}{l}\text { Foot per } \\
100 \text { feet }\end{array}$ & $\begin{array}{l}\text { Feet per } \\
\text { mile }\end{array}$ & & \\
\hline $1 / 4$ & .13 & 6.67 & .82 & 80 \\
\hline $1 / 2$ & .25 & 13.33 & 1.16 & 1.00 \\
\hline $3 / 4$ & .38 & 20.00 & 1.42 & 1.30 \\
\hline 1 & .51 & 26.67 & 1.64 & 1.50 \\
\hline $11 / 4$ & .63 & 33.33 & 1.84 & 1.70 \\
\hline $11 / 2$ & .76 & 40.00 & 2.02 & 1.80 \\
\hline $13 / 4$ & .88 & 46.67 & 2.18 & 2.00 \\
\hline 2 & 1.01 & 53.33 & 2.34 & 2.10 \\
\hline $21 / 2$ & 1.26 & 66.67 & 2.61 & 2.40 \\
\hline
\end{tabular}

Farm Ditch No. 3

\begin{tabular}{l|r|r|r|r}
\hline \hline $1 / 8$ & .06 & 3.33 & .79 & 2.08 \\
$1 / 4$ & .13 & 6.67 & 1.13 & 3.00 \\
$1 / 2$ & .25 & 13.33 & 1.60 & 4.20 \\
$3 / 4$ & .38 & 20.00 & 1.97 & 5.20 \\
1 & .51 & 26.67 & 2.28 & 6.00 \\
$11 / 4$ & .63 & 33.33 & 2.57 & 6.80 \\
\hline
\end{tabular}

Farm Ditch No 4

\begin{tabular}{l|r|r|r|r}
\hline \hline$\frac{1}{16}$ & .03 & 1.58 & .84 & 4.20 \\
$1 / 8$ & .06 & 3.33 & 1.08 & 5.40 \\
$1 / 4$ & .13 & 6.67 & 1.54 & 7.70 \\
$3 / 8$ & .19 & 10.00 & 1.89 & 9.50 \\
$1 / 2$ & .25 & 13.33 & 2.20 & 11.00 \\
$5 / 8$ & .31 & 16.67 & 2.45 & 12.20 \\
$3 / 4$ & .38 & 20.00 & 269 & 13.40 \\
\hline
\end{tabular}

When the natural grade of the land is so steep as to make it dangerous to employ ditches of the same grade, suitable drops must be installed at various points. (Figs. 135, 136.) To carry water from the laterals to furrows, in 
434

IRRIGATION PRACTICE

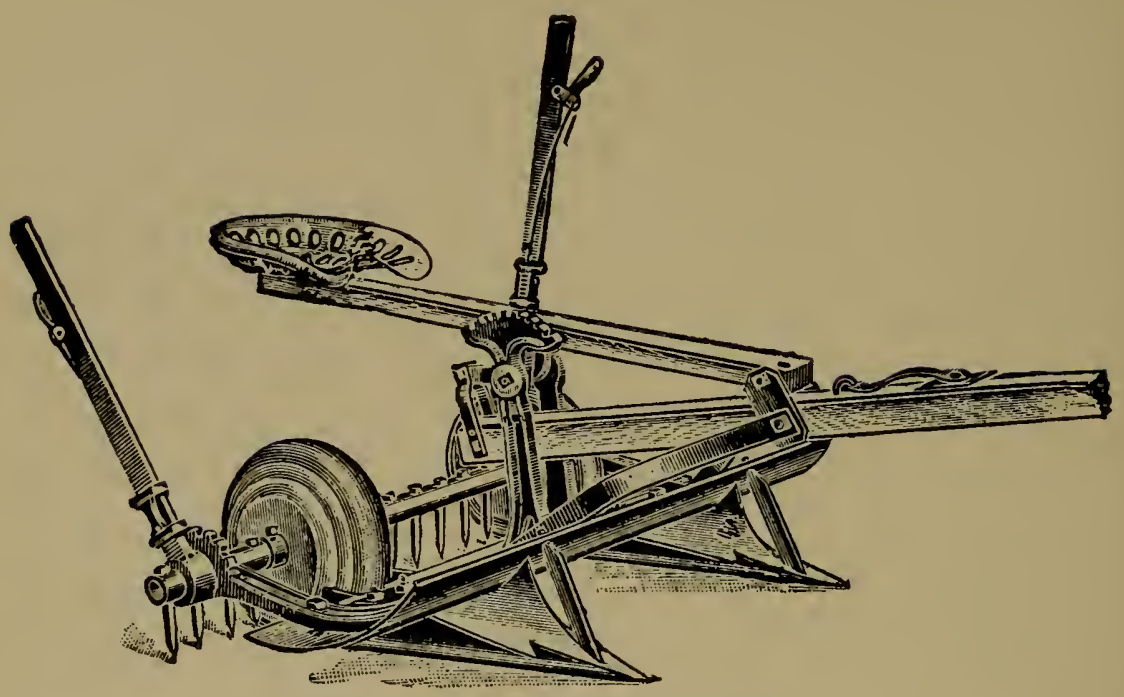

FIG. 152. Utah layoff and pulverizer.

soils that "wash" easily, lath boxes, already mentioned, or pipes are often used. (Fig. 137, 138.)

In constructing ditches it is usually sufficient to step off the distances, and any simple leveling device gives the necessary levels. (Fig. 139.)

255. Gates and checks. -Gates for the admission of water from the supply ditches into the laterals may be

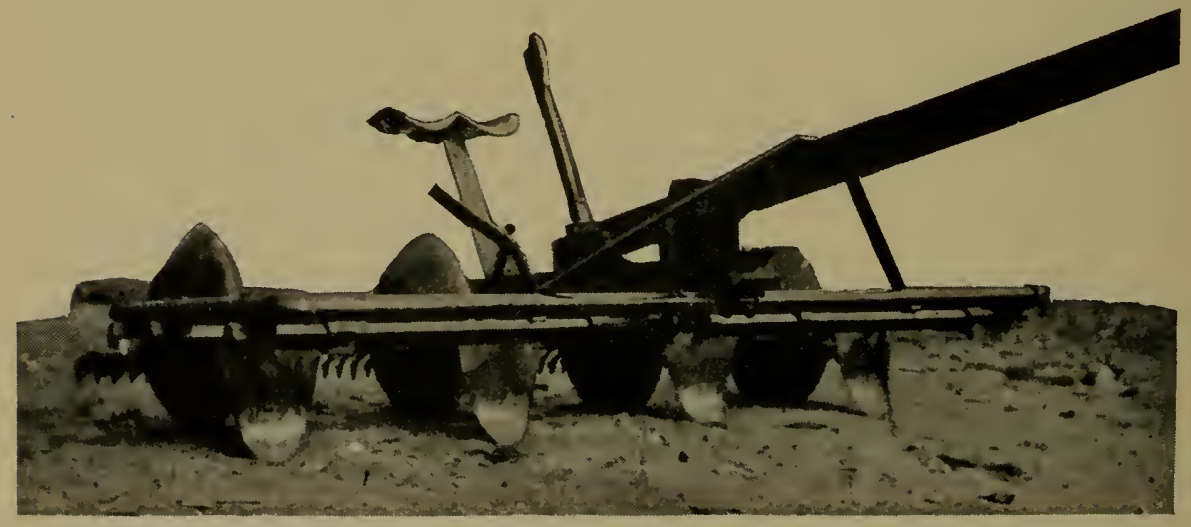

Fra. 153. Robinson's adjustable corrugator and renovator. 
made in almost any way to suit the farmer, from a simple board, removed when the flow is desired, to elaborate doors hoisted by machinery. In ordinary farm practice, permanent plain wooden or concrete frames into which the gate may be dropped constitute the most effective device. (Fig. 140.)

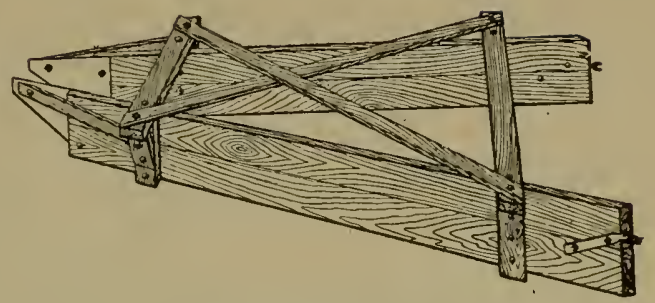

FIG. 154. Ridger in check and basin irriga ion.

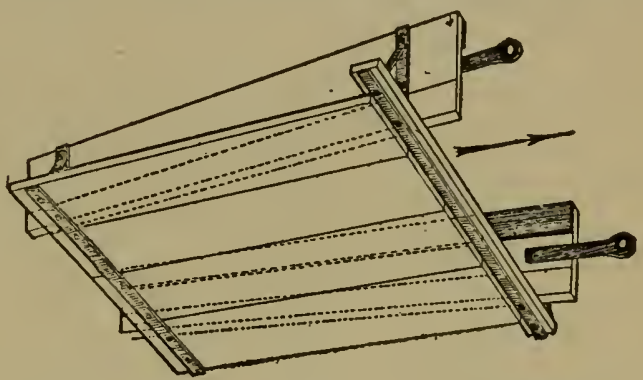

FIG. 155. Ridger in check and basin irrigation.

To guide the water from the lateral ditches on to the land, devices to check or dam the flow are employed. The

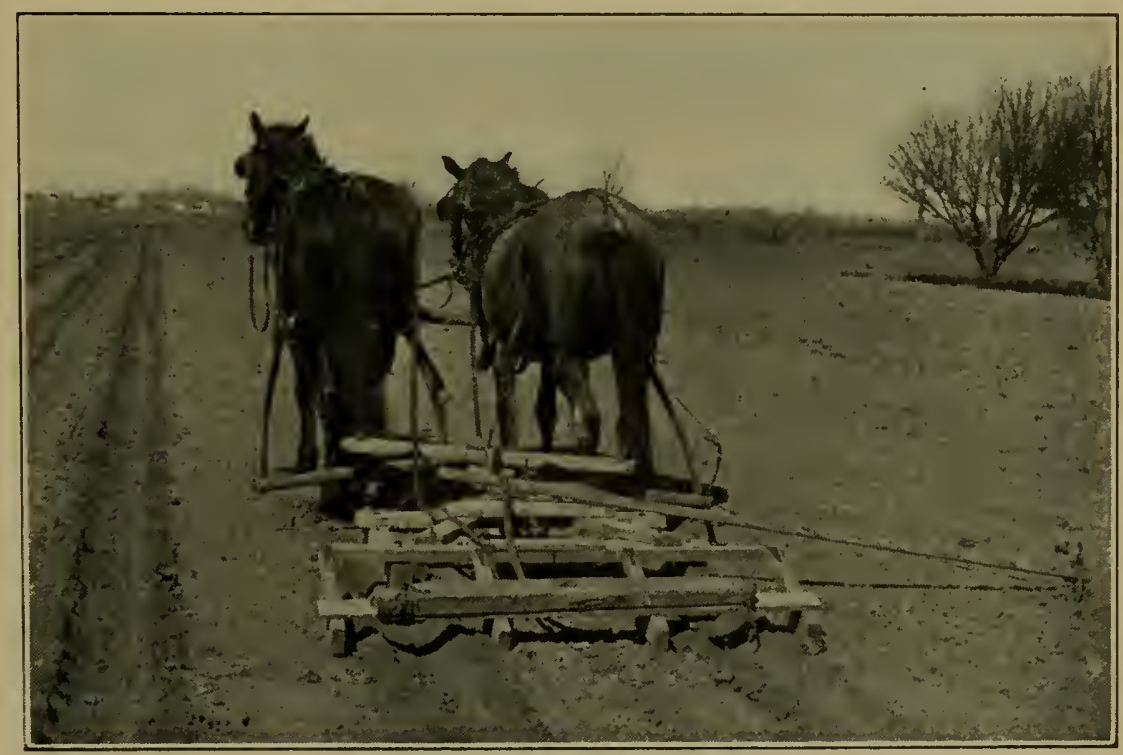

FIG. 156. Furrower in action. 


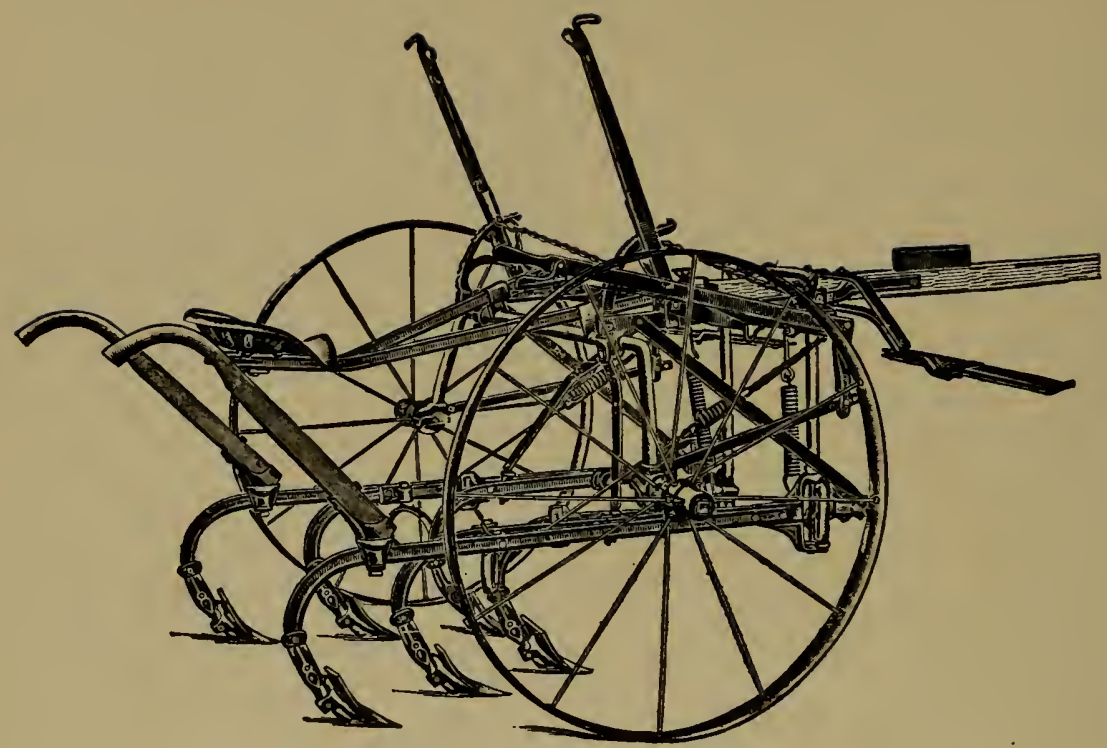

FIg. 157. Cultivator.

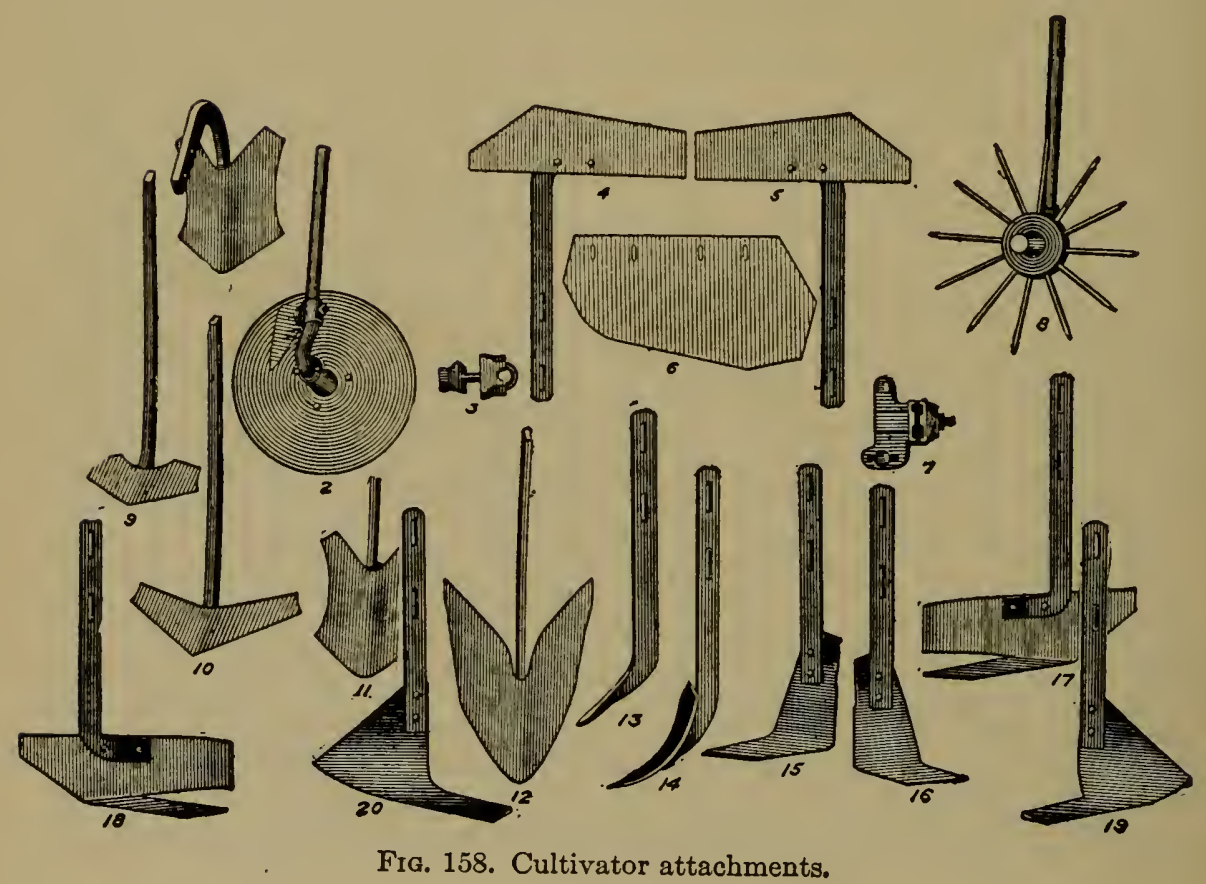

(436) 
most common check is a shovelful of dirt placed in the ditch at the point where the division of water is desired. At times the checks are made by a dammer, while the ditch is dry before the irrigation. The dirt check is only temporary, is often washed away, and involves considerable labor. A portable wooden dam or check, or dam made of a board with one or more holes in it, which can
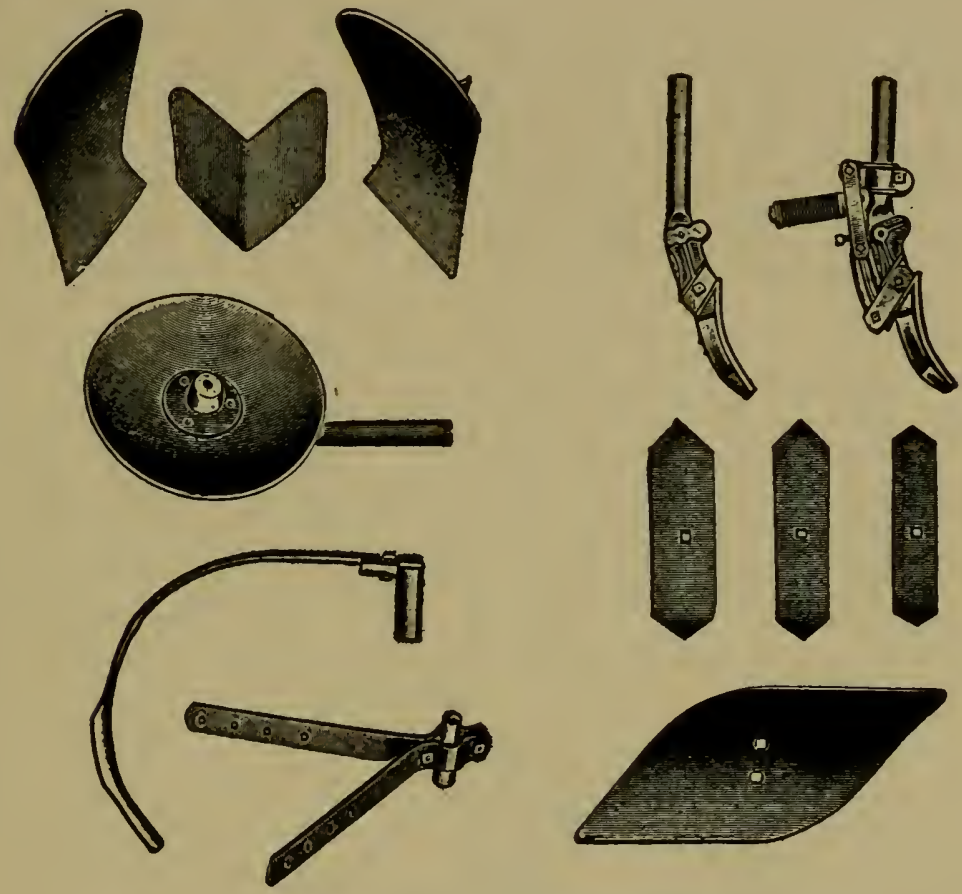

FIG. 159. Beet cultivator attachments.

be inserted wherever needed and removed at will, has been found very satisfactory. The metal dam or tappoon has also given satisfaction. The canvas dam has of recent years been extensively adopted, and is said to be of especial value because it may be made to fit the ditch snugly. It is held down by a shovelful of dirt, so that it is really a modification of the original dirt check. The 


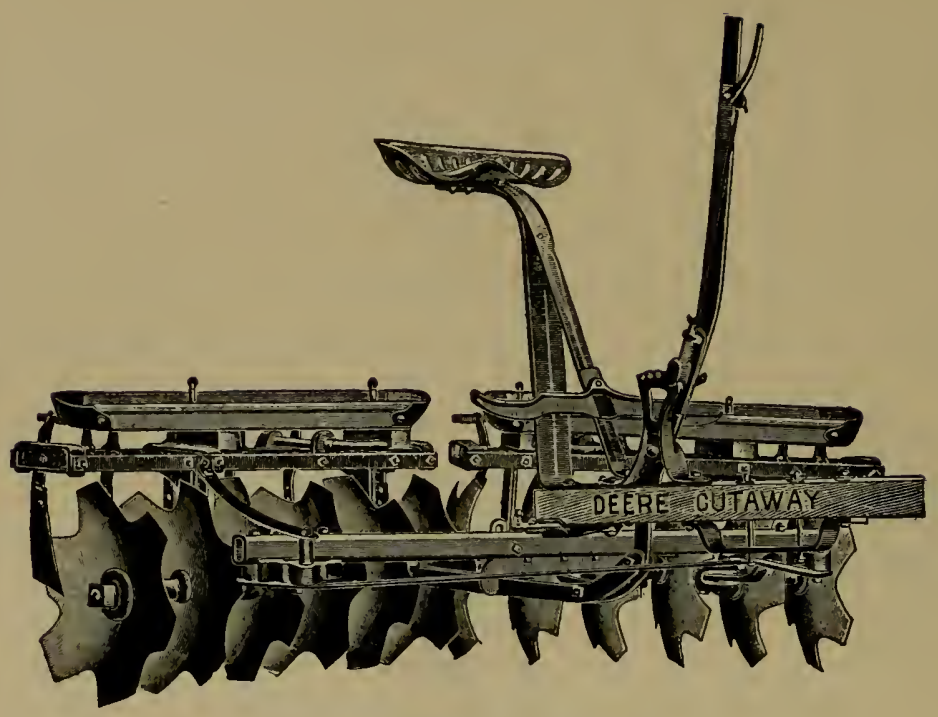

FIG. 160. Cutaway disk harrow.

canvas dam is made of a piece of strong canvas, nailed firmly to a wooden cross piece. At times there is an opening in it to divide the irrigation stream. Sometimes a small obstruction such as a submerged flashboard or a lath dropped across the bottom of the ditch is sufficient to divert the water into the lateral. (Figs. 141-150.)

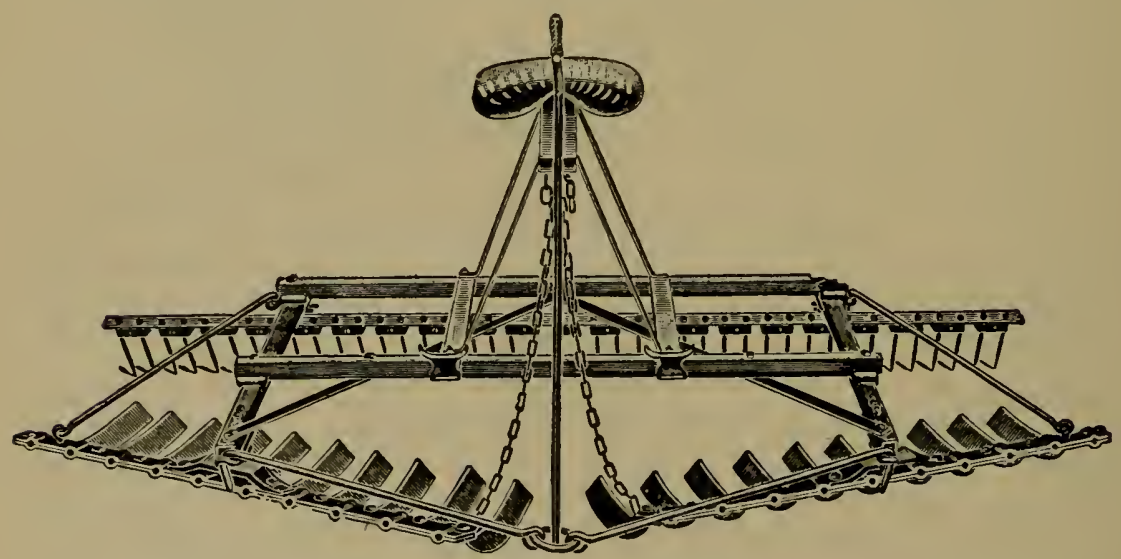

FIG. 161. Clod crusher, pulverizęr, leveler and smoother. 


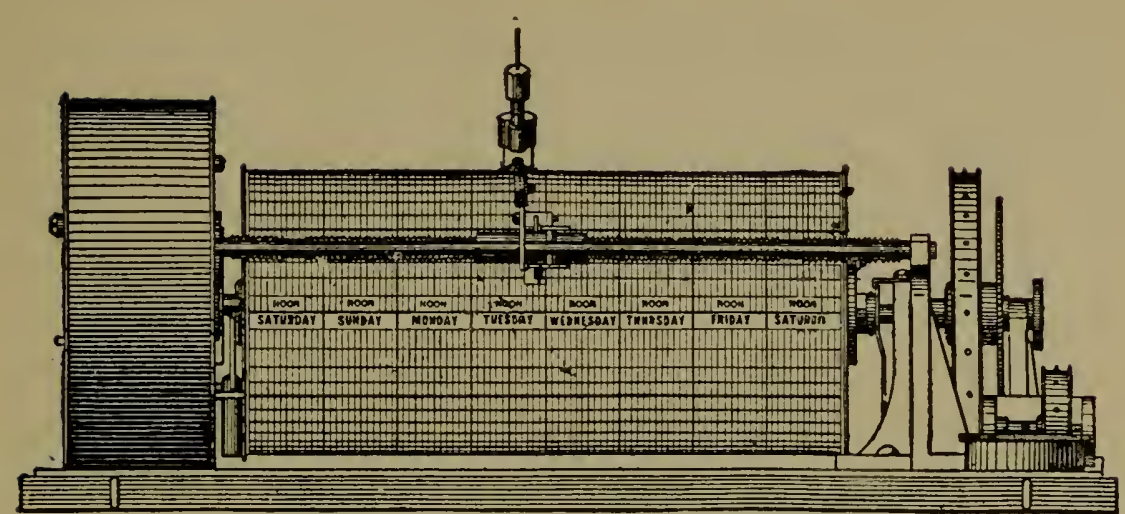

FIG. 162. Frieze water register.

256. Ridging and furrowing.-The field-ditch method of irrigation requires only that a few rather small furrows may be made to assist in guiding the water over the land. These furrows are ordinarily made by the point of the hoe or as a very shallow plow furrow. The check, border and basin methods of irrigation require that ridges or levees be thrown up around the plots. For this purpose any of the ordinary farm implements may be employed, although special "ridgers" and "crowders" are made and used on many farms.

The furrow system of irrigation requires that parallel, uniform furrows be made for guiding the water over the
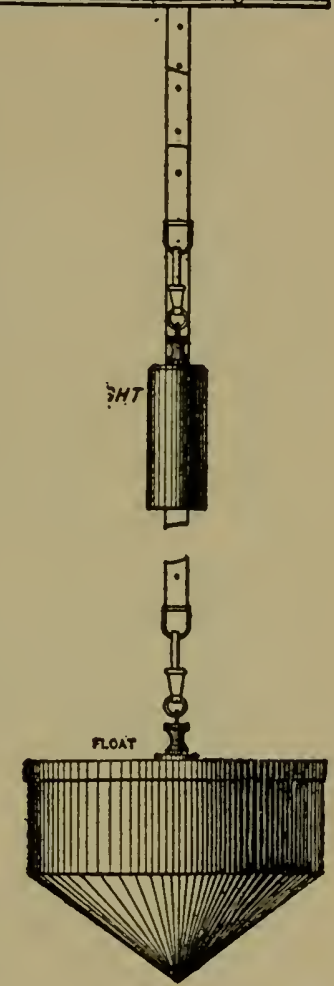
land. These may be made by hand with a hoe, but only with great labor. Numerous devices have been proposed for making uniform furrows with horse labor. The shovel attachment to the cultivator has been used, but with 
indifferent success, because the furrows were not left smouth. One of the first devices of the Utah pioneers was a large roller with several wooden "shoes" each one

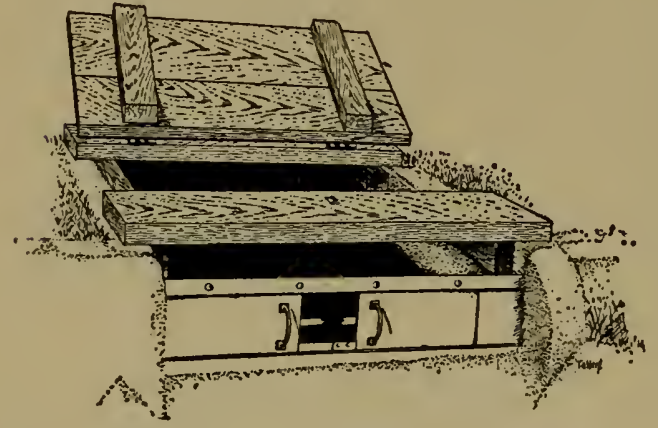

FIG. 163. Device for measuring miner's inches. of which made a furrow. (Fig. 151.) This gave excellent satisfaction except that the rolling of the land made rapid evaporation possible. From this implement has developed the Utah layoff and pulverizer (Fig. 152), especially adapted for alfalfa fields. The furrows are cut, the clods pulverized and the smoothed ground mulched by a rear attachment of spike teeth. Many other devices for furrowing have been made. (Figs. 153-156.)

257. Mulching the soil.-Well-cultivated soils produce crops with the least expenditure of water. Implements for cultivation are therefore of the highest importance to the farmer. Such implements are now on the market in great

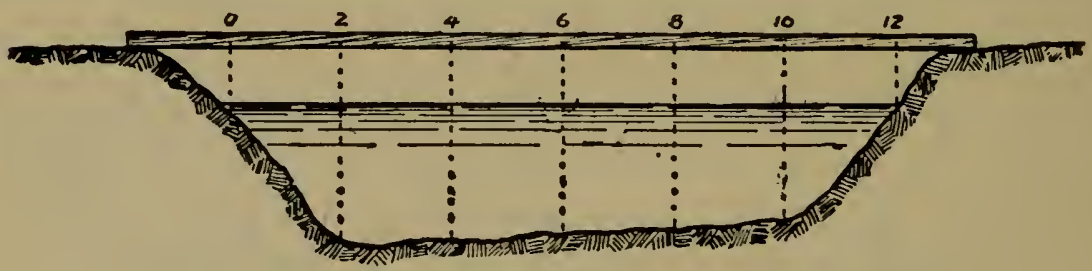

Frg. 164. Cross section of canal for measurement of flow.

numbers. Clods may be broken by the corrugated roller; the alfalfa fields disked by the disk with jagged cutting edges; the mulch may be made by one of the tooth harrows, the disk-harrow or any one of the many available culti- 
vators. The main thing is to fit the tool to the crop and the soil. Particularly important is the soil. Most harrows and cultivators are now so built that different kinds of teeth and shovels may be attached; thereby a much larger field of service is possible. (Figs. 157-161.)

258. Measuring the flow of water.-Brief consideration of this subject has been given in Chapter XVII.

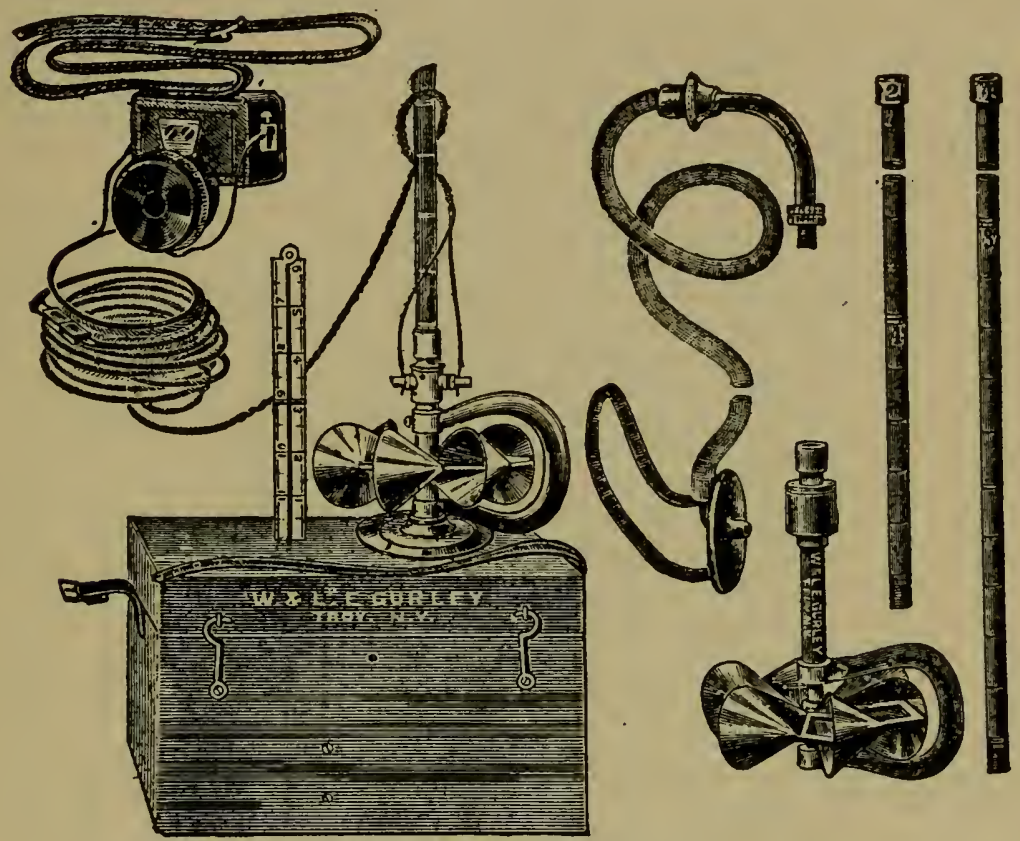

FIG. 165. Current meters.

Special engineering treatises should be consulted for more information. All in all, some form of the weir is the best measuring device on the farm. It often becomes desirable for the farmer to keep a constant record of the water flowing over a weir. To do this, automatic registers connected with floats, and run by clockwork, have been devised. The rising and falling of the float, indicating the 
rise and fall of the water, is registered on a record sheet that may be preserved for future use. (Fig. 162.)

Where miners' inches are units of measurement, devices like that of Fig. 163 are used. The United States Geological Survey makes a cross-section of a canal or river at a given point (Fig. 164) and determines the velocity of the flow there, with current meters. (Fig. 165.) Many

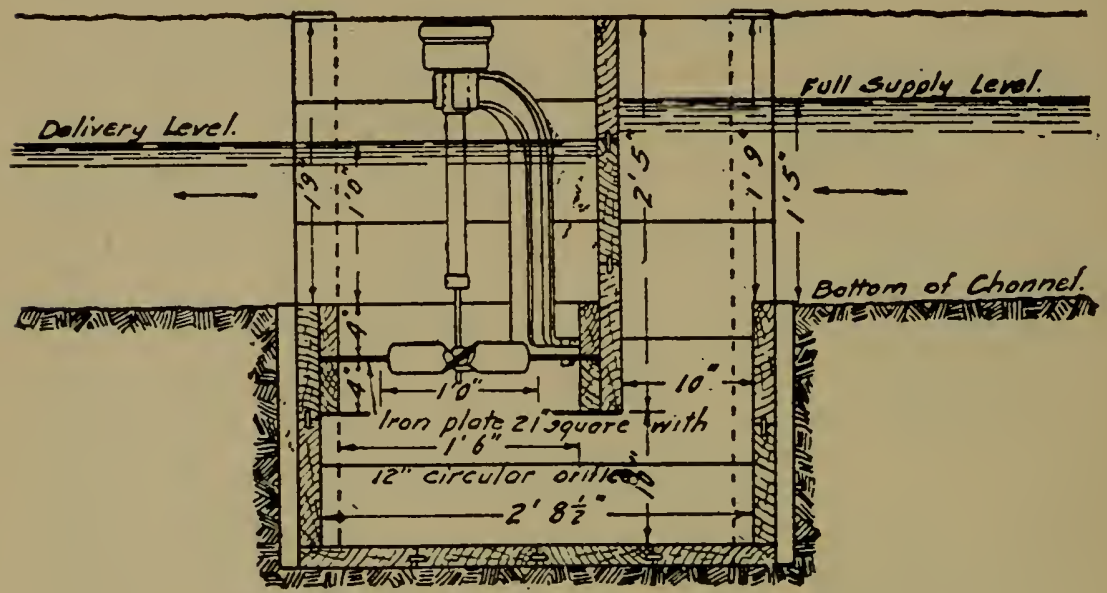

Fig. 16 6. Grant-Mitchell meter.

special measuring devices are also available, as the GrantMitchell meter. (Fig. 166.)

Similarly, a great number of water divisors, in addition to those mentioned in Chapter XVII, have been tried out with varying success.

A very great amount of work has been done by engineers on the measurement of flowing water. The results obtained are of high practical value. It must be said, however, that the engineers, themselves, have not as yet agreed upon the measuring device best suited to the use of the farmer. Engineering books should be consulted for further information on this subject. 


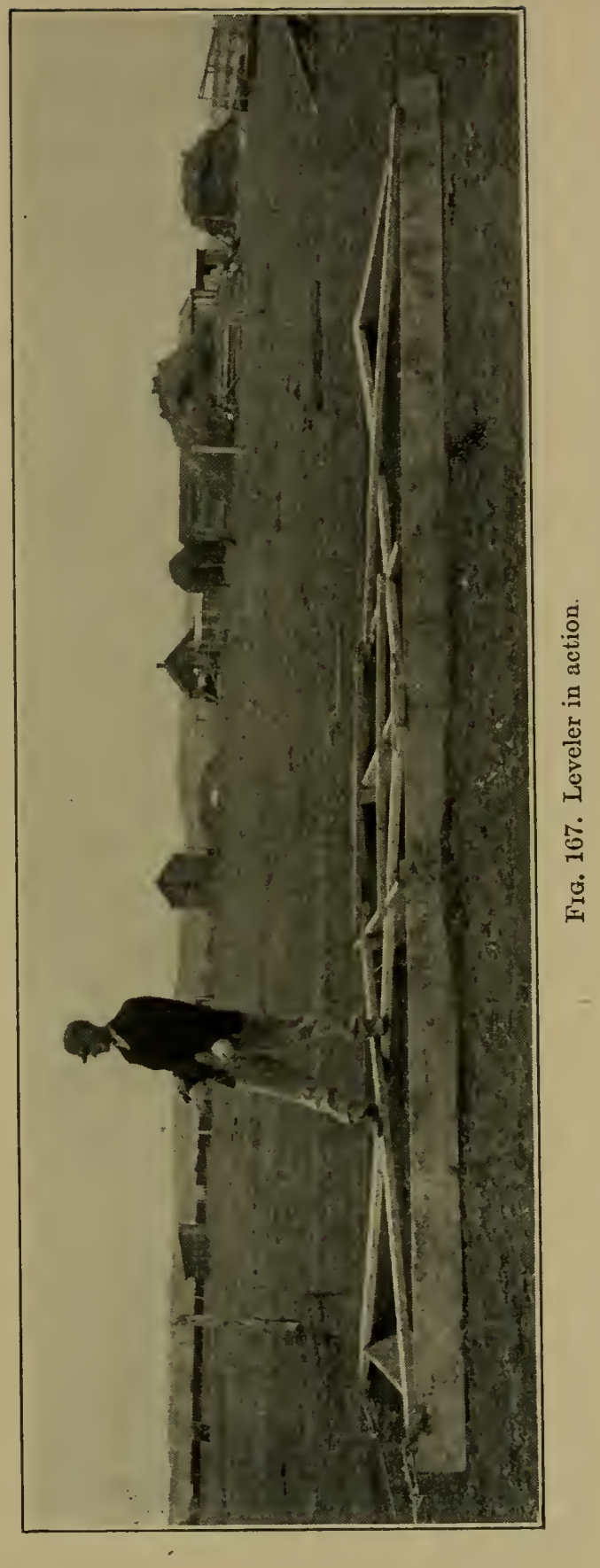




\section{REFERENCES}

Fortier, SAmuel. Practical Information for Beginners in Irrigation United States Department of Agriculture, Farmers' Bulletin No. 263 (1906).

Johnston, C. T., and Srannard, J. D. How to Build Small Irrigation Ditches. United States Department of Agriculture, Farmers' Bulletin No. 158 (1902).

Teele, R. P. Preparing Land for Irrigation. United States Department of Agriculture, Yearbook for 1903.

Widtsoe, J. A. Dry-Farming. Chapter XV. The Macmillan Company (1911). 


\section{CHAPTER XXI}

\section{THE HISTORY OF IRRIGATION}

THE history of irrigation is full of interest, for it is virtually the story of the most progressive peoples of historical times. Like all human history, it is fragmentary and can be pieced together only by much labor. The history of irrigation is yet to be written; this chapter is but a brief and incomplete sketch of the subject.

259. The antiquity of irrigation.-The practice of irrigation antedates recorded history in every great country of antiquity. Whether it originated in Asia, Africa, Europe or America, no man can tell. Beyond question, where man first appeared, there, not long after, irrigation began to be practised. Together with the stirring of the soil and the sowing of seed, irrigation is one of the first agricultural practices of mankind.

The monuments of Egypt declare that Menes, the first king of the first dynasty, extended greatly the irrigation structures of his day. How long before him, in the unrecorded past, irrigation had been practised in Egypt, is not known. Certain it is, however, that in the succession of dynasties, throughout the glory of Egypt, even to the present humble day, the waters of the Nile, used in irrigation, have made of Egypt a granary of food. In the days of Joseph, the son of Jacob, "all countries" came to Egypt for food.

The monuments of Babylon and Asssyria declare with equal emphasis that irrigation was a full-grown practice 
on the vast Mesopotamian plains, when the first records were laid aside for our use in the latest day. Hammurabi, a contemporary of Abraham, built a great and wonderful canal by which the desert was made into gardens, and an elaborate system of irrigation covered the Babylonian plain, under which grain returned 300-fold. These mighty structures fell into disuse and decay as the power of the

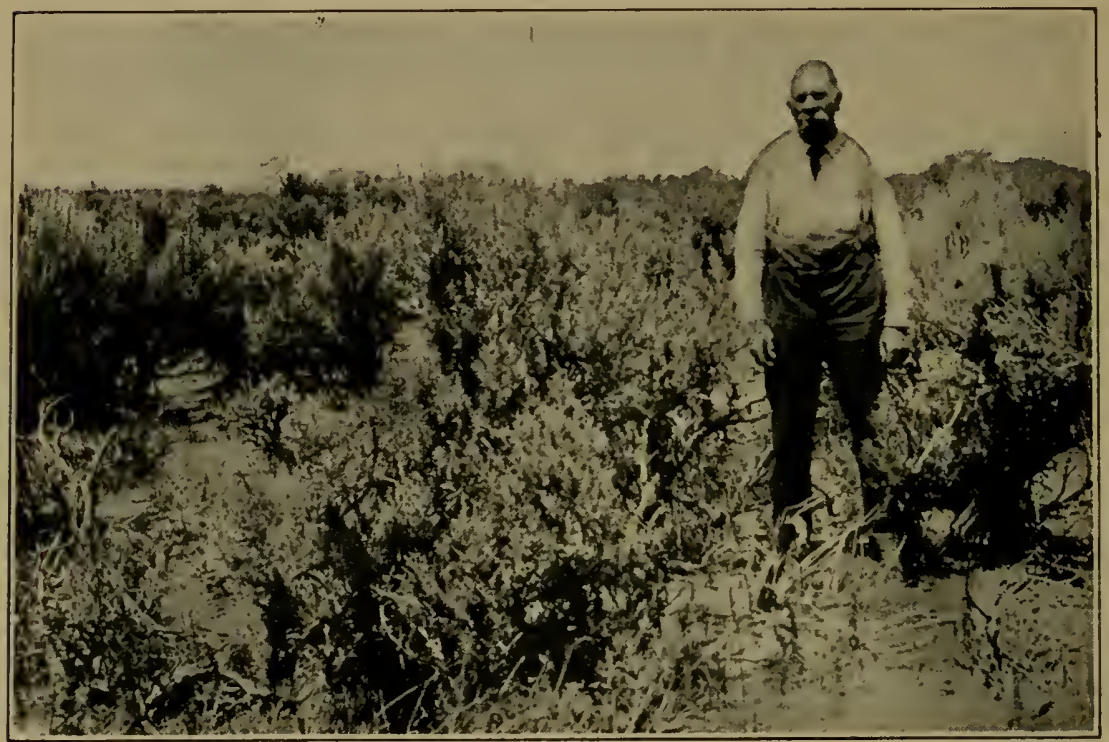

FIG. 168. Sagebrush land.

ruling nation receded from Babylon, but the remains of the canals are visible today, and the fertile soil is as ready as ever to respond to the touch of water. Moreover, the recently unearthed codes of laws concerning the use of irrigation water prove a degree of irrigation refinement scarcely ever surpassed.

In Persia, India, Ceylon, China, Syria, Palestine, and practically every country of high antiquity, irrigation has been practised, without cessation, since the beginnings of 
history. It is unquestioned that in Egypt and the Asiatic countries the practice of irrigation goes back 2,000 years, and it may be 4,000 years.

On the American continent, also, the practice of irrigation goes back to immemorial times. At the time of the Spanish Conquest, irrigation practice was found well developed, and irrigation structures existed then which dated back to the first traditions of the native population. In Peru are remains of irrigation structures of undoubted antiquity and of a quality comparable with the best of

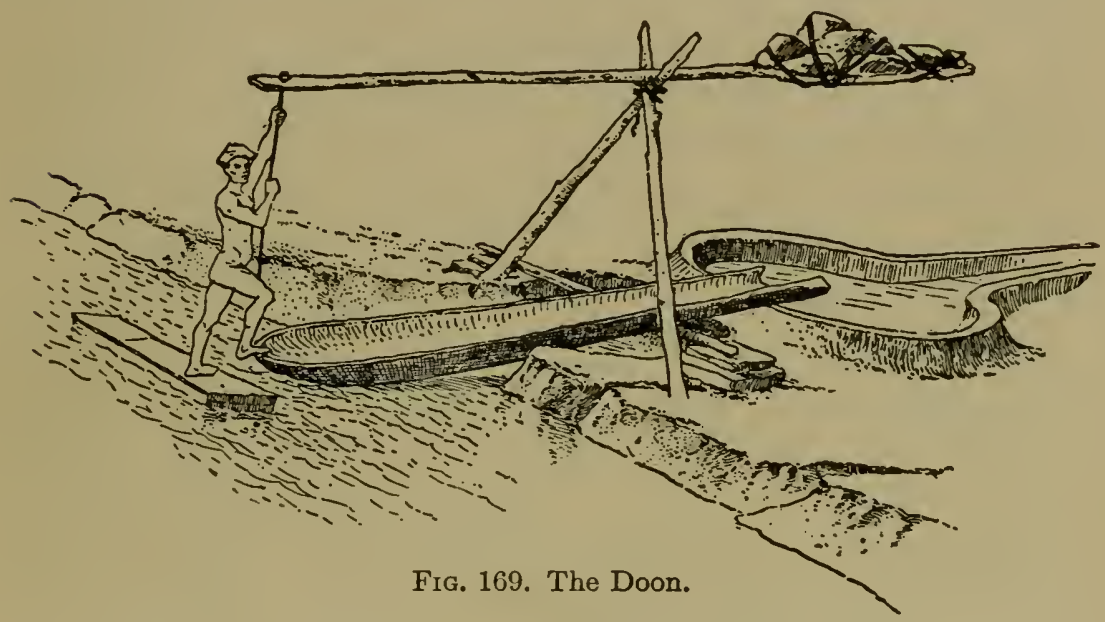

the present day. In Chile, similar remains are found. In Argentina, there are remains of vast irrigation structures. In fact, along the Atlantic and Pacific drainages of South America, wherever the climate made it desirable, great irrigation structures were built in a remote antiquity. In some places stupendous irrigation canals may be traced-400 to 500 miles long-far beyond our modern attempts. There is evidence to show, also, that on the American continent refinements of irrigation were practised, superior to any others known. 


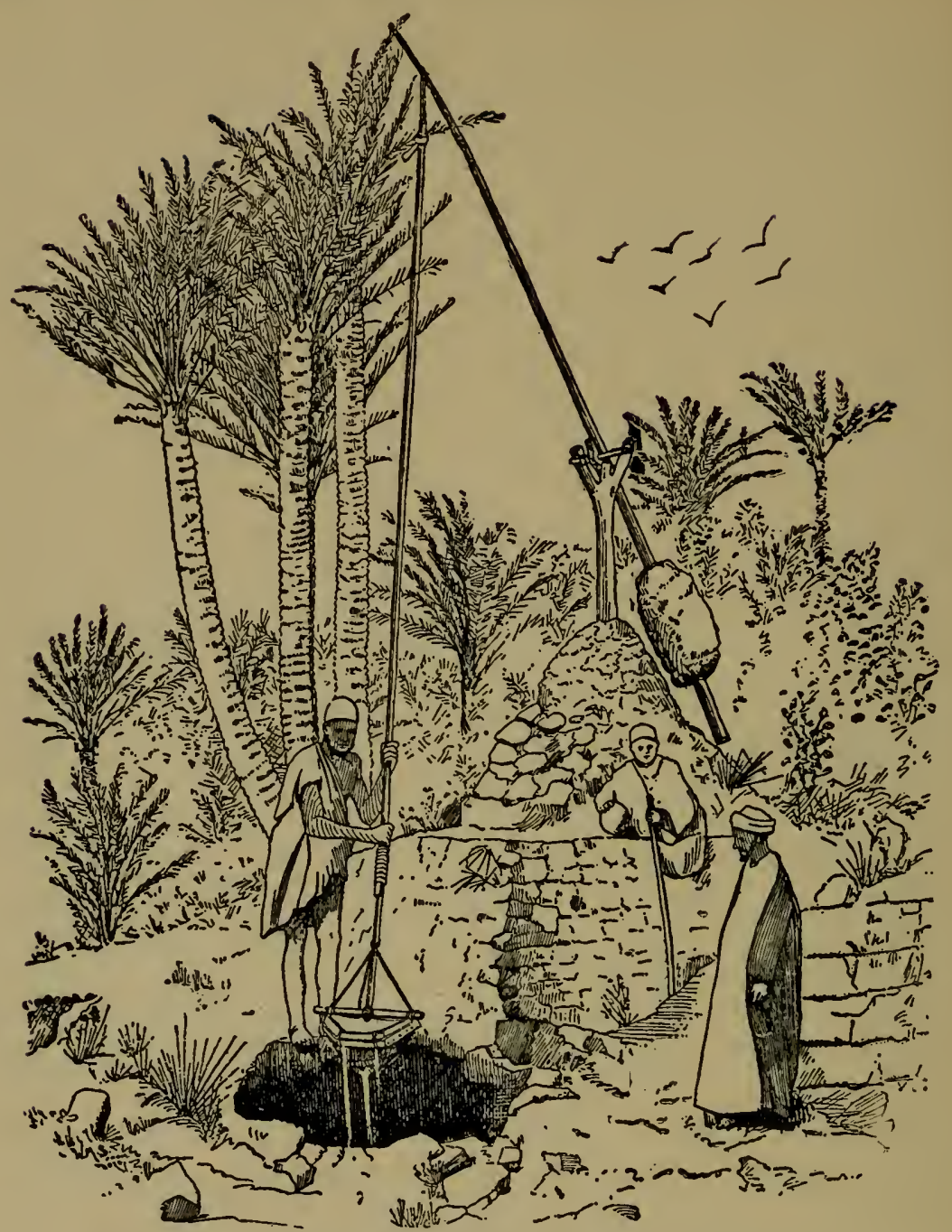

FIG. 170. Shadof of Egypt or paecottah of India.

Likewise, in Mexico and the southwestern United States are remains of prehistoric canals, which prove amply the high antiquity of irrigation in North America. To the past belongs the credit of having originated irrigation; our present day must refine it and make it imperishable. 
260. The Christian era, to 1800 . - Clearly, a valuable practice so ancient and so widespread, as is irrigation, could not vanish from the earth. Therefore, in spite of the changing fortunes of the race which has covered but a small part of the earth, irrigation has remained a continuous practice. In some places, as in Babylon, with the decline in civilization and the diminution of population, irrigation disappeared wholly or in part; while in other places, as in Egypt, China and Persia, it has continued and often increased. New countries have adopted it; and most of the older ones have maintained it. The most enlightened peoples have always practised and do now practice irrigation, if the climatic conditions make it desirable. It is difficult for an unintelligent or shiftless people to become good irrigators.

During the Christian era, the practice of irrigation has moved westward, with the general western movement of civilization. During the days of the Roman Empire, irrigation was fostered in all the Mediterranean countries, although relatively few remains of the Roman structures are known. That it was of high importance in Roman days is well shown by the attention given irrigation in the famous codes of law formulated in the fifth and sixth centuries after Christ. As another trifling but interesting evidence, Carpenter gives the word "rivals," derived from "rivus," an artificial water channel, or ditch. The users from a "rivus" were rivals - the usual contests over water are clearly implied.

The invasion of southern Europe by the Moors, in the ninth and tenth centuries after Christ, became a great stimulus to irrigation. The Moorish conquerors had a good traditional and practical knowledge of irrigation, and sensed quickly the value, to southern Europe, of more CC 
extensive irrigation. Therefore, during their rule, especially in Spain, many large canals were built, and irrigation practices perfected. To Roman and Moorish rule, together, must be ascribed the beginnings of many of the splendid irrigation structures of France, Spain and Italy.

In France, irrigation has been practised under a great variety of conditions. The first great canal in France, the St. Julien, seems to date from about 1171. Other and minor structures were built in the centuries that followed, up to $1800 \mathrm{~A}$. D.

Spain, among the countries of southern Europe, has most need of irrigation, and many of her smaller irrigation canals date back to Roman times. After the Moorish occupation, from the eleventh to the thirteenth centuries, particularly in the valley of the Genil, in Granada, many great canals were built, which have endured to the present time. The delivery of water was so greatly perfected in those days that the Valencia Canal, for instance, has been managed for 600 years with the laws that now prevail. From the thirteenth century, onward, there was some added irrigation development under many of the enlightened rulers of Spain. The modern irrigation activity began in Spain as early as 1759, earlier than in any other land.

Italian irrigation has grown so steadily and intelligently from the eleventh to the nineteenth centuries that Italy has been denominated the classic land of irrigation. In the eleventh century, the old Roman canals in Lombardy were reconstructed. In Italy, the twelfth century was marked by tremendous irrigation activity. The thirteenth, fourteenth, fifteenth and sixteenth centuries all contributed largely to irrigation development, and the canals then built are now in service. In the seventeenth 
century, under the domination of Spain, the proper details of irrigation practice were vigorously promoted and some canals were built. During the eighteenth century, few large additions were made to the irrigation system of Italy, but the existing canals were used diligently.

After the discovery of America, the zealous Catholic missionaries established missions in various parts of the two American continents. These priests were chiefly from southern Europe and well acquainted with irrigation. Whenever a mission was established in an arid section, a small irrigation system was also built for the support of the mission. The remains of these mission irrigation systems are found in various parts of America, notably in California. In a few cases, also, the Catholic fathers taught the natives irrigation, or rather insisted upon the use of the ancient knowledge. The Catholic missionaries did not succeed in establishing American irrigation on a community scale, beyond that already existing among the aborigines.

During the first 1,800 years of the Christian era, the irrigated countries of antiquity continued their irrigation practices; the countries of Europe, particularly France, Spain and Italy, adopted and extended the practice greatly, and the new lands brought under the domination of civilized man made little or no irrigation progress.

261. Irrigation in recent times. - The new light of advancing science finally showed the great nations of the nineteenth century that irrigation is a great world problem. Even in the countries of southern Europe, in which irrigation had developed under the influence of a growing civilization, new structures were planned and completed, methods of practice perfected and more intelligent laws enacted. In France, since about 1839, many 
large canals have been constructed; in Spain, also, much irrigation progress has taken place during the nineteenth century, and in Italy the Great Cavour Canal was built about 1844, with minor ones since that date, and in 1865 the valuable irrigation code of Victor Emmanuel was promulgated.

The greatest recent progress in irrigation has occurred, chiefly, under Anglo-Saxon direction in newly settled countries or in older settled countries brought under Anglo-Saxon rule.

Thus, in Egypt, under English rule, with the wise initiative of Mehemet Ali Pasha in 1820, an irrigation revival has begun which promises to eclipse in its results the noonday of ancient Egyptian irrigation. The old channels have been deepened and extended, new and more economical methods of irrigation have been adopted, new and profitable crops have been introduced, and, as the climax, the great Assuan Dam has been built as the first main step toward utilizing the varying flow of the Nile in an unvarying manner. True, while this revival began early in the nineteenth century, it was only in the last quarter of the century that the really big things in recent Egyptian irrigation have been done.

India, under English rule, is likewise in an irrigation development far beyond the greatest in the history of this age-old land. From immemorial times droughts, with consequently fearful famines, have vexed India. Early in the nineteenth century, the rulers began to look to an extended irrigation for relief from famine. The year 1878, at the end of a disastrous famine, may be said to be the beginning of modern irrigation in India. Commissions were appointed, new canals constructed and great efforts made to establish a large and thoroughly modern irrigation 
system. As a result of these activities, the irrigated area of India was increased, between 1877 and 1897, from 6 per cent to 7.5 per cent of all the arable land. Irrigation development in some phase is being pushed with undiminished vigor.

South Africa has also shared in the recent irrigation development. Cape Colony, ceded to England in 1814, began its recent growth with the diamond discoveries of 1870. Soon afterwards, in 1877, irrigation boards were organized to consider the small and scattered irrigation efforts of the past and to propose new and greater plans which have been in part carried out. Since 1904, in the other states of British South Africa, irrigation development has been undertaken on a large scale. In fact, so urgent had the interest in irrigation become that, in 1909, an irrigation congress was held for all British South Africa. Much irrigation progress may be looked for in South Africa.

Australian irrigation has had a similar history. Isolated irrigation plants were established soon after the settlement of the continent, but it was only in 1884 that a royal commission was appointed to consider ways and means of irrigation development. Since 1885 governmental consideration has been given to irrigation with the result that notable structures have been built and much advance made in the reclamation of the arid lands.

In many other countries, on all the continents, interest in irrigation has been developed in recent years, and in many of them irrigation dams and canals have been constructed. Argentina, for example, although only at the threshold of her agricultural development, has already constructed several irrigation works of considerable extent. 
The greatest recent progress in irrigation has come about in every country during the last forty or fifty years. The year 1880 may well be taken as a convenient marker for the beginning of modern irrigation on a large scale, with governmental support and based upon modern knowledge.

262. The founding of modern irrigation in America.During the first half of the nineteenth century, there was no irrigation progress in America. The native Indians in some few places in Mexico and South America, were irrigating small fields. The old missions in the United States were falling into decay. The European conquerors of the new continent were busily engaged in the humid portions of the country. The more arid or remoter parts of the country had been explored only by the handful of trappers and a few others, who had ventured westward largely in search of adventure or scientific truth. The great territory now covered by the mountain states was designated on the school maps as the Great American Desert, and with the country adjoining it on every side, was held to be unfit for agricultural purposes.

The opening of the Oregon country brought venturesome settlers across the continent more frequently, until the old Oregon trail was pretty well defined, but those who traveled it sought their homes on the Pacific Coast, where the rainfall was quite as heavy as in the far East. The old southwest trail from Santa Fe was practically unused by emigrants. There was no American irrigation of any consequence during the first half of the nineteenth century.

Early in the spring of 1847 , a party of pioneers, under the leadership of Brigham Young, set out from their winter camp, near what is now Council Bluffs, to find in 
the far West a place where their people could settle. On July 24, 1847, this party of pioneers entered the Great Salt Lake Valley, chosen as the place of settlement, and on that day planted potatoes in what is now the business section of Salt Lake City, and gave the soil a "good soaking" of water brought from the neighboring City Creek through a plow furrow that served as a ditch. This was the birth of modern irrigation in America.

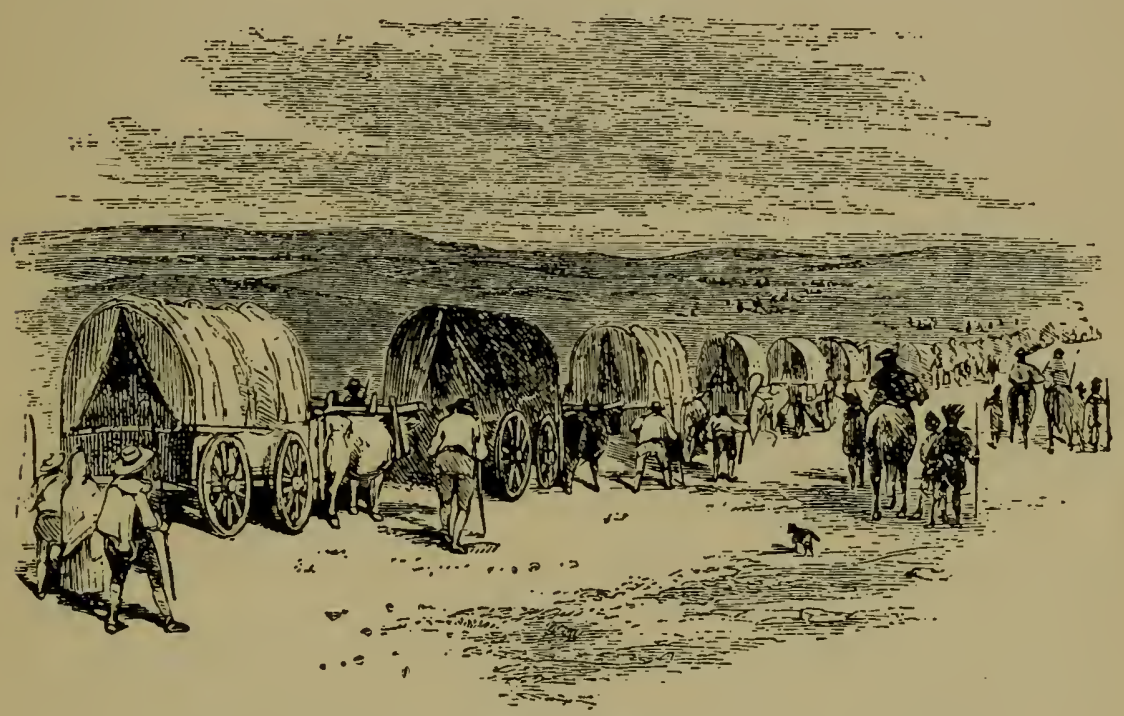

FIG. 171. Caravan crossing the plains in early irrigation days.

The Mormon pioneers possess the honor of having founded modern irrigation in America, not because of the initial irrigation on July 24, 1847, but because the Mormon people continued the work, dug extensive canals, brought thousands of acres under irrigation, devised methods of irrigation, established laws, rules and usages for the government of populous settlements living "under the ditch,"-in short, because they developed permanent irrigation agriculture on a community scale, under the 
conditions and with the knowledge of modern civilization. Irrigation knowledge and inspiration have been drawn by the whole world from the work of the first American irrigation pioneers.

The far-reaching consequences of this original experiment resulted from a combination of conditions not before known in irrigation history. The pioneers settled in the very heart of the arid section at a time when the nearest settlements to the east or to the west were 1,000 miles away. Starvation or successful agriculture was the only alternative offered, since a return to civilization was almost impossible to the weary people with worn-out equipment. They were compelled to make irrigation successful. Then, they were wholly unfamiliar with irrigation practices. True, they were men and women of good intelligence and information, and knew the place of irrigation in the world's history; some of them also had probably seen, in their native New England, the occasional irrigated meadow; but, they had no real knowledge of irrigation as the central idea of agriculture. They were, therefore, unhampered by traditional irrigation practices, and built from the foundation as their needs and intelligence directed. Moreover, these irrigation pioneers were of the race that had carried onward modern civilization; of a country with huge courage to achieve great tasks, and of a day when new and increasing truth rendered easier the work of man. They founded their irrigation, therefore, in vision and with modern intelligence. Naturally, under such conditions, the system of irrigation that arose in the heart of the Great American Desert was modern and original in method and application, and became a system to which modern man, interested in the conquest of the desert, has since looked for help. 
263. The growth of American irrigation.-The original irrigation pioneers of July 24, 1847, numbered 147 ; in 1865 , nearly 64,000 souls were living in Utah and were deriving: their main sustenance from irrigation. During these eighteen years more than 1,000 miles of irrigation canals had been constructed, another 500 miles were being dug, and 154,000 acres of cultivated land were under irrigation.

In 1865 the average acre-yield of wheat was 23 bushels; of barley, 30 bushels; of oats, 31 bushels; of corn, 20 bushels; of potatoes, 139 bushels; of beets, 265 "bushels;" of carrots, 344 "bushels;" of meadow hay, $12 / 3$ tons; of cotton, 151 pounds; and of sorghum, 79 gallons. Considering that the rapidly arriving farmers had to be taught irrigation, and were provided with poor machinery, these yields showed the great possibilities of irrigation.

Soon after the founding of irrigation in the Great Salt Lake Valley, gold was discovered in. California. Most of the tens of thousands who flocked to the gold-fields passed through Utah and Salt Lake City and thus became in a measure acquainted with irrigation. Many of these emigrants, upon their arrival in California, found irrigation agriculture more profitable than gold-hunting. Others, rich or discouraged, returned to their homes in the East, and told not only of the gold-fields, but of the conversion of the heartless desert into a fruitful garden by the intelligent will of a courageous people. The stories of the travelers gained currency until the whole country knew a little of the practice and possibilities of irrigation in the Great West. Moreover, big-visioned men, like Major J. W. Powell, and his great associates on the United States Geological Survey who had explored the arid region, or like Horace Greeley, who had carefully informed himself, 
spoke and wrote of the great opportunities of the West under irrigation.

However, the year 1870 was almost reached before the American people began to give serious attention to the irrigable West, so strange and forbidding did irrigation seem to the rainfall farmers. With the opening of the '70's came a slight change of heart. Many colonies were established, and with every year the emigration increased. In 1878, Major J. W. Powell's report on the arid lands was published by the government. The public interest became aroused. The westward movement was already covering the Great Plains, and overflowing steadily into the region where irrigation was at that time generally held to be indispensable. All classes of people discussed the Great West as a great hope of the Republic.

From 1870 to 1880 , the population of the mountain states doubled; from 1880 to 1890, it almost doubled again. The future of irrigation was safe. Then, the cautious men of money thought their opportunity had come. Great sums were spent in building splendid canals above fertile lands, with the thought that the farmers who settled below the canal would pay a royal annual tribute for the water delivered to the land. But the process of settling a new country is slow; irrigation succeeds best under a close social and economic organization in which canalowner and water-user must be equal members, and the West is large; so, in face of the slow adjusting of difficulties and the slower settlement of the projects, capital often became discouraged and surrendered its property at a loss rather than to await the sure harvest that the years would bring. Occasionally, also, as in all enterprises, the careless or dishonest or ignorant speculator appeared and for a time misled both capital and farmer. 


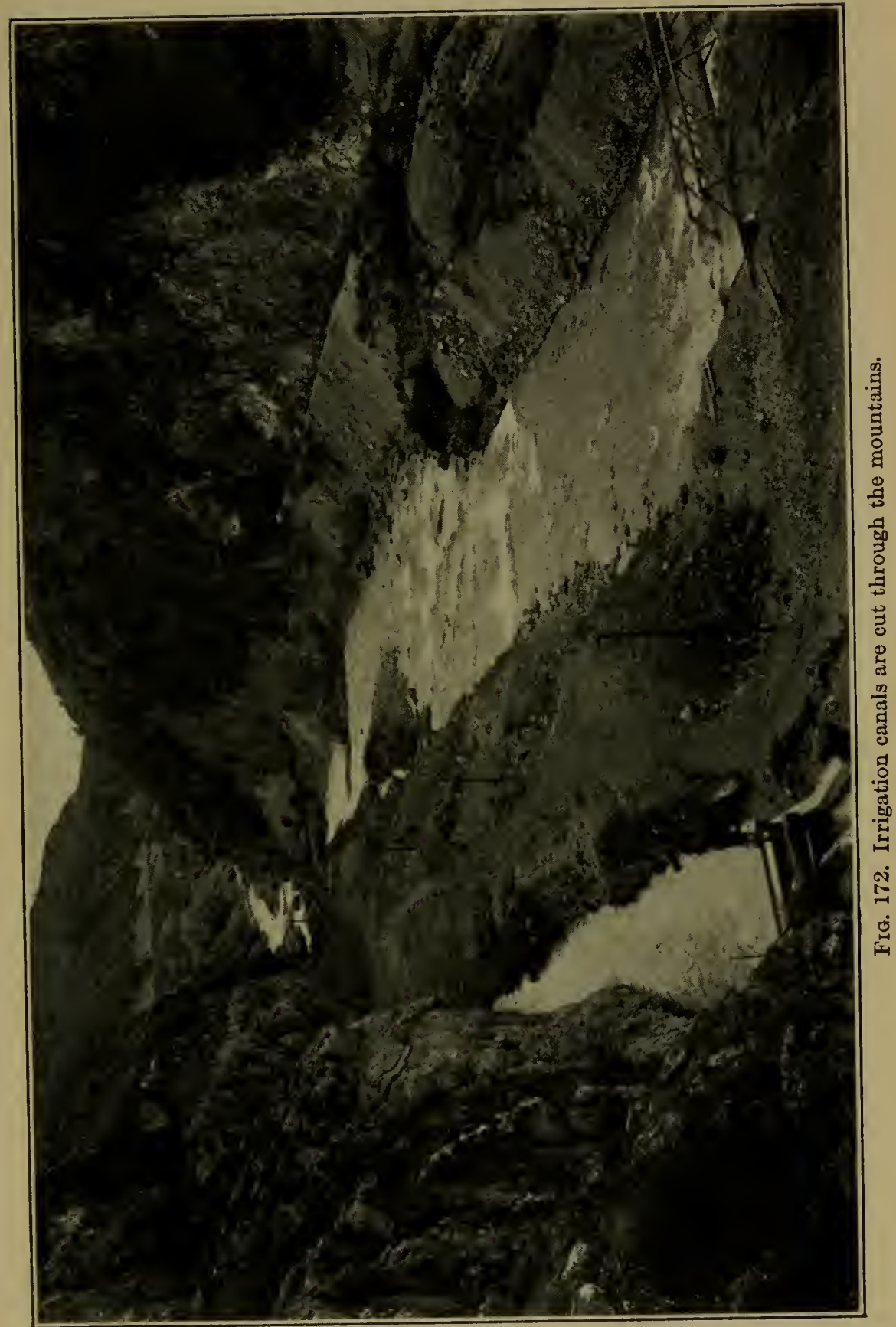


Soon after 1890 , the era of the irrigation speculator ended. The development of irrigation continued undiminished, but along safe and legitimate lines. Legislation by state and federal governments (such as the Carey Act) encouraged sane irrigation progress. Western Canada, lying under the same general conditions as western United States, joined vigorously in the movement, constructed canals and opened fertile lands for settlement. Finally, the greatest irrigation experiment of modern days was officially declared successful when the Congress of the United States in 1902 passed the great reclamation act.

The irrigation structures existing in the United States in 1910 irrigated nearly 14,000,000 acres, and could irrigate nearly 20,000,000 acres. All this has been done since 1847; and the work, still going on, is far from being finished.

264. The Union Colony of Colorado.-This colony, which in 1870 founded Greeley, Colorado, is next to the Utah settlement the most important in the history of American irrigation, for it also established the practice on a community scale and demonstrated the essential correctness of the methods of the Utah pioneers. The colony was organized on the coöperative plan by N. C. Meeker, who had earlier in life belonged to coöperative settlements and who had also become familiar with the Utah method of settlement. The members of the enterprise were men and women of a high order of intelligence and ideals, who carried onward the coöperative spirit. The early success of the colony, upon which the later success rests firmly, may be credited to the union feature. It has been observed that all irrigation enterprises in which many families draw support from one ditch or 
system of ditches become more successful as the coöperative spirit grows. Other colonies were soon founded near and in imitation of the Union Colony, as, for instance, the Chicago Colony at Longmont, the Fountain Colony at Colorado Springs, the Agricultural Colony at Fort Collins, and the Southwestern Colony at Green City. The work of these colonies helped to place on a sounder basis the practice of irrigation in the United States, and made of northeastern Colorado one of the most famous agricultural districts of the country.

The Union Colony, with its outgrowths, is entitled to the credit of being associated with the first serious attempts to measure and distribute water accurately for irrigation. In this part of Colorado, also, were suggested and initiated many of the systematic investigations of the conditions determining successful irrigation. Many famous names are connected with the struggles of the Colorado irrigation pioneers, originating with the Union Colony of 1870. The Colorado experiments confirmed the Utah experience.

265. The United States Reclamation Service.-During the first fifty years of irrigation in the United States, the Federal government gave little direct assistance to the reclamation of arid lands beyond the enactment of laws that made the public domain readily available to the settler. As the public lands under large rainfall passed into private ownership, and the demand for homesteads continued, Congress gave consideration to federal aid to irrigation, and on June 17, 1902, nearly fifty-five years after the founding of modern American irrigation, passed the justly famous reclamation act.

This act provides that all moneys received from the sale and disposal of public lands in all the states west of 
and including North and South Dakota, Kansas and Oklahoma, excepting the 5 per cent set aside for educational purposes, shall be made a "reclamation fund" for the "examination and survey for and the construction and maintenance of irrigation works for the storage, division, and development of waters for the reclamation of arid and semi-arid land in the said states." The lands brought under irrigation by this act shall be open to bona-fide settlers under the regulations of the Secretary of the Interior, and at a price that will return in time to the reclamation fund a sum equal to that expended by the government upon the project. The fund, thus made permanent, may continue to serve until all irrigation projects feasible under the terms of the act shall have been constructed.

Work under the reclamation act has been pushed with vigor almost from the day the act was signed by Theodore Roosevelt. The workers have been assembled under the head of the United States Reclamation Service, the director of which almost from the beginning has been F. H. Newell, a life-long student of water supply and irrigation, assisted by a most admirable and efficient corps of irrigation experts. During its first decade of work, the Reclamation Service undertook projects which, when completed, will cost over $\$ 100,000,000$. In 1910 the projects of the Reclamation Service irrigated 3 per cent of all the irrigated lands in the country, and, when completed, would irrigate nearly 7 per cent of the area to be irrigated under all projects, private and public.

Many projects that private enterprise felt unable to undertake have been constructed by the Reclamation Service. Confidence in the arid section has been strengthened by the national approval of irrigation contained in 
the reclamation act. The real problems and possibilities of irrigation are being brought home to our national leaders by this work as would be possible in no other way. It is a great act of endless service to the country.

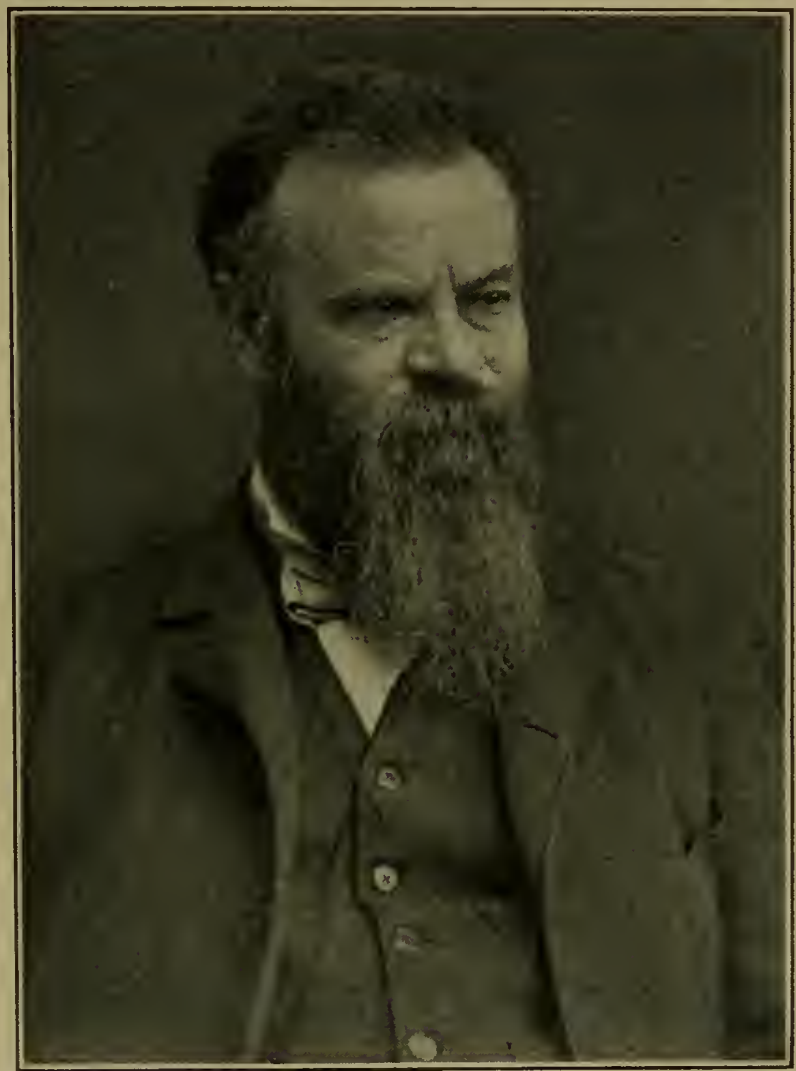

Fig. 173. Major J. W. Powell, who, as director of the United States Geological and Geographical Surveys, was one of the first to understand and teach the value of the arid and semi-arid parts of the United States.

It was fitting that the Interior Department should be entrusted with the execution of the reclamation act, for it was the Geological Survey that among government agencies first studied the beginnings of irrigation in the far West, and spoke hopefully of the reclamation of the 
Great American Desert. Major J. W. Powell, Director of the United States Geological and Geographical Surveys, and lover of the West, together with G. K. Gilbert and other colleagues, did much to advance the early cause of irrigation. Under tha direction of the Geological Survey, also, with F. H. Newell as hydrographer, the notable water-supply papers were issued which laid a foundation of knowledge concerning stream flow upon which irrigation plans could be builded.

266. The United States Department of Agriculture.The building of dams and canals will end, but the use of the impounded or diverted water must go on forever. Irrigation is essentially an agricultural practice to which the civil and mechanical engineers can give only initial help. In the earlier days water was plentiful and people few, and little water scarcity was felt. The big thing was to dig more canals and induce more people to settle under the ditch. Now, the question of the best use of the water on the land is the big one, because the opportunities are fewer, the people more numerous, and those of the arid region more determined to build permanently and largely. The Department of Agriculture, although somewhat slow in sensing the needs of the irrigation farmers, organized in 1898 the Irrigation Investigations of the Office of Experiment Stations, to expend a Congressional appropriation "for the purpose of collecting from agricultural colleges, agricultural experiment stations, and other sources, valuable information and data on the subject of irrigation and publishing the same in bulletin form." Elwood Mead, already of long and splendid irrigation service, was first appointed chief of the Investigations, followed in 1906 by Samuel Fortier, also with a long and honorable irrigation record. In a short time, a series of remarkable 


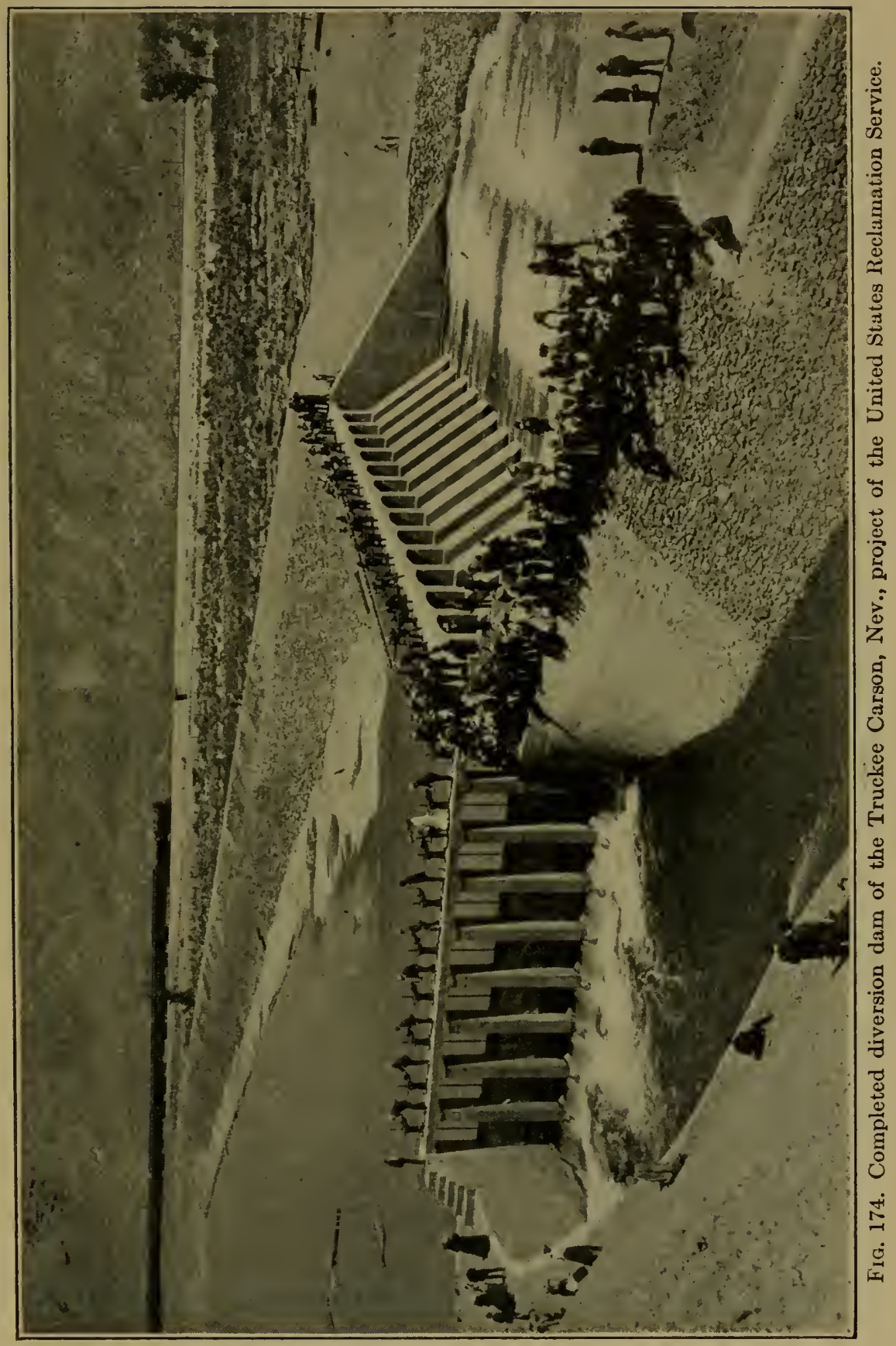


irrigation bulletins appeared, which have continued to the present. Doctors Mead and Fortier gathered about themselves a body of young able men, who for half a generation have been devoting themselves to a study of the farmers' side of irrigation. The practices of irrigation have been collected and organized; the irrigation systems of foreign countries have been studied; experiments have been conducted, and in numerous ways the irrigation

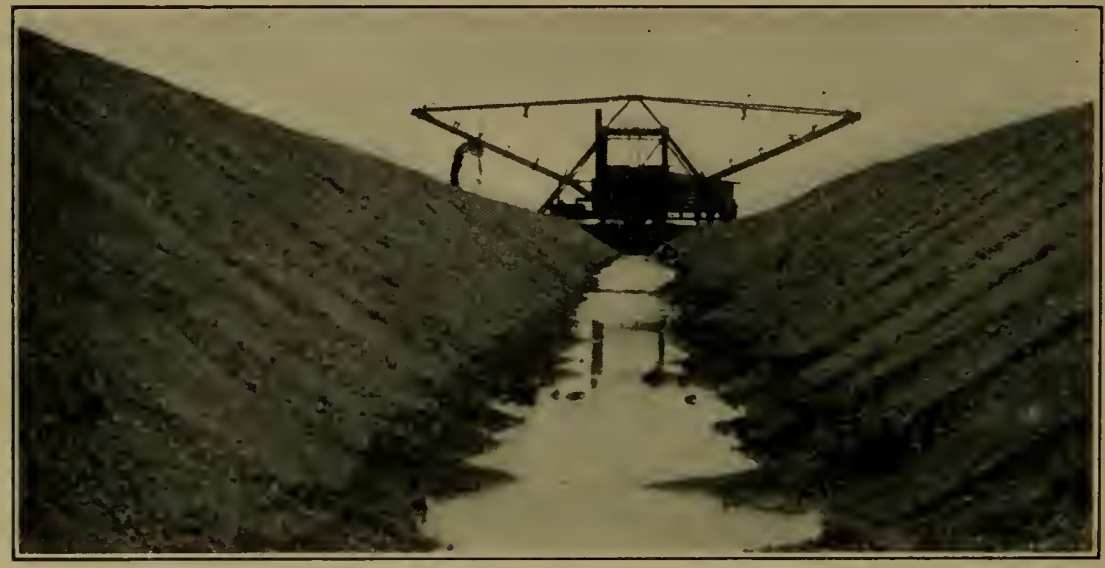

FIG. 175. Steam power digs the modern canals.

farmer has been given needed help. Not the least of the achievements of the United States Irrigation Investigations has been the encouragement it has given irrigation studies at the experiment stations by an intelligent and liberal system of coöperative work.

267. The experiment stations.-Modern agriculture was founded in humid regions and, naturally, little attention was at first given irrigation. When, however, in 1887, an agricultural experiment station was established in each of the states and territories, irrigation problems presented themselves for solution at most of the western stations. E. W. Hilgard, the great man of arid agri- 


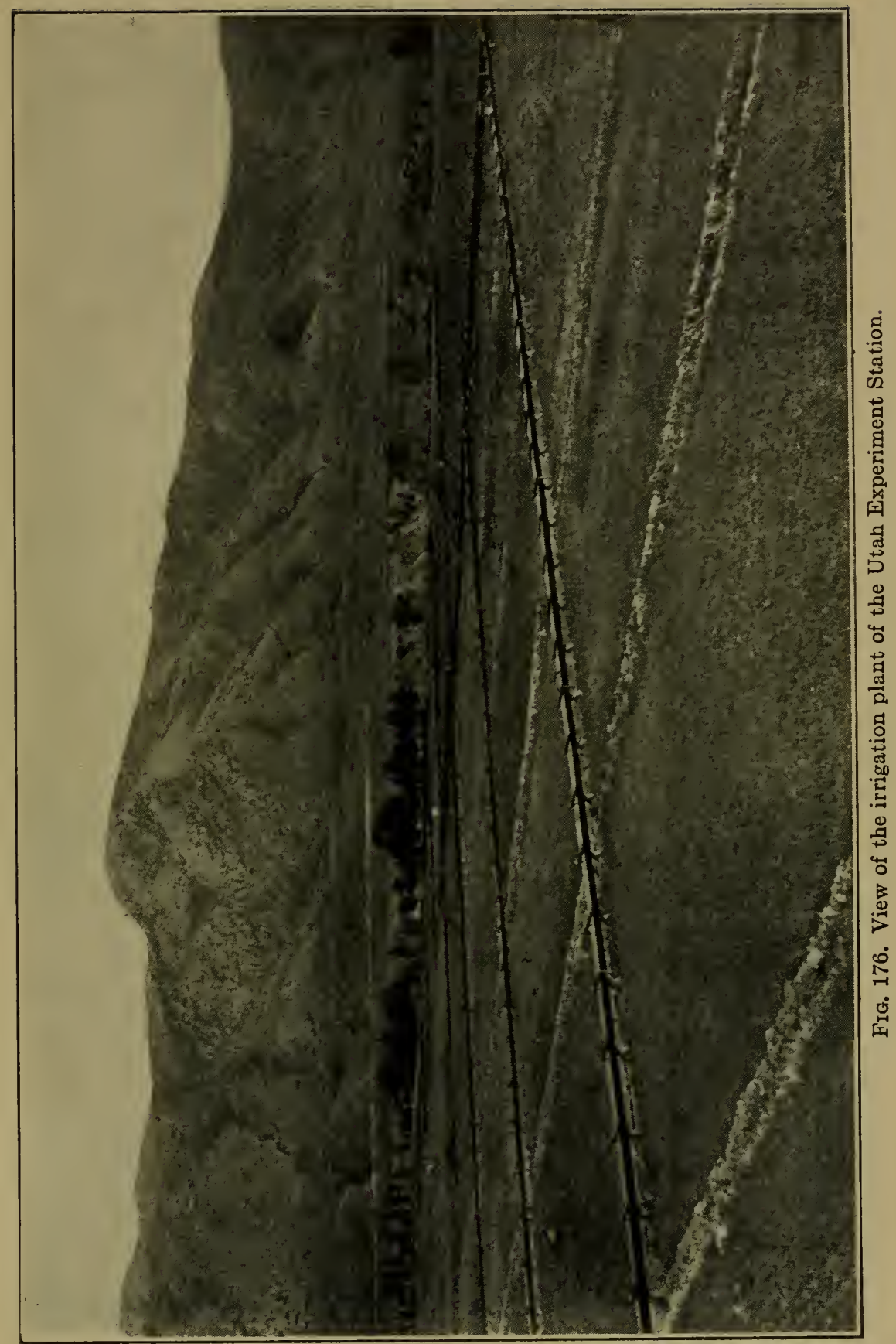


culture, had already made observations on Californian irrigation for half a generation, but his fundamental soil studies had crowded out systematic irrigation experiments.

The Colorado and Utah stations were the first to undertake special irrigation work. At the Colorado Station, among the many workers who gave some attention

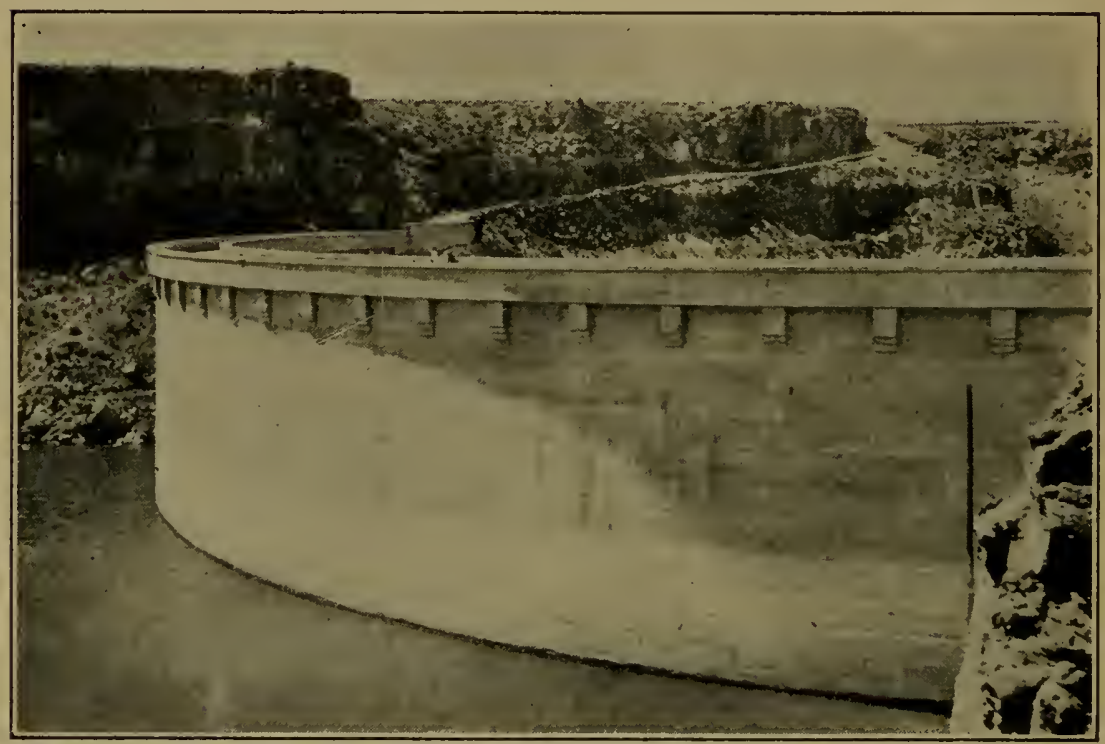

FIG. 177. Dam of Salmon River project, Idaho, built by private enterprise.

to irrigation, Elwood Mead and, later and chiefly, L. G. Carpenter, made classical studies of the measurement, division, seepage and underflow of water, together with many allied questions. True to its traditional interest in the engineering phases of irrigation, the Colorado Station, in coöperation with the United States Irrigation Investigations, completed in 1913 an experimental plant for the study of the methods for measuring and dividing water, which is unequaled. At the Utah Station, J. W. Sanborn, 
a great pioneer of modern American agriculture, assisted by Mills, inaugurated the pioneer investigations of the correct use of water on the farm. J. A. Widtsoe, L. A. Merrill and others later organized the exhaustive study of the relationships existing between soils, crops and water, having for its purpose the determination of the most economical use of water, which, in new hands, is still being continued. The Utah experimental equipment for

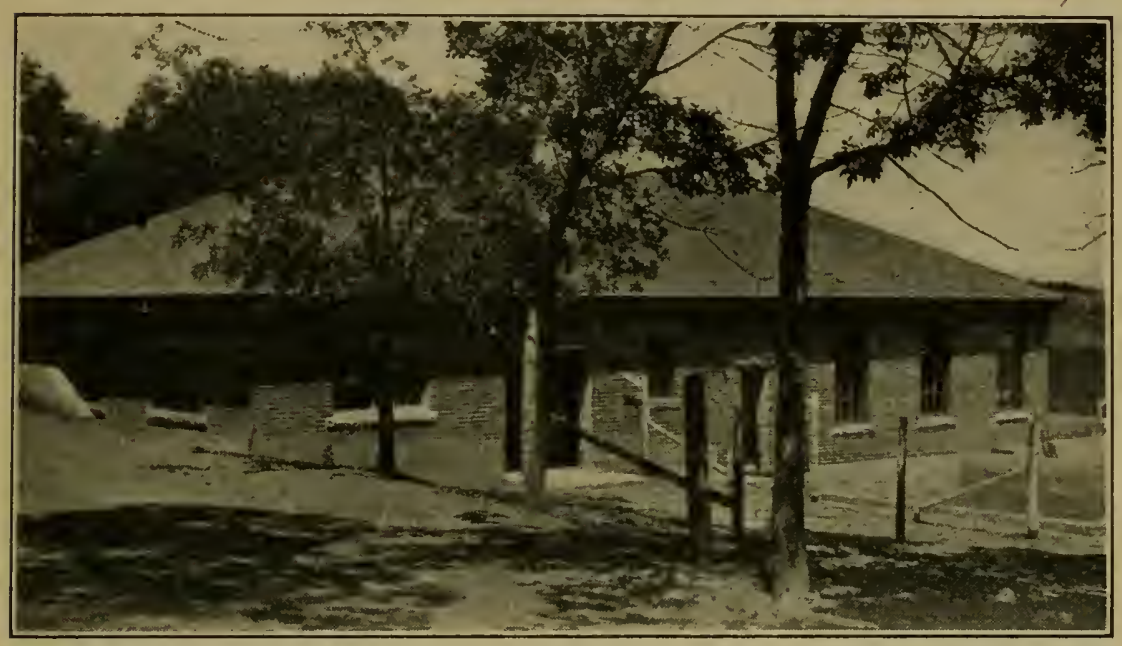

Fig. 178. Plant for the study of the measurement and division of water. The Colorado Experiment Station.

these investigations was long unique among the stations. At the Utah Station, Samuel Fortier also did some of his early experimental work, and many members of the station staff have conducted investigations bearing more or less directly on irrigation.

The other western stations have all done some excellent irrigation work; but the preponderance has been on the subject of alkali, rather than on the actual use of water on the farm. E. B. Voorhees, of the New Jersey Station, studied with care the value of irrigation in humid countries. 
The experiment stations have brought forth much new irrigation knowledge, and have disseminated widely. all the sound information existing upon the subject. Nearly all the stations in the arid region are now undertaking systematic studies having for their purpose the establishment of a science of irrigation practice.

268. The Irrigation Congress.-The reclamation act, the land laws making irrigation settlement possible, the founding and work of the experiment stations, are all the result of the championship of irrigation by clear-headed, far-seeing, courageous men, in and out of office, who, in legislative halls, from the platform, on the printed page and in private conversation, have taught the needs and the possible future of irrigation in America.

These men, whose names are easily forgotten, now that the work is done, organized in Salt Lake City the Irrigation Congress. The first session was held in September, 1891, since when sessions have been held in practically all of the irrigation states. Its lists of officers during these many years include the names of the irrigation leaders of America -names of national renown for great service rendered. The proceedings of the Congress developed and sustained the enthusiasm which has made irrigation a national issue. No doubt the Irrigation Congress made possible much of our recent irrigation progress. Now that reservoirs and canals are being rapidly built and irrigation has been firmly established, the mission of the Congress looms larger than ever-to make systematic, profitable and permanent the use of the water upon the land.

Major Richard W. Young, a grandson of the founder of modern irrigation in America, is the present President of the Irrigation Congress. The Congress for 1914 will be held in the province of Alberta, Canada. 


\section{REFERENCES}

Powell, J. W., with Gilbert, G. C., Dutton, C. E., and Thompson, A. H. The Lands of the Arid Region of the United States. United States Department of the Interior (1878).

United States Department of State. Canals and Irrigation in Foreign Countries. Special Consular Reports, Vol. V (1898).

Gray, E. D. McQueen. Government Reclamation Work in Foreign Countries. United States Government Printing Office (1909). 


\section{CHAPTER XXII}

\section{PERMANENT AGRICULTURE UNDER IRRIGATION}

"The desert shall blossom as the rose," said the ancient prophet; and a modern man, witnessing the fulfillment, by irrigation, of the ancient prediction, was so wrought upon by the transformation of desert into garden that he declared it a miracle. Later, another man, perceiving clearly the permanency of the work, declared that irrigation is a continuous miracle. That was nearer the truth. Today, with our greater understanding, irrigation is less of a miracle; it is more of an intelligent conquesta continuous conquest of the untoward forces of the desert.

269. The big irrigation problem.-The word "continuous," whether it be of miracle or of conquest, lingers, for it expresses the essence of the virtue of irrigation. The mountain stream or the sluggish river, once brought through reservoir and canal upon the desert land, will make that land yield in plenty and in beauty, not for a generation or two, but, if man so decrees, during the coming ages of the earth-at least while climatic conditions remain unchanged. Therefore is the builder of the irrigation canal a master-builder.

The battle for recognition has been fought and won. Arid and humid regions look to irrigation as one of the chief weapons with which to conquer drought and to make the land yield richly. Private capital and public funds vie with each other for the privilege of fostering 
irrigation. It seems certain that as scon as sound growth will allow all the water, especially in the arid regions, will be stored and diverted for purposes of irrigation.

The mighty dams and endless lines of canals will soon be completed. If the work has been well done, we shall need only to maintain in a sound condition the structures of steel and rock and cement and wood and earth that have been built. The overshadowing problem then, as it is the great one now, will be that of using the water in the best manner for the production of crops. Twoheaded is this problem: First, the water must be made to produce the largest total yield of crops for the support of man; second, the practice of irrigation on a given area of land must be made continuous and increasingly desirable. To this double problem is this volume devoted.

270. The spirit of irrigation.-Our modern knowledge is teaching the methods whereby irrigation may be made to produce the maximum crops for each unit of water used. All irrigation advocates are rapidly accepting the new truth. The very spirit of the conquest of the desert is that men shall be benefited-many men; the more men the better. The largest possible area of land must be reclaimed by the stored waters, even if the acre-yield does not reach so high an average.

271. No essential difference between irrigation- and humid-farming.-Our modern knowledge teaches also that there is no essential difference between rainfallfarming and irrigation-farming, except in the manner in which water is applied to the soil. Every argument against the permanency of irrigation-farming may be urged against rainfall-farming; and every argument for the permanency of rainfall-farming may be used with equal force in behalf of irrigation-farming. The everlasting relation- 
ships among soils, waters and plants are the same over all the earth. Under irrigation, the great water factor may be controlled, and thereby greater power for good or for evil is possessed by the farmer under the ditch.

Yet there are some who, while admitting the great present value of irrigation, fear that in it is an element of weakness which will make the practice temporary.

272. History assures permanence of irrigation.-A sufficient answer may be the history of the past. As shown in the preceding chapter, great tracts of lands are known that have been farmed successfully, under irrigation, during the last 2,000 to 4,000 years and are today as productive as ever. In fact, the human race was cradled and grew to maturity in irrigated countries. That some of the great nations of antiquity crumbled to dust was not because they dwelt on irrigated lands; their fall was rather delayed because of the bounteous yields of their irrigated fields; and, in truth, the fallen nations of the past practised irrigation for so long-often for thousands of years-that the permanent nature of this branch of agriculture was well demonstrated before the shifting scenes of history brought new lands and other peoples into emphatic view.

273. The question of plant-food.- - The fertility of the soils must be carefully guarded under irrigation as under rainfall. When moderate quantities of water are used no more plant-foods are washed away than under an equivalent rainfall. Instead, the deep, rich soils of the arid regions, because of the possible water storage in them, can better retain the essential elements of plant-food. During the course of modern American irrigation, extending over two-thirds of a century, the average productive power of the irrigated lands has steadily increased. Against the 


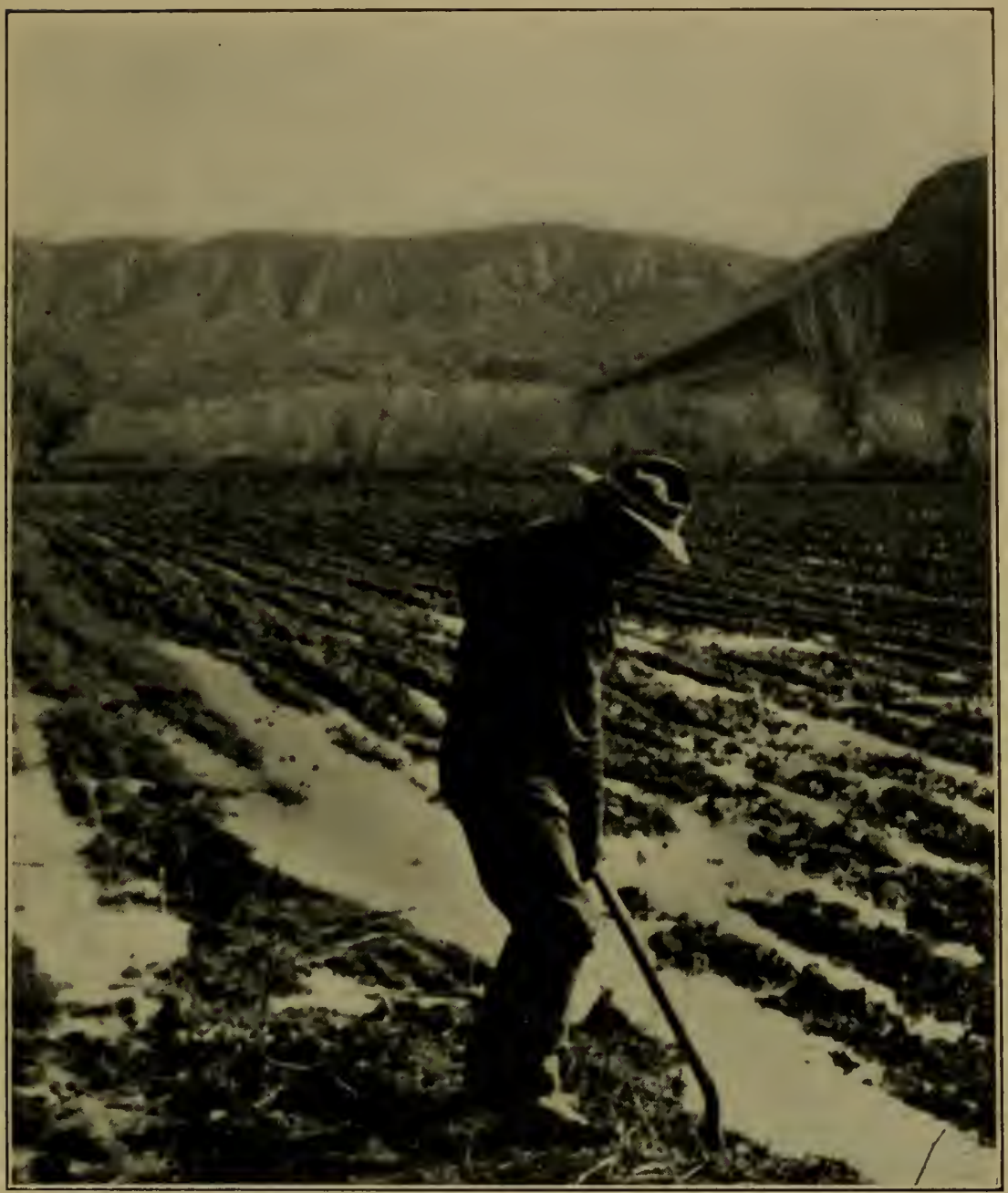

FIG. 179. Work for a man. Irrigation requires strength of body, good intelligence and sound and rapid judgment.

fifteen or twenty bushels of wheat per acre harvested in the first years of irrigation, forty to fifty bushels are now harvested on the same lands. True, this must be due chiefly to improved methods of culture, with modern tools, but certainly there is in this record no sign of deterioration. 
274. Some advantages of irrigation.-There are many reasons why irrigation-farming should become and remain very attractive. Under irrigation, crop-yields may be depended on from year to year. Crop failures are very rare and are usually due to hail-storms or some unusual atmospheric disturbances. The possibility of varying the quantity of water applied to the land gives the farmer a control over the yield and quality of the crop that does much to vitalize the routine of the work and to make the harvest more profitable. The soil and climatic conditions prevailing over most of the territory demanding irrigation are of a kind to make life enjoyable.

275. Finally.-The nature of irrigation is such as to bring into close social relationship the people living under the same canal. A common interest binds them together. If the canal breaks or water is misused, the danger is for all. In the distribution of the water in the hot summer months when the flow is small and the need great, the neighbor and his rights loom large, and men must gird themselves with the golden rule. The intensive culture, which must prevail under irrigation, makes possible close settlements, often with the village as a center. Out of the desert, as the canals are dug, will come great results of successful experiments in intimate rural life; and out of the communities reared under irrigation will come men who, confident that it is best, can unflinchingly consider their neighbors' interests with their own; and who, therefore, can assume leadership in the advancing of a civilization based upon order and equal rights.

The environment of wise irrigation-farming compels the belief that of all kinds of farming it may be the most enduring.

KING, F. H. Farmers of Forty Centuries (1911). 


\section{APPENDIX A \\ WATER CONSTANTS}

Chemical formula for water $=\mathrm{H}_{2} \mathrm{O}$.

Specific gravity of water $=1$.

Maximum density of water occurs at $4^{\circ} \mathrm{C}$. or $39.2^{\circ} \mathrm{F}$.

1 cubic foot of water at $4^{\circ} \mathrm{C} .=62.2786$ pounds.

1 cubic foot of water at $49^{\circ} \mathrm{F} .=62.2515$ pounds.

1 gallon (U. S.) of water $=8.3254$ pounds.

1 cubic foot of water $=7.48$ gallons.

1 litre of water $=2.1997$ pounds.

1 ton $=32.1$ cubic feet of water.

1 acre-foot $=$ the volume of water which will cover an acre 1 foot deep.

1 acre-inch $=$ the volume of water will cover an acre 1 inch deep.

1 acre-foot $=43,560$ cubic feet.

1 acre-foot $=2,712,856$ pounds.

1 California "miner's inch" $=0.020$ cubic feet per second.

1 Colorado "miner's inch" $=0.026$ cubic feet per second.

1 Arizona "miner's inch" $=0.025$ cubic feet per second.

1 cusec $=1$ second-foot $=1$ cubic foot of water per second.

1 second-foot flowing for twenty-four hours ( $=86,400$ cubic feet) will cover 1 acre 1.9835 feet deep $=1.9835$ acre-feet (approximately 2 feet).

1 second-foot flowing for 120 days will cover:

240 acres 1 foot deep.

180 acres $1 \frac{1}{2}$ feet deep.
120 acres 2 feet deep.

80 acres 3 feet deep. 


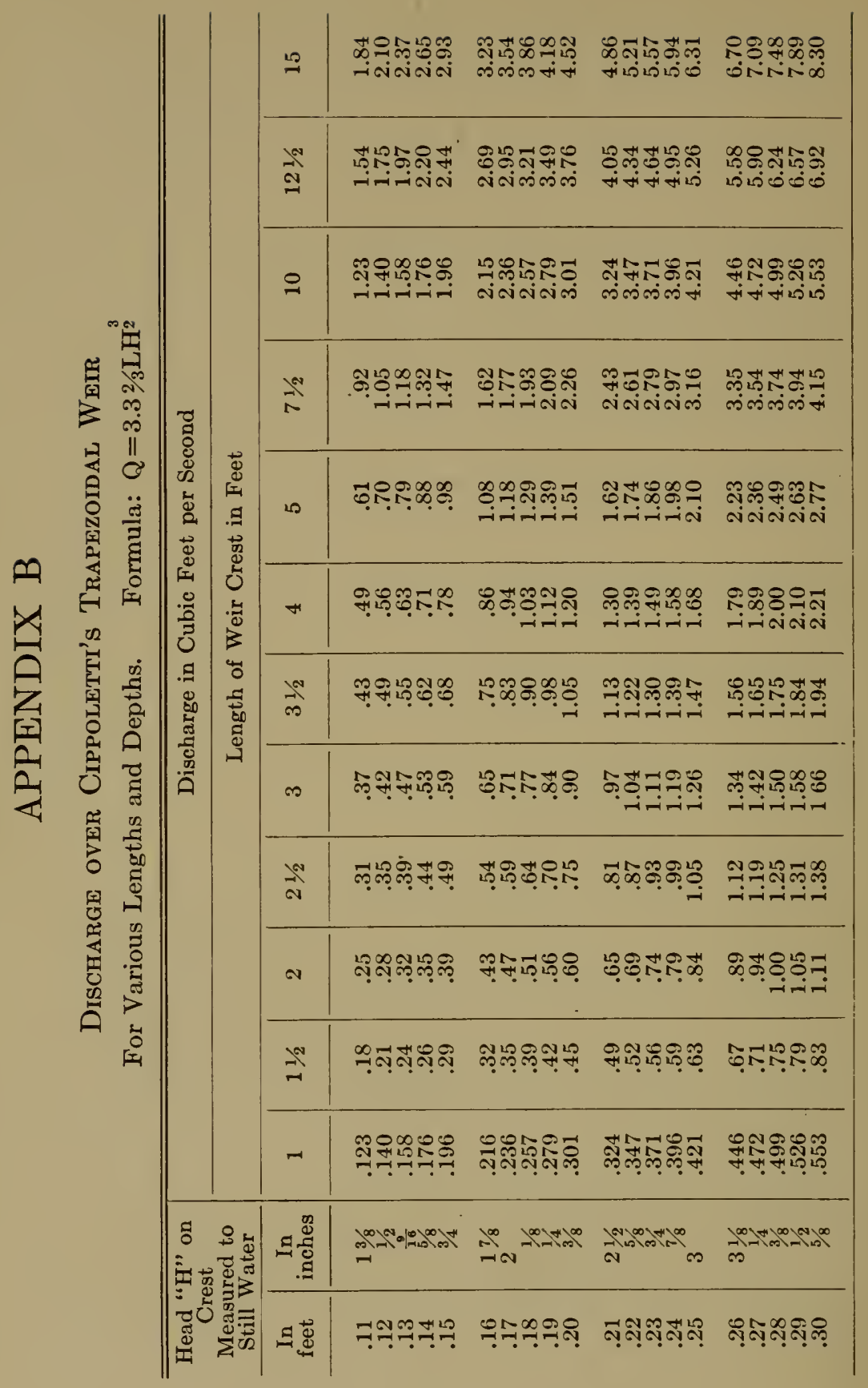




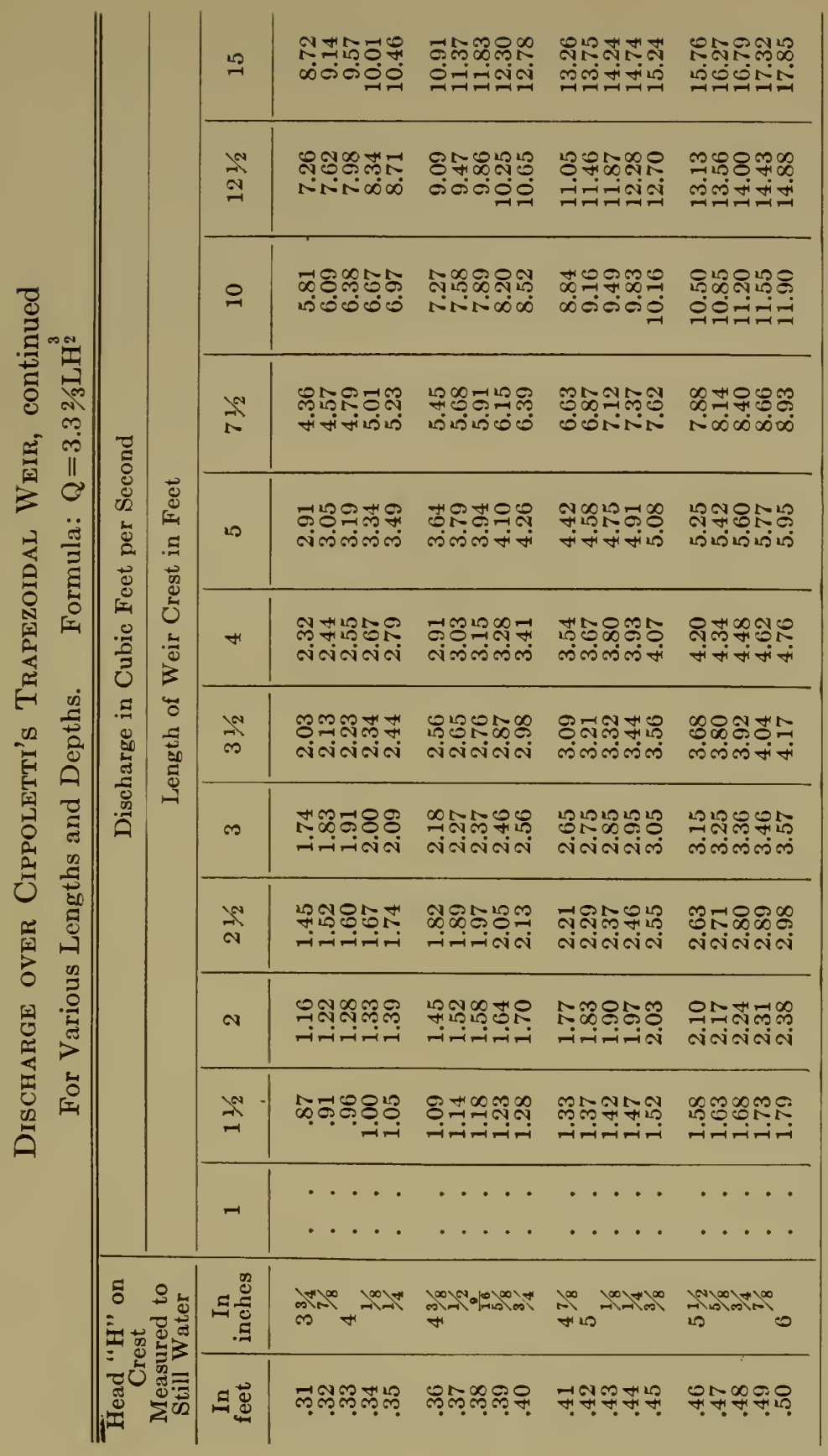




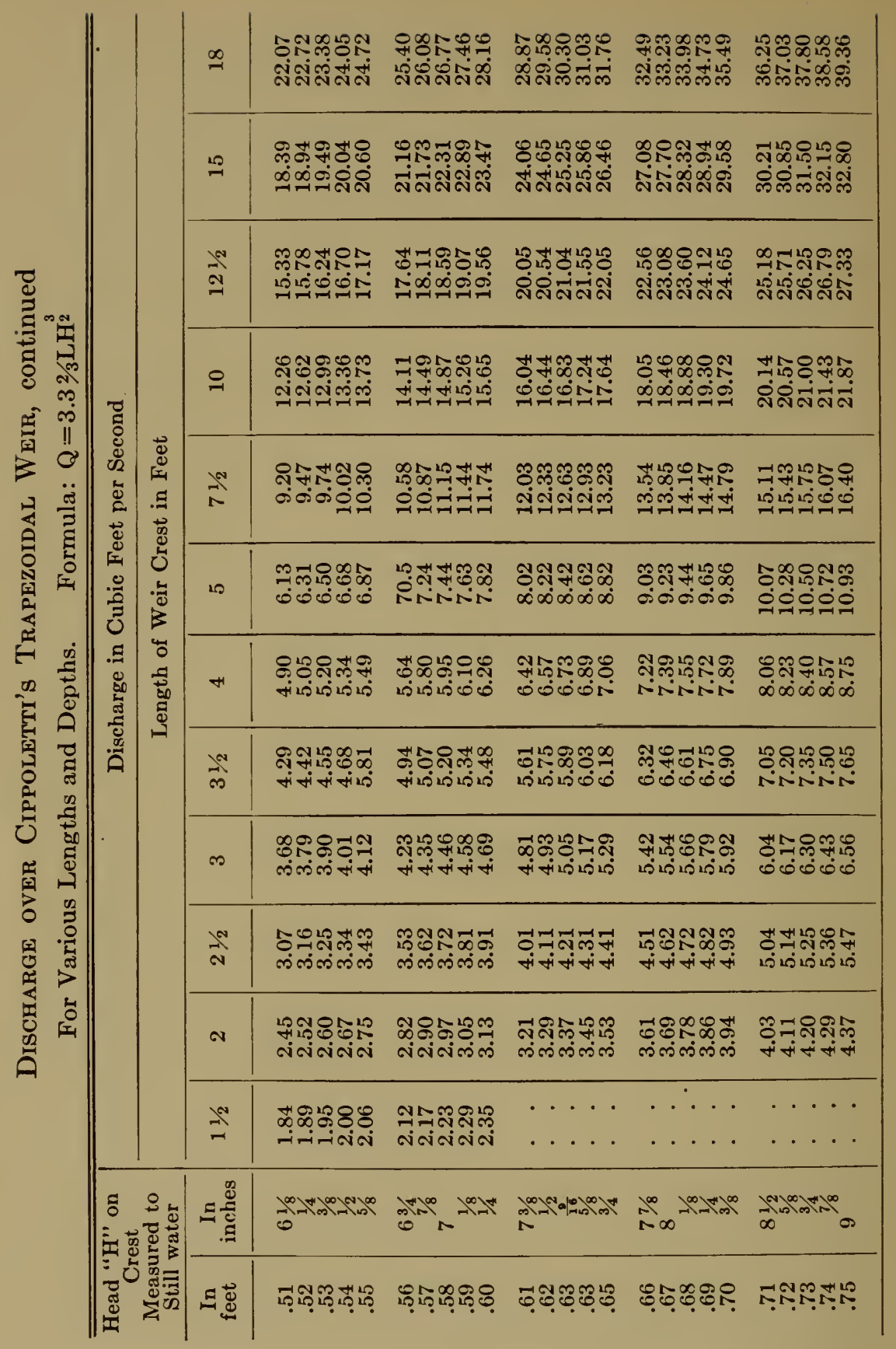




\begin{tabular}{|c|c|c|c|c|c|c|}
\hline \multirow{12}{*}{ 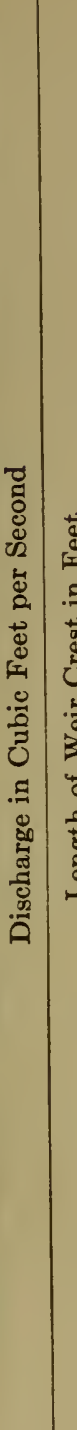 } & $\stackrel{\infty}{=}$ & 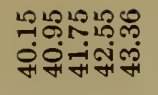 & 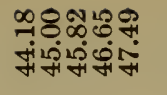 & 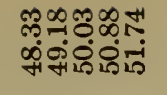 & 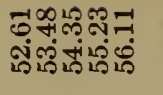 & 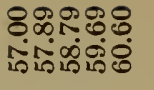 \\
\hline & 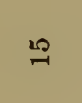 & 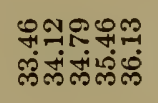 & 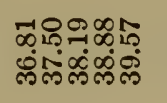 & 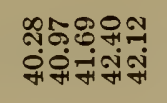 & 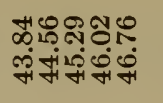 & 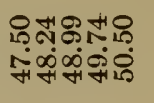 \\
\hline & $\stackrel{\Xi}{N}$ & 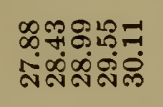 & 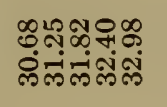 & 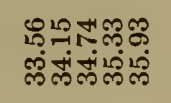 & 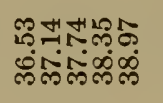 & 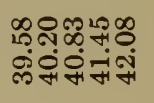 \\
\hline & 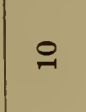 & 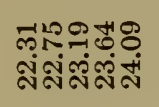 & 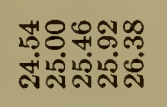 & 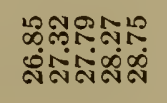 & 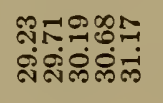 & 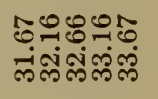 \\
\hline & $\stackrel{+\infty}{n}$ & 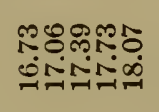 & 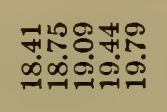 & 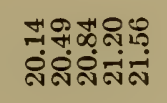 & 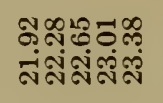 & 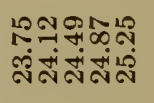 \\
\hline & 10 & 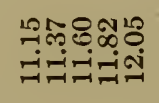 & 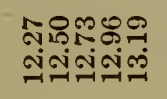 & 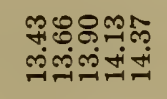 & 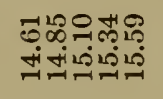 & 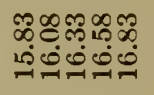 \\
\hline & $H$ & 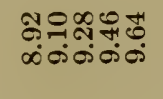 & 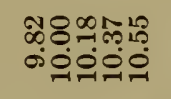 & 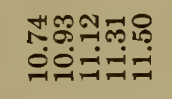 & 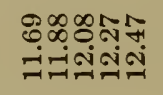 & 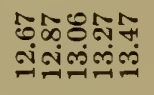 \\
\hline & $\vec{\infty}$ & 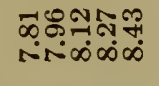 & 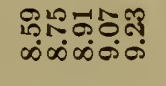 & 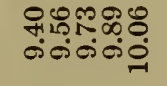 & 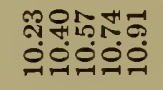 & 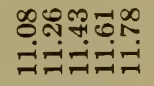 \\
\hline & $\infty$ & 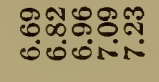 & 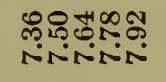 & 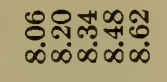 & 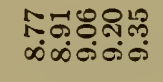 & 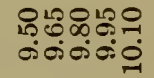 \\
\hline & $\vec{N}^{\infty}$ & 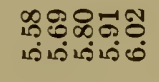 & 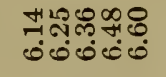 & 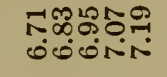 & 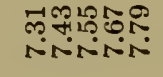 & 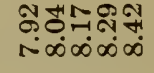 \\
\hline & N & 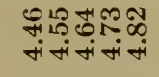 & 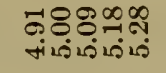 & 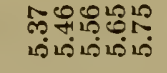 & & \\
\hline & $\Rightarrow$ & & & & & \\
\hline \multirow{2}{*}{ 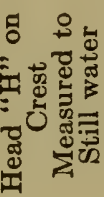 } & g. & 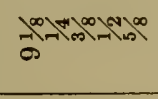 & $\cos ^{\infty} \underbrace{\infty}$ & 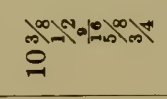 & $\stackrel{\infty}{=\infty}=$ & 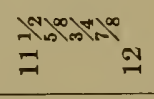 \\
\hline & 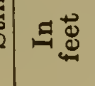 & 유: & 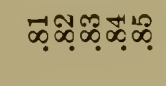 & 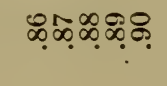 & 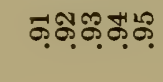 & 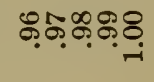 \\
\hline
\end{tabular}

EE 


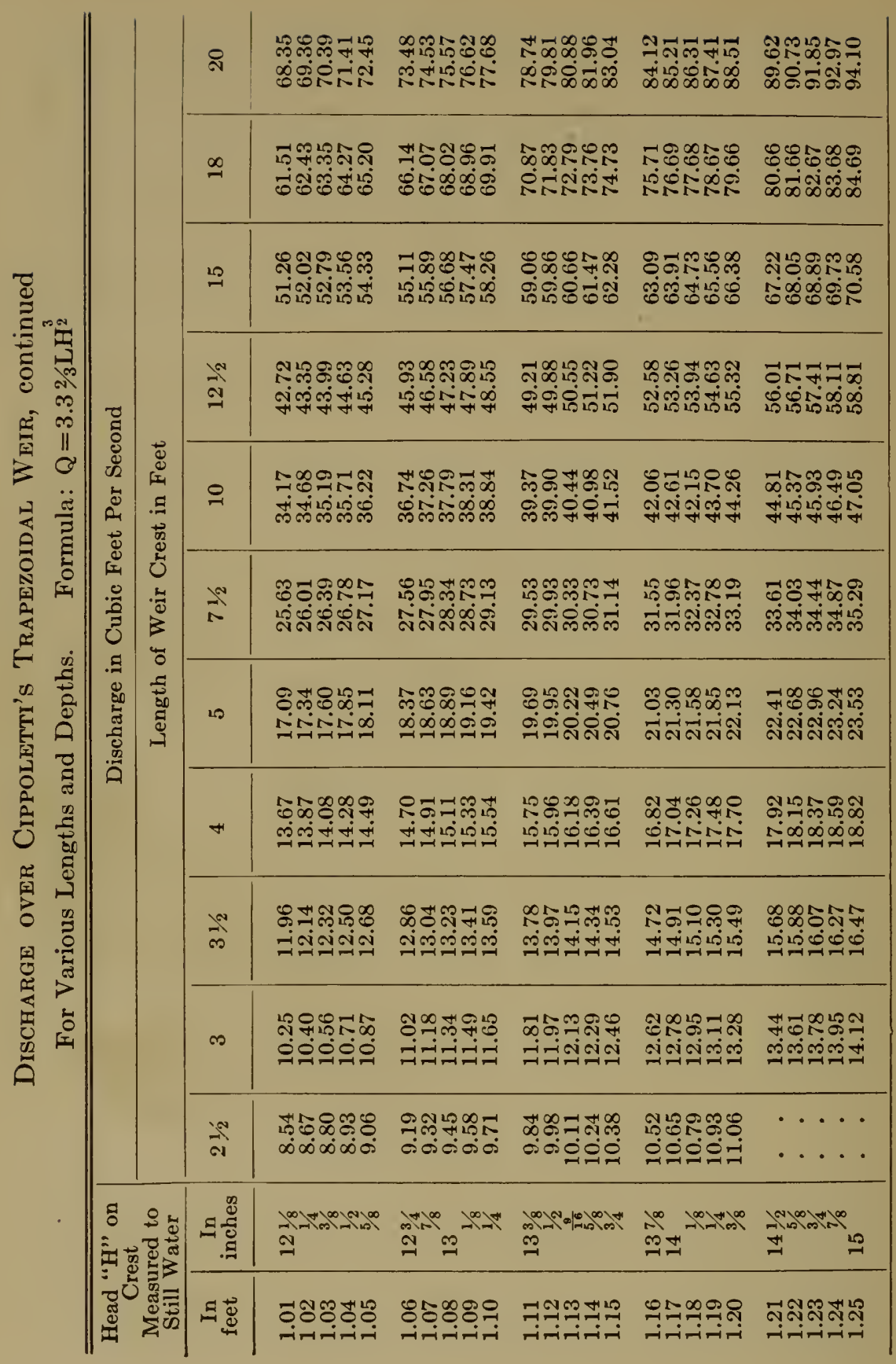




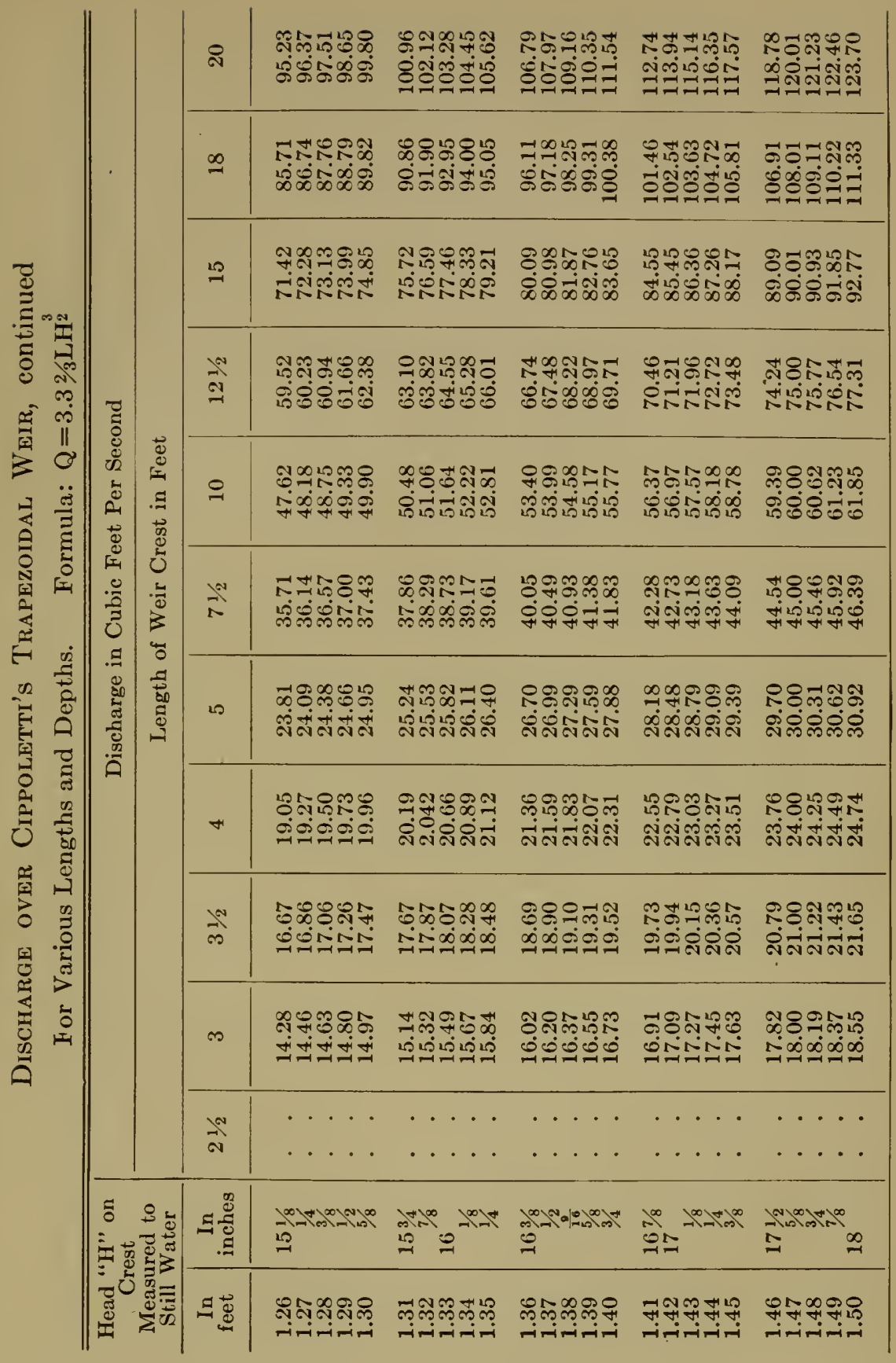




\section{APPENDIX C}

The following brief list gives the titles of the few books on irrigation for the farmer published in the United States:

Anderson, D. H. Primer of Irrigation. D. H. Anderson Publishing Company, Chicago (1903).

BowIE, A. J. Practical Irrigation. McGraw Publishing Company (1908).

KING. F. H. Irrigation and Drainage. The Macmillan Company, New York (1899).

Mead, Elwood. Irrigation Institutions. The Macmillan Company, New York (1903).

Neweld, F. H. Irrigation. T. Y. Crowell \& Co., New York (1902).

Ouin, W. H. American Irrigation Farming. A. C. McClurg \& Co., Chicago (1913).

Sirythe, W. E. The Conquest of Arid America. The Macmillan Company, New York (1905).

Stewart, Henry. Irrigation in Field and Garden. Orange Judd Company, New York (1886).

Wilcox, Lucius M. Irrigation Farming. Orange Judd Company, New York (1902). 


\section{INDEX}

Abraham, $446 . \quad$ '

Absolute duty of water, 335.

Absorption by soils, 76 .

of water by roots, 109 ,

effect of initial percentage, 111.

Adams, 368, 369.

Advantage of irrigation, 476.

Africa, duty of water in, 338 . use of saline water in, 387 .

Agricultural Colony, 461.

Alfalfa, 152.

See also Lucern.

time of watering, 186.

protein in, 221.

yield due to rainfall, 234.

under irrigation, 266.

cultivation of, 268.

method of irrigation, 269.

time of irrigation, 270.

quantity of water for, 274 .

duty of water, 344 .

Alfalfa seed, 277.

Algeria, 83.

Alkali. See also Over-irrigation and Seepage, 371.

drainage from a soil, 78.

upward leaching, 81.

use of concentrated water, 89 .

defined, 383.

and seepage, 384 .

upward leaching, 385.

use of saline water, 387 .

deposits, 388 .

kinds, 390 .

white, brown and black, 392 .

plant tolerance for, 392 .

tolerance of various plants, 394 .

tolerance according to Bureau of Soils, 395.

cropping against, 397.

chemical treatment for, 398 .

tillage against, 399.

scraping against, 399 .

washing out, 400 .

drainage, the remedy, 400 .

Almonds, spacing of, 317 .

Alway, 39 .
Amazon, 84.

America, founding of modern irrigation, 454.

Ames, Iowa, 407.

Anderson, 405.

Anderson, D.H., 484.

Anglo-Saxon irrigation, 452.

Apples, protein in, 221.

duty of water for, 322 .

sugar in, 225.

spacing, 317.

Application, distribution on, 364 .

Apricots, spacing, 317.

Argentina, 453.

Arizona Station, 179.

Arkansas River, 83.

Artesian water, 410.

Ash constituents. See also Plant-food in plants, 219.

Assia; duty of water in, 339.

Asparagus, under irrigation, 309.

Assam, India, rainfall at, 2.

Assimilation of carbon by plants, 128 , 129.

Assuan, 338, 452.

Assyria, 445.

Atlanta, 408.

Attraction of near bodies, 8 .

Australia, 453.

duty of water expression, 331 .

duty of water in, 343.

Australian saltbush, alkali-resistant, 397.

Babylon, 445.

Bacteria, soil, and water, 104.

Bark, 234, 248, 249, 264, 273, 284, 345, 369.

Barley, under irrigation, 255.

duty of water, 344 .

alkali-resistant, 396.

in humid climates, 411 .

early yield, 457.

Barri-Doab Canal, 341.

Bartlett, 405.

Basin irrigation, 207.

Beans under irrigation, 301. 
Bear River, 83.

Bear River Canal, duty of water, 253, 344.

Beckett, 63, 215.

Beets, early yield, 457.

Bell, 106.

Belle Fourche River, 96.

Belz, 44, 63 .

Bennett, 329.

Bighorn River, 96.

Billings, Mont., 78.

alkali experiment, 402 .

Blackberries, 326.

protein in, 221.

sugar in, 225.

in humid climates, 410 .

Bond, 264.

Bonsteel, 403.

Border irrigation, 202.

Bouyoucos, 118, 125, 156.

Bowie, 409, 417, 484.

Breaking land, 419.

Briggs, 20, 44, 63, 126, 156.

Brome-grass, 278.

Brown, 403.

Buckingham, 51, 52, 63.

Buckley, 340, 369.

Buds affected by irrigation, 320 .

Buergerstein, 126.

Burke, 403, 405.

Burr, 39.

Cabbage under irrigation, 308.

Cache la Poudre River, 83.

California, 457.

flooding irrigation in, 315 .

duty of water in, 323 .

lined ditches in, 378 .

rivers, 84 .

California station, 15, 30 .

Cameron, 48, 63, 66, 68, 70, 106, 387, 392.

Campbell, 62, 239.

Canals, loss from Indian, 341. seepage from, 371 .

Cantaloupe, 171. under irrigation, 306.

Canvas dam, 438.

Canada, 460 . rivers, 85 . duty of water expression, 331 . irrigation in, 339.

Cape Colony, 339, 453.

Capillarity. See Soil moisture, Soils, Water. maximum capacity, 17.

Carbohydrates in plants, 224
Carbon, assimilation by plants, 128 , 129.

Carey Act, 460.

Carpenter, 352, 369, 372, 374, 403, 449 . 468.

Carrots, time of irrigation, 185.

under irrigation, 296.

early yield, 457 .

Catholic Fathers, 451.

Cauliflower under irrigation, 308.

Cavour Canal, 452.

Celery under irrigation, 309.

Cement concrete, as ditch-lining, 377.

Cereals, irrigation of, 240.

Ceylon, 446.

Chalis River, 83.

Check irrigation, 202.

Checks for ditches, 434.

Cherries, protein in, 221. sugar in, 225.

spacing, 317.

Chicago Colony, 461.

Chili, 447. duty of water in, 342 .

China, 416, 446.

Cincinnati, 408.

Cippoletti's weir, 352. See also Weir. discharge over, 478.

Citrus trees under irrigation, 321.

duty of water for, 322 .

water requirements, 323 .

Clark, 39, 312.

Clarke, 83, 90, 106.

Clearing land, 419.

Clover, red, under irrigation, 281. in humid climates, 411 .

Coburn, 284.

Coit, 312, 327, 329.

Collins, 106.

Color of plants, 227.

Colorado, time of irrigation in, 320 . alkali from, 391.

Colorado River, 96.

Colorado Station, 355, 468.

Colorado Springs, 461 .

Columbia, S. C., 407.

Colver, 170, 230.

Composition, effect of tillage on, 228 .

Cone, 369.

Connecticut, 411.

Constants for water, 477.

Continuous flow, for distribution, 358 .

Continuous rotation, for distribution, 361

Cooking value of plants, 228 .

Corbet, 312.

Corn, transpiration, 60 . 
Corn, time of irrigation, 185. protein in, 221. yield due to rainfall, 234 . under irrigation, 255.

cultivation of, 256.

yield with varying water, 256 .

time to irrigate, 258.

quantity of water for, 259 .

in humid climates, $410,411$.

early yield, 457 .

Cotton, early yield, 457 .

Council Bluffs, 454.

Craigentinny, 415.

Cranberries, 326.

Crane, 410.

Crawley, 29.

Crop. See also Plant.

development under irrigation, 158. time to irrigate short-season crops, 183.

composition, 216.

use of rainfall in production, 231.

value of rainfall in irrigation, 233. tolerance of various, for alkali, 394 .

yields under early irrigation, 457.

Crowder, 428.

Cultivation. See also Mulching.

saving water by, 40 .

against evaporation, 49 .

time, 53.

depth, 55 .

frequency, 58.

and soil fertility, 59.

effect on water use, 121.

in dry-farming, 237.

of wheat, 243.

of corn, 256.

of alfalfa, 268.

of sugar beets, 288 .

tools for, 440.

Cultivator, with shovel attachment, 439.

Cultural operations, effect on watercost, 141.

Currants, 326. in humid climates, 410.

Cusec defined, 332.

Cushman, 106.

Dammer, 437.

Danube, 97.

Date, 314.

under irrigation 328.

alkali-resistant, 396 .

Davis and Weber Counties Canal, 366 , 378.

Day irrigation, 187.
Dead Sea, 83.

Definition of irrigation, 4.

Denver, 408.

Desert, rainfall on, 1 .

Dewberries, sugar in, 225, 326.

Distribution of water, 357 .

methods, $358,361,364$.

organization for, 365 .

cost of, 267.

regulations and records, 368 .

Ditch, concrete, 197.

lined, against seepage, 376.

locating, $420,421$.

permanent, 196.

typical farm, 425 .

making, 426.

discharge of various, 432 .

Ditch-tenders, for water distribution, 367.

Divisors, 350, 355.

Dole, 106.

Dorsey, 403.

Drainage-water, composition of, 78 .

loss of plant-food, 79 .

of wet lands, 381.

remedy for alkali, 400 .

Drill, in sowing wheat, 242.

Droughts, 407.

Dry-farming, 231. See also Rainfall. conditions of, 3 .

mission of, 7,231 .

defined, 233.

results of, 233.

cultivation, 237.

relation to irrigation, 237.

homesteads for, 238.

mission of, 239.

Congress, 239.

orchard experience, 324.

Dry-matter. See also Water-Cost. water-cost of, 127.

Duty of water for

wheat, $248,252,253$.

oats, 253.

barley, 255 .

rye, 255.

corn, 259.

rice, 263.

alfalfa, 274.

hay crops, 278.

clover, 281.

pastures and meadows, 281.

sugar beets, 293 .

carrots, 297.

potatoes, 299.

peas and beans, 301 .

fiber crops, 305. 
Duty of water for

hops, 306.

tomatoes, 306 .

watermelons, 307 .

squash, 307; pumpkin, 307; eggplant, 307.

cantaloupes, 307.

cabbage, 308 .

cauliflower, 308 .

spinach,308; lettuce,308; parsley,309. asparagus, 309; for celery, 309 .

onions, 310.

rhubarb, 310 ; tobacco, 310 ; peanuts, 310.

orchards, 322.

Duty of water.

defined, 331.

common meaning, 332.

classes of, 334 .

formula for, 334 .

difficulty of determining, 336 .

and profit from crops, 337.

cause of differences in, 338 .

in Africa, 338.

in Asia, 339.

in Europe, 341.

in South America, 342.

in Australia, 343.

in North America, 343.

under Bear River Canal, 344.

miscellaneous results, 345 .

in Idaho, 345.

Utah Station results, 346.

the new duty, 347.

in humid climates, 413.

Eaton, 106.

Economical irrigation, wheat, 252. against seepage, 381 .

Edinburgh, 415.

Eggplant under irrigation, 307.

Egypt, 445, 452.

duty of water in, 338 .

Elbe, 84.

Elliot, 403.

Etcheverry, 329, 403.

Europe, duty of water in, 341 .

Evans, 284, 285.

Evaporation and loss of soil moisture, 43 . intensity, 44.

conditions determining, 46 .

mulching against, 49 .

effect of rolling, 62 .

conditions determining use of water by plants, 108 .

Evapo-transpiration ratio, 132.

Experiment stations, 466.
Factory waste, 417.

Fall irrigation, 175.

time of application, 177.

Farmers' Canal, 366.

Fat in plants, 223.

Fiber crops under irrigation, 305 .

Field-ditch irrigation, 198.

Field-lateral irrigation, 198.

Field moisture-capacity, 29.

Fippin, 13.

Fitterer, 404.

Flavor of plants, 227.

Flax and alkali, 398.

Fleming, 403.

Flour composition of, 227.

Flynn, 369.

Forage crops under irrigation, 266, 278.

Forbes, 101, 106.

Fort Collins, 461.

Fortier, 46, 48, 49, 63, 156, 215, 239, $274,284,322,329,343,344,404$, $444,464,466,469$.

Fountain Colony, 461 .

France, 450, 451.

duty of water in, 342 .

Free water, 17.

Fresno, alkali experiment, 402.

Fruit. See also Orchard.

composition, 171.

quality under irrigation, 225.

Fruit-growing. See also Fruits, Orchard. under irrigation, 314.

Furrow-irrigation, 207. See also Method of Irrigation.

Furrowing, tools for, 439 .

Fuller, 403.

Gage Canal, 366.

Gain, 162.

Gallagher, 66, 68, 70, 106.

Gates for ditches, 434 .

Genil, 450.

Gilbert, 133, 464.

Gooseberries, 326.

in humid climates, 410 .

Grains. See also Cereals.

proportion of grain, 166 .

time of irrigation, 183.

irrigation of, 240.

destiny of grain-farming, 241.

duty of water in Africa, 339.

Grant-Mitchell meter, 442.

Grapes, protein in, 221.

sugar in, 225.

under irrigation, 327.

Gray, 471.

Gravel, 34. 
Greasewood, 397.

Great Basin rivers, 84 .

Great Britain rivers, 84 .

Great Plains, 458.

Great Salt Lake, 83, 389. alkali experiment, 401 . water, 91.

Great Salt Lake Valley, 455.

Greaves, 105, 106, 405.

Greeley, 457.

Greeley, Colo., 460.

Green City, 461.

Greenhouse irrigation, 192.

Green River, 98.

Gross duty of water, 335 .

Ground-water, 373.

Growth, conditions of plant, 130 .

Grubb, 312.

Guilford, 313.

Gunnison River, 96.

Hammurabi, 446.

Hanksville, Utah, 324.

Hardpan, 30.

Hare, 106.

Harris, 146, 156, 172, 187, 264, 405.

Hawaii, 29, 411.

Hay, time of irrigation, 186. crops under irrigation 278 .

Headden, 404.

Head of water, 194. proportion of, 166.

Hellriegel, 133, 167

Henry, 7.

Herrick, 329.

Hilgard, 20, 106, 239, 393, 398, 404, 466.

Homesteads on dry-farms, 238.

Hood River Valley, time of irrigation to, 320 .

Hops under irrigation, 306.

Horton, 369.

Hirst, 230.

History of irrigation, 445

Humbert, 157, 264.

Humid climates, irrigation in, 406. results of irrigation in, 409.

Hunt, 264.

Hygroscopic coefficient, 13.

Idaho, time of irrigation in, 320 . duty of water in, 345 .

Imperial Valley, 327.

India, 446, 452 . duty of water expression, 331 . duty of water in, 339 . duty of water, 341 .

India rivers, 84 .
Initial percentage, effect on evaporation, 48.

effect on use by plants, 111 .

Interculture of orchards, 323.

Irrigation. See also Time, Method, Quantity of Irrigation.

defined, 4, 231.

conditions, 4.

extent of, 5 .

need of, 5 .

mission of, 7 .

intermittent practice, 21.

response to, 159.

supplementary to rainfall, 231.

crop value of rainfall in, 233 .

relation to dry-farming, 237 .

for dry-farm homesteads, 238.

mission of, 239.

engineer to measure water, 349.

engineer for water distribution, 366 .

in humid climates, 406.

results in humid climates, 409.

history of, 445 .

antiquity of, 445 .

during Christian era, 449.

in recent times, 451 .

Congress in British South Africa, 453.

modern founding in America, 454.

permanent agriculture under, 472.

the big problem, 472 .

spirit of, 473 .

difference between arid and irrigation farming, 473.

history assures permanence of, 474 . social condition of, 476 .

advantages of, 476.

Irrigation Congress, 470.

Irrigation Engineer. See Irrigation; Water Master.

Italy, 450.

duty of water in, 342 .

Java rivers, 84 .

Johnston, 444.

Jones, 170, 224, 230.

Jordan River, Utah, 83

Joseph, 445.

Kafir corn, alkali-resistant, 396.

Kearney, 387, 392, 404.

Keeney, 264.

Kennedy, 341.

Khankhaje, 156.

Kiesselbach, 156.

King, 14, 20, 76, 106, 133, 156, 411, $415,418,476,484$. 
Kneale, 405.

Knight, 390.

Kraus, 230, 329.

Lake waters, salinity of, 86 .

Lateral organization, 367.

Lath-boxes, 212.

Laying-out farm, 420.

Lay-off, 440.

in furrow irrigation, 209.

Lawes, 133.

Leaching upward, 81, 385.

Leather, 39, 133, 134, 136, 156.

Leaves, proportion of, 163 .

Le Clerc, 230.

Legumes, not alkali-resistant, 398 .

Lemon, 314.

Lento-capillary point, 16 .

Lettuce under irrigation, 308.

Leveling land, 423.

Lewis, 230, 326, 329.

Loganberries, 326.

Lombardy, 450. sugar in, 225.

Longmont, 461.

Longyear, 329.

Loughridge, 30, 39, 215, 392, 393, 404.

Lucern. See Alfalfa.

Lyman, 352, 369.

Lyon, 13, 146.

Lysimeter, 77.

Macdonald, 239.

Manager for water-distribution, 366 .

Manuring effect on water-use, 121.

Manufactured crops, importance of, 266.

Marking, in furrow irrigation, 208.

Mawson, 339.

Maxwell, 411418.

Mayer, 156, 145, 167.

McClatchie, 179, 188, 239, 404.

McDowell, 188.

McLaughlin, 20, 39, 63, 126, 248, 264, $284,313$.

McKee, 285.

Mead, 7, 215, 239, 343, 346, 369, 404, $418,464,466,468,484$.

Meadow hay, early yield, 407

Meadows under irrigation, 281

Means, 404.

Measurement of water. See also Weir. Instruments for, 441.

need of, 347 .

classes of measurements, 349 . who shall measure, 349 .

Meeker, 460.

Mehemet Ali-Pasha, 452.
Menes, 445

Merrill, 188, 215, 265, 239, 285, 313, 370,469 .

Meteorology, effect on evaporation, 44 , 47.

Method of irrigation, 189.

sub-surface irrigation, 189.

permanent ditches, 196.

open and closed fields, 196.

field-ditch or lateral method, 198.

check method, 202.

border method, 202.

furrow method, 207.

basin method, 207.

summary of methods, 214.

of wheat, 243.

of alfalfa, 269.

of sugar beets, 289 .

of orchard, 315 .

in humid climates, 412.

Mexico, 447.

Milan, 408, 415.

Mill waste, 417 .

Mills, 468.

Mineral oil, as ditch-lining, 377.

Miner's inch, 332.

Mitchell, 106.

Modules, 350.

Moisture in soil. See Soil Moisture.

Montgomery, 156.

Moors, 449.

Morgan, 146, 157.

Morgan, E. R., 264, 278, 284, 313.

Mormon pioneers, 455, 201.

Mulching. See Cultivation. to check evaporation, 49 . self-mulching soils, 52 .

Nebraska Station, 37.

Net duty of water, 335 .

Newell, 7, 346, 369, 462, 464, 484.

New England, 406.

New Jersey, 410.

New Jersey Station, 469.

New Mexico, alkali from, 391.

Night irrigation, 187.

Nile, 84, 85, 97, 104, 339, 445.

Nitrogen. See Protein.

North America, duty of water in, 343 .

North Platte River, 96.

Nowell, 264, 313.

Nursery stock, under irrigation, 326 .

Nuts, 314.

Oats, ash in leaves, 219.

ash in stalks, 219.

protein in, 221. 
Oats, yield due to rainfall, 234 . under irrigation, 253. duty of water for, 253. early yield, 457 .

Ocean water, 91. composition, 92 .

Office of Experiment Stations, 464.

Olin, 484, 285.

Olive, duty of water for, 322 .

Omaha, 408.

Onions under irrigation, 310. in humid climates, 410 .

Orange, 314 . spacing, 317 .

Orchard. See also Fruit-growing. time of fall irrigation, 177. time to irrigate, 187.

furrowing, 210.

under irrigation, 314.

method of irrigation, 315 .

care of young, 315.

furrows for young trees, 317 .

time of irrigation, 319.

effect of irrigation on buds, 320 .

quantity of water for, 322 .

danger of over-irrigation, 323 .

inter-culture, 323.

growth without irrigation, 324 .

duty of water in Africa, 339.

Orchard-grass, 278.

Organization, for distribution, 365 .

Ornamental Plants under irrigation 328.

Oshkosh, Wis., 407.

Overfalls, 351.

Over-irrigation, 371. See also Seepage, Alkali.

delays ripening, 251.

danger in orchards, 323 . water-loss from, 373 .

Packard, 312, 329.

Packing, natural, of soil, 70 .

Paddock, 329.

Palestine, 446.

Palmer, 224.

Pastures under irrigation, 281.

Patten, 71, 106.

Peach, protein in, 221.

sugar in, 225.

spacing, 317.

Peanuts, 310.

Pears, protein in, 221. spacing, 317. duty of water for, 322 .

Peas, protein in, 221. under irrigation, 301.
Pecos River, 96.

Pennsylvania, 409.

Permanence of irrigation agriculture, 472.

of irrigation assured by history, 474 .

Persia, 446.

Peru, 447.

duty of water in, 342 .

Peterson, 390.

Phelps, 411, 418.

Phœnix, 408.

Pinckney, 403.

Plant. See also Crop.

use of soil moisture by, 108 .

absorption of water by plant-roots, 109.

initial percentage and water use, 111 . effect of water distribution on water use, 114 .

effect of time on water-use, 115 .

effect of soil depth on water use, 116.

effect of soil composition on water use, 117,118 .

effect of, on water use, 120 .

rigor of, and water use, 121.

effect of cultivation on water use, 121 .

effect of age on water use, 122 .

effect of roots on water use, 122 .

effect of kind on water use, 123.

effect of seasons on water use, 123.

water-cost of dry matter, 127.

carbon assimilation, 128.

age of, and carbon assimilation, 129. conditions of growth, 130 .

water-cost of several plants in different countries, 133, 134.

range of water-cost, 134 .

effect of soil on water-cost, 137.

effect of plant-food on water cost, 139 .

effect of cultural operations on watercost, 141.

vigor of, and water-cost, 143 .

water-cost and varying quantities of water, 144.

nature of, and water-cost, 154 .

development under irrigation, 158.

response to irrigation, 159.

proportion of roots, 160 .

proportion of leaves and stems, 163.

proportion of heads and grain, 166.

proportion of parts, 169.

composition, 216.

water in, 217.

constituents, 217.

ash constituents in, 219.

protein in various, 220 .

fat in, 223. 
Plant, carbohydrates in, 224.

sugar in, 224.

woodiness in, 226.

sugar in, 226.

color and flavor of, 227.

cooking value, 228 .

composition of flour, 228.

tillage and composition, 228.

use of rainfall in production, 231 .

producing power of rainfall, 232 .

toleration for saline water, 387 .

tolerance for alkali, 392 .

tolerance of various plants for alkali, 394.

Plant-food. See also Ash constituents. loss by drainage, 78, 79 .

added by water, 87 .

added by river sediments, 101 .

and water used by planting, 118 .

effect on water-cost, 139.

and alkali, 390.

Plowing, effect on water use, 120.

Plow, lateral, 427.

made first irrigation furrow, 427.

breaking, 419.

Plum, protein in, 221. sugar in, 225.

Poplars, 328.

Potatoes, ash in, 219.

protein in, 221.

yield due to rainfall, 234 .

under irrigation, 298.

duty of water, 344 .

in humid climates, 411.

early yield, 457 .

Powell, 457, 458, 464, 471.

Protein, in various plants, 220.

Prunes, sugar in, 225.

Puddling, as ditch-lining, 377.

Pumpkin under irrigation, 307.

Quantity of water in one irrigation, 23.

Quince, 314.

Rainfall. See also Dry-farming. annual, 1.

variations, 2 .

seasonal, 2 .

conservation, 3 .

average, 3 .

use of in crop production, 231.

irrigation supplementary to, 231.

crop-producing power, 232.

crop value in irrigation, 233.

distribution of, 235 .

conservation of, 235.

types of, 235.
Rainfall, storage in soil, 236. proportion conserved, 237.

Raspberries, 326. protein in, 221.

in humid climates, 410 .

Reclamation Act, 460.

Red River, 96.

Rees, 230, 329.

Registers for water measurement,s, 441.

Relative humidity, effect on evaporation, 47.

Reservoirs, seepage from, 371 .

Response to irrigation, 159.

Rhine, 84, 97.

Rhubarb, 310.

Rice, under irrigation, 262.

Richman, 188.

Ridging, tools for, 439 .

Rio Grande River, 91, 96.

Ripening, delayed by over-irrigation, 251.

River water, salinity of, 82 .

Riverside, Cal., 197.

Roeding, 290, 313.

Rolling, 62.

Roman Empire, 449.

Roosevelt, 462.

Roots, absorption of water by, 109 .

effect on water use, 122.

development in spring, 182 .

proportion of, 160 .

Root crops under irrigation, 297.

Root-hairs, 109.

Rotation, method of distribution, 361 .

Run-off, 40.

how to prevent, 41.

Rye, under irrigation, 255.

Rye-grass, 278.

Sacramento, 408 .

Salt Lake City, 78, 455, 470.

Salt River, 96.

Sanborn, 187, 188, 468.

San Joaquin River, 91.

Saskatchewan River, 84.

Schantz, 20.

Schlichter, 405.

Schultze, 74.

Season, effect of, on water use, 123. time to irrigate short-season crops, 183. dry, 407.

Second-foot, defined, 331. equivalents, 332 .

Sediments, cracked, 68. river, composition of, 101. physical effect on soil, 102. 
Sediments, cultural treatment of, 103. effect on crop yields, 104 .

Seelhorst, 157.

Seepage. See also Over-irrigation and Alkali.

from Indian canals, 341.

from reservoirs and canals, 371.

from over-irrigation, 373 .

arid vs. humid, 375 .

lined with ditches against, 376 .

drainage against, 381 .

economical use of water against, 381 . and alkali, 384.

Selina, Ala., 407.

Sevier River, 375.

Sewage, value in irrigation, 414 . use of, 415.

Shade, effect on evaporation, 47.

Shad-scale, 397.

Shantz, 14, 126, 156.

Shaw, 239.

Showers, 59.

Silting, as ditch-lining, 378.

Slosson, 390.

Small fruits, under irrigation, 326.

Smith, 329, 405.

Smythe, 7, 484 .

Snake River, 91.

Snow. See also Rain. loss by thawing, 41 .

Society under irrigation, 476.

Soil, size of particles, 9 . composition, 9 . surface of particles, 10 . moisture film of, 11. relation of particle and film, 12. hygroscopic coefficient, 13. wilting coefficient, 14 .

lento-capillary point, 16 . maximum capillary capacity, 17. fill water in, 17.

as water reservoir, 21. capacity for water of different, 22. unsaturated under irrigation, 22. field capacity of moisture, 29. hardpan in, 30.

gravel in, 34 .

quantity water stored in, 35 .

best for irrigation, 35 .

absorption of water by, 38 . effect of evaporation, 47. self-mulching, 52 .

fertility and cultivation, 59 . contraction of, 64 .

changes due to water, 64 . cohesion of particles, 65 . volume change, 67 .
Soil, cracking of, 68 . effect of water on top, 69 .

natural packing of, 70 . successive wetting and drying, 70 . temperature, 71 .

arid and humid contrasted, 73. continuous solubility, 74 .

absorption by, 76 .

composition of drainage water from, 78. depth of arid, 82.

plant-food added by water, 93 .

washing of, 95.

seasonal washing of, 98 .

suspended matter added by irriga. tion, 100.

suspended matter from surface, 100. composition of river sediment, 101 . physical effect of sediments, 102 . cultural treatment of sediments, 103. water and soil life, 104.

effect of sediments on crop yields, 104 . effect of soil depth on water use, 116 . effect of composition on water use, $117,118$.

effect on water-cost, 137. storage of water in, 236.

Soil fertility and cultivation, 59 .

Soil moisture, 8.

See also Evaporation, Soil, Water,

Water-film, and Moisture-film. attraction of near bodies, 8 .

film of, 11 .

relation of particle and film, 12 . hygroscopic coefficient, 13.

wilting coefficient, 14.

lento-capillary point, 16. maximum capillary capacity, 17.

free water, 17.

summary, 19.

soil as reservoir, 21.

capacity of different soils, 22.

unsaturated soils under irrigation, 22. movement of, 23.

distribution of, 25.

field capacity, 29.

effect of hardpan, 30 .

distribution in furrow irrigation, 30 .

effect of water table, 34 .

effect of gravel, 34 .

quantity water stored, 35 .

absorption by soils, 38 .

saving by cultivation, 40 .

how disposed of, 40 .

upward movement, 42.

and evaporation, 43.

contraction of film, 64 . 
Soil moisture, concentration of, 79 . contrasted with natural waters, 87 . use of, by plants, 108 .

initial percentage and use by plants, 111. effect of distribution on water use, 114.

water-cost of dry matter, 127.

Eorghum, alkali-resistant, 396. early yield, 457 .

South Africa, 453.

South America, duty of water in, 342 .

South Dakota, 410.

Southwestern Colony, 461 .

Sowing wheat, 241, 242.

Spain, 450. duty of water in, 342 .

Spinach under irrigation, 308.

Spring irrigation, 178.

Springs, mineral, salinity of, 86 .

Squash under irrigation, 307.

Sugar beets, 152 .

cultural treatment, 286.

method of irrigation, 289.

Stabler, 106.

Stannard, 444.

Starch in plants, 226.

Strawberries, protein in, 221.

Strawberries, 326. sugar in, 225.

in humid climates, 411 .

Stem, proportion of, 163.

Stewart, R., 105, 106, 172, 230, 390, 405.

Stewart, Henry, 484.

St. Julian Canal, 450.

St. Lawrence River, 84.

Storer, 415.

Storing Water in Soil. See Reservoir, Soil and Soil Moisture.

Sub-surface packer, 62.

Sub-surface irrigation, 189.

Sugar beets, time of irrigation, 185. ash in, 219.

protein in, 221.

time to irrigate, 290.

quantity of water for, 293.

duty of water, 344 .

alkali-resistant, 396 .

Sugar-cane, duty of water in Africa, 339.

under irrigation, 411.

Sugar in plants, 224.

Superintendent for water distribution, 366.

Surface irrigation, 193.

Surveys, water need of, 90 .

Suspended matter. See also Sediments.
Suspended matter in river water, 95 . seasonal variation of, 98 . quantity added to soil, 100.

Syria, 446.

Talmage, 405 .

Tannatt, $370,405$.

Teele, 264, 285, 313, 343, 370, 405, 444.

Temperature effect on evaporation, 47 . of soil, 71 .

Tillage is water, 142.

effect on composition, 228. against alkali, 399 .

Time, a factor in water use, 115.

Time of irrigation, 29, 173.

at lento-capillary point, 22.

early spring irrigation, 178 .

winter irrigation, 178.

irrigation during growth, 182.

short-season crops, 183.

long-season crops, 184.

frequency of irrigation, 185.

night vs. day irrigation, 187.

effect on composition, 229.

wheat, 246.

for corn, 258.

of alfalfa, 270 .

of sugar beets, 290 .

for orchards, 319 .

Timothy, 278.

Tobacco, 310 .

Tollens, 219, 230.

Tomato, 171.

under irrigation, 306.

Tools. See also Machines.

for irrigation, 419.

Townsend, 313.

Transpiration, 110. See also Water-cost. water cost of dry matter, 127.

water of various plants, 133, 134 .

range of ratio, 134 .

effect of seasons, 136 .

ratio, effect of soil on, 137 .

ratio, defined, 131.

Transvaal, 339.

True, 405.

Tucker, 145, 157.

Union Colony, 460.

United States, duty of water expression, 331.

Department of Agriculture, 343, 464.

Bureau of Soils, 78, 395, 401 .

Geological Survey, 442, 457, 464.

Interior Department, 463.

Irrigation Investigations, 372, 464.

Office of Experiment Stations, 383. 
United States Reclamation Service, $370,461$.

Utah, alkali from, 391 .

Utah Station, 15, 17, 26, 29, 30, 35, $38,48,60,77,88,111,126,129$, $136,142,146,154,159,165,166$, $167,184,190,213,225,228,250$, $255,259,292,294,336,468,469$. duty of water results, 346 .

Utah, time of irrigation in, 320.

Valencia Canal, 450.

Vineland, N. J., 407.

Von Seelhorst, 145.

Voorhees, $410,418,469$.

Walnuts, spacing, 317.

Warington, 93.

Washington, time of irrigation in, 320 .

Water. See also Soil moisture, Rainfall and Snow.

film, 11.

soil as reservoir, 21 .

how disposed of in soils, 40 .

soil changes due to, 64 .

cracked sediments, 68 .

effect on top soil, 69.

successive wetting and drying, 70.

universal solvent, 72 .

continuous solubility of soil, 74 .

composition of drainage, 78 .

river, salinity of, 82 .

composition of river waters, 84 .

river, arid and humid, contrasted, 85 .

lake, salinity of, 86 .

mineral springs, salinity of, 86 .

natural and soil-moisture, contrasted, 87.

plant-food added by, 87 .

use of concentrated w. in irrigation, 89.

surveys, need of, 90 .

natural composition of, 90,91 .

natural, classification of, 92 .

plant-food value of, 93 .

river, suspended matter in, 95 .

seasonal variation of suspended matter, 98.

suspended matter from surface soil, 120.

suspended matter added to soil by, 100.

composition of river sediments, 101 . and soil life, 104.

effect of sediments on crop yields, 104. absorption by roots, 109 .

tillage is, 142 .
Water, cost and varying quantities of, 144.

in plants, 217.

quantity for wheat, 248 .

storage in soil, 236.

duty, measurement and division, 331 .

units for measuring, 332 .

measurement of, 347 .

distribution of, 357 .

ground, 374.

use of saline, 387 .

irrigation, sources of, in humid climates, 413.

conservation methods in humid climates, 414 .

constants, 477 .

Water-cost. See also Transpiration. of dry matter, 127.

defined, 131.

of various plants, 133, 134.

range of ratio, 134 .

effect of seasons, 136 .

effect of soil on, 137 .

effect of cultural operations in, 141 .

vigor of plant and, 143.

and varying quantities of water, 144 .

nature of plant and, 154.

summary of factors, 155 .

of dry matter, 232.

Water-film, relation to particle, 12.

Water-logging, drainage against, 381 .

Water master. See also Irrigation engineer.

for water distribution, 367 .

Watermelons under irrigation, 307.

Waters, 410.

Water-table, 34.

Weir, 351.

rectangular, 351.

trapezoidal, 352.

triangular, 352.

discharge over Cippoletti, 478.

Welch, 188, 234, 265, 285, 313.

Westgate, 285.

Wheat, $152,168$.

protein in, 221.

composition of flour from, 228.

yield due to rainfall, 234 .

spring vs. fall, 241.

quantity to sow, 241.

method of sowing, 241, 242.

method of irrigation, 243.

cultivation of, 243.

time of irrigation, 246.

duty of water, 248.

yields with varying water, 250 .

possible yields with water, 252 . 
Wheat, duty of water, 344 . early yield, 457 .

Wheelon, 253, 344.

Whipple, 329 ,

Whitney, 48, 63 .

Widtsoe, $7,20,39,63,106,126,133$, $134,157,172,188,215,230,239$, $265,285,313,370,405,444,469$.

Wickson, 215, 313, 323, 329.

Wilcox, 285, 323, 338, 370, 484.

Willard, 157.

Williams, 418.

Wilson, 345, 370.

Wilting coefficient, 14.

Wind, effect on evaporation, 47.

Wing, 285.
Winkle, Van, 106.

Winsor, 356, 370.

Winter irrigation, 178.

Wollny, 133.

Woodiness, in plants, 226.

Woodward, 405.

Wright, 405.

Wyoming, duty of water in, 323 .

Wyoming, alkali from, 391.

Wyoming Station, 303.

Yield, effect of sediments on crop, 104.

Yoder, 418.

Young, Brigham, 454.

Young, R. W., 470. 


THE following pages contain advertisements of books by the same author or on kindred subjects. 



\section{BY THE SAME AUTHOR}

\section{R Y - F A R M I N G}

Cloth, ill., I2mo, \$ I.50 net

Professor Widtsoe's book is the first attempt to assemble and organize the known facts of science in their relations to the profitable production of plants without irrigation in regions of limited rainfall. The needs of the actual farmer, who must understand the principles before his practices can be wholly satisfactory, have been kept in view primarily, but it is believed that the enlarging group of dry farm investigators will also be materially helped by this clear presentation of the subject.

"Soil students and agriculturists will welcome the book as a useful summary by a man on the spot of what has been achieved so far, and they will be put in a position better than before to disentangle the real from the imaginary in the accounts of dry farming they come across." - Nalure.

“. . . Carries the weight of authority from the author's practical experiences. . . . Covers the whole subject of carrying on agriculture, without irrigation, in regions of low rainfall." - American Academy of Political and Social Science.

"The most complete discussion of the principles and practices of dry farming yet published." - The Ohio Farmer.

\section{THE MACMILLAN COMPANY}

Publishers 64-66 Fifth Avenue New York




\title{
NEW VOLUMES IN \\ The Rural Text-Book Series \\ Edited by L. H. Bailey
}

\section{TEXT-BOOK ON FORAGE CROPS}

\author{
By Professor C. V. PIPER \\ Of the United States Department of Agriculture
}

Cloth, I2mo

A clear and concise account of the present knowledge of forage cropping in North America, intended primarily as a text-book for the use of agricultural college students. The author presents the subject in such a way as to make the student realize the shortcomings of the present knowledge on the subject, as well as the progress which has been definitely accomplished. All the plants and crops which are used for forage and for hay are described, and their botanical characteristics and means of cultivation are carefully discussed. The grasses, alfalfa, the clovers, the millets, and the various fodder crops are all treated.

\section{SMALL GRAINS}

\author{
By M. A. CARLETON \\ Cerealist of the United States Department of Agriculture
}

Cloth, I2mo

The cereal grains and buckwheat are described carefully. Their methods of cultivation and of handling and marketing are thoroughly discussed. Among the grains thus treated are wheat, oats, rye, barley, and the minor crops. This book will prove an admirable complement to Montgomery's "The Corn Crops." Both these books are intended primarily for use as texts in college courses, and may very well be used in conjunction in the general course on grain crops. These books also are of distinct interest and value to the farmer.

\section{THE MACMILLAN COMPANY

Publishers 64-66 Fifth Avenue New York




\section{IRRIGATION}

\section{By JOHN A. WIDTSOE}

President of the Utah Agricultural College

Illustrated, Cloth, r2mo

Although much of the writing on irrigation has been from the engineering point of view, this book is written distinctly from the point of view of practical farming. President Widtsoe has drawn not only upon his own intimate knowledge of conditions in an irrigated country, but also upon all the available literature on the application of water to land for irrigating purposes. The effect of water on the soil, the losses by seepage and evaporation, the service that water renders to the plants, and the practical means of employing water for the growing of the different crops are all discussed clearly and thoroughly.

\section{WEEDS}

\section{By ADA E. GEORGIA}

Of the New York State College of Agriculture at Cornell University

\section{Illustrated, $\cdot$ Cloth, $\mathbf{2}$ mo}

A summary of our present knowledge regarding weeds as they affect horticultural and agricultural practices. The relations of weeds to agriculture are described, and the causes making certain plants weeds are explained. Every separate species of weed known to occur in the United States or Canada is described, and its range and habitat stated. The crops which each species particularly infests and the means of controlling each species are also discussed. Between 300 and 400 original illustrations, made directly from the plants, greatly enhance the practical value of this book.

\section{FIELD CROPS}

\section{By GEORGE LIVINGSTON \\ Assistant Professor of Agronomy, Ohio State University \\ Illustrated, Cloth, I2mo, \$ I.40 net}

This text is intended to meet the needs of agricultural high schools and of brief courses in Field Crops in the colleges. Based on actual experiment, it points out the "better way" of raising field crops; of selecting the field; of preparing the soil; of sowing the seed; of cultivating the plant; of harvesting the crop. It is to be fully illustrated with reproductions from photographs of unusual excellence.

\section{THE MACMILLAN COMPANY

Publishers 64-66 Fifth Avenue New York




\title{
Edited by L. H. Bailey
}

\section{THE FARM WOODLOT}

\author{
By E. G. CHEYNEY
}

Director of the College of Forestry of the University of Minnesota

\section{AND J. G. WENTLING}

Associate Professor of Forestry in the University of Minnesota

\section{Illustrated. Cloth, I2mo, \$1.50 net}

The whole subject of raising forests and producing timber as a part of a farming business is covered in this book. Here will be found fully treated such topics as the rise of forestry knowledge in relation particularly to agriculture, forest influences, forest economics, the growth of the tree, the kinds of trees and the means of distinguishing them, the regeneration of the woodlot, the practical propagation of trees, methods of planting and thinning, the production of the forest, the best utilization of forests, the durability and preservation of timber. There are also included tables of interest to lumbermen and a chapter on ornamental planting. The volume is well illustrated, the illustrations alone largely explaining forest practices and making evident the differences in trees.

\section{THE MACMILLAN COMPANY Publishers 64-66 Fifth Avenue New York}




\section{FARM STRUCTURES}

By K. J. T. EKBLAW, M.S.

Associate in Agricultural Engineering, University of Illinois ; Associate

'Member of American Society of Agricultural Engineers

Illus., Cloth, Crown 8vo, 347 pp., \$r.75 net; postpaid, \$1.88

In the preparation of this book it has been purposed to provide a treatise concerning farm structures which will appeal not only to the teacher who desires to present the subject to his students in a straightforward and practical way, but to the progressive farmer who recognizes the advantages of good farm buildings. The popular literature on this subject consists mainly of compilations of plans accompanied by criticisms of more or less value, or of discussions of farmsteads too expensive or impractical to be applied to present ordinary conditions. The elimination of these faults has been among the objects of the author in the writing of this text.

The development of the subject is manifestly the most logical, beginning with a description of building materials, followed by a discussion of the basic methods employed in simple building construction, then presenting typical plans of various farm buildings in which the principles of construction and arrangement have been applied. Descriptions of the more essential requirements in the way of equipment and farm-life conveniences are appended. The illustrations have been prepared with the object of making them truly illustrative and of aid in the understanding of the subject matter which they accompany. Comparatively few building plans are included, since most building problems possess so many local requirements that a general solution is impossible; however, the plans presented are typical, and are so suggestive in presenting fundamental principles that a study of them will aid in the solution of any particular individual problem.

It is not intended that the study of this text will produce an architect; but it is hoped that it will provide the student with a sufficient knowledge of building operations to enable him, with some knowledge of carpentry, to erect his own minor structures and to differentiate between good and bad construction in larger ones.

\section{THE MACMILLAN COMPANY}

Publishers 64-66 Fifth Avenue New York




\title{
INJURIOUS INSECTS HOW TO RECOGNIZE AND CONTROL THEM
}

\author{
By WALTER C. O'KANE
}

Entomologist of the New Hampshire Experiment Station, and Professor of Economic Entomology in New Hampshire College

\section{Decorated Cloth. 4I4 pages. Over 600 Photographic Illustrations $\$ 2.00$ net; postpaid, \$2.17}

Written out of a large scientific knowledge, but in a popular style, this book discusses concisely and yet fully the characteristics, life histories, and means of control of our common injurious insects.

The illustrations are from photographs throughout. The idea of the author has been to picture graphically the injurious stages and the work of the various pests, so that they may easily be recognized, independently from the text. More than $\mathbf{I}_{35}$ of the illustrations are photomicrographs.

All of the common injurious forms are described, including the pests of orchard, garden, field crops, domestic animals, and the household.

The arrangement of species is original and unique. In each division the pests are grouped according to the place where found at work and the characteristics. Prompt identification is thus made easy.

Other valuable features of the volume are:

Complete directions for the preparation and use of insecticides. Spray formulæ, repellents, and fumigants described in detail.

Descriptions and photographs of spray machinery and accessories.

An illustrated discussion of the structure of insects. How they live: their habits, senses, and manner of growth. others.

Insects as carriers of disease. The typhoid fly, the malarial mosquitoes, and

The classification of insects, including illustrated descriptions of the various important groups into which insects are divided.

An account of the means by which insects are dispersed.

The natural enemies of insects. How they are held in check by parasites, by fungous and bacterial diseases, and by birds and other larger animals.

How farm practice assists in insect control, showing the influence of plowing, cultivating, destruction of weeds, and the like.

A complete bibliography, giving an authoritative reference for each species treated in the book.

\section{THE MACMILLAN COMPANY \\ Publishers 64-66 Fifth Avenue New York}


"Every library, every country home, every city home with even the smallest window box, every school, and every office whose business in any way touches outdoor life, will find pleasure, profit, and inspiration in this great set of books."

\section{THE STANDARD CYCLOPEDIA OF HORTICULTURE}

\section{Edited By L. H. BAILEY}

With the assistance of over 500 collaborators. New edition, entirely rewritten and enlarged, with many new features; with 24 plates in color, 96 full-page half-tones, and over 4000 text illustrations. To be complete in six volumes. Sold only in sets by subscription.

Volume I (A-B), Cloth, 8vo, \$6.00; Leather, \$10.00

This work, an enlarged version of the famous Cyclopedia of American Horticulture, has been freshly written in the light of the most recent research and the most modern experience. It is not merely an ordinary revision or corrected edition of the old Cyclopedia, but it is a new work from start to finish, with enlarged boundaries both geographically and practically. It supersedes and displaces all previous editions or reprints of every kind whatsoever.

It is the fullest, the newest, the most authoritative of all works of its kind, and constitutes the most conscientious attempt that has ever been made to compress the whole story of our horticultural thought, learning, and achievement into one set of books. The text is under alphabetical arrangement supplemented by a Synopsis of the Plant Kingdom, a Key to the identification of the species, and an Index to the complete set.

\section{THE MACMILLAN COMPANY}

\section{Publishers \\ 64-66 Fifth Avenue \\ Now York}












\section{LIBRARY OF CONGRESS}

||||||||||||||||||||||||||||||||||||||||||||||||

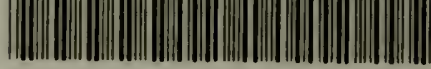

0000936己939 